GISLAINE MASSUIA DA SILVEIRA

ANÁLISE DE SENSIBILIDADE DE HIDROGRAMAS DE PROJETO AOS PARÂMETROS DE SUA DEFINIÇÃO INDIRETA

São Paulo 
GISLAINE MASSUIA DA SILVEIRA

\section{ANÁLISE DE SENSIBILIDADE DE HIDROGRAMAS DE PROJETO AOS PARÂMETROS DE SUA DEFINIÇÃO INDIRETA}

Dissertação apresentada à Escola

Politécnica da Universidade de São Paulo

para obtenção do título de Mestre em

Engenharia Civil 
GISLAINE MASSUIA DA SILVEIRA

\title{
ANÁLISE DE SENSIBILIDADE DE HIDROGRAMAS DE PROJETO AOS PARÂMETROS DE SUA DEFINIÇÃO INDIRETA
}

\author{
Dissertação apresentada à Escola \\ Politécnica da Universidade de São Paulo \\ para obtenção do título de Mestre em \\ Engenharia Civil \\ Área de Concentração: \\ Engenharia Hidráulica \\ Orientador: \\ Prof. Dr. Kamel Zahed Filho
}


Este exemplar foi revisado e alterado em relação à versão original, sob responsabilidade única do autor e com a anuência de seu orientador.

São Paulo, 26 de abril de 2010.

Assinatura do autor

Assinatura do orientador

FICHA CATALOGRÁFICA

Silveira, Gislaine Massuia da

Análise de sensibilidade de hidrogramas de projeto aos parâmetros de sua definição indireta / G.M. da Silveira. -- ed.rev. -- São Paulo, 2010.

$243 p$.

Dissertação (Mestrado) - Escola Politécnica da Universidade de São Paulo. Departamento de Engenharia Hidráulica e Sanitária.

1. Hidrologia 2. Drenagem urbana 3. Tomada de decisão 4. Recursos hídricos I. Universidade de São Paulo. Escola Politécnica. Departamento de Engenharia Hidráulica e Sanitária II. t. 
Dedico este trabalho aos meus pais: Antônio e Marcelina. 


\section{AGRADECIMENTOS}

A Deus, criador de tudo que existe, razão da minha existência.

Ao Prof. Dr. Kamel Zahed Filho, pela orientação e pelo nobre ato de transmitir seus conhecimentos, sua experiência profissional e pessoal durante toda a elaboração deste trabalho.

Ao Prof. Dr. Paulo Takashi Nakayama, pelas primeiras lições de hidrologia.

Ao Prof. Dr. Noboru Minei, pelos tantos incentivos prestados.

Ao Dr. Gré Araújo Lobo, pelas oportunidades.

Ao Prof. Dr. José Rodolfo Scarati Martins, pelo incentivo à escolha do tema e sugestões dadas durante a elaboração deste trabalho.

Ao Prof. Dr. Abel Maia Genovez, pelo material bibliográfico concedido.

A Dra Silvana S. Marcellini, pelas contribuições que permitiram elevar a qualidade técnica do trabalho.

À equipe da Coordenadoria do Programa Água Limpa do DAEE: Cidinha, Ruth, Folino, Bezerra e Rodrigo. Ao nosso coordenador, José Soares Pimentel, pelo apoio e pela disponibilidade de tempo concedida na elaboração deste trabalho.

Ao Eng. Ney Meyer, do DAEE, pelas informações e fotos concedidas dos piscinões da RMSP.

Ao Eng. Cristiano de Pádua Milagres Oliveira, da equipe técnica do Labsid, pelos esclarecimentos a respeito do SSD ABC 6. 
À Carolina Ramos e à lara Guimarães, pela colaboração na elaboração das figuras deste trabalho.

Ao Eng. Civil Alessandro Fenyves Filho, pelas oportunidades concedidas, enquanto estive na Poente Engenharia Ltda.

Ao Eng. Civil Antônio Eurides Conte e ao Eng. Civil Carlos Netto Cardoso, por compartilharem seus conhecimentos adquiridos ao decorrer dos anos trabalhados.

Aos colegas da DEO/DAEE, do CTH/DAEE e da Poente Engenharia Ltda., pelo apoio em momentos decisórios.

Aos Professores e funcionários do Departamento de Engenharia Hidráulica e Sanitária da Escola Politécnica da Universidade de São Paulo.

À bibliotecária Fátima, pela revisão das referências bibliográficas.

Aos meus colegas de mestrado e doutorado, que mesmo em momentos diferentes, partilhamos das mesmas aflições.

Às minhas grandes amigas Eliane, Marlene e Mariele, por toda a consequência de nossa amizade.

Ao meu amigo José Moraes Nobre, exemplo de sabedoria.

À família Melo, pelo apoio e palavras de encorajamento.

À minha família, pelo apoio e afeto. Aos meus irmãos e aos meus pais, pelo exemplo humilde de vida. Por me ensinarem que nossos sonhos podem ser realizados com esforço e dedicação.

Ao Douglas, um agradecimento muito especial, pelo amor, compreensão, companheirismo e por todo o tempo dedicado a me auxiliar na elaboração deste trabalho. 
"What we know is a drop.

What we don't know is an ocean."

Isaac Newton 


\section{RESUMO}

É realizada neste trabalho uma análise de sensibilidade das variáveis de entrada na determinação de hidrogramas de cheia em bacias hidrográficas desprovida de dados hidrológicos. Analisou-se a influência do $\mathrm{CN}$ (número de curva), da área de drenagem, do tempo de concentração, da duração da chuva e do período de retorno sobre os hidrogramas de cheia calculados. É feita uma comparação entre os métodos do hidrograma do SCS, Santa Bárbara e Clark. Para dar subsídio às análises de sensibilidade, utiliza-se o sistema de suporte à decisão $A B C$ 6, desenvolvido na Universidade de São Paulo (USP). Um estudo de aplicação prática é elaborado para avaliar a influência da vazão no projeto de estruturas hidráulicas. Os resultados mostram quanto as variáveis de entrada influenciam na determinação das vazões e quanto estas vazões influenciam no projeto das estruturas hidráulicas. Como recomendação geral, visto a facilidade no uso de ferramentas computacionais e sistemas de suporte a decisão, sugere-se que sempre seja realizada uma análise de sensibilidade nos estudos hidrológicos. A análise de sensibilidade irá permitir a avaliação dos erros e incertezas que são cometidos quando da adoção das variáveis de entrada.

Palavras-chave: Hidrograma de Cheia. Hidrogramas Sintéticos. Pequenas bacias hidrográficas. Sistema de suporte à decisão. ABC 6. 


\begin{abstract}
A sensitivity analysis of input variables for flood hydrographs determination in watersheds without observed hydrological data is presented in this work. Influence of CN (number of curve), drainage area, time of concentration, rainfall duration and return period on the calculated flood hydrographs is analyzed. It is made a comparison among three unit hydrographs methods: SCS, Santa Barbara and Clark. ABC 6, a decision support system developed at USP (Universidade de São Paulo) is used as a tool for sensitivity analysis. A study of practical application is made to examine the influence of flow in design of hydraulic structures. Results show how input variables influence calculated flows and how these flows influence design of hydraulic structures. It is suggested, by the fact that computational tools and decision support systems are easy to use, that a sensitivity analysis in hydrological studies must be always be performed. Sensitivity analysis will allow evaluation of hydrologic design results due to errors and uncertainness caused by input variables.
\end{abstract}

Keywords: Flood Hydrograph. Synthetic Hydrograph. Small Watershed. Decision support system.ABC 6; 


\section{APRESENTAÇÃO}

Engenheira Civil, Gislaine Massuia da Silveira, atua desde 2004, na área de recursos hídricos. Estagiou na Fundação Centro Tecnológico de Hidráulica onde participou do desenvolvimento de um Plano Diretor de Prevenção e Combate a Enchentes e preparação de cursos de Drenagem Urbana. Atuou na iniciativa privada, desenvolvendo estudos Hidrometeorológicos, Sedimentológicos e de Hidráulica Fluvial direcionados ao projeto de PCH's e AHE's. Atualmente, trabalha no DAEE. É professora de laboratório das disciplinas de Mecânica dos Fluídos e Hidráulica, pela FESP.

Antes do acesso à informática, as atividades relacionadas aos estudos hidrológicos, podiam ser consideradas exaustivas. A determinação das variáveis hidrológicas, como o levantamento das características fisiográficas da bacia hidrográfica, a organização dos dados observados e a resolução de cálculos matemáticos, eram atividades trabalhosas e que despendiam de tempo até sua conclusão. A popularização dos computadores e os avanços da tecnologia da informação permitiram que estas atividades fossem mais facilmente executadas. Além disso, possibilitou melhorar os modelos hidrológicos. Mesmo assim, em decorrência de certos fatores, (séries de vazões não estacionárias, dificuldade de modelar certos fenômenos físicos do ciclo hidrológico, falta de séries históricas de dados, suficientemente longas, pouco investimento na instalação e operação de postos de medição, falta de interesse político continuado na área, entre outros) ainda hoje, são aplicados métodos sintéticos de obtenção de hidrogramas de cheia, baseados em teorias desenvolvidas há mais de 70 anos.

Admitida a importância destes métodos, devida a aplicabilidade em estudos como os de drenagem urbana, disponibilidade de água, previsão de vazões, impactos da urbanização no volume do escoamento superficial direto, projeto de vertedores de pequenos reservatórios etc., surgiu a curiosidade em se conhecer a influência dos parâmetros de entrada de tais métodos nos hidrogramas resultantes. A motivação à realização desta pesquisa foi a de tentar verificar se a estimativa de um determinado 
parâmetro fosse feita a partir de um valor menor ou maior do que o tido como ideal, qual seria a influência nas vazões de dimensionamento.

Foi a partir deste cenário que surgiu o tema deste trabalho, intitulado: "Análise de sensibilidade de hidrogramas de projeto aos parâmetros de sua definição indireta". A técnica de análise de sensibilidade permitirá verificar a influência dos parâmetros de entrada nos valores de saída.

Espera-se, que este trabalho possa fornecer subsídios aos estudos hidrológicos, para os quais a determinação do volume do escoamento superficial direto e vazão de pico sejam importantes, visto que:

- Aborda os conceitos teóricos fundamentais à área;

- Mostra a importância e como as análises de sensibilidades podem ser realizadas;

- Apresenta, como ferramenta de cálculo, o SSD ABC 6;

- Fornece recomendações referentes à determinação dos parâmetros de entrada dos hidrogramas sintéticos.

Destaca-se ainda, o valor acadêmico do trabalho, como material didático direcionado aos iniciantes e profissionais da área.

Sabendo-se que os trabalhos de pesquisas são ilimitados, no sentido de gerarem conhecimentos, vislumbra-se a possibilidade do desenvolvimento de um aplicativo para o SSD ABC6, que incorpore a opção de realizar análises de sensibilidade.

Os leitores poderão consultar, além do próprio texto, as referências bibliográficas lidas e não citadas no texto, assim como os sites visitados, que contribuíram no desenvolvimento deste trabalho. 


\section{LISTA DE ILUSTRAÇÕES}

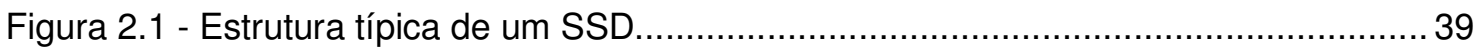

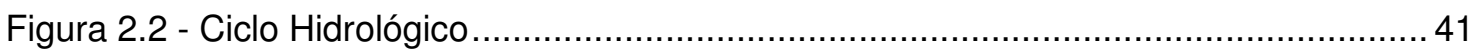

Figura 2.3 - Exemplos de modelo linear e não-linear ......................................................... 43

Figura 2.4 - Exemplos de modelo contínuo e discreto..................................................... 43

Figura 2.5 - Exemplos de modelo concentrado e distribuído ........................................... 44

Figura 2.6 - Exemplos de modelo determinístico e aleatório ........................................... 44

Figura 2.7 - Discretização dos modelos: subdivisão concentrada, distribuída por sub-bacia ou distribuída por módulo 46

Figura 2.8 - Fluxograma da estrutura básica de integração dos processos dos modelos hidrológicos ................................................................................ 47

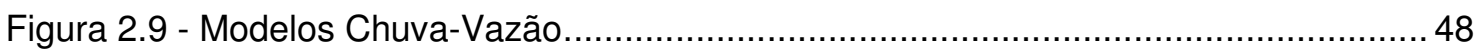

Figura 2.10 - Fenômenos naturais do ciclo hidrológico simulados pelo SSD ABC ..............50

Figura 2.11 - Representação pictórica esquemática e topologia do SSD ABC $6 \ldots \ldots \ldots \ldots \ldots . . . . .51$

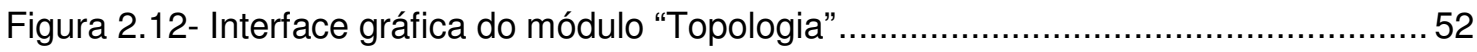

Figura 2.13 - Interface gráfica do módulo "Intervalo"................................................. 53

Figura 2.14 - Interface gráfica do módulo "Modelos" .................................................... 53

Figura 2.15 - Interface gráfica do módulo “Dados” .......................................................... 54

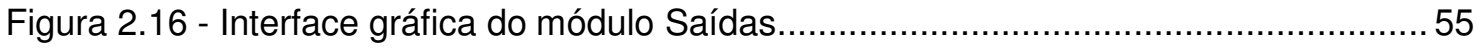

Figura 2.17 - Fluxograma de entrada de dados e saídas de resultados para o estudo de uma

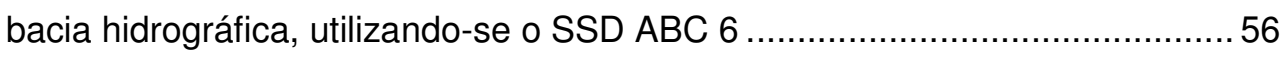

Figura 2.18 - Representação do traçado de uma bacia hidrográfica ................................ 62

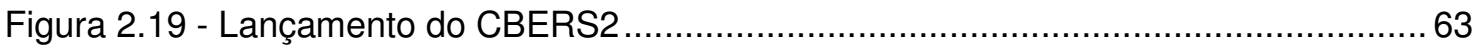

Figura 2.20 - Imagens do satélite obtidas pelo CBERS. (A) Belém. (B) Belo Horizonte. (C) Brasília. (D) Manaus. (E) Rio de Janeiro. (F) São Paulo............................. 64

Figura 2.21 - Determinação da declividade equivalente pela média aritmética ................... 64

Figura 2.22 - Determinação da declividade equivalente pela compensação de áreas......... 65 
Figura 2.23 - Determinação da declividade equivalente pela média harmônica

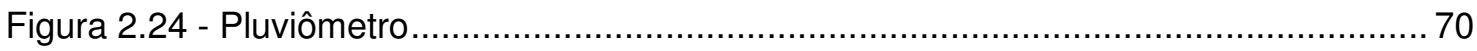

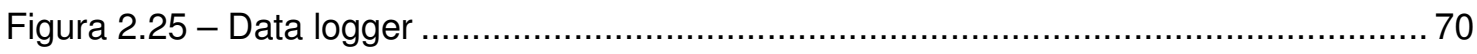

Figura 2.26 - Imagens do radar de Ponte Nova do DAEE ................................................ 71

Figura 2.27 - Satélite TRRM sendo montado na Goddard Space Flight Center ................. 72

Figura 2.28 - Curva de fator de redução de área desenvolvida pelo U.S Weather Bureau.. 75

Figura 2.29 - Pluviograma de uma chuva real......................................................... 76

Figura 2.30 - Municípios com equação IDF no estado de São Paulo (sem escala)............. 77

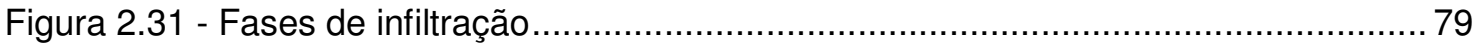

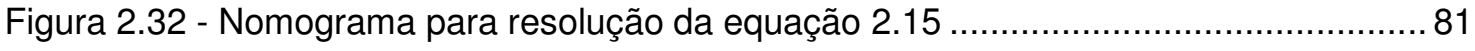

Figura 2.33 - Extensão da Figura 2.32, além de 200 mm de chuva ................................. 82

Figura 2.34 - Parâmetros de um hidrograma ................................................................... 91

Figura 2.35 - Constância do Tempo de Base (1), Proporcionalidade das descargas (2) e Principio da Aditividade (3) ............................................................ 92

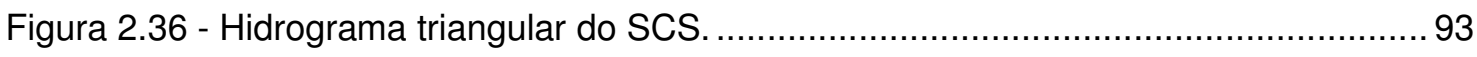

Figura 2.37 - Isócronas e histograma tempo-área..................................................... 97

Figura 2.38 - Reservatório linear do método de Clark .................................................... 98

Figura 2.39 - Algoritmo para construção do histograma tempo-área................................. 99

Figura 4.1 - (A) Variação da vazão de pico em função do $C N$, (B) proporção da vazão de pico em relação ao valor da vazão de pico para o $\mathrm{CN}$ de $95,(\mathrm{C})$ variação entre as vazões de pico em função do CN para o método do SCS......................... 115

Figura 4.2 - Hidrogramas de cheia para o período de retorno igual a 100 anos - SCS...... 116

Figura 4.3 - Gráfico da variação do volume do hidrograma de cheia em função do CN SCS.

Figura 4.4 - Proporção do volume em relação ao volume para o CN de 95 .......................118

Figura 4.5 - Variação entre os volumes em função do CN ......................................... 118

Figura 4.6 - Comparação dos gradientes de vazão de pico e volume - SCS....................118

Figura 4.7 - (A) Variação da vazão de pico em função da área de drenagem, (B) proporção da vazão de pico em relação ao valor da vazão de pico para a área de 
drenagem de $200 \mathrm{~km}^{2}$, (C) variação entre as vazões de pico em função da área de drenagem para o método do SCS...................................................... 120

Figura 4.8 - Hidrogramas de cheia para o período de retorno igual a 100 anos - SCS...... 121

Figura 4.9 - Gráfico da variação do volume do hidrograma de cheia em função da área de drenagem - SCS. 122

Figura 4.10 - Proporção do volume em relação ao valor do volume para a área de drenagem de $200 \mathrm{~km}^{2}$ 122

Figura 4.11 - Variação entre os volumes em função da área de drenagem 122

Figura 4.12 - Comparação dos gradientes de vazão de pico e volume - SCS 123

Figura 4.13 - (A) Variação da vazão de pico em função do tempo de concentração, (B) proporção da vazão de pico em relação ao valor da vazão de pico para o tempo de concentração de $0,5 \mathrm{~h}$, (C) variação entre as vazões de pico em função do tempo de concentração para o método do SCS 125

Figura 4.14 - Hidrogramas de cheia para os períodos de retorno igual a 100 anos - SCS 126

Figura 4.15 - Variação da vazão de pico em função do tempo de concentração, para o período de retorno de 100 anos - SCS 128

Figura 4.16 - Gráfico da variação do volume do hidrograma de cheia em função do tempo de concentração - SCS. 130

Figura 4.17 - (A) Variação da vazão de pico em função da duração da chuva de projeto, (B) proporção da vazão de pico em relação ao valor da vazão de pico para duração da chuva de projeto de 360 minutos, (C) variação entre as vazões de pico em função da duração da chuva de projeto para o método do SCS 132

Figura 4.18 - Hidrogramas de cheia para os período de retorno igual a 100 anos - SCS.. 133

Figura 4.19 - Gráfico da variação do volume do hidrograma de cheia em função da duração da chuva de projeto - SCS. 135

Figura 4.20 - Proporção do volume em relação ao valor do volume para a duração de chuva de projeto de 360 minutos 135

Figura 4.21 - Variação entre os volumes em função da duração da chuva de projeto....... 135

Figura 4.22 - Comparação dos gradientes de vazão de pico e volume - SCS 136

Figura 4.23 - (A) Variação da vazão de pico em função do CN, (B) proporção da vazão de pico em relação ao valor da vazão de pico para o CN de 95, (C) variação entre as vazões de pico em função do CN para o método de Santa Bárbara 137 
Figura 4.24 - (A) Variação da vazão de pico em função da área de drenagem, (B) proporção da vazão de pico em relação ao valor da vazão de pico para a área de drenagem de $200 \mathrm{~km}^{2}$, (C) variação entre as vazões de pico em função da área de drenagem Santa Bárbara. 138

Figura 4.25 - (A) Variação da vazão de pico em função do tempo de concentração, (B) proporção da vazão de pico em relação ao valor da vazão de pico para o tempo de concentração de $0,50 \mathrm{~h},(\mathrm{C})$ variação entre as vazões de pico em função do tempo de concentração Santa Bárbara. 139

Figura 4.26 - (A) Variação da vazão de pico em função da duração da chuva de projeto, (B) proporção da vazão de pico em relação ao valor da vazão de pico para a duração da chuva de projeto de 360 minutos, (C) variação entre as vazões de pico em função da duração da chuva de projeto para o método de Santa Bárbara 140

Figura 4.27 - Variação da constante $\mathrm{k}_{\mathrm{SB}}$ em função da vazão de pico - Método de Santa Bárbara. 141

Figura 4.28 - Variação da constante $\mathrm{k}_{\mathrm{SB}}$ em função do tempo de concentração - Método de Santa Bárbara 141

Figura 4.29 - Variação da constante $\mathrm{k}_{\mathrm{SB}}$ em função da área de drenagem - Método de Santa Bárbara. 142

Figura 4.30 - (A) Variação da vazão de pico em função do CN, (B) proporção da vazão de pico em relação ao valor da vazão de pico para o $\mathrm{CN}$ de $95,(\mathrm{C})$ variação entre as vazões de pico em função do $\mathrm{CN}$ para o método de Clark. 143

Figura 4.31 - (A) Variação da vazão de pico em função da área de drenagem, (B) proporção da vazão de pico em relação ao valor da vazão de pico para a área de drenagem de $200 \mathrm{~km}^{2}$, (C) variação entre as vazões de pico em função da área de drenagem para o método de Clark. 144

Figura 4.32 - (A) Variação da vazão de pico em função do tempo de concentração, (B) proporção da vazão de pico em relação ao valor da vazão de pico para o tempo de concentração de $0,50 \mathrm{~h},(\mathrm{C})$ variação entre as vazões de pico em função do tempo de concentração para o método de Clark 145

Figura 4.33 - (A) Variação da vazão de pico em função da duração da chuva de projeto, (B) proporção da vazão de pico em relação ao valor da vazão de pico para a duração da chuva de projeto de 360 minutos, (C) variação entre as vazões de pico em função da duração da chuva de projeto para o método de Clark 146 
Figura 4.34 - (A) Variação da vazão de pico em função do fator de forma, (B) proporção da vazão de pico em relação ao valor da vazão de pico para o fator de forma igual a 2, (C) variação entre as vazões de pico em função do fator de forma para o método de Clark 147

Figura 4.35 - Variação da constante kCL em função da vazão de pico - Método de Clark 166

Figura 4.36 - Variação da constante kCL em função do tempo de concentração - Método de Clark. 148

Figura 4.37 - Variação da constante kCL em função da área de drenagem - Método de Clark 149

Figura 4.38 - Hidrograma de cheia para o método do SCS, variação do CN, período de retorno de 100 anos. 151

Figura 4.39 - Hidrograma de cheia para o método de Santa Bárbara, variação do CN, período de retorno de 100 anos...... 151

Figura 4.40 - Hidrograma de cheia para o método do SCS, variação da área de drenagem, período de retorno de 100 anos. 151

Figura 4.41 - Hidrograma de cheia para o método de Santa Bárbara, variação da área de drenagem, período de retorno de 100 anos 151

Figura 4.42 - Hidrograma de cheia para o método do SCS, variação da duração da chuva de projeto, período de retorno de 100 anos 152

Figura 4.43 - Hidrograma de cheia para o método de Santa Bárbara, variação da duração da chuva de projeto, período de retorno de 100 anos. 152

Figura 4.44 - Hidrograma de cheia para o método do SCS, variação do tempo de concentração, período de retorno de 100 anos. 152

Figura 4.45 - Hidrograma de cheia para o método de Santa Bárbara, variação do tempo de concentração, período de retorno de 100 anos. 152

Figura 4.46 - Relação entre as vazões do método de Santa Bárbara e SCS, variando CN e período de retorno 155

Figura 4.47 - Relação entre as vazões do método de Santa Bárbara e SCS, variando área de drenagem e período de retorno 156

Figura 4.48 - Relação entre as vazões do método de Santa Bárbara e SCS, variando tempo de concentração e período de retorno 156 
Figura 4.49 - Relação entre as vazões do método de Santa Bárbara e SCS, variando duração da chuva e período de retorno .................................................... 156

Figura 4.50 - Hidrograma de cheia para o método do SCS, variação do CN, período de retorno de 100 anos. 159

Figura 4.51 - Hidrograma de cheia para o método de Clark, variação do $\mathrm{CN}$, período de retorno de 100 anos 159

Figura 4.52 - Hidrograma de cheia para o método do SCS, variação da área de drenagem, período de retorno de 100 anos. 159

Figura 4.53 - Hidrograma de cheia para o método de Clark, variação da área de drenagem, período de retorno de 100 anos 159

Figura 4.54 - Hidrograma de cheia para o método do SCS, variação da duração da chuva de projeto, período de retorno de 100 anos 160

Figura 4.55 - Hidrograma de cheia para o método de Clark, variação da duração da chuva de projeto, período de retorno de 100 anos 160

Figura 4.56 - Hidrograma de cheia para o método do SCS, variação do tempo de concentração, período de retorno de 100 anos. 160

Figura 4.57 - Hidrograma de cheia para o método de Clark, variação do tempo de concentração, período de retorno de 100 anos. 160

Figura 5.1 - Tipos de revestimentos para canais trapezoidais e retangulares 168

Figura 5.2 - Grandezas envolvidas no dimensionamento de canais 169

Figura 5.3 - Piscinão RT - 1a/Paço Municipal de Mauá 175

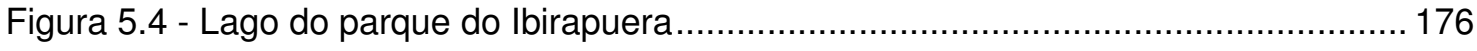

Figura 5.5 - Reservatório em série. Reservatório RVBo -1/Bonança............................... 177

Figura 5.6 - Reservatório em paralelo. Reservatório RPI-6/Sharp.................................... 177

Figura 5.7 - Vertedor lateral do reservatório RPI-6/Sharp 178

Figura 5.8 - Esquema representativo do escoamento sobre um vertedor de soleira delgada 180

Figura 5.9 - Hietograma e hidrograma para o cenário de projeto 182

Figura 5.10 - Dimensões do canal para o cenário de projeto 183

Figura 5.11 - Curva cota-volume 184 
Figura 5.12 - Representação esquemática do perfil do reservatório e da seção onde está posicionado o vertedor de soleira livre ...................................................... 185

Figura 5.13 - Hidrogramas afluente e efluente ao reservatório de controle de cheias ........ 185

Figura 5.14 - Volume Armazenado e lâmina d'água em função do tempo ......................... 186

Figura 5.15 - Hietograma e hidrograma de projeto - C - I ............................................ 188

Figura 5.16 - Hidrograma afluente e efluente - C - I ................................................ 188

Figura 5.17 - Volume armazenado e lâmina d'água em função do tempo para o cenário C - I 188

Figura 5.18 - Hietograma e hidrograma de projeto - C - II ........................................... 189

Figura 5.19 - Hidrograma afluente e efluente - C - II .................................................. 189

Figura 5.20 - Volume armazenado e lâmina d'água em função do tempo para o cenário C - II

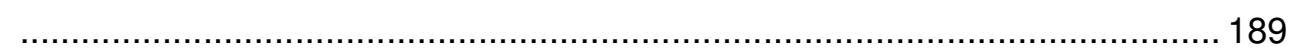

Figura 5.21 - Hietograma e hidrograma de projeto - C - III........................................ 190

Figura 5.22 - Hidrograma afluente e efluente - C - III ................................................ 190

Figura 5.23 - Volume armazenado e lâmina d'água em função do tempo para o cenário C -

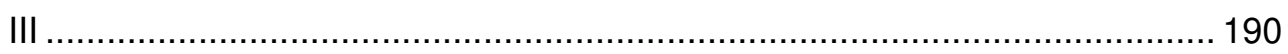

Figura 5.24 - Hietograma e hidrograma de projeto - C - IV ....................................... 191

Figura 5.25 - Hidrograma afluente e efluente - C - IV ................................................. 191

Figura 5.26 - Volume armazenado e lâmina d'água em função do tempo para o cenário C -

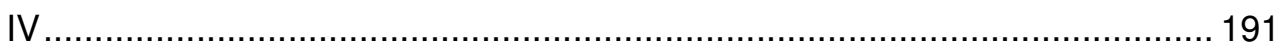

Figura 5.27 - Hietograma e hidrograma de projeto - C - V .......................................... 192

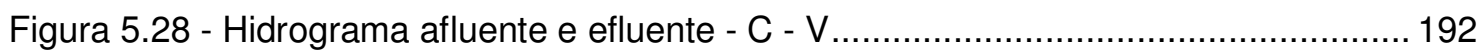

Figura 5.29 - Volume armazenado e lâmina d'água em função do tempo para o cenário C - V 192

Figura 5.30 - Hietograma e hidrograma de projeto - C - VI ..................................... 193

Figura 5.31 - Hidrograma afluente e efluente - C - VI............................................ 193

Figura 5.32 - Volume Armazenado e lâmina d'água em função do tempo para o cenário C -

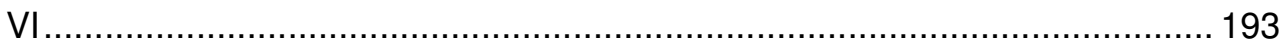

Figura 5.33 - Hietograma e hidrograma de projeto - C - VII......................................... 194

Figura 5.34 - Hidrograma afluente e efluente - C - VII.................................................. 194 
Figura 5.35 - Volume Armazenado e lâmina d'água em função do tempo para o cenário C -

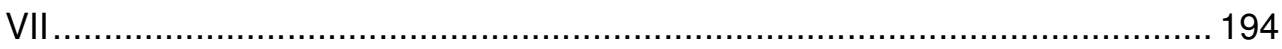

Figura 5.36 - Hietograma e hidrograma de projeto - C - VIII........................................... 195

Figura 5.37 - Hidrograma afluente e efluente - C - VIII................................................. 195

Figura 5.38 - Volume Armazenado e lâmina d'água em função do tempo para o cenário C -

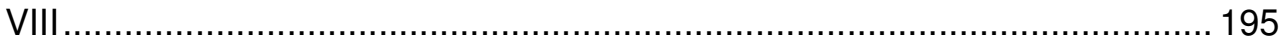

Figura 5.39 - Variação da lâmina d'água dos cenários alternativos em relação ao cenário de

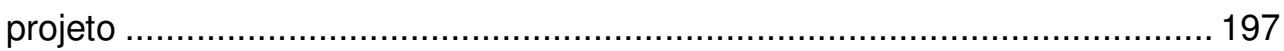

Figura 5.40 - Variações das vazões de pico e lâmina d'água no canal para os cenários

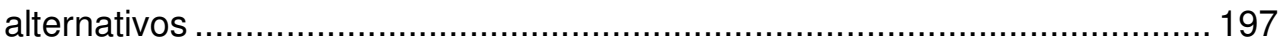

Figura 5.41 - Variação da carga hidráulica sobre o vertedor para os cenários alternativos em relação ao cenário de projeto................................................................... 200

Figura 5.42 - Variação da vazão efluente, lâmina d'água e volume armazenado............... 200 


\section{LISTA DE TABELAS}

Tabela 2.1 - Período de retorno para diferentes ocupações da área. 59

Tabela 2.2 - Riscos percentuais de falha em função do período de retorno e vida útil da obra

Tabela 2.3 - Conversão das Curvas CN para as diferentes condições de umidade do solo....

Tabela 2.4 - Valores de CN em função do grupo hidrológico, ocupação e tratamento do solo 84

Tabela 2.5 - Parâmetros de Horton para diferentes tipos de solo 87

Tabela 2.6 - Correspondência entre $\mathrm{CN}$ e os parâmetros de Green e Ampt, $\mathrm{f}_{\mathrm{C}}(\mathrm{mm} / \mathrm{h})$ e $\mathrm{S}_{\mathrm{f}}$ $(\mathrm{mm})$ 89

Tabela 2.7 - Valores para transformação do hidrograma triangular para o hidrograma curvilíneo do SCS 95

Tabela 3.1 - Faixa de variação dos valores para as variáveis analisadas 108

Tabela 3.2 - Quantidade de hidrogramas gerados para os parâmetros analisados 109

Tabela 3.3 - Variáveis do cenário de projeto e cenários alternativos 111

Tabela 4.1 - Análise de sensibilidade da vazão de pico em função da variação do valor do CN para o método do SCS 115

Tabela 4.2 - Análise de sensibilidade do volume do hidrograma de cheia em função da variação do valor do CN para o método do SCS

Tabela 4.3 - Análise de sensibilidade da vazão de pico em função da variação da área de drenagem para o método do SCS 120

Tabela 4.4 - Análise de sensibilidade do volume do hidrograma de cheia em função da variação da área de drenagem para o método do SCS 122

Tabela 4.5 - Análise de sensibilidade da vazão de pico em função da variação do valor do tempo de concentração para o método do SCS 125

Tabela 4.6 - Tempos de concentração para a bacia hidrográfica em estudo 127

Tabela 4.7 - Tempos de concentração para a bacia hidrográfica em estudo a partir da equação da Onda Cinemática 
Tabela 4.8 - Análise de sensibilidade do volume do hidrograma de cheia em função da variação do tempo de concentração para o método do SCS 129

Tabela 4.9 - Análise de sensibilidade da vazão de pico em função da variação da duração da chuva de projeto para o método do SCS 132

Tabela 4.10 - Análise de sensibilidade do volume do hidrograma de cheia em função da variação da duração da chuva de projeto para o método do SCS 135

Tabela 4.11 - Análise de sensibilidade da vazão de pico em função da variação do valor do CN para o método de Santa Bárbara. 137

Tabela 4.12 - Análise de sensibilidade da vazão de pico em função da variação da área de drenagem para o método de Santa Bárbara 138

Tabela 4.13 - Análise de sensibilidade da vazão de pico em função da variação do tempo de concentração para o método de Santa Bárbara. 139

Tabela 4.14 - Análise de sensibilidade da vazão de pico em função da variação da duração da chuva de projeto para o método de Santa Bárbara 140

Tabela 4.15 - Análise de sensibilidade da vazão de pico em função da variação do valor do CN para o método de Clark 143

Tabela 4.16 - Análise de sensibilidade da vazão de pico em função da variação da área de drenagem para o método de Clark 144

Tabela 4.17 - Análise de sensibilidade da vazão de pico em função da variação do tempo de concentração para o método de Clark 145

Tabela 4.18 - Análise de sensibilidade da vazão de pico em função da variação da duração da chuva de projeto para o método de Clark 146

Tabela 4.19 - Análise de sensibilidade da vazão de pico em função da variação do fator de forma para o método de Clark 147

Tabela 4.20 - Diferença percentual das vazões de pico entre os métodos de SCS e Santa Bárbara, variando o $\mathrm{CN}$. 153

Tabela 4.21 - Relação das vazões de pico entre os métodos de SCS e Santa Bárbara, variando a área de drenagem 154

Tabela 4.22 - Diferença percentual das vazões de pico entre os métodos de SCS e Santa Bárbara, variando o tempo de concentração 154

Tabela 4.23 - Diferença percentual das vazões de pico entre os métodos de SCS e Santa Bárbara, variando a duração da chuva 155 
Tabela 4.24 - Diferença percentual das vazões de pico entre os métodos de Clark e SCS,

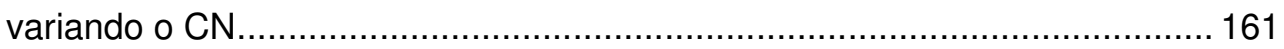

Tabela 4.25 - Diferença percentual das vazões de pico entre os métodos de Clark e SCS, variando a área de drenagem .................................................................... 161

Tabela 4.26 - Diferença percentual das vazões de pico entre os métodos de Clark e SCS, variando a duração do tempo de concentração 162

Tabela 4.27 - Diferença percentual das vazões de pico entre os métodos de Clark e SCS, variando a duração da chuva de projeto .................................................... 162

Tabela 5.1 - Valores de Manning sugeridos pelo DAEE.................................................. 172

Tabela 5.2 - Limites superiores para velocidades em canais ....................................... 173

Tabela 5.3 - Relação dos piscinões do Estado de São Paulo ....................................... 173

Tabela 5.4 - Variáveis do cenário de projeto e cenários alternativos............................... 186

Tabela 5.5 - Resumo dos resultados das simulações ................................................... 187

Tabela 5.6 - Lâmina d'água, velocidade máxima, altura do canal e variações das vazões e lâmina d'água ......................................................................................... 196

Tabela 5.7 - Vazão de pico efluente, carga hidráulica sobre o vertedor, volume armazenado no reservatório e as respectivas variações ................................................... 199 


\section{LISTA DE ABREVIATURAS E SIGLAS}

$A B C$

AHE

ANA

ASCE

CABC

CBERS

CL

$\mathrm{CTH}$

DAEE

DEO

EPUSP

ELETROBRÁS

ESD

EUA

FESP

FCTH

HidroWeb

HS

$\mathrm{HU}$

IAG

IDF

INPE

JAXA

LabSid

NASA

$\mathrm{PCH}$

RMSP

SAISP

SB
Análise de Bacias Complexas

Aproveitamento hidrelétrico

Agência Nacional de Águas

American society of civil engineers

Software para simulação hidrológica de bacias complexas

China-Brazil Earth Resource Satellite

Clark

Centro Tecnológico de Hidráulica

Departamento de Águas e Energia Elétrica do Governo do Estado de São Paulo

Departamento de Engenharia e Obras

Escola Politécnica da Universidade de São Paulo

Centrais elétricas brasileiras S/A

Escoamento superficial direto

Estados Unidos da América

Faculdade de Engenharia São Paulo

Fundação Centro Tecnológico de Hidráulica

Sistemas de Informações Hidrológicas na internet da ANA

Hidrograma sintético

Hidrograma unitário

Instituto Astronômico e Geofísico

Intensidade-duração-frequência

Instituto Nacional de Pesquisas Espaciais

Japan Aerospace Exploration Agency

Laboratório de suporte à decisão

National Aeronautics and Space Administration

Pequena central hidrelétrica

Região metropolitana de São Paulo

Sistema de Alerta a Inundações de São Paulo

Santa Bárbara 


$\begin{array}{ll}\text { SBC } & \text { São Bernardo do Campo } \\ \text { SBUH } & \text { Santa Barbara Unit Hydrograph } \\ \text { SCS } & \text { Soil Conservation Service } \\ \text { SIG } & \text { Sistemas de informações geográficas } \\ \text { SIGRH } & \text { Sistema Integrado de Gerenciamento de Recursos Hídricos } \\ \text { SP } & \text { São Paulo } \\ \text { SSD } & \text { Sistema de Suporte a Decisões } \\ \text { TCPO } & \text { Tabela para composição de preços e orçamentos } \\ \text { TRRM } & \text { Tropical Rainfall Measuring Mission } \\ \text { URSS } & \text { União das Repúblicas Socialistas Soviéticas } \\ \text { USDA } & \text { United States Department of Agriculture } \\ \text { USGS } & \text { United States Geological Survey } \\ \text { USP } & \text { Universidade de São Paulo }\end{array}$




\section{LISTA DE SÍMBOLOS}

$\begin{array}{ll}\Delta \mathrm{h} & \text { Diferença entre cotas } \\ \Delta \mathrm{t} & \text { Intervalo de tempo } \\ \Delta \mathrm{t}^{\prime} & \text { Período de tempo incrementado } \\ \theta_{\mathrm{n}} & \text { Água contida no solo nas condições naturais de saturação } \\ \theta_{\mathrm{i}} & \text { Quantidade de água inicial do solo } \\ \mathrm{A} & \text { Área de drenagem da bacia hidrográfica } \\ \mathrm{Ai} & \text { Área contribuinte } \\ \mathrm{A}_{\text {iso }} & \text { Área entre as isócronas } \\ \mathrm{A}_{\mathrm{m}} & \text { Área molhada } \\ \mathrm{b} & \text { Borda livre } \\ \mathrm{C} & \text { Coeficiente de Chézy } \\ \mathrm{C} & \text { Rugosidade de retardo } \\ \mathrm{Cd} & \text { Coeficiente de descarga (ou vazão) } \\ \mathrm{CN} & \text { Número de curva (Curve number) } \\ \mathrm{El} . & \text { Elevação do terreno } \\ \mathrm{d} & \text { Duração da chuva de projeto } \\ \mathrm{d} & \text { Porção impermeável diretamente conectada da bacia de drenagem } \\ \mathrm{Dh} & \text { Diâmetro hidráulico } \\ \mathrm{dt} & \text { Intervalo de discretização } \\ \mathrm{F} & \text { Infiltração acumulada } \\ \mathrm{F}(\Delta \mathrm{t}) & \text { Infiltração durante o incremento de tempo } \\ \mathrm{f} & \text { Taxa de infiltração no tempo } \\ \mathrm{f}_{0} & \text { Taxa de infiltração inicial } \\ \mathrm{f}_{\mathrm{c}} & \text { Taxa de infiltração final } \\ \mathrm{g} & \text { Aceleração da gravidade } \\ \mathrm{h} & \text { Horas } \\ \mathrm{H}_{0} & \text { Lâmina de água depositada sobre o solo } \\ \mathrm{H}_{\mathrm{c}} & \text { Altura do canal } \\ \mathrm{H}_{\mathrm{f}} & \text { Sucção capilar exercida pelo solo } \\ \mathrm{h}_{\mathrm{f}} & \text { Perda de carga } \\ & \\ & \end{array}$




\begin{tabular}{|c|c|}
\hline $\mathrm{H}_{\mathrm{v}}$ & Carga hidráulica sobre o vertedor \\
\hline I & Intensidade da chuva \\
\hline i & Declividade do fundo do canal \\
\hline Ip & Declividade piezométrica \\
\hline J & Declividade da linha de energia \\
\hline $\mathrm{k}_{\mathrm{CL}}$ & Coeficiente de armazenamento de Clark \\
\hline $\mathrm{k}_{\mathrm{F}}$ & Constante da fórmula de Horton \\
\hline km & Quilômetro \\
\hline $\mathrm{k}_{\mathrm{SB}}$ & Coeficiente de armazenamento de Santa Bárbara \\
\hline L & Comprimento do Talvegue \\
\hline $\mathrm{L}_{\mathrm{c}}$ & Largura do canal \\
\hline$L_{v}$ & Largura do vertedor \\
\hline $\mathrm{m}$ & metro \\
\hline $\mathrm{mi}$ & Milhas \\
\hline $\min$ & minuto \\
\hline N & Número de isócronas \\
\hline $\mathrm{n}$ & Coeficiente de Manning \\
\hline$n_{f}$ & Fator de forma \\
\hline$P$ & Total precipitado \\
\hline $\mathrm{P}(\Delta \mathrm{t})$ & Acúmulo de chuva durante o incremento de tempo \\
\hline$P_{\text {acum }}$ & Total precipitado acumulado \\
\hline$P_{\text {ESCacum }}$ & Escoamento superficial direto acumulado \\
\hline$P_{\text {exc }}$ & Chuva excedente \\
\hline $\mathrm{P}_{\mathrm{m}}$ & Perímetro molhado \\
\hline Q & Vazão \\
\hline Qaflu & Vazão afluente \\
\hline Qeflu & Vazão efluente \\
\hline Qp & Vazão de pico \\
\hline $\mathrm{R}$ & Risco \\
\hline $\mathrm{R}(\Delta \mathrm{t})$ & Acúmulo do escoamento para cada período acumulado \\
\hline $\mathrm{Rh}$ & Raio Hidráulico \\
\hline $\mathrm{R}(\mathrm{I})$ & Áreas impermeáveis \\
\hline$R(P)$ & Áreas permeáveis \\
\hline
\end{tabular}


Declividade média em cada trecho do talvegue

S

$\mathrm{S}_{\mathrm{i}}$

$S_{f}$

$\mathrm{T}$

$\mathrm{t}$

$t_{a}$

$t_{c}$

$t_{b}$

$t_{r}$

V

v

Vútil

W

Y

$Y_{c}$

Z
Retenção potencial do solo

Declividade equivalente do talvegue

Sucção exercida pela camada superior do solo

Período de retorno

Tempo

Tempo de ascensão

Tempo de concentração

Tempo de base

Tempo de retardamento

Volume

Velocidade

Vida útil

Quantidade de água acumulada no solo

Profundidade

Lâmina d'água no canal

Carga de posição 


\section{SUMÁRIO}

OBJETIVO

1 INTRODUÇÃO

2 REVISÃO DA LITERATURA

2.1 SISTEMA DE SUPORTE A DECISÕES EM RECURSOS HÍDRICOS ........36

2.2 MODELOS MATEMÁTICOS DE SIMULAÇÃO HIDROLÓGICA ..................41

2.3 SISTEMA DE SUPORTE A DECISÕES PARA ANÁLISE DE ONDAS DE CHEIAS EM BACIAS COMPLEXAS - SSD ABC ..................................49

2.4 CONCEITUAÇÕES HIDROLÓGICAS DO SSD ABC .................................58

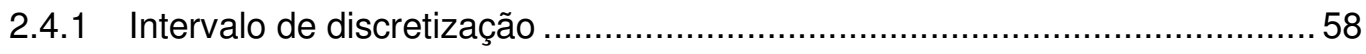

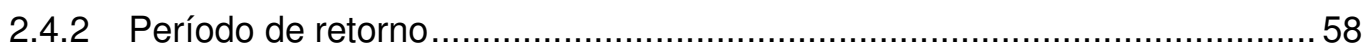

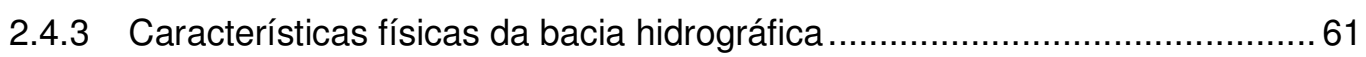

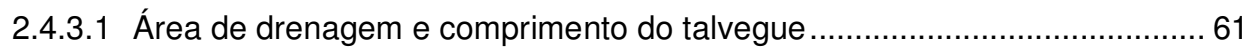

2.4.3.2 Declividade do rio e diferença entre cotas ................................................ 64

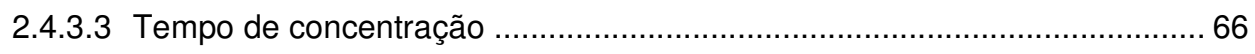

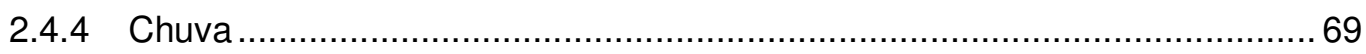

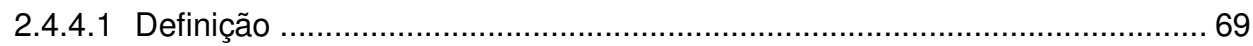

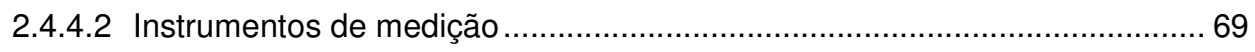

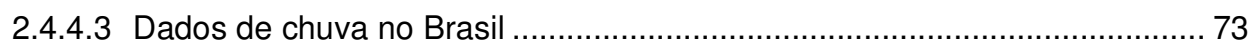

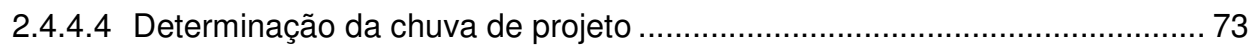

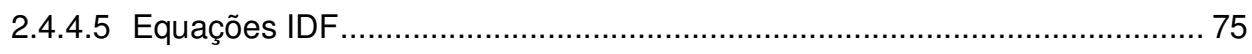

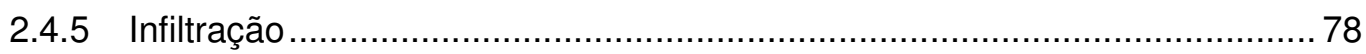

2.4.5.1 Método do SCS (SCS runoff curve number method) ................................. 80

2.4.5.2 Método de Horton................................................................................. 86

2.4.5.3 Método de Green e Ampt .................................................................... 88

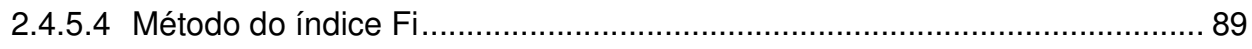

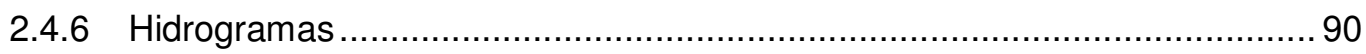

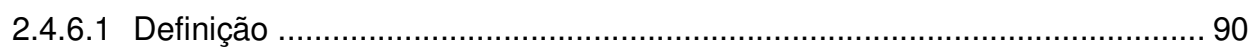

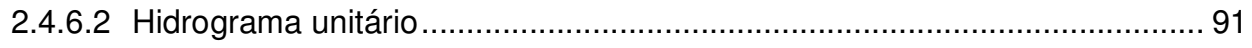

2.4.6.3 Método do hidrograma unitário sintético do Soil Conservation Service ............

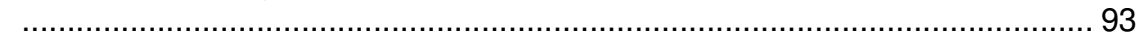

2.4.6.4 Método do hidrograma unitário sintético de Clark ..................................... 95

2.4.6.5 Método do hidrograma unitário sintético de Santa Bárbara........................ 100

2.4.6.6 Comparação teórica entre os métodos ................................................... 103 
3 METODOLOGIA

3.1 METODOLOGIA DOS ESTUDOS DE ANÁLISE DE SENSIBILIDADE ....104

3.1.1 Métodos de obtenção de hidrogramas avaliados .................................... 104

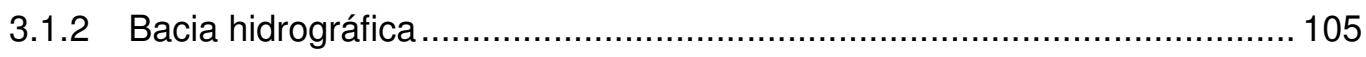

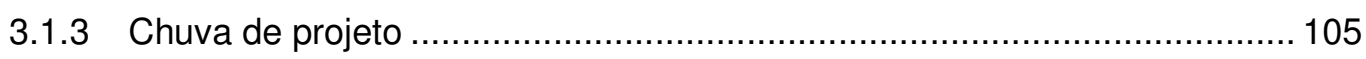

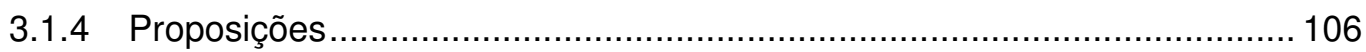

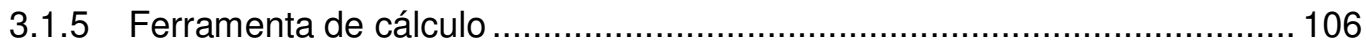

3.1.6 Desenvolvimento das análises...................................................... 107

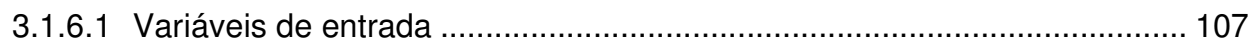

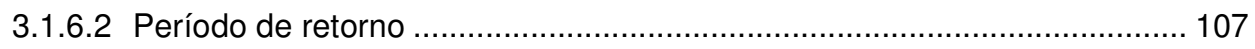

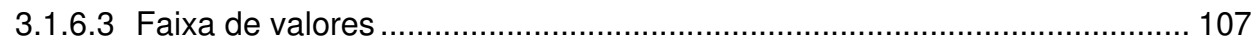

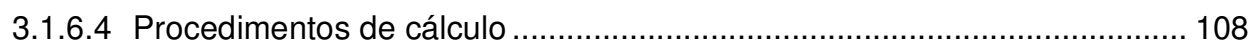

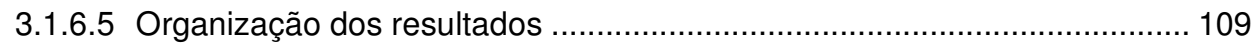

3.2 METODOLOGIA DO ESTUDO DE APLICAÇÃO PRÁTICA .....................110

3.2.1 Definição das estruturas hidráulicas ..................................................... 110

3.2.2 Variável hidráulica de análise ...................................................... 110

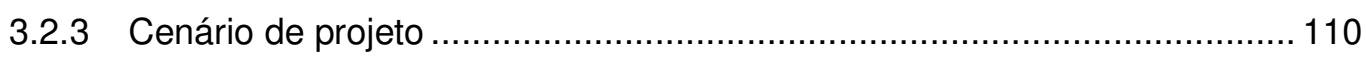

3.2.4 Cenários alternativos ............................................................................ 110

3.2.5 Variáveis hidrológicas avaliadas ........................................................ 111

3.2.6 Equações de dimensionamento ..................................................... 111

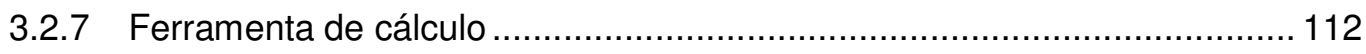

3.2.8 Organização dos resultados .......................................................... 113

4 RESULTADOS E DISCUSSÃO....................................................................114

4.1 MÉTODO DO HIDROGRAMA UNITÁRIO SINTÉTICO DO SCS ..............114

4.1.1 Análise de sensibilidade em relação ao valor de CN .............................. 114

4.1.2 Análise de sensibilidade em relação ao valor da área de drenagem........... 119

4.1.3 Análise de sensibilidade em relação ao tempo de concentração ................ 123

4.1.4 Análise de sensibilidade em relação à duração a ser adotada para a chuva de projeto .............................................................................. 130

4.2 MÉTODO DE SANTA BÁRBARA ................................................... 136

4.3 MÉTODO DE CLARK ................................................................ 142

4.4 COMPARAÇÃO ENTRE OS MÉTODOS SINTÉTICOS DE OBTENÇÃO DE HIDROGRAMAS DE CHEIA ..................................................... 149

4.4.1 Método do hidrograma unitário do SCS versus Santa Bárbara .................. 157

4.4.2 Método do hidrograma unitário do SCS versus Clark ............................. 175 


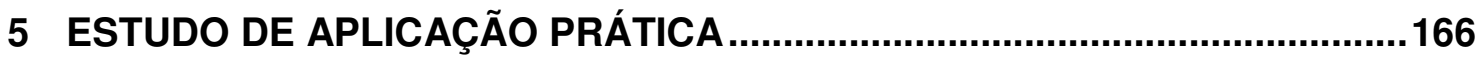

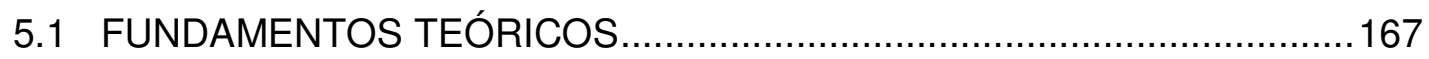

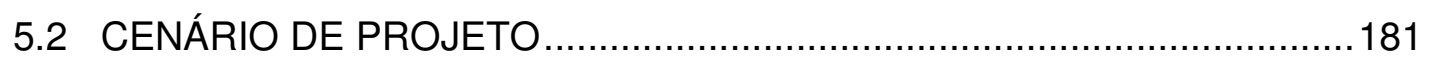

5.2.1 Dimensionamento do canal para o cenário de projeto ................................ 182

5.2.2 Dimensionamento do vertedor do reservatório de controle de cheias para o cenário de projeto, verificação da redução da vazão de pico e volume

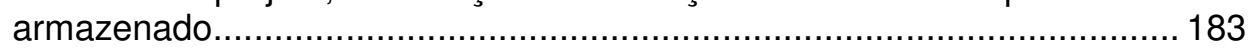

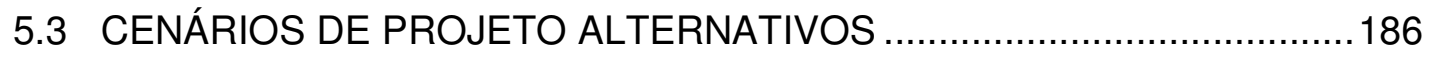

5.3.1 Verificação da lâmina d'água do canal para as vazões correspondentes aos

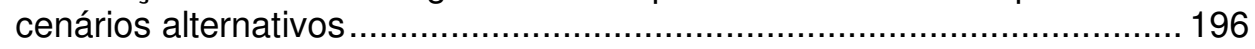

5.3.2 Verificação da carga hidráulica sobre o vertedor do reservatório de controle de cheias e diferenças na redução da vazão de pico efluente e volume armazenado.....

6 CONCLUSÕES .202

7 RECOMENDAÇÕES .204

REFERÊNCIAS BIBLIOGRÁFICAS .206

BIBLIOGRAFIA CONSULTADA .213

APÊNDICE 


\section{OBJETIVO}

O objetivo do trabalho proposto é o de realizar a análise de sensibilidade de hidrogramas sintéticos às variações dos seus parâmetros de definição, utilizando como ferramenta o SSD ABC 6, desenvolvido no Labsid do Departamento de Engenharia Hidráulica e Sanitária da Escola Politécnica da Universidade de São Paulo. 


\section{INTRODUÇÃO}

Para que as estruturas hidráulicas possam ser dimensionadas e construídas, é necessário o conhecimento do hidrograma de projeto. A partir deste hidrograma, tem-se o conhecimento do volume do escoamento superficial direto $\left(\mathrm{V}_{\text {esd }}\right)$ e da máxima vazão que pode ocorrer em função de um determinado período de retorno.

Em hidrologia, as vazões e os respectivos hidrogramas de projeto são determinados a partir da análise direta dos dados observados de vazões ou da análise indireta de determinadas características físicas da bacia hidrográfica e de dados observados de chuva.

$\mathrm{Na}$ análise direta, a vazão de pico e o hidrograma de projeto são definidos por inferência estatística.

$\mathrm{Na}$ análise indireta, quando não existem registros de dados observados ou quando o período de observação é insuficiente, ou seja, a amostra não é representativa da população, a estimativa é feita com métodos de obtenção do hidrograma unitário sintético. Basicamente, nos métodos indiretos, a vazão de pico e o respectivo hidrograma são definidos a partir dos dados de chuvas, que são menos escassos do que os dados de vazões e sofrem menor influência em decorrência de alterações antrópicas da bacia hidrográfica. Se, ainda os dados de chuva forem insuficientes, são usadas as equações intensidade-duração-frequência (IDF) da região mais próxima a do estudo.

Consta que a determinação da vazão, a partir de métodos indiretos, iniciou-se por volta do século XIX. O método Racional, de uso frequente em estudos de drenagem urbana, para bacias com áreas de drenagem com limite aproximado de $5 \mathrm{~km}^{2}$, foi pela primeira vez mencionado na literatura americana, em 1889, por Kuichling (CHOW, 1964). 
Em 1932, Sherman propôs a teoria do hidrograma unitário.Um dos primeiros hidrogramas unitários sintéticos foi o proposto por McCarthy, em 1938. Neste mesmo ano, Snyder, após analisar um grande número de bacias hidrográficas na região dos montes Apalaches (EUA), apresentou, baseado nos princípios do hidrograma unitário de Sherman, o seu método de hidrograma sintético, utilizado até hoje (CHOW, 1964).

No ano de 1945, consta uma publicação de Clark, que apresenta a teorização de um hidrograma sintético, que considera os efeitos de translação e amortecimento determinados pelo trânsito da chuva excedente sobre a bacia (CLARK, 1945).

Em 1972, foi introduzido pelo Departamento de Agricultura dos EUA, um método capaz de uma simplificação geométrica do processo físico, para o qual o volume de escoamento superficial direto, corresponde à área do hidrograma de formato triangular (SCS, 1972). Mais tarde, coeficientes que permitem a transformação do formato triangular em curvilíneo foram apresentados (SCS, 1986 apud WANIELISTA, KERSTEN E EAGLIN, 1997).

O método de Santa Bárbara, desenvolvido por Stubchaer, foi pela primeira vez apresentado no Simpósio Nacional de Hidrologia Urbana e Controle de Sedimentos, realizado na Universidade de Kentuchy, em 1975. Este método, também considera os efeitos de translação e amortecimento (STRUBCHAER, 1975).

Apesar destes métodos serem embasados em teorias desenvolvidas há mais de setenta anos, são largamente utilizados em estudos, para os quais o conhecimento do volume do escoamento superficial direto e a vazão de pico são fundamentais.

Não se deve esquecer que os métodos sintéticos são válidos desde que aplicados às condições que se aproximem daquelas para as quais foram desenvolvidos. No entanto, algumas vezes, a adoção destes métodos é feita sem as devidas adaptações e análises mais criteriosas. Neste sentido, a técnica da análise de sensibilidade pode, em caráter preliminar, representar um instrumento útil, uma vez que permite a avaliação da importância dos parâmetros de entrada destes métodos sobre o resultado final da vazão de pico e do respectivo hidrograma de cheia. 
Considerando-se que será utilizado como ferramenta de auxílio aos cálculos hidrológicos, o Sistema de Suporte a Decisão ABC 6 (SSD ABC 6) desenvolvido no Laboratório de Sistemas de Suporte a Decisão (Labsid) do Departamento de Engenharia Hidráulica e Sanitária da Escola Politécnica da Universidade de São Paulo, as análises de sensibilidade serão feitas em relação aos parâmetros que definem os hidrogramas de cheia, obtidos a partir do método do hidrograma unitário do Soil Conservation Service (SCS), do método de Santa Bárbara e do método de Clark.

Nas análises de sensibilidade, serão avaliados: número de curva $(\mathrm{CN})$, área de drenagem (A), tempo de concentração (tc) e duração da chuva de projeto (d), para os métodos que compõem o SSD ABC 6. Também foi feita uma comparação entre estes métodos.

Nos estudos que envolvem a previsão de cenários futuros, existe grande dificuldade na estimativa do valor de $\mathrm{CN}$.

Em relação ao tempo de concentração, restam as incertezas devidas à estimativa das velocidades do ESD sobre a superfície da bacia hidrográfica e dos canais.

Há de se ressaltar que os sistemas de informações geográficas (SIG) ajudam a melhor definir as características fisiográficas das bacias, minimizando as incertezas na determinação destas características.

Todos os parâmetros foram avaliados em função do período de retorno da precipitação. Foram escolhidos os períodos de retorno de 5, 10, 50, 100 e 500 anos.

A respeito do período de retorno da precipitação e do hidrograma de projeto, Tucci (2004, p. 549) cita o seguinte:

O hidrograma de projeto resultante não terá vazão e volume com o mesmo risco, além disso, o risco associado está relacionado com a precipitação escolhida, o que não é necessariamente o risco da vazão ou do volume máximo resultante. O risco é escolhido de acordo com o projeto. 
Espera-se, que este trabalho possa fornecer subsídios aos estudos hidrológicos nos campos em que a determinação do escoamento superficial direto seja importante, que sirva de material didático e desperte o interesse na construção de um aplicativo que integre a função de análise de sensibilidade.

Este trabalho está dividido em sete capítulos. No Capítulo 2 são discutidos os pontos fundamentais de um sistema de suporte a decisões em recursos hídricos e dos modelos matemáticos de simulação hidrológica, visando introduzir uma explicação mais detalhada a respeito do SSD ABC 6. É feita uma revisão bibliográfica das conceituações hidrológicas para as quais o SSD ABC 6 foi desenvolvido.

No Capítulo 3, é apresentada a metodologia dos estudos de análise de sensibilidade e do estudo de aplicação prática.

No Capítulo 4, são apresentados os resultados das análises de sensibilidade para os parâmetros e métodos avaliados.

No Capítulo 5, foi desenvolvido um estudo de aplicação prática. Realizou-se o dimensionamento de um canal e um vertedor retangular de soleira livre de um reservatório de controle de cheias.

Finalmente, as conclusões e recomendações são feitas no Capítulo 6 e 7 , respectivamente. 


\section{REVISÃO DA LITERATURA}

\subsection{SISTEMA DE SUPORTE A DECISÕES EM RECURSOS HÍDRICOS}

Tomar decisões e solucionar problemas são atividades próprias do ser humano. Não fosse a capacidade de decidir racionalmente e solucionar problemas, a espécie humana não teria alcançado os estágios atuais de desenvolvimento e talvez não tivesse sobrevivido a tantos fatores adversos.

O homem, em sua tarefa de solucionar problemas e tomar decisões, necessita de informações a respeito do problema e uma base conceitual adequada para sua formulação. Equacionada as possíveis soluções do problema, o homem está apto a tomar decisões. Acontece que nem todos os problemas são de fácil resolução e, portanto, seu equacionamento e suas possíveis soluções não se processam tão rapidamente quanto se necessita. Neste cenário, o homem criou o computador, para que este pudesse apoiá-lo em sua tarefa. Assim, nestes últimos trinta anos, viu-se nascer e prosperar uma metodologia de auxílio à tomada de decisões, baseada na intensa utilização de base de dados, modelos matemáticos e na facilidade do diálogo entre usuário e computador.

Em sentido amplo, qualquer coisa que ajude (ou apóie) uma tomada de decisão pode ser considerada como um Sistema de Suporte a Decisões (SSD). O principal componente de sistemas deste tipo é sua base de dados, capaz de reunir todas as informações importantes sobre o problema e gerenciá-las de forma apropriada. Não é a toa que grande parte dos SSD hoje existentes surgiu como uma evolução dos chamados "Sistemas de Gerenciamento de Dados" ou "Sistemas Integrados de Informações" (PORTO et al., 2002).

Uma definição mais restritiva de SSD e aceita por diversos autores (SPRAGUE E CARLSON, 1982; KLEIN E METHLE, 1990; SPRAGUE E WATSON, 1993; SAGE, 1991; GUARISO, 1984; TURBAN, 1993 apud PORTO et. al., 2002, p. 45) é a 
descrita da seguinte maneira:

SSD são sistemas computacionais que tem por objetivo ajudar indivíduos que tomam decisões na solução de problemas não estruturados (ou parcialmente estruturados).

Para melhor entendimento desta definição, os problemas estruturados são aqueles que podem ser formulados como um algoritmo, ou seja, a solução do problema é feita sem ambiguidades, como uma sequência lógica de etapas em que a solução de cada etapa leva à solução da próxima. Nesta situação o uso da ferramenta computacional é importante, mas não decisiva. Ao contrário, um problema não estruturado não pode ser formulado a partir de algoritmos bem definidos e não são facilmente tratáveis por computador. Em consequência, a solução destes problemas exige uma estreita interação entre o homem e o computador.

Na definição acima, também deve ser enfatizado o conceito de suporte (no sentido de ajuda ou apoio), no qual o computador deve ser colocado à disposição do tomador de decisões para que ele possa dispor de informações, identificar e formular problemas, conceber e analisar alternativas e, finalmente, escolher o melhor curso de ação. Desde o início deve ficar claro que um SSD não deve ser construído para tomar decisões, mas para auxiliar o homem em sua missão de decidir.

Como características necessárias (ou desejáveis), após revisão de 350 publicações sobre o assunto, Parker e Al-Utabi (1986 apud PORTO et. al., 2002, p. 48) afirmam que um SSD deve:

- Assessorar administradores no processo de tomada de decisões a respeito de problemas não estruturados ou semi-estruturados;

- Apoiar e aprimorar o julgamento humano e não tentar substituí-lo;

- Melhorar mais a eficácia da decisão do que sua eficiência, ou em outros termos, dar mais importância à qualidade da decisão do que ao tempo necessário para encontrá-la;

- Combinar o uso de modelos (ou técnicas analíticas) com funções de acesso a dados; 
- Enfatizar as características de flexibilidade e adaptabilidade no que diz respeito à mudança de contexto do processo decisório;

- Enfatizar a facilidade de uso, inclusive por usuários inexperientes ou não especializados.

Passados alguns anos de avanços tecnológicos, Porto (2002) complementou a relação acima, com as seguintes características adicionais:

- Facilitar a interação entre o usuário e o sistema e permitir a busca de soluções por processos tentativos;

- Permitir a incorporação de julgamentos subjetivos;

- Incorporar o conhecimento de especialistas;

- Incorporar, quando necessário, variáveis de cunho social, político e psicológico.

Segundo Porto (2002), a estrutura típica de um SSD é apresentada na Figura 2.1 e é composta pelos seguintes componentes:

- Base de dados: Deve ser capaz de reunir todas as informações importantes sobre o problema e gerenciá-las de forma apropriada. Deve reunir o "conhecimento" que se tem do problema e torná-lo disponível, de forma adequada aos outros componentes do sistema;

- Base de Modelos: deve conter os modelos, ou seja, toda a base conceitual necessária à análise e formulação de alternativas de solução do problema em questão.

- Base de Conhecimento: permite incorporar ao sistema conhecimentos que se referem à experiência de especialistas, conhecimentos empíricos, disposição de normas e regulamentos.

- Módulo de Diálogo: responsável pela comunicação do usuário com o computador. 


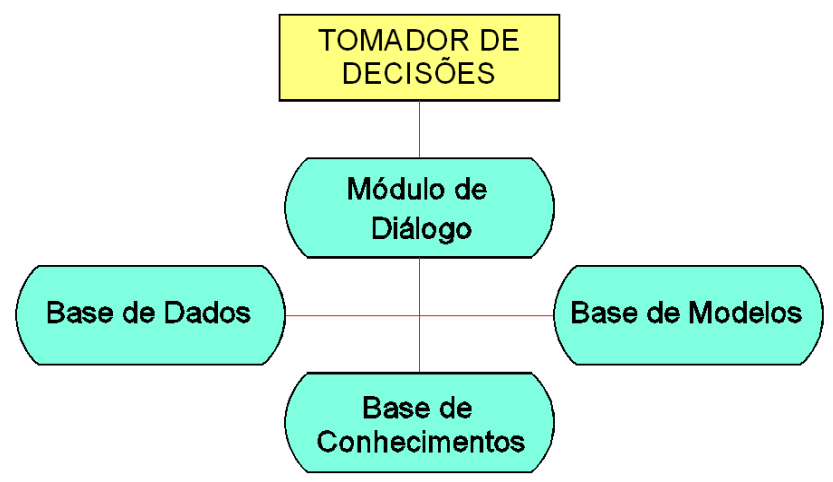

Figura 2.1 - Estrutura típica de um SSD

Fonte: Porto, 2002. p. 87.

Quanto à construção de um SSD, não existem fórmulas ou determinações acabadas, apenas algumas orientações estratégicas. Em linhas gerais, a construção de um SSD está relacionada com a combinação criativa de técnicas já existentes, para produzir informações a partir das quais indivíduos tomarão decisões. Um SSD deve ser centrado no problema da decisão e não obrigatoriamente na utilização das melhores e mais avançadas técnicas; este deve ser capaz de induzir às melhores decisões.

Um dos usos do SSD é descrito por Porto (2002, p. 47):

A experiência tem mostrado, também, que os Sistemas de Suporte a Decisão são instrumentos eficientes para auxiliar os chamados "Grupos de Tomada de Decisões". Nestes grupos, as naturais diferenças de ponto de vista, interesses, ideologias e formação dos participantes costumam dificultar e até mesmo impossibilitar a escolha dos melhores cursos de ação. A idéia central, neste caso, é permitir que cada um dos participantes avalie as consequências da implementação de suas idéias com o auxilio de modelos aceitos por todos, a partir de uma base comum de informações. Começam a surgir, a partir daí, as oportunidades de soluções negociadas e participativas que tendem a contar com o apoio e o comprometimento de todo o grupo.

Diante desta breve discussão a respeito de SSD, não é difícil supor que se trata de uma ferramenta indispensável na tomada de decisões em recursos hídricos, uma área caracterizada por conflitos, incertezas de diversas naturezas, investimentos de porte elevado e de repercussões econômicas, sociais e ambientais significativas. 
Decisões de boa qualidade nesta área contribuem enormemente para o desenvolvimento do país e, em contrapartida, situações concretizadas baseadas em decisões pobres podem acarretar prejuízos de vários tipos, geralmente de correção onerosa, quando não impossível.

Outro fator a ser considerado, devido à consciência ecológica, marcada pelo conceito de desenvolvimento sustentável, é a participação de grupos heterogêneos dotados de níveis de informações, interesses e ideologias diferentes, que apesar de tornarem as decisões a respeito da utilização dos recursos hídricos mais democráticas, tendem torná-las muito mais complexas. Assim, o uso de SSD auxilia os tomadores de decisão a levar em conta, na resolução dos problemas relativos aos recursos hídricos, os aspectos hidrológicos, ambientais, econômicos, políticos, sociais, financeiros e legais mutáveis no tempo e associados a incertezas de difícil quantificação.

Como exemplo de SSD aplicado a problemas de recursos hídricos pode ser citado o SSD ABC 6, desenvolvido no Laboratório de Sistemas de Suporte a Decisões (LabSid), do Departamento de Engenharia Hidráulica e Sanitária da Escola Politécnica, que permite a análise de cheias em bacias complexas e o estudo de diversos cenários que auxiliam significativamente a tomada de decisões em projeto de obras de drenagem urbana em pequenas bacias hidrográficas desprovidas de dados fluviométricos.

O SSD ABC 6 enquadra-se como um sistema de suporte à decisão, uma vez que possui módulo de diálogo, caracterizado por uma interface gráfica amigável e simples de operar. Possui uma base de dados, composta por equações de chuva intensa para várias regiões brasileiras, tabelas de rugosidade e tabelas que relacionam o valor de $\mathrm{CN}$. $\mathrm{Na}$ base modelos, estão disponíveis para o cálculo da infiltração os métodos do SCS, Horton, Green e Ampt e Índice Fi. Para o traçado dos hidrogramas de projeto, os métodos dos hidrogramas do SCS, Santa Bárbara e Clark. O usuário pode incorporar ao sistema, dados relativos à sua experiência e disposições de normas e regulamentos. Este SSD será discutido no item 2.3 e possibilitará o estudo de sensibilidade proposto nesta pesquisa. 


\subsection{MODELOS MATEMÁTICOS DE SIMULAÇÃO HIDROLÓGICA}

Como visto no item 2.1, os sistemas de suporte a decisões são constituídos pela base modelo. Nesta base, estão todas as conceituações necessárias à análise e formulação de alternativas de solução do problema em questão.

O modelo é uma representação simplificada da realidade, segundo Tucci (2005, p.17):

O modelo é a representação de algum objeto ou sistema, numa linguagem ou forma de fácil acesso e uso, com o objetivo de entendê-lo e buscar suas respostas para diferentes entradas.

O modelo hidrológico é uma das ferramentas que a ciência desenvolveu para melhor entender e representar o comportamento da bacia hidrográfica e prever condições diferentes das observadas. Podem representar todo o ciclo hidrológico ou parte deste, uma vez que os fenômenos naturais como precipitação, evaporação, infiltração e o escoamento em rios, dependem de um grande número de fatores, que dificulta a análise quantitativa e qualitativa dos mesmos. O ciclo hidrológico é ilustrado na Figura 2.2

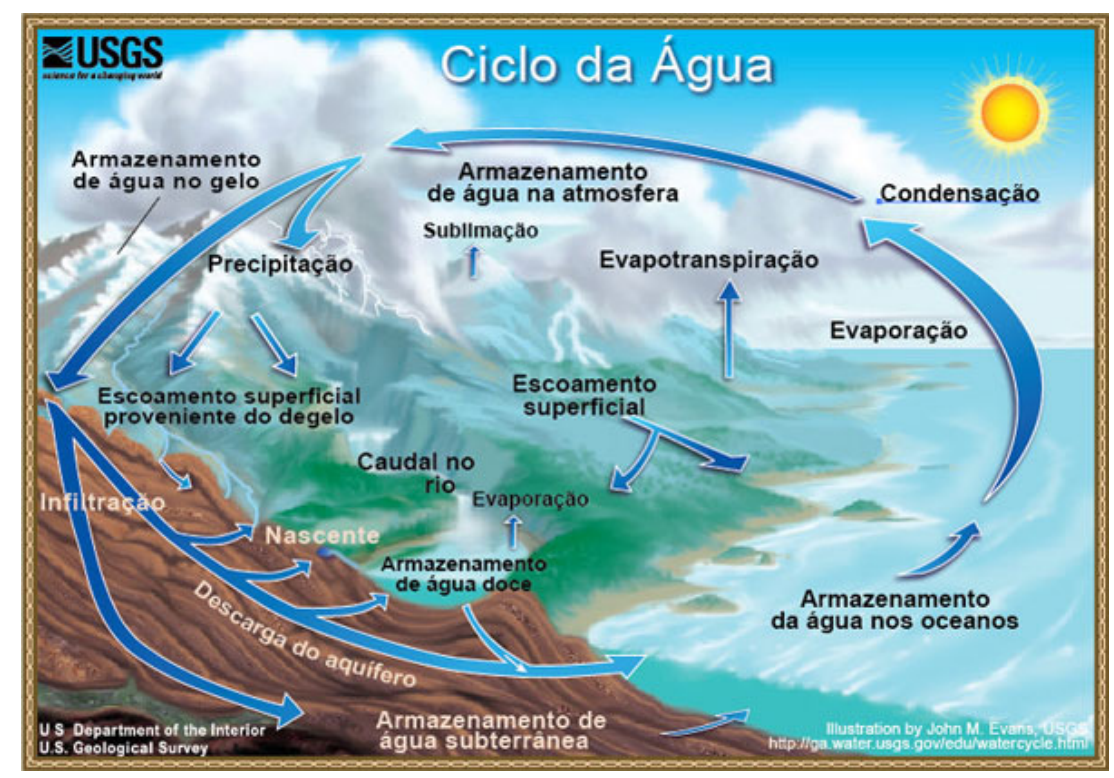

Figura 2.2 - Ciclo Hidrológico Fonte: USGS, $2009^{1}$.

\footnotetext{
${ }^{1}$ Disponível em: <http://ga.water.usgs.gov/edu/watercycleportuguese.html>. Acesso em 08 ago. 2009.
} 
Sobre os modelos hidrológicos, Rennó (2004, p. 11) escreve o seguinte:

\begin{abstract}
Os modelos hidrológicos são ferramentas úteis para o entendimento do comportamento hidrológico de bacias hidrográficas. Estes modelos deveriam representar grande parte dos processos hidrológicos a fim de produzir resultados realistas. Entretanto, os modelos são apenas uma aproximação da realidade e requerem uma boa inicialização das variáveis de estado e uma grande quantidade de dados para representar apropriadamente os processos.
\end{abstract}

Cabe salientar que os modelos são aplicáveis em todas as áreas de conhecimento. Estes, podem ser: físicos, analógicos e matemáticos. A definição apresentada é dada por Tucci (2005, p. 20).

O modelo físico representa o sistema por um protótipo em escala. Como exemplos podem ser citados os modelos reduzidos de obras hidráulicas, produzidos de acordo com a teoria da semelhança.

Os modelos analógicos valem-se da analogia das equações que regem diferentes fenômenos, para modelar o sistema mais conveniente. A representação de um fenômeno hidráulico ou hidrológico por um circuito elétrico é um exemplo deste tipo de modelo.

Já os modelos matemáticos representam a natureza do sistema através de equações matemáticas. Estes são mais flexíveis que os anteriores, pois permitem com grande facilidade a variação de seus parâmetros e possuem grande velocidade de resposta. Sua desvantagem está na discretização de processos contínuos e na dificuldade na representação matemática de alguns processos físicos. Em geral, os modelos matemáticos de simulação são classificados em:

- Linear e não-linear: Um sistema é linear quando o princípio de superposição é válido. Para caracterizar este princípio, considere que $Y_{1}$ é uma entrada do sistema que produz a saída $X_{1}$. Da mesma forma, a entrada $Y_{2}$ resulta na saída $X_{2}$ do mesmo sistema. Sendo assim, o sistema é linear quando $n Y_{1}$ produz a saída $\mathrm{nX}$. No exemplo da Figura 2.3, o comprimento da mola 
aumenta proporcionalmente à massa adicionada em sua extremidade (sistema linear). Isto ocorre até que a força peso seja inferior ao limite de deformação elástica do material da mola, quando o sistema se torna nãolinear;

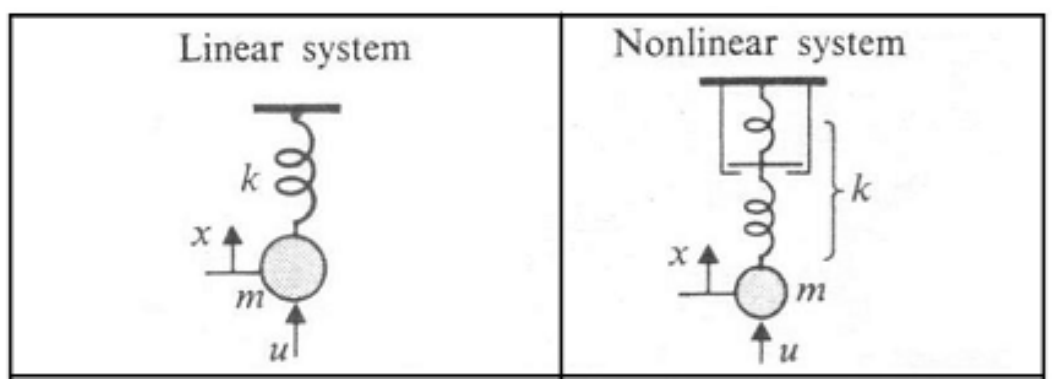

Figura 2.3 - Exemplos de modelo linear e não-linear Fonte: Takahashi et al. apud Trivelato, 2003.

- Contínuos e Discretos: Um modelo é contínuo quando os fenômenos são contínuos no tempo. Ao contrário, quando as mudanças ocorrem em intervalos, é denominado discreto. Para Kelton et al. (2003), um modelo contínuo é aquele em que o status do sistema pode se alterar continuamente ao longo do tempo, tal como o nível de um reservatório, com o fluxo de entrada e saída de água, ocorrência de evaporação e precipitação. Já em um modelo discreto, os eventos podem ocorrer apenas em momentos isolados, tal qual uma fábrica, em que peças e materiais entram e saem em horários específicos e pontuais. Na Figura 2.4, tem-se um exemplo de um fenômeno qualquer, sendo medido continuadamente e pontualmente (discretamente);

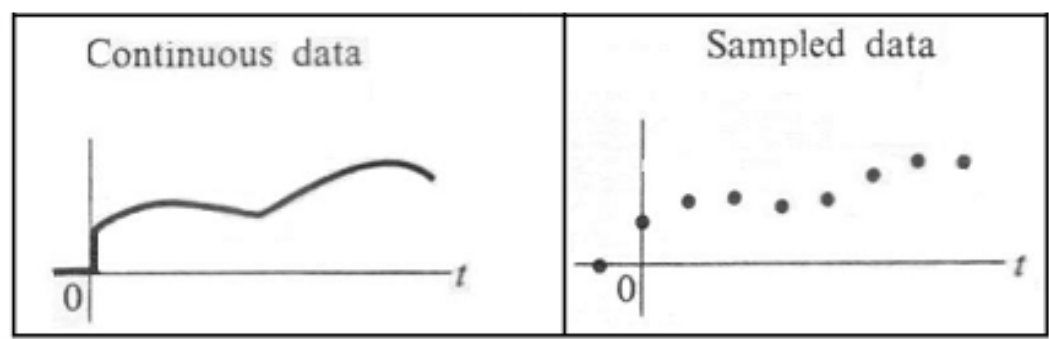

Figura 2.4 - Exemplos de modelo contínuo e discreto Fonte: Takahashi et al. apud Trivelato, 2003. 
- Concentrado (lumped) e Distribuído: Um modelo é concentrado quando não leva em conta a variabilidade espacial, em geral utilizam apenas o tempo como variável. Quando é considerada a variabilidade espacial no tempo, o modelo é dito distribuído. Na Figura 2.5, o comprimento da mola é avaliado levando em consideração apenas a massa acrescentada em sua extremidade - modelo concentrado - e em seguida, a avaliação do comprimento leva em consideração todos os fatores envolvidos: temperatura do ambiente, fixação da mola, tipo de material etc.;

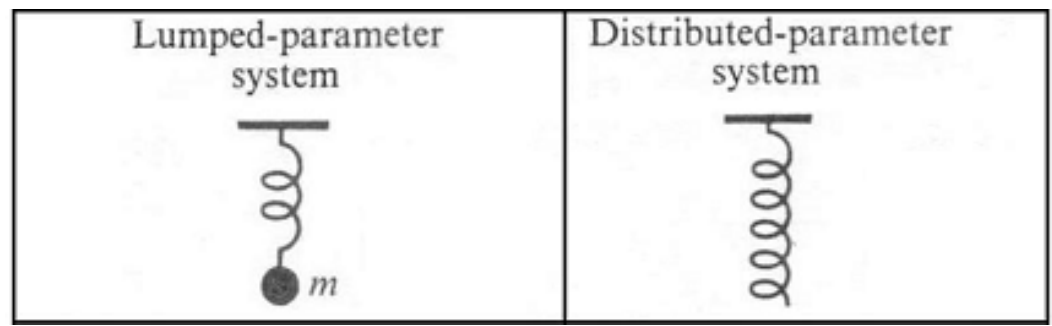

Figura 2.5 - Exemplos de modelo concentrado e distribuído Fonte: Takahashi et al. apud Trivelato, 2003.

- Estocástico e Determinístico: Se a chance de ocorrência das variáveis é levada em conta, e o conceito de probabilidade é introduzido na formulação do modelo, o processo e o modelo são classificados como estocástico. O oposto, ou seja, a não consideração da chance de ocorrência e a chance de não ocorrência caracteriza o modelo determinístico. A Figura 2.6 mostra exemplos de modelo determinístico (determinados por uma função matemática) e estocástico;

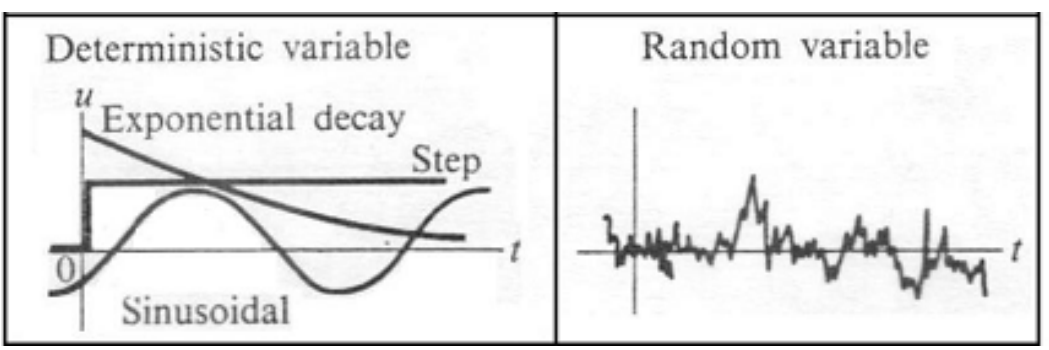

Figura 2.6 - Exemplos de modelo determinístico e aleatório Fonte: Takahashi et al. apud Trivelato, 2003. 
- Conceitual e Empírico: o modelo é dito conceitual, quando as funções utilizadas na sua elaboração levam em consideração os processos físicos. Os modelos empíricos são aqueles que se ajustam os valores calculados aos dados observados, através de funções que não tem nenhuma relação com os processos físicos envolvidos.

Como esta pesquisa objetiva a análise da sensibilidade de hidrogramas de cheia em função dos parâmetros de entrada dos métodos sintéticos de transformação chuvavazão, serão brevemente discutidos, de acordo com Tucci (2005), os aspectos fundamentais destes modelos.

Os modelos de evento chuva-vazão representam a parte do ciclo hidrológico de transformação da chuva em escoamento superficial. Estes modelos devem descrever a distribuição espacial da precipitação, as perdas por interceptação, evaporação, depressão do solo, o fluxo através do solo pela infiltração, escoamento superficial, subsuperficial e no rio. Estes modelos surgiram devido à necessidade de se obterem séries históricas mais longas e representativas de vazões a partir das séries de chuvas, que em geral são mais longas e estacionárias. Através dos dados de chuva, é possível completar dados desconhecidos de vazões e/ou estimá-los para novos cenários de estudos.

Os modelos chuva-vazão possuem os seguintes elementos:

- Discretização da bacia: representa o critério de subdivisão espacial para representar a bacia. Pode ser concentrada, distribuída por sub-bacia ou distribuída por módulo. Na subdivisão concentrada, a bacia é representada por uma precipitação média e os processos hidrológicos por variáveis concentradas no espaço. Na subdivisão distribuída por sub-bacias, a bacia é dividida em sub-bacias, de acordo com a drenagem principal da mesma. E na subdivisão distribuída por módulos, a discretização é feita por formas geométricas sem relação direta com a forma da bacia. A Figura 2.7 representa os tipos de discretização dos modelos; 


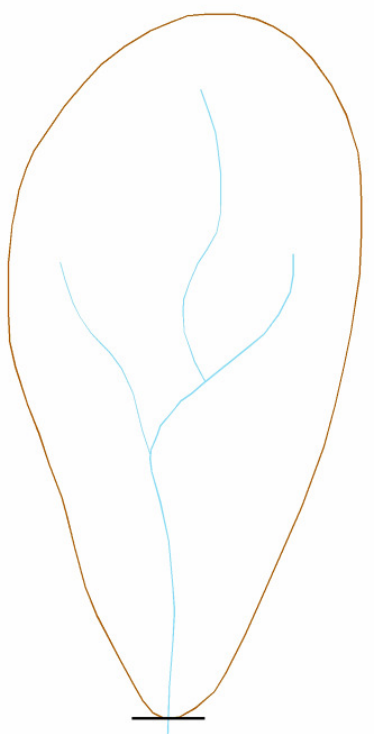

Concentrada

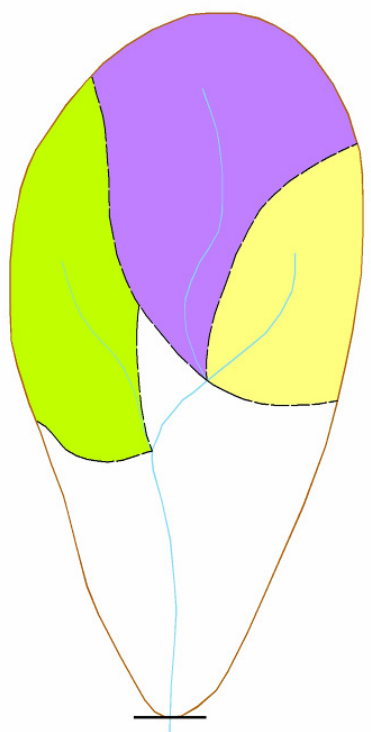

Distribuída por sub-bacia

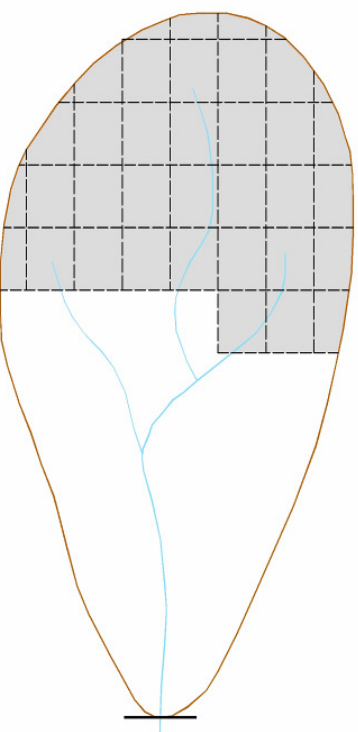

Distribuída por módulo

Figura 2.7 - Discretização dos modelos: subdivisão concentrada, distribuída por sub-bacia ou distribuída por módulo

Fonte: Tucci, 2005, p. 235.

- Variáveis temporais de entrada: as variáveis temporais de entrada utilizadas pelos modelos são: chuva, evapotranspiração potencial e vazão. A chuva é a principal variável de entrada. Normalmente, existem pouquíssimos dados de evapotranspiração potencial. Os dados de vazões são usados para o ajuste do modelo;

- Estrutura básica de integração dos processos: na Figura 2.8 é apresentado o fluxograma de estrutura na qual os processos são integrados para representar a parte do ciclo hidrológico entre a chuva e a vazão. Usualmente, esta estrutura é aplicada separadamente para o trecho entre o divisor da bacia até a calha do rio e para o trecho de rio; 


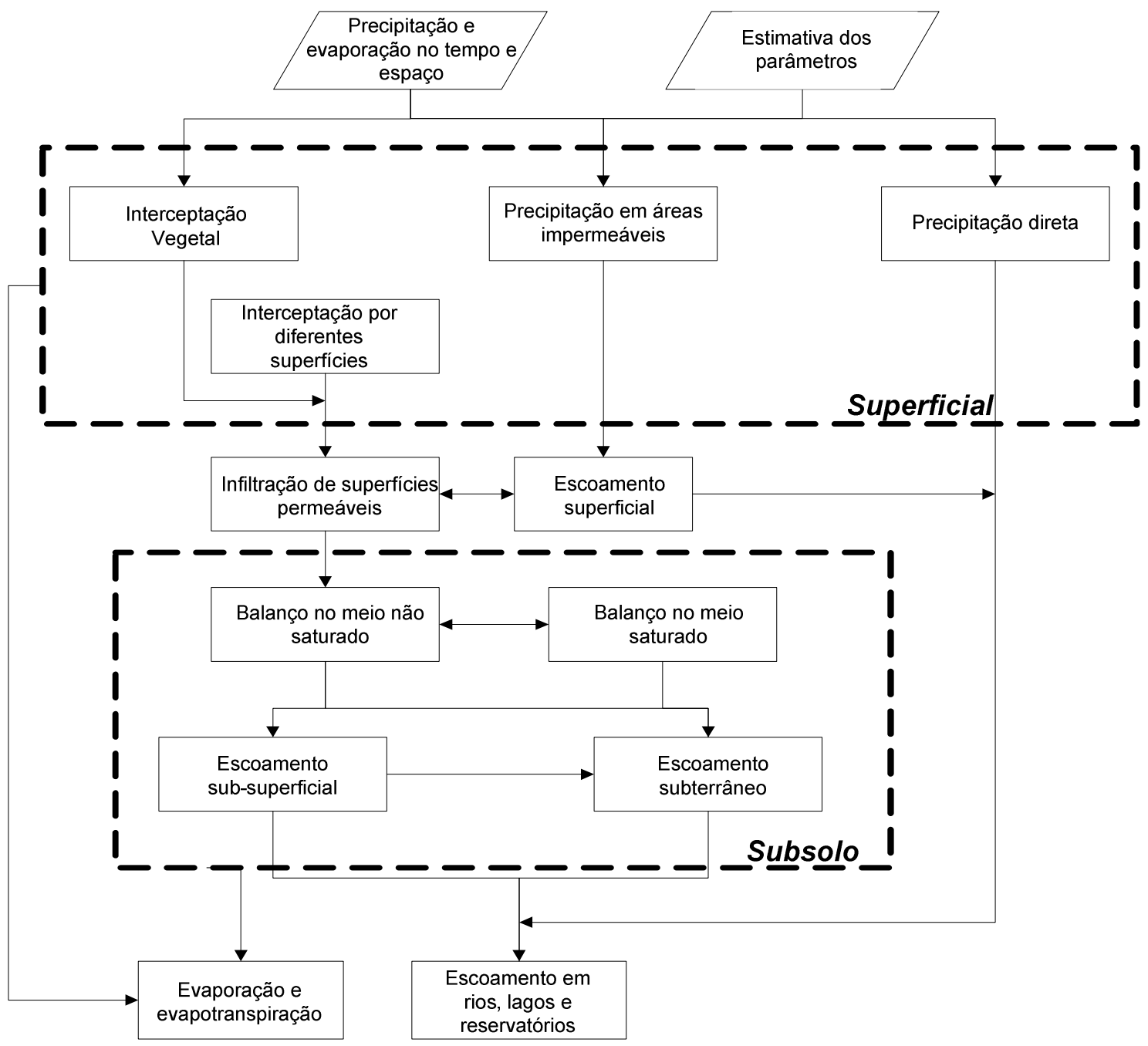

Figura 2.8 - Fluxograma da estrutura básica de integração dos processos dos modelos hidrológicos Fonte: Tucci, 2005. p. 236.

- Aquisição dos dados físicos das bacias: a grande variabilidade das características físicas e do uso do solo resulta numa grande quantidade de informações a serem transferidas para os modelos. Hoje, devido às facilidades da informática, grande parte destes dados é obtida a partir dos Sistemas de Informações Geográficas e Sensoriamento Remoto e, por isso, este tem feito parte da estrutura de entrada de grande parte dos modelos;

- Determinação dos parâmetros: alguns parâmetros são estimados com base nas características físicas, enquanto outros devem ser ajustados com base 
em dados observados das variáveis de entrada e saída. Alguns modelos possuem módulo para ajuste destes parâmetros através da otimização.

A relação de alguns programas que utilizam modelos chuva-vazão, e os países onde estes foram desenvolvidos é apresentada esquematicamente na Figura 2.9.

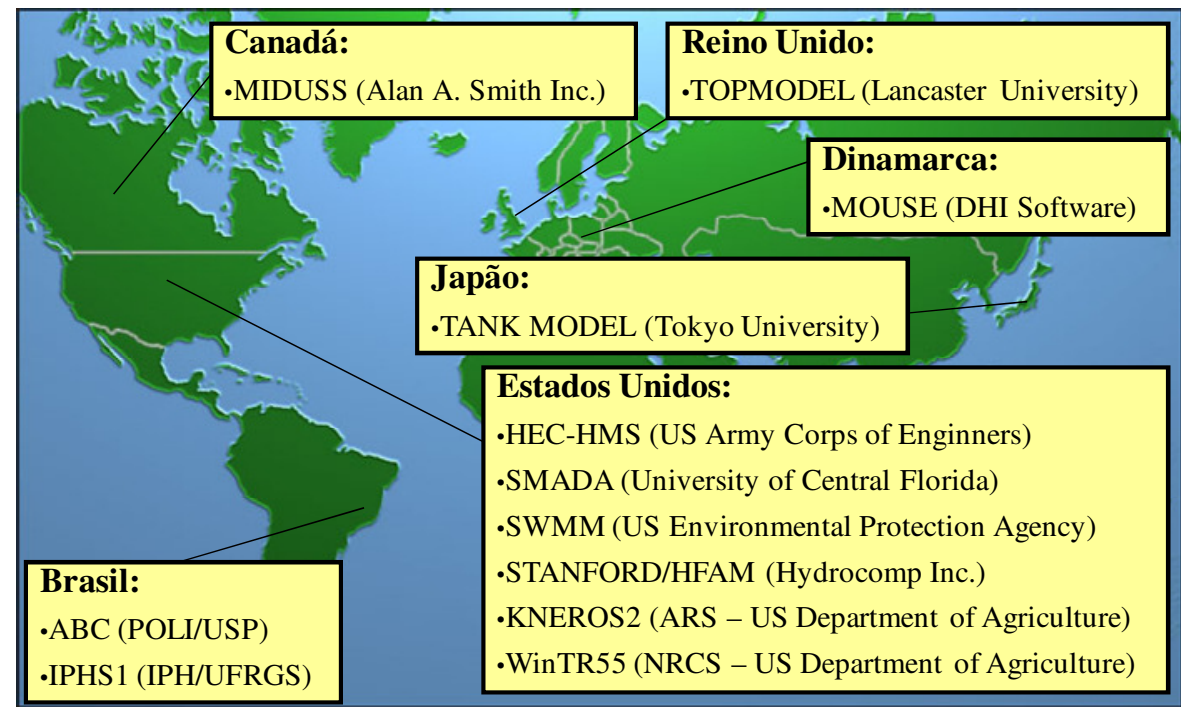

Figura 2.9 - Modelos Chuva-Vazão

Fonte: Zahed Filho, 2009. ${ }^{2}$

Os aspectos mais importantes a serem avaliados quando do uso de um modelo chuva-vazão são:

- Os objetivos para os quais o modelo será utilizado;

- As limitações do modelo na representação dos fenômenos em função dos objetivos definidos e;

- A qualidade de a quantidade das informações utilizadas em conjunto com o modelo.

\footnotetext{
${ }^{2}$ Apresentação eletrônica, da Disciplina "Hidrologia Aplicada" - PHD 2307, do Prof. Dr. Kamel Zahed Filho, disponível no endereço: <http://200.144.189.36/phd/LeArq.aspx?id arq=3268>, em 15 jun. 2009.
} 


\subsection{SISTEMA DE SUPORTE A DECISÕES PARA ANÁLISE DE ONDAS DE CHEIAS EM BACIAS COMPLEXAS - SSD ABC}

O SSD ABC desenvolvido no LabSid pelo Prof. Dr. Rubem La Laina Porto, Prof. Dr. Kamel Zahed Filho, Cristiano de Pádua Milagres de Oliveira e Alexandre Nunes Roberto originou-se com finalidades didáticas, para atender a alunos de graduação e pós-graduação do Departamento de Engenharia Hidráulica e Sanitária da Universidade de São Paulo. Entretanto, devido às facilidades de utilização da sua interface gráfica e dos seus métodos de cálculo, este SSD tem sido utilizado profissionalmente.

Até o estágio atual, foram desenvolvidas algumas versões do SSD ABC: o $A B C 3$ (1985), ABC4 (1990), ABC5 (1996) e ABC6 (2001) ${ }^{3}$.

Existe uma versão comercial, o CABC, desenvolvida pela FCTH, que possui interface gráfica amigável e relativamente simples de operar, que possibilita a geração de hidrogramas de cheia, apenas pelo método do SCS.

A última versão, o ABC6 (2001), com formulação matemática fundamentada nos métodos convencionais sintéticos, permite o estudo de bacias múltiplas (também denominadas complexas) e a criação de diversos cenários que auxiliam significativamente a tomada de decisões quando da obtenção de hidrogramas de cheia.

As principais funções executadas pelo SSD ABC 6 são:

- Interfaces de entrada e saída gráficas, permitindo a análise de várias bacias hidrográficas interligadas, através da criação de uma topologia esquemática na tela.

- Determinação de chuvas de projeto (distribuição espacial e temporal) para os períodos de retorno escolhidos pelo usuário;

\footnotetext{
${ }^{3}$ Informação obtida em: <http://200.144.189.36/labsid/Programas.aspx>. Acesso em: em 06 jan. 2010.
} 
- Cálculo de hidrogramas de cheia, a partir da chuva de projeto em função das características físicas da bacia hidrográfica;

- Composição e caminhamento das ondas de cheia pelas bacias (por reservatórios e canais naturais e artificiais);

- Pré-dimensionamento de reservatórios de controle de cheias;

- Pré-dimensionamento de largura de vertedores de soleira livre;

- Formulação de alternativas e análise de cenários por parte do usuário.

Os fenômenos naturais do ciclo hidrológico simulados pelo SSD ABC 6 são: chuva, infiltração e escoamento superficial direto e estão esquematicamente representados na Figura 2.10.

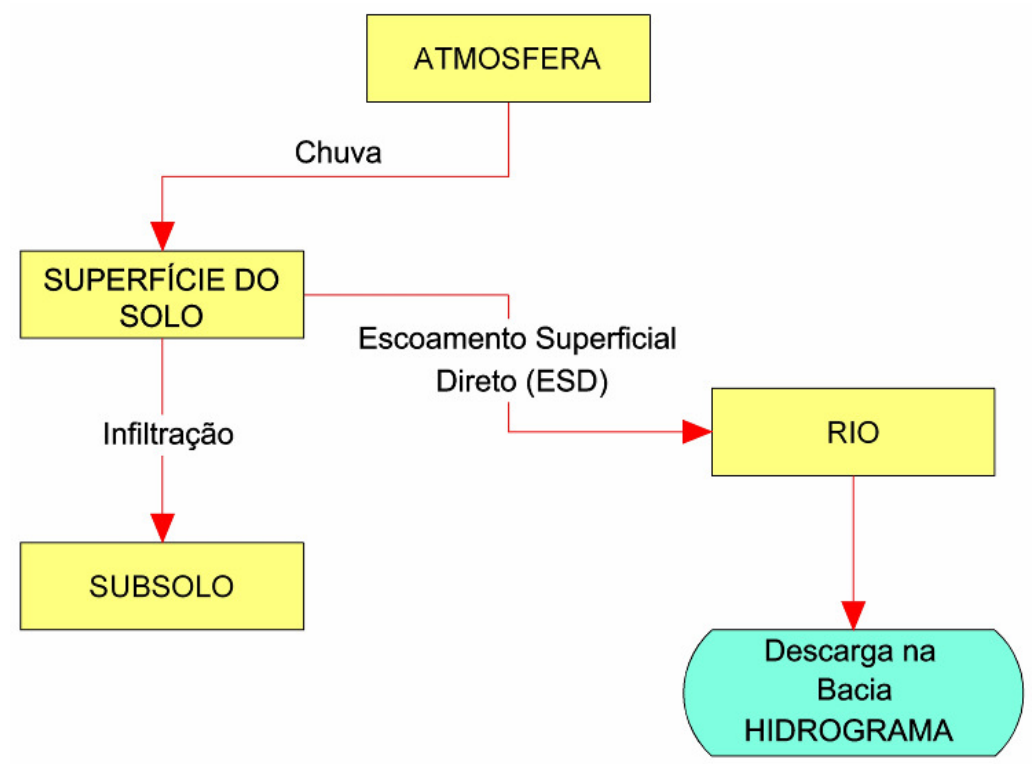

Figura 2.10 - Fenômenos naturais do ciclo hidrológico simulados pelo SSD ABC Fonte: Zahed Filho, 2009. ${ }^{4}$

\footnotetext{
${ }^{4}$ Apresentação eletrônica, da Disciplina "Hidrologia Aplicada" - PHD 2307, do Prof. Dr. Kamel Zahed Filho, disponível no endereço: <http://200.144.189.36/phd/LeArq.aspx?id arq=3268> em 15 jun. 2009.
} 
Segundo, Roberto, Porto e Zahed (1997), as rotinas hidrológicas do SSD ABC estão organizadas nos módulos: Topologia, Intervalo, Dados, Modelos e Saída descritos a seguir.

O módulo "Topologia" permite a representação da bacia (ou das bacias) em análise. Os nós representam os pontos de início, final e confluência de bacias ou reservatórios. Os arcos representam as bacias hidrográficas e trechos de canais naturais e artificiais. Para a bacia hidrográfica, cada arco contém os dados que a caracterizam e uma função de transformação responsável pela produção de uma saída (vazão) a partir de uma entrada (chuva). Para os canais, a função de transformação é o amortecimento do hidrograma de entrada no trecho e a saída é o hidrograma amortecido. A Figura 2.11 mostra uma representação pictórica de uma bacia hidrográfica sobre a qual foi representada a topologia do SSD ABC 6. A Figura 2.12 apresenta a interface gráfica deste módulo.

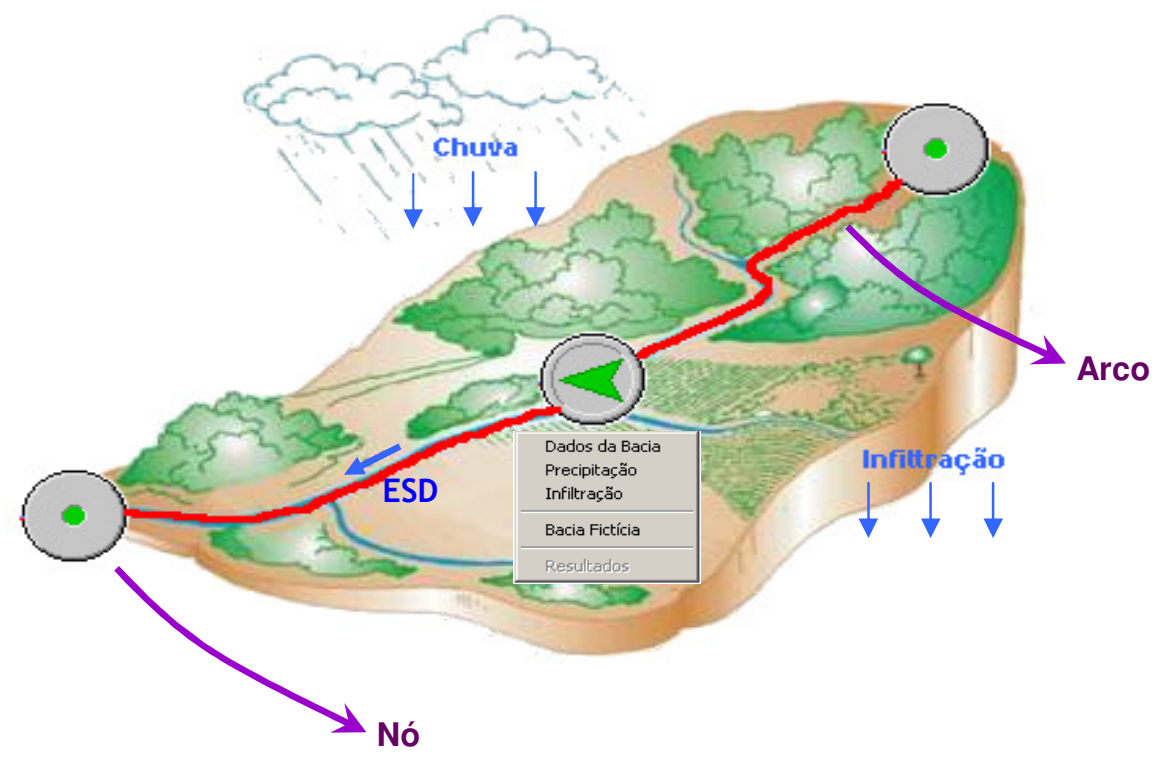

Figura 2.11 - Representação pictórica esquemática e topologia do SSD ABC 6 Fonte: DAEE, 2008. p. 13. (adaptada). 


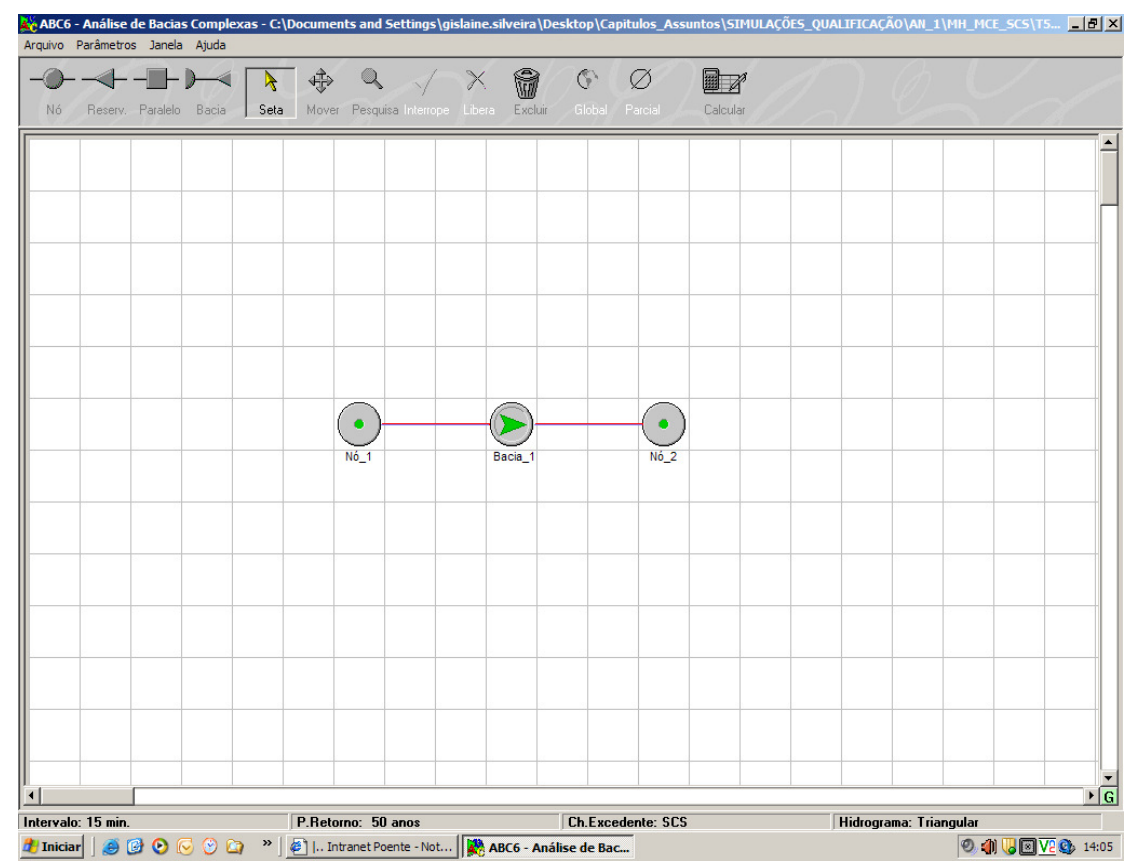

Figura 2.12- Interface gráfica do módulo "Topologia"

O módulo "Intervalo" possibilita a escolha do intervalo do tempo de discretização dos cálculos. Esse intervalo é obrigatoriamente o mesmo para todos os trechos da bacia hidrográfica. No SSD ABC 6 o intervalo de discretização de cálculo é igual ao intervalo de discretização da chuva de projeto. A Figura 2.13 mostra o menu que possibilita a definição do intervalo de discretização.

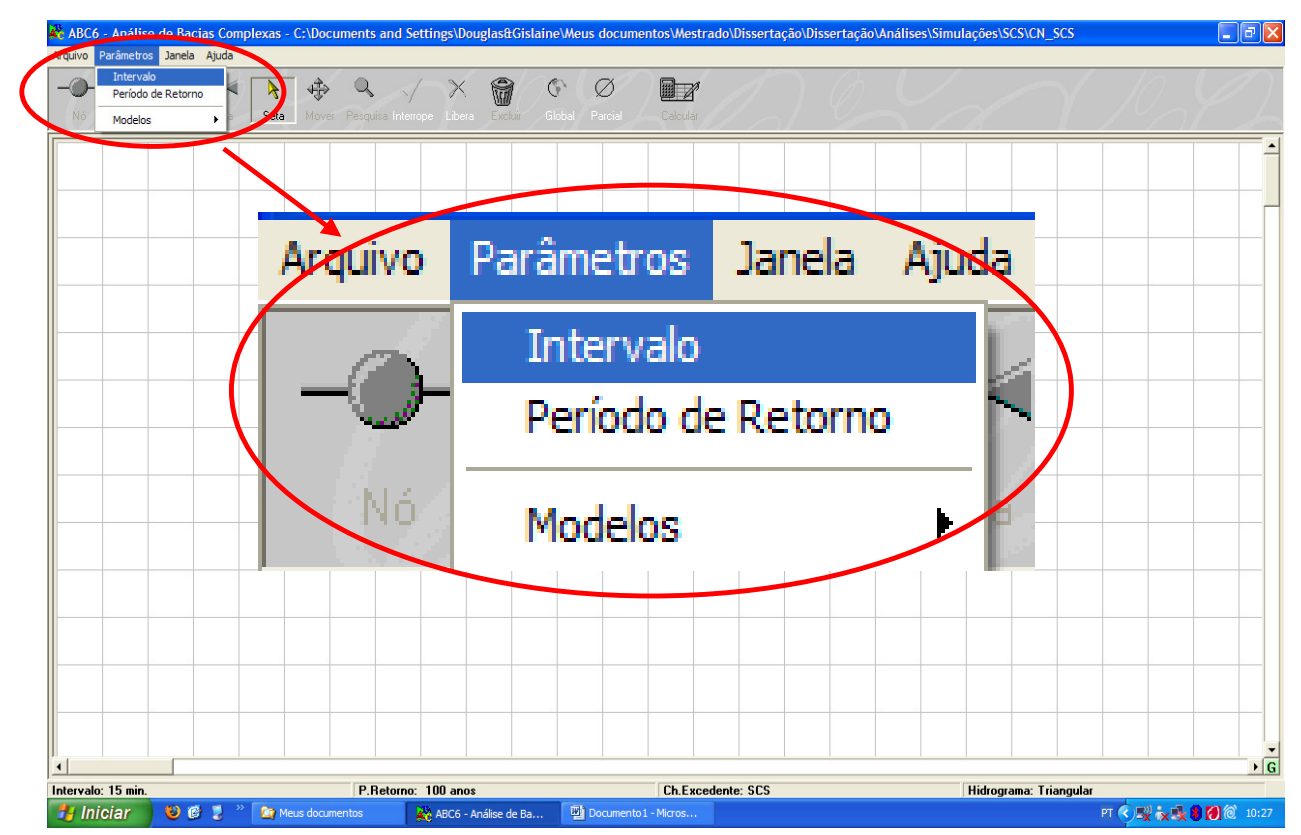

Figura 2.13 - Interface gráfica do módulo "Intervalo" 
No módulo "Modelos", é possível escolher os modelos para o cálculo da chuva excedente e o modelo de traçado de hidrograma de escoamento superficial direto que será utilizado. Para o cálculo da chuva excedente, o usuário pode escolher entre os métodos de Horton, Green e Ampt, SCS e Índice Fi. Para o traçado do hidrograma de cheia, o SSD possibilita a escolha dos métodos de Santa Bárbara, Clark e do SCS. A Figura 2.14 mostra o menu que possibilita a escolha dos modelos.

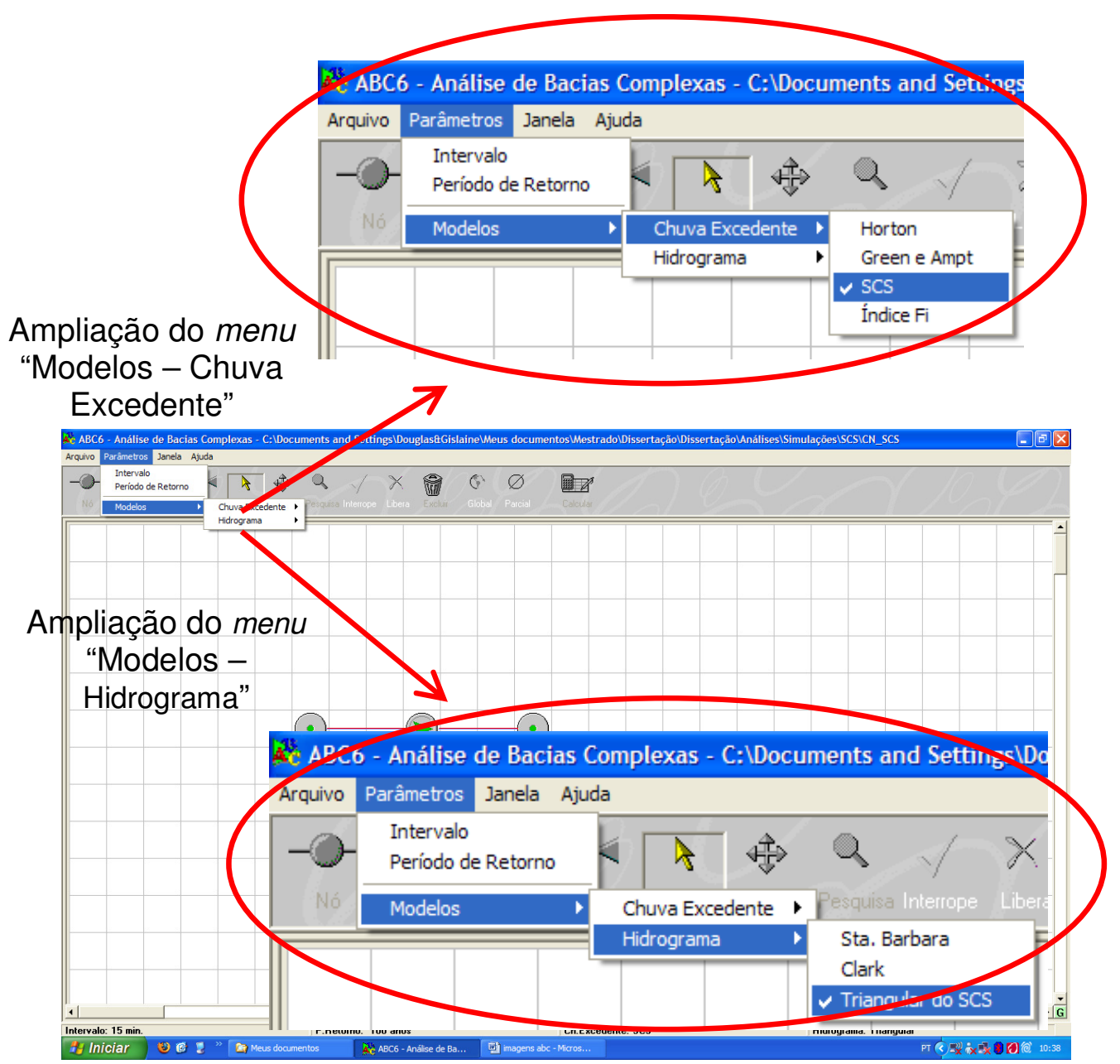

Figura 2.14 - Interface gráfica do módulo "Modelos"

No módulo "Dados", o usuário insere as informações relativas às características fisiográficas da bacia, os parâmetros dos métodos de determinação da infiltração, a distribuição temporal da tormenta de projeto (ou a determina a partir das relações IDF disponibilizadas no SSD), a duração e o coeficiente de redução espacial da chuva. A Figura 2.15 mostra as interfaces gráficas do módulo "Dados" do SSD ABC6. 


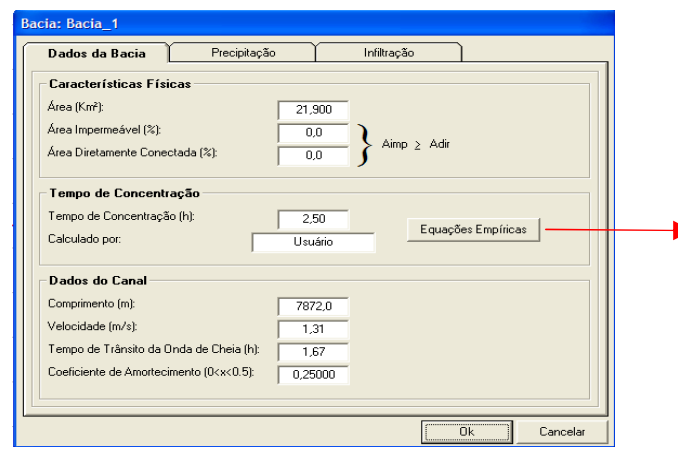

Entrada dos dados relativos às características físicas da bacia hidrográfica

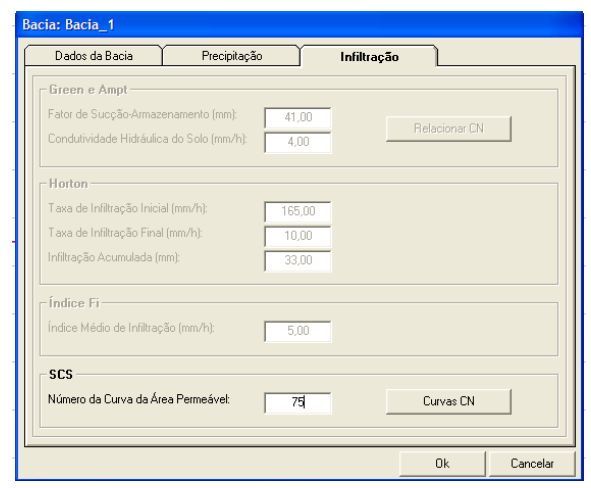

Entrada dos parâmetros dos métodos de determinação da infiltração

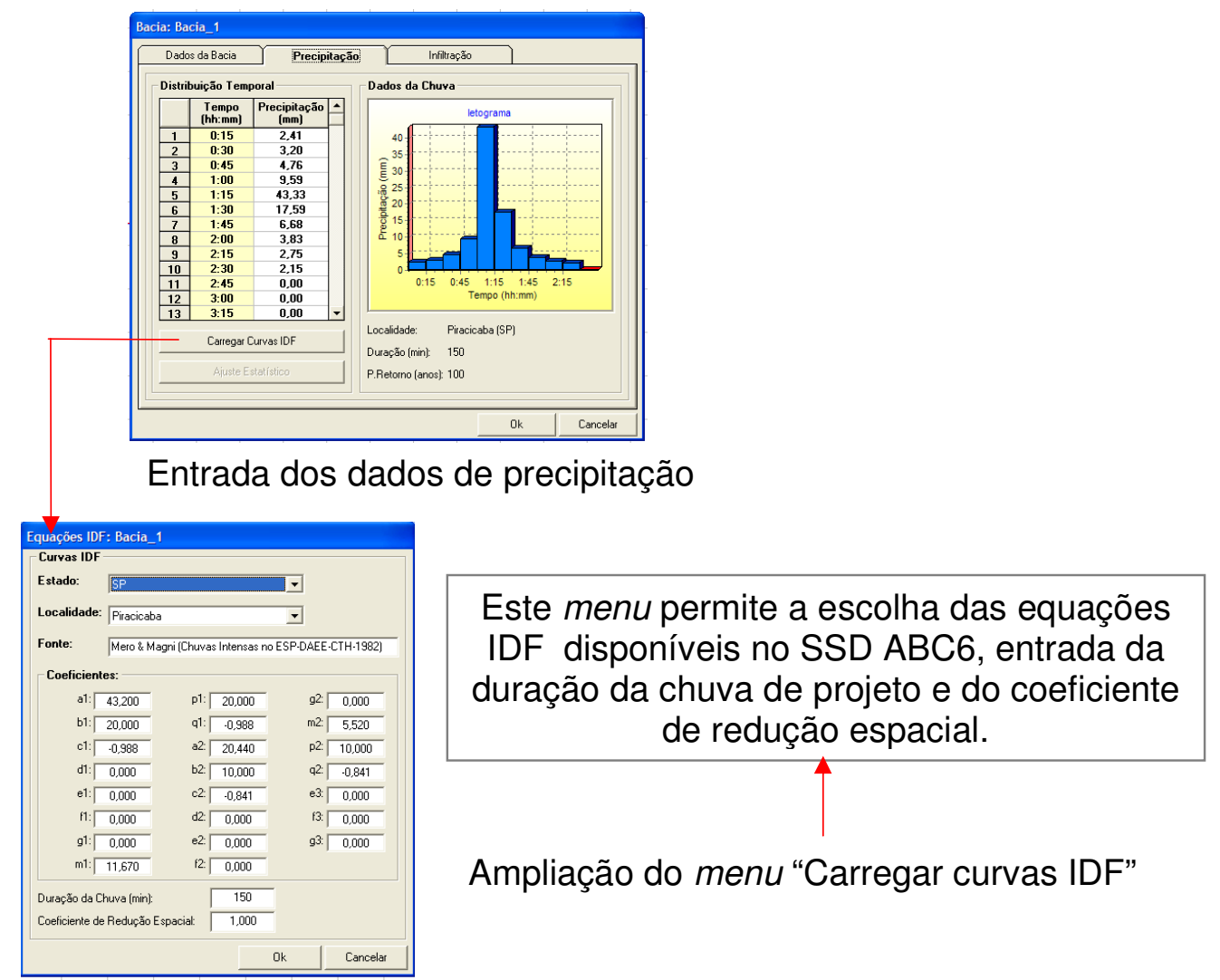

Figura 2.15 - Interface gráfica do módulo "Dados" 
No módulo "Saída", o usuário clica em um ponto do esquema representativo e obtém os resultados do respectivo ponto. Os resultados: chuva total, chuva excedente e o hidrograma, são apresentados em tabelas e gráficos, como mostra a Figura 2.16.

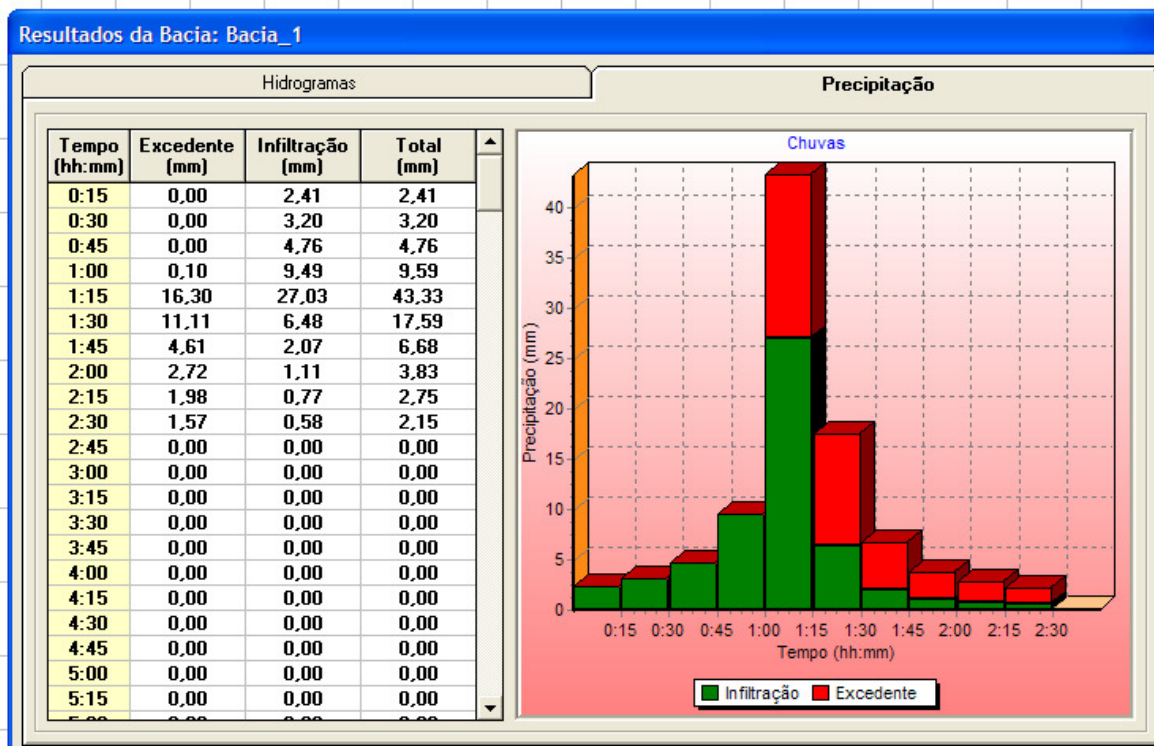

Hietograma

Tabela e Gráfico

\section{Hidrograma}

Tabela e Gráfico
Resultados da Bacia: Bacia_1

\begin{tabular}{|c|c|c|c|c|c|c|}
\hline \multicolumn{6}{|c|}{ Hidrogramas } & \multirow[t]{2}{*}{ Precipitação } \\
\hline $\begin{array}{l}\text { Tempo } \\
\text { (hh:mm) }\end{array}$ & $\begin{array}{c}\text { Montante } \\
{\left[\mathrm{m}^{3} / \mathrm{s}\right]}\end{array}$ & $\begin{array}{c}\text { Amortecido } \\
{\left[\mathrm{m}^{3} / \mathrm{s}\right]}\end{array}$ & $\begin{array}{c}\text { Contribuição } \\
{\left[\mathrm{m}^{3} / \mathrm{s}\right]}\end{array}$ & $\begin{array}{l}\text { Total } \\
{\left[\mathrm{m}^{3} / \mathrm{s}\right]}\end{array}$ & $\Delta$ & \\
\hline 0:15 & 0,000 & 0,000 & 0,000 & 0,000 & & $60 f$ \\
\hline 0:30 & 0,000 & 0,000 & 0,000 & 0,000 & & 55 \\
\hline $0: 45$ & 0,000 & 0,000 & 0,000 & 0,000 & & \\
\hline 1:00 & 0,000 & 0,000 & 0,013 & 0,013 & & $50-$ \\
\hline 1:15 & 0,000 & 0,000 & 2,050 & 2,050 & & 45 \\
\hline $1: 30$ & 0,000 & 0,000 & 3,468 & 3,468 & & $40-$ \\
\hline $1: 45$ & 0,000 & 0,000 & 8,579 & 8,579 & & \\
\hline $2: 00$ & 0,000 & 0,000 & 13,081 & 13,081 & & \\
\hline 2:15 & 0,000 & 0,000 & 20,785 & 20,785 & & \\
\hline $2: 30$ & 0,000 & 0,000 & 29,011 & 29,011 & & \\
\hline $2: 45$ & 0,000 & 0,000 & 36,982 & 36,982 & & \\
\hline $3: 00$ & 0,000 & 0,000 & 46,149 & 46,149 & & 20 \\
\hline 3:15 & 0,000 & 0,000 & 52,212 & 52,212 & & 15 \\
\hline 3:30 & 0,000 & 0,000 & 57,702 & 57.702 & & \\
\hline $3: 45$ & 0,000 & 0,000 & 60,750 & 60,750 & & \\
\hline 4:00 & 0,000 & 0,000 & 60,251 & 60,251 & & 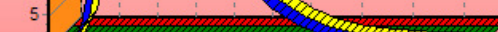 \\
\hline 4:15 & 0,000 & 0,000 & 59,690 & 59,690 & & ${ }_{0} \mathrm{~L}$ \\
\hline 4:30 & 0,000 & 0,000 & 55,371 & 55,371 & & \multirow{2}{*}{$\begin{array}{c}0: 15 \text { 1:45 3:15 4:45 6:15 7:45 9:15 11:15 13:15 } 15: 15 \\
\text { Tempo (hh:mm) }\end{array}$} \\
\hline $4: 45$ & 0,000 & 0,000 & 51,882 & 51,882 & & \\
\hline 5:00 & 0,000 & 0,000 & 46,507 & 46,507 & & \multirow{2}{*}{ 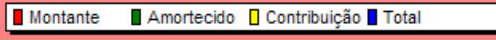 } \\
\hline 5:15 & 0,000 & 0,000 & 41,442 & 41,442 & - & \\
\hline & & & & & & \\
\hline
\end{tabular}

Figura 2.16 - Interface gráfica do módulo "Saídas" 
Para elucidar a utilização o SSD, foi elaborado o fluxograma apresentado na Figura 2.17. O fluxograma mostra os passos a seguir depois de estabelecida a topologia do SSD. De maneira sucinta, o usuário deve informar o intervalo de discretização, o período de retorno, o modelo de chuva excedente e de traçado do hidrograma de cheia. Em função do modelo de chuva excedente escolhido, o usuário deve informar os parâmetros do método. Ao entrar com os dados das características físicas da bacia, o SSD ABC 6 mostra o resultado do tempo de concentração a partir de seis equações empíricas. No caso da fórmula empírica de Kerby, é necessário entrar com o valor da rugosidade de retardo e para a fórmula Onda Cinemática, o valor da rugosidade de Manning.

O SSD também permite que o tempo de concentração seja definido pelo usuário. $\mathrm{Na}$ definição da chuva de projeto, o usuário tem a opção de fornecer a distribuição temporal ou usar uma das equações IDF do banco de dados do SSD, deve fornecer ainda a duração e a distribuição espacial da chuva. Depois destes procedimentos o usuário pressiona o botão calcular, o sistema valida os cálculos e fornece os resultados a partir de tabelas e gráficos. 


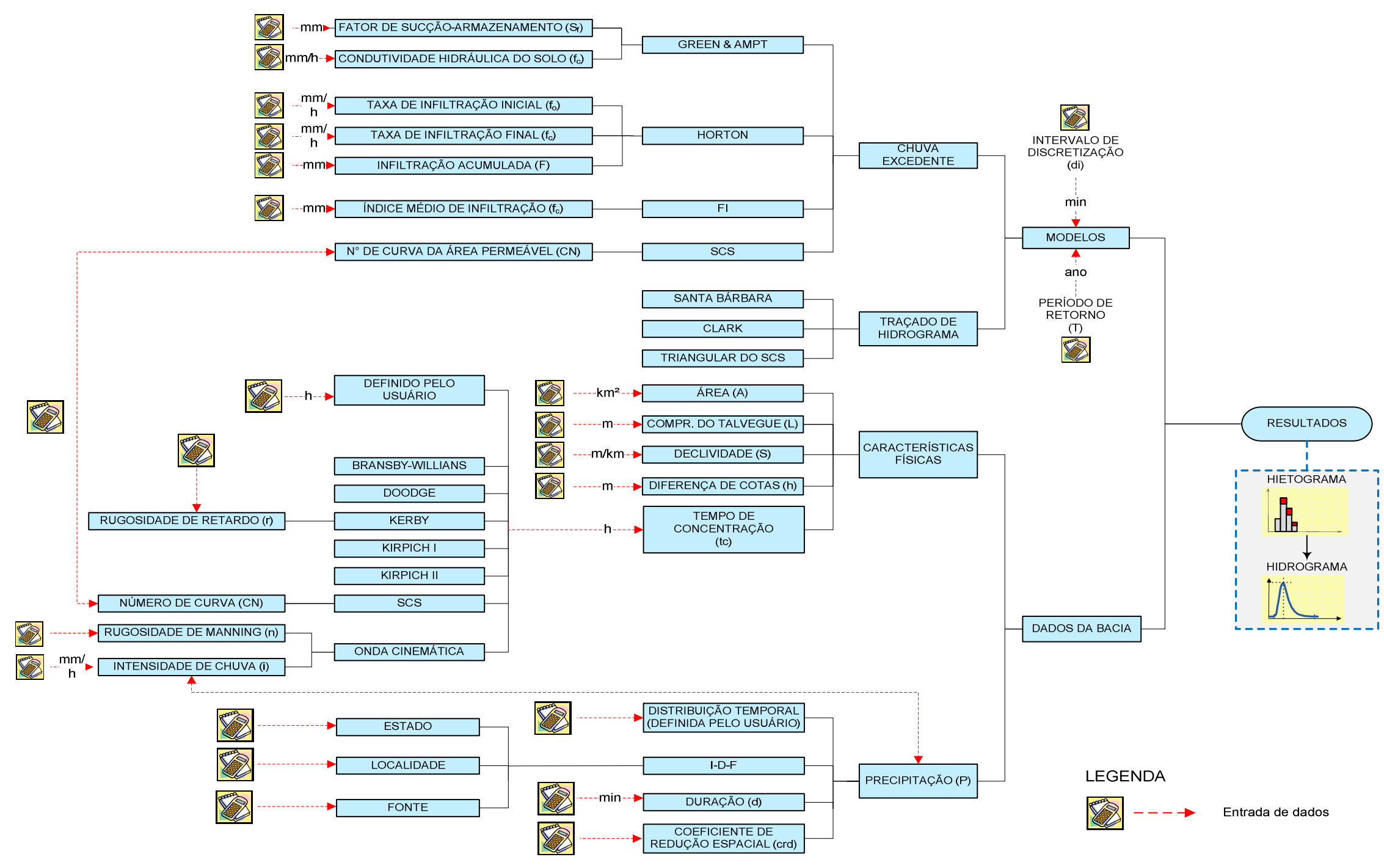

Figura 2.17 - Fluxograma de entrada de dados e saídas de resultados para o estudo de uma bacia hidrográfica, utilizando-se o SSD ABC 6 


\subsection{CONCEITUAÇÕES HIDROLÓGICAS DO SSD ABC}

\subsubsection{Intervalo de discretização}

Nos modelos de simulação hidrológica, a escolha deste intervalo é função da economia desejada e da precisão dos resultados que são conflitantes. À medida que o intervalo de discretização diminui, o custo para medir os dados da computação aumenta em favor da melhoria da precisão dos resultados (TUCCI, 2005).

Para obter uma melhor precisão nos resultados, os autores do SSD ABC recomendam que o intervalo de discretização dos cálculos seja da ordem de 1/10 do tempo médio de concentração das bacias. Há de se ater ao limite inferior do intervalo válido para as equações IDF do banco de dados do modelo. Em geral o intervalo válido é para durações de chuva entre 10 a 1.440 minutos.

\subsubsection{Período de Retorno}

O período de retorno é o inverso da probabilidade de um determinado evento (chuva ou vazão) ser igualado ou excedido em um ano qualquer.

Ao decidir-se que uma estrutura hidráulica será projetada para uma chuva ou vazão com período de retorno $T$ anos, automaticamente, decide-se o grau de proteção conferido à população, uma vez que se define qual é o "risco aceitável", ou seja, a probabilidade de uma determinada estrutura hidráulica vir a falhar pelo menos uma vez durante sua vida útil.

Esse conceito leva em conta que uma estrutura hidráulica projetada para um período de retorno T expõe-se, todo o ano, a uma probabilidade 1/T de vir a falhar. É intuitivo que, ao longo de sua vida útil, essa obra terá um risco de falha maior do que $1 / T$, uma vez que ficará exposta, repetidamente, a essa possibilidade (PORTO,1995). 
A expressão para o cálculo do "risco aceitável", deduzida da teoria das probabilidades é representada por:

$$
R=100 \times\left[1-\left(1-\frac{1}{T}\right)\right]^{\text {Vútil }}
$$

Onde:

- R: é o risco em porcentagem

- T: é o período de retorno em anos

- $V_{\text {útill }}$ é a vida útil da obra em anos

Em pequenas bacias, onde é comum a construção de pequenas estruturas hidráulicas destinadas à drenagem urbana, tem sido aceito pelo meio técnico, os valores apresentados na Tabela 2.1.

Tabela 2.1 - Período de retorno para diferentes ocupações da área

\begin{tabular}{cll}
\hline Tipo de Obra & \multicolumn{1}{c}{ Tipo de Ocupação da Área } & T (anos) \\
\hline & Residencial & 2 \\
& Comercial & 5 \\
& Áreas com edifícios de serviços ao público & 5 \\
Microdrenagem & Aeroportos & $2-5$ \\
& Áreas comerciais e artérias de tráfego & $5-10$ \\
& Áreas comerciais e residenciais & $50-100$ \\
Macrodrenagem & Áreas de importância específica & $500-$
\end{tabular}

Fonte: Porto, 1995. p. 111.

Caso seja possível o aproveitamento hidroelétrico da bacia hidrográfica, a vazão de cheia para o dimensionamento do vertedor de pequenas centrais hidrelétricas deve ser uma vazão associada a um período de retorno de 1.000 anos. Para as obras de desvio, é usual adotar valores correspondentes a vazões com 25, 50 e 100 anos, dependo do período hidrológico em que serão construídas e dos riscos a jusante do aproveitamento (ELETROBRÁS, 2007).

Para melhor interpretação do conceito de período de retorno e risco aceitável foi elaborada a Tabela 2.2 que correlaciona o período de retorno versus a vida útil da obra e apresenta o risco desta estrutura vir a falhar, pelo menos uma vez, durante sua vida útil. 
Tabela 2.2 - Riscos percentuais de falha em função do período de retorno e vida útil da obra

\begin{tabular}{cccccc}
\hline T (anos) & $\mathbf{5}$ & \multicolumn{5}{c}{ Vida Útil da Obra (anos) } \\
\cline { 2 - 6 } & $\mathbf{2}$ & $\mathbf{5}$ & $\mathbf{2 5}$ & $\mathbf{5 0}$ & $\mathbf{1 0 0}$ \\
\hline $\mathbf{2}$ & 75 & 97 & 99,9 & 99,9 & 99,9 \\
$\mathbf{5}$ & 36 & 67 & 99,9 & 99,9 & 99,9 \\
$\mathbf{1 0}$ & 19 & 41 & 93 & 99 & 99,9 \\
$\mathbf{2 5}$ & 25 & 18 & 64 & 87 & 98 \\
$\mathbf{5 0}$ & 40 & 10 & 40 & 64 & 87 \\
$\mathbf{1 0 0}$ & 2 & 5 & 22 & 39 & 63 \\
$\mathbf{5 0 0}$ & 0,4 & 1 & 5 & 9 & 18 \\
\hline
\end{tabular}

Como exemplo, considere-se que uma determinada estrutura hidráulica tenha vida útil de 50 anos. $O$ risco de esta estrutura vir a falhar, pelo menos uma vez, durante sua vida útil, é de praticamente $100 \%$ quando o período de retorno é igual a 2 e 5 anos, $99 \%$ para quando igual a 10 anos, $87 \%$ quando 25 anos, $64 \%$ quando 50 anos, $39 \%$ quando 100 anos e $9 \%$ quando 500 anos.

A ASCE (1992) recomenda que a escolha do período de retorno deva ser precedida de um estudo de risco associado aos danos provocados por um evento hidrológico superior ao de projeto durante a vida útil da estrutura hidráulica. Diante deste critério, devem ser avaliados: o porte da obra, a densidade de população da região, o volume de tráfego do sistema viário do local, o entorno da região, proximidade de escolas, hospitais, estádios, estações ferroviárias ou de metrô, terminais de ônibus, aeroportos, "shoppings" etc. Esse critério deve ser definido politicamente, uma vez que a população e os seus representantes governamentais decidirão o grau de proteção desejável e o quanto estarão dispostos a pagar por ele.

Para Tucci et al. (1995), existem certas dificuldades em se estabelecer o período de retorno, objetivamente. Estas dificuldades estão ligadas a aspectos políticos, sociais, econômicos e hidrológicos:

Estudos econômicos, como uma análise custo-benefício, poderiam orientar essa escolha. Mas, a necessidade de se considerar custos e benefícios de difícil quantificação e, ainda mais, a impossibilidade de se levar em conta uma série de aspectos que não podem ser expressos em termos monetários, limitam a aplicação desta metodologia 
Quando da elaboração de projetos de drenagem urbana, deve ser avaliado que minimizar custos e interferências é um objetivo importante: níveis altos de segurança implicam em custos elevados e geram maiores interferências no meio urbano. Por outro lado, baixos níveis de segurança, aumentam a probabilidade de a estrutura vir a falhar e, caso isto ocorra, os prejuízos provavelmente serão consideráveis, principalmente se houver perdas de vidas humanas.

\subsubsection{Características Físicas da Bacia Hidrográfica}

A maior parte dos problemas práticos de hidrologia refere-se a uma determinada bacia hidrográfica. Conceitua-se como bacia hidrográfica a área definida e fechada topograficamente num ponto do curso d'água, de forma que toda a vazão afluente possa ser medida ou descarregada neste ponto (GARCEZ; ALVAREZ, 1988;).

As características físicas da bacia, tais como área de drenagem, perímetro, forma, rede e densidade de drenagem, número de ordem, declividade do rio, tipo e uso do solo auxiliam na interpretação dos resultados dos estudos hidrológicos e permitem estabelecer relações e comparações com outras bacias conhecidas. Todas estas características podem ser obtidas através de mapas, fotografias aéreas e imagens de satélite. Algumas destas características podem ser obtidas por mapas arquivados eletronicamente através de Sistemas de Informações Geográficas (SIG).

As características físicas consideradas como variáveis no SSD ABC 6 são: área de drenagem, comprimento do talvegue, declividade do rio, diferença entre cotas e o tempo de concentração.

\subsubsection{1 Área de drenagem e comprimento do talvegue}

A área de drenagem é a superfície total, a montante sobre um ponto do rio para onde o escoamento superficial direto converge. Pode ser determinada, através de bases cartográficas, por planímetro ou por técnicas de geoprocessamento. A Figura 
2.18 mostra o traçado de uma bacia hidrográfica qualquer. Geralmente o valor é dado em $\mathrm{km}^{2}$.

O comprimento do talvegue é a extensão desenvolvida do curso d'água. É definido a partir do ponto mais distante e de cota mais alta até a seção de saída. Quando existem meandros, pode ser considerado como o comprimento do fundo de vale, no qual, durante o período de cheia, ocorre o escoamento superficial. Geralmente é expresso em $\mathrm{km}$ ou $\mathrm{m}$, dependendo da ordem de grandeza da bacia hidrográfica.

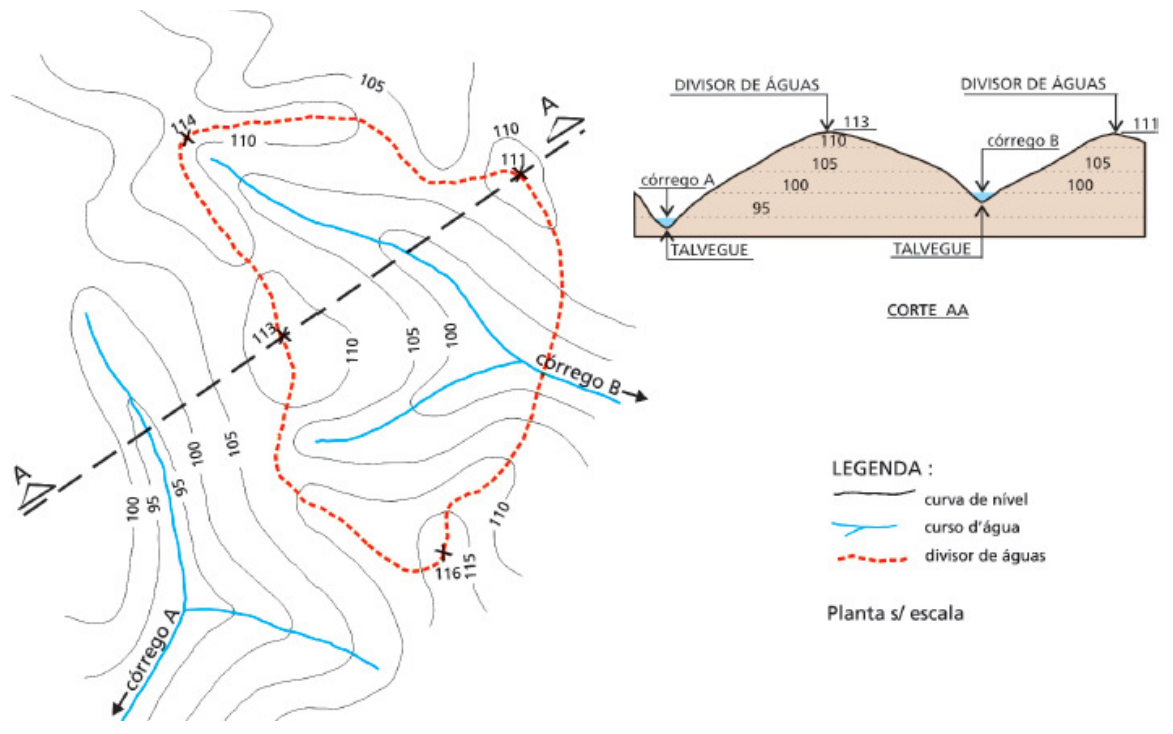

Figura 2.18 - Representação do traçado de uma bacia hidrográfica Fonte: DAEE, 2008. p. 14.

A dificuldade na obtenção da área de drenagem existe quando há indisponibilidade de bases cartográficas ou quando a escala do mapa não abrange os pequenos cursos d'água em estudo. Existe também a dificuldade em se determinar a área de drenagem em áreas onde há pouco relevo topográfico. Em áreas urbanas, sua determinação não pode ser apenas feita com base no divisor topográfico, visto que na maioria dos casos, a rede de drenagem natural sofre modificações devido às atividades antrópicas realizadas.

No Brasil, têm sido liberadas pelo INPE - Instituto Nacional de Pesquisas Espaciais, as imagens do satélite CBERS, Satélite Sino Brasileiro de Recursos Terrestres. O CBERS foi lançado no dia 14 de outubro de 1999 pelo foguete Longa Marcha 4B, a 
partir do Centro de Lançamento de Tayuan, na China ${ }^{5}$ A Figura 2.19 mostra o lançamento do satélite CBERS-2 e a Figura 2.20 as imagens de satélites parciais de alguns Estados Brasileiros.

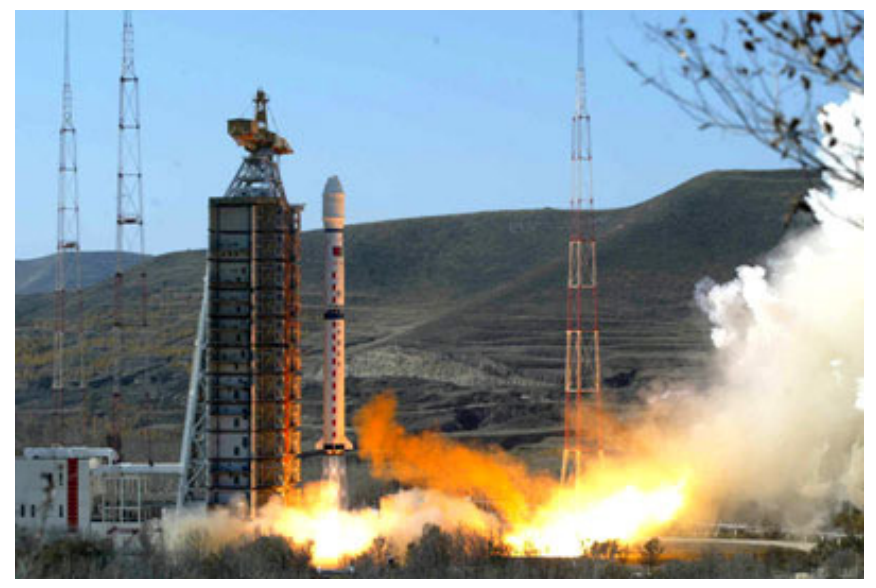

Figura 2.19 - Lançamento do CBERS2

Fonte: CBERS/ INPE - divulgação, 2010.

(A)

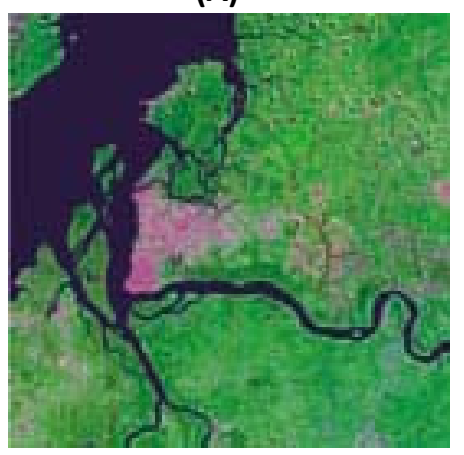

(D)

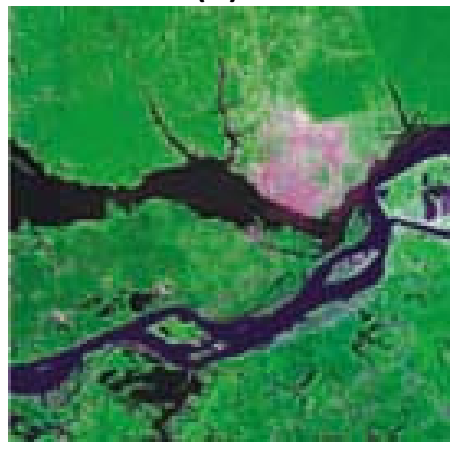

(B)

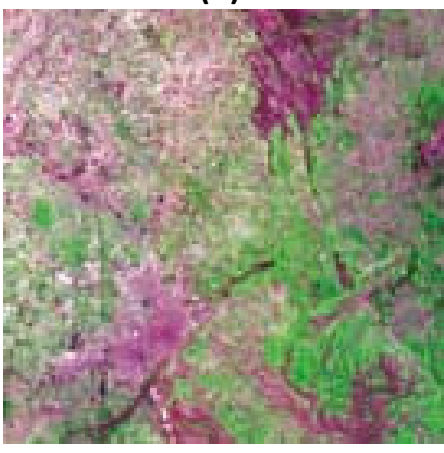

(E)

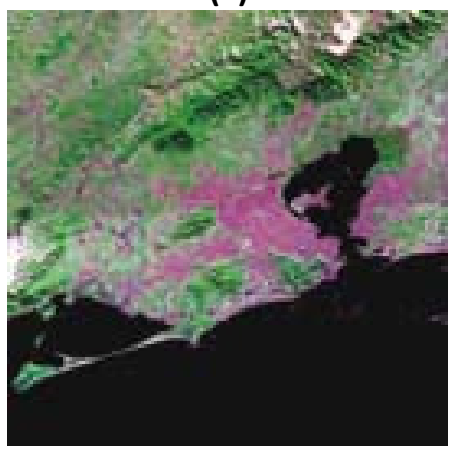

(C)

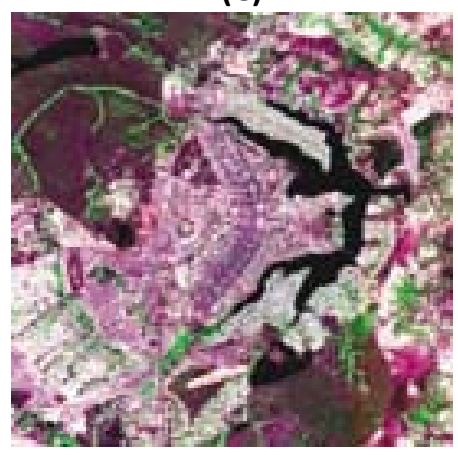

(F)

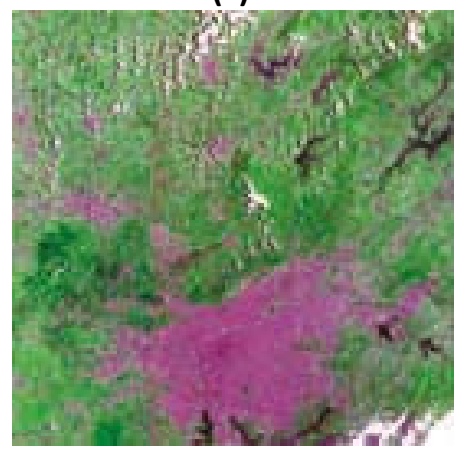

Figura 2.20 - Imagens do satélite obtidas pelo CBERS. (A) Belém. (B) Belo Horizonte. (C) Brasília. (D) Manaus. (E) Rio de Janeiro. (F) São Paulo.

Fonte: CBERS/ INPE - divulgação, 2010.

\footnotetext{
${ }^{5}$ Informação obtida no site <www.cbers.inpe.br/noticias/index.php?cod=not176 $>$ Acesso em: 04 fev.
} 2010. 


\subsubsection{Declividade do rio e diferença entre cotas}

Para determinação da declividade, é necessário o traçado do perfil do rio. Este perfil é traçado marcando-se os comprimentos desenvolvidos nas abscissas e a altitude do fundo ou a cota do nível d'água nas ordenadas. Nos casos em que é necessário atribuir uma única declividade para todo o curso de água, a determinação desta declividade, denominada declividade equivalente, pode ser feita pela média aritmética, pela compensação de áreas e pela média harmônica (GARCEZ; ALVAREZ, 1988)

- Média Aritmética

A declividade equivalente é o quociente entre a diferença de suas cotas e sua extensão horizontal. Ver Figura 2.21 e eq.(2.2).

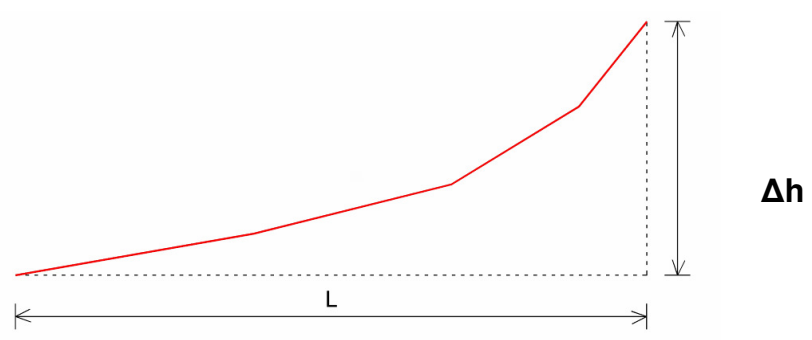

Figura 2.21 - Determinação da declividade equivalente pela média aritmética

$$
S i=\frac{\Delta h}{L}
$$

Onde:

- $\mathrm{S}_{\mathrm{i}} \quad$ é a declividade equivalente do talvegue;

- $\Delta h$ : é a diferença entre as cotas do ponto mais distante e da seção considerada, em m;

○ L: é o comprimento do talvegue principal, em $\mathrm{m}$.

- Compensação de áreas

Para obter a declividade equivalente, traça-se no gráfico do perfil longitudinal uma 
linha reta, tal que, a área compreendida entre ela e o eixo das abscissas (extensão horizontal) seja igual à compreendida entre a curva do perfil e a abscissa. Ver Figura 2.22 e eq. (2.3).

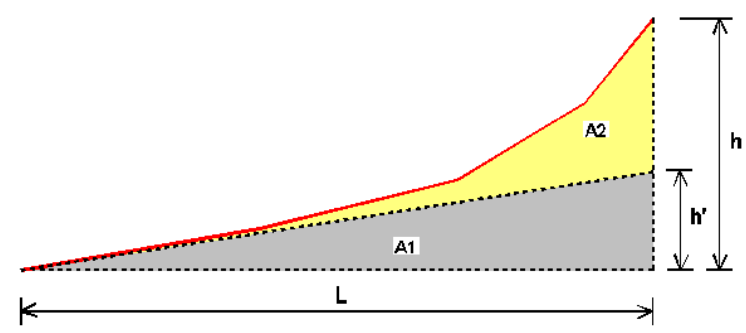

Figura 2.22 - Determinação da declividade equivalente pela compensação de áreas

$$
S i=\frac{2 \cdot A_{T R}}{L^{2}}
$$

Onde:

- $\mathrm{S}_{\mathrm{i}} \quad$ é a declividade equivalente do talvegue;

- ATR: é a área abaixo do perfil (área do triângulo);

- L: é o comprimento do talvegue principal.

- Média Harmônica

A declividade equivalente a partir da média harmônica é dada pela eq.(2.4). Ver Figura 2.23. A declividade equivalente é dada por um índice idealizado que representa o tempo de translação da água ao longo da extensão longitudinal.

$$
S i=\left[\frac{L}{\sum_{i=1}^{n} \frac{L_{i}}{\sqrt{s i}}}\right]^{2}
$$

Onde:

- $S_{i} \quad$ é a declividade equivalente do talvegue;

- L: é o comprimento do talvegue principal, que é dividido em $\mathrm{n}$ trechos em $\mathrm{m}$;

- $\mathrm{L}_{\mathrm{i}}$ : é a extensão horizontal em cada trecho do talvegue, em m;

- si: é a declividade média em cada trecho do talvegue, em $\mathrm{m} / \mathrm{m}$. 


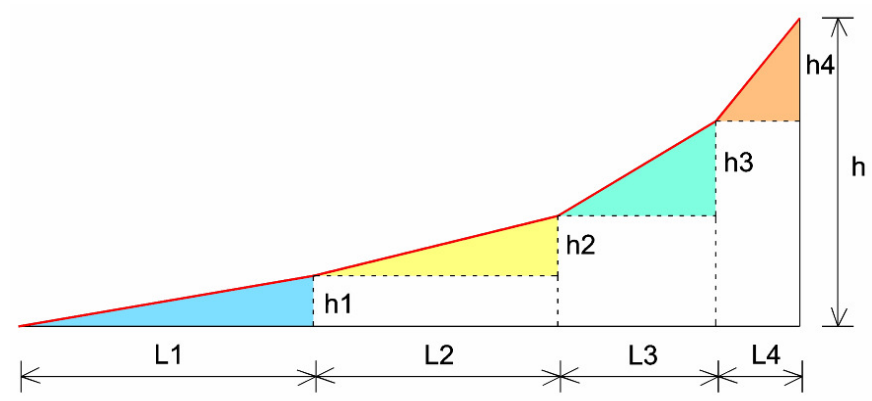

Figura 2.23 - Determinação da declividade equivalente pela média harmônica

A diferença entre cotas é dada pela subtração entre as cotas do ponto mais distante e da seção considerada.

As características físicas discutidas acima são importantes na definição do tempo de concentração da bacia, que por sua vez, influenciam na forma dos hidrogramas de cheia e nas vazões de pico, mas não no volume do hidrograma. Conforme o tempo de concentração aumenta, o pico do hidrograma demora um pouco mais para acontecer e é menor. A partir das análises de sensibilidade, é possível verificar estas informações. O tempo de concentração é discutido a seguir. A área de drenagem influencia diretamente a obtenção dos hidrogramas de cheia, uma vez que é constitui uma das variáveis de entradas dos métodos de hidrograma unitários sintéticos.

\subsubsection{Tempo de Concentração}

O tempo de concentração é o tempo necessário que a água precipitada no ponto mais distante na bacia leva para deslocar-se até a seção de saída. Esse tempo é definido também como o tempo entre o fim da precipitação e o ponto de inflexão do hidrograma. Existe uma grande quantidade de fórmulas que fornecem o valor do tempo de concentração em função de características da bacia como área, declividade, comprimento do talvegue, rugosidade das superfícies e, eventualmente, da intensidade da chuva. 
Mundialmente, a determinação do tempo de concentração é feita a partir da aplicação de fórmulas originadas de estudos experimentais de campo ou laboratório. De modo geral, estas fórmulas são obtidas em função das características da bacia hidrográfica como a área, o comprimento do talvegue, a rugosidade e a declividade do rio, córrego ou canal. É fundamental que as fórmulas do tempo de concentração sejam aplicadas em condições semelhantes para as quais foram determinadas (TUCCl et al., 2004).

As fórmulas que constam no SSD ABC 6 são apresentadas nas eq. (2.5) a (2.12).

\begin{tabular}{|c|}
\hline Bransby-Willians (1922) \\
\hline$t_{c}=306 \cdot \frac{L}{5280} \cdot\left(\frac{1}{A^{0,1} \cdot S i^{0,2}}\right)$ \\
\hline
\end{tabular}

\begin{tabular}{|c|}
\hline Kerby (1959) \\
\hline$t_{c}=7,23 \cdot\left(\frac{L . c}{S i^{0,5}}\right)^{0,467}$ \\
\hline
\end{tabular}

(2.7)

\begin{tabular}{|c|}
\hline Kirpich II (1940) \\
\hline$t_{c}=0,28 .\left(\frac{L^{2}}{S i}\right)^{0,385}$ \\
\hline
\end{tabular}

\begin{tabular}{|c|}
\hline Kirpich I (1940) \\
\hline$t_{c}=0,0196 .\left(\frac{L^{3}}{\Delta h}\right)^{0,385}$ \\
\hline
\end{tabular}

\begin{tabular}{|c|}
\hline Dooge (1956) \\
\hline$t_{c}=70,8 .\left(\frac{A^{0,41}}{S i^{0,17}}\right)$ \\
\hline
\end{tabular}

$$
\begin{aligned}
& \text { SCS - "lag equation” (1975) } \\
& t_{c}=0,43 \cdot \frac{L^{0,8}}{S i^{0,5}} \cdot\left(\frac{1000}{C N}-9\right)^{0,7}
\end{aligned}
$$

Equação Padrão SSD ABC 6

$$
t_{c}=\frac{\sqrt{A}}{2}
$$


Onde:

- L: é o comprimento do talvegue, em m

- A: é a área da bacia, em $\mathrm{km}^{2}$

- $\mathrm{S}_{\mathrm{i}}$ : é a declividade equivalente, em $\mathrm{m} / \mathrm{km}$

- c: é o rugosidade de retardo

- $\Delta \mathrm{h}$ : é a diferença de cotas, em m

- $\mathrm{n}$ : é a rugosidade de Manning

- I: é a intensidade da precipitação, em $\mathrm{mm} / \mathrm{h}$

- CN: é o número da curva do método SCS

A fórmula de Dooge (1956) foi determinada com dados de 10 bacias rurais com áreas na faixa de 140 a $930 \mathrm{~km}^{2}$. É de se supor, portanto, que seus parâmetros reflitam melhor o comportamento de bacias médias e escoamento predominante em canais (PORTO, 1995, p. 133)

A fórmula de Kirpich (1940) foi desenvolvida a partir de dados do SCS para sete bacias rurais, no Tenessee, com canal bem definido, declividades variando de 3 a $10 \%$ e áreas de no máximo, $0.5 \mathrm{~km}^{2}$. Para escoamentos em superfície de concreto ou asfalto multiplica-se o tempo de concentração obtido por 0,4. Para canais em concreto, por 0,2. Não há ajustes para escoamentos em superfícies em solo nu ou acostamento de estradas. (CHOW; MAIDMENT; MAYS, 1988, p. 500; PORTO, 1995, p. 133).

A equação da Onda Cinemática (1963) foi deduzida a partir da teoria da onda cinemática, aplicada à superfícies a partir das hipótese de escoamento turbulento e chuva de intensidade constante. O comprimento das superfícies variou de 15 a 30 metros. É adequada para bacias muito pequenas, em que o escoamento em superfícies seja predominante. (PORTO, 1995, p. 133)

A fórmula do SCS - Lag Equation (1975) foi desenvolvida em bacias rurais com áreas de drenagem de até $8 \mathrm{Km}^{2}$ e reflete, fundamentalmente, o escoamento em superfícies. Para aplicação em bacias urbanas, o SCS sugere procedimentos para ajuste em função da área impermeabilizada e da parcela em canais que sofreram modificações.. Essa fórmula superestima o valor do tempo de concentração em comparação com as expressões de Kirpich e Dooge.(PORTO, 1995, p. 133) 
Uma contribuição importante, que avaliou o erro de vinte e três fórmulas de concentração e que pode ser consultada, é a de Silveira (2005). Silveira (2005) confrontou as informações disponíveis sobre as origens das fórmulas e limitações teóricas, com o desempenho obtido em aplicações em bacias urbanas e rurais com dados observados.

\subsubsection{Chuva}

Como visto no item 2.2, a chuva é a principal variável de entrada dos modelos chuva-vazão. Isto se deve à relativa facilidade de medição desta variável, à disponibilidade de séries longas e que sofrem menor influência devido a alterações antrópicas na bacia.

\subsubsection{Definição}

Entende-se por chuva, as águas originadas do vapor de água atmosférico e que se precipitam sobre a superfície da terra. A chuva representa o importante papel de elo entre os fenômenos meteorológicos propriamente ditos e os de escoamento superficial, de maior interesse aos engenheiros (GARCEZ; ALVAREZ, 1988).

\subsubsection{Instrumentos de medição}

Em geral, as medições de chuva são feitas com o uso de um pluviômetro, aparelho formado por um recipiente cilíndrico com medidas padronizadas que, exposto às intempéries, armazena a água da chuva precipitada no período decorrido entre as leituras. Uma proveta graduada permite a medição do volume de água acumulado dentro do pluviômetro. Esse volume, dividido pela área de captação do pluviômetro, resulta em uma altura equivalente de chuva, dada em milímetros. As leituras são 
feitas diariamente, sempre no mesmo horário (DAEE, 2008, p. 15). A Figura 2.24 apresenta a imagem de um pluviômetro.

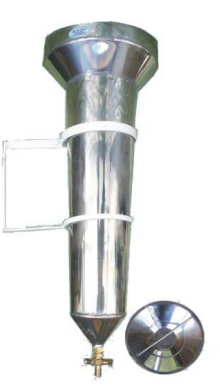

Figura 2.24 - Pluviômetro Fonte: DAEE, 2008. p. 15.
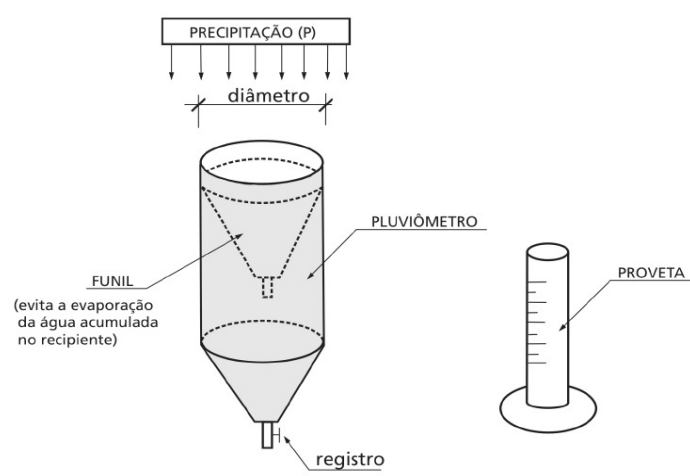

Outro tipo de medidor de chuvas é o pluviógrafo. Existe uma grande variedade de aparelhos, usando princípios diferentes para medir e gravar continuamente as precipitações. Os pluviográfos permitem medir as intensidades das chuvas durante intervalos de tempo inferiores àqueles obtidos com as observações manuais feitas nos pluviômetros (TUCCI, 2004).

São conhecidos os pluviógrafos com datalogger, que consistem em acumular digitalmente dados por algum período para recuperação posterior em computador. A Figura 2.25 mostra alguns tipos de data loggers.

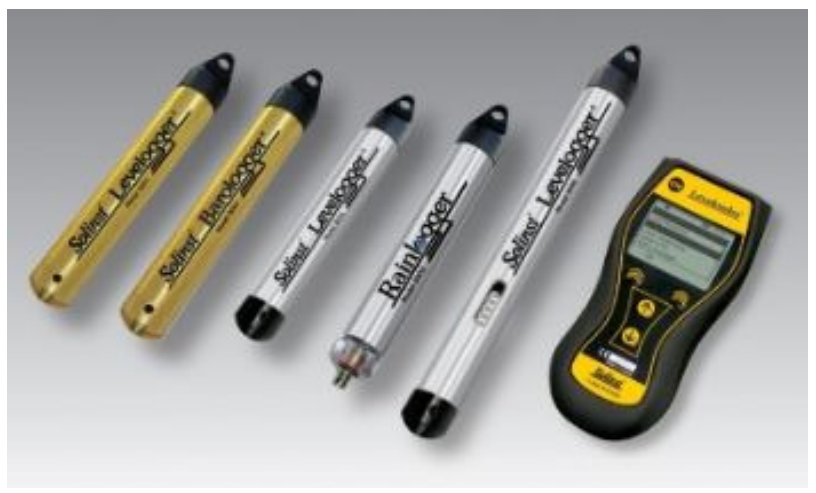

Figura 2.25 - Data logger Fonte: Edie, $2010 .^{6}$

Atualmente, as chuvas também têm sido medidas por radares e satélites, que compõem os sistemas de sensoriamento remoto.

\footnotetext{
${ }^{6}$ Disponível em: < http://www.edie.net/products/view entry.asp?id=4001> Acesso em: 10 fev. 2010.
} 
A técnica de sensoriamento remoto consiste na medição das propriedades dos objetos sobre a superfície da Terra, usando dados adquiridos a partir de radares e satélites (SCHOWENGERDT, 1997).

A rede telemétrica do Estado de São Paulo conta com o radar, fabricado pela "McGill University" do Canadá e instalado na Barragem de Ponte Nova, localizada na cabeceira do Rio Tietê. A Figura 2.26 mostra as imagens de satélite do radar do DAEE, para o evento de chuva do dia 05 de fevereiro de 2010.
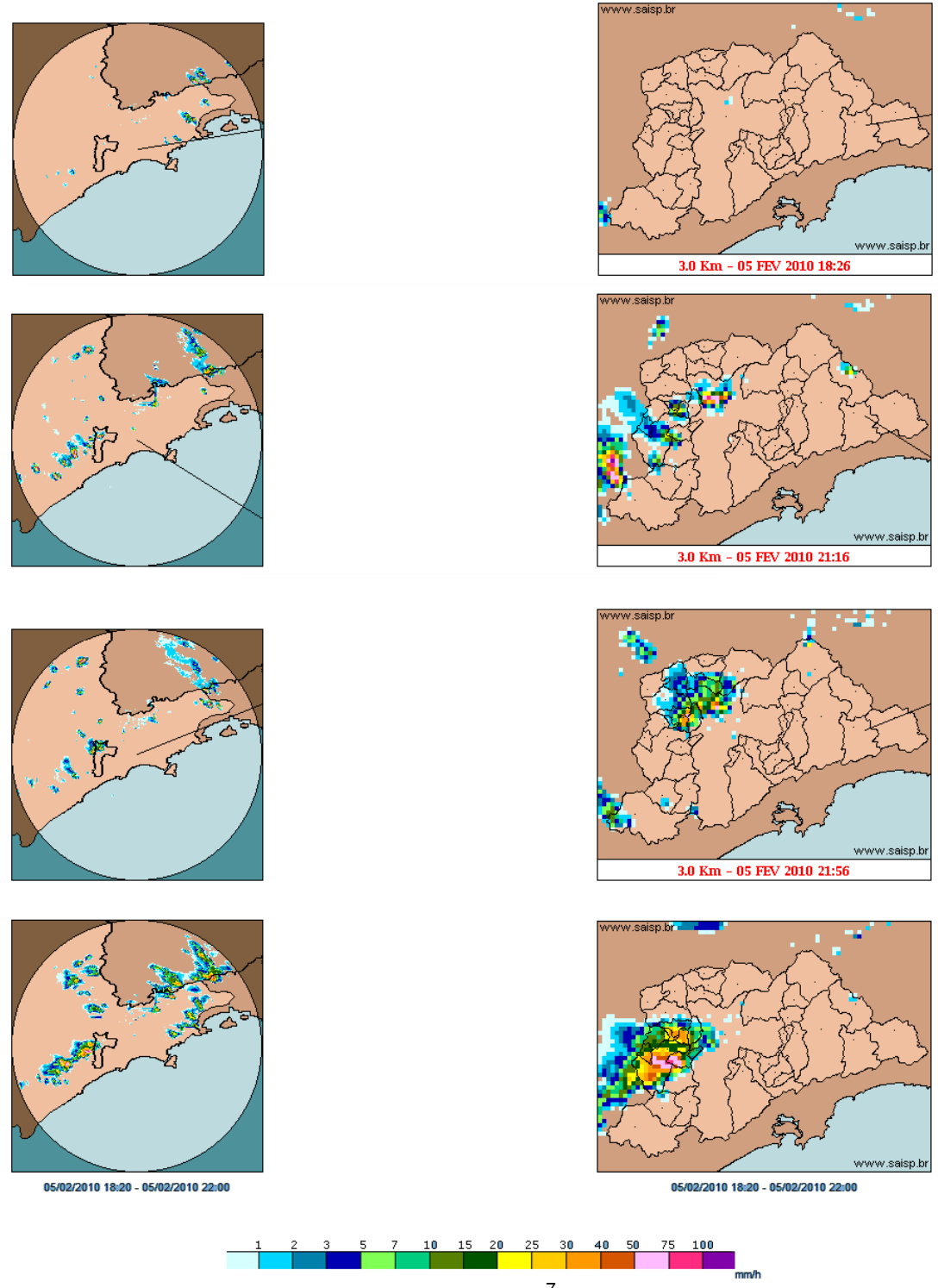

Figura 2.26 - Imagens do radar de Ponte Nova do $\mathrm{DAEE}^{7}$ Fonte: SAISP, 2010.

\footnotetext{
${ }^{7}$ Imagens obtidas na página da internet do SAISP: < http://www.saisp.br/online/>. Acesso em: 06 fev 2010.
} 
Futuramente, em virtude da inexistência de série histórica significativa, os dados obtidos a partir dos sistemas de sensoriamento remoto poderão preencher as lacunas entre a descrição da variabilidade temporal e espacial da chuva e do entendimento de mecanismos físicos importantes que gerenciam esta variabilidade (MARCELLINI, 1994).

Um importante satélite é o TRRM da missão Tropical Rainfall Measuring Mission. Esta é uma missão conjunta entre a NASA e a Agência de Exploração Aerospacial do Japão (JAXA) projetada para monitora e estudar as chuvas tropicais. A Figura 2.27 apresenta a imagem do satélite TRRM sendo montado. ${ }^{8}$

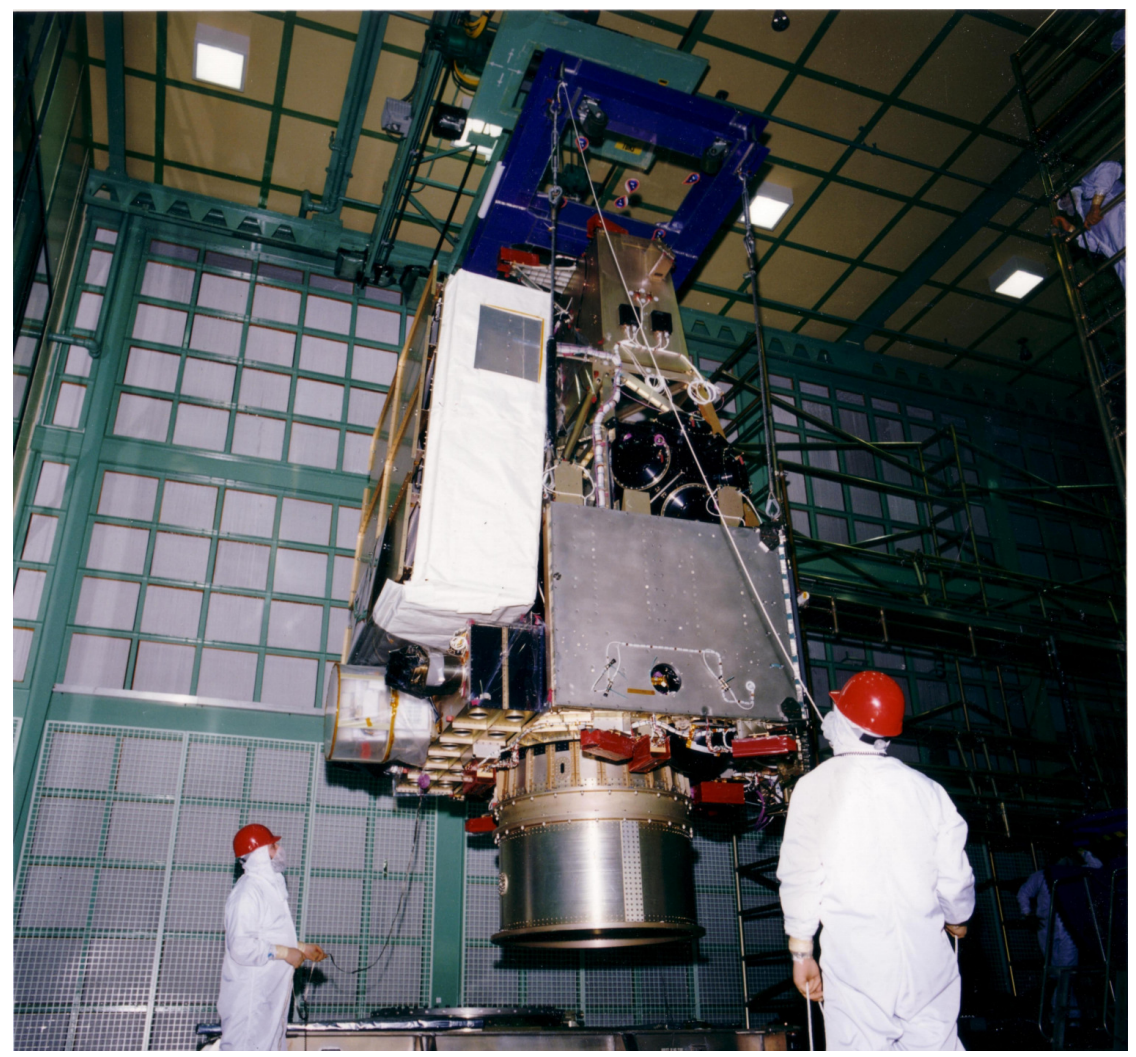

Figura 2.27 - Satélite TRRM sendo montado na Goddard Space Flight Center Fonte: NASA, 2010.

No Brasil, a missão TRMM-Brasil pretende estudar as características dinâmicas, microfísicas, elétricas e de aquecimento diabático da convecção tropical em duas

\footnotetext{
${ }^{8}$ Informação disponível no endereço eletrônico: <http://trmm.gsfc.nasa.gov/>, em 02 fev. 2010.
} 
regiões no país: na região de Rondônia na Amazônia e no Estado do Paraná. Os dados colhidos pelo programa serão usados, em parte, para a validação de produtos do satélite do TRMM, que repetidamente passará sobre a região. Paralelamente, o programa de campo apresenta uma oportunidade enorme para responder a questões científicas relacionadas ao estudo da convecção tropical na região.

\subsubsection{Dados de chuva no Brasil}

A Agência Nacional de Águas (ANA) disponibiliza uma relação dos postos pluviométricos instalados e operados em todo o território brasileiro e os respectivos dados de chuva. Estas informações podem ser obtidas pela Internet através do Sistema de Informações Hidrológicas (HidroWeb). Para o Estado de São Paulo, existe o Sistema de Informações para o Gerenciamento de Recursos Hídricos do Estado de São Paulo (SIGRH), onde pode ser acessado o banco de dados pluviométricos.

É importante salientar que, deve-se conhecer a qualidade dos dados que estão sendo utilizados, pois isso pode comprometer a confiabilidade dos resultados dos estudos hidrológicos. Tratando-se de projetos em área urbana, recomenda-se que seja instalado ao menos um pluviógrafo, para melhorar a qualidade dos estudos hidrológicos que apoiarão, por exemplo, os projetos de controle de inundação. $O$ custo de instalação e operação deste instrumento é de ordem residual quando comparado à economia e à segurança que seus dados podem transmitir (TUCCl et al., 1995).

\subsubsection{Determinação da chuva de projeto}

Quando há disponibilidade de dados de chuva no local em estudo, a determinação da chuva de projeto é feita considerando-se as seguintes etapas: 
- Escolha dos postos pluviométricos de maior interesse;

- Levantamento, análise e consistência dos dados de chuva;

- Determinação da chuva de projeto a partir de estudos estatísticos: escolha do período de retorno e da distribuição de probabilidade (Normal, Log-Normal, Gumbel, Log-Gumbel ou Pearson Tipo III, por exemplo);

- Determinação da chuva de projeto média na bacia a partir dos métodos da média aritmética, dos Polígonos de Thiessen ou das Isoietas;

- Definição da duração da chuva de projeto;

- Definição da distribuição temporal da chuva de projeto a partir de métodos como: de Chicago, dos blocos alternados e de Huff.

Informações a respeito de como realizar os estudos estatísticos e como definir a distribuição espaço-temporal da chuva podem ser facilmente encontradas. Uma contribuição significativa foi feita por Marcellini (1994) que realizou uma revisão bibliográfica destes assuntos, objetivando analisar a influência das distribuições temporais nos hidrogramas de projeto de pequenas bacias hidrográficas. Marcellini (1994) mostrou que há uma variação significativa da vazão de pico de acordo com a distribuição temporal da chuva, evidenciando que a escolha do método de determinação da distribuição temporal é um dos fatores que influencia os hidrogramas de projeto.

Não havendo dados observados, recorrem-se às relações intensidade-duraçãofrequência (IDF). Definida a relação IDF, obtém-se a chuva de projeto. A chuva média na bacia é determinada multiplicando o valor obtido pelo fator de redução de área. A partir daí, define-se a distribuição temporal da chuva escolhendo-se um dos métodos de distribuição temporal.

Utiliza-se o fator de redução de área com o intuito de não superestimar a chuva de projeto, que por falta informação, é admitida constante em toda a bacia hidrográfica. Os fatores de redução de área estabelecidos pelo United States Weather Bureau, apresentados na Figura 2.28, podem ser utilizados. No Brasil, alguns pesquisadores 
desenvolveram algumas curvas para regiões diferentes e, constataram que existem poucas diferenças regionais. (ZAHED E MARCELLINI, 1995).

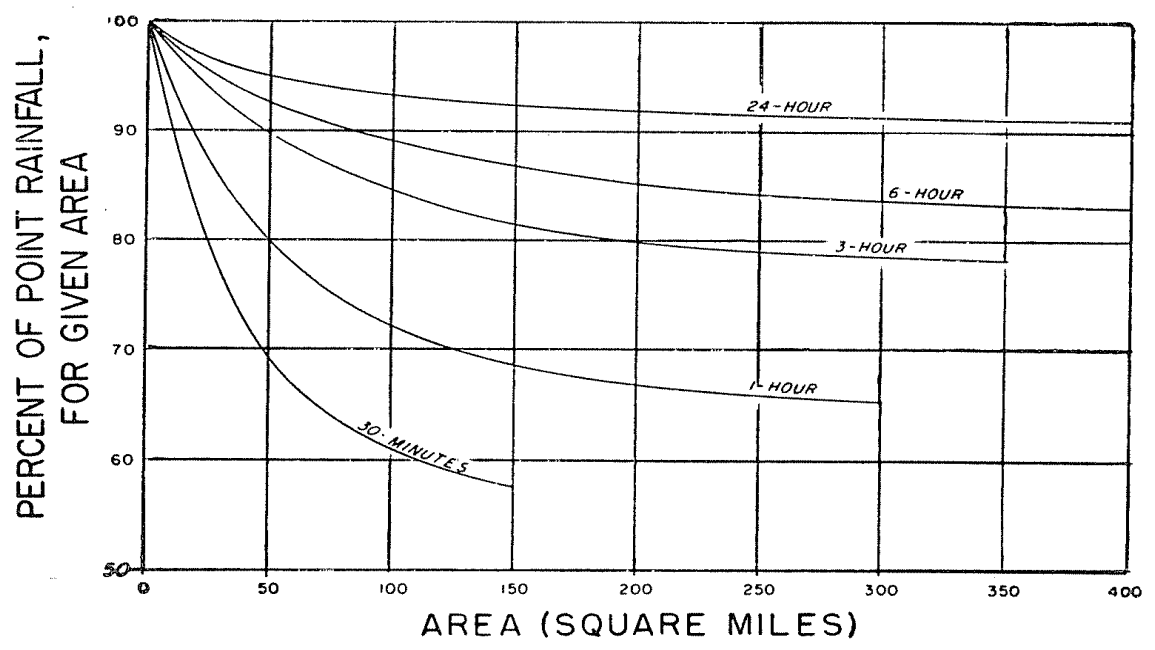

Figura 2.28 - Curva de fator de redução de área desenvolvida pelo U.S Weather Bureau Fonte: U.S Weather Bureau, 1957

\subsubsection{Equações IDF}

As equações IDF são obtidas através de uma série de dados de chuvas intensas, suficientemente longas e representativas do local de interesse.

Chuva intensa é um evento em que há grande volume precipitado em um intervalo de tempo relativamente pequeno. Para a definição das equações IDF, são analisadas, através de ajustes de distribuições de probabilidade de extremos, as máximas chuvas anuais observadas para cada duração.

A origem das equações IDF é discutida por alguns estudiosos, como McPherson (1958) apud Marcellini (1994), que questiona o fato das intensidades representarem apenas a chuva média para o período mais intenso e não o período real. A Figura 2.29, mostra um pluviograma de uma chuva real. 


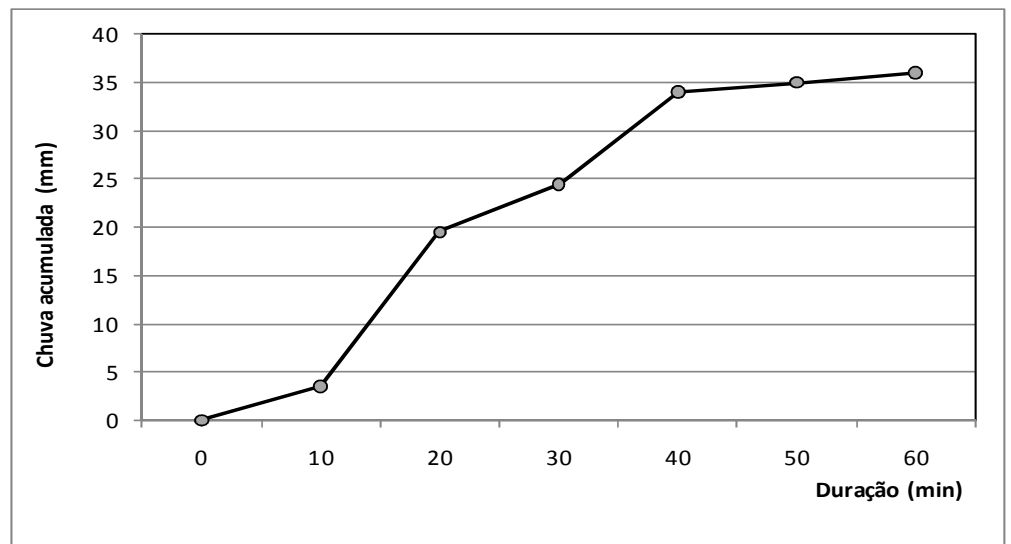

Figura 2.29 - Pluviograma de uma chuva real Fonte: Marcellini, 1994. p. 13.

Da Figura 2.29, pode-se observar que de uma tormenta com duração real de 60 minutos pode-se obter um trecho de 20 minutos, correspondente, ao trecho mais intenso desta chuva. Para o desenvolvimento das equações IDF, esta chuva teve duração de 20 minutos.

Marcellini (1994) analisou a diferença entre os valores de intensidade de chuvas obtidas pelas equações IDF conhecidas, que adotam como duração da chuva o trecho mais intenso e pelas equações desenvolvidas por ela, que adotam a duração real da chuva. Concluiu, para os 33 postos estudados, na região de São Paulo que, as intensidades médias máximas obtidas de eventos com durações reais, é cerca de três vezes inferior às obtidas dos períodos críticos de eventos com durações maiores. Também, pode ser observado que a medida que a duração da chuva aumenta, a diferença entre as intensidades médias obtidas das duas maneiras diminui, pois as chuvas de longa duração têm praticamente sua duração igual à duração real.

O trabalho de maior representatividade para diferentes regiões brasileiras na determinação das relações intensidade-duração-frequência foi apresentado por Pfafstetter (1957) para 98 postos pluviográficos espalhados pelo Brasil, com base em séries parciais. Para o Estado de São Paulo, dispõe-se de equações de intensidade, duração e freqüência, elaboradas por Mero e Magni (1982), através de um convênio Departamento de Águas e Energia Elétrica (DAEE) e a Universidade de São Paulo (USP). Foi feita por Martinez e Magni (1999) uma atualização e ampliação do número de equações de chuvas intensas disponíveis no Estado, 
obtidas a partir de um maior número de postos pluviográficos. A Figura 2.30 mostra, esquematicamente, os municípios com equação IDF no Estado de São Paulo.

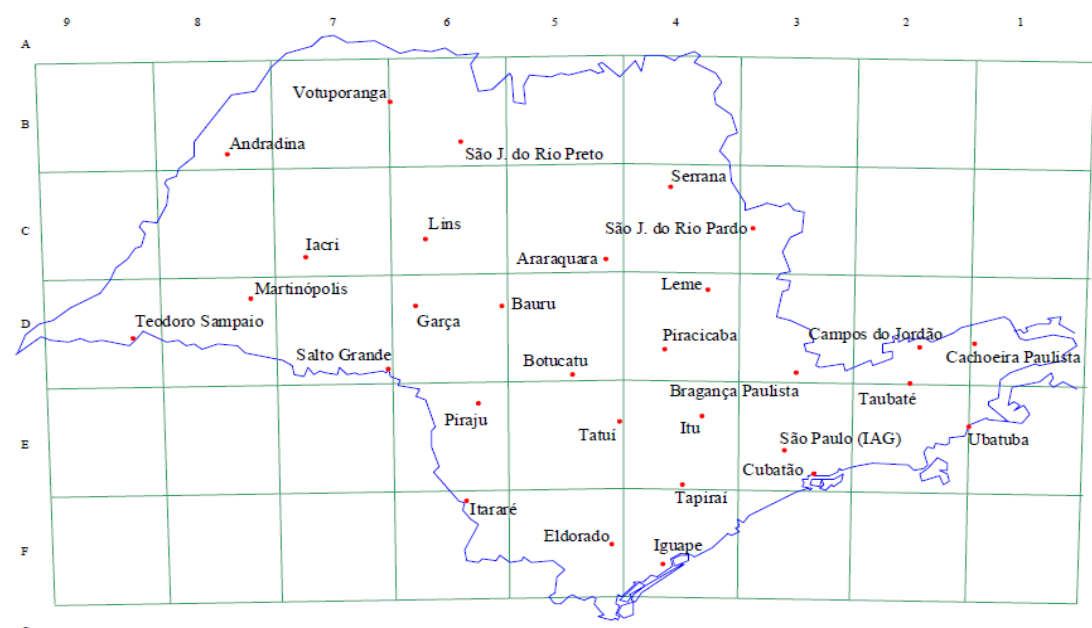

Figura 2.30 - Municípios com equação IDF no estado de São Paulo (sem escala) Fonte: Martinez Júnior e Magni, 1999. p. 16.

Caso não existam equações IDF, pode-se recorrer a equações empíricas, como as desenvolvidas por Bell (1969), com base em dados dos EUA, Austrália, URSS, Porto Rico, Alasca, África do Sul e Havaí. Utilizando séries parciais, Bell obteve a seguinte relação:

$$
P_{T}^{d}=(0,21 \ln T+0,52) \cdot\left(0,54 d^{0,25}-0,50\right) P_{10}^{60}
$$

Onde:

- d: é a duração da chuva, variável entre 5 e 120 minutos;

- T: é o período de retorno, variável entre 2 e 100 anos;

- $P_{T}^{d}$ : é o total precipitado em $\mathrm{mm}$.

Semelhantemente, Uehara et al. (1980) desenvolveu duas equações empíricas, uma válida para séries parciais e outra válida para séries anuais, a partir de um estudo efetuado com 26 postos brasileiros, obtidos do trabalho de Otto Pfafstetter (1957), que possuíam séries com 25 anos de dados ou mais. Estas equações são apresentadas a seguir. 


$$
\begin{gathered}
P_{T}^{d}=(0,1824 \ln T+0,58) \cdot\left(0,4966 d^{0,27}-0,50\right) P_{10}^{60} \\
P_{T}^{d}=(0,22 \ln T+0,50) \cdot\left(0,38 d^{0,31}-0,39\right) P_{10}^{60}
\end{gathered}
$$

Obviamente, a precisão dos resultados não pode ser comparada àquela dos valores obtidos com dados de observação do local em estudo. Servem, portanto, como uma estimativa, enquanto não se dispõe de dados.

\subsubsection{Infiltração}

Dentre estes processos, para a determinação da chuva excedente, o SSD ABC 6 quantifica a infiltração a partir de quatro métodos de avaliação: SCS, Horton, GreenAmpt, e método do Índice Fi. Antes da apresentação destes métodos, serão introduzidos os conceitos teóricos nos quais estes estão fundamentados. É importante salientar que no SSD ABC 6 os parâmetros dos métodos de Horton, Índice Fi e Green-Ampt estão associados ao grupo hidrológico do solo proposto pelo SCS e ao valor de CN.

Denomina-se infiltração, ao fenômeno de penetração da água nas camadas de solo próximas à superfície do terreno, movendo-se para baixo, através dos vazios, sob a ação da gravidade, até atingir uma camada impermeável, que a retém, formando então a água do solo (PINTO et al., 1976).

Podem ser destacadas três fases da infiltração: fase de intercâmbio, fase de descida e fase de circulação. A fase de intercâmbio ocorre na camada superficial de terreno, onde as partículas de água estão sujeitas a retornar à atmosfera, seja devido à aspiração capilar provocada pela evaporação à superfície, seja devido ao fenômeno de transpiração das plantas. A fase de descida corresponde ao deslocamento 
vertical da água quando seu peso próprio supera a adesão e a capilaridade do meio poroso. A fase de circulação acontece quando o solo está saturado e formam-se os lençóis subterrâneos. A água escoa devido à declividade das camadas impermeáveis. As regiões do solo onde ocorrem as fases de intercâmbio e descida são denominadas zonas de aeração e aquela onde se desenvolve a fase de circulação é a zona de saturação (GARCEZ; ALVAREZ, 1988). A Figura 2.31 mostra, esquematicamente, as fases de infiltração.

As grandezas características envolvidas no fenômeno de infiltração são: capacidade de infiltração, distribuição granulométrica, porosidade do solo, velocidade de infiltração, coeficiente de permeabilidade, suprimento específico, retenção específica e níveis estático e dinâmico.

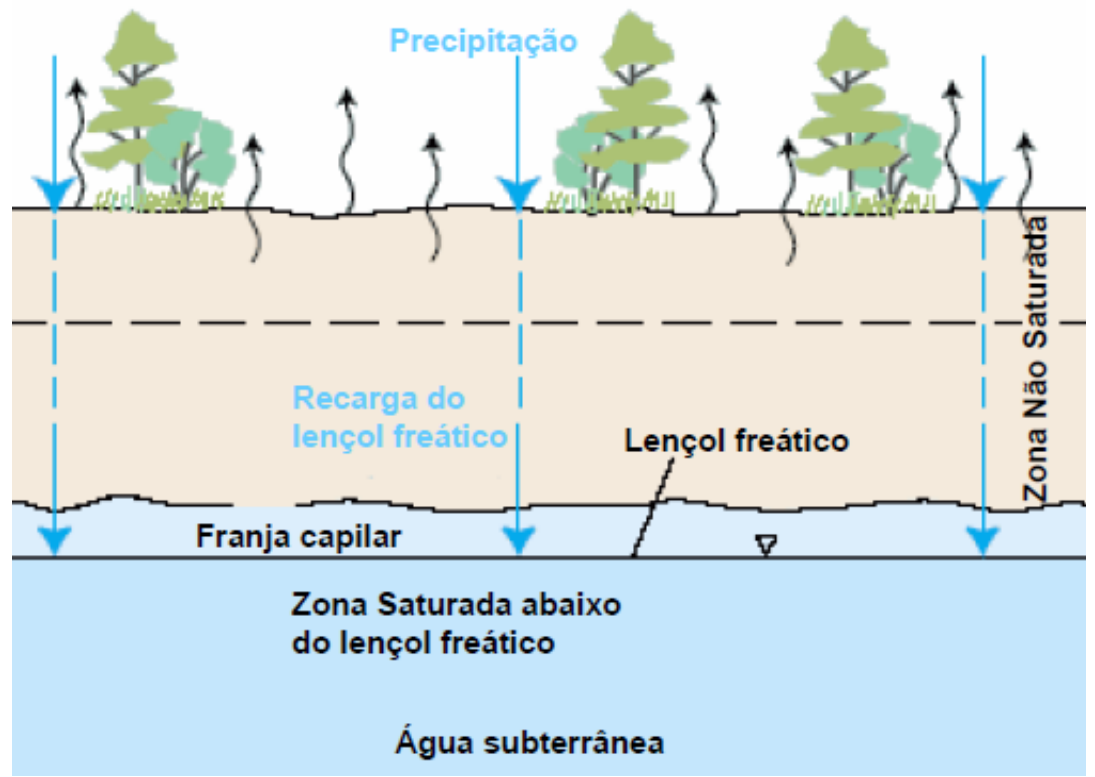

Figura 2.31 - Fases de infiltração Fonte: USGS, 2010.

Os principais fatores que influenciam no processo de infiltração são tipo de solo, declividade do terreno, altura de retenção superficial e espessura da camada saturada, grau de umidade do solo, ação da precipitação sobre o solo, compactação devida ao homem e aos animais, macroestrutura do terreno, cobertura vegetal, temperatura, presença do ar e variação da capacidade de infiltração. 


\subsubsection{Método do SCS (SCS runoff curve number method)}

Um dos métodos de utilização corrente que se aplica especialmente quando não se dispõe de dados hidrológicos para determinar o escoamento superficial direto é o método do USDA Natural Resources Conservation Service (o antigo Soil Conservation Service ou simplesmente SCS). O método é descrito em detalhes no National Engineering Handbook (USDA-SCS, 1985) e no Urban Hydrology for Small Watersheds (USDA, 1986).

A fórmula proposta pelo método é:

$$
P_{E S D a c u m}=\frac{\left(P_{\text {acum }}-0,2 S\right)^{2}}{P_{\text {acum }}+0,8 S}, P_{\text {acum }}>0,2 S
$$

Onde:

- PESDacum: é o escoamento superficial direto acumulado, em $\mathrm{mm}$

- Pacum: é a precipitação acumulada de um evento, em $\mathrm{mm}$

- S: $\quad$ é a retenção potencial do solo, em mm

O valor de "S" depende do tipo e da ocupação do solo. A quantidade de 0,2S é uma estimativa de perdas iniciais, devidas à interceptação e retenção em depressões. Por esta razão, impõe-se a condição $P_{\text {acum }}>0,2 S$ (USDA, 1986).

Para facilitar a solução da eq.(2.16), faz-se a seguinte mudança de variável:

$$
C N=\frac{1.000}{10+\frac{S}{25,4}}
$$

Onde:

- CN: é chamado de "número de curva" e varia, teoricamente, de 0 a 100. De acordo com a Tabela 2.3, a variação para o valor de $\mathrm{CN}$ é de 26 a 98 . 
Os valores de $\mathrm{CN}$ foram estabelecidos a partir da análise empírica do escoamento superficial de pequenas bacias hidrográficas monitoradas pelo USDA. O parâmetro depende basicamente do tipo, condições de uso, ocupação e umidade antecedente do solo (PONCE e HAWKINS, 1986).

Valores baixos de CN indicam reduzido potencial de escoamento superficial, 0 contrário, maior potencial. Ou seja, quanto mais impermeabilizada for a superfície do solo, maior será o valor do CN.

As figuras 2.32 e 2.33 apresentam a solução da eq. (2.16) para diferentes valores de $\mathrm{CN}$.

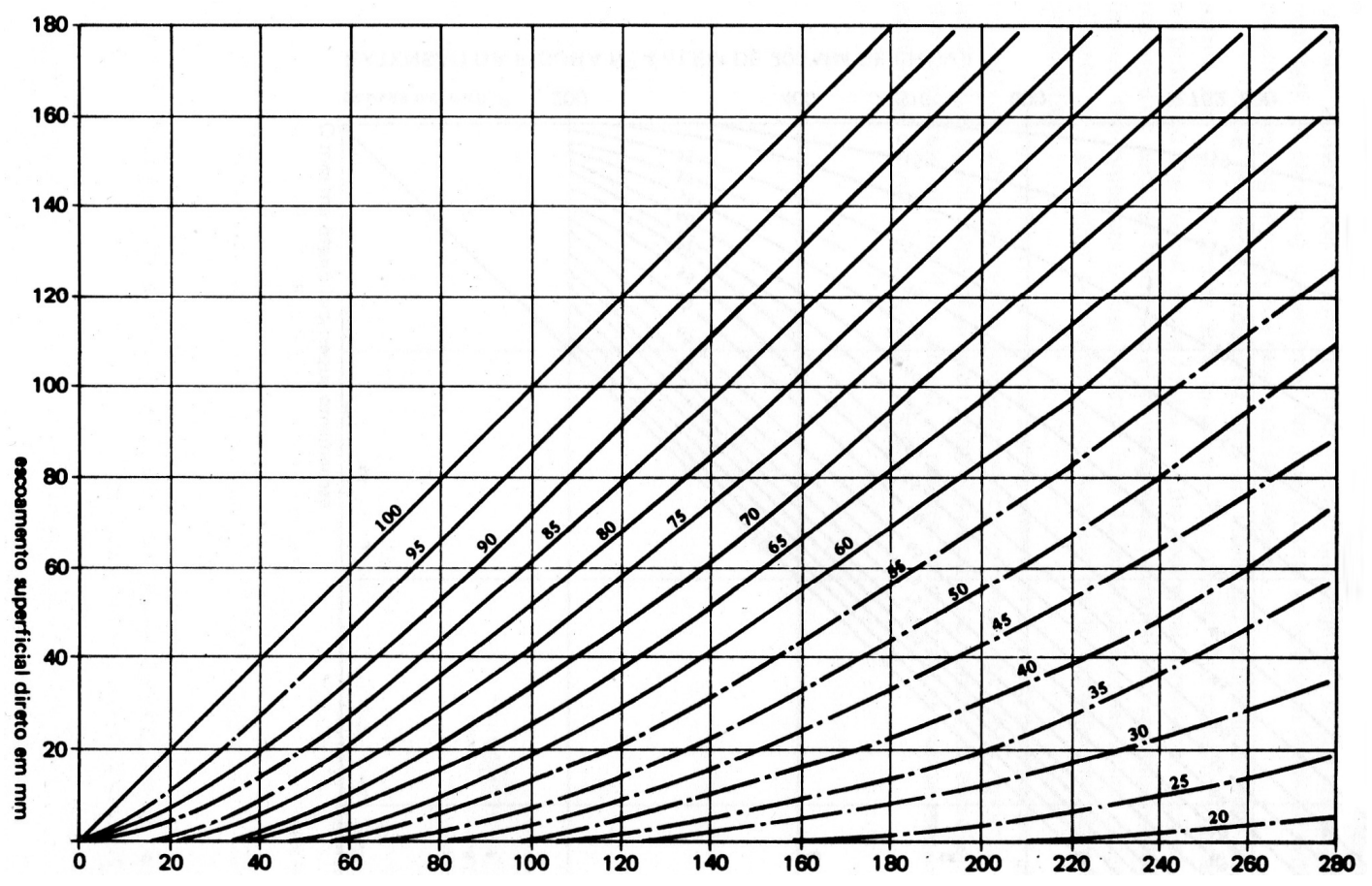

Figura 2.32 - Nomograma para resolução da equação 2.16 Fonte: Setzer e Porto, 1979. p. 99. 


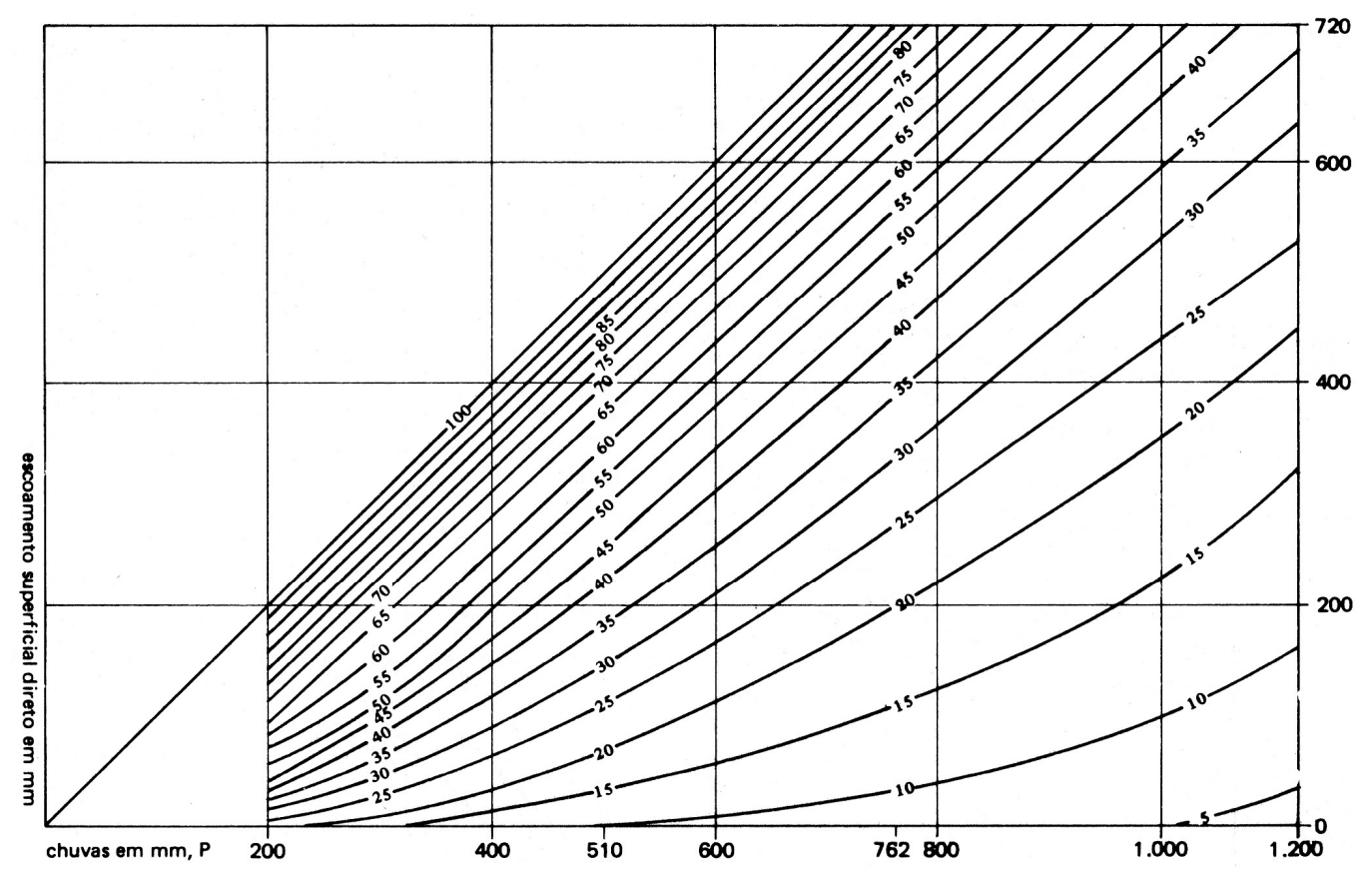

Figura 2.33 - Extensão da Figura 2.32, além de 200 mm de chuva Fonte: Setzer e Porto, 1979. p. 100.

Das figuras 2.32 e 2.33, para bacias rurais, pode-se observar, que à medida que chuva aumenta, o escoamento superficial vai se aproximando do valor da chuva. Os mesmos dados mostram que enquanto $P$ continua a crescer, $P_{\text {acum }}-P_{\text {ESDacum }}$ aproxima-se de uma constante (SETZER; PORTO, 1979).

O método distingue 4 grupos hidrológicos e 3 condições de umidade antecedente do solo apresentadas por Porto (1995) e descritas nos quadros 2.1 a 2.3.

\begin{tabular}{cl}
\hline Grupo & \multicolumn{1}{c}{ Descrição } \\
\hline A $\quad \begin{array}{l}\text { Solos arenosos com baixo teor de argila total, inferior a uns } 8 \% \text {, não há rocha nem } \\
\text { camadas argilosas e nem mesmo densificadas até a profundidade de 1,5m. O teor } \\
\text { de húmus é muito baixo, não atingindo } 1 \% .\end{array}$ \\
\\
Solos arenosos menos profundos que os do Grupo A e com menor teor de argila \\
total, porém ainda inferior a 15\%. No caso de terras roxas este limite pode subir a \\
B $\quad \begin{array}{l}\text { respectivamente, a 1,2 e 1,5\%. Não pode haver pedras e nem camadas argilosas } \\
\text { até 1,5m, mas é quase sempre presente camada mais densificada que a camada } \\
\text { superficial. }\end{array}$
\end{tabular}




\begin{tabular}{cl}
\hline Grupo & \multicolumn{1}{c}{ Descrição } \\
\hline & Solos barrentos com teor total de argila de $20 \%$ a $30 \%$ mas sem camadas \\
argilosas impermeáveis ou contendo pedras até profundidades de $1,2 \mathrm{~m}$. \\
C & No caso de terras roxas, estes dois limites máximos podem ser $40 \%$ e 1,5 \\
& m. Nota-se a cerca de $60 \mathrm{~cm}$ de profundidade camada mais densificada que \\
& no Grupo B, mas ainda longe das condições de impermeabilidade. \\
& Solos arenosos menos profundos que os do Grupo A e com menor teor de \\
& argila total, porém ainda inferior a 15\%. No caso de terras roxas este limite \\
& pode subir a 20\% graças à maior porosidade. Os dois teores de húmus \\
podem subir, respectivamente, a 1,2 e 1,5\%. Não pode haver pedras e nem \\
camadas argilosas até 1,5m, mas é quase sempre presente camada mais \\
densificada que a camada superficial
\end{tabular}

Quadro 2.2 - Grupos hidrológicos do solo (continuação)

Fonte: Porto, R. L. L., 1995. p. 116.

\begin{tabular}{cl}
\hline Condição & \multicolumn{1}{c}{ Descrição } \\
\hline I & Solos secos - as chuvas nos últimos 5 dias não ultrapassam $15 \mathrm{~mm}$. \\
II $\quad \begin{array}{l}\text { Situação média na época das cheias - as chuvas nos últimos } 5 \text { dias } \\
\text { totalizaram entre } 15 \mathrm{~mm} \text { e } 40 \mathrm{~mm} .\end{array}$ & $\begin{array}{l}\text { Solo úmido (próximo da saturação) - as chuvas nos últimos } 5 \text { dias foram } \\
\text { III } \quad \text { superiores a } 40 \mathrm{~mm} \text { e as condições meteorológicas foram desfavoráveis a } \\
\end{array}$ \\
& altas taxas de evaporação.
\end{tabular}

Quadro 2.3 - Condições de umidade antecedente do solo

Fonte: Porto, R. L. L., 1995. p. 117.

Setzel e Porto (1979) desenvolveram um trabalho com o objetivo de avaliar o escoamento superficial de acordo com o solo e recobrimento vegetal nas condições do Estado de São Paulo.

Outros trabalhos, mais recentes, têm sido desenvolvidos por Genovez e Sartori e estão relacionados na bibliografia consultada deste trabalho.

A Tabela 2.3 permite converter o valor de CN para condição I ou III, dependendo da situação que se desejar representar. 
Tabela 2.3 - Conversão das Curvas CN para as diferentes condições de umidade do solo

\begin{tabular}{crrr}
\hline \multicolumn{3}{c}{ Numeração das curvas para as condições de } \\
\hline $\mathbf{I}$ & $\mathbf{I I}$ & $\mathbf{I I I}$ \\
\hline 100 & 100 & 100 \\
87 & 95 & 99 \\
78 & 90 & 98 \\
70 & 85 & 97 \\
63 & 80 & 94 \\
57 & 75 & 91 \\
51 & 70 & 87 \\
45 & 65 & 83 \\
40 & 60 & 79 \\
35 & 55 & 75 \\
31 & 50 & 70 \\
27 & 45 & 65 \\
23 & 40 & 60 \\
19 & 35 & 55 \\
15 & 30 & 50 \\
12 & 25 & 45 \\
9 & 20 & 39 \\
7 & 15 & 33 \\
4 & 10 & 26 \\
2 & 5 & 17 \\
0 & 0 & 0 \\
\hline
\end{tabular}

Fonte: Porto, R. L. L., 1995. p. 119.

Quanto às condições de uso e ocupação do solo, a Tabela 2.4 fornece valores de $\mathrm{CN}$ para os diferentes tipos de solo e respectivas condições de ocupação. Essa Tabela refere-se à condição II de umidade antecedente do solo.

Tabela 2.4 - Valores de CN em função do grupo hidrológico, ocupação e tratamento do solo

(continua)

\begin{tabular}{|c|c|c|c|c|c|}
\hline \multirow{2}{*}{\multicolumn{2}{|c|}{$\begin{array}{c}\text { Tipo de uso do solo e Tratamento } \\
\text { Condições Hidrológicas }\end{array}$}} & \multicolumn{4}{|c|}{ Grupo Hidrológico } \\
\hline & & $\mathbf{A}$ & B & C & $\mathbf{D}$ \\
\hline \multicolumn{6}{|c|}{ Uso Residencial } \\
\hline Tamanho Médio do Lote & \% Impermeável & & & & \\
\hline Até $500 \mathrm{~m}^{2}$ & 65 & 77 & 85 & 90 & 92 \\
\hline $1.000 \mathrm{~m}^{2}$ & 38 & 61 & 75 & 83 & 87 \\
\hline $1.500 \mathrm{~m}^{2}$ & 30 & 57 & 72 & 81 & 86 \\
\hline $2.000 \mathrm{~m}^{2}$ & 25 & 54 & 70 & 80 & 85 \\
\hline $4.000 \mathrm{~m}^{2}$ & 20 & 51 & 68 & 79 & 84 \\
\hline \multicolumn{2}{|c|}{ Estacionamentos pavimentados, telhados } & 98 & 98 & 98 & 98 \\
\hline \multicolumn{6}{|c|}{ Ruas e Estradas } \\
\hline \multicolumn{2}{|c|}{ Pavimentadas, com guias e drenagem } & 98 & 98 & 98 & 98 \\
\hline \multicolumn{2}{|c|}{ Com cascalho } & 76 & 85 & 89 & 91 \\
\hline \multicolumn{2}{|c|}{ de terra } & 72 & 82 & 87 & 89 \\
\hline
\end{tabular}


Tabela 2.4 - Valores de CN em função do grupo hidrológico, ocupação e tratamento do solo

(conclusão)

\begin{tabular}{|c|c|c|c|c|c|}
\hline \multicolumn{2}{|c|}{ Áreas Comerciais (85\% de impermeabilização) } & 89 & 92 & 94 & 95 \\
\hline \multicolumn{2}{|c|}{ Distritos Industriais (72\% de impermeabilização) } & 81 & 88 & 91 & 93 \\
\hline \multicolumn{6}{|c|}{ Espaços abertos, parques, jardins } \\
\hline \multicolumn{2}{|c|}{ Boas condições, cobertura de grama $>75 \%$} & 39 & 61 & 74 & 80 \\
\hline \multicolumn{2}{|c|}{ Condições Médias, cobertura de grama $>50 \%$} & 49 & 69 & 79 & 84 \\
\hline \multicolumn{6}{|c|}{ Terreno preparado para plantio, descoberto } \\
\hline \multicolumn{2}{|c|}{$\begin{array}{l}\text { Plantio em linha reta } \\
\text { Cultura em fileira }\end{array}$} & 77 & 86 & 91 & 94 \\
\hline \multirow{2}{*}{ Linha Reta } & Condições Ruins & 72 & 81 & 88 & 91 \\
\hline & Boas & 67 & 78 & 85 & 89 \\
\hline \multirow{2}{*}{ Curva de Nível } & Condições Ruins & 70 & 79 & 84 & 88 \\
\hline & Boas & 65 & 75 & 82 & 86 \\
\hline \multirow{2}{*}{ Curva de Nível + Terraço } & Condições Ruins & 66 & 74 & 80 & 82 \\
\hline & Boas & 62 & 71 & 78 & 81 \\
\hline \multicolumn{6}{|c|}{ Cultura de grãos } \\
\hline \multirow{2}{*}{ Linha Reta } & Condições Ruins & 65 & 76 & 84 & 88 \\
\hline & Boas & 63 & 75 & 83 & 87 \\
\hline \multirow{2}{*}{ Curva de Nível } & Condições Ruins & 63 & 74 & 82 & 85 \\
\hline & Boas & 61 & 73 & 81 & 84 \\
\hline \multirow{2}{*}{ Curva de Nível + Terraço } & Condições Ruins & 61 & 72 & 79 & 82 \\
\hline & Boas & 59 & 70 & 78 & 81 \\
\hline \multicolumn{6}{|c|}{ Plantação de legumes } \\
\hline \multirow{2}{*}{ Linha Reta } & Condições Ruins & 66 & 77 & 85 & 89 \\
\hline & Boas & 58 & 72 & 81 & 85 \\
\hline \multirow{2}{*}{ Curva de Nível } & Condições Ruins & 64 & 75 & 83 & 85 \\
\hline & Boas & 55 & 69 & 78 & 83 \\
\hline \multirow{2}{*}{ Curva de Nível + Terraço } & Condições Ruins & 63 & 73 & 80 & 83 \\
\hline & Boas & 51 & 67 & 76 & 80 \\
\hline \multicolumn{6}{|c|}{ Pasto } \\
\hline \multirow{6}{*}{ Curva de Nível } & Condições Ruins & 68 & 79 & 86 & 89 \\
\hline & Médias & 49 & 69 & 79 & 84 \\
\hline & Boas & 39 & 61 & 74 & 80 \\
\hline & Condições Ruins & 47 & 67 & 81 & 88 \\
\hline & Médias & 25 & 59 & 75 & 83 \\
\hline & Boas & 6 & 35 & 70 & 79 \\
\hline \multirow[t]{2}{*}{ Campos } & Condições Boas & 30 & 58 & 71 & 78 \\
\hline & Condições Ruins & 45 & 66 & 77 & 83 \\
\hline \multirow[t]{2}{*}{ Florestas } & Boas & 36 & 60 & 73 & 79 \\
\hline & Médias & 25 & 55 & 70 & 77 \\
\hline \multicolumn{2}{|c|}{ Núcleo de moradia em fazenda } & 59 & 74 & 82 & 86 \\
\hline
\end{tabular}

Fonte: Porto, R. L. L., 1995. p. 118.

O valor de $\mathrm{CN}$ destacado na Tabela 2.3 (para pastos, curva de nível, condições boas) deve ser corrigido de 6 para 26, como apresentado por Woo SunG Ye, Lee Hee Sun e Lee Kyoo Seock ${ }^{9}$

Morel-Seytoux (1987) apud Marcellini (1994) faz algumas críticas quando ao método:

9 Artigo disponível em <http://proceedings.esri.com/library/userconf/proc95/to250/p246html>, acessado em 02 fev. 2010. 
- A Fórmula 2.15, proposta pelo método, não tem base física. Derivando-se a equação proposta em função do tempo a taxa de infiltração torna-se proporcional a taxa de chuva. A teoria física mostra que para um solo saturado, a taxa de infiltração decresce com o tempo, independente da chuva;

- O método produz uma curva decrescente da infiltração somente para a taxa de chuva constante. Para chuvas de longas durações, o método fornece resultados apropriados;

- O método utiliza a chuva total para o cálculo da infiltração. A discretização para o cálculo da chuva efetiva é uma simplificação grosseira do método.

Apesar destas observações, o método não deve ser abandonado, visto sua facilidade de aplicação. $O$ conhecimento destas restrições permite que o método seja aplicado de maneira correta.

\subsubsection{Método de Horton}

A partir de experimentos de campo, Horton (1939) estabeleceu, para o caso de um solo submetido a uma precipitação com intensidade sempre superior à capacidade de infiltração, uma relação empírica para representar o decaimento da infiltração com o tempo (CHOW; MAIDMENT; MAYS, 1988), que pode ser representada da seguinte forma:

$$
f=f_{c}+\left(f_{0}-f_{c}\right) \cdot e^{-\frac{\Delta t}{k_{F}}}
$$

Onde:

- f: é a taxa de infiltração no tempo, em $\mathrm{mm} / \mathrm{h}$;

- $\mathrm{f}_{0}$ : é a taxa de infiltração inicial, em $\mathrm{mm} / \mathrm{h}$;

- $f_{c}$ : é a taxa de infiltração final, em $\mathrm{mm} / \mathrm{h}$;

- $\mathrm{k}_{\mathrm{F}}$ : é uma constante que depende do tipo do solo;

- $\Delta \mathrm{t}$ : é o intervalo de tempo em horas. 
Integrando-se a eq. (2.18), chega-se a equação que representa a infiltração acumulada, ou potencial de infiltração, dada por:

$$
F=f_{c} \cdot \Delta t+\frac{1}{k} \cdot\left(f_{0}-f_{c}\right) \cdot\left(1-e^{-k_{T} \cdot \Delta t}\right)
$$

Onde F é a infiltração acumulada, em mm.

Segundo Porto (1995), a fórmula pode, entretanto, ser aplicada a situações em que i $<\mathrm{f}$, desde que se utilizem algoritmos especiais como, por exemplo, o proposto por Berthelot (1970) e o utilizado pelo SSD ABC (PORTO et al.,2001).

Berthelot propôs um algoritmo para calcular a infiltração e a percolação de água na camada superior do solo, combinando, num balanço hídrico a equação da continuidade, a equação de Horton e uma equação empírica para a percolação (TUCCl et al., 2004).

Os coeficientes da fórmula de Horton oriundos da classificação hidrológica dos solos a partir da experiência do SCS são apresentados na Tabela 2.5.

Tabela 2.5 - Parâmetros de Horton para diferentes tipos de solo

\begin{tabular}{ccccc}
\hline \multirow{2}{*}{$\begin{array}{c}\text { Parâmetros da fórmula de } \\
\text { Horton }\end{array}$} & \multicolumn{4}{c}{ Classificação Hidrológica do Solo - SCS } \\
\cline { 2 - 5 } & Tipo A & Tipo B & Tipo C & Tipo D \\
\hline$f_{0}(\mathrm{~mm} / \mathrm{h})$ & 250 & 200 & 130 & 80 \\
$f_{C}(\mathrm{~mm} / \mathrm{h})$ & 25 & 13 & 7 & 3 \\
$K_{T}$ & 2 & 2 & 2 & 2 \\
\hline Fonyyyy
\end{tabular}

Fonte: Porto, 1995. p. 122. 


\subsubsection{Método de Green e Ampt}

A fórmula de Green e Ampt pode ser deduzida das equações que regem o fluxo de água nas camadas superiores do solo (CHOW, 1988) mediante a introdução de algumas simplificações. A expressão de Sf originada destas equações é:

$$
S_{f}=\left(\theta_{n}-\theta_{i}\right) \cdot\left(H_{f}+H_{0}\right)
$$

Onde:

- $\quad \mathrm{S}_{\mathrm{f}:} \quad$ sucção exercida pela camada superior do solo, em mm;

- $\theta_{n}$ : é a água contida no solo nas condições naturais de saturação, expressa em fração do volume do solo;

- $\theta_{i}$ : é a quantidade de água inicial do solo expressa em fração do volume do solo;

- $\mathrm{H}_{0}$ : é a lâmina de água depositada sobre o solo, em mm;

- $\mathrm{H}_{\mathrm{f}:} \quad$ é a sucção capilar exercida pelo solo, em $\mathrm{mm}$.

O valor de $\theta_{n}$ é limitado superiormente pela porosidade do solo e atinge, portanto, valores máximos da ordem de 0.4. Solos secos apresentam valores de umidade da ordem $0,1 \mathrm{e}$, portanto, o termo $\left(\theta_{n}-\theta_{i}\right)$ costuma variar na faixa de 0 a 0.3 . O valor de $H_{0}$ é normalmente pouco significativo em relação à $H_{f}$. Valores médios de $H_{f}$ para diversos tipos de solos podem ser obtidos em textos de hidrologia ou pedologia (PORTO, 1995).

Em 1911, Green e Ampt apresentaram a seguinte fórmula para cálculo da capacidade de infiltração:

$$
f=f c .\left(1+\frac{S_{f}}{W}\right)
$$


Onde:

- $\quad \mathrm{S}_{\mathrm{f}:} \quad$ sucção exercida pela camada superior do solo, em $\mathrm{mm}$;

- W: é a quantidade de água acumulada no solo, em mm;

- f: é a taxa de infiltração no tempo, em mm/h;

- $\mathrm{f}_{\mathrm{c}}$ : é a taxa de infiltração final, em $\mathrm{mm} / \mathrm{h}$.

A Tabela 2.6 apresenta uma correspondência entre números de curva do SCS, CN, e os parâmetros $S_{f}$ e $f_{c}$ de Green e Ampt.

\begin{tabular}{ccc}
$\begin{array}{l}\text { Tabela } 2.6 \\
\text { Ampt, } \mathrm{f}_{\mathrm{C}}(\mathrm{mm} / \mathrm{h}) \text { e } \mathrm{S}_{\mathrm{f}}(\mathrm{mm})\end{array}$ & \multicolumn{3}{c}{} \\
\hline $\mathbf{C N}$ & $\boldsymbol{f}_{\boldsymbol{c}}(\mathbf{m m} / \mathbf{h})$ & $\mathbf{S f}(\mathbf{m m})$ \\
\hline 100 & - & - \\
95 & 0,40 & 11,2 \\
90 & 0,80 & 22,4 \\
85 & 1,20 & 33,6 \\
80 & 1,60 & 44,9 \\
75 & 2,00 & 54,9 \\
70 & 4,00 & 40,5 \\
65 & 6,00 & 35,8 \\
60 & 7,90 & 29,1 \\
55 & 9,90 & 25,0 \\
50 & 11,80 & 22,2 \\
45 & 13,80 & 20,3 \\
40 & 15,70 & 18,9
\end{tabular}

Fonte: Porto, 1995. p. 124.

\subsubsection{Método do índice Fi}

Outro método simples de uso bastante corrente é o chamado "método do índice Fi" (LINSLEY; FRANZINI, 1917). O índice Fi nada mais é do que a taxa de infiltração "f" suposta constante ao longo do tempo.

O índice Fi, embora seja uma aproximação grosseira do método de Horton (1939), pode ser utilizado sem introduzir grandes erros em estudos de cheias, pois 
usualmente ocorrem quando o solo já foi umedecido por chuvas anteriores. Neste caso o valor inicial $f_{0}$ aproxima-se de $f_{c} \circ$ que torna a hipótese de Fi mais realista.

\subsubsection{Hidrogramas}

Considerando que será usada como ferramenta de cálculo o SSD ABC 6 nas análises de sensibilidade, serão discutidos neste capítulo, os três métodos de traçado de hidrograma disponíveis neste SSD: os métodos de Santa Bárbara, Clark e Soil Conservation Service. Estes métodos baseiam-se na teoria do hidrograma unitário.

\subsubsection{Definição}

Genericamente, o hidrograma é a representação gráfica da variação da vazão em relação ao tempo numa determinada seção de controle do curso de água em estudo. A vazão nesta seção é a soma da precipitação recolhida diretamente pela superfície livre das águas, do escoamento superficial propriamente dito, do escoamento subsuperficial e da contribuição do lençol de água subterrâneo.

Um hidrograma é caracterizado pelo seu volume e pela sua forma, que em conjunto, determina o valor da vazão de pico. O hidrograma é, em última análise, um determinado hietograma de chuva excedente, modificado pelas características de escoamento da bacia somado às contribuições dos escoamentos sub-superficial e subterrâneo. Para os estudos de cheia, costuma-se tratar apenas a forma do escoamento superficial direto (ESD). A contribuição do escoamento sub-superficial e subterrâneo é admitida de forma simplificada. Daqui em diante, subentende-se hidrograma como uma identidade ao hidrograma ESD.

A forma do hidrograma é usualmente determinada em função de alguns parâmetros de tempo como os indicados na Figura 2.34 (TUCCl et al., 1995). 


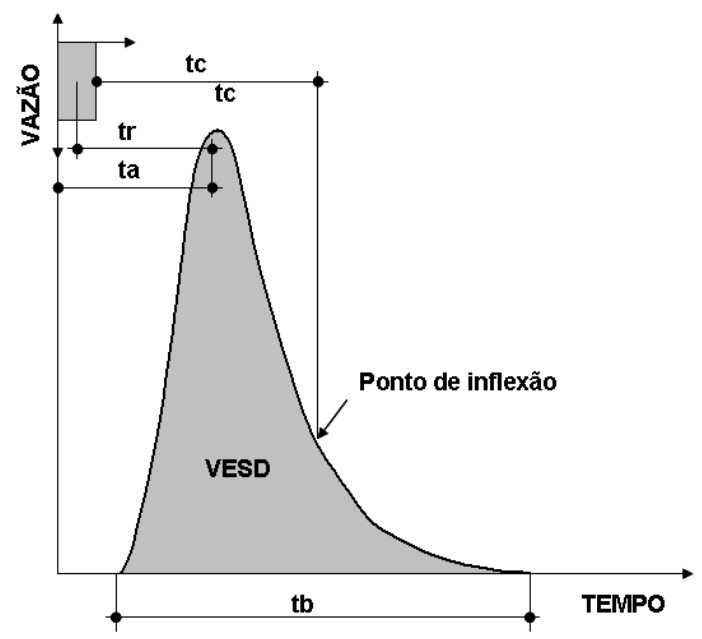

Figura 2.34 - Parâmetros de um hidrograma

A Figura 2.34 representa um hidrograma causado por um bloco único de chuva excedente com duração $d$ e intensidade constante durante esta duração. $O$ tempo de concentração, tc, já definido, é indicado na figura como o tempo decorrido desde o término da chuva até o ponto de inflexão situado no trecho descendente do hidrograma. Esta inflexão representa o instante em que a contribuição do ponto mais distante da bacia passa pela seção de controle. A partir deste ponto passará por esta seção somente a água que estava temporariamente armazenada em superfícies e canais da bacia.

O tempo decorrido desde o início da chuva excedente até o pico do hidrograma é chamado "tempo de ascensão" ( $\mathrm{t}_{\mathrm{a}}$ ) e a duração total do escoamento superficial direto é chamada de tempo base $\left(\mathrm{t}_{\mathrm{b}}\right)$. O tempo de retardamento $\left(\mathrm{t}_{\mathrm{r}}\right)$ ou simplesmente retardamento é o tempo que vai do centro de massa do hietograma de chuva excedente até o pico do hidrograma.

\subsubsection{Hidrograma unitário}

O hidrograma unitário (HU) é o hidrograma resultante de um escoamento superficial de volume unitário. O volume unitário é decorrente da chuva unitária, que corresponde à altura pluviométrica e duração unitária. Conhecido o hidrograma 
unitário de uma bacia, pode-se calcular as ordenadas do escoamento superficial correspondentes a qualquer chuva, de intensidade uniforme e duração igual àquela que gerou o HU. A teoria do hidrograma unitário baseia-se nas três proposições descritas a seguir:

1) Para chuvas de iguais durações, as durações dos escoamentos superficiais correspondentes são iguais;

2) Duas chuvas de mesma duração, mas com volumes escoados diferentes, resultam em hidrogramas cujas ordenadas são proporcionais aos correspondentes volumes escoados;

3) Considera-se que as precipitações anteriores não influenciam a distribuição no tempo do escoamento superficial de uma dada chuva.

A Figura 2.35 apresenta graficamente estes três princípios.

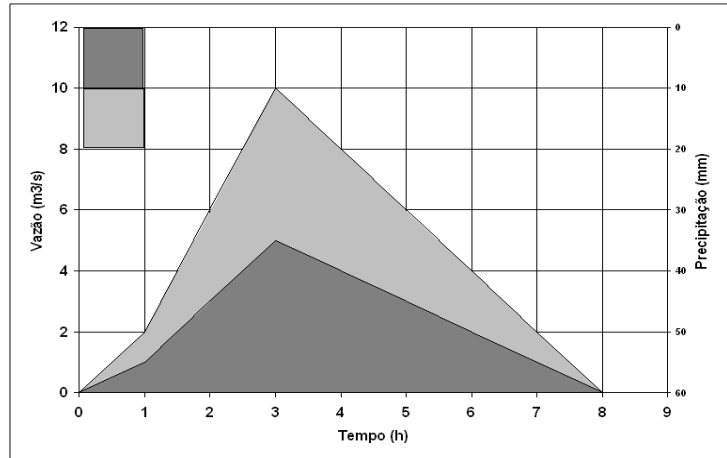

(1)

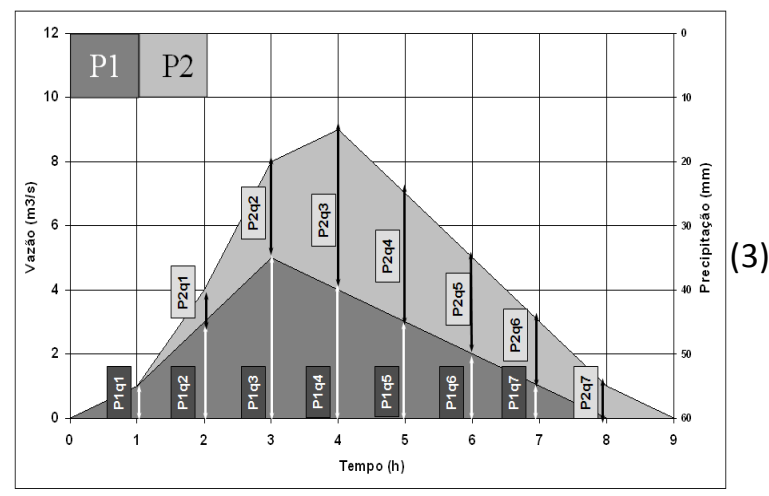

Figura 2.35 - Constância do Tempo de Base (1), Proporcionalidade das descargas (2) e Principio da Aditividade (3)

Fonte: Zahed Filho, $2009^{10}$

\footnotetext{
${ }^{10}$ Apresentação eletrônica, da Disciplina "Hidrologia Aplicada" - PHD 2307, do Prof. Dr. Kamel Zahed Filho, disponível no endereço: < http://200.144.189.36/phd/LeArq.aspx?id arq=3293> em 15 jul. 2009.
} 
O hidrograma unitário é um dos métodos mais práticos disponíveis para determinar a relação entre precipitação e o hidrograma resultante.

O HU é determinado para bacias com disponibilidade de dados observados a partir das equações de convoluções. Para regiões onde não há dados históricos, o HU é estimado pelo chamado hidrograma unitário sintético, determinado a partir dos parâmetros relacionados com as características físicas da bacia. A seguir são apresentados os três métodos de hidrograma unitário sintético disponíveis no SSD ABC 6.

\subsubsection{Método do hidrograma unitário sintético do Soil Conservation Service}

O método do hidrograma triangular unitário do SCS é um método mais geométrico do que físico, pois admite que o escoamento superficial direto é igual à área de um triângulo. Não leva em conta os fenômenos de translação e o amortecimento do escoamento na bacia hidrográfica.

O método da SCS (McCUEN, 1982) admite que o hidrograma de cheia apresente formato triangular como apresentado na Figura 2.36. Conhecida a área do triângulo, que corresponde ao volume d'água precipitado sobre a bacia e o tempo de base, pode-se determinar a vazão de pico.

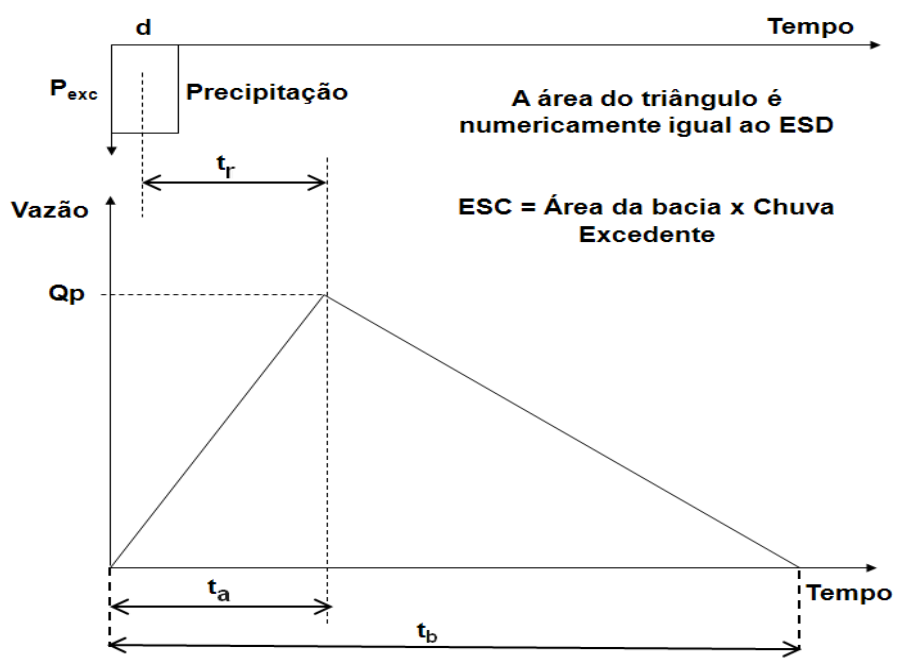

Figura 2.36 - Hidrograma triangular do SCS. 
O tempo de base pode ser obtido valendo-se das seguintes relações:

$$
t_{b}=2,67 . t_{a}
$$

Onde:

- $t_{b}$ : é o tempo de base do hidrograma;

- $t_{a}$ : é o tempo de ascensão do hidrograma, dado por:

$$
t_{a}=t_{r}+d / 2
$$

Onde:

- $d$ : é a duração da chuva excedente;

- $t_{r}$ : é o tempo de retardamento da bacia, que é o intervalo de tempo entre instante correspondente a metade da duração da chuva e o instante do pico do hidrograma; o $t_{p}$ pode ser obtido da seguinte forma (em horas):

$$
t_{p}=0,6 \cdot t_{c}
$$

Onde:

- $t_{c}$ : é o tempo de concentração da bacia.

O método admite que cada chuva excedente de duração $\Delta$ t gera um hidrograma triangular, com sua correspondente vazão de pico. O hidrograma final de projeto é a composição de $n$ hidrogramas parciais ( $n$ é o número de intervalos em que a chuva de projeto foi subdividida).

Caso, se deseje traçar o hidrograma curvilíneo, o mesmo pode ser obtido a partir do hidrograma triangular, utilizando um gráfico adimensional elaborado pelo SCS com valores tabelados. Os valores tabelados são em função do tempo de ascensão do hidrograma e da vazão de pico para um tempo t e uma vazão q qualquer. Este formato curvilíneo é o utilizado no SSD ABC 6. 
Tabela 2.7 - Valores para transformação do hidrograma triangular para o hidrograma curvilíneo do SCS

\begin{tabular}{|c|c|c|c|c|}
\hline \multirow[b]{2}{*}{$\begin{array}{l}\text { Tempo } \\
\left(\mathrm{t} / \mathrm{t}_{\mathrm{p}}\right)^{\mathrm{b}}\end{array}$} & \multicolumn{2}{|c|}{ Hidrograma curvilíneo } & \multicolumn{2}{|c|}{ Hidrograma triangular } \\
\hline & $\begin{array}{c}\text { Descarga } \\
\left(q / q_{p}\right)^{b}\end{array}$ & $\begin{array}{l}\text { Massa } \\
\left(Q_{a} / Q\right)\end{array}$ & $\begin{array}{c}\text { Descarga } \\
\left(q / q_{p}\right)\end{array}$ & $\begin{array}{l}\text { Massa } \\
\left(Q_{a} / Q\right)\end{array}$ \\
\hline 0 & r & 0 & 0 & 0 \\
\hline 0,1 & 0,015 & 0,001 & 0,1 & 0,004 \\
\hline 0,2 & 0,075 & 0,006 & 0,2 & 0,015 \\
\hline 0,3 & 0,16 & 0,018 & 0,3 & 0,034 \\
\hline 0,4 & 0,28 & 0,037 & 0,4 & 0,060 \\
\hline 0,5 & 0,43 & 0,068 & 0,5 & 0,094 \\
\hline 0,6 & 0,6 & 0,110 & 0,6 & 0,135 \\
\hline 0,7 & 0,77 & 0,163 & 0,7 & 0,184 \\
\hline 0,8 & 0,89 & 0,223 & 0,8 & 0,240 \\
\hline 1,0 & 0,01 & 0,375 & 1,0 & 0,375 \\
\hline 1,1 & 0,98 & 0,450 & 0,94 & 0,448 \\
\hline 1,2 & 0,92 & 0,517 & 0,88 & 0,516 \\
\hline 1,3 & 0,84 & 0,577 & 0,82 & 0,579 \\
\hline 1,4 & 0,75 & 0,634 & 0,76 & 0,639 \\
\hline 1,5 & 0,65 & 0,683 & 0,70 & 0,694 \\
\hline 1,6 & 0,57 & 0,727 & 0,64 & 0,744 \\
\hline 1,8 & 0,43 & 0,796 & 0,52 & 0,831 \\
\hline 2,0 & 0,32 & 0,848 & 0,40 & 0,900 \\
\hline 2,2 & 0,24 & 0,888 & 0,28 & 0,951 \\
\hline 2,4 & 0,18 & 0,916 & 0,16 & 0,984 \\
\hline 2,6 & 0,13 & 0,938 & 0,04 & 0,999 \\
\hline 2,8 & 0,098 & 0,954 & 0 & 1 \\
\hline 3,5 & 0,036 & 0,984 & & \\
\hline 4,0 & 0,018 & 0,993 & & \\
\hline 4,5 & 0,009 & 0,997 & & \\
\hline 5,0 & 0,004 & 0,999 & & \\
\hline Infinito & 0 & 1 & & \\
\hline
\end{tabular}

Fonte: Wanielista, Kersten e Eaglin, 1997.

\subsubsection{Método do hidrograma unitário sintético de Clark}

O método considera os efeitos de translação e armazenamento determinados pelo trânsito da chuva excedente sobre a bacia. O conceito de translação e armazenamento é definido por Porto (1995): 
Translação: é o movimento da água ao longo dos canais em direção paralela ao fundo. É o tempo que uma partícula de água leva para percorrer uma determinada distância. O tempo de concentração é o tempo de translação do ponto mais distante da bacia até a seção de controle.

Armazenamento: pode ser interpretado como o movimento da água na direção perpendicular ao fundo do canal e representa a parcela da chuva excedente que fica temporariamente retida na bacia e que chegará à seção de controle com certo atraso.

O método de Clark é baseado nos conceitos de isócronas e de histograma tempoárea. Isócronas são linhas imaginárias formadas pelos pontos da bacia que têm o mesmo tempo de translação até a seção de saída da bacia. Para obter o traçado das isócronas, pode ser desenhada sobre a bacia, uma matriz de linhas dispostas em ângulos retos ("grid"). Nos vértices da primeira linha da matriz, devem ser localizados os pontos iniciais, que correspondem aos pontos mais distantes do curso d'água e de cotas mais elevadas. Os pontos iniciais são ligados aos próximos pontos, que estão sobre o curso d'água, assim, é definido o primeiro trajeto do escoamento, para o qual é definido o tempo de translação do escoamento sobre a superfície da bacia. Este tempo é função da declividade, natureza da superfície do terreno e distância. Do ponto, correspondente ao início do curso d'água, até o ponto de saída do escoamento, é definido o trajeto do escoamento dos canais. O tempo de propagação do escoamento nos canais é determinado, em geral, de maneira expedita, a partir da rugosidade e inclinação do curso d'água. Conhecidos os tempos de translação, estes são interpolados e assim, traçadas as isócronas.

$\mathrm{Na}$ bacia esquematizada na Figura 2.37, indicam-se as isócronas de 1, 2, 3 e 4 horas. Se considerarmos uma chuva excedente com 1 hora de duração, a área $A_{1}$ situada a jusante da isócrona 1 representa a parte da bacia que contribuiu para 0 escoamento até 0 instante $t=1$ hora, na seção de controle, neste instante a contribuição dos pontos situados acima da isócrona 1 ainda não chegaram à seção.

Entre os instantes $t=1$ hora e $t=2$ horas, a área contribuinte é $A_{2}$, uma vez que a contribuição de $A_{1}$ já escoou totalmente e a contribuição de $A_{3}$ ainda não chegou à 
seção de controle. Este raciocínio pode ser expresso em forma gráfica por meio de um histograma tempo-área como é mostrado na Figura 2.37, ao lado da indicação das isócronas.
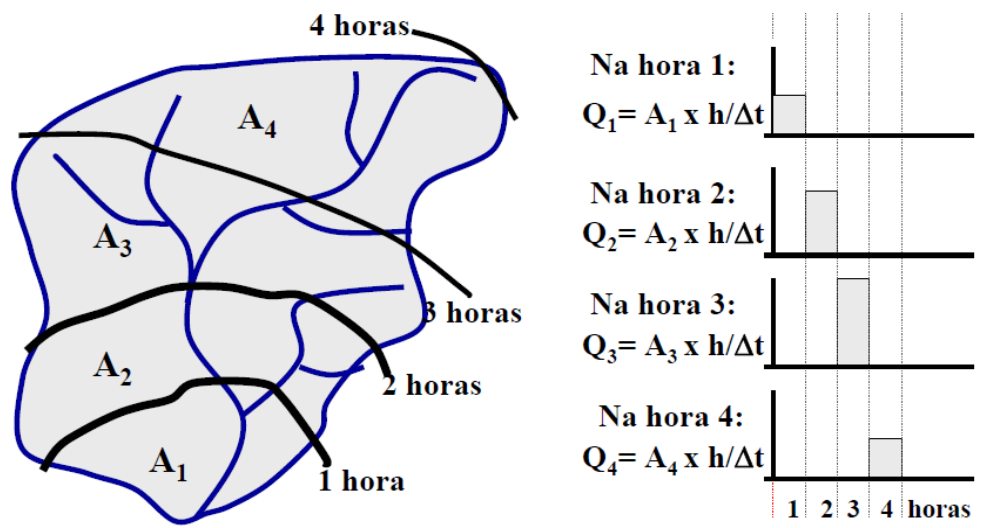

Figura 2.37 - Isócronas e histograma tempo-área Fonte: Zahed Filho, $2009^{11}$

Neste exemplo, o tempo de concentração da bacia é de 4 horas, pois após este tempo toda a bacia já contribuiu para o escoamento na seção de controle.

O volume escoado a cada intervalo de tempo é igual a área contribuinte $\mathrm{Ai}$ multiplicada pela chuva excedente. A vazão média no intervalo é o volume escoado dividido pelo intervalo de tempo, ou seja, a área $A_{i}$ multiplicada pela intensidade da chuva excedente $P_{\text {exci, }}$, conforme mostra as equações 2.24 e 2.25

$$
\begin{gathered}
V_{i}=A_{i} P_{e x c i} \\
Q_{i}=A_{i} \frac{P_{e x i}}{\Delta t}=A_{i} I_{e x c i}
\end{gathered}
$$

Onde:

- $\mathrm{V}_{\mathrm{i}} \quad$ Volume escoado a cada intervalo de tempo

\footnotetext{
${ }^{11}$ Apresentação eletrônica, da Disciplina "Hidrologia Determinística - PHD 5013, do Prof. Dr. Kamel Zahed Filho, disponível no endereço: <http://200.144.189.36/phd/LeArq.aspx?id arq=3218> em 15 jun. 2009
} 
- $\mathrm{A}_{\mathrm{i}} \quad$ Área contribuinte

- Pexci Chuva excedente

- $\Delta t \quad$ Intervalo de tempo

- lexci Intensidade da chuva excedente

Para introduzir o efeito de armazenamento, Clark propôs que este efeito fosse introduzido por um reservatório linear (Figura 2.38) situado na saída da bacia em cuja constante de armazenamento $\mathrm{K}_{\mathrm{CL}}$ estaria englobada toda a difusão sofrida pelo hidrograma.

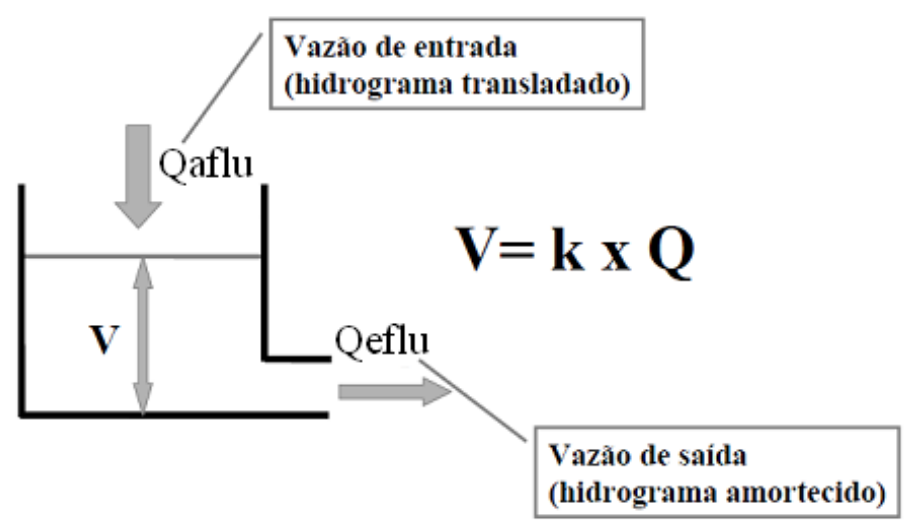

Figura 2.38 - Reservatório linear do método de Clark Fonte: Zahed Filho, 2009

Neste reservatório tem-se:

$$
\begin{gathered}
V_{2}-V_{1}=K_{C L}\left(Q_{e f f u_{2}}-Q_{e f f u_{1}}\right) \\
V_{2}-V_{1}=\left[\left(\frac{Q_{a f u_{1}}+Q_{\text {aff }}}{2}\right)-\left(\frac{Q_{\text {effu }}+Q_{\text {effu }}}{2}\right)\right] \Delta t
\end{gathered}
$$

Eliminando-se $V_{2}-V_{1}$ e isolando $Q_{\text {eflu2, obtém-se: }}$ 


$$
Q_{e f l u_{2}}=Q_{e f l u_{1}}+C\left(Q_{a f l u_{1}}+Q_{a f l u_{2}}-2 Q_{e f l u_{1}}\right)
$$

$$
C=\frac{\Delta t}{2 K_{C L}+\Delta t}
$$

Nestas equações V é o volume, $Q_{\text {aflu }}$ é a vazão de entrada e $Q_{\text {eflu }}$ é a vazão de saída. Os valores de $Q_{\text {aflu2 }}$ e $Q_{\text {eflu2 }}$ são obtidos por recorrência.

No SSD ABC 6, a construção do histograma tempo-área é feita a partir do "fator de forma", que pode variar entre 1 e 2 . O algoritmo de cálculo é mostrado na Figura 2.39:

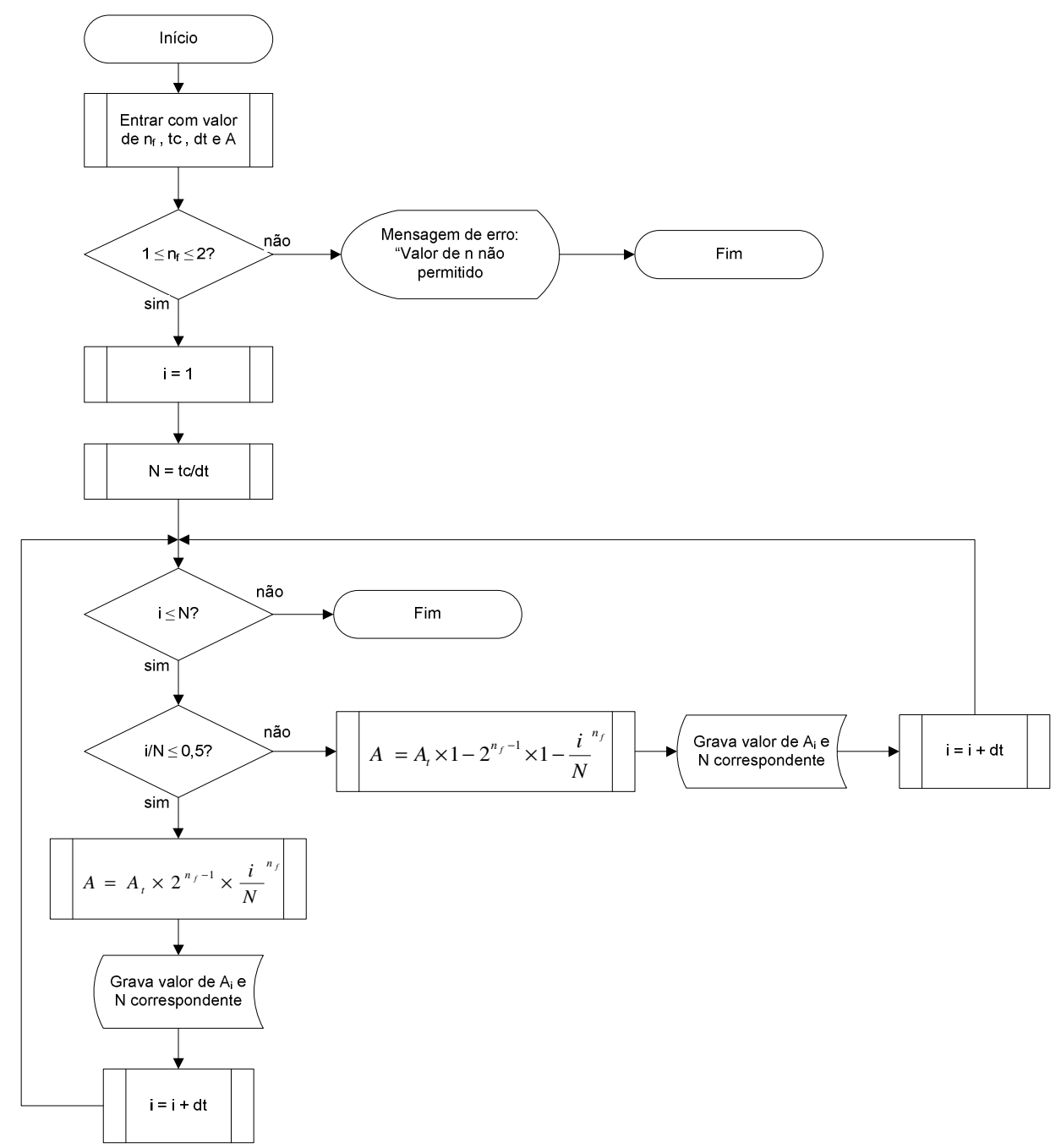

Figura 2.39 - Algoritmo para construção do histograma tempo-área 
Onde:

- $\mathrm{n}_{\mathrm{f}}$ : Fator de forma;

- N Número de isócronas;

- tc Tempo de concentração;

- dt Intervalo de discretização

- $A_{\text {iso }}$ área entre as isócronas

- A Área da bacia hidrográfica.

A constante linear que representa o fenômeno de armazenamento é função da relação entre comprimento do talvegue e área de drenagem da bacia hidrográfica.

No SSD ABC 6 estão disponíveis duas equações empíricas, a equação de Dooge (1973) e a equação de Sabol (1988) apresentadas a seguir:

$$
k_{C L}=80,75 \cdot \frac{A^{0,23}}{S_{i}^{0,7}}
$$

Onde a área é dada em $\mathrm{mi}^{2} \mathrm{e}$ a declividade em partes por 10.000 .

$$
k_{C L}=t c \cdot\left[1,46-867 \cdot 10^{-10} \cdot\left(\frac{L^{2}}{A}\right)\right]^{-1}
$$

Onde tc é dado em $\mathrm{h}, \mathrm{L}$ em $\mathrm{km}$ e A em $\mathrm{m}^{2}$

\subsubsection{Método do hidrograma unitário sintético de Santa Bárbara}

O método de Santa Bárbara (SBUH) foi desenvolvido por James M. Stubchaer no condado de Santa Bárbara, na Califórnia. Foi pela primeira vez apresentado no Simpósio Nacional de Hidrologia Urbana e Controle de Sedimentos realizado na Universidade de Kentucky em 1975 (WANIELISTA; KERSTEN; EAGLIN, 1997). 
O método do hidrograma de Santa Bárbara é uma simplificação do método de Clark. Semelhantemente ao método de Clark, o cálculo do hidrograma se dá através de áreas de contribuição. Entretanto, no método do hidrograma de Santa Bárbara, a bacia não é dividida em subáreas, mas é considerada como uma única área de contribuição.

O coeficiente $\mathrm{k}_{\mathrm{SB}}$ de armazenamento é admitido igual ao tc ou menor que este. $\mathrm{A}$ contribuição da chuva para o escoamento superficial direto é discretizada pelas parcelas referentes às áreas impermeáveis, $R(i)$, e permeáveis, $R(P)$. $O$ acúmulo do escoamento, $\mathrm{R}\left(\Delta \mathrm{t}^{\prime}\right)$, para cada período é calculado através da eq. (2.33).

$$
\begin{gathered}
R\left(\Delta t^{\prime}\right)=R(I)+R(P) \\
R(I)=d^{\prime} . P\left(\Delta t^{\prime}\right) \\
R(P)=\left(1-d^{\prime}\right)\left[P\left(\Delta t^{\prime}\right)-F\left(\Delta t^{\prime}\right)\right]
\end{gathered}
$$

Onde:

- $\mathrm{P}\left(\Delta \mathrm{t}^{\prime}\right)$ : $\quad$ é o acúmulo de chuva durante o incremento de tempo $\Delta \mathrm{t}^{\prime}$.

- $F\left(\Delta t^{\prime}\right)$ : é a infiltração durante o incremento de tempo $\Delta t^{\prime}$.

- d': é a porção impermeável diretamente conectada da bacia de drenagem (fração da área total da bacia).

- $\Delta \mathrm{t}^{\prime}$ : $\quad$ é o período de tempo incrementado, em horas.

O hidrograma instantâneo (para cada período) é calculado a partir da eq. (2.36.)

$$
I\left(\Delta t^{\prime}\right)=\frac{R\left(\Delta t^{\prime}\right) \cdot A}{\Delta t^{\prime}}
$$

Onde:

- $\mathrm{R}\left(\Delta \mathrm{t}^{\prime}\right)$ : é o acúmulo total do escoamento

- A: área de drenagem da bacia hidrográfica

- $\Delta \mathrm{t}^{\prime}$ : incremento de tempo 
O formato do hidrograma de saída, $Q_{\text {eflu }}\left(\Delta t^{\prime}\right)$, é então obtido pelo amortecimento destes hidrogramas instantâneos, $Q_{\text {aflu }}\left(\Delta t^{\prime}\right)$, em um reservatório linear equivalente. Esta rotina pode ser feita através do uso da equação da continuidade no reservatório linear para estimar $Q_{\text {eflu }}$ (semelhante ao de Clark) como mostra a eq. (2.37):

$$
Q_{\text {eflu }}(2)=m_{0} \cdot Q_{\text {affu }}(2)+m_{1} \cdot Q_{\text {affu }}(1)+m_{2} \cdot Q_{\text {eflu }}(1)
$$

Onde:

- $Q_{\text {aflu: }}$ correspondem às vazões de entrada no reservatório;

- $\mathrm{m}_{0}$ : é igual a $(0,5 . \mathrm{t}) /(\mathrm{tc}+0,5 . \mathrm{t})$;

- $\mathrm{m}_{1}$ : é igual a $(0,5 . t) /(\mathrm{tc}+0,5 . \mathrm{t})$;

- $\mathrm{m}_{2}$ : é igual a (tc - 0,5.t)/(tc + 0,5.t);

- tc: é o tempo de concentração.

O formato do hidrograma é função da escolha do intervalo de tempo ( $\left.\Delta \mathrm{t}^{\prime}\right)$ e do tempo de concentração. No método de Santa Bárbara, toda a chuva que cai na porção impermeável da bacia é considerada chuva excedente.

No SSD ABC 6 o intervalo de tempo da isócrona é igual a um quinto do tempo de concentração.

A constante linear que representa o fenômeno de armazenamento é calculada pela eq. (2.38).

$$
k_{S B}=\frac{d t}{2 t c+d t}
$$

Onde:

- $\mathrm{k}_{\mathrm{SB}}$ é o coeficiente de armazenamento de Santa Barbara

- tc: é o tempo de concentração

- dt: é o intervalo de discretização 


\subsubsection{Comparação teórica entre os métodos}

Os métodos sintéticos de obtenção dos hidrogramas cheia são de aplicação bastante simples. Principalmente em estudos ligados a drenagem urbana, são preferidos a métodos mais sofisticados, que exigem um número maior de variáveis para sua utilização.

Em geral, os métodos anteriormente descritos são aplicáveis em bacias hidrográficas com área de drenagem maiores que $5 \mathrm{~km}^{2}$. Para bacias menores, usase o Método Racional, utilizado em obras de microdrenagem.

O método do hidrograma triangular do Soil Conservation Service faz uma simplificação geométrica do processo físico, pois parte do princípio de que o volume precipitado é igual à área de um triângulo. Não considera os fenômenos de translação e amortecimento do escoamento superficial na bacia. Quando comparado aos métodos de Santa Bárbara e Clark, verificou-se que fornece os maiores valores de vazão de pico.

Os métodos de Santa Bárbara e Clark diferem na maneira como consideram o efeito de translação e amortecimento do escoamento superficial na bacia. O método de Santa Bárbara considera a bacia hidrográfica com apenas uma isócrona, cujo intervalo de tempo é igual ao tempo de concentração. No método de Clark, a bacia hidrográfica é dividida em mais de uma isócrona, possibilitando ao escoamento uma defasagem no tempo. No método de Santa Bárbara a constante linear que representa o amortecimento, varia em função do tempo de concentração. No método de Clark a constante linear é dada em relação ao comprimento do talvegue e área de drenagem da bacia hidrográfica. 


\section{METODOLOGIA}

Neste capítulo são apresentados os passos tomados para realização da análise de sensibilidade e do estudo de aplicação prática.

\subsection{METODOLOGIA DOS ESTUDOS DE ANÁLISE DE SENSIBILIDADE}

A análise de sensibilidade pode ser definida com uma técnica que permite a avaliação das variáveis de saída em função de alterações nos valores das variáveis de entrada.

O objetivo das análises de sensibilidade deste trabalho é o de verificar a variação da vazão de pico e do volume do hidrograma de cheia em função da alteração nos valores das variáveis de entrada de três métodos sintéticos de obtenção de hidrogramas.

\subsubsection{Métodos de obtenção de hidrogramas avaliados}

Os métodos de obtenção de hidrogramas sintéticos de cheia avaliados na análise de sensibilidade são: método do hidrograma unitário do SCS (MCCUEN, 1982), o método de Santa Bárbara (STRUBCHAER, 1975) e o método de Clark (1945), descritos no Capítulo 2. 


\subsubsection{Bacia Hidrográfica}

Para o desenvolvimento dos estudos, foi considerada uma bacia hidrográfica hipotética com as seguintes características:

- Área de drenagem, igual a 21,9 km²;

- Comprimento e declividade do talvegue, igual a $7.872 \mathrm{~m}$ e $5,1 \mathrm{~m} / \mathrm{km}$, respectivamente;

- Tempo de Concentração, igual a 2,5 h.

O tipo de solo da bacia hidrográfica se aproxima da classificação do grupo hidrológico do solo do tipo $\mathrm{C}$ e da condição de umidade antecedente do tipo II do SCS.

Em algumas análises, foi considerado, que a bacia hidrográfica sofreu alterações antrópicas e, portanto, o valor do CN igual a 75 passou para 80.

\subsubsection{Chuva de Projeto}

Adotou-se uma chuva de projeto calculada a partir da equação IDF de Magni e Mero (1986), obtida para a cidade de Piracicaba, Estado de São Paulo. Considerou-se uma duração da 2,5 horas para a chuva de projeto. A equação IDF é apresenta a seguir:

$$
\begin{gathered}
I_{d, T}=\left\{(d+10)^{-0,841} \cdot[20,44+5,52 \cdot \ln (T-0,5)] \mid 10 \leq d<60\right\} \\
I_{d, T}=\left\{(d+20)^{-0,988} \cdot[43,20+11,67 \cdot \ln (T-0,5)] \mid 60 \leq d \leq 1440\right\}
\end{gathered}
$$


Onde:

- I: é a intensidade da chuva, em $\mathrm{mm} / \mathrm{min}$;

- d: é a duração da chuva, em min;

- T: é o período de retorno, em anos.

A chuva excedente foi determinada a partir do método do SCS (1985). O método do SCS é apresentado no Capítulo 2.

\subsubsection{Proposições}

Na determinação dos hidrogramas foram consideradas as seguintes proposições:

- O intervalo de discretização, correspondente ao intervalo de tempo dos dados e de cálculo, é de 15 minutos;

- A chuva é homogênea em toda a bacia, logo o coeficiente de distribuição espacial (ou o fator de redução de área) é igual a 1;

- A distribuição temporal da chuva foi determinada a partir do método dos blocos alternados.

\subsubsection{Ferramenta de cálculo}

Como ferramenta de cálculo para gerar os hidrogramas de cheia utilizou-se o SSD ABC6, desenvolvido no Labsid, do departamento de Engenharia Hidráulica e Sanitária da Escola Politécnica da Universidade de São Paulo. As considerações sobre o SSD ABC 6 foram feitas no Capítulo 2. 


\subsubsection{Desenvolvimento das análises}

\subsubsection{Variáveis de entrada}

Para os três métodos sintéticos de obtenção de hidrogramas de cheia serão avaliadas as seguintes variáveis:

- Valor de CN;

- Área de drenagem;

- Tempo de concentração;

- Duração da chuva de projeto.

Para o método de Santa Bárbara e Clark, será avaliado, além das variáveis descritas acima, o coeficiente de armazenamento. Para o método de Clark, será avaliado ainda o fator de forma da bacia hidrográfica.

\subsubsection{Período de retorno}

Dada a importância da escolha do período de retorno na definição dos hietogramas e hidrogramas de cheia, as análises foram feitas para os períodos de retorno de 5 , $10,50,100$ e 500 anos.

\subsubsection{Faixa de valores}

A definição da faixa de valores do tempo de concentração e duração da chuva de projeto foi definida em função da obtenção de uma curva assintótica. O valor de $\mathrm{CN}$ foi estabelecido de maneira a compreender o intervalo correspondente às bacias 
urbanas e rurais. A definição da faixa de valores para a área de drenagem foi limitada ao estudo de pequenas bacias hidrográficas. A Tabela 3.1 mostra a faixa dos valores para cada um das variáveis analisadas para os métodos sintéticos de SCS, Santa Bárbara e Clark.

\begin{tabular}{cccc}
\multicolumn{4}{c}{ Tabela 3.1 - Faixa de variação dos valores para as variáveis analisadas } \\
\hline Variável & Faixa de Variação & Incremento & Unidade \\
\hline CN & 60 a 95 & 5 & - \\
A & 12 a 200 & 20 & $\mathrm{~km}^{2}$ \\
tc & 0,5 a 6 & 0,5 & $\mathrm{~h}$ \\
$\mathrm{~d}$ & 30 a 360 & 30 & min \\
$\mathrm{n}_{\mathrm{f}}$ & 1 a 2 & 0,2 & - \\
$\mathrm{k}_{\mathrm{SB}}$ & 0,02 a 0,2 & - & - \\
$\mathrm{K}_{\mathrm{CL}}$ & 1 a 5 & - & - \\
\hline
\end{tabular}

Avaliou-se também o hidrograma de cheia para uma área de drenagem igual a 10 $\mathrm{km}^{2}$.

A faixa de variação dos valores do coeficiente de armazenamento do método de Santa Bárbara e Clark foi definida em função da faixa de variação do tempo de concentração e da área de drenagem, respectivamente. Por esta razão, o incremento entre os pontos não são iguais.

\subsubsection{Procedimentos de cálculo}

Para cada um dos métodos, variáveis definidas, períodos de retorno avaliados e valores das variáveis, utilizando-se o SSD ABC 6, elaboraram-se o hietograma e o respectivo hidrograma de cheia.

A Tabela 3.2 mostra o número de hidrogramas gerados para cada um dos parâmetros analisados. 
Tabela 3.2 - Quantidade de hidrogramas gerados para os parâmetros analisados

\begin{tabular}{ccccc}
\hline \multirow{2}{*}{ Variável } & \multicolumn{4}{c}{$\mathbf{N}^{\circ}$ de Hidrogramas } \\
\cline { 2 - 5 } & SCS & $\begin{array}{c}\text { Santa } \\
\text { Bárbara }\end{array}$ & Clark & Total \\
\hline CN & 40 & 40 & 40 & 120 \\
$\mathrm{~A}$ & 55 & 55 & 55 & $\mathbf{1 6 5}$ \\
tc & 60 & 60 & 60 & 180 \\
$\mathrm{~d}$ & 60 & 60 & 60 & 180 \\
$\mathrm{~K}_{\mathrm{SB}}$ & - & 60 & - & 180 \\
$\mathrm{~K}_{\mathrm{CL}}$ & - & - & 60 & 180 \\
$\mathrm{n}_{\mathrm{f}}$ & - & - & 30 & 90 \\
Total & $\mathbf{2 1 5}$ & $\mathbf{2 7 5}$ & $\mathbf{3 0 5}$ & $\mathbf{7 9 5}$ \\
\hline
\end{tabular}

Para obtenção do traçado das curvas de variação dos parâmetros hidrológicos analisados, foram gerados 795 hidrogramas.

\subsubsection{Organização dos resultados}

Foi elaborado um banco de dados para arquivar os dados dos 795 hietogramas e hidrogramas resultantes.

A partir do banco de dados, foram extraídas as informações necessárias ao traçado das curvas de variação. As tabelas e os gráficos das análises de sensibilidade estão apresentados no Capítulo 4. 


\subsection{METODOLOGIA DO ESTUDO DE APLICAÇÃO PRÁTICA}

\subsubsection{Definição das estruturas hidráulicas}

Vista a aplicabilidade dos métodos sintéticos de obtenção de hidrogramas de cheia para o dimensionamento hidráulico de canais e reservatórios, consideraram-se estas estruturas no estudo de aplicação prática.

\subsubsection{Variável hidráulica de análise}

Para verificar a influência da vazão de cheia no dimensionamento hidráulico das estruturas, optou-se por verificar apenas a variação da lâmina d'água, mantendo-se constantes todas as demais características das estruturas.

\subsubsection{Cenário de projeto}

O cenário de projeto representa a área em estudo. Para compor o cenário de projeto, considerou-se a mesma bacia hidrográfica, chuva de projeto e proposições das análises de sensibilidade.

Nos estudos de aplicação prática, considerou-se que a bacia hidrográfica sofreu alterações antrópicas e, portanto, o valor do $\mathrm{CN}$ igual a 75 passou para 80 .

\subsubsection{Cenários alternativos}

Para avaliar a variação da lâmina d'água das estruturas hidráulicas propostas em 
função da alteração das variáveis hidrológicas, foram criados cenários alternativos que englobam a alteração do valor do $\mathrm{CN}$, tempo de concentração, duração da chuva de projeto e período de retorno.

Foram criados oito cenários alternativos, dentre os quais, sete, avaliam a alteração isolada de cada uma das variáveis, mencionadas no parágrafo anterior, e um cenário para o qual foi alterado, simultaneamente, o valor do $\mathrm{CN}$, tempo de concentração e duração da chuva de projeto.

\subsubsection{Variáveis hidrológicas avaliadas}

A seguir, são mostradas, na Tabela 3.3, as variáveis que foram alteradas para os cenários alternativos em relação ao cenário de projeto. As variáveis alteradas estão em negrito.

Tabela 3.3 - Variáveis do cenário de projeto e cenários alternativos

\begin{tabular}{crrrr}
\hline Cenário & CN & \multicolumn{1}{c}{ tc } & \multicolumn{1}{c}{ d } & \multicolumn{1}{c}{ T } \\
(h) & & \multicolumn{1}{c}{ (min) } & \multicolumn{1}{c}{ (anos) } \\
\hline Projeto & 80 & 2,5 & 150 & 100 \\
C - I & $\mathbf{7 5}$ & 2,5 & 150 & 100 \\
C - II & $\mathbf{8 5}$ & 2,5 & 150 & 100 \\
C - III & 80 & $\mathbf{1 , 5}$ & 150 & 100 \\
C - IV & 80 & $\mathbf{3 , 5}$ & 150 & 100 \\
C - V & 80 & 2,5 & $\mathbf{9 0}$ & 100 \\
C - VI & 80 & 2,5 & $\mathbf{2 1 0}$ & 100 \\
C - VII & 85 & $\mathbf{3 , 5}$ & $\mathbf{2 1 0}$ & 100 \\
C - VIII & 80 & 2,5 & 150 & $\mathbf{5 0}$ \\
\hline
\end{tabular}

\subsubsection{Equações de dimensionamento}

O canal foi dimensionado com base na equação de Manning-Strickler associada à equação de Chézy, dada por: 


$$
Q=\frac{1}{n} \cdot A_{m} \cdot R h^{2 / 3} \cdot i^{1 / 2}
$$

Onde:

- Q: é a vazão em m³/s;

- $A_{m}$ : é a área molhada em $\mathrm{m}^{2}$;

- Rh: é o raio hidráulico em m;

- i: é a declividade do fundo em $\mathrm{m} / \mathrm{m}$;

- $\mathrm{n}$ : é o coeficiente de Manning.

O vertedor retangular de soleira delgada foi dimensionado a partir da equação:

$$
Q=\frac{2}{3} \cdot C d \cdot \sqrt{2 \cdot g} \cdot L_{v} \cdot H_{v}^{\frac{3}{2}}
$$

Onde:

- Q: é a vazão, em m³/s;

- C: é o coeficiente de vazão,

- $\mathrm{L}_{\mathrm{v}}$ : é o comprimento da crista da soleira, em m;

- $\mathrm{H}_{\mathrm{v}}$ : é a carga hidráulica acima da soleira, em $\mathrm{m}$.

\subsubsection{Ferramenta de cálculo}

Para auxiliar no dimensionamento das estruturas, foi utilizando como ferramenta de cálculo o SSD ABC 6. A partir do SSD ABC 6, foram determinados os hietogramas, hidrogramas afluentes e efluentes, lâmina d'água e volume armazenado no reservatório. 


\subsubsection{Organização dos resultados}

Os resultados foram apresentados organizados em tabelas, gráficos e ilustrações que compõem o Capítulo 5. 


\section{$4 \quad$ RESULTADOS E DISCUSSÃO}

\subsection{MÉTODO DO HIDROGRAMA UNITÁRIO SINTÉTICO DO SCS}

\subsubsection{Análise de sensibilidade em relação ao valor de $\mathrm{CN}$}

Para esta análise, utilizaram-se as considerações e a caracterização da bacia hidrográfica descrita no Capítulo 3. Variou-se o valor de $\mathrm{CN}$ de 60 a 95, para compreender o intervalo correspondente às bacias rurais e urbanas. O valor do $\mathrm{CN}$ é um parâmetro fundamental do método do SCS para o cálculo da chuva excedente, que multiplicada pela área de drenagem da bacia, fornece o volume do escoamento superficial direto.

Conforme mencionado no Capítulo 2, o valor de CN representa a capacidade de infiltração do solo da bacia hidrográfica, caracterizada pelo tipo, ocupação e umidade antecedente do solo.

A partir das simulações, elaboraram-se a Tabela 4.1 e a Figura 4.1 que apresentam os resultados das análises da variação da vazão de pico em função da variação do valor do $\mathrm{CN}$.

Na Tabela 4.1 são apresentados:

- O valor da vazão de pico, em m³/s;

- O tempo de ascensão do hidrograma, em hh:mm

- O tempo de base, tendo seu término quando a vazão se reduz a $1 \%$ da vazão de pico, em hh:mm;

- A relação entre o valor da vazão de pico para o valor $\mathrm{CN}$ escolhido e o valor da vazão de pico para o $\mathrm{CN}$ de 95;

- A relação entre o valor da vazão de pico para o valor $\mathrm{CN}$ escolhido e o valor da vazão de pico para o $\mathrm{CN}$ anterior. 
Tabela 4.1 - Análise de sensibilidade da vazão de pico em função da variação do valor do CN para o método do SCS

\begin{tabular}{|c|c|c|c|c|c|c|c|c|c|c|c|c|c|c|c|c|c|c|c|c|c|c|c|c|c|}
\hline \multirow[b]{2}{*}{$\mathrm{CN}$} & \multicolumn{5}{|c|}{$\mathrm{T}=5$ anos } & \multicolumn{5}{|c|}{$\mathrm{T}=10$ anos } & \multicolumn{5}{|c|}{$\mathrm{T}=50$ anos } & \multicolumn{5}{|c|}{$\mathrm{T}=100$ anos } & \multicolumn{5}{|c|}{$\mathrm{T}=500$ anos } \\
\hline & $\begin{array}{c}Q_{\mathbf{p}} \\
\left(m^{3} / \mathbf{s}\right)\end{array}$ & $\begin{array}{l}\text { ta } \\
\text { (hh: }\end{array}$ & $\begin{array}{r}\text { tb } \\
\text { mm })\end{array}$ & $\frac{Q_{P i}}{Q_{P 95}}$ & $\frac{Q_{P i+1}}{Q_{P i}}$ & $\begin{array}{c}Q_{\mathbf{p}} \\
\left(m^{3} / \mathbf{s}\right)\end{array}$ & $\begin{array}{l}\text { ta } \\
\text { (hh: }\end{array}$ & $\begin{array}{r}\text { tb } \\
\text { :mm) }\end{array}$ & $\frac{Q_{P i}}{Q_{P 95}}$ & $\frac{Q_{P i+1}}{Q_{P i}}$ & $\begin{array}{c}Q_{\mathbf{p}} \\
\left(\mathbf{m}^{3} / \mathbf{s}\right)\end{array}$ & $\begin{array}{l}\text { ta } \\
\text { (hh: }\end{array}$ & $\begin{array}{r}\text { tb } \\
: m m)\end{array}$ & $\frac{Q_{P i}}{Q_{P 95}}$ & $\frac{Q_{P i+1}}{Q_{P i}}$ & $\begin{array}{c}Q_{\mathbf{p}} \\
\left(m^{3} / \mathbf{s}\right)\end{array}$ & $\begin{array}{l}\text { ta } \\
\text { (hh }\end{array}$ & $\begin{array}{r}\text { tb } \\
\mathrm{mm})\end{array}$ & $\frac{Q_{P i}}{Q_{P 95}}$ & $\frac{Q_{P i+1}}{Q_{P i}}$ & $\begin{array}{c}Q_{\mathbf{P}} \\
\left(m^{3} / \mathbf{s}\right)\end{array}$ & $\begin{array}{l}\text { ta } \\
\text { (hh }\end{array}$ & $\begin{array}{r}\text { tb } \\
: m m)\end{array}$ & $\frac{Q_{P i}}{Q_{P 95}}$ & $\frac{Q_{P i+1}}{Q_{P i}}$ \\
\hline 60 & 8,795 & 03:15 & 09:15 & 0,08 & & 14,674 & $03: 15$ & 09:15 & 0,11 & & 31,923 & 03:00 & 09:00 & 0,18 & & 40,790 & 03:00 & 09:00 & 0,20 & & 64,092 & 03:00 & 09:00 & 0,26 & \\
\hline 65 & 15,497 & 03:15 & $09: 15$ & 0,14 & 1,76 & 23,514 & 03:00 & 09:15 & 0,17 & 1,60 & 45,638 & 03:00 & 09:00 & 0,25 & 1,43 & 56,386 & 03:00 & 09:00 & 0,28 & 1,38 & 83,849 & 03:00 & 09:00 & 0,34 & 1,31 \\
\hline 70 & 24,513 & 03:00 & 09:00 & 0,21 & 1,58 & 34,840 & 03:00 & 09:00 & 0,26 & 1,48 & 61,639 & 03:00 & 09:00 & 0,34 & 1,35 & 74,241 & 03:00 & 09:00 & 0,37 & 1,32 & 105,700 & 03:00 & 09:00 & 0,43 & 1,26 \\
\hline 75 & 35,988 & 03:00 & 09:00 & 0,31 & 1,47 & 48,602 & 03:00 & 09:00 & 0,36 & 1,40 & 80,052 & 03:00 & 09:00 & 0,44 & 1,30 & 94,410 & 03:00 & 09:00 & 0,47 & 1,27 & 129,486 & 03:00 & 09:00 & 0,53 & 1,23 \\
\hline 80 & 50,205 & 03:00 & 09:00 & 0,44 & 1,40 & 65,115 & 03:00 & 09:00 & 0,48 & 1,34 & 100,915 & 03:00 & 09:00 & 0,56 & 1,26 & 116,866 & 03:00 & 09:00 & 0,58 & 1,24 & 155,189 & 03:00 & 09:00 & 0,63 & 1,20 \\
\hline 85 & 67,602 & 03:00 & 09:00 & 0,59 & 1,35 & 84,644 & 03:00 & 09:00 & 0,63 & 1,30 & 124,387 & 03:00 & 09:00 & 0,69 & 1,23 & 141,723 & 03:00 & 09:00 & 0,71 & 1,21 & 182,734 & 03:00 & 09:00 & 0,74 & 1,18 \\
\hline 90 & 88,720 & 03:00 & 09:00 & 0,77 & 1,31 & 107,614 & 03:00 & 09:00 & 0,80 & 1,27 & 150,518 & 03:00 & 09:00 & 0,83 & 1,21 & 168,992 & $02: 45$ & 09:00 & 0,84 & 1,19 & 212,736 & 02:45 & $08: 45$ & 0,87 & 1,16 \\
\hline 95 & 114,730 & $02: 45$ & 08:45 & 1,00 & 1,29 & 135,272 & $02: 45$ & 08:45 & 1,00 & 1,26 & 181,077 & $02: 45$ & $08: 45$ & 1,00 & 1,20 & 200,474 & $02: 45$ & $08: 45$ & 1,00 & 1,19 & 245,479 & $02: 45$ & 08:45 & 1,00 & 1,15 \\
\hline
\end{tabular}
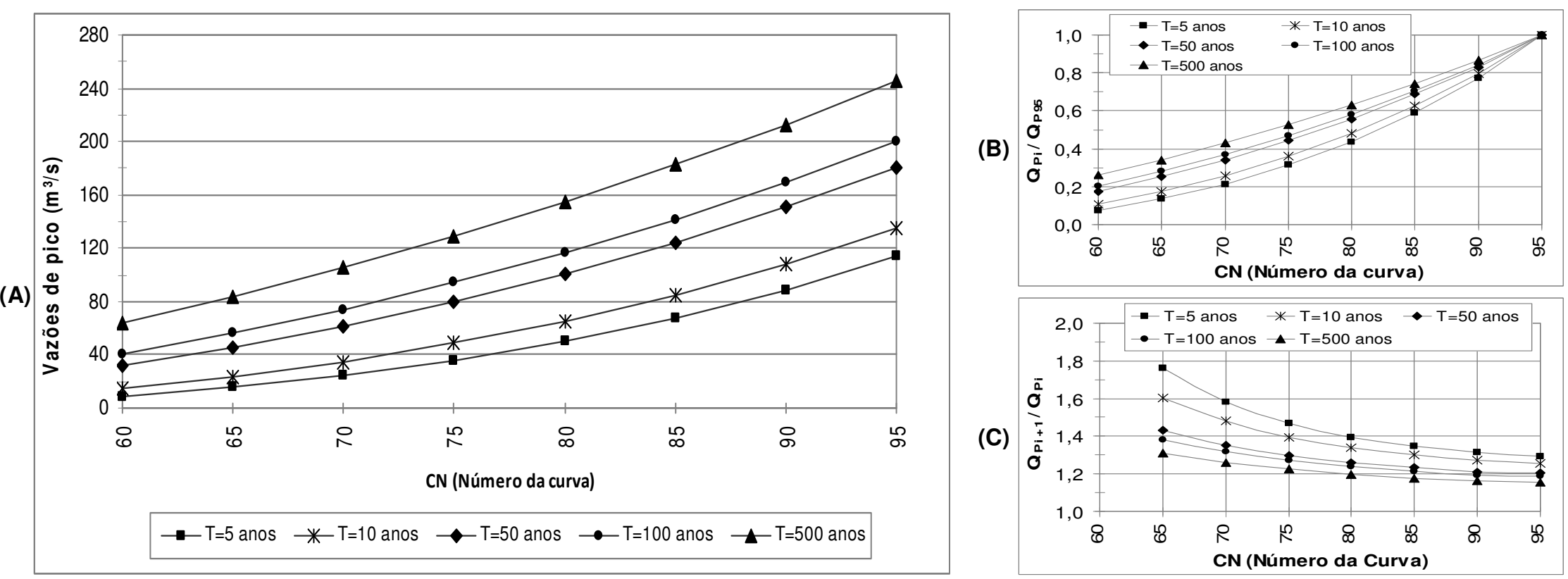

Figura 4.1 - (A) Variação da vazão de pico em função do CN, (B) proporção da vazão de pico em relação ao valor da vazão de pico para o $\mathrm{CN}$ de 95 , (C) variação entre as vazões de pico em função do $\mathrm{CN}$ para o método do SCS 
Ao observar os resultados, é possível inferir que:

- A vazão de pico é crescente com o valor de $\mathrm{CN}$ e a relação é fortemente não linear;

- Os tempos de ascensão dos hidrogramas de cheia variam em função do período de retorno conforme mostra a Tabela 4.1. A Figura 4.2 mostra o comportamento dos hidrogramas para o período de retorno de 100 anos, para cada valor de CN simulado. Este mesmo comportamento, exceto pelo tempo de ascensão, foi verificado para os demais períodos de retorno avaliados;

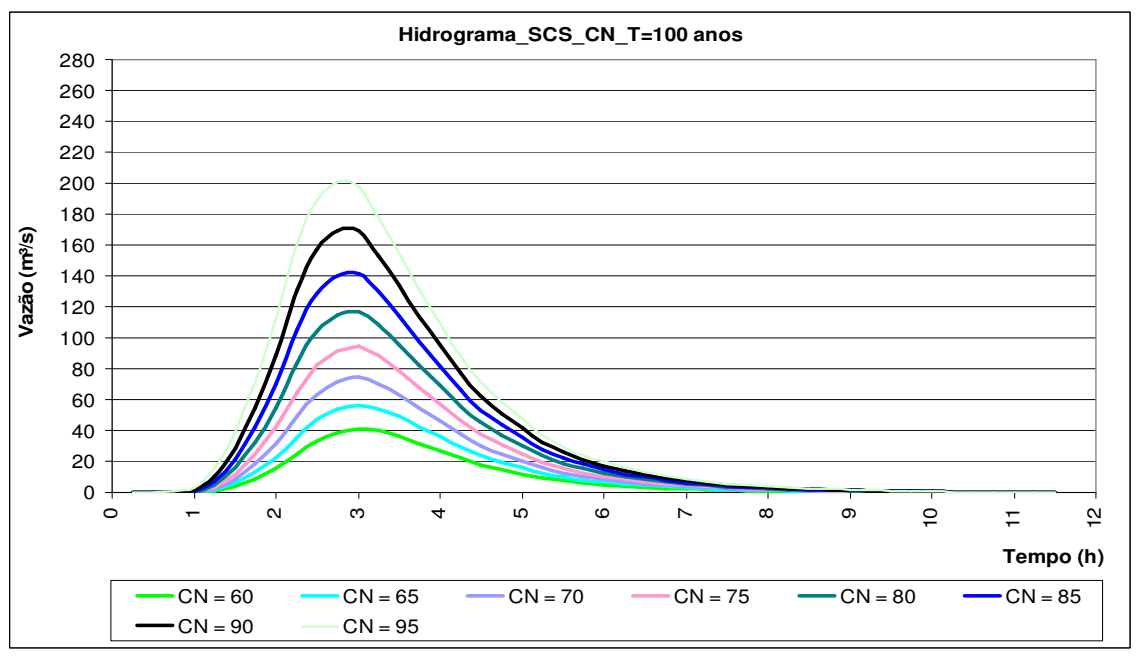

Figura 4.2 - Hidrogramas de cheia para o período de retorno igual a 100 anos - SCS

- As variações das vazões de pico para os valores de CN testados são elevadas e diferem em função do período de retorno. Quanto menor o período de retorno maior a variação do valor da vazão. Analisando os valores da Tabela 4.1, tem-se:

- Para o período de retorno igual a 5 anos, o valor da vazão de pico para o $\mathrm{CN}$ de 60 é $8,80 \mathrm{~m}^{3} / \mathrm{s}$, para o $\mathrm{CN}$ de $65,15,5 \mathrm{~m}^{3} / \mathrm{s}$. A diferença é de $6,70 \mathrm{~m}^{3} / \mathrm{s}$, correspondente a $76 \%$ da vazão de $8,80 \mathrm{~m}^{3} / \mathrm{s}$. Esta variação decai a medida que o $\mathrm{CN}$ aumenta, entretanto, continua significativa. Considerando ainda, o período de retorno igual a 5 anos, o valor da vazão de pico para o $\mathrm{CN}$ de 90 é $88,7 \mathrm{~m}^{3} / \mathrm{s}$, para o $\mathrm{CN}$ de 95 é 115 
$\mathrm{m}^{3} / \mathrm{s}$. A diferença é de $26,3 \mathrm{~m}^{3} / \mathrm{s}$, correspondente a $29 \%$ da vazão de $88,7 \mathrm{~m}^{3} / \mathrm{s}$.

- Para o período de retorno igual a 500 anos, o valor da vazão de pico para o $\mathrm{CN}$ de 60 é $64,1 \mathrm{~m}^{3} / \mathrm{s}$, para o $\mathrm{CN}$ de 65 é $83,8 \mathrm{~m}^{3} / \mathrm{s}$. A diferença é de $19,7 \mathrm{~m}^{3} / \mathrm{s}$, correspondente a $31 \%$ da vazão de $64,1 \mathrm{~m}^{3} / \mathrm{s}$. O valor da vazão de pico para o CN de 90 é 213 m³/s, para o CN de 95 é 245 $\mathrm{m}^{3} / \mathrm{s}$. A diferença é de $32 \mathrm{~m} 3 / \mathrm{s}$, correspondente a $15 \%$ da vazão de 213 $\mathrm{m}^{3} / \mathrm{s}$.

- Esta mesma análise é apresentada na Tabela 4.1 para todos os valores de CN e períodos de retorno avaliados.

Quanto aos volumes dos hidrogramas, a Tabela 4.2 e as figuras 4.3 a 4.5 mostram sua variação em função da alteração do valor do $\mathrm{CN}$.

Tabela 4.2 - Análise de sensibilidade do volume do hidrograma de cheia em função da variação do valor do CN para o método do SCS

\begin{tabular}{|c|c|c|c|c|c|c|c|c|c|c|c|c|c|c|c|}
\hline \multirow[b]{2}{*}{$\mathrm{CN}$} & \multicolumn{3}{|c|}{$\mathrm{T}=5$ anos } & \multicolumn{3}{|c|}{$\mathrm{T}=10$ anos } & \multicolumn{3}{|c|}{$\mathrm{T}=50$ anos } & \multicolumn{3}{|c|}{$\mathrm{T}=100$ anos } & \multicolumn{3}{|c|}{$\mathrm{T}=500$ anos } \\
\hline & $\begin{array}{c}\mathrm{V} \\
\left(\mathrm{Mm}^{3}\right) \\
\end{array}$ & $\frac{V_{i}}{V_{95}}$ & $\frac{V_{i+1}}{V_{i}}$ & $\begin{array}{c}\mathrm{V} \\
\left(\mathrm{Mm}^{3}\right) \\
\end{array}$ & $\frac{V_{i}}{V_{95}}$ & $\frac{V_{i+1}}{V_{i}}$ & $\begin{array}{c}V \\
\left(\mathrm{Mm}^{3}\right) \\
\end{array}$ & $\frac{V_{i}}{V_{95}}$ & $\frac{V_{i+1}}{V_{i}}$ & $\begin{array}{c}\mathrm{V} \\
\left(\mathrm{Mm}^{3}\right) \\
\end{array}$ & $\frac{V_{i}}{V_{95}}$ & $\frac{V_{i+1}}{V_{i}}$ & $\begin{array}{c}\mathrm{V} \\
\left(\mathrm{Mm}^{3}\right) \\
\end{array}$ & $\frac{V_{i}}{V_{95}}$ & $\frac{V_{i+1}}{V_{i}}$ \\
\hline 60 & 0,080 & 0,08 & & 0,134 & 0,11 & & 0,292 & 0,18 & & 0,372 & 0,21 & & 0,582 & 0,26 & \\
\hline 65 & 0,142 & 0,14 & 1,79 & 0,216 & 0,18 & 1,61 & 0,415 & 0,25 & 1,42 & 0,511 & 0,28 & 1,37 & 0,758 & 0,34 & 1,30 \\
\hline 70 & 0,224 & 0,22 & 1,57 & 0,317 & 0,26 & 1,47 & 0,557 & 0,34 & 1,34 & 0,670 & 0,37 & 1,31 & 0,952 & 0,43 & 1,26 \\
\hline 75 & 0,326 & 0,31 & 1,46 & 0,439 & 0,36 & 1,39 & 0,721 & 0,44 & 1,29 & 0,850 & 0,47 & 1,27 & 1,165 & 0,52 & 1,22 \\
\hline 80 & 0,453 & 0,44 & 1,39 & 0,586 & 0,48 & 1,33 & 0,908 & 0,55 & 1,26 & 1,052 & 0,58 & 1,24 & 1,398 & 0,63 & 1,20 \\
\hline 85 & 0,608 & 0,59 & 1,34 & 0,762 & 0,62 & 1,30 & 1,121 & 0,68 & 1,23 & 1,278 & 0,70 & 1,21 & 1,650 & 0,74 & 1,18 \\
\hline 90 & 0,800 & 0,77 & 1,31 & 0,971 & 0,79 & 1,28 & 1,363 & 0,83 & 1,22 & 1,531 & 0,84 & 1,20 & 1,923 & 0,87 & 1,17 \\
\hline 95 & 1,037 & 1,00 & 1,30 & 1,222 & 1,00 & 1,26 & 1,637 & 1,00 & 1,20 & 1,813 & 1,00 & 1,18 & 2,221 & 1,00 & 1,15 \\
\hline
\end{tabular}

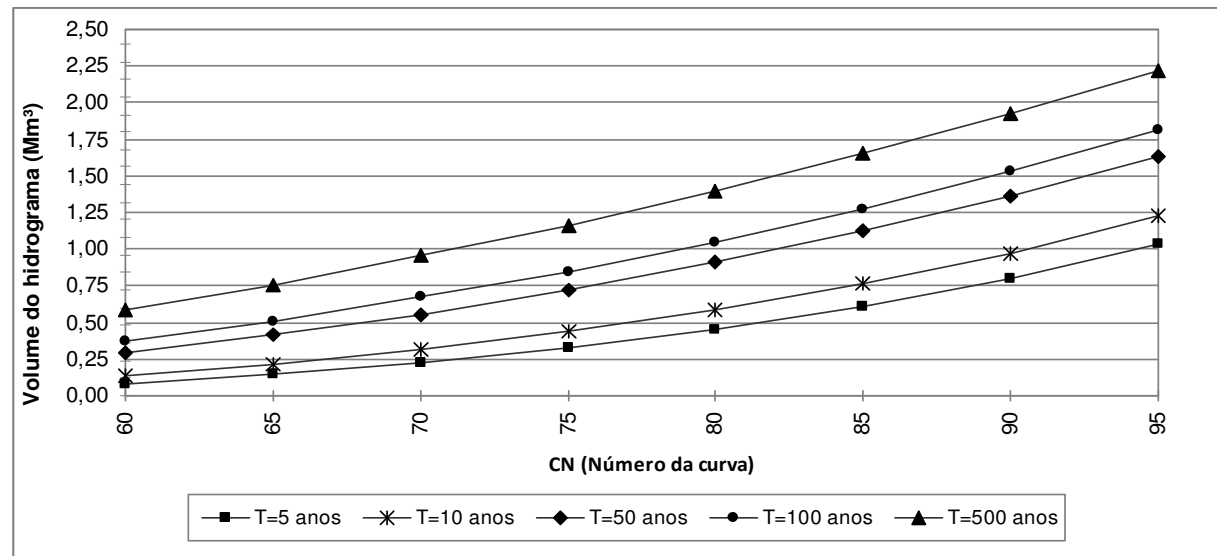

Figura 4.3 - Gráfico da variação do volume do hidrograma de cheia em função do CN - SCS 


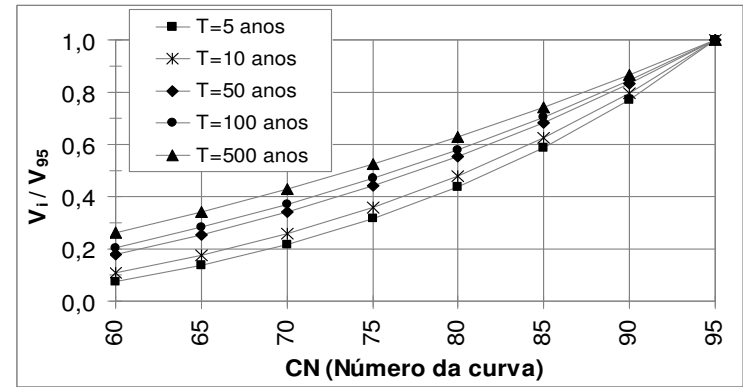

Figura 4.4 - Proporção do volume em relação ao volume para o CN de 95 - SCS

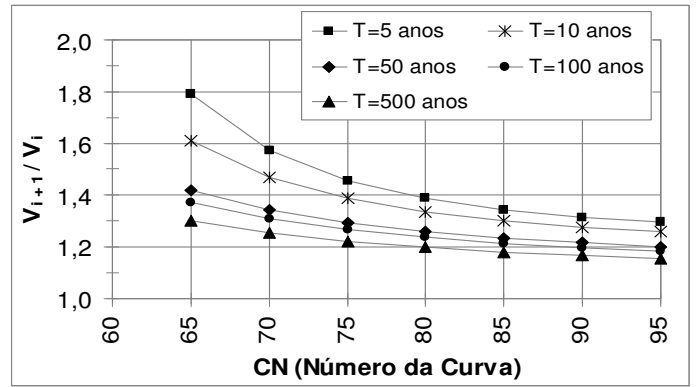

Figura 4.5 - Variação entre os volumes em função do CN - SCS

Das figuras 4.4 e 4.5, pode-se verificar que o volume do hidrograma tem variação semelhante à vazão de pico. A Figura 4.6, que mostra que os gradientes de vazão de pico e volume são praticamente os mesmos para qualquer valor de $\mathrm{CN}$.

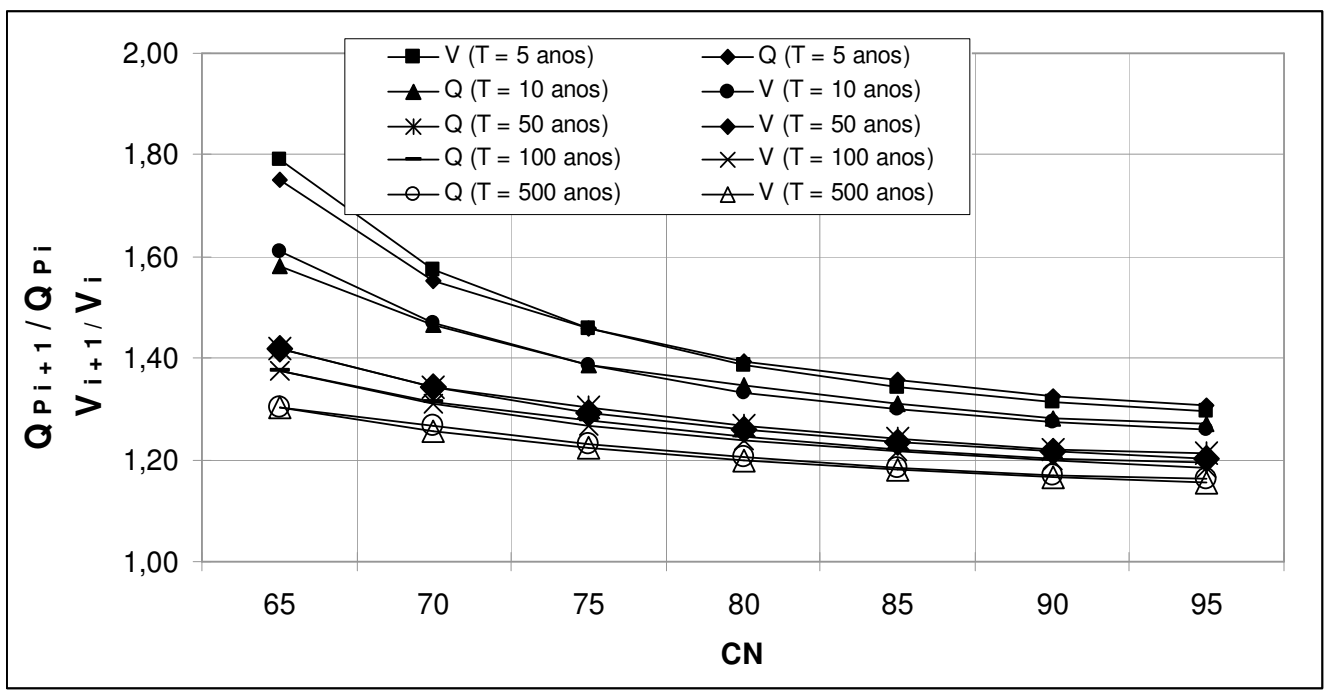

Figura 4.6 - Comparação dos gradientes de vazão de pico e volume - SCS

O que se pode notar através destas análises é que o parâmetro $C N$ tem forte influência nos valores da vazão de pico e no volume do hidrograma de cheia. Para pequenas variações nos valores de $\mathrm{CN}$, a variação da vazão de pico e do respectivo volume do hidrograma é bastante acentuada. 


\subsubsection{Análise de sensibilidade em relação ao valor da área de drenagem}

Para esta análise, utilizaram-se as considerações e a caracterização da bacia hidrográfica descrita no Capítulo 3. Variou-se o valor da área de drenagem de $10 \mathrm{a}$ $200 \mathrm{~km}^{2}$. Simultaneamente, variou-se também o tempo de concentração da bacia hidrográfica. A estimativa do tempo de concentração foi feita a partir da relação empírica, padrão do SSD ABC 6, dada pela eq. (4.1), descrita a seguir:

$$
t c=\frac{\sqrt{A}}{2}
$$

Onde:

- tc: é o tempo de concentração, em h;

- A: é igual a área da bacia hidrográfica, em $\mathrm{km}^{2}$.

A partir das simulações, elaboraram-se a Tabela 4.3 e a Figura 4.7, que apresentam os resultados das análises da variação da vazão de pico em função da área de drenagem da bacia hidrográfica.

Na Tabela 4.3 são apresentados:

- O valor da vazão de pico, em m³/s;

- O tempo de ascensão do hidrograma, em hh:mm;

- O tempo de base, tendo seu término quando a vazão se reduz a $1 \%$ da vazão de pico, em hh:mm;

- A relação entre o valor da vazão de pico para o valor da área de drenagem escolhida e o valor da vazão de pico para a área de drenagem de 200 km²;

- A relação entre o valor da vazão de pico para a área de drenagem escolhida e o valor da vazão de pico para a área de drenagem anterior. 
Tabela 4.3 - Análise de sensibilidade da vazão de pico em função da variação da área de drenagem para o método do SCS

\begin{tabular}{|c|c|c|c|c|c|c|c|c|c|c|c|c|c|c|c|c|c|c|c|c|c|c|c|c|c|c|}
\hline \multirow[b]{2}{*}{$\begin{array}{r}\text { A } \\
\left(\mathbf{k m}^{2}\right) \\
\end{array}$} & \multirow[b]{2}{*}{$\begin{array}{l}\text { tc } \\
\text { (h) }\end{array}$} & \multicolumn{5}{|c|}{$\mathrm{T}=5$ anos } & \multicolumn{5}{|c|}{$\mathrm{T}=10$ anos } & \multicolumn{5}{|c|}{$\mathrm{T}=50$ anos } & \multicolumn{5}{|c|}{$\mathrm{T}=100$ anos } & \multicolumn{5}{|c|}{$\mathrm{T}=500$ anos } \\
\hline & & $\begin{array}{c}Q_{p} \\
\left(m^{3} / s\right)\end{array}$ & $\begin{array}{l}\text { ta } \\
\text { (hh: }\end{array}$ & $\begin{array}{r}\text { tb } \\
\mathrm{mm})\end{array}$ & $\frac{Q_{P i}}{Q_{P 200}}$ & $\frac{Q_{P i+1}}{Q_{P i}}$ & $\begin{array}{c}Q_{p} \\
\left(m^{3} / s\right)\end{array}$ & $\begin{array}{l}\text { ta } \\
\text { (hh: }\end{array}$ & $\begin{array}{r}\text { tb } \\
\mathrm{mm})\end{array}$ & $\frac{Q_{P i}}{Q_{P 200}}$ & $\frac{Q_{P i+1}}{Q_{P i}}$ & $\begin{array}{c}Q_{\mathbf{p}} \\
\left(\mathbf{m}^{3} / \mathbf{s}\right)\end{array}$ & $\begin{array}{l}\text { ta } \\
\text { (hh }\end{array}$ & $\begin{array}{r}\mathrm{tb} \\
\mathrm{nm})\end{array}$ & $\frac{Q_{P i}}{Q_{P 200}}$ & $\frac{Q_{P i+1}}{Q_{P i}}$ & $\begin{array}{c}Q_{\mathbf{p}} \\
\left(\mathbf{m}^{3} / \mathbf{s}\right)\end{array}$ & $\begin{array}{l}\text { ta } \\
\text { (hh }\end{array}$ & $\begin{array}{r}\text { tb } \\
\mathrm{mm})\end{array}$ & $\frac{Q_{P i}}{Q_{P 200}}$ & $\frac{Q_{P i+1}}{Q_{P i}}$ & $\begin{array}{c}Q_{\mathbf{p}} \\
\left(\mathbf{m}^{3} / \mathbf{s}\right)\end{array}$ & $\begin{array}{l}\text { ta } \\
\text { (hh }\end{array}$ & $\begin{array}{r}\text { tb } \\
\mathrm{mm} \text { ) }\end{array}$ & $\frac{Q_{P i}}{Q_{P 200}}$ & $\frac{Q_{P i+1}}{Q_{P i}}$ \\
\hline 10 & 1,58 & 22,716 & $02: 30$ & $06: 30$ & 0,18 & & 30,585 & $02: 30$ & 06:30 & 0,18 & & 51,064 & $02: 15$ & $06: 30$ & 0,18 & & 60,526 & $02: 15$ & $06: 15$ & 50,18 & & 83,743 & $02: 15$ & $06: 15$ & $\begin{array}{ll}5 & 0,18\end{array}$ & \\
\hline 0 & 24 & 5,482 & 02:45 & $08: 15$ & 0,28 & 1,56 & 48,041 & 2:45 & $08: 15$ & 0,28 & 1,57 & & $02: 45$ & & 50,28 & 1,56 & & & & $\begin{array}{ll}5 & 0,28\end{array}$ & 1,55 & & & & & \\
\hline & &, 7 & & $11: C$ & 0 & & & & & 0 & 1,51 & & & & & 1,50 & & & & 50 & 1, & & & & & \\
\hline & & , & & 1 & 0 & & & & & 0 , & 1,24 & & & & & 1,25 & & & 3:00 & 0,52 & 1,25 & & & 3:00 & & 21, \\
\hline & & 3,3 & & 14: & 0,61 & & & & & & 1,17 & & & & & 1,17 & & & & 0,62 & 1,18 & & & 30 & & 1,18 \\
\hline 0 & & 0 & & $16: 1$ & 0,69 & & & & & & 1,13 & & & & & 1,12 & & & $16: 15$ & $5 \quad 0,69$ & 1,12 & & & $6: 00$ & & 91,12 \\
\hline & & & & $17: 30$ & 76 & 1 & & & & & 1,10 & & & & 0 , & 1,11 & & & $17:$ & 0,76 & 1,11 & & & $7: 30$ & 300 & 1,10 \\
\hline 10 & & & & $18: 4$ & 0 & & & & & & 1,09 & & & & & 1,09 & & & & 50 , & 1,0 & & & & & 1,09 \\
\hline 60 & & & & 20:00 & 0,89 & 07 & & $: 15$ & 20 & $0, \varepsilon$ & 1,07 & & & & & 1,07 & & & $20: 00$ & 0,89 & 1,07 & & & 20:00 & 00 , & 1,07 \\
\hline 80 & & & & $21: 15$ & 0,95 & 06 & & & & 0 & 1,06 & & & & & 1,06 & & & & 0 & $1, \mathrm{C}$ & & & $21: 00$ & 0 & 51,06 \\
\hline & 07 & 127,843 & 05:45 & 22:15 & 1,00 & 1,06 & 172,269 & $05: 45$ & $22: 15$ & 51,00 & 1,06 & 282,908 & $05: 45$ & 22:00 & 1,00 & 1,06 & 333,435 & $05: 45$ & 22:00 & $\begin{array}{l}0 \\
0\end{array}$ & 1,06 & 457,003 & 05:45 & $22: 00$ & $\begin{array}{ll}0 & 1,00\end{array}$ & 1,05 \\
\hline
\end{tabular}

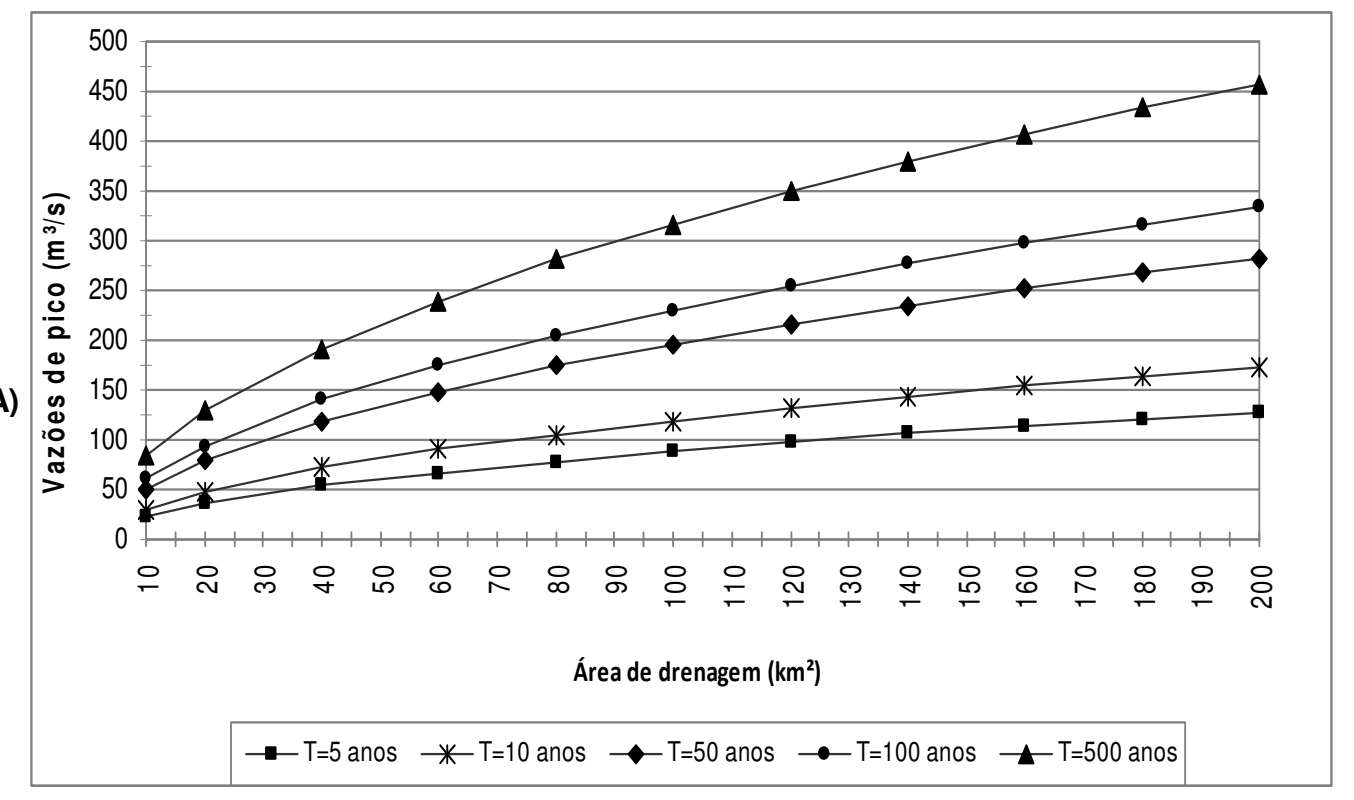

(B)

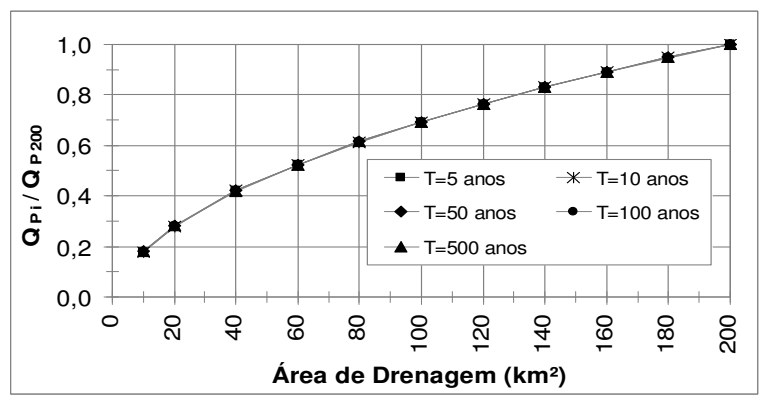

(A)

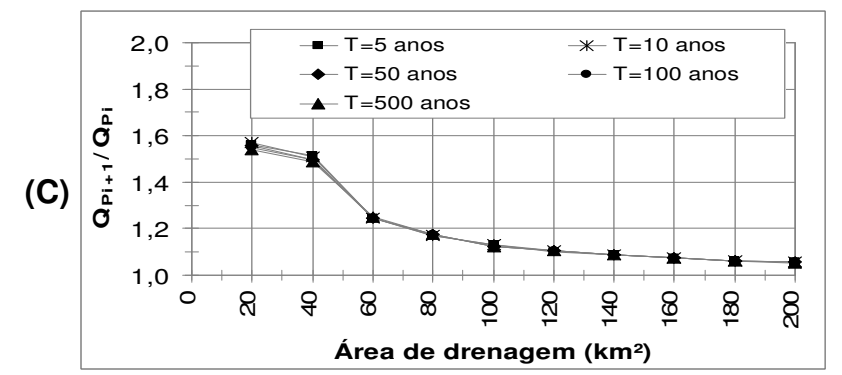

Figura 4.7 - (A) Variação da vazão de pico em função da área de drenagem, (B) proporção da vazão de pico em relação ao valor da vazão de pico para a área de drenagem de $200 \mathrm{~km}^{2},(C)$ variação entre as vazões de pico em função da área de drenagem para o método do SCS 
Ao observar os resultados, é possível inferir que:

- A vazão de pico é crescente com o valor da área de drenagem;

- Os tempos de ascensão dos hidrogramas de cheia são mostrados na Tabela 4.3. A Figura 4.8 mostra o comportamento dos hidrogramas com o período de retorno de 100 anos, para cada valor de área de drenagem simulada. Este mesmo comportamento, exceto pelo tempo de ascensão, foi verificado para os demais períodos de retorno avaliados;

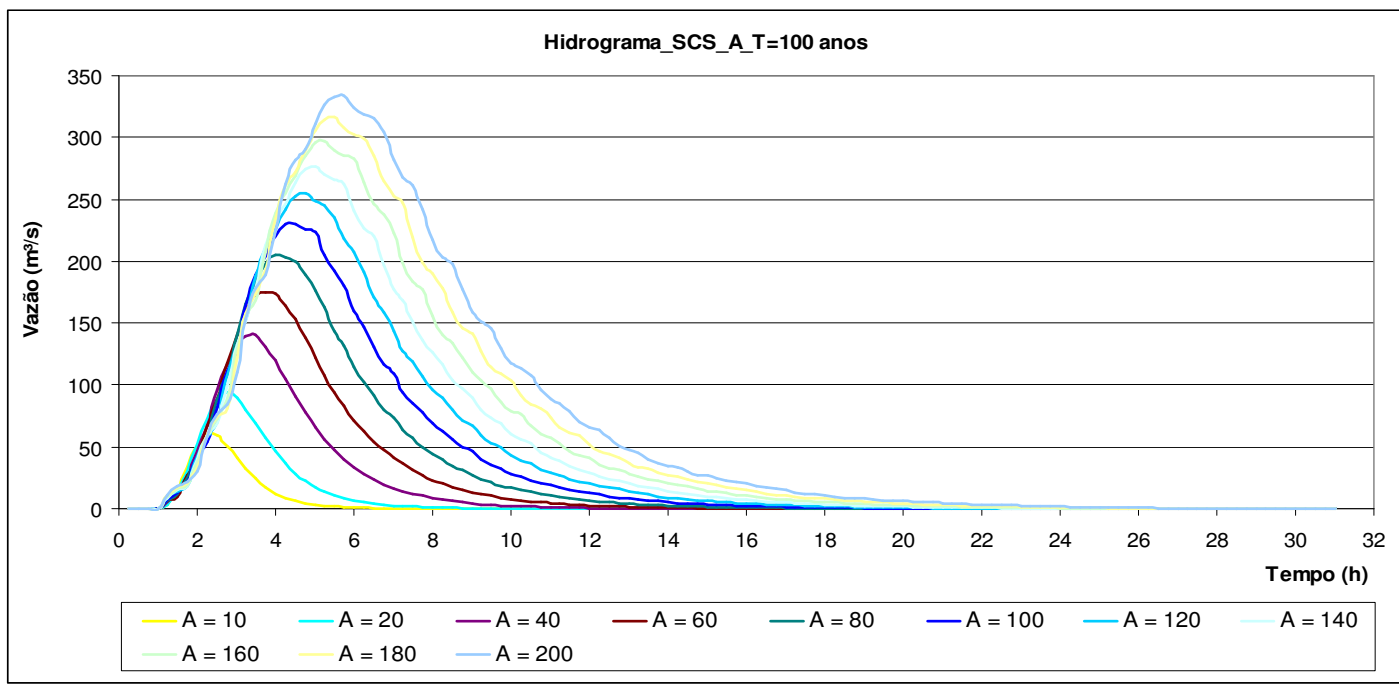

Figura 4.8 - Hidrogramas de cheia para o período de retorno igual a 100 anos - SCS

- As variações das vazões de pico para as áreas de drenagem testadas são decrescentes. A variação no valor da vazão de pico, considerando o período de retorno de 5 anos, por exemplo, para a área de drenagem de $10 \mathrm{~km}^{2}$ a 20 $\mathrm{km}^{2}$ é de $12,8 \mathrm{~m}^{3} / \mathrm{s}$, corresponde a $56 \%$ do valor da vazão de pico para a área de drenagem de $10 \mathrm{~km}^{2}$. A variação no valor da vazão de pico para a área de drenagem de $180 \mathrm{~km}^{2}$ a $200 \mathrm{~km}^{2}$ é de $6,76 \mathrm{~m}^{3} / \mathrm{s}$, corresponde a $6 \%$ do valor da vazão de pico para a área de drenagem de $200 \mathrm{~km}^{2}$. Esta mesma variação é verificada para os demais períodos de retorno avaliados e pode ser verificada na Tabela 4.3. Pode-se dizer que variações nos valores da área de drenagem na faixa de 20 a $80 \mathrm{~km}^{2}$ são mais relevantes na determinação das vazões de pico do que na faixa de 100 a $200 \mathrm{~km}^{2}$. 
Quanto aos volumes dos hidrogramas, a Tabela 4.4 e as figuras 4.9 a 4.11 mostram sua variação em função da variação da área de drenagem e indicam a linearidade nesta relação, uma vez que a altura da chuva excedente é constante para cada período de retorno.

Tabela 4.4 - Análise de sensibilidade do volume do hidrograma de cheia em função da variação da área de drenagem para o método do SCS

\begin{tabular}{|c|c|c|c|c|c|c|c|c|c|c|c|c|c|c|c|c|}
\hline \multirow[b]{2}{*}{$\begin{array}{c}A \\
\left(\mathrm{~km}^{2}\right)\end{array}$} & \multirow[b]{2}{*}{$\begin{array}{l}\text { tc } \\
\text { (h) }\end{array}$} & \multicolumn{3}{|c|}{$\mathrm{T}=5$ anos } & \multicolumn{3}{|c|}{$T=10$ anos } & \multicolumn{3}{|c|}{$\mathrm{T}=50$ anos } & \multicolumn{3}{|c|}{$\mathrm{T}=100$ anos } & \multicolumn{3}{|c|}{$\mathrm{T}=500$ anos } \\
\hline & & $\begin{array}{c}\mathrm{V} \\
\left(\mathrm{Mm}^{3}\right)\end{array}$ & $\frac{V_{i}}{V_{200}}$ & $\frac{V_{i+1}}{V_{i}}$ & $\begin{array}{c}\mathrm{V} \\
\left(\mathrm{Mm}^{3}\right)\end{array}$ & $\frac{V_{i}}{V_{200}}$ & $\frac{V_{i+1}}{V_{i}}$ & $\begin{array}{c}\mathrm{V} \\
\left(\mathrm{Mm}^{3}\right)\end{array}$ & $\frac{V_{i}}{V_{200}}$ & $\frac{V_{i+1}}{V_{i}}$ & $\begin{array}{c}\mathrm{V} \\
\left(\mathrm{Mm}^{3}\right)\end{array}$ & $\frac{V_{i}}{V_{200}}$ & $\frac{V_{i+1}}{V_{i}}$ & $\begin{array}{c}\mathrm{V} \\
\left(\mathrm{Mm}^{3}\right)\end{array}$ & $\frac{V_{i}}{V_{200}}$ & $\frac{V_{i+1}}{V_{i}}$ \\
\hline 10 & 1,58 & 0,15 & 0,05 & & 0,20 & 0,05 & & 0,33 & 0,05 & & 0,39 & 0,05 & & 0,53 & 0,05 & \\
\hline 20 & 2,24 & 0,30 & 0,10 & 2,00 & 0,40 & 0,10 & 2,00 & 0,66 & 0,10 & 2,00 & 0,78 & 0,10 & 2,00 & 1,06 & 0,10 & 2,00 \\
\hline 40 & 3,16 & 0,60 & 0,20 & 2,00 & 0,80 & 0,20 & 2,00 & 1,32 & 0,20 & 2,00 & 1,55 & 0,20 & 2,00 & 2,13 & 0,20 & 2,00 \\
\hline 60 & 3,87 & 0,89 & 0,30 & 1,50 & 1,20 & 0,30 & 1,50 & 1,97 & 0,30 & 1,50 & 2,33 & 0,30 & 1,50 & 3,19 & 0,30 & 1,50 \\
\hline 80 & 4,47 & 1,19 & 0,40 & 1,33 & 1,60 & 0,40 & 1,33 & 2,63 & 0,40 & 1,33 & 3,10 & 0,40 & 1,33 & 4,25 & 0,40 & 1,33 \\
\hline 100 & 5,00 & 1,49 & 0,50 & 1,25 & 2,00 & 0,50 & 1,25 & 3,29 & 0,50 & 1,25 & 3,88 & 0,50 & 1,25 & 5,31 & 0,50 & 1,25 \\
\hline 120 & 5,48 & 1,79 & 0,60 & 1,20 & 2,40 & 0,60 & 1,20 & 3,95 & 0,60 & 1,20 & 4,65 & 0,60 & 1,20 & 6,38 & 0,60 & 1,20 \\
\hline 140 & 5,92 & 2,08 & 0,70 & 1,17 & 2,81 & 0,70 & 1,17 & 4,60 & 0,70 & 1,17 & 5,43 & 0,70 & 1,17 & 7,44 & 0,70 & 1,17 \\
\hline 160 & 6,32 & 2,38 & 0,80 & 1,14 & 3,21 & 0,80 & 1,14 & 5,26 & 0,80 & 1,14 & 6,20 & 0,80 & 1,14 & 8,50 & 0,80 & 1,14 \\
\hline 180 & 6,71 & 2,68 & 0,90 & 1,13 & 3,61 & 0,90 & 1,12 & 5,92 & 0,90 & 1,12 & 6,98 & 0,90 & 1,12 & 9,56 & 0,90 & 1,12 \\
\hline 200 & 7,07 & 2,98 & 1,00 & 1,11 & 4,01 & 1,00 & 1,11 & 6,58 & 1,00 & 1,11 & 7,75 & 1,00 & 1,11 & 10,62 & 1,00 & 1,11 \\
\hline
\end{tabular}

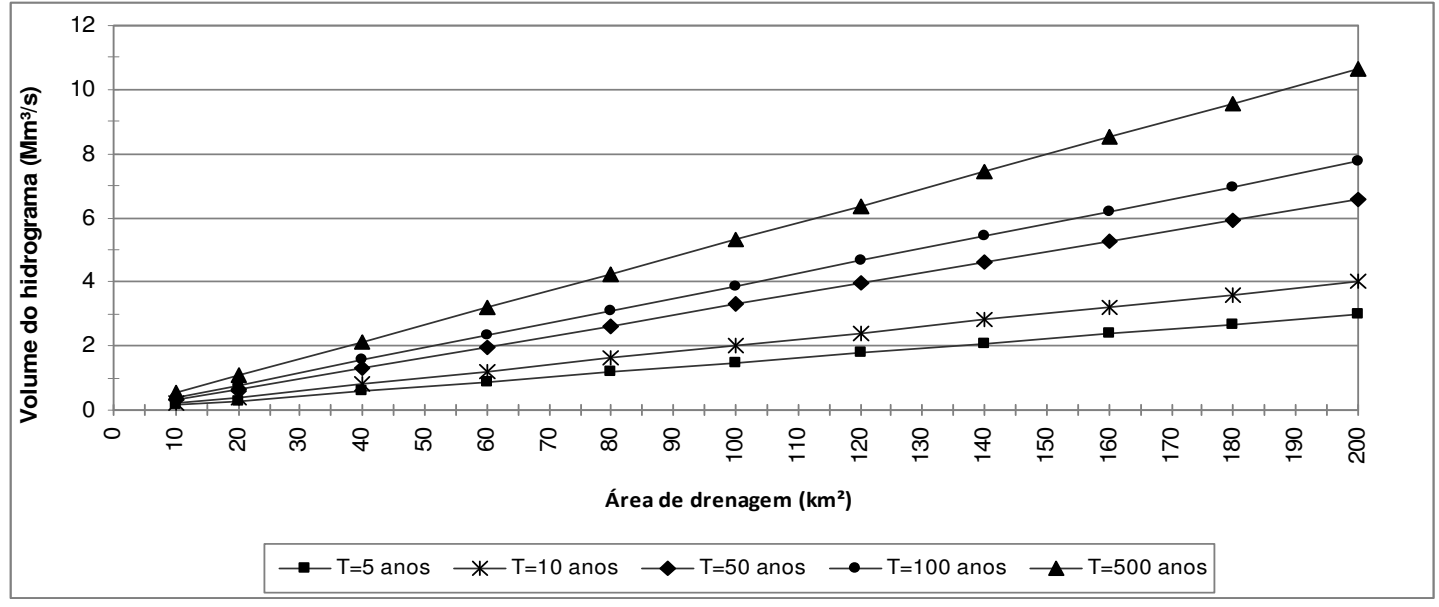

Figura 4.9 - Gráfico da variação do volume do hidrograma de cheia em função da área de drenagem - SCS

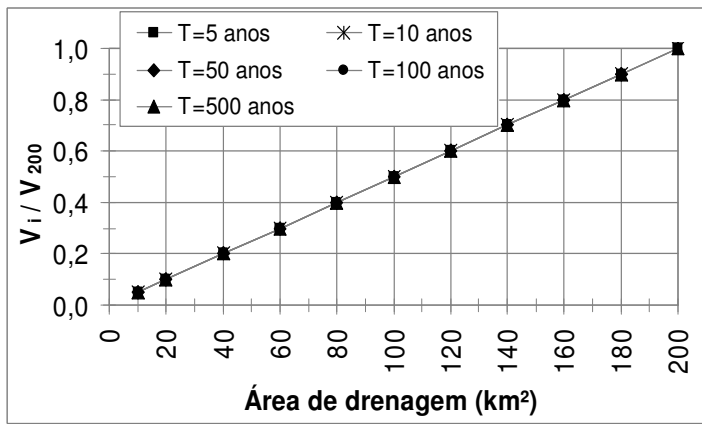

Figura 4.10 - Proporção do volume em relação ao valor do volume para a área de drenagem de $200 \mathrm{~km}^{2}$ - SCS

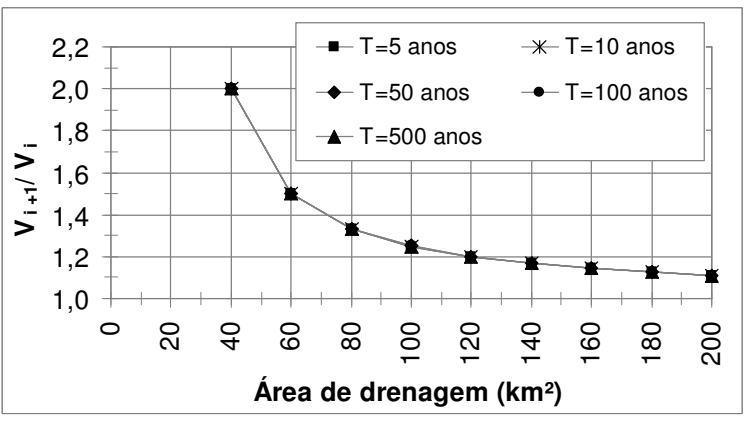

Figura 4.11 - Variação entre os volumes em função da área de drenagem - SCS 
Das figuras 4.10 e 4.11, pode-se verificar que o volume do hidrograma tem variação diferente da vazão de pico. A Figura 4.12 mostra a diferenças entre os gradientes de vazão de pico e volume.

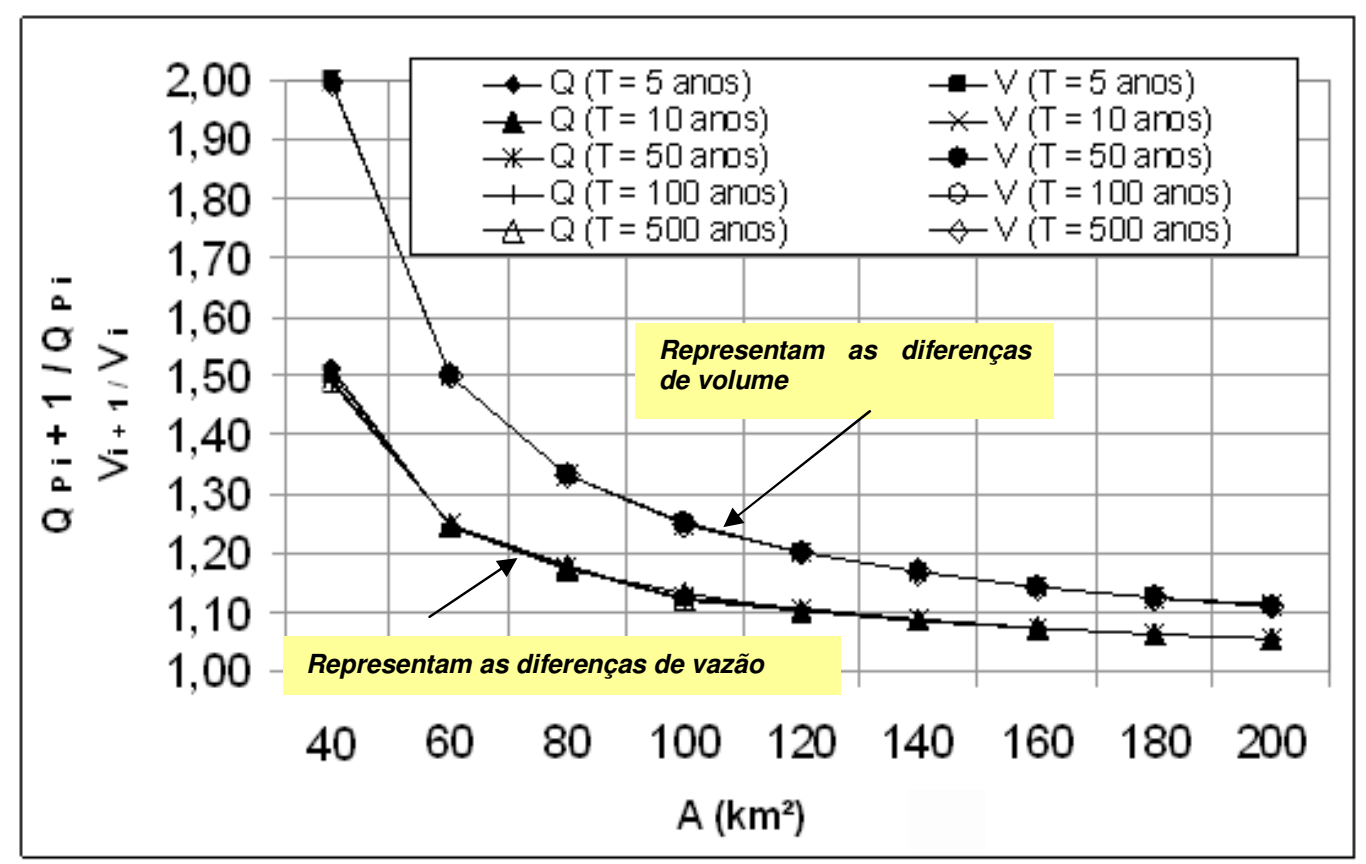

Figura 4.12 - Comparação dos gradientes de vazão de pico e volume - SCS

Esta análise permite afirmar que, para bacias pequenas, a incerteza na determinação área de drenagem tem influencia significante no cálculo da vazão de pico.

\subsubsection{Análise de sensibilidade em relação ao tempo de concentração}

Para esta análise, utilizaram-se as considerações e a caracterização da bacia hidrográfica descrita no Capítulo 3. Variou-se o tempo de concentração de 30 minutos (0,5 hora) a 360 minutos (6 horas). Nesta aplicação, foi mantida a área de drenagem da bacia igual a 21,9 km². A intenção desta análise foi verificar qual a 
variação da vazão de pico, quando existem dúvidas em relação apenas ao tempo de concentração da bacia hidrográfica.

As análises foram feitas considerando os períodos de retorno de 5, 10, 50, 100 e 500 anos.

A partir das simulações, elaboraram-se a Tabela 4.5 e os gráficos apresentados na Figura 4.13, que apresentam os resultados das análises da variação da vazão de pico em função da variação do tempo de concentração.

Na Tabela 4.5 são apresentados:

- O valor da vazão de pico, em m³/s;

- O tempo de ascensão do hidrograma, em hh:mm;

- O tempo de base, tendo seu término quando a vazão se reduz a $1 \%$ da vazão de pico, em hh:mm;

- A relação entre o valor da vazão de pico para o tempo de concentração escolhido e o valor da vazão de pico para o tempo de concentração de 30 minutos;

- A relação entre o valor da vazão de pico para o tempo de concentração escolhido e o valor da vazão de pico para o tempo de concentração anterior;

- O complementar da relação entre o valor da vazão de pico para o tempo de concentração escolhido e o valor da vazão de pico para o tempo de concentração anterior. 
Tabela 4.5 - Análise de sensibilidade da vazão de pico em função da variação do valor do tempo de concentração para o método do SCS

\begin{tabular}{|c|c|c|c|c|c|c|c|c|c|c|c|c|c|c|c|c|c|c|c|c|c|c|c|c|c|c|c|c|c|c|}
\hline \multirow[b]{2}{*}{$\begin{array}{l}\text { tc } \\
\text { (h) }\end{array}$} & \multicolumn{6}{|c|}{$\mathrm{T}=5$ anos } & \multicolumn{5}{|c|}{$\mathrm{T}=10$ anos } & \multicolumn{7}{|c|}{$\mathrm{T}=50$ anos } & \multicolumn{5}{|c|}{$\mathrm{T}=100$ anos } & \multicolumn{7}{|c|}{$\mathrm{T}=500$ anos } \\
\hline & $\begin{array}{c}Q_{p} \\
\left(m^{3} / s\right)\end{array}$ & $\begin{array}{l}\text { ta } \\
\text { (hh }\end{array}$ & $\begin{array}{r}\text { tb } \\
\mathrm{mm})\end{array}$ & $\frac{Q_{p i}}{Q_{p 0.5}}$ & $\frac{Q_{p i+1}}{Q_{p i}}$ & $\frac{Q_{p i+1}}{Q_{p i}}$ & $\begin{array}{c}Q_{p} \\
\left(m^{3} / s\right)\end{array}$ & $\begin{array}{l}\text { ta } \\
\text { (hh }\end{array}$ & $\begin{array}{r}\text { tb } \\
\mathrm{mm})\end{array}$ & $\frac{Q_{p i}}{Q_{p 0,5}}$ & $\frac{Q_{p i+1}}{Q_{p i}}$ & $-\frac{Q_{p i+1}}{Q_{p i}}$ & $\begin{array}{c}Q_{p} \\
\left(m^{3} / s\right)\end{array}$ & $\begin{array}{l}\text { ta } \\
\text { (hh: }\end{array}$ & $\begin{array}{r}\text { tb } \\
\mathrm{mm})\end{array}$ & $\frac{Q_{p i}}{Q_{p 0.5}}$ & $\frac{Q_{p i+1}}{Q_{p i}}$ & $-\frac{Q_{p i+1}}{Q_{p i}}$ & $\underset{\left(m^{3} / \mathbf{s}\right)}{Q_{p}}$ & $\begin{array}{l}\text { ta } \\
\text { (hh: }\end{array}$ & $\begin{array}{r}\text { tb } \\
\mathrm{mm} \text { ) }\end{array}$ & $\frac{Q_{p i}}{Q_{p 0.5}}$ & $\frac{Q_{p i+1}}{Q_{p i}}$ & $\frac{Q_{p i+1}}{Q_{p i}}$ & $\begin{array}{c}Q_{p} \\
\left(m^{3} / s\right)\end{array}$ & & $\begin{array}{r}\text { tb } \\
\mathrm{mm})\end{array}$ & $\frac{Q_{p i}}{Q_{p 0.5}}$ & $\frac{Q_{p i+1}}{Q_{p i}}$ & $\frac{Q_{p i+1}}{Q_{p i}}$ \\
\hline 50 & 189 & $: 45$ & $3: 30$ & 1,00 & & & 2,334 & $1: 45$ & 03:30 & 1,00 & & & 211,753 & $01: 30$ & 03:30 & 1,00 & & & 54,620 & 01:30 & 03:30 & 1,00 & & & 360,476 & $01: 30$ & 03:30 & 1,00 & & \\
\hline & & & $t: 45$ & & &, 26 & & & & & & 0,25 & & $2: 00$ & & & 0,72 & 0,28 & & 00 & & 71 & & 0,29 & & 2.00 & & ,69 & 0,69 & 0,31 \\
\hline & & & 6:15 & & & 24 & & & & & & & & :15 & & & & & & & & & & & & 15 & & & & ,23 \\
\hline 0 & & & 07:45 & & & 18 & $8 / 8$ & :45 & & & & & & :45 & & & & ,20 & & $: 30$ & & & & 20 & & 30 & & & & ,20 \\
\hline 50 & & & 9:00 & & 35 &, 15 & 602 & :00 & & & & & & :00 & & 38 & $0, \varepsilon$ & 14 & & 3:00 & & 37 & & 14 & 486 & 3:00 & 9:00 & & & 0,15 \\
\hline 00 & 628 & & $10: 30$ & & 85 & 15 & 315 & :15 & & & & 15 & & :15 & :30 & & & 0,15 & ,094 & 3:00 & & & & 0,15 & 109,835 & 3:15 & $0: 30$ & & & 0,15 \\
\hline 50 & & & 5.00 & & & 13 & & & & & & & & 30 & & & & & & & & & & 13 & & 30 & & & & 0,13 \\
\hline 00 & & & & & & & & & & & & & & & & & & & & & & & & & & :45 & & & &, 11 \\
\hline 50 & & & & & & & & & & & & & & & & & & & & & & & & & & & & & &, 10 \\
\hline bo & & & $: 15$ & & & 09 & & & & & & & & & & & & & & & & & & & & $: 15$ & & & &, 10 \\
\hline 50 & & & $7: 45$ & & &, 08 & & & & & & & & & & & & & & & & & & ,08 & & 1:45 & 30 & & &, 08 \\
\hline 00 & ,445 & 5:00 & 9:00 & 18 & 0,92 & 0,08 & 22,178 & $05: 00$ & $19: 00$ & ,18 & 0,93 & 0,07 & 36,467 & 05:00 & 19:00 & 0,17 & 0,93 & 0,07 & 42,996 & 05:00 & $19: 00$ & 0,17 & 0,93 & 0,07 & 58,966 & 05:00 & $19: 00$ & 0,16 & 0,93 & 0,07 \\
\hline
\end{tabular}

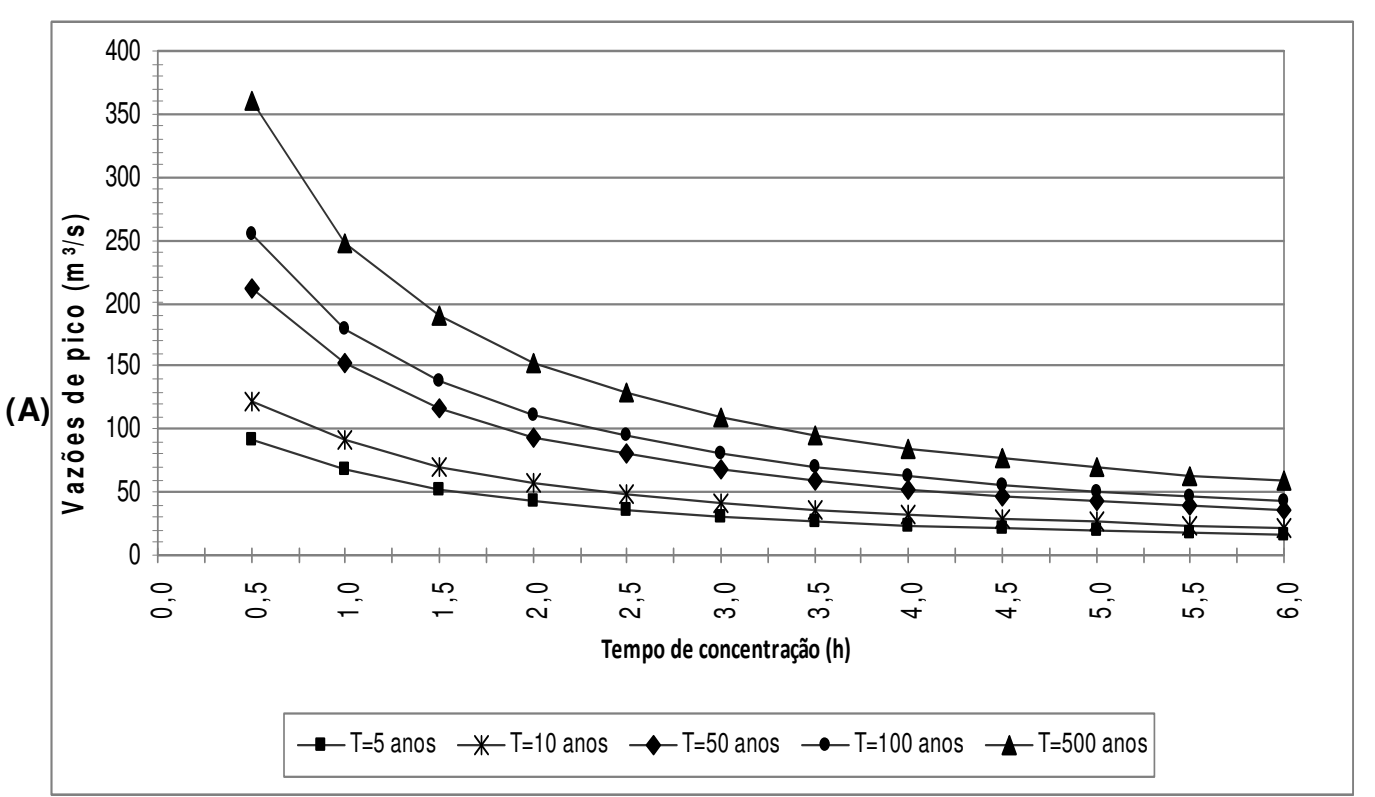

(B)

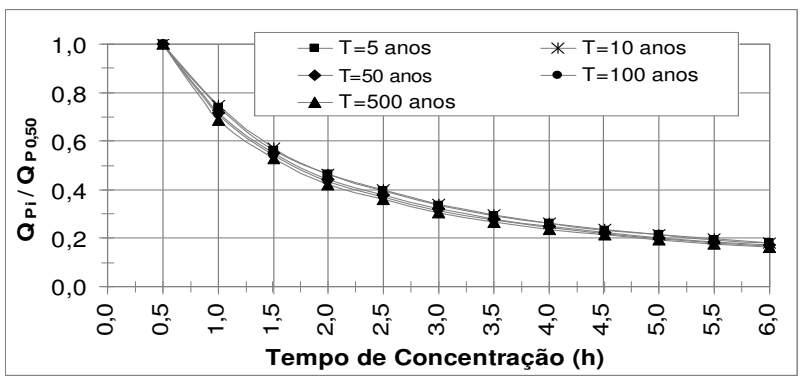

(C)

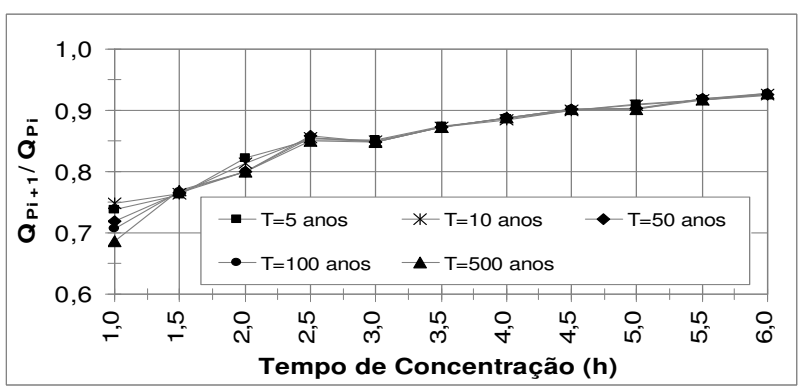

Figura 4.13 - (A) Variação da vazão de pico em função do tempo de concentração, (B) proporção da vazão de pico em relação ao valor da vazão de pico para o tempo de concentração de $0,5 \mathrm{~h},(\mathrm{C})$ variação entre as vazões de pico em função do tempo de concentração para o método do SCS 
Ao observar os resultados, é possível inferir que:

- A vazão de pico é decrescente com o tempo de concentração. Quanto menor o tempo de concentração, maior será a vazão de pico;

- Aumentando-se o tempo de concentração, o hidrograma desloca-se para a direita e o pico diminui. A Figura 4.14 mostra a forma e o comportamento dos hidrogramas para o período de retorno de 100 anos, para cada valor do tempo de concentração simulado. Este mesmo comportamento foi verificado para os demais períodos de retorno avaliados.

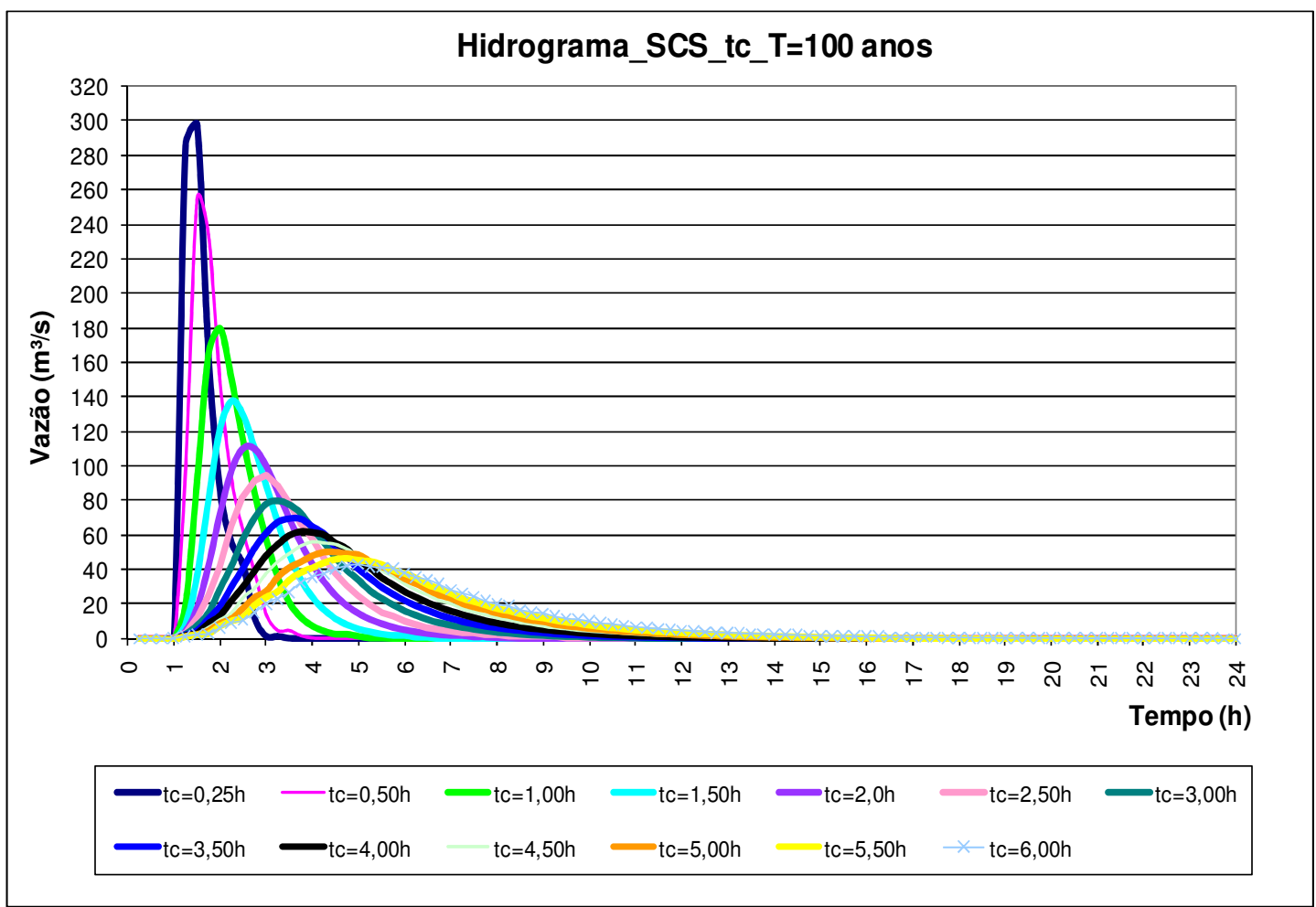

Figura 4.14 - Hidrogramas de cheia para os períodos de retorno igual a 100 anos - SCS

- Da Figura 4.13, pode se distinguir aproximadamente três faixas de variação. A maior variação dos valores de vazão, para todos os períodos de retorno avaliados, ocorre no intervalo de 0,5 a 2 horas. Neste intervalo, o valor da vazão de pico para o tempo de concentração de 0,5 h é aproximadamente 2 vezes maior que o tempo de concentração de 2 horas. A segunda faixa compreende o intervalo de 2 a 4 horas. Neste intervalo, o valor da vazão de 
pico para o tempo de concentração de $2 \mathrm{~h}$ é aproximadamente 1,8 vezes maior que o tempo de concentração de 4 horas. A menor variação ocorre no intervalo de 4 a 6 horas. Neste intervalo, o valor da vazão de pico para o tempo de concentração de $4 \mathrm{~h}$ é aproximadamente 1,4 vezes maior que o tempo de concentração de 6 horas. A despeito disso, mesmo neste intervalo a variação não é desprezível.

Com o intuito de melhor interpretar esta análise de sensibilidade, considerem-se as equações para o cálculo do tempo de concentração disponíveis no SSD ABC 6.

Para a aplicação das equações, utilizaram-se as considerações e a caracterização da bacia hidrográfica descrita no Capítulo 3. Foi adotado o coeficiente de rugosidade igual a 0,06 e a rugosidade de Manning igual a 0,035. A Tabela 4.6 apresenta os resultados do tempo de concentração em minutos e em horas.

Tabela 4.6 - Tempos de concentração para a bacia hidrográfica em estudo

\begin{tabular}{ccc} 
Fórmula & \multicolumn{2}{c}{ tc } \\
\cline { 2 - 3 } & (min) & (h) \\
\hline Bransby-Willians & 190 & 3,2 \\
Dooge & 516 & 8,6 \\
Kerby & 88 & 1,5 \\
Kirpich I & 150 & 2,5 \\
Kirpich II & 150 & 2,5 \\
SCS & 696 & 11,6 \\
\hline
\end{tabular}

Dentre as equações disponíveis no SSD ABC 6, a equação da Onda Cinemática é a única que varia em função do período de retorno, uma vez que esta equação leva em conta a intensidade da chuva de projeto. A Tabela 4.7 apresenta os valores do tempo de concentração em minutos e em horas e a intensidade da chuva de projeto em $\mathrm{mm} / \mathrm{h}$ para os períodos de retorno avaliados. 
Tabela 4.7 - Tempos de concentração para a bacia hidrográfica em estudo a partir da equação da Onda Cinemática

\begin{tabular}{cccc}
\hline $\begin{array}{c}\mathbf{T} \\
\text { (anos) }\end{array}$ & (min) & tc & $\begin{array}{c}\mathbf{I} \\
(\mathbf{m})\end{array}$ \\
\hline 5 & 275 & 4,6 & 24,2 \\
10 & 261 & 4,4 & 27,6 \\
50 & 232 & 3,9 & 35,3 \\
100 & 228 & 3,8 & 38,5 \\
500 & 212 & 3,5 & 46,0 \\
\hline
\end{tabular}

Para as equações apresentadas na Tabela 4.6, a variação do valor do tempo de concentração é de 1,5 a 11,6 horas. Sem analisar a origem das fórmulas e desprezando o valor de 8,6 h e 11,6 h, discrepante entre os outros, a variação do tempo de concentração, considerando o período de retorno de 100 anos para equação da Onda Cinemática, é de 1,5 a 3,8 horas.

A variação da vazão de pico para o intervalo de 1,5 a 3,8 horas para o período de retorno de 100 anos é mostrada na Figura 4.15. Esta, por sua vez, é originária da Figura 4.13.

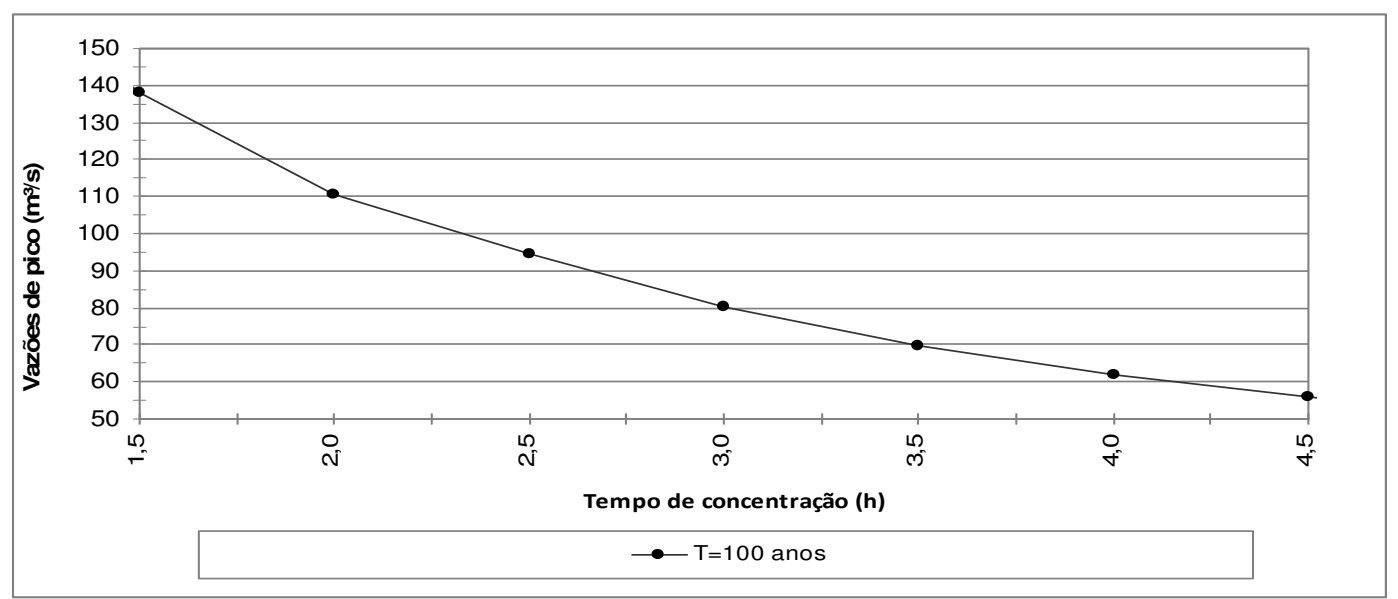

Figura 4.15 - Variação da vazão de pico em função do tempo de concentração, para o período de retorno de 100 anos - SCS

Se adotarmos o valor da vazão de pico de aproximadamente $138 \mathrm{~m} 3 / \mathrm{s}$, para o tempo de concentração de $1,5 \mathrm{~h}$, a diferença no valor da vazão de pico para o tempo de concentração de $3,8 \mathrm{~h}$ é de $73 \mathrm{~m} / \mathrm{s}$. A vazão de pico para o tempo de concentração de $3,8 \mathrm{~h}$, conforme Figura 4.15 , é de $65 \mathrm{~m}^{3} / \mathrm{s}$. A diferença de $73 \mathrm{~m}^{3} / \mathrm{s}$ representa uma variação de $53 \%$ do valor da vazão para o tempo de concentração de $1,5 \mathrm{~h}$. 
Analisando a origem das fórmulas e comparando à bacia adotada nestes estudos, verificamos que a equação que mais se aplica, dentre as disponíveis no SSD ABC 6 , é a equação de Kirpich, para a qual o tempo de concentração é de 2,5 h. A diferença entre o valor da vazão de pico para este tempo de concentração e os tempos de concentração de 1,5 h e 3,8 h é de $43,6 \mathrm{~m}^{3} / \mathrm{s}$ e $29,4 \mathrm{~m}^{3} / \mathrm{s}$, respectivamente.

A vazão de pico para o tempo de concentração de 1,5 h é $46 \%$ maior que o valor de pico para o tempo de concentração de $2,5 \mathrm{~h}$, enquanto a vazão de pico para o tempo de concentração de $3,8 \mathrm{~h}$ é $31 \%$ menor.

Esta exemplificação mostra que o tempo de concentração é um dos parâmetros que influência significativamente o valor da vazão de pico. Portanto, sua escolha deve ser criteriosa.

Em relação ao volume dos hidrogramas, a Tabela 4.8 e a Figura 4.16 mostram os estudos de sensibilidade referentes à variação do volume do hidrograma de cheia em função da variação do tempo de concentração.

Tabela 4.8 - Análise de sensibilidade do volume do hidrograma de cheia em função da variação do tempo de concentração para o método do SCS

\begin{tabular}{|c|c|c|c|c|c|c|c|c|c|c|c|c|c|c|c|}
\hline \multirow[b]{2}{*}{$\begin{array}{l}\text { tc } \\
\text { (h) }\end{array}$} & \multicolumn{2}{|c|}{$T=5$ anos } & \multicolumn{4}{|c|}{$\mathrm{T}=10$ anos } & \multicolumn{2}{|c|}{$T=50$ anos } & \multicolumn{3}{|c|}{$T=100$ anos } & \multicolumn{4}{|c|}{$T=500$ anos } \\
\hline & $\begin{array}{c}\mathrm{V} \\
\left(\mathrm{Mm}^{3}\right)\end{array}$ & $\frac{V_{i}}{V_{0,5}}$ & $\frac{V_{i+1}}{V_{i}}$ & $\begin{array}{c}\mathrm{V} \\
\left(\mathrm{Mm}^{3}\right)\end{array}$ & $\frac{V_{i}}{V_{0,5}}$ & $\frac{V_{i+1}}{V_{i}}$ & $\begin{array}{c}\mathrm{V} \\
\left(\mathrm{Mm}^{3}\right)\end{array}$ & $\frac{V_{i}}{V_{0,5}}$ & $\frac{V_{i+1}}{V_{i}}$ & $\begin{array}{c}\mathrm{V} \\
\left(\mathrm{Mm}^{3}\right)\end{array}$ & $\frac{V_{i}}{V_{0,5}}$ & $\frac{V_{i+1}}{V_{i}}$ & $\begin{array}{c}\mathrm{V} \\
\left(\mathrm{Mm}^{3}\right)\end{array}$ & $\frac{V_{i}}{V_{0,5}}$ & $\frac{V_{i+1}}{V_{i}}$ \\
\hline 0,5 & 0,33 & 1,00 & & 0,44 & 1,00 & & 0,72 & 1,00 & & 0,85 & 1,00 & & 1,17 & 1,00 & \\
\hline 1,0 & 0,33 & 1,00 & 1,00 & 0,44 & 1,00 & 1,00 & 0,72 & 1,00 & 1,00 & 0,85 & 1,00 & 1,00 & 1,17 & 1,00 & 1,00 \\
\hline 1,5 & 0,33 & 1,00 & 1,00 & 0,44 & 1,00 & 1,00 & 0,72 & 1,00 & 1,00 & 0,85 & 1,00 & 1,00 & 1,17 & 1,00 & 1,00 \\
\hline 2,0 & 0,33 & 1,00 & 1,00 & 0,44 & 1,00 & 1,00 & 0,72 & 1,00 & 1,00 & 0,85 & 1,00 & 1,00 & 1,17 & 1,00 & 1,00 \\
\hline 2,5 & 0,33 & 1,00 & 1,00 & 0,44 & 1,00 & 1,00 & 0,72 & 1,00 & 1,00 & 0,85 & 1,00 & 1,00 & 1,17 & 1,00 & 1,00 \\
\hline 3,0 & 0,33 & 1,00 & 1,00 & 0,44 & 1,00 & 1,00 & 0,72 & 1,00 & 1,00 & 0,85 & 1,00 & 1,00 & 1,17 & 1,00 & 1,00 \\
\hline 3,5 & 0,33 & 1,00 & 1,00 & 0,44 & 1,00 & 1,00 & 0,72 & 1,00 & 1,00 & 0,85 & 1,00 & 1,00 & 1,17 & 1,00 & 1,00 \\
\hline 4,0 & 0,33 & 1,00 & 1,00 & 0,44 & 1,00 & 1,00 & 0,72 & 1,00 & 1,00 & 0,85 & 1,00 & 1,00 & 1,17 & 1,00 & 1,00 \\
\hline 4,5 & 0,33 & 1,00 & 1,00 & 0,44 & 1,00 & 1,00 & 0,72 & 1,00 & 1,00 & 0,85 & 1,00 & 1,00 & 1,17 & 1,00 & 1,00 \\
\hline 5,0 & 0,33 & 1,00 & 1,00 & 0,44 & 1,00 & 1,00 & 0,72 & 1,00 & 1,00 & 0,85 & 1,00 & 1,00 & 1,17 & 1,00 & 1,00 \\
\hline 5,5 & 0,33 & 1,00 & 1,00 & 0,44 & 1,00 & 1,00 & 0,72 & 1,00 & 1,00 & 0,85 & 1,00 & 1,00 & 1,17 & 1,00 & 1,00 \\
\hline 6,0 & 0,33 & 1,00 & 1,00 & 0,44 & 1,00 & 1,00 & 0,72 & 1,00 & 1,00 & 0,85 & 1,00 & 1,00 & 1,17 & 1,00 & 1,00 \\
\hline
\end{tabular}




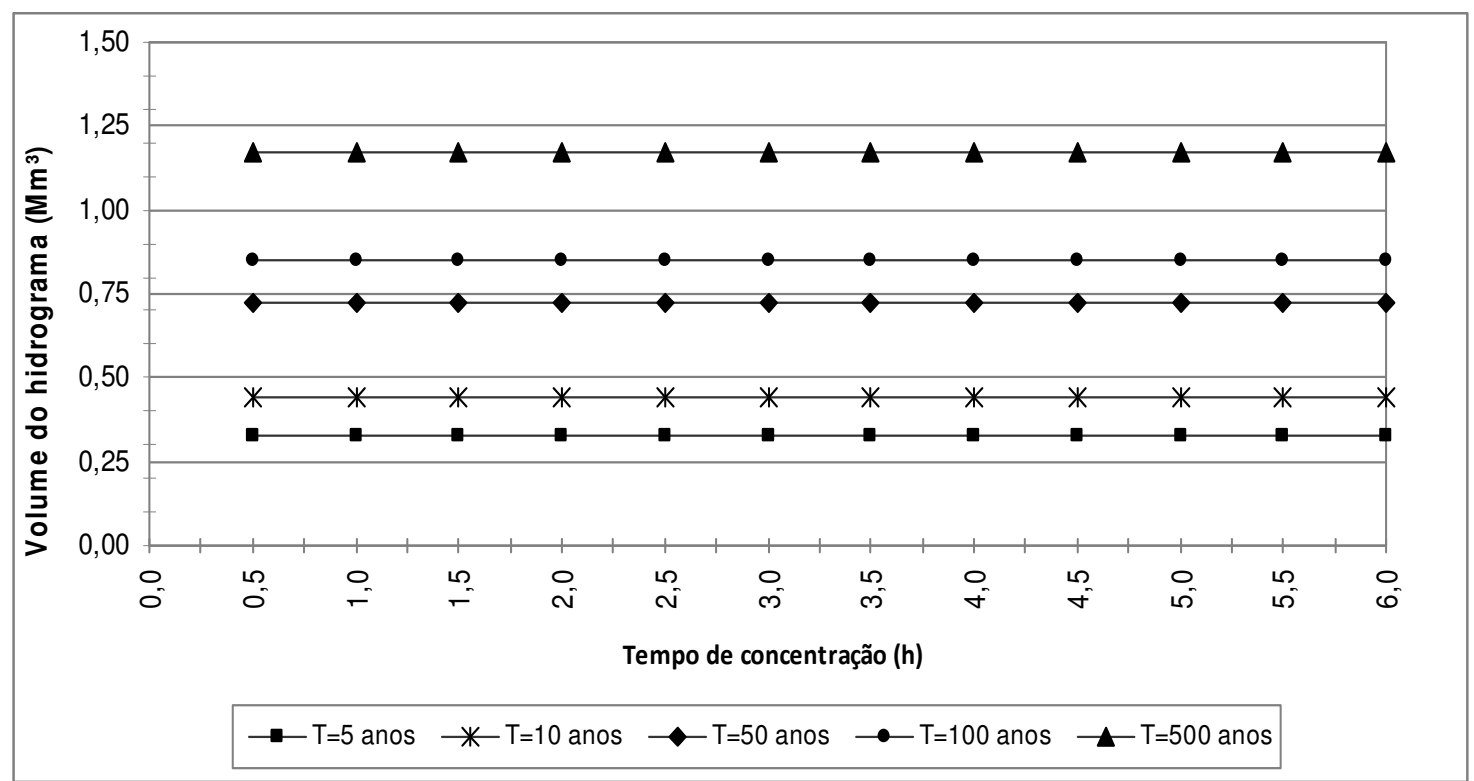

Figura 4.16 - Gráfico da variação do volume do hidrograma de cheia em função do tempo de concentração - SCS

Como se esperava, os volumes dos hidrogramas não variam em função do tempo de concentração, uma vez que o volume do hidrograma de projeto é condicionado em função do valor do $\mathrm{CN}$, área de drenagem e duração da chuva de projeto, que permaneceram constantes nesta análise de sensibilidade. Portanto, o efeito do tempo de concentração reflete-se apenas na estimativa da vazão de pico.

\subsubsection{Análise de sensibilidade em relação à duração a ser adotada para a chuva de projeto}

Para esta análise, utilizaram-se as considerações e a caracterização da bacia hidrográfica descrita no Capítulo 3. Variou-se a duração da chuva de 30 minutos a 6 horas. Cabe ressaltar que o tempo de concentração da bacia hidrográfica adotado é de 2,5 horas. As análises foram feitas considerando os períodos de retorno de 5, 10, 50,100 e 500 anos.

A partir das simulações, elaboraram-se a Tabela 4.9 e a Figura 4.17, que apresentam os resultados das análises da variação da vazão de pico em função da variação da duração da chuva de projeto. 
Na Tabela 4.9 são apresentados:

- O valor da vazão de pico, em m³/s;

- O tempo de ascensão do hidrograma, em hh:mm;

- O tempo de base, tendo seu término quando a vazão se reduz a $1 \%$ da vazão de pico, em hh:mm;

- A relação entre o valor da vazão de pico para a duração da chuva escolhida e o valor da vazão de pico para a duração de 360 minutos;

- A relação entre o valor da vazão de pico para a duração da chuva escolhida e o valor da vazão de pico para a duração anterior. 
Tabela 4.9 - Análise de sensibilidade da vazão de pico em função da variação da duração da chuva de projeto para o método do SCS

\begin{tabular}{|c|c|c|c|c|c|c|c|c|c|c|c|c|c|c|c|c|c|c|c|c|c|c|c|c|c|c|}
\hline \multirow[b]{2}{*}{$\begin{array}{c}d \\
(\min )\end{array}$} & \multicolumn{5}{|c|}{$T=5$ anos } & \multicolumn{5}{|c|}{$\mathrm{T}=10$ anos } & \multicolumn{5}{|c|}{$\mathrm{T}=50$ anos } & \multicolumn{5}{|c|}{$T=100$ anos } & \multicolumn{5}{|c|}{$\mathrm{T}=500$ anos } & \multirow[b]{2}{*}{$\frac{d_{i+1}}{d_{i}}$} \\
\hline & $\begin{array}{c}Q_{\mathbf{p}} \\
\left(m^{3} / \mathbf{s}\right)\end{array}$ & $\begin{array}{l}\text { ta } \\
\text { (hh: }\end{array}$ & $\begin{array}{r}\text { tb } \\
\mathrm{mm} \text { ) }\end{array}$ & $\frac{Q_{P i}}{Q_{P 360}}$ & $\frac{Q_{P i+1}}{Q_{P i}}$ & $\begin{array}{c}Q_{\mathbf{p}} \\
\left(m^{3} / \mathbf{s}\right)\end{array}$ & $\begin{array}{l}\text { ta } \\
\text { (hl }\end{array}$ & tb & $\frac{Q_{P i}}{Q_{P 360}}$ & $\frac{Q_{P i+1}}{Q_{P i}}$ & $\begin{array}{c}Q_{\mathbf{p}} \\
\left(m^{3} / s\right)\end{array}$ & $\begin{array}{l}\text { ta } \\
\text { (hh }\end{array}$ & $\begin{array}{r}\text { tb } \\
\mathrm{mm})\end{array}$ & $\frac{Q_{P_{i}}}{Q_{P_{360}}}$ & $\frac{Q_{P i+1}}{Q_{P_{i}}}$ & $\begin{array}{c}Q_{\mathbf{P}} \\
\left(m^{3} / \mathbf{s}\right)\end{array}$ & $\begin{array}{l}\text { ta } \\
\text { (hh }\end{array}$ & $\begin{array}{r}\text { tb } \\
\mathrm{mm})\end{array}$ & $\frac{Q_{P i}}{Q_{P 360}}$ & $\frac{Q_{P i+1}}{Q_{P i}}$ & $\begin{array}{c}Q_{\mathbf{p}} \\
\left(m^{3} / \mathbf{s}\right)\end{array}$ & $\begin{array}{l}\text { ta } \\
\text { (hh: }\end{array}$ & $\begin{array}{r}\text { tb } \\
\mathrm{mm} \text { ) }\end{array}$ & $\frac{Q_{P_{i}}}{Q_{P 360}}$ & $\frac{Q_{P i+1}}{Q_{P i}}$ & \\
\hline 30 & 11,271 & 01:45 & 07:45 & 0,25 & & 16,972 & 01:45 & 07:45 & 0,28 & & 32,328 & 01:45 & 07:45 & 0,34 & & 39,768 & 01:45 & 07:45 & 0,35 & & 58,684 & 01:45 & $07: 45$ & 0,39 & & \\
\hline 60 & 22,261 & 02:15 & 08:00 & 0,50 & 1,98 & 31,236 & $02: 15$ & 08:00 & 0,52 & 1,84 & 54,486 & 02:00 & 08:00 & 0,57 & 1,69 & 65,398 & 02:00 & 08:00 & 0,58 & 1,64 & 92,563 & 02:00 & 08:00 & 0,61 & 1,58 & 2,00 \\
\hline 90 & 28,900 & 02:30 & $08: 15$ & 0,64 & 1,30 & 39,683 & $02: 30$ & 08:15 & 0,66 & 1,27 & 66,907 & $02: 30$ & $08: 15$ & 0,70 & 1,23 & 79,486 & $02: 30$ & $08: 15$ & 0,71 & 1,22 & 110,500 & $02: 30$ & $08: 15$ & 0,73 & 1,19 & 1,50 \\
\hline 120 & 33,095 & 02:45 & $08: 45$ & 0,74 & 1,15 & 44,969 & 02:45 & $08: 45$ & 0,75 & 1,13 & 74,732 & $02: 45$ & $08: 45$ & 0,78 & 1,12 & 88,403 & $02: 45$ & $08: 45$ & 0,79 & 1,11 & 121,883 & 02:45 & $08: 45$ & 0,80 & 1,10 & 1,33 \\
\hline 150 & 35,988 & 03:00 & 09:00 & 0,80 & 1,09 & 48,602 & 03:00 & 09:00 & 0,81 & 1,08 & 80,052 & 03:00 & 09:00 & 0,84 & 1,07 & 94,410 & 03:00 & 09:00 & 0,84 & 1,07 & 129,486 & 03:00 & 09:00 & 0,85 & 1,06 & 1,25 \\
\hline 180 & 38,091 & 03:15 & 09:30 & 0,85 & 1,06 & 51,226 & 03:15 & 09:15 & 0,86 & 1,05 & 83,845 & 03:15 & 09:15 & 0,88 & 1,05 & 98,679 & 03:15 & 09:15 & 0,88 & 1,05 & 134,867 & 03:15 & 09:15 & 0,89 & 1,04 & 1,20 \\
\hline 210 & 39,678 & 03:30 & 09:45 & 0,88 & 1,04 & 53,213 & 03:30 & 09:45 & 0,89 & 1,04 & 86,667 & 03:30 & 09:45 & 0,90 & 1,03 & 101,861 & 03:30 & 09:45 & 0,91 & 1,03 & 138,847 & 03:30 & $09: 30$ & 0,92 & 1,03 & 1,17 \\
\hline 240 & 40,963 & 03:45 & 10:00 & 0,91 & 1,03 & 54,817 & 03:45 & 10:00 & 0,92 & 1,03 & 88,934 & 03:45 & $10: 00$ & 0,93 & 1,03 & 104,392 & 03:45 & 10:00 & 0,93 & 1,02 & 142,026 & 03:45 & $10: 00$ & 0,94 & 1,02 & 1,14 \\
\hline 270 & 42,113 & 04:00 & $10: 30$ & 0,94 & 1,03 & 56,232 & 04:00 & 10:15 & 0,94 & 1,03 & 90,919 & 04:00 & $10: 15$ & 0,95 & 1,02 & 106,632 & 04:00 & $10: 15$ & 0,95 & 1,02 & 144,803 & $04: 00$ & $10: 15$ & 0,96 & 1,02 & 1,13 \\
\hline 300 & 43,138 & 04:15 & $10: 45$ & 0,96 & 1,02 & 57,490 & 04:15 & 10:45 & 0,96 & 1,02 & 92,693 & 04:15 & $10: 30$ & 0,97 & 1,02 & 108,635 & 04:15 & $10: 30$ & 0,97 & 1,02 & 147,263 & 04:15 & $10: 30$ & 0,97 & 1,02 & 1,11 \\
\hline 330 & 44,076 & 04:30 & 11:00 & 0,98 & 1,02 & 58,638 & $04: 30$ & 11:00 & 0,98 & 1,02 & 94,308 & 04:30 & $11: 00$ & 0,98 & 1,02 & 110,430 & 04:30 & 11:00 & 0,99 & 1,02 & 149,487 & $04: 30$ & $11: 00$ & 0,99 & 1,02 & 1,10 \\
\hline 360 & 44,942 & 04:45 & $11: 30$ & 1,00 & 1,02 & 59,692 & $04: 45$ & $11: 30$ & 1,00 & 1,02 & 95,780 & $04: 45$ & $11: 15$ & 1,00 & 1,02 & 112,074 & $04: 45$ & $11: 15$ & 1,00 & 1,01 & 151,513 & $04: 45$ & $11: 15$ & 1,00 & 1,01 & 1,09 \\
\hline
\end{tabular}

(A)

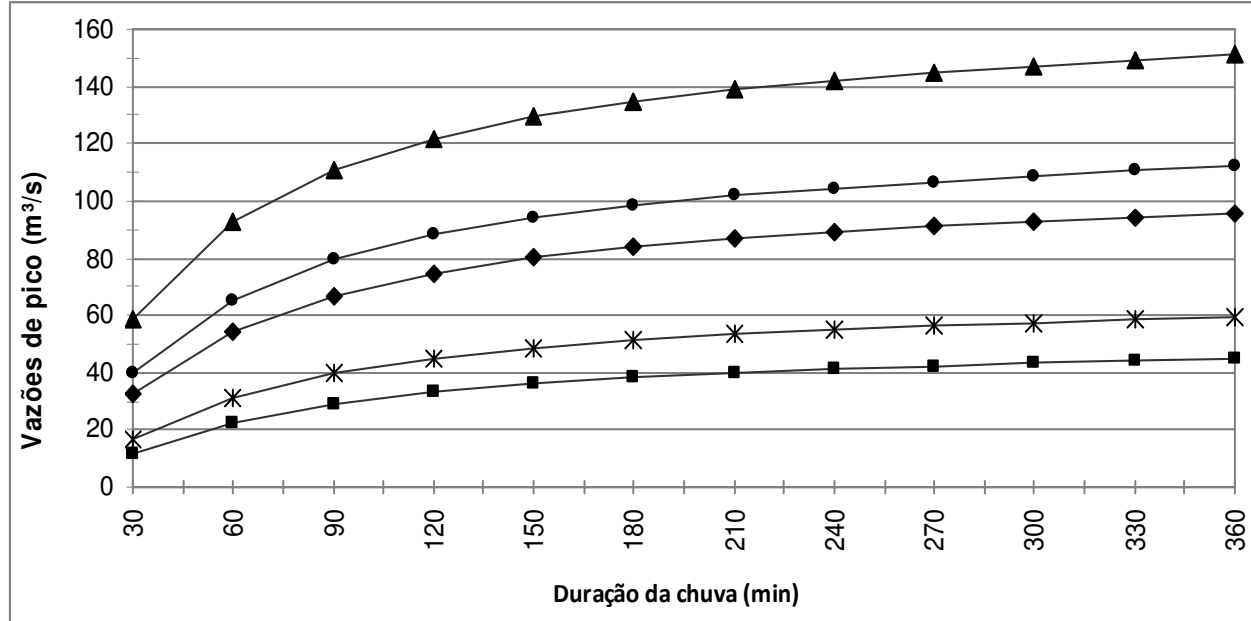

$\longrightarrow \mathrm{T}=5$ anos $\rightarrow \mathrm{T}=10$ anos $\longrightarrow \mathrm{T}=50$ anos $\longrightarrow \mathrm{T}=100$ anos $\longrightarrow \mathrm{T}=500$ anos

(B)
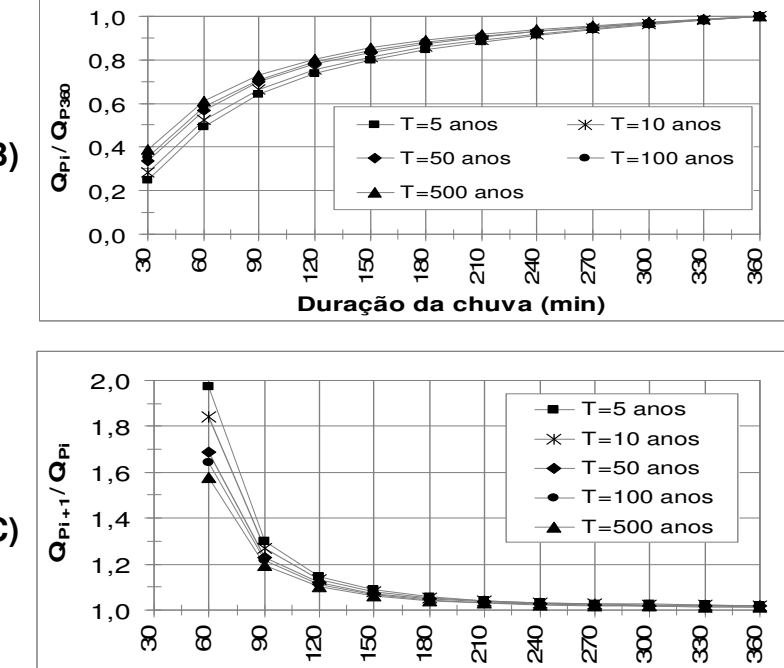

Duração da chuva $(\min )$

Figura 4.17 - (A) Variação da vazão de pico em função da duração da chuva de projeto, (B) proporção da vazão de pico em relação ao valor da vazão de pico para duração da chuva de projeto de 360 minutos, $(\mathrm{C})$ variação entre as vazões de pico em função da duração da chuva de projeto para o método do SCS 
Ao observar os resultados, é possível inferir que:

- A vazão de pico é crescente com a duração da chuva, com variações pequenas para as durações maiores;

- A partir da duração de 60 minutos, a cada incremento de 30 minutos, o tempo de ascensão do hidrograma, varia em 15 minutos. Para a duração de 60 minutos, o tempo de ascensão é de duas horas e 15 minutos, para 90, duas horas e 30 minutos, e assim sucessivamente. Aumentando-se a duração da chuva de projeto, o hidrograma desloca-se para a direita. A Figura 4.18 mostra o comportamento dos hidrogramas para o período de retorno de 100 anos, para cada duração da chuva de projeto simulada. Este mesmo comportamento foi verificado para os demais períodos de retorno avaliados;

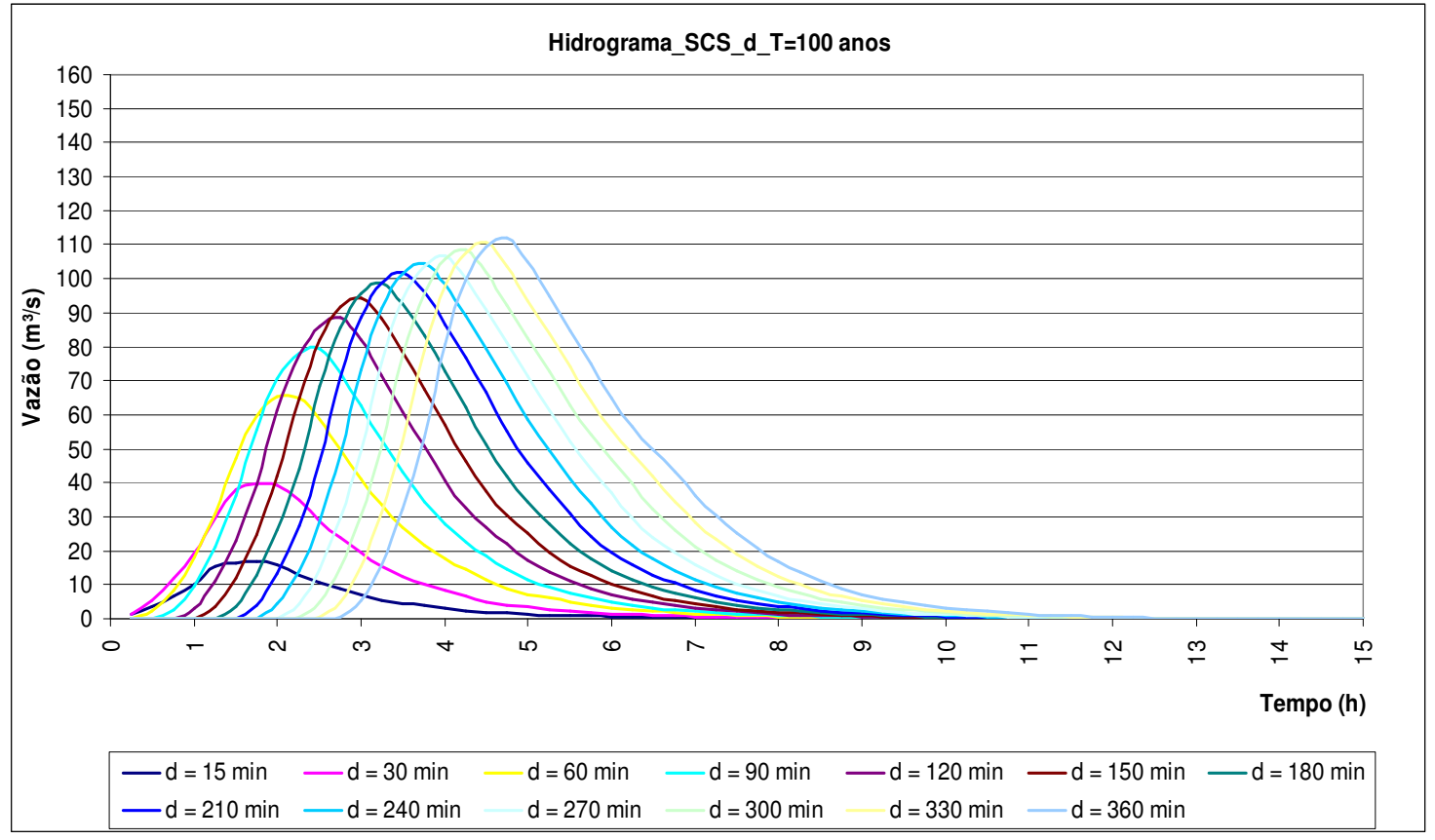

Figura 4.18 - Hidrogramas de cheia para os período de retorno igual a 100 anos - SCS

- A maior variação dos valores de vazão, para todos os períodos de retorno avaliados, ocorre no intervalo de 30 a 120 minutos. Neste intervalo, o valor da vazão de pico para a duração de 120 minutos é cerca de 2,9 vezes maior que o valor da vazão de pico de 30 minutos para o período de retorno de 5 anos. 
Para $T=10$ anos, 2,6 vezes. Para $T=50$ anos, 2,3 vezes. Para $T=100$ anos, 2,2 vezes. Para $T=500$ anos, 2,1 vezes. Neste intervalo, as variações nos valores da vazão de pico são diferentes em função do período de retorno. A partir da duração de 150 minutos esta variação diminui e tende a se igualar;

- Como pode ser notado na Figura 4.17, a qual apresenta o gradiente das vazões de pico, os gradientes maiores acontecem para as durações menores que o tempo de concentração da bacia (2,5 h ou 150 minutos), a partir daí, à medida que a duração da chuva aumenta, o gradiente da vazão tende a uma assíntota;

- No intervalo de 150 a 360 minutos, a variação é pequena. O valor da vazão de pico para a chuva com duração de 360 minutos é de 1,2 vezes o valor da vazão de pico para a duração de 150 minutos. A partir da duração de 150 minutos, a máxima variação observada é da ordem de 6\%. A partir de 210 minutos, pode-se considerar que a variação na vazão de pico tem a mesma ou menor precisão do que as medições de vazão.

- Para estas análises de sensibilidade, verifica-se que a variação no valor da vazão de pico é menor em função da duração da chuva de projeto do que em função tempo de concentração.

- Quanto aos volumes dos hidrogramas de cheia, a Tabela 4.10 e as figuras 4.19 a 4.21 mostram sua variação em função da variação da duração da chuva de projeto. 
Tabela 4.10 - Análise de sensibilidade do volume do hidrograma de cheia em função da variação da duração da chuva de projeto para o método do SCS

\begin{tabular}{|c|c|c|c|c|c|c|c|c|c|c|c|c|c|c|c|}
\hline \multirow[b]{2}{*}{$\begin{array}{c}d \\
(\min ) \\
\end{array}$} & \multicolumn{3}{|c|}{$\mathrm{T}=5$ anos } & \multicolumn{3}{|c|}{$\mathrm{T}=10$ anos } & \multicolumn{3}{|c|}{$\mathrm{T}=50$ anos } & \multicolumn{3}{|c|}{$T=100$ anos } & \multicolumn{3}{|c|}{$\mathrm{T}=500$ anos } \\
\hline & $\begin{array}{c}\mathrm{V} \\
\left(\mathrm{Mm}^{3}\right)\end{array}$ & $\frac{V_{i}}{V_{360}}$ & $\frac{V_{i+1}}{V_{i}}$ & $\begin{array}{c}\mathrm{V} \\
\left(\mathrm{Mm}^{3}\right)\end{array}$ & $\frac{V_{i}}{V_{360}}$ & $\frac{V_{i+1}}{V_{i}}$ & $\begin{array}{c}\mathrm{V} \\
\left(\mathrm{Mm}^{3}\right)\end{array}$ & $\frac{V_{i}}{V_{360}}$ & $\frac{V_{i+1}}{V_{i}}$ & $\begin{array}{c}\mathrm{V} \\
\left(\mathrm{Mm}^{3}\right)\end{array}$ & $\frac{V_{i}}{V_{360}}$ & $\frac{V_{i+1}}{V_{i}}$ & $\begin{array}{c}\mathrm{V} \\
\left(\mathrm{Mm}^{3}\right)\end{array}$ & $\frac{V_{i}}{V_{360}}$ & $\frac{V_{i+1}}{V_{i}}$ \\
\hline 30 & 0,094 & 0,20 & & 0,142 & 0,23 & & 0,271 & 0,27 & & 0,333 & 0,29 & & 0,491 & 0,32 & \\
\hline 60 & 0,189 & 0,40 & 2,00 & 0,265 & 0,43 & 1,87 & 0,462 & 0,47 & 1,71 & 0,554 & 0,48 & 1,67 & 0,784 & 0,51 & 1,60 \\
\hline 90 & 0,247 & 0,52 & 1,31 & 0,340 & 0,54 & 1,28 & 0,575 & 0,58 & 1,24 & 0,683 & 0,59 & 1,23 & 0,951 & 0,61 & 1,21 \\
\hline 120 & 0,291 & 0,61 & 1,18 & 0,396 & 0,63 & 1,16 & 0,657 & 0,67 & 1,14 & 0,777 & 0,67 & 1,14 & 1,071 & 0,69 & 1,13 \\
\hline 150 & 0,326 & 0,69 & 1,12 & 0,439 & 0,70 & 1,11 & 0,721 & 0,73 & 1,10 & 0,850 & 0,74 & 1,09 & 1,165 & 0,75 & 1,09 \\
\hline 180 & 0,356 & 0,75 & 1,09 & 0,476 & 0,76 & 1,08 & 0,775 & 0,78 & 1,07 & 0,910 & 0,79 & 1,07 & 1,242 & 0,80 & 1,07 \\
\hline 210 & 0,381 & 0,80 & 1,07 & 0,508 & 0,81 & 1,07 & 0,821 & 0,83 & 1,06 & 0,963 & 0,84 & 1,06 & 1,308 & 0,85 & 1,05 \\
\hline 240 & 0,404 & 0,85 & 1,06 & 0,536 & 0,86 & 1,05 & 0,861 & 0,87 & 1,05 & 1,009 & 0,88 & 1,05 & 1,367 & 0,88 & 1,04 \\
\hline 270 & 0,424 & 0,89 & 1,05 & 0,561 & 0,90 & 1,05 & 0,897 & 0,91 & 1,04 & 1,049 & 0,91 & 1,04 & 1,419 & 0,92 & 1,04 \\
\hline 300 & 0,442 & 0,93 & 1,04 & 0,584 & 0,94 & 1,04 & 0,929 & 0,94 & 1,04 & 1,086 & 0,94 & 1,03 & 1,465 & 0,95 & 1,03 \\
\hline 330 & 0,459 & 0,97 & 1,04 & 0,605 & 0,97 & 1,04 & 0,960 & 0,97 & 1,03 & 1,120 & 0,97 & 1,03 & 1,509 & 0,97 & 1,03 \\
\hline 360 & 0,475 & 1,00 & 1,03 & 0,624 & 1,00 & 1,03 & 0,987 & 1,00 & 1,03 & 1,151 & 1,00 & 1,03 & 1,547 & 1,00 & 1,03 \\
\hline
\end{tabular}

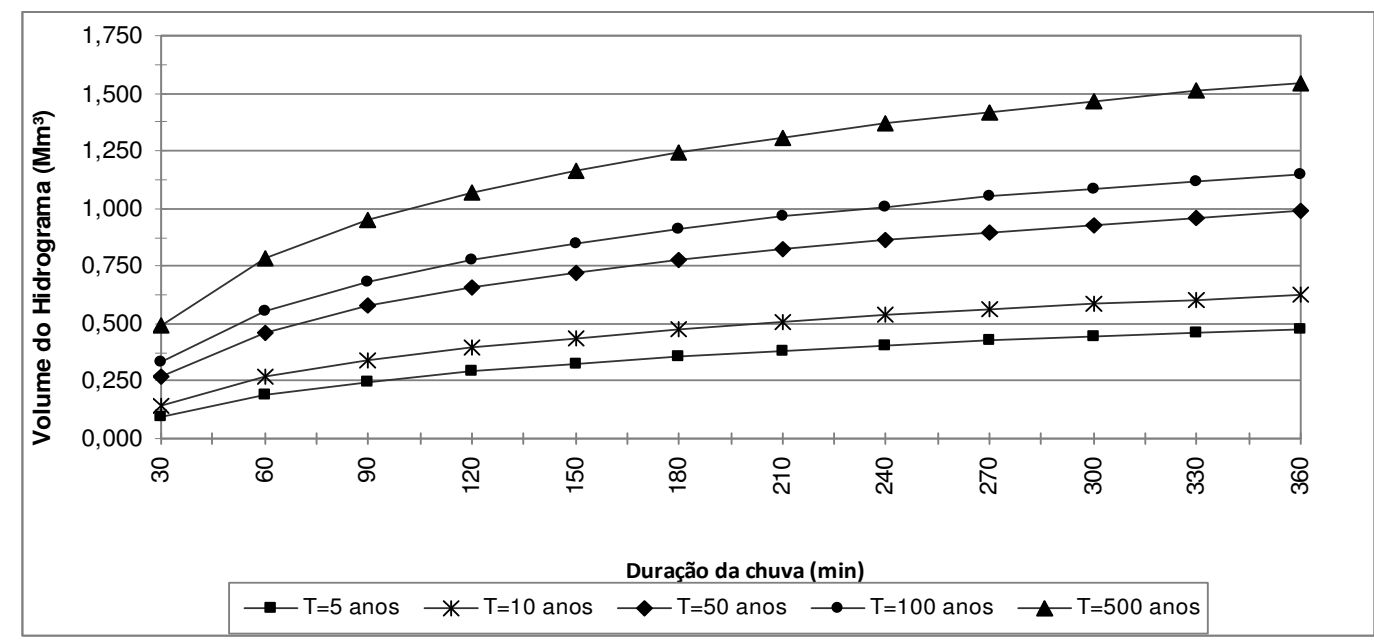

Figura 4.19 - Gráfico da variação do volume do hidrograma de cheia em função da duração da chuva de projeto - SCS

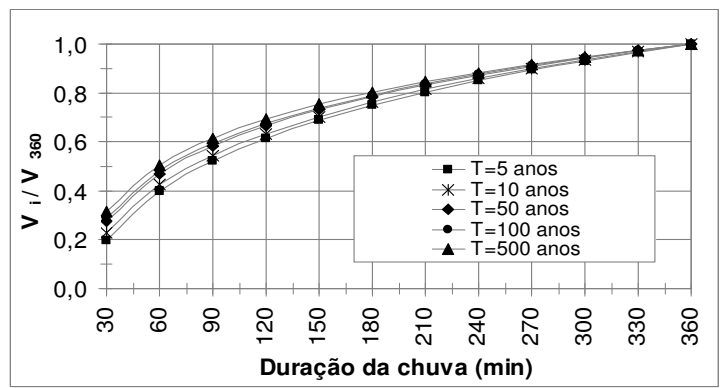

Figura 4.20 - Proporção do volume em relação ao valor do volume para a duração de chuva de projeto de 360 minutos - SCS

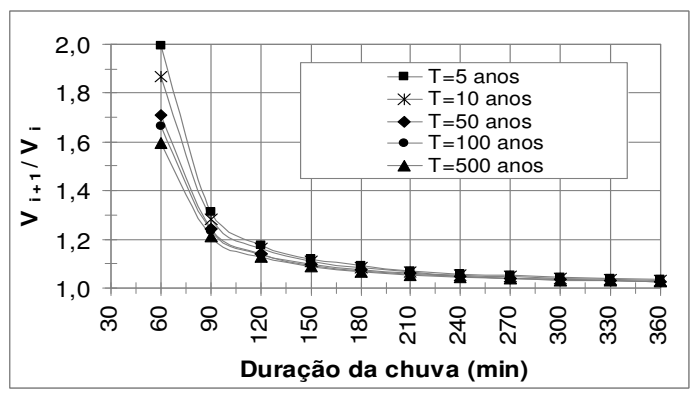

Figura 4.21 - Variação entre os volumes em função da duração da chuva de projeto - SCS 
- Das Figuras 4.17 e 4.19, pode-se verificar que o volume do hidrograma de cheia, tem variação semelhante à vazão de pico. A Figura 4.19 mostra que os gradientes de vazão de pico e volume são praticamente os mesmo para qualquer duração de projeto.

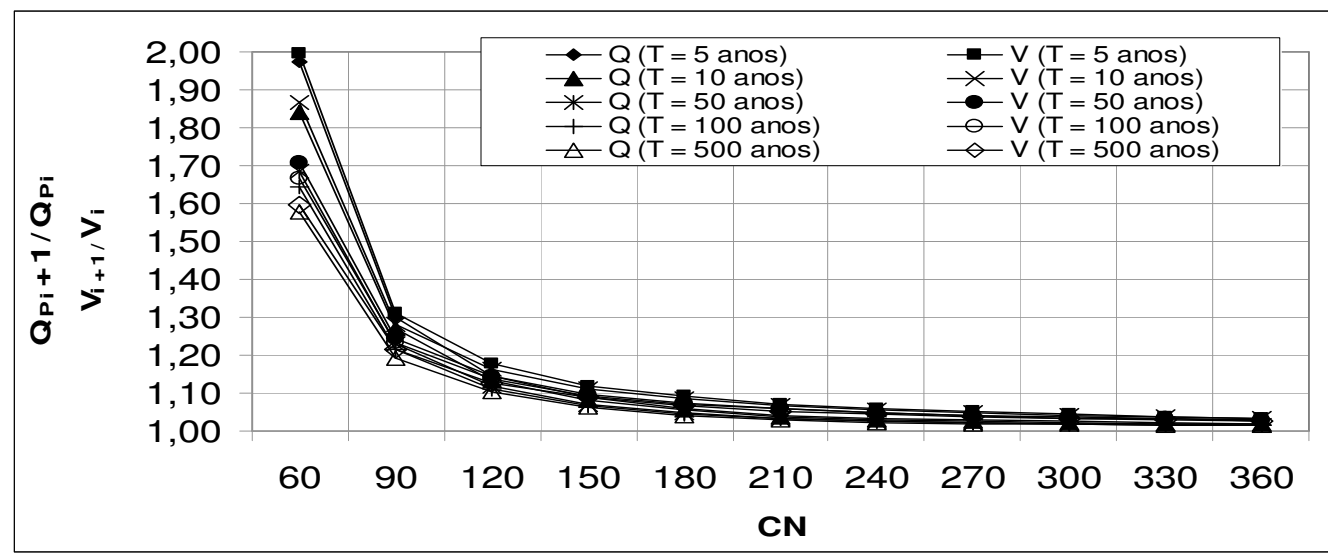

Figura 4.22 - Comparação dos gradientes de vazão de pico e volume - SCS

Em geral, como critério de projeto, a duração da chuva de projeto é adotada com valor igual ao tempo de concentração da bacia. Esta análise de sensibilidade possibilitou verificar que o valor da vazão de pico e o respectivo volume do hidrograma de cheia não variam significativamente se a duração da chuva de projeto adotada for maior que o tempo de concentração da bacia hidrográfica.

\subsection{MÉTODO DE SANTA BÁRBARA}

Os resultados das análises de sensibilidades em função da vazão de pico para o método de Santa Bárbara estão apresentados nas tabelas 4.11 a 4.14 e nas figuras 4.23 a 4.26. Como realizado para o método do hidrograma unitário do SCS, foram realizadas as seguintes análises:

- Análise de sensibilidade em relação ao valor de CN;

- Análise de sensibilidade em relação à área de drenagem;

- Análise de sensibilidade em relação ao tempo de concentração;

- Análise de sensibilidade em relação à duração da chuva de projeto;

- Análise de sensibilidade em relação ao coeficiente de armazenamento. 
Tabela 4.11 - Análise de sensibilidade da vazão de pico em função da variação do valor do CN para o método de Santa Bárbara

\begin{tabular}{|c|c|c|c|c|c|c|c|c|c|c|c|c|c|c|c|c|c|c|c|c|c|c|c|c|c|}
\hline \multirow[b]{2}{*}{$\mathrm{CN}$} & \multicolumn{5}{|c|}{$\mathrm{T}=5$ anos } & \multicolumn{5}{|c|}{$T=10$ anos } & \multicolumn{5}{|c|}{$\mathrm{T}=50$ anos } & \multicolumn{5}{|c|}{$\mathrm{T}=100$ anos } & \multicolumn{5}{|c|}{$\mathrm{T}=500$ anos } \\
\hline & $\begin{array}{c}Q_{P} \\
\left(m^{3} / s\right)\end{array}$ & $\begin{array}{l}\text { ta } \\
\text { (hh }\end{array}$ & $\begin{array}{r}\text { tb } \\
\mathrm{mm})\end{array}$ & $\frac{Q_{P i}}{Q_{P 95}}$ & $\frac{Q_{P i+1}}{Q_{P i}}$ & $\begin{array}{c}Q_{\mathbf{p}} \\
\left(m^{3} / \mathbf{s}\right)\end{array}$ & $\begin{array}{l}\text { ta } \\
\text { (hh }\end{array}$ & $\begin{array}{r}\text { tb } \\
\mathrm{mm})\end{array}$ & $\frac{Q_{P i}}{Q_{P 95}}$ & $\frac{Q_{P i+1}}{Q_{P i}}$ & $\begin{array}{c}Q_{P} \\
\left(m^{3} / s\right)\end{array}$ & $\begin{array}{l}\text { ta } \\
\text { (hh: }\end{array}$ & $\begin{array}{r}\text { tb } \\
\mathrm{mm})\end{array}$ & $\frac{Q_{P i}}{Q_{P 95}}$ & $\frac{Q_{P i+1}}{Q_{P i}}$ & $\begin{array}{c}Q_{p} \\
\left(m^{3} / s\right)\end{array}$ & $\begin{array}{l}\text { ta } \\
\text { (hh: }\end{array}$ & $\begin{array}{r}\text { tb } \\
\mathrm{mm} \text { ) }\end{array}$ & $\frac{Q_{P i}}{Q_{P 95}}$ & $\frac{Q_{P i+1}}{Q_{P i}}$ & $\begin{array}{c}Q_{p} \\
\left(m^{3} / s\right)\end{array}$ & $\begin{array}{l}\text { ta } \\
\text { (hh }\end{array}$ & $\begin{array}{r}\text { tb } \\
\mathrm{mm} \text { ) }\end{array}$ & $\frac{Q_{P i}}{Q_{P 95}}$ & $\frac{Q_{P i+1}}{Q_{P i}}$ \\
\hline 60 & 6,242 & $02: 30$ & $14: 15$ & 0,08 & & 10,370 & 02:30 & $14: 15$ & 0,11 & & 22,196 & 02:30 & $14: 15$ & 0,17 & & 28,216 & $02: 15$ & $14: 15$ & 0,20 & & 44,116 & $02: 15$ & $14: 15$ & 0,25 & \\
\hline 65 & 10,938 & $02: 30$ & 14:15 & 0,14 & 1,75 & 16,404 & $02: 30$ & $14: 15$ & 0,17 & 1,58 & 31,457 & 02:15 & $14: 15$ & 0,25 & 1,42 & 38,781 & 02:15 & $14: 15$ & 0,27 & 1,37 & 57,447 & 02:15 & $14: 15$ & 0,33 & 1,30 \\
\hline 70 & 16,968 & 02:15 & 14:15 & 0,21 & 1,55 & 24,024 & $02: 15$ & 14:15 & 0,25 & 1,46 & 42,264 & $02: 15$ & $14: 15$ & 0,33 & 1,34 & 50,896 & 02:00 & $14: 15$ & 0,36 & 1,31 & 72,788 & 02:00 & $14: 00$ & 0,42 & 1,27 \\
\hline 75 & 24,742 & 02:15 & $14: 15$ & 0,31 & 1,46 & 33,320 & 02:15 & 14:15 & 0,35 & 1,39 & 55,105 & 02:00 & 14:00 & 0,43 & 1,30 & 65,123 & 02:00 & $14: 00$ & 0,46 & 1,28 & 89,669 & 02:00 & $14: 00$ & 0,51 & 1,23 \\
\hline 80 & 34,487 & 02:00 & $14: 15$ & 0,43 & 1,39 & 44,874 & 02:00 & 14:00 & 0,47 & 1,35 & 69,912 & 02:00 & $14: 00$ & 0,55 & 1,27 & 81,108 & 02:00 & $14: 00$ & 0,57 & 1,25 & 108,071 & $02: 00$ & $14: 00$ & 0,62 & 1,21 \\
\hline 85 & 46,809 & 02:00 & $14: 00$ & 0,58 & 1,36 & 58,769 & 02:00 & $14: 00$ & 0,61 & 1,31 & 86,744 & 02:00 & $14: 00$ & 0,68 & 1,24 & 98,985 & 02:00 & $14: 00$ & 0,70 & 1,22 & 128,009 & $02: 00$ & $14: 00$ & 0,73 & 1,18 \\
\hline 90 & 61,967 & 02:00 & $14: 00$ & 0,77 & 1,32 & 75,332 & 02:00 & 14:00 & 0,79 & 1,28 & 105,759 & $02: 00$ & $14: 00$ & 0,82 & 1,22 & 118,830 & 02:00 & $14: 00$ & 0,84 & 1,20 & 149,915 & $01: 45$ & $14: 00$ & 0,86 & 1,17 \\
\hline 95 & 80,952 & $01: 45$ & 14:00 & 1,00 & 1,31 & 95,601 & 01:45 & $14: 00$ & 1,00 & 1,27 & 128,278 & 01:45 & $14: 00$ & 1,00 & 1,21 & 142,139 & $01: 45$ & $14: 00$ & 1,00 & 1,20 & 174,327 & $01: 45$ & $14: 00$ & 1,00 & 1,16 \\
\hline
\end{tabular}

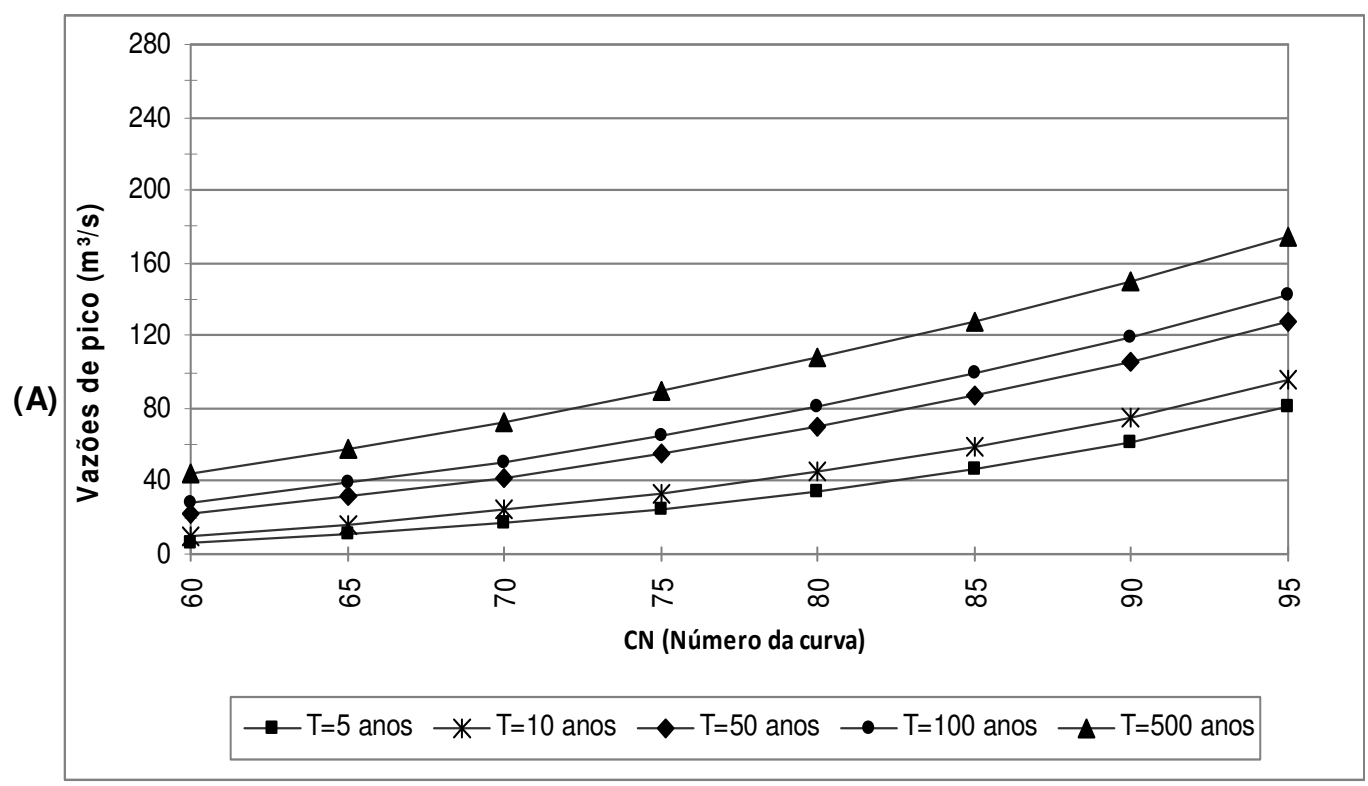

(B)

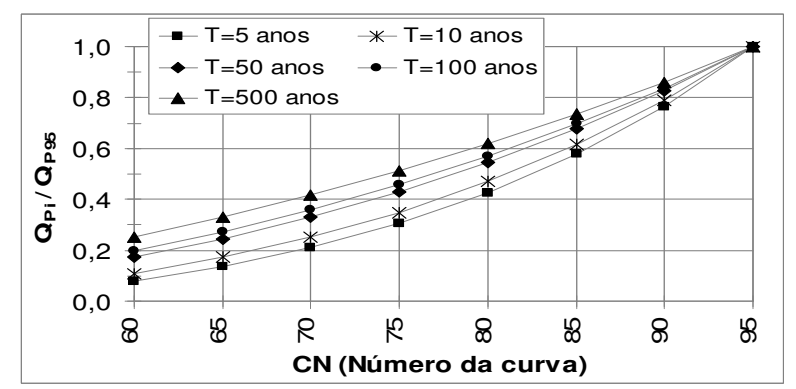

Figura 4.23 - (A) Variação da vazão de pico em função do CN, (B) proporção da vazão de pico em relação ao valor da vazão de pico para o CN de 95 , (C) variação entre as vazões de pico em função do CN para o método de Santa Bárbara 
Tabela 4.12 - Análise de sensibilidade da vazão de pico em função da variação da área de drenagem para o método de Santa Bárbara

\begin{tabular}{|c|c|c|c|c|c|c|c|c|c|c|c|c|c|c|c|c|c|c|c|c|c|c|c|c|c|c|c|}
\hline \multirow[b]{2}{*}{$\begin{array}{c}\text { A } \\
\left(\mathbf{k m}^{2}\right)\end{array}$} & \multirow[b]{2}{*}{$\begin{array}{l}\text { tc } \\
\text { (h) }\end{array}$} & \multirow{2}{*}{$k_{S B}$} & \multicolumn{5}{|c|}{$\mathrm{T}=5$ anos } & \multicolumn{5}{|c|}{$T=10$ anos } & \multicolumn{5}{|c|}{$T=50$ anos } & \multicolumn{5}{|c|}{$\mathrm{T}=100$ anos } & \multicolumn{5}{|c|}{$\mathrm{T}=500$ anos } \\
\hline & & & $\begin{array}{c}Q_{\mathbf{p}} \\
\left(m^{3} / \mathbf{s}\right)\end{array}$ & $\begin{array}{l}\text { ta } \\
\text { (hh: }\end{array}$ & $\begin{array}{r}\text { tb } \\
\mathrm{mm})\end{array}$ & $\frac{Q_{P_{i}}}{Q_{P 200}}$ & $\frac{Q_{P_{i+1}}}{Q_{P_{i}}}$ & $\begin{array}{c}Q_{\mathbf{p}} \\
\left(m^{3} / \mathbf{s}\right)\end{array}$ & & & $\frac{Q_{P_{i}}}{Q_{P 200}}$ & $\frac{Q_{P_{i+1}}}{Q_{P i}}$ & $\begin{array}{c}Q_{\mathbf{P}} \\
\left(m^{3} / \mathbf{s}\right)\end{array}$ & $\begin{array}{l}\text { ta } \\
\text { (hh: }\end{array}$ & $\begin{array}{r}\text { tb } \\
\mathrm{mm} \text { ) }\end{array}$ & $\frac{Q_{P_{i}}}{Q_{P 200}}$ & $\frac{Q_{P_{i+1}}}{Q_{P i}}$ & $\begin{array}{c}Q_{\mathbf{p}} \\
\left(m^{3} / \mathbf{s}\right)\end{array}$ & $\begin{array}{l}\text { ta } \\
\text { (hh: }\end{array}$ & $\begin{array}{r}\mathrm{tb} \\
\mathrm{mm})\end{array}$ & $\frac{Q_{P_{i}}}{Q_{P 200}}$ & $\frac{Q_{P_{i+1}}}{Q_{P i}}$ & $\begin{array}{c}Q_{\mathbf{p}} \\
\left(m^{3} / \mathbf{s}\right)\end{array}$ & $\begin{array}{l}\text { ta } \\
\text { (hh: }\end{array}$ & $\begin{array}{r}\text { tb } \\
\mathrm{mm})\end{array}$ & $\frac{Q_{P i}}{Q_{P 200}}$ & $\frac{Q_{P_{i+1}}}{Q_{P_{i}}}$ \\
\hline 10 & 1,58 & 0,07 & 15,757 & 02:00 & 09:45 & 0,16 & & 21,315 & 02:00 & 09:45 & 0,16 & & 35,170 & 02:00 & 09:45 & 0,16 & & 41,642 & 01:45 & 09:45 & 0,16 & & 57,754 & 01:45 & 09:45 & 0,16 & \\
\hline 20 & 2,24 & 0,05 & 24,424 & $02: 15$ & $13: 00$ & 0,25 & 1,55 & 33,078 & 02:00 & $13: 00$ & 0,25 & 1,55 & 54,778 & 02:00 & 13:00 & 0,25 & 1,56 & 64,718 & 02:00 & $12: 45$ & 0,25 & 1,55 & 89,061 & 02:00 & $12: 45$ & 0,25 & 1,54 \\
\hline 40 & 3,16 & 0,04 & 37,893 & 02:15 & $17: 15$ & 0,38 & 1,55 & 51,097 & $02: 15$ & $17: 15$ & 0,38 & 1,54 & 83,968 & 02:15 & $17: 15$ & 0,38 & 1,53 & 98,978 & 02:15 & $17: 15$ & 0,38 & 1,53 & 135,795 & 02:00 & $17: 15$ & 0,39 & 1,52 \\
\hline 60 & 3,87 & 0,03 & 48,857 & $02: 30$ & $20: 30$ & 0,49 & 1,29 & 65,608 & $02: 30$ & $20: 30$ & 0,49 & 1,28 & 107,374 & 02:15 & $20: 30$ & 0,49 & 1,28 & 126,626 & 02:15 & $20: 30$ & 0,49 & 1,28 & 173,719 & 02:15 & 20:30 & 0,49 & 1,28 \\
\hline 80 & 4,47 & 0,03 & 58,183 & $02: 30$ & $23: 15$ & 0,59 & 1,19 & 78,182 & $02: 30$ & $23: 15$ & 0,59 & 1,19 & 127,843 & 02:30 & 23:15 & 0,58 & 1,19 & 150,479 & 02:30 & $23: 15$ & 0,58 & 1,19 & 205,959 & $02: 15$ & 23:15 & 0,58 & 1,19 \\
\hline 100 & 5,00 & 0,02 & 66,424 & 02:30 & $25: 45$ & 0,67 & 1,14 & 89,296 & $02: 30$ & $25: 45$ & 0,67 & 1,14 & 146,114 & 02:30 & $25: 45$ & 0,67 & 1,14 & 172,022 & 02:30 & $25: 45$ & 0,67 & 1,14 & 235,316 & $02: 30$ & $25: 45$ & 0,67 & 1,14 \\
\hline 120 & 5,48 & 0,02 & 73,888 & 02:30 & 28:00 & 0,75 & 1,11 & 99,363 & $02: 30$ & $28: 00$ & 0,75 & 1,11 & 162,667 & 02:30 & 28:00 & 0,74 & 1,11 & 191,540 & 02:30 & $28: 00$ & 0,74 & 1,11 & 262,095 & 02:30 & 28:00 & 0,74 & 1,11 \\
\hline 140 & 5,92 & 0,02 & 80,783 & 02:30 & $30: 00$ & 0,82 & 1,09 & 108,662 & $02: 30$ & $30: 00$ & 0,81 & 1,09 & 177,958 & 02:30 & 30:00 & 0,81 & 1,09 & 209,572 & 02:30 & $30: 00$ & 0,81 & 1,09 & 286,836 & $02: 30$ & 30:00 & 0,81 & 1,09 \\
\hline 160 & 6,32 & 0,02 & 87,324 & 02:30 & $32: 00$ & 0,88 & 1,08 & 117,484 & $02: 30$ & $32: 00$ & 0,88 & 1,08 & 192,463 & 02:30 & 32:00 & 0,88 & 1,08 & 226,676 & 02:30 & 32:00 & 0,88 & 1,08 & 310,302 & 02:30 & $31: 45$ & 0,88 & 1,08 \\
\hline 180 & 6,71 & 0,02 & 93,307 & $02: 30$ & $33: 45$ & 0,94 & 1,07 & 125,555 & $02: 30$ & $33: 45$ & 0,94 & 1,07 & 205,738 & 02:30 & $33: 45$ & 0,94 & 1,07 & 242,330 & 02:30 & 33:45 & 0,94 & 1,07 & 331,784 & 02:30 & 33:45 & 0,94 & 1,07 \\
\hline 200 & 7,07 & 0,02 & 99,078 & 02:30 & $35: 30$ & 1,00 & 1,06 & 133,339 & $02: 30$ & $35: 30$ & 1,00 & 1,06 & 218,539 & 02:30 & $35: 15$ & 1,00 & 1,06 & 257,426 & 02:30 & $35: 15$ & 1,00 & 1,06 & 352,498 & 02:30 & $35: 15$ & 1,00 & 1,06 \\
\hline
\end{tabular}

(A)

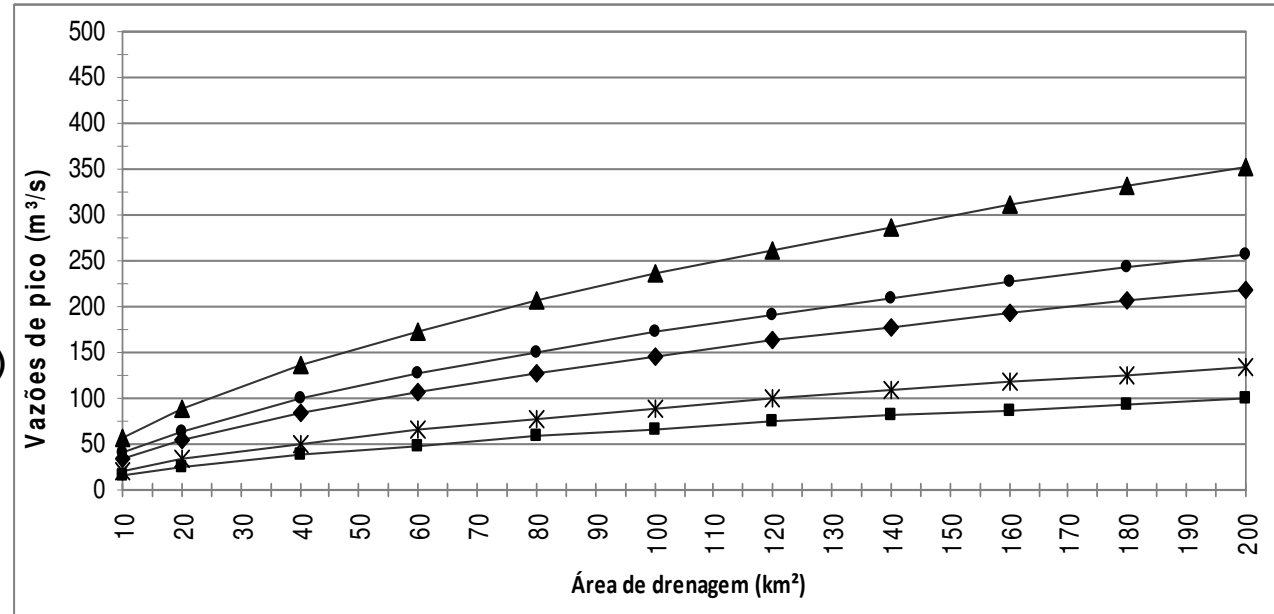

(B)

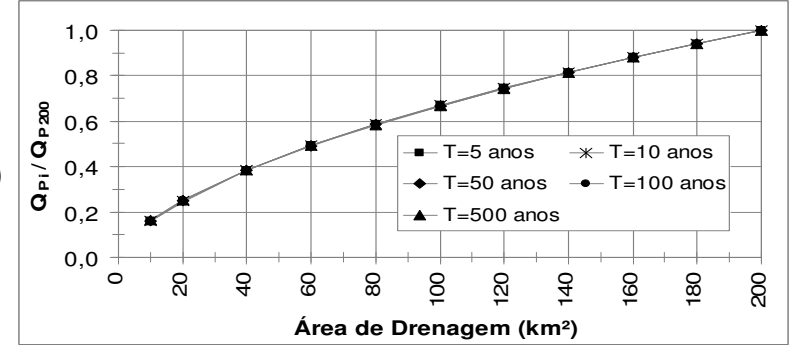

- $\mathrm{T}=5$ anos $\rightarrow \mathrm{T}=10$ anos $\longrightarrow \mathrm{T}=50$ anos $\rightarrow \mathrm{T}=100$ anos $\longrightarrow \mathrm{T}=500$ anos

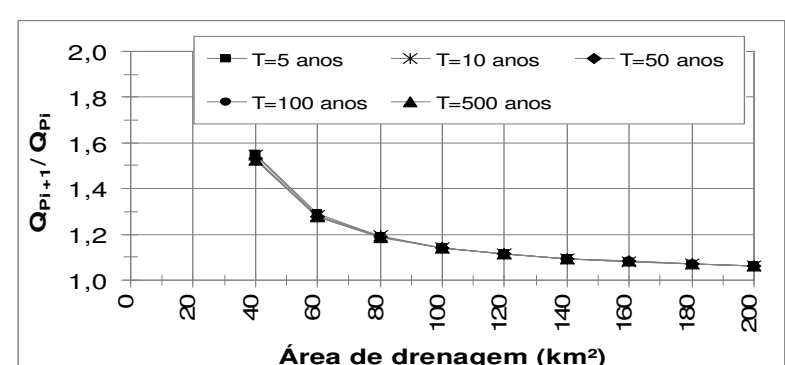

Figura 4.24 - (A) Variação da vazão de pico em função da área de drenagem, (B) proporção da vazão de pico em relação ao valor da vazão de pico para a área de drenagem de $200 \mathrm{~km}^{2}$, (C) variação entre as vazões de pico em função da área de drenagem Santa Bárbara 
Tabela 4.13 - Análise de sensibilidade da vazão de pico em função da variação do tempo de concentração para o método de Santa Bárbara

\begin{tabular}{|c|c|c|c|c|c|c|c|c|c|c|c|c|c|c|c|c|c|c|c|c|c|c|c|c|c|c|c|c|c|c|c|}
\hline \multirow[b]{2}{*}{$\begin{array}{l}\text { tc } \\
\text { (h) }\end{array}$} & \multirow{2}{*}{$\mathbf{k}_{\mathrm{SB}}$} & \multicolumn{6}{|c|}{$\mathrm{T}=5$ anos } & \multicolumn{5}{|c|}{$\mathrm{T}=10$ anos } & \multicolumn{7}{|c|}{$\mathrm{T}=50$ anos } & \multicolumn{5}{|c|}{$T=100$ anos } & \multicolumn{7}{|c|}{$\mathrm{T}=500$ anos } \\
\hline & & $\underset{\left(\mathrm{m}^{3 /} \mathbf{s}\right)}{\mathrm{Q}_{\mathbf{p}}}$ & $\begin{array}{l}\text { ta } \\
\text { (hh }\end{array}$ & $\begin{array}{r}\text { tb } \\
\mathrm{mm} \text { ) }\end{array}$ & $\frac{Q_{p i}}{Q_{p 0,5}}$ & $\frac{Q_{p i+1}}{Q_{p i}}$ & $\frac{Q_{p i+1}}{Q_{p i}}$ & $\underset{\left(m^{3 / s}\right)}{Q_{p}}$ & $\begin{array}{l}\text { ta } \\
\text { (hh }\end{array}$ & $\begin{array}{r}\text { tb } \\
\mathrm{mm})\end{array}$ & $\frac{Q_{p i}}{Q_{p 0,5}}$ & $\frac{Q_{p i+1}}{Q_{p i}}$ & $\frac{Q_{p i+1}}{Q_{p i}}$ & $\underset{\left(m^{3 / s} \mathbf{s}\right)}{Q_{p}}$ & $\begin{array}{l}\text { ta } \\
\text { (hh }\end{array}$ & $\begin{array}{r}\text { tb } \\
\mathrm{mm})\end{array}$ & $\frac{Q_{p i}}{Q_{p 0.5}}$ & $\frac{Q_{p i+1}}{Q_{p i}}$ & $\frac{Q_{p i+1}}{Q_{p i}}$ & $\begin{array}{c}\mathrm{Q}_{\mathrm{p}} \\
\left(\mathrm{m}^{3 /} \mathbf{s}\right)\end{array}$ & $\begin{array}{l}\text { ta } \\
\text { (hh:r }\end{array}$ & $\begin{array}{r}\text { tb } \\
\mathrm{mm})\end{array}$ & $\frac{Q_{p i}}{Q_{p 0,5}}$ & $\frac{Q_{p i+1}}{Q_{p i}}$ & $\frac{Q_{p i+1}}{Q_{p i}}$ & $\underset{\left(m^{3 / s}\right)}{Q_{p}}$ & $\begin{array}{l}\text { ta } \\
\text { (hh: }\end{array}$ & $\begin{array}{r}\text { tb } \\
\text { :mm) }\end{array}$ & $\frac{Q_{p i}}{Q_{p 0.5}}$ & $\frac{Q_{p i+1}}{Q_{p i}}$ & $\frac{Q_{p i+1}}{Q_{p i}}$ \\
\hline 0,50 & 0,20 & 70,383 & 01:45 & $04: 45$ & 1,00 & & & 95,290 & 01:45 & 04:30 & 1,00 & & & 157,190 & 01:45 & 04:30 & 1,00 & & & 185,387 & 01:45 & 04:30 & 1,00 & & & 256,482 & 01:30 & 04:30 & 1,00 & & \\
\hline 1,00 & 0,11 & 46,931 & $01: 45$ & 07:00 & 0,67 & 0,67 & 0,33 & 64,124 & 01:45 & 07:00 & 0,67 & 0,67 & 0,33 & 107,280 & 01:45 & 07:00 & 0,68 & 0,68 & 0,32 & 127,101 & 01:45 & 07:00 & 0,69 & 0,69 & 0,31 & 175,684 & 01:45 & 07:00 & 0,68 & 0,68 & 0,32 \\
\hline 1,50 & 0,08 & 35,751 & 02:00 & $09: 30$ & 0,51 & 0,76 & 0,24 & 48,339 & 02:00 & 09:30 & 0,51 & 0,75 & 0,25 & 80,007 & 01:45 & $09: 15$ & 0,51 & 0,75 & 0,25 & 94,937 & 01:45 & 09:15 & 0,51 & 0,75 & 0,25 & 131,627 & 01:45 & 09:15 & 0,51 & 0,75 & 0,25 \\
\hline 2,00 & 0,06 & 29,122 & 02:00 & $11: 45$ & 0,41 & 0,81 & 0,19 & 39,461 & 02:00 & 11:45 & 0,41 & 0,82 & 0,18 & 65,281 & 02:00 & $11: 45$ & 0,42 & 0,82 & 0,18 & 77,101 & 02:00 & $11: 45$ & 0,42 & 0,81 & 0,19 & 106,031 & 02:00 & $11: 45$ & 0,41 & 0,81 & 0,19 \\
\hline 2,50 & 0,05 & 24,742 & 02:15 & $14: 15$ & 0,35 & 0,85 & 0,15 & 33,320 & 02:15 & $14: 15$ & 0,35 & 0,84 & 0,16 & 55,105 & 02:00 & $14: 00$ & 0,35 & 0,84 & 0,16 & 65,123 & 02:00 & 14:00 & 0,35 & 0,84 & 0,16 & 89,669 & 02:00 & 4:00 & 0,35 & 0,85 & 0,15 \\
\hline 3,00 & 0,04 & 21,597 & 02:15 & $16: 30$ & 0,31 & 0,87 & 0,13 & 29,114 & 02:15 & $16: 30$ & 0,31 & 0,87 & 0,13 & 47,824 & 02:15 & $16: 30$ & 0,30 & 0,87 & 0,13 & 56,366 & 02:15 & 16:30 & 0,30 & 0,87 & 0,13 & 77,571 & 02:00 & 6:30 & 0,30 & 0,87 & 0,13 \\
\hline 3,50 & 0 & , 243 & 02:30 & $18: 45$ & 0,27 & 0,89 & 0,11 & 25,827 & 02:30 & $18: 45$ & 0,27 & 0,89 & 0,11 & 42,463 & 02:15 & $18: 45$ & 0,27 & 0,89 & 0,11 & 50,066 & 02:15 & 18:45 & 0,27 & 0,89 & 0,11 & 68,657 & 02:15 & 18:45 & 0,27 & 0,89 & 0,11 \\
\hline 4,00 & 0,03 & 17,384 & 02:30 & 21:15 & 0,25 & 0,90 & 0,10 & 23,347 & 02:30 & 21:15 & 0,25 & 0,90 & 0,10 & 38,156 & 02:15 & 21:15 & 0,24 & 0,90 & 0,10 & 45,000 & 02:15 & 21:15 & 0,24 & 0,90 & 0,10 & 61,744 & 02:15 & 21:00 & 0,24 & 0,90 & 0,10 \\
\hline 4,50 & 0,03 & 15,843 & 02:30 & 23:30 & 0,23 & 0,91 & 0,09 & 21,289 & 02:30 & 23:30 & 0,22 & 0,91 & 0,09 & 34,813 & 02:30 & $23: 30$ & 0,22 & 0,91 & 0,09 & 40,977 & 02:30 & 23:30 & 0,22 & 0,91 & 0,09 & 56,070 & 02:15 & 23:30 & 0,22 & 0,91 & 0,09 \\
\hline 5,00 & 0,02 & 14,547 & 02:30 & 25:45 & 0,21 & 0,92 & 0,08 & 19,556 & 02:30 & 25:45 & 0,21 & 0,92 & 0,08 & 31,999 & 02:30 & $25: 45$ & 0,20 & 0,92 & 0,08 & 37,673 & 02:30 & 25:45 & 0,20 & 0,92 & 0,08 & 51,534 & 02:30 & 25:45 & 0,20 & 0,92 & 0,08 \\
\hline 5,50 & 0 , & 444 & 02:30 & 28:00 & 0,19 &, 92 & 0,08 & 18,079 & 02:30 & 28:00 & 0,19 & 0,92 & 0,08 & 29,597 & 02:30 & 28:00 & 0,19 & 0,92 & 0,08 & 34,851 & 02:30 & 28:00 & 0,19 & 0,93 & 0,07 & 47,689 & 02:30 & 8:00 & 0,19 & 0,93 & 0,07 \\
\hline 6,00 & 0,02 & 12,494 & $02: 30$ & $30: 30$ & 0,18 & 0,93 & 0,07 & 16,806 & 02:30 & $30: 30$ & 0,18 & 0,93 & 0,07 & 27,526 & 02:30 & $30: 30$ & 0,18 & 0,93 & 0,07 & 32,416 & 02:30 & 30:30 & 0,17 & 0,93 & 0,07 & 44,369 & 02:30 & $30: 30$ & 0,17 & 0,93 & 0,07 \\
\hline
\end{tabular}

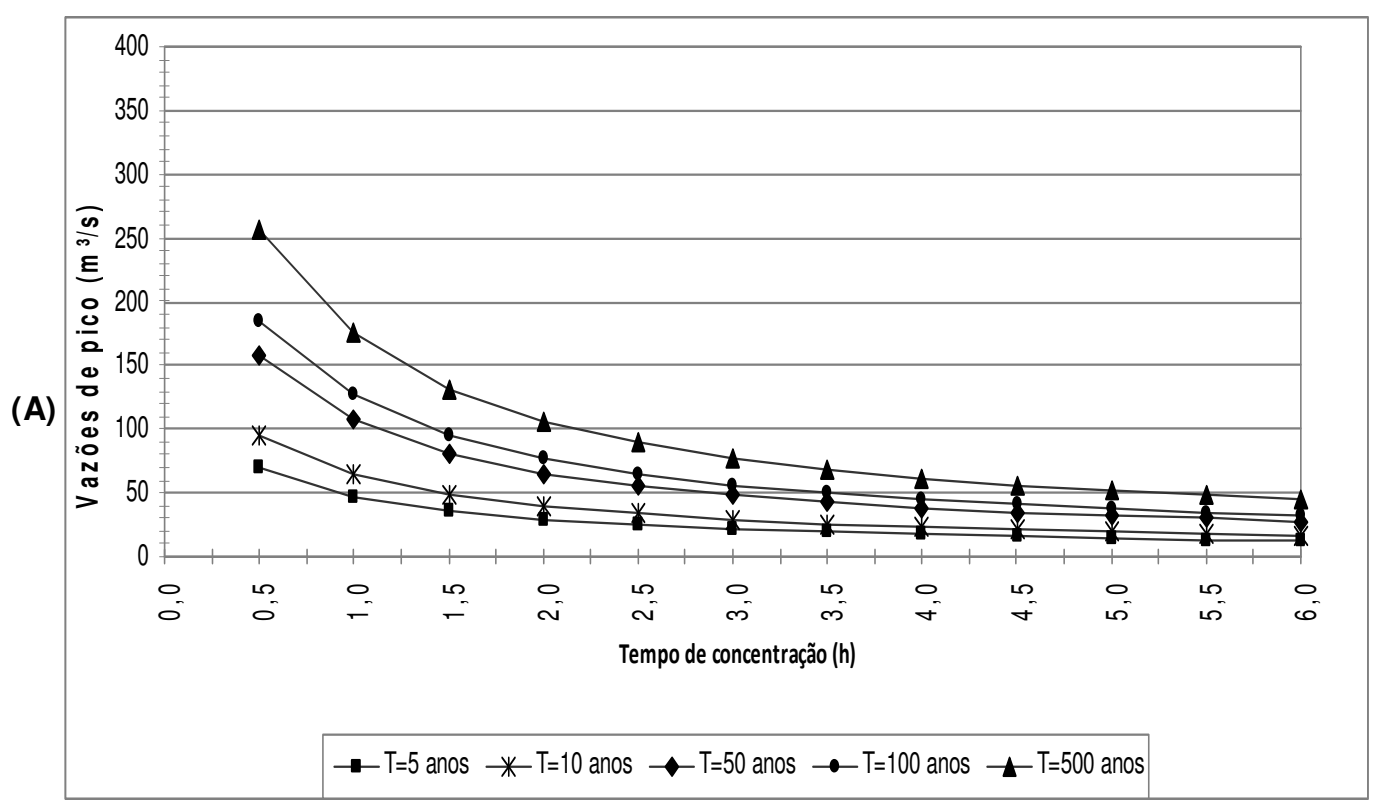

(B)

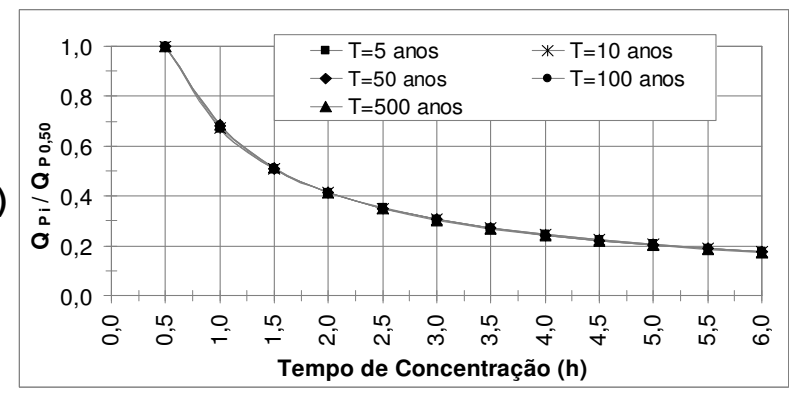

(C)

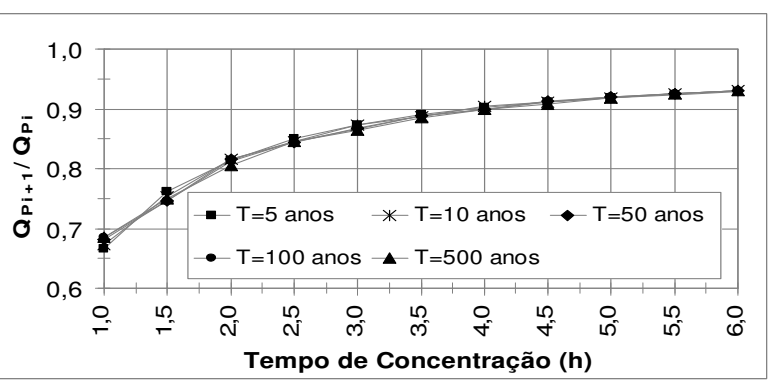

Figura 4.25 - (A) Variação da vazão de pico em função do tempo de concentração, (B) proporção da vazão de pico em relação ao valor da vazão de pico para o tempo de concentração de $0,50 \mathrm{~h},(\mathrm{C})$ variação entre as vazões de pico em função do tempo de concentração Santa Bárbara 
Tabela 4.14 - Análise de sensibilidade da vazão de pico em função da variação da duração da chuva de projeto para o método de Santa Bárbara

\begin{tabular}{|c|c|c|c|c|c|c|c|c|c|c|c|c|c|c|c|c|c|c|c|c|c|c|c|c|c|c|}
\hline \multirow[b]{2}{*}{$\begin{array}{c}d \\
(\min ) \\
\end{array}$} & \multicolumn{5}{|c|}{$\mathrm{T}=5$ anos } & \multicolumn{5}{|c|}{$\mathrm{T}=10$ anos } & \multicolumn{5}{|c|}{$\mathrm{T}=50$ anos } & \multicolumn{5}{|c|}{$\mathrm{T}=100$ anos } & \multicolumn{5}{|c|}{$\mathrm{T}=500$ anos } & \multirow[b]{2}{*}{$\frac{d_{i+1}}{d_{i}}$} \\
\hline & $\begin{array}{c}Q_{p} \\
\left(m^{3} / s\right)\end{array}$ & $\begin{array}{l}\text { ta } \\
\text { (hh: }\end{array}$ & $\begin{array}{r}\text { tb } \\
\mathrm{mm})\end{array}$ & $\frac{Q_{P i}}{Q_{P 360}}$ & $\frac{Q_{P_{i+1}}}{Q_{P i}}$ & $\begin{array}{c}Q_{p} \\
\left(m^{3 /} s\right)\end{array}$ & $\begin{array}{l}\text { ta } \\
\text { (h) }\end{array}$ & $\begin{array}{c}\text { tb } \\
\mathrm{nm})\end{array}$ & $\frac{Q_{P i}}{Q_{P 360}}$ & $\frac{Q_{P i+1}}{Q_{P i}}$ & $\begin{array}{c}Q_{p} \\
\left(m^{3} / s\right)\end{array}$ & $\begin{array}{l}\text { ta } \\
\text { (hh }\end{array}$ & $\begin{array}{r}\text { tb } \\
\mathrm{mm})\end{array}$ & $\frac{Q_{P i}}{Q_{P 360}}$ & $\frac{Q_{P i+1}}{Q_{P i}}$ & $\begin{array}{c}Q_{\mathbf{p}} \\
\left(\mathbf{m}^{3} / \mathbf{s}\right)\end{array}$ & $\begin{array}{l}\text { ta } \\
\text { (hh: }\end{array}$ & $\begin{array}{r}\text { tb } \\
\mathrm{mm})\end{array}$ & $\frac{Q_{P i}}{Q_{P 360}}$ & $\frac{Q_{P_{i+1}}}{Q_{P i}}$ & $\begin{array}{c}Q_{p} \\
\left(m^{3} / s\right)\end{array}$ & $\begin{array}{l}\text { ta } \\
\text { (hh }\end{array}$ & $\begin{array}{r}\text { tb } \\
\mathrm{mm} \text { ) }\end{array}$ & $\frac{Q_{P i}}{Q_{P 360}}$ & $\frac{Q_{P i+1}}{Q_{P i}}$ & \\
\hline 30 & 9,191 & $00: 45$ & $12: 30$ & 0,30 & & 13,756 & $00: 45$ & $12: 30$ & 0,34 & & 25,976 & $00: 45$ & $12: 30$ & 0,39 & & 31,874 & 00:45 & $12: 30$ & 0,41 & & 46,828 & $00: 45$ & $12: 30$ & 0,45 & & \\
\hline 60 & 16,932 & $01: 15$ & $13: 00$ & 0,55 & 1,84 & 23,671 & 01:15 & $13: 00$ & 0,58 & 1,72 & 40,868 & 01:15 & $13: 00$ & 0,62 & 1,57 & 48,890 & 01:15 & $13: 00$ & 0,63 & 1,53 & 68,834 & 01:00 & $13: 00$ & 0,66 & 1,47 & 2,00 \\
\hline 90 & 21,058 & 01:30 & 13:15 & 0,69 & 1,24 & 28,910 & $01: 30$ & $13: 15$ & 0,71 & 1,22 & 48,715 & $01: 30$ & $13: 15$ & 0,74 & 1,19 & 57,864 & 01:30 & $13: 15$ & 0,75 & 1,18 & 80,411 & $01: 30$ & 13:15 & 0,77 & 1,17 & 1,50 \\
\hline 120 & 23,333 & 02:00 & $13: 45$ & 0,76 & 1,11 & 31,554 & 02:00 & $13: 45$ & 0,77 & 1,09 & 52,336 & 01:45 & $13: 45$ & 0,79 & 1,07 & 61,990 & 01:45 & $13: 45$ & 0,80 & 1,07 & 85,684 & $01: 45$ & 13:45 & 0,82 & 1,07 & 1,33 \\
\hline 150 & 24,742 & 02:15 & $14: 15$ & 0,81 & 1,06 & 33,320 & 02:15 & $14: 15$ & 0,82 & 1,06 & 55,105 & 02:00 & $14: 00$ & 0,84 & 1,05 & 65,123 & 02:00 & $14: 00$ & 0,84 & 1,05 & 89,669 & 02:00 & $14: 00$ & 0,85 & 1,05 & 1,25 \\
\hline 180 & 25,899 & 02:30 & $14: 30$ & 0,85 & 1,05 & 34,783 & 02:15 & $14: 30$ & 0,85 & 1,04 & 57,347 & 02:15 & $14: 30$ & 0,87 & 1,04 & 67,656 & 02:15 & $14: 30$ & 0,88 & 1,04 & 92,886 & 02:15 & $14: 30$ & 0,88 & 1,04 & 1,20 \\
\hline 210 & 26,877 & 02:45 & $15: 00$ & 0,88 & 1,04 & 36,093 & $02: 30$ & $15: 00$ & 0,89 & 1,04 & 59,232 & $02: 30$ & $14: 45$ & 0,90 & 1,03 & 69,790 & 02:30 & $14: 45$ & 0,90 & 1,03 & 95,581 & $02: 30$ & $14: 45$ & 0,91 & 1,03 & 1,17 \\
\hline 240 & 27,730 & 03:00 & $15: 15$ & 0,91 & 1,03 & 37,233 & 02:45 & $15: 15$ & 0,91 & 1,03 & 60,869 & 02:45 & 15:15 & 0,92 & 1,03 & 71,628 & 02:45 & $15: 15$ & 0,93 & 1,03 & 97,915 & 02:45 & 15:00 & 0,93 & 1,02 & 1,14 \\
\hline 270 & 28,502 & 03:00 & $15: 45$ & 0,93 & 1,03 & 38,243 & 03:00 & $15: 30$ & 0,94 & 1,03 & 62,308 & 03:00 & $15: 30$ & 0,95 & 1,02 & 73,261 & 03:00 & $15: 30$ & 0,95 & 1,02 & 99,966 & 03:00 & $15: 30$ & 0,95 & 1,02 & 1,13 \\
\hline 300 & 29,228 & 03:15 & $16: 00$ & 0,96 & 1,03 & 39,142 & 03:15 & $16: 00$ & 0,96 & 1,02 & 63,597 & $03: 15$ & 15:45 & 0,97 & 1,02 & 74,724 & 03:15 & $15: 45$ & 0,97 & 1,02 & 101,792 & $03: 15$ & 15:45 & 0,97 & 1,02 & 1,11 \\
\hline 330 & 29,895 & 03:30 & $16: 15$ & 0,98 & 1,02 & 39,965 & 03:30 & $16: 15$ & 0,98 & 1,02 & 64,773 & 03:30 & $16: 15$ & 0,98 & 1,02 & 76,041 & 03:30 & $16: 15$ & 0,98 & 1,02 & 103,448 & 03:30 & $16: 00$ & 0,99 & 1,02 & 1,10 \\
\hline 360 & 30,511 & $03: 45$ & $16: 45$ & 1,00 & 1,02 & 40,722 & 03:45 & $16: 45$ & 1,00 & 1,02 & 65,848 & 03:45 & $16: 30$ & 1,00 & 1,02 & 77,252 & 03:45 & $16: 30$ & 1,00 & 1,02 & 104,964 & 03:45 & $16: 30$ & 1,00 & 1,01 & 1,09 \\
\hline
\end{tabular}

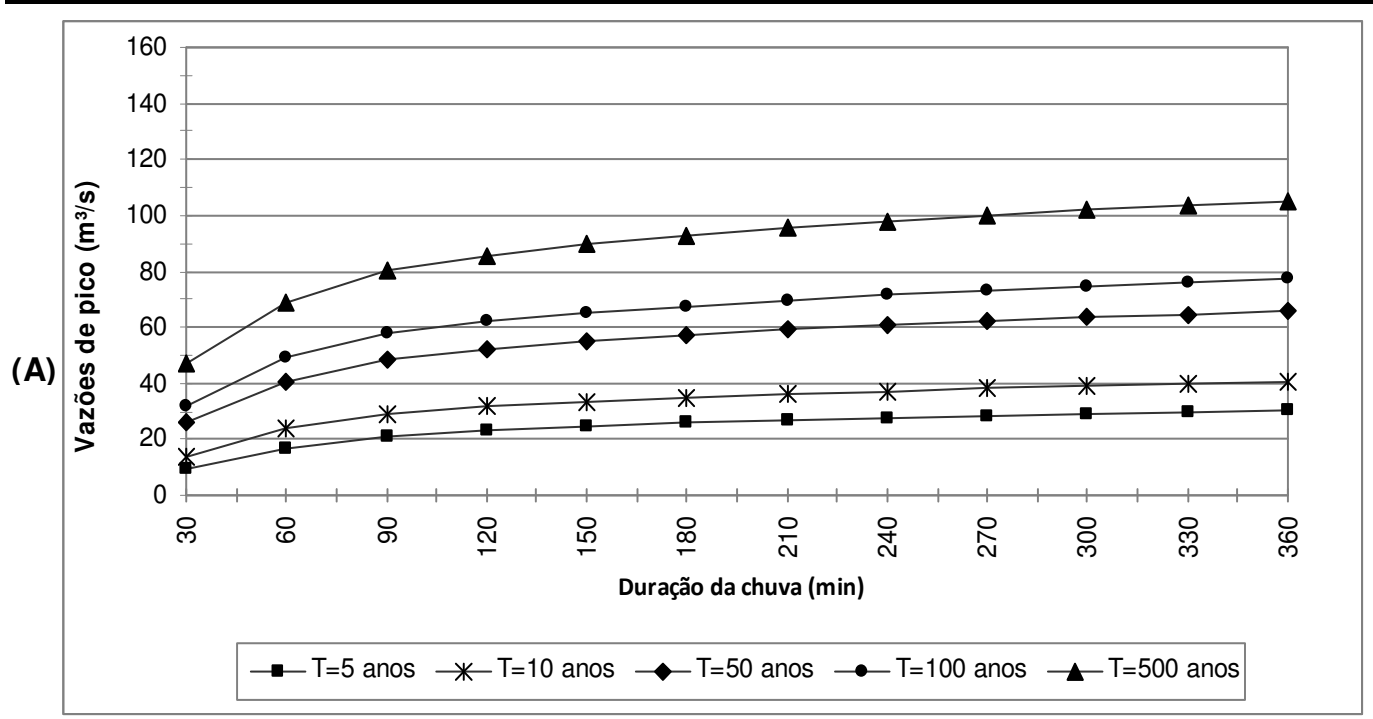

(B)
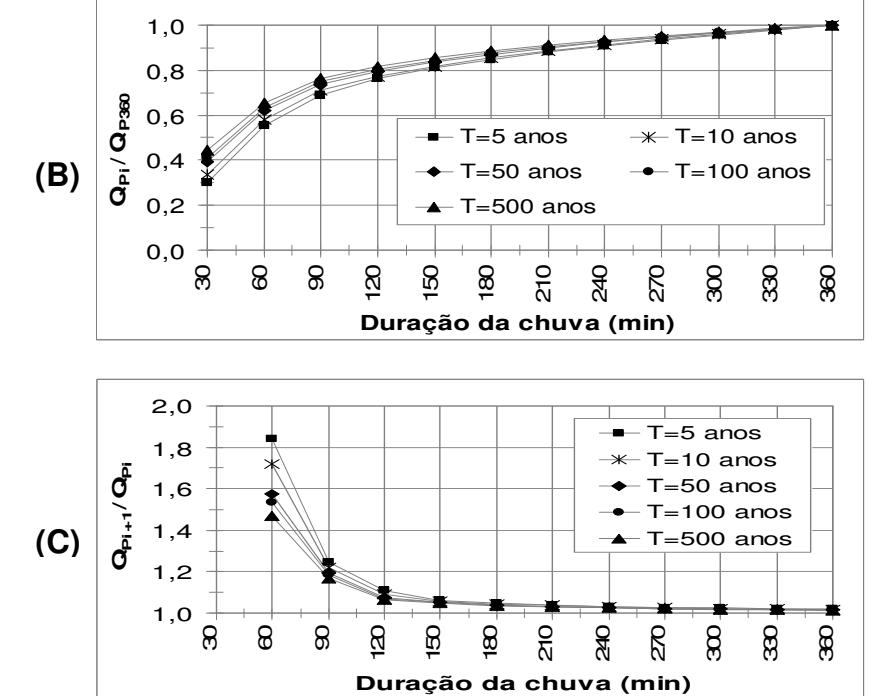

Figura 4.26 - (A) Variação da vazão de pico em função da duração da chuva de projeto, (B) proporção da vazão de pico em relação ao valor da vazão de pico para a duração da chuva de projeto de 360 minutos, (C) variação entre as vazões de pico em função da duração da chuva de projeto para o método de Santa Bárbara 
Conforme já mencionado, o método de Santa Bárbara leva em conta o efeito de armazenamento da bacia hidrográfica representado pela constante de armazenamento $\mathrm{k}_{\mathrm{SB}}$, determinada em função do tempo de concentração da bacia. $\mathrm{A}$ Tabela 4.12 mostra a variação da constante $\mathrm{k}_{S B}$ em função do tempo de concentração. A Figura 4.27 mostra a variação da constante $k_{S B}$ em função da vazão de pico e a Figura 4.28 demonstra essa mesma variação, mas em função do tempo de concentração da bacia hidrográfica.

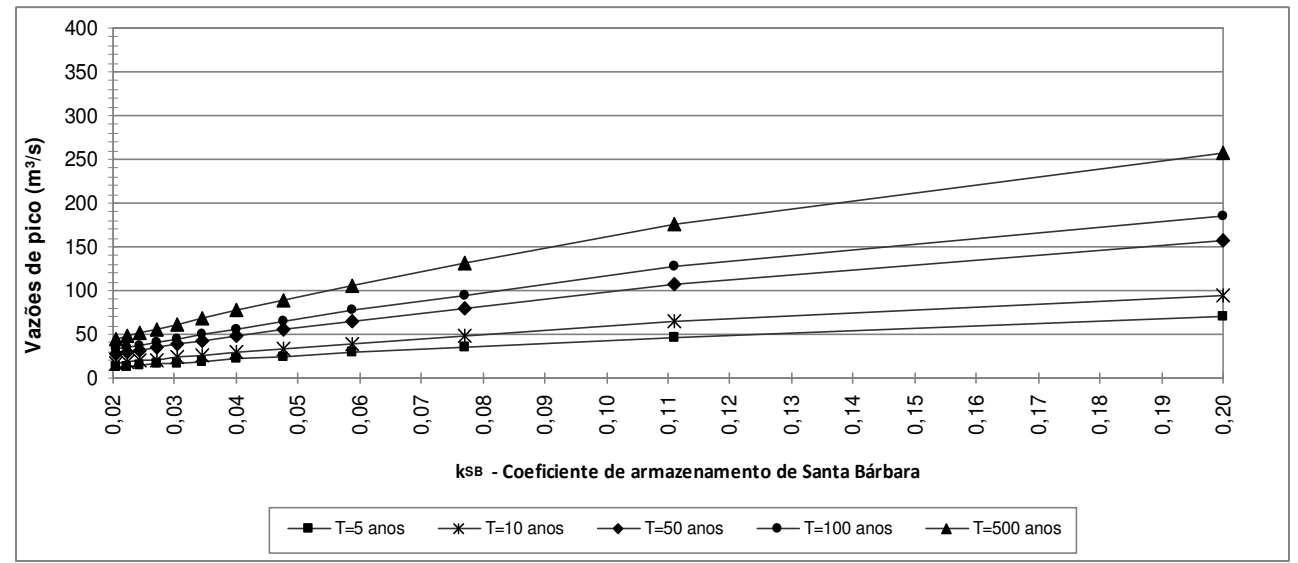

Figura 4.27 - Variação da constante $\mathrm{k}_{\mathrm{SB}}$ em função da vazão de pico - Método de Santa Bárbara

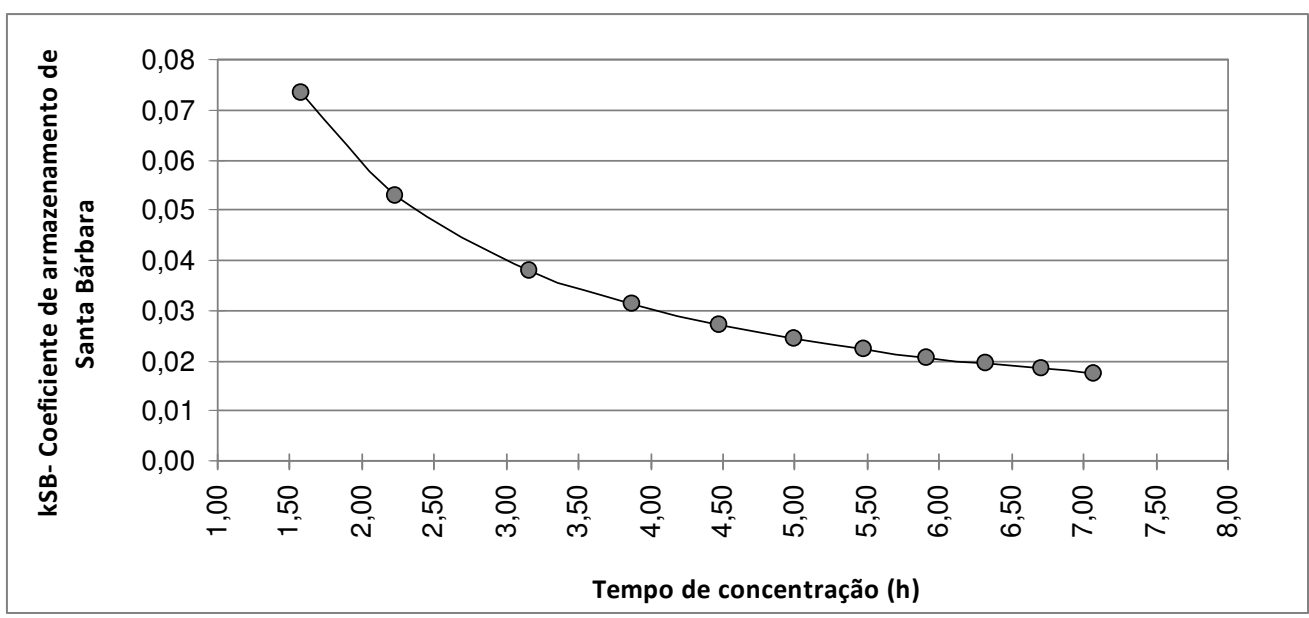

Figura 4.28 - Variação da constante $\mathrm{k}_{\mathrm{SB}}$ em função do tempo de concentração - Método de Santa Bárbara

Da Tabela 4.13, também é possível verificar o comportamento do coeficiente de armazenamento de Santa Bárbara com a área de drenagem da bacia hidrográfica. A Figura 4.29 mostra a variação da constante $\mathrm{k}_{\mathrm{SB}}$ em função da área de drenagem da bacia hidrográfica. 


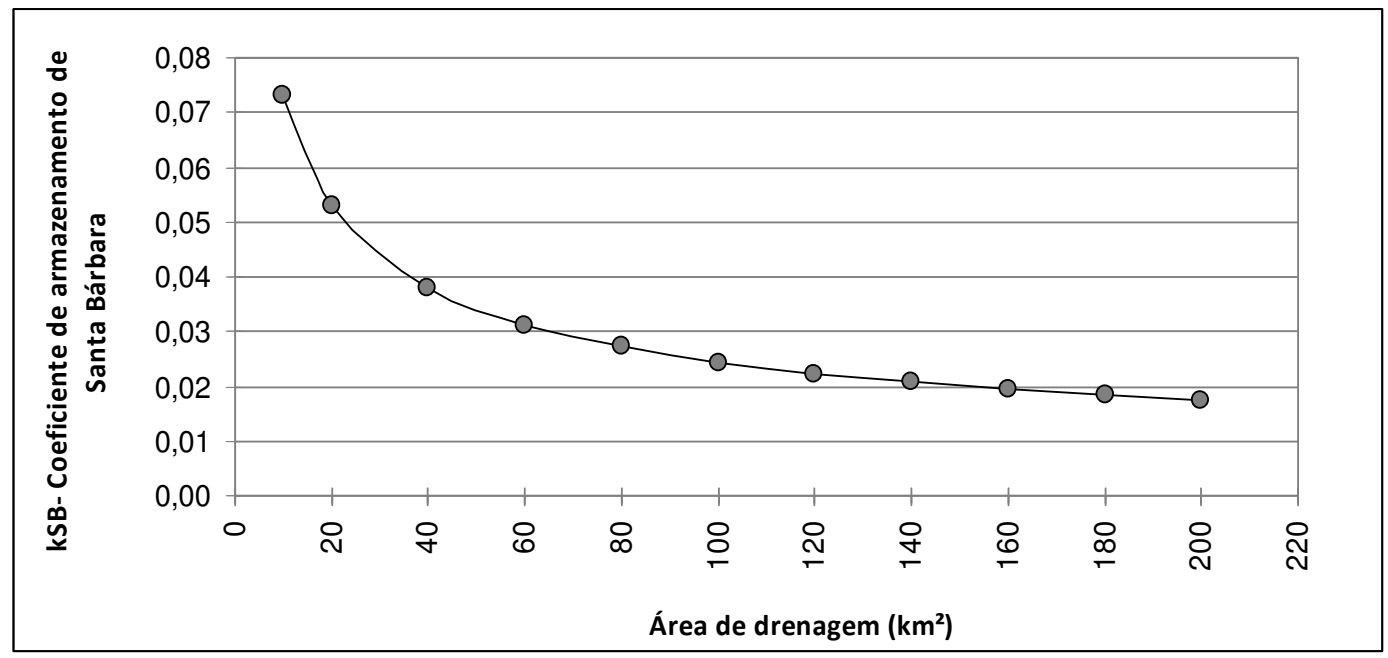

Figura 4.29 - Variação da constante $\mathrm{k}_{\mathrm{SB}}$ em função da área de drenagem - Método de Santa Bárbara

\subsection{MÉTODO DE CLARK}

Os resultados das análises de sensibilidades em função da vazão de pico para o método de Clark estão apresentados nas tabelas 4.15 a 4.19 e nas figuras 4.30 a 4.34 .

Como realizado para o método do hidrograma unitário do SCS e Santa Bárbara foram realizadas as seguintes análises de sensibilidade para o método de Clark:

- Análise de sensibilidade em relação ao valor de CN;

- Análise de sensibilidade em relação à área de drenagem;

- Análise de sensibilidade em relação ao tempo de concentração;

- Análise de sensibilidade em relação à duração da chuva de projeto;

- Análise de sensibilidade em relação ao fator de forma;

- Análise de sensibilidade em relação ao coeficiente de armazenamento. 
Tabela 4.15 - Análise de sensibilidade da vazão de pico em função da variação do valor do CN para o método de Clark

\begin{tabular}{|c|c|c|c|c|c|c|c|c|c|c|c|c|c|c|c|c|c|c|c|c|c|c|c|c|c|}
\hline \multirow[b]{2}{*}{$\mathrm{CN}$} & \multicolumn{5}{|c|}{$\mathrm{T}=5$ anos } & \multicolumn{5}{|c|}{$\mathrm{T}=10$ anos } & \multicolumn{5}{|c|}{$\mathrm{T}=50$ anos } & \multicolumn{5}{|c|}{$\mathrm{T}=100$ anos } & \multicolumn{5}{|c|}{$\mathrm{T}=500$ anos } \\
\hline & $\begin{array}{c}Q_{p} \\
\left(m^{3} / s\right)\end{array}$ & $\begin{array}{l}\text { ta } \\
\text { (hh: }\end{array}$ & $\begin{array}{r}\text { tb } \\
\mathrm{mm})\end{array}$ & $\frac{Q_{P i}}{Q_{P 95}}$ & $\frac{Q_{P i+1}}{Q_{P i}}$ & $\begin{array}{c}Q_{p} \\
\left(m^{3} / s\right)\end{array}$ & $\begin{array}{l}\text { ta } \\
\text { (hh }\end{array}$ & $\begin{array}{r}\text { tb } \\
\mathrm{mm})\end{array}$ & $\frac{Q_{P i}}{Q_{P 95}}$ & $\frac{Q_{P i+1}}{Q_{P i}}$ & $\begin{array}{c}Q_{\mathbf{p}} \\
\left(\mathbf{m}^{3} / \mathbf{s}\right)\end{array}$ & $\begin{array}{l}\text { ta } \\
\text { (hh: }\end{array}$ & $\begin{array}{r}\text { tb } \\
\text { :mm) }\end{array}$ & $\frac{Q_{P i}}{Q_{P 95}}$ & $\frac{Q_{P i+1}}{Q_{P i}}$ & $\begin{array}{c}Q_{\mathbf{p}} \\
\left(m^{3} / \mathbf{s}\right)\end{array}$ & $\begin{array}{l}\text { ta } \\
\text { (hh }\end{array}$ & $\begin{array}{r}\text { tb } \\
\text { tm) }\end{array}$ & $\frac{Q_{P i}}{Q_{P 95}}$ & $\frac{Q_{P_{i+1}}}{Q_{P_{i}}}$ & $\begin{array}{c}Q_{p} \\
\left(m^{3} / \mathbf{s}\right)\end{array}$ & $\begin{array}{l}\text { ta } \\
\text { (hh }\end{array}$ & $\begin{array}{r}\text { tb } \\
\mathrm{nm})\end{array}$ & $\frac{Q_{P i}}{Q_{P 95}}$ & $\frac{Q_{P i+1}}{Q_{P_{i}}}$ \\
\hline 60 & 5,309 & 04:45 & $13: 30$ & 0,08 & & 8,934 & 04:45 & 13:15 & 0,11 & & 19,461 & 04:45 & 13:15 & 0,18 & & 24,767 & 04:45 & 13:15 & 0,20 & & 38,732 & 04:30 & 13:15 & 0,26 & \\
\hline 65 & 9,486 & $04: 45$ & $13: 15$ & 0,14 & 1,79 & 14,357 & 04:45 & $13: 15$ & 0,18 & 1,61 & 27,604 & 04:30 & $13: 15$ & 0,25 & 1,42 & 34,057 & $04: 30$ & $13: 15$ & 0,28 & 1,38 & 50,533 & 04:30 & $13: 15$ & 0,34 & 1,30 \\
\hline 70 & 14,899 & $04: 45$ & 13:15 & 0,22 & 1,57 & 21,077 & $04: 30$ & 13:15 & 0,26 & 1,47 & 37,163 & $04: 30$ & $13: 15$ & 0,34 & 1,35 & 44,719 & $04: 30$ & 13:15 & 0,37 & 1,31 & 63,577 & $04: 30$ & 13:15 & 0,43 & 1,26 \\
\hline 75 & 21,732 & $04: 30$ & $13: 15$ & 0,31 & 1,46 & 29,300 & 04:30 & $13: 15$ & 0,36 & 1,39 & 48,154 & $04: 30$ & $13: 15$ & 0,44 & 1,30 & 56,772 & $04: 30$ & $13: 15$ & 0,47 & 1,27 & 77,863 & $04: 30$ & $13: 15$ & 0,53 & 1,22 \\
\hline 80 & 30,220 & $04: 30$ & $13: 15$ & 0,44 & 1,39 & 39,159 & 04:30 & 13:15 & 0,48 & 1,34 & 60,686 & $04: 30$ & $13: 15$ & 0,56 & 1,26 & 70,295 & $04: 30$ & $13: 15$ & 0,58 & 1,24 & 93,425 & $04: 30$ & $13: 00$ & 0,63 & 1,20 \\
\hline 85 & 40,649 & 04:30 & $13: 15$ & 0,59 & 1,35 & 50,914 & 04:30 & 13:15 & 0,62 & 1,30 & 74,921 & 04:30 & $13: 00$ & 0,69 & 1,23 & 85,416 & 04:30 & $13: 00$ & 0,71 & 1,22 & 110,303 & $04: 30$ & 13:00 & 0,75 & 1,18 \\
\hline 90 & 53,470 & $04: 30$ & $13: 00$ & 0,77 & 1,32 & 64,927 & $04: 30$ & 13:00 & 0,80 & 1,28 & 91,036 & $04: 30$ & $13: 00$ & 0,83 & 1,22 & 102,248 & $04: 30$ & $13: 00$ & 0,85 & 1,20 & 128,510 & $04: 30$ & 13:00 & 0,87 & 1,17 \\
\hline 95 & 69,257 & 04:30 & 13:00 & 1,00 & 1,30 & 81,596 & 04:30 & $13: 00$ & 1,00 & 1,26 & 109,147 & 04:30 & $13: 00$ & 1,00 & 1,20 & 120,816 & 04:30 & $13: 00$ & 1,00 & 1,18 & 147,910 & $04: 30$ & $13: 00$ & 1,00 & 1,15 \\
\hline
\end{tabular}

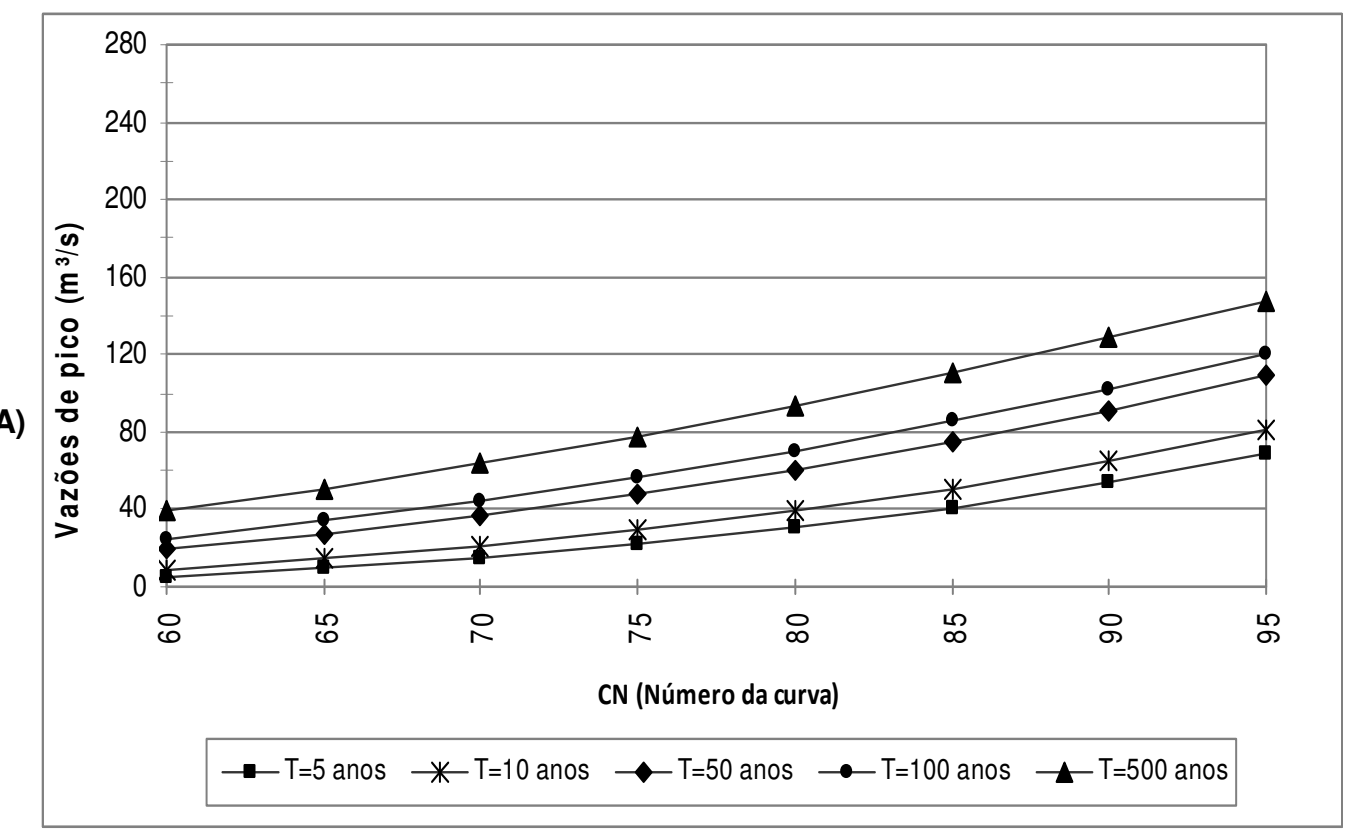

(B)

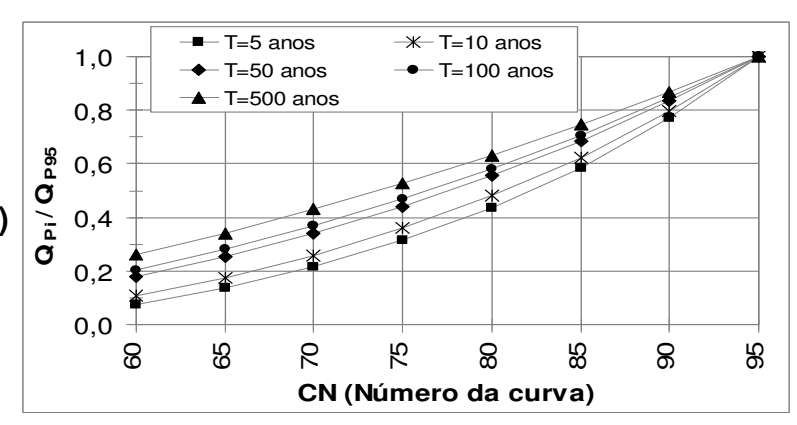

Figura 4.30 - (A) Variação da vazão de pico em função do CN, (B) proporção da vazão de pico em relação ao valor da vazão de pico para o CN de 95, (C) variação entre as vazões de pico em função do CN para o método de Clark 
Tabela 4.16 - Análise de sensibilidade da vazão de pico em função da variação da área de drenagem para o método de Clark

\begin{tabular}{|c|c|c|c|c|c|c|c|c|c|c|c|c|c|c|c|c|c|c|c|c|c|c|c|c|c|c|c|}
\hline \multirow[b]{2}{*}{$\begin{array}{c}\text { A } \\
\left(\mathbf{k m}^{2}\right)\end{array}$} & \multirow[b]{2}{*}{$\begin{array}{l}\text { tc } \\
\text { (h) }\end{array}$} & \multirow[b]{2}{*}{$\mathbf{k}_{\mathrm{CL}}$} & \multicolumn{5}{|c|}{$\mathrm{T}=5$ anos } & \multicolumn{5}{|c|}{$T=10$ anos } & \multicolumn{5}{|c|}{$\mathrm{T}=50$ anos } & \multicolumn{5}{|c|}{$T=100$ anos } & \multicolumn{5}{|c|}{$T=500$ anos } \\
\hline & & & $\begin{array}{c}Q_{\mathbf{P}} \\
\left(m^{3} / \mathbf{s}\right)\end{array}$ & $\begin{array}{l}\text { ta } \\
\text { (hh: }\end{array}$ & $\begin{array}{r}\text { tb } \\
\mathrm{mm})\end{array}$ & $\frac{Q_{P_{i}}}{Q_{P 200}}$ & $\frac{Q_{P_{i+1}}}{Q_{P_{i}}}$ & $\begin{array}{c}Q_{\mathbf{P}} \\
\left(\mathbf{m}^{3} / \mathbf{s}\right)\end{array}$ & $\begin{array}{l}\text { ta } \\
\text { (hh:n }\end{array}$ & $\begin{array}{r}\text { tb } \\
\mathrm{mm})\end{array}$ & $\frac{Q_{P_{i}}}{Q_{P 200}}$ & $\frac{Q_{P_{i+1}}}{Q_{P i}}$ & $\begin{array}{c}Q_{\mathbf{P}} \\
\left(m^{3} / \mathbf{s}\right)\end{array}$ & $\begin{array}{l}\text { ta } \\
\text { (hh }\end{array}$ & $\begin{array}{r}\text { tb } \\
\mathrm{mm} \text { ) }\end{array}$ & $\frac{Q_{P_{i}}}{Q_{P 200}}$ & $\frac{Q_{P_{i+1}}}{Q_{P i}}$ & $\begin{array}{c}Q_{\mathbf{p}} \\
\left(m^{3} / \mathbf{s}\right)\end{array}$ & $\begin{array}{l}\text { ta } \\
\text { (hh: }\end{array}$ & $\begin{array}{r}\text { tb } \\
\mathrm{mm})\end{array}$ & $\frac{Q_{P i}}{Q_{P 200}}$ & $\frac{Q_{P_{i+1}}}{Q_{P_{i}}}$ & $\begin{array}{c}\mathbf{Q}_{\mathbf{p}} \\
\left(\mathbf{m}^{3} / \mathbf{s}\right)\end{array}$ & $\begin{array}{l}\text { ta } \\
\text { (hh: }\end{array}$ & $\begin{array}{r}\text { tb } \\
\mathrm{mm} \text { ) }\end{array}$ & $\frac{Q_{P_{i}}}{Q_{P 200}}$ & $\frac{Q_{P_{i+1}}}{Q_{P_{i}}}$ \\
\hline 10 & 1,58 & 1,08 & 17,916 & 02:45 & $08: 15$ & 0,19 & & 24,171 & $02: 45$ & $08: 15$ & 0,19 & & 39,740 & $02: 45$ & $08: 15$ & 0,19 & & 46,840 & $02: 45$ & $08: 15$ & 0,19 & & 64,167 & 02:45 & $08: 15$ & 0,19 & \\
\hline 20 & 2,24 & 1,53 & 28,189 & 03:15 & $10: 30$ & 0,30 & 1,57 & 37,937 & 03:15 & $10: 30$ & 0,30 & 1,57 & 62,498 & 03:00 & $10: 30$ & 0,30 & 1,57 & 73,831 & 03:00 & 10:30 & 0,31 & 1,58 & 101,597 & 03:00 & 10:30 & 0,31 & 1,58 \\
\hline 40 & 3,16 & 2,17 & 40,348 & 04:00 & $14: 45$ & 0,44 & 1,43 & 54,401 & 04:00 & $14: 45$ & 0,44 & 1,43 & 89,406 & 04:00 & $14: 45$ & 0,44 & 1,43 & 105,396 & 04:00 & $14: 45$ & 0,44 & 1,43 & 144,500 & 04:00 & $14: 45$ & 0,44 & 1,42 \\
\hline 60 & 3,87 & 2,65 & 49,616 & 04:45 & $17: 45$ & 0,53 & 1,23 & 66,812 & 04:45 & $17: 45$ & 0,53 & 1,23 & 109,605 & $04: 45$ & $17: 45$ & 0,53 & 1,23 & 129,246 & 04:30 & 17:45 & 0,53 & 1,23 & 177,379 & 04:30 & $17: 45$ & 0,54 & 1,23 \\
\hline 80 & 4,47 & 3,06 & 58,236 & 05:00 & $20: 00$ & 0,63 & 1,17 & 78,517 & 05:00 & 20:00 & 0,63 & 1,18 & 129,050 & 05:00 & $20: 00$ & 0,63 & 1,18 & 152,149 & 05:00 & $20: 00$ & 0,63 & 1,18 & 208,687 & 05:00 & $20: 00$ & 0,63 & 1,18 \\
\hline 100 & 5,00 & 3,42 & 64,740 & 05:45 & 22:00 & 0,70 & 1,11 & 87,205 & 05:45 & 22:00 & 0,70 & 1,11 & 143,139 & $05: 45$ & 22:00 & 0,70 & 1,11 & 168,688 & 05:45 & 22:00 & 0,70 & 1,11 & 231,199 & 05:45 & 22:00 & 0,70 & 1,11 \\
\hline 120 & 5,48 & 3,75 & 71,677 & 06:00 & $24: 15$ & 0,77 & 1,11 & 96,552 & 05:00 & 24:15 & 0,77 & 1,11 & 158,487 & 06:00 & $24: 15$ & 0,77 & 1,11 & 186,780 & 06:00 & $24: 00$ & 0,77 & 1,11 & 256,009 & 06:00 & 24:00 & 0,77 & 1,11 \\
\hline 140 & 5,92 & 4,05 & 77,095 & 06:30 & $26: 00$ & 0,83 & 1,08 & 103,821 & 06:30 & $26: 00$ & 0,83 & 1,08 & 170,410 & $06: 15$ & $26: 00$ & 0,83 & 1,08 & 200,885 & $06: 15$ & $26: 00$ & 0,83 & 1,08 & 275,489 & $06: 15$ & 26:00 & 0,83 & 1,08 \\
\hline 160 & 6,32 & 4,33 & 82,806 & 06:45 & $27: 30$ & 0,89 & 1,07 & 111,559 & $06: 45$ & $27: 30$ & 0,89 & 1,07 & 183,165 & $06: 45$ & 27:15 & 0,89 & 1,07 & 215,885 & 06:45 & 27:15 & 0,89 & 1,07 & 295,969 & 06:45 & 27:15 & 0,89 & 1,07 \\
\hline 180 & 6,71 & 4,59 & 88,309 & 07:00 & $29: 00$ & 0,95 & 1,07 & 118,967 & 07:00 & 29:00 & 0,95 & 1,07 & 195,315 & 07:00 & 29:00 & 0,95 & 1,07 & 230,201 & 07:00 & 29:00 & 0,95 & 1,07 & 315,584 & 07:00 & 29:00 & 0,95 & 1,07 \\
\hline 200 & 7,07 & 4,84 & 92,746 & 07:30 & $30: 30$ & 1,00 & 1,05 & 124,914 & 07:30 & 30:30 & 1,00 & 1,05 & 205,002 & 07:30 & $30: 30$ & 1,00 & 1,05 & 241,590 & 07:30 & $30: 15$ & 1,00 & 1,05 & 331,129 & 07:30 & $30: 15$ & 1,00 & 1,05 \\
\hline
\end{tabular}
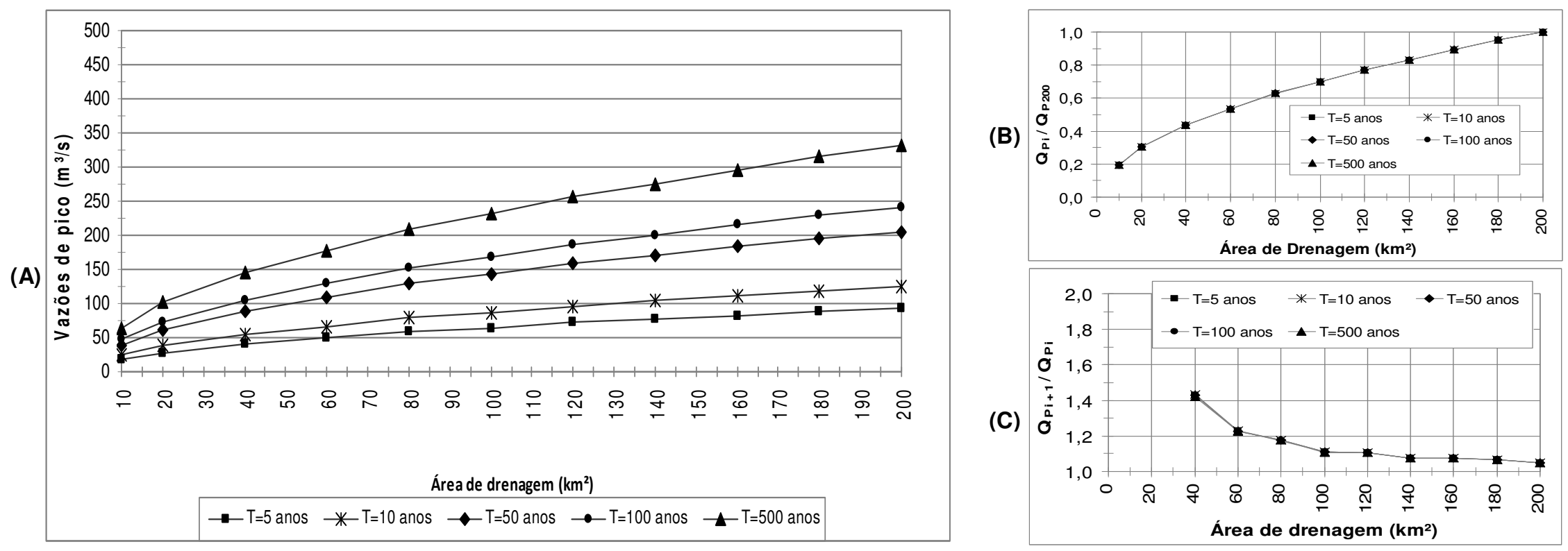

Figura 4.31 - (A) Variação da vazão de pico em função da área de drenagem, (B) proporção da vazão de pico em relação ao valor da vazão de pico para a área de drenagem de $200 \mathrm{~km}^{2}$, (C) variação entre as vazões de pico em função da área de drenagem para o método de Clark 
Tabela 4.17 - Análise de sensibilidade da vazão de pico em função da variação do tempo de concentração para o método de Clark

\begin{tabular}{|c|c|c|c|c|c|c|c|c|c|c|c|c|c|c|c|c|c|c|c|c|c|c|c|c|c|c|c|c|c|c|c|}
\hline \multirow[b]{2}{*}{$\begin{array}{l}\text { tc } \\
\text { (h) }\end{array}$} & \multirow[b]{2}{*}{$\mathbf{k}_{\mathrm{cL}}$} & \multicolumn{6}{|c|}{$\mathrm{T}=5$ anos } & \multicolumn{5}{|c|}{$\mathrm{T}=10$ anos } & \multicolumn{7}{|c|}{$\mathrm{T}=50$ anos } & \multicolumn{5}{|c|}{$\mathrm{T}=100$ anos } & \multicolumn{7}{|c|}{$T=500$ anos } \\
\hline & & $\begin{array}{c}Q_{p} \\
\left(m^{3} / s\right)\end{array}$ & $\begin{array}{l}\text { ta } \\
\text { (hh: }\end{array}$ & $\begin{array}{r}\text { tb } \\
\mathrm{mm})\end{array}$ & $\frac{Q_{p i}}{Q_{p 0.5}}$ & $\frac{Q_{p i+1}}{Q_{p i}}$ & $-\frac{Q_{p i+1}}{Q_{p i}}$ & $\underset{\left(m^{3} / \mathbf{s}\right)}{Q_{p}}$ & $\begin{array}{l}\text { ta } \\
\text { (hh:r }\end{array}$ & $\begin{array}{r}\text { tb } \\
\mathrm{mm} \text { ) }\end{array}$ & $\frac{Q_{p i}}{Q_{p 0.5}}$ & $\frac{Q_{p i+1}}{Q_{p i}}$ & $-\frac{Q_{p i+1}}{Q_{p i}}$ & $\begin{array}{c}\mathbf{Q}_{\mathbf{p}} \\
\left(\mathrm{m}^{3} / \mathbf{s}\right)\end{array}$ & $\begin{array}{l}\text { ta } \\
\text { (hh }\end{array}$ & $\begin{array}{r}\text { tb } \\
\mathrm{mm} \text { ) }\end{array}$ & $\frac{Q_{p i}}{Q_{p 0,5}}$ & $\frac{Q_{p+1}}{Q_{p i}}$ & $\frac{Q_{p i+1}}{Q_{p i}}$ & $\begin{array}{c}\mathbf{Q}_{\mathrm{p}} \\
\left(\mathrm{m}^{3} / \mathrm{s}\right)\end{array}$ & $\begin{array}{l}\text { ta } \\
\text { (hh:r }\end{array}$ & $\begin{array}{r}\text { tb } \\
\mathrm{mm})\end{array}$ & $\frac{Q_{p i}}{Q_{p 0,5}}$ & $\frac{Q_{p i+1}}{Q_{p i}}$ & $\frac{Q_{p i+1}}{Q_{p i}}$ & $\begin{array}{c}Q_{p} \\
\left(m^{3} / s\right)\end{array}$ & $\begin{array}{l}\text { ta } \\
\text { (hh: }\end{array}$ & $\begin{array}{r}\text { tb } \\
\mathrm{mm} \text { ) }\end{array}$ & $\frac{Q_{p i}}{Q_{p 0.5}}$ & $\frac{Q_{p i+1}}{Q_{p i}}$ & $\frac{Q_{p i+1}}{Q_{p i}}$ \\
\hline 0,50 & 0,3 & 83,581 & 01:45 & 04:00 & 1,00 & & & 114,695 & 01:45 & $03: 45$ & 1,00 & & & 193,047 & $01: 45$ & 03:45 & 1,00 & & & 228,936 & 01:45 & $03: 45$ & 1,00 & & & 316,512 & $01: 45$ & 03:45 & 1,00 & & \\
\hline 1,00 & 0,7 & 953 & $02: 15$ & $06: 00$ & 0,63 & 0,63 & 0,37 & 71,849 & 02:15 & $06: 00$ & 0,63 & 0,63 & 0,37 & 119,061 & $02: 15$ & 06:00 & 0,62 & 0,62 & 0,38 & 140,637 & 02:15 & 06:00 & 0,61 & 0,61 & 0,39 & 193,317 & 02:15 & 6:00 & 0,61 & 0,61 & 0,39 \\
\hline 1, & 1,0 & 067 & 2:45 & $: 45$ & 0,49 & 0,78 & 0,22 & 55,357 & 2:45 & ::45 &, 48 & 0,77 & 0,23 & , 891 & 2:45 & $: 45$ & 0,47 & 0,76 & 0,24 & 7,084 & 2:45 & 7:45 & 0,47 & 0,76 & 0,24 & 147,393 & $2: 30$ & 7:45 & 0,47 & 0,76 & 0,24 \\
\hline 2 , & & 931 & :15 & 10:15 & 0,38 & 0,78 & 0,22 & 43,015 & 03:00 & $10: 00$ & 0,38 & 0,78 & 0,22 & 1,159 & 3:00 & 10:00 & 0,37 & 0,78 & 0,22 & 4,045 & 03:00 & $10: 00$ & 0,37 & 0,78 & 0,22 & 115,607 & 03:00 & $10: 00$ & 0,37 & 0,78 & 0,22 \\
\hline 2,50 & 1,7 & 2 & 30 & 12:00 & 0,32 & 0,85 & 0,15 & 36,443 & & $: 00$ & 0,32 & 0,85 & 0,15 & & & & 31 & 0,84 & 16 & & & & 0,31 & 0,84 & 0,16 & & 3:30 & & , & 0,84 & , 16 \\
\hline 3,00 & 2, & & & & & 0,84 & 16 & 30,5 & & & 0,27 & 0,8 & & & & & & 0,84 & 0,16 & & & & 26 & 0 , & 0,16 & & :00 & & & 0,83 & , 17 \\
\hline 3,50 & 2, & 8,830 & 1:30 & $6: 00$ & 0,24 & 0,88 &, 12 & 26,704 & :30 & 6:00 & 0,23 & 0,88 & 0,12 & 3,813 & 4:30 & 16:00 & 0,23 & 0,87 & 0,13 & 621 & 4:30 & 16:00 & 0,23 & 0,87 & 0,13 & 0,839 & $4: 15$ & 16:00 & 0,22 & 0,87 & 0,13 \\
\hline 4,00 & 2 & 17,610 & 04:45 & 18:00 & 0,21 & 0,89 & 0,11 & 23,745 & 4:45 & $18: 00$ & 0,21 & 0,89 & 0,11 & 39,032 & 04:45 & $17: 45$ & 0,20 & 0,89 & 0,11 & 46,020 & 04:45 & 17:45 & 0,20 & 0,89 & 0,11 & 63,123 & 04:45 & 17:45 & 0,20 & 0,89 & 0,11 \\
\hline 4,50 & 3,1 & 15,599 & $05: 15$ & $20: 15$ & 0,19 & 0,89 & 0,11 & 21,022 & $05: 15$ & $20: 15$ & 0,18 & 0,89 & 0,11 & 34,528 & 05:15 & $20: 15$ & 0,18 & 0,88 & 0,12 & 40,699 & 05:15 & 20:15 & 0,18 & 0,88 & 0,12 & 55,801 & 05:15 & 20:15 & 0,18 & 0,88 & 0,12 \\
\hline 0 & & & 05:45 & 22:00 & 0,17 & 0,91 & 0,09 & 9,080 & & 22:00 &, 17 & 0,91 & 0,09 & & & & 16 & 0,91 & 0,09 & & 5:45 & 0 & 0,16 & 0,91 & 0,09 & 0,585 & 5:45 & 0 & 0,16 & 0,91 & 0,09 \\
\hline 5 & & & & & & 0,90 & 10 & & & & 0,15 & & 0,1 & & & & & 0,90 & 0 , & & & & & 0,90 & 0,1 & & $: 00$ & & & 0,90 & 10 \\
\hline 6,00 & 4,1 & 11,838 & 06:30 & $26: 15$ & 0,14 & 0,92 & 0,08 & 15,950 & 06:30 & $26: 15$ & 0,14 & 0,92 & 0,08 & 26,192 & 06:30 & $26: 15$ & 0,14 & 0,93 & 0,07 & 30,873 & 06:30 & $26: 15$ & 0,13 & 0,93 & 0,07 & 42,329 & 06:30 & $26: 15$ & 0,13 & 0,92 &, 08 \\
\hline
\end{tabular}

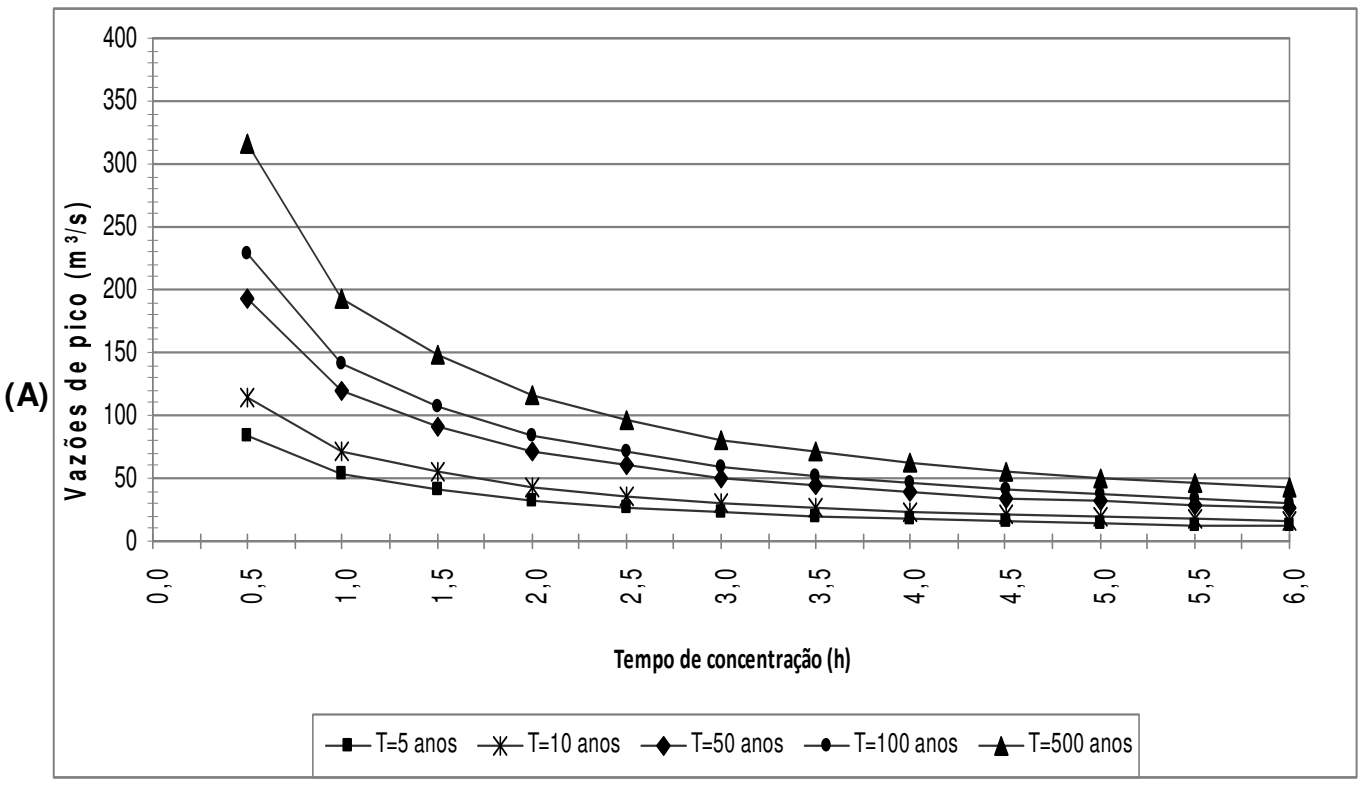

(B)

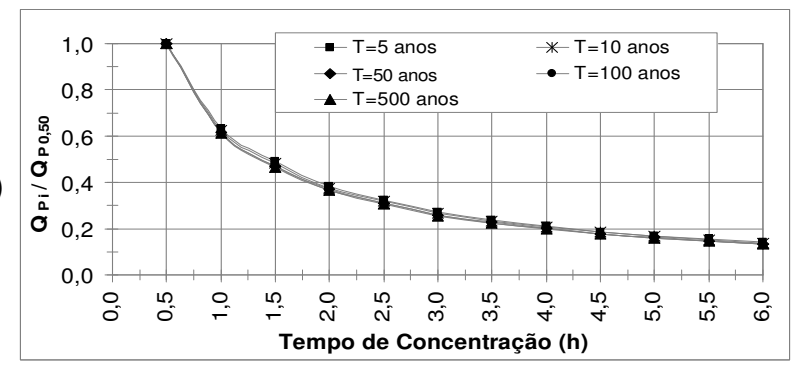

Figura 4.32 - (A) Variação da vazão de pico em função do tempo de concentração, (B) proporção da vazão de pico em relação ao valor da vazão de pico para o tempo de concentração de $0,50 \mathrm{~h},(\mathrm{C})$ variação entre as vazões de pico em função do tempo de concentração para o método de Clark 
Tabela 4.18 - Análise de sensibilidade da vazão de pico em função da variação da duração da chuva de projeto para o método de Clark

\begin{tabular}{|c|c|c|c|c|c|c|c|c|c|c|c|c|c|c|c|c|c|c|c|c|c|c|c|c|c|c|}
\hline \multirow[b]{2}{*}{$\begin{array}{c}d \\
(\min )\end{array}$} & \multicolumn{5}{|c|}{$\mathrm{T}=5$ anos } & \multicolumn{5}{|c|}{$T=10$ anos } & \multicolumn{5}{|c|}{$\mathrm{T}=50$ anos } & \multicolumn{5}{|c|}{$T=100$ anos } & \multicolumn{5}{|c|}{$\mathrm{T}=500$ anos } & \multirow[b]{2}{*}{$\frac{d_{i+1}}{d_{i}}$} \\
\hline & $\begin{array}{c}Q_{\mathbf{p}} \\
\left(m^{3} / \mathbf{s}\right)\end{array}$ & $\begin{array}{l}\text { ta } \\
\text { (hh }\end{array}$ & $\begin{array}{r}\text { tb } \\
\mathrm{mm})\end{array}$ & $\frac{Q_{P_{i}}}{Q_{P 360}}$ & $\frac{Q_{P_{i+1}}}{Q_{P i}}$ & $\begin{array}{c}Q_{\mathbf{p}} \\
\left(m^{3} / \mathbf{s}\right)\end{array}$ & $\begin{array}{l}\text { ta } \\
\text { (h }\end{array}$ & $\begin{array}{c}\text { tb } \\
\mathrm{nm})\end{array}$ & $\frac{Q_{P i}}{Q_{P 360}}$ & $\frac{Q_{P i+1}}{Q_{P i}}$ & $\begin{array}{c}Q_{p} \\
\left(m^{3} / s\right)\end{array}$ & $\begin{array}{l}\text { ta } \\
\text { (hh }\end{array}$ & $\begin{array}{r}\text { tb } \\
\text { :mm) }\end{array}$ & $\frac{Q_{P_{i}}}{Q_{P 360}}$ & $\frac{Q_{P i+1}}{Q_{P i}}$ & $\begin{array}{c}\mathbf{Q}_{\mathbf{p}} \\
\left(\mathbf{m}^{3} / \mathbf{s}\right)\end{array}$ & $\begin{array}{l}\text { ta } \\
\text { (hh: }\end{array}$ & $\begin{array}{r}\text { tb } \\
\mathrm{mm})\end{array}$ & $\frac{Q_{P i}}{Q_{P 360}}$ & $\frac{Q_{P i+1}}{Q_{P i}}$ & $\begin{array}{c}Q_{\mathbf{p}} \\
\left(\mathbf{m}^{3} / \mathbf{s}\right)\end{array}$ & $\begin{array}{l}\text { ta } \\
\text { (hh }\end{array}$ & $\begin{array}{r}\text { tb } \\
\mathrm{mm} \text { ) }\end{array}$ & $\frac{Q_{P i}}{Q_{P 360}}$ & $\frac{Q_{P i+1}}{Q_{P_{i}}}$ & \\
\hline 30 & 6,432 & 03:30 & 07:45 & 0,22 & & 9,675 & 03:30 & 07:45 & 0,25 & & 18,397 & 03:30 & $07: 45$ & 0,30 & & 22,621 & 03:30 & 07:45 & 0,32 & & 33,352 & 03:30 & $07: 45$ & 0,35 & & \\
\hline 60 & 12,816 & $03: 45$ & 08:00 & 0,44 & 1,99 & 18,018 & 03:45 & 08:00 & 0,47 & 1,86 & 31,362 & 03:45 & 08:00 & 0,51 & 1,70 & 37,611 & 03:45 & 08:00 & 0,52 & 1,66 & 53,153 & 03:45 & 08:00 & 0,55 & 1,59 & 2,00 \\
\hline 90 & 16,729 & 04:00 & 08:15 & 0,57 & 1,31 & 23,001 & 04:00 & 08:15 & 0,59 & 1,28 & 38,860 & $04: 00$ & $08: 15$ & 0,63 & 1,24 & 46,195 & 04:00 & $08: 15$ & 0,64 & 1,23 & 64,294 & 04:00 & 08:15 & 0,67 & 1,21 & 1,50 \\
\hline 120 & 19,559 & 04:15 & 08:45 & 0,67 & 1,17 & 26,571 & 04:15 & 08:45 & 0,69 & 1,16 & 44,152 & 04:15 & 08:45 & 0,72 & 1,14 & 52,229 & 04:15 & $08: 45$ & 0,73 & 1,13 & 72,047 & 04:15 & 08:45 & 0,75 & 1,12 & 1,33 \\
\hline 150 & 21,732 & 04:30 & 09:00 & 0,74 & 1,11 & 29,300 & 04:30 & 09:00 & 0,76 & 1,10 & 48,154 & $04: 30$ & 09:00 & 0,78 & 1,09 & 56,772 & 04:30 & 09:00 & 0,79 & 1,09 & 77,863 & 04:30 & 09:00 & 0,81 & 1,08 & 1,25 \\
\hline 180 & 23,481 & 05:00 & 09:30 & 0,80 & 1,08 & 31,452 & 04:45 & 09:15 & 0,81 & 1,07 & 51,289 & 04:45 & $09: 15$ & 0,83 & 1,07 & 60,323 & 04:45 & 09:15 & 0,84 & 1,06 & 82,390 & 04:45 & 09:15 & 0,85 & 1,06 & 1,20 \\
\hline 210 & 24,952 & 05:15 & $09: 45$ & 0,85 & 1,06 & 33,252 & $05: 15$ & 09:45 & 0,86 & 1,06 & 53,801 & 05:00 & $09: 45$ & 0,88 & 1,05 & 63,173 & 05:00 & $09: 45$ & 0,88 & 1,05 & 86,003 & 05:00 & $09: 30$ & 0,89 & 1,04 & 1,17 \\
\hline 240 & 26,163 & 05:30 & 10:00 & 0,89 & 1,05 & 34,759 & 05:30 & $10: 00$ & 0,90 & 1,05 & 55,878 & 05:30 & $10: 00$ & 0,91 & 1,04 & 65,492 & 05:15 & $10: 00$ & 0,91 & 1,04 & 88,950 & 05:15 & $10: 00$ & 0,92 & 1,03 & 1,14 \\
\hline 270 & 27,179 & 05:45 & $10: 30$ & 0,93 & 1,04 & 36,016 & 05:45 & 10:15 & 0,93 & 1,04 & 57,666 & 05:45 & $10: 15$ & 0,94 & 1,03 & 67,468 & 05:45 & $10: 15$ & 0,94 & 1,03 & 91,376 & 05:30 & $10: 15$ & 0,95 & 1,03 & 1,13 \\
\hline 300 & 28,027 & 06:00 & 10:45 & 0,95 & 1,03 & 37,065 & 06:00 & $10: 45$ & 0,96 & 1,03 & 59,157 & 06:00 & $10: 30$ & 0,96 & 1,03 & 69,157 & 06:00 & $10: 30$ & 0,96 & 1,03 & 93,384 & 05:45 & $10: 30$ & 0,97 & 1,02 & 1,11 \\
\hline 330 & 28,746 & 06:15 & 11:00 & 0,98 & 1,03 & 37,951 & $06: 15$ & 11:00 & 0,98 & 1,02 & 60,417 & $06: 15$ & $11: 00$ & 0,98 & 1,02 & 70,566 & 06:15 & $11: 00$ & 0,98 & 1,02 & 95,108 & 06:15 & $11: 00$ & 0,98 & 1,02 & 1,10 \\
\hline 360 & 29,358 & $06: 30$ & $11: 30$ & 1,00 & 1,02 & 38,701 & 06:30 & $11: 30$ & 1,00 & 1,02 & 61,478 & $06: 30$ & $11: 15$ & 1,00 & 1,02 & 71,758 & 06:30 & $11: 15$ & 1,00 & 1,02 & 96,595 & 06:30 & $11: 15$ & 1,00 & 1,02 & 1,09 \\
\hline
\end{tabular}

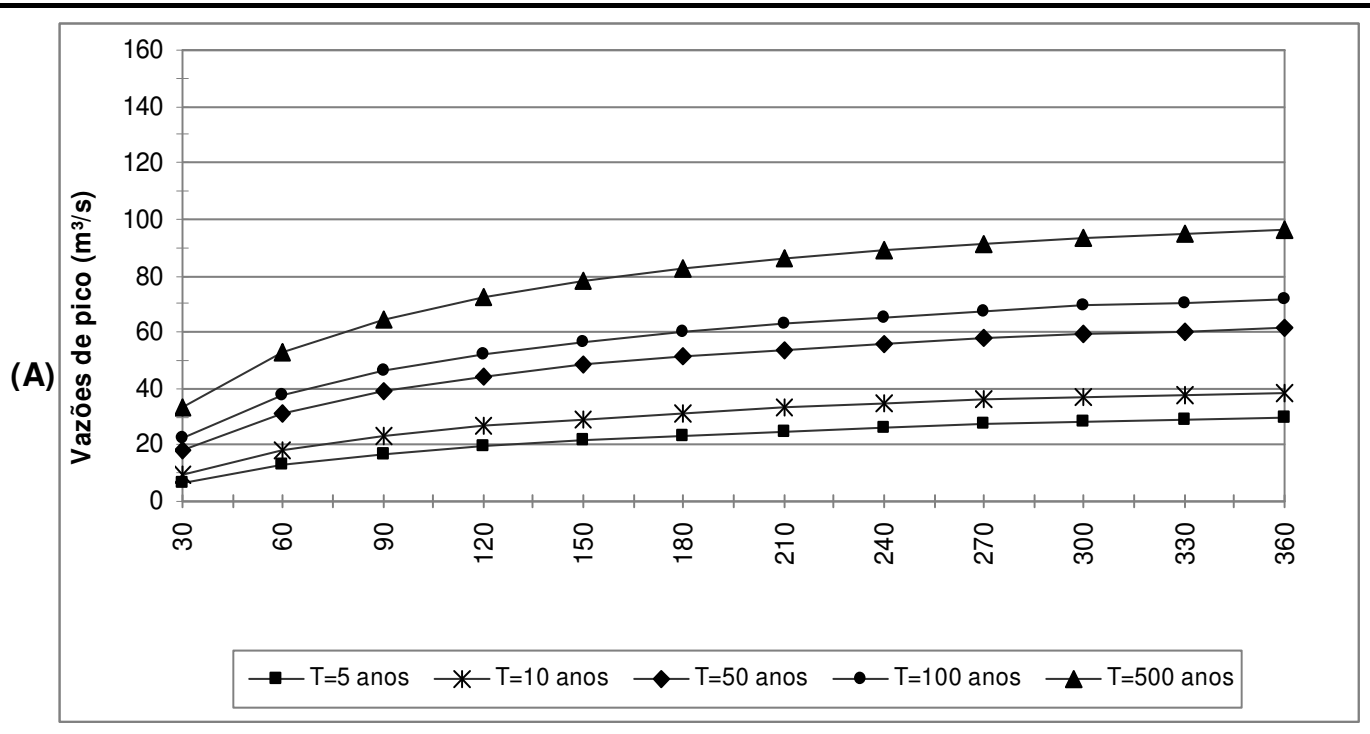

(B)

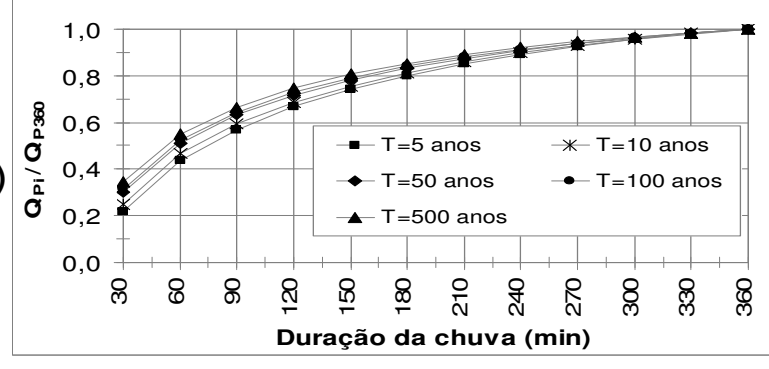

(C)

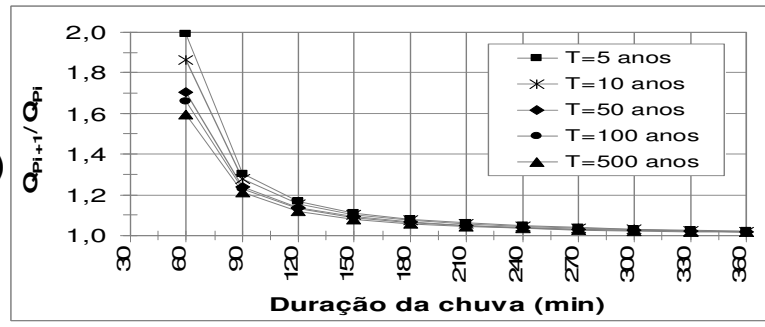

Figura 4.33 - (A) Variação da vazão de pico em função da duração da chuva de projeto, (B) proporção da vazão de pico em relação ao valor da vazão de pico para a duração da chuva de projeto de 360 minutos, (C) variação entre as vazões de pico em função da duração da chuva de projeto para o método de Clark 
Tabela 4.19 - Análise de sensibilidade da vazão de pico em função da variação do fator de forma para o método de Clark

\begin{tabular}{|c|c|c|c|c|c|c|c|c|c|c|c|c|c|c|c|c|c|c|c|c|c|c|c|c|c|c|}
\hline \multirow[b]{2}{*}{$\begin{array}{c}\mathrm{n}_{\mathrm{f}} \\
(\min )\end{array}$} & \multicolumn{5}{|c|}{$\mathrm{T}=5$ anos } & \multicolumn{5}{|c|}{$\mathrm{T}=10$ anos } & \multicolumn{5}{|c|}{$\mathrm{T}=50$ anos } & \multicolumn{5}{|c|}{$T=100$ anos } & \multicolumn{5}{|c|}{$T=500$ anos } & \\
\hline & $\begin{array}{c}\mathbf{Q}_{\mathrm{p}} \\
\left(\mathrm{m}^{3} / \mathrm{s}\right)\end{array}$ & $\begin{array}{l}\text { ta } \\
\text { (hh }\end{array}$ & $\begin{array}{l}\text { tb } \\
\mathrm{mm})\end{array}$ & $\frac{Q_{P_{i}}}{Q_{P 2}}$ & $\frac{Q_{P_{i+1}}}{Q_{P i}}$ & $\begin{array}{c}Q_{\mathbf{p}} \\
\left(m^{3} / s\right)\end{array}$ & $\begin{array}{l}\text { ta } \\
\text { (h }\end{array}$ & tb & $\frac{Q_{P i}}{Q_{P 2}}$ & $\frac{Q_{P_{i+1}}}{Q_{P_{i}}}$ & $\begin{array}{c}\mathbf{Q}_{\mathbf{p}} \\
\left(\mathbf{m}^{3} / \mathbf{s}\right)\end{array}$ & $\begin{array}{l}\text { ta } \\
\text { (hh }\end{array}$ & $\begin{array}{r}\text { tb } \\
\mathrm{mm})\end{array}$ & $\frac{Q_{P_{1}}}{Q_{P 2}}$ & $\frac{Q_{P_{i+1}}}{Q_{P i}}$ & $\begin{array}{c}Q_{\mathbf{P}} \\
\left(\mathrm{m}^{3} / \mathbf{s}\right)\end{array}$ & $\begin{array}{l}\text { ta } \\
\text { (hh }\end{array}$ & $\begin{array}{c}\text { tb } \\
\mathrm{mm})\end{array}$ & $\frac{Q_{P_{i}}}{Q_{P_{2}}}$ & $\frac{Q_{P_{i+1}}}{Q_{P_{i}}}$ & $\begin{array}{c}Q_{\mathbf{p}} \\
\left(\mathbf{m}^{3} / \mathbf{s}\right)\end{array}$ & $\begin{array}{l}\text { ta } \\
\text { (hh }\end{array}$ & $\begin{array}{c}\text { tb } \\
\mathrm{mm} \text { ) }\end{array}$ & $\frac{Q_{P_{i}}}{Q_{P_{2}}}$ & $\frac{Q_{P_{i+1}}}{Q_{P i}}$ & \\
\hline 1,0 & 25,442 & 03:45 & $12: 00$ & 0,90 & & 34,310 & 03:45 & $12: 00$ & 0,90 & & 56,401 & 03:45 & $12: 00$ & 0,90 & & 66,485 & 03:45 & $12: 00$ & 0,90 & & 91,126 & 03:45 & 12:00 & 0,90 & & \\
\hline 1,2 & 26,012 & 03:45 & $12: 00$ & 0,92 & 1,02 & 35,017 & 03:45 & $12: 00$ & 0,92 & 1,02 & 57,600 & 03:30 & $12: 00$ & 0,92 & 1,02 & 67,991 & 03:30 & $12: 00$ & 0,92 & 1,02 & 93,444 & 03:30 & $12: 00$ & 0,92 & 1,03 & 1,20 \\
\hline 1,4 & 26,661 & 03:30 & $12: 00$ & 0,94 & 1,02 & 36,010 & 03:30 & $12: 00$ & 0,94 & 1,03 & 59,333 & 03:30 & $12: 00$ & 0,95 & 1,03 & 69,997 & 03:30 & $12: 00$ & 0,95 & 1,03 & 96,092 & 03:30 & 12:00 & 0,95 & 1,03 & 1,17 \\
\hline 1,6 & 27,328 & 03:30 & $12: 00$ & 0,96 & 1,03 & 36,875 & 03:30 & $12: 00$ & 0,97 & 1,02 & 60,666 & 03:30 & $12: 00$ & 0,97 & 1,02 & 71,534 & 03:30 & $12: 00$ & 0,97 & 1,02 & 98,110 & 03:30 & $12: 00$ & 0,97 & 1,02 & 1,14 \\
\hline 1,8 & 27,854 & 03:30 & $12: 00$ & 0,98 & 1,02 & 37,552 & 03:30 & $12: 00$ & 0,98 & 1,02 & 61,702 & 03:30 & $12: 00$ & 0,99 & 1,02 & 72,726 & 03:30 & $12: 00$ & 0,99 & 1,02 & 99,667 & 03:30 & $12: 00$ & 0,99 & 1,02 & 1,13 \\
\hline 2,0 & 28,327 & 03:30 & $11: 45$ & 1,00 & 1,02 & 38,163 & 03:30 & $11: 45$ & 1,00 & 1,02 & 62,635 & 03:30 & $11: 45$ & 1,00 & 1,02 & 73,799 & 03:30 & $11: 45$ & 1,00 & 1,01 & 101,070 & 03:30 & $11: 45$ & 1,00 & 1,01 & 1,11 \\
\hline
\end{tabular}

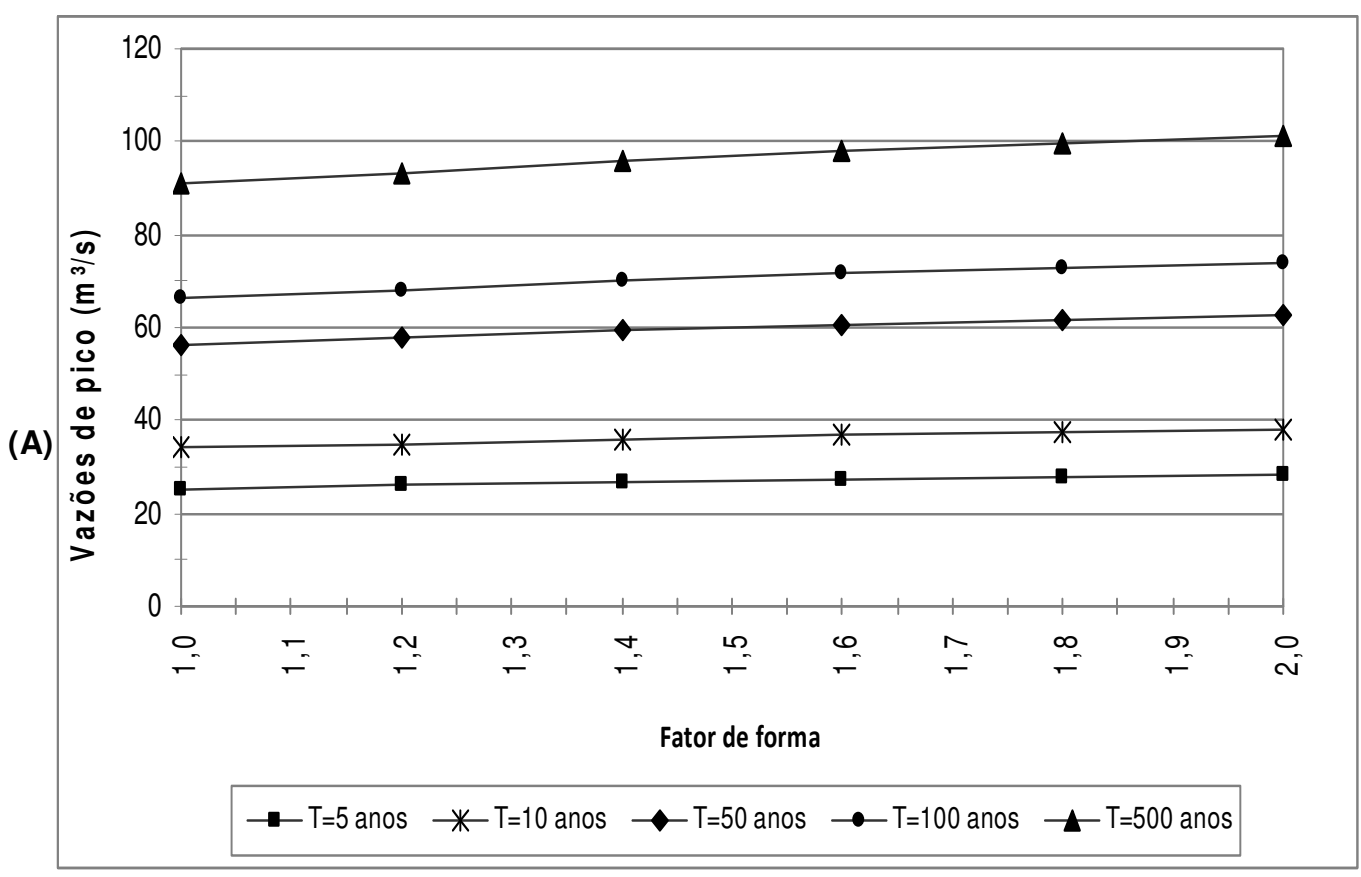

(B)

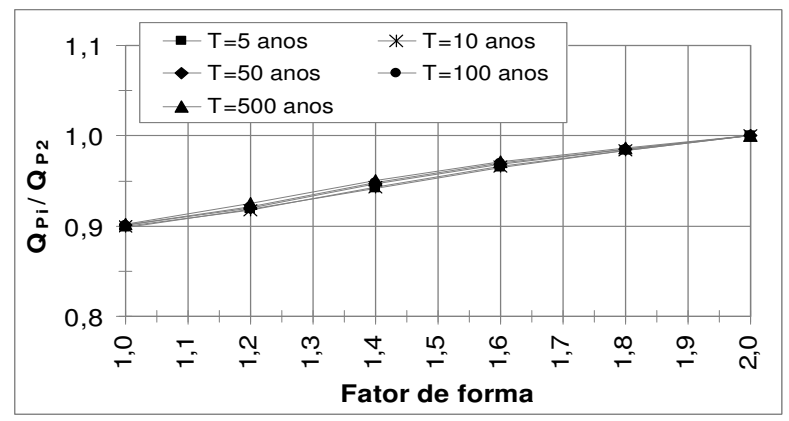

Figura 4.34 - (A) Variação da vazão de pico em função do fator de forma, (B) proporção da vazão de pico em relação ao valor da vazão de pico para o fator de forma igual a 2, (C) variação entre as vazões de pico em função do fator de forma para o método de Clark 
Assim como no método de Santa Bárbara, o método de Clark também considera o efeito de amortecimento da bacia hidrográfica representado pela constante $\mathrm{k}_{\mathrm{CL}}$, que varia em função do tempo de concentração, do comprimento do talvegue e área de drenagem da bacia hidrográfica. Neste estudo, para a determinação da constante $\mathrm{k}_{\mathrm{CL}}$ de armazenamento do método de Clark, foi considerada a relação empírica de Sabol apresentada no Capítulo 2.

Da Tabela 4.17, pode-se verificar a variação da constante $\mathrm{k}_{\mathrm{CL}}$ em função da vazão de pico, do tempo de concentração e da área de drenagem. As figuras 4.35, 4.36 e 4.37 apresentam os resultados das análises de variação da constante $\mathrm{k}_{C L}$ em função da vazão de pico, do tempo de concentração e da área de drenagem.

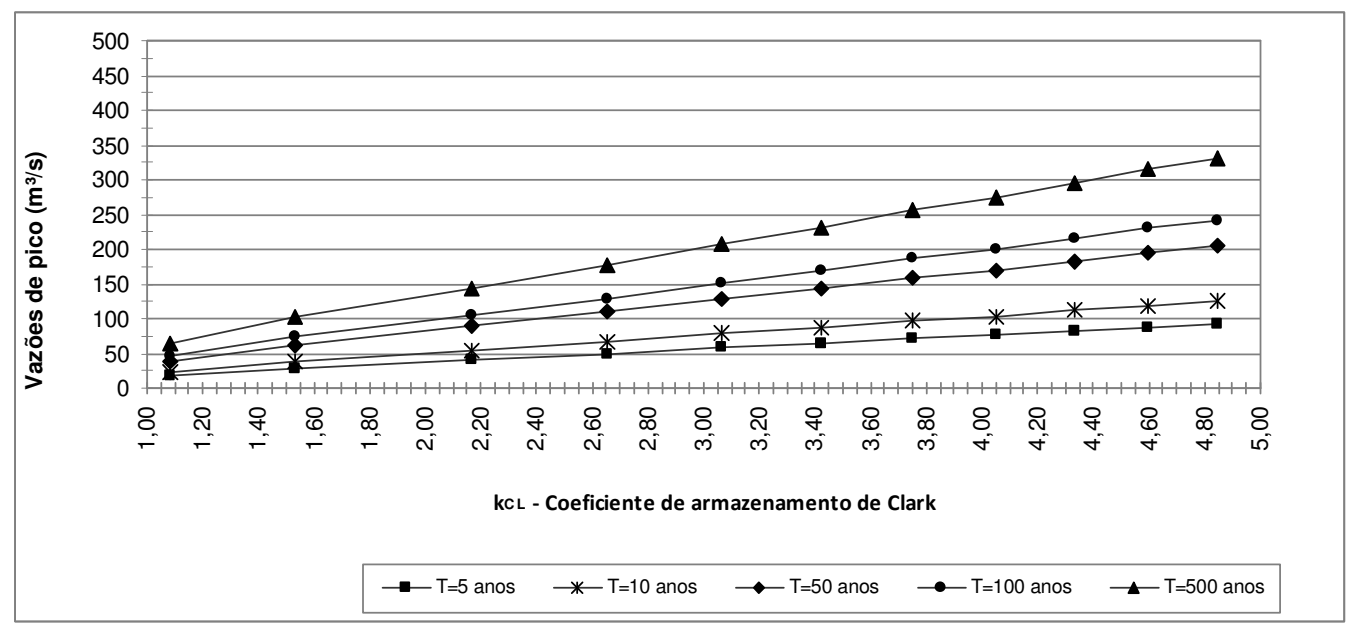

Figura 4.35 - Variação da constante $\mathrm{k}_{\mathrm{CL}}$ em função da vazão de pico - Método de Clark

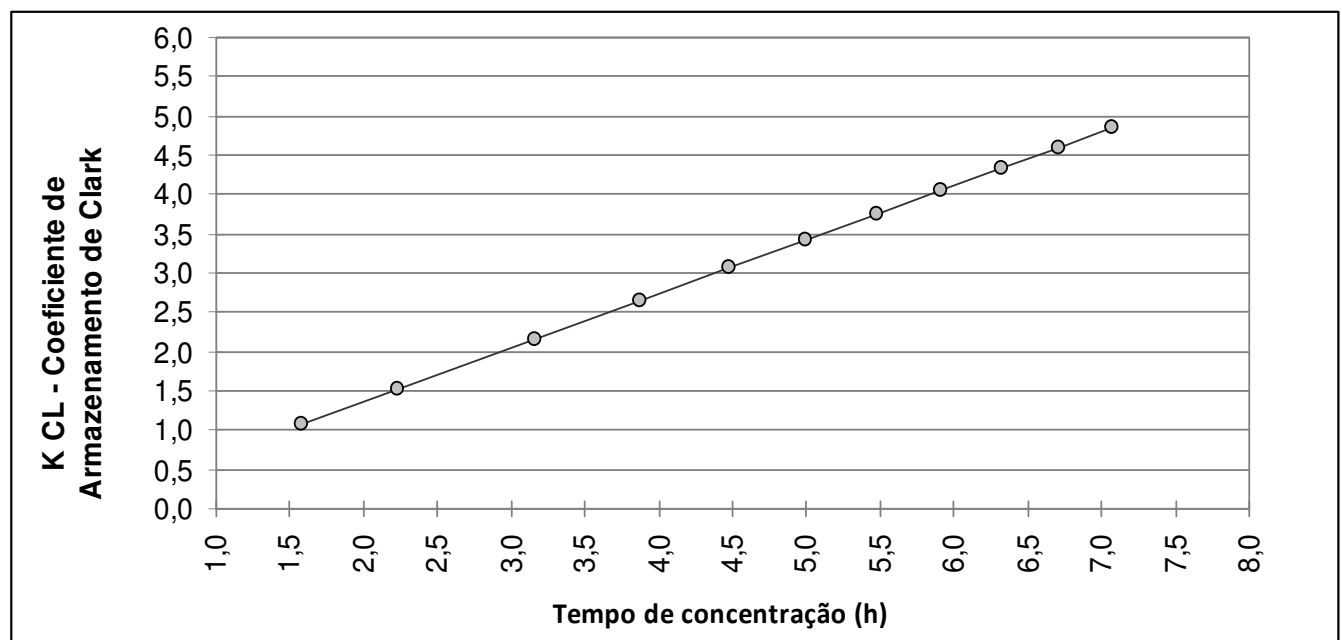

Figura 4.36 - Variação da constante $\mathrm{k}_{\mathrm{CL}}$ em função do tempo de concentração - Método de Clark 


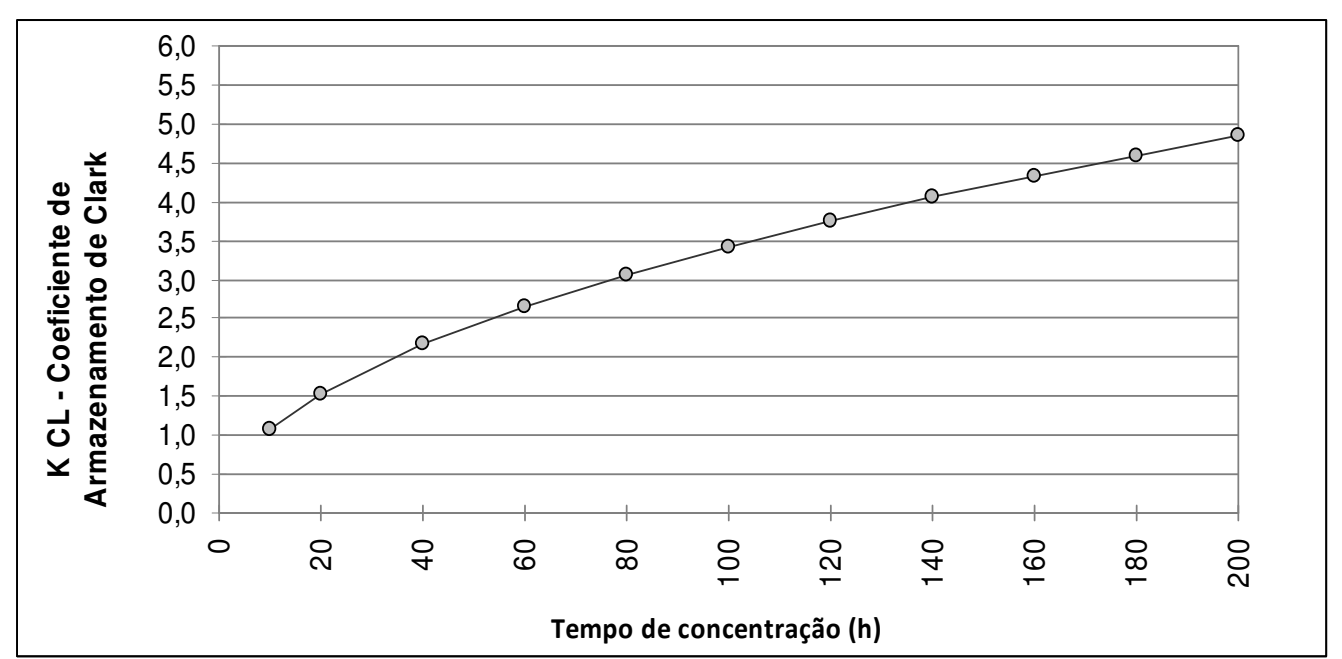

Figura 4.37 - Variação da constante $\mathrm{k}_{\mathrm{CL}}$ em função da área de drenagem - Método de Clark

\subsection{COMPARAÇÃO ENTRE OS MÉTODOS SINTÉTICOS DE OBTENÇÃO DE HIDROGRAMAS DE CHEIA}

\subsubsection{Método do hidrograma unitário do SCS versus Santa Bárbara}

Comparando-se o método do SCS e o método de Santa Bárbara, a partir das análises de sensibilidade pode-se verificar que:

- As variações entre as vazões de pico calculadas a partir do método do SCS e Santa Bárbara são semelhantes. A maior diferença verificada entre as variações para a análise de sensibilidade quanto ao valor de $\mathrm{CN}$ é de aproximadamente $3 \%$ para o valor de $\mathrm{CN}$ de 65 e 70 . Para os demais valores de $\mathrm{CN}$ a variação na vazão de pico entre os métodos do SCS e Santa Bárbara é praticamente a mesma. Já em relação à área de drenagem da bacia hidrográfica, a maior diferença ocorre para o intervalo de 20 a $40 \mathrm{~km}^{2}$. A diferença na vazão de pico entre os métodos para a área de drenagem de 20 e $40 \mathrm{~km}^{2}$ é de, aproximadamente, $4 \%$. Quanto às análises de sensibilidade referentes ao tempo de concentração e a duração da chuva de projeto, as variações são diferentes para as primeiras faixas de valores analisadas. A variação na vazão de pico para os tempos de concentração de 0,5 a 1 hora 
para o período de retorno de 5 e 10 anos, difere de um método ao outro, em aproximadamente $7 \%$ e $8 \%$, respectivamente. Para os demais valores do tempo de concentração, a variação entre as vazões de pico é praticamente igual entre os dois métodos. Em relação à análise de sensibilidade quanto a duração da chuva de projeto, no intervalo de 30 a 60 minutos a diferença na variação entre as vazões de pico de um método a outro para estas durações é de cerca de $12 \%$. Para os demais valores de duração da chuva de projeto, a variação entre as vazões de pico é praticamente igual entre os dois métodos;

- Os tempos de ascensão e os tempos de base dos hidrogramas são diferentes entre os dois métodos e variam conforme demonstrado nas tabelas $4.1,4.3$, 4.5 e 4.9 (SCS) e 4.11, 4.12, 4.13 e 4.14 (Santa Bárbara). Nota-se que os picos dos hidrogramas de cheia calculados pelo método de Santa Bárbara ocorrem antes do que os calculados pelo método do SCS. Esta análise também pode ser feita se observado as Figuras 4.38 a 4.45, que mostram o comportamento dos hidrogramas para o período de retorno de 100 anos para as análises de sensibilidade quanto ao valor de $\mathrm{CN}$, área de drenagem, duração da chuva de projeto e tempo de concentração; 


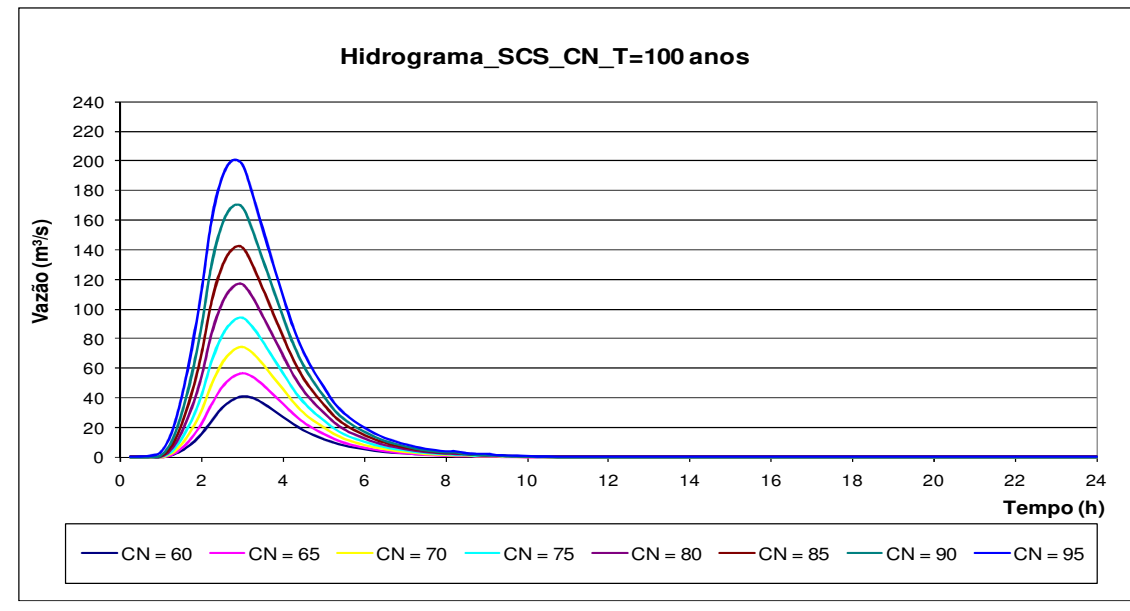

Figura 4.38 - Hidrograma de cheia para o método do SCS, variação do CN período de retorno de 100 anos

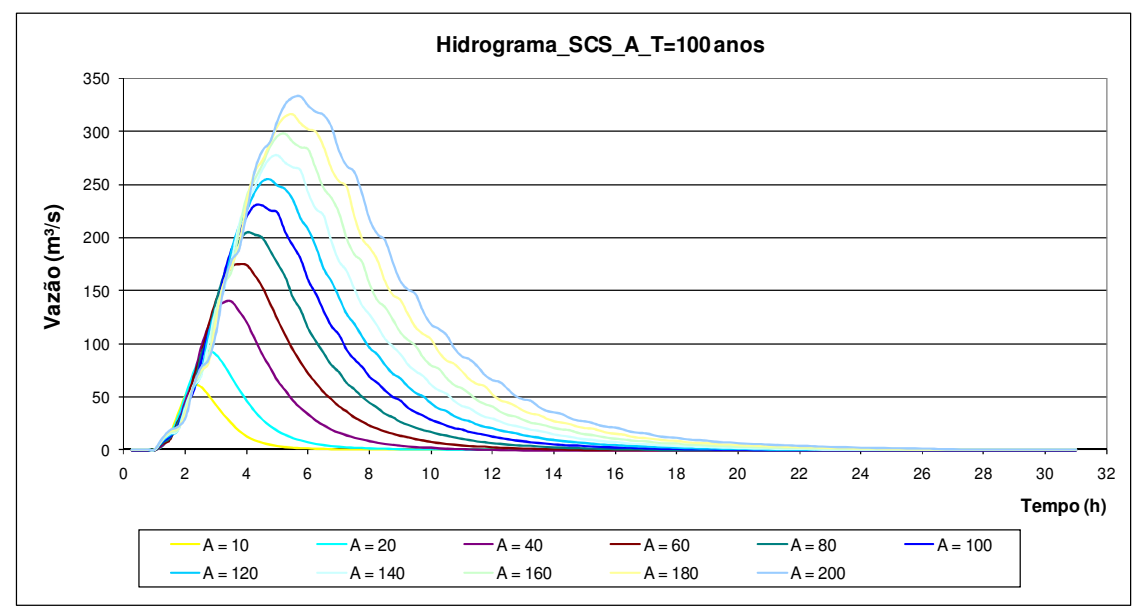

Figura 4.40 - Hidrograma de cheia para o método do SCS, variação da área de drenagem, período de retorno de 100 anos

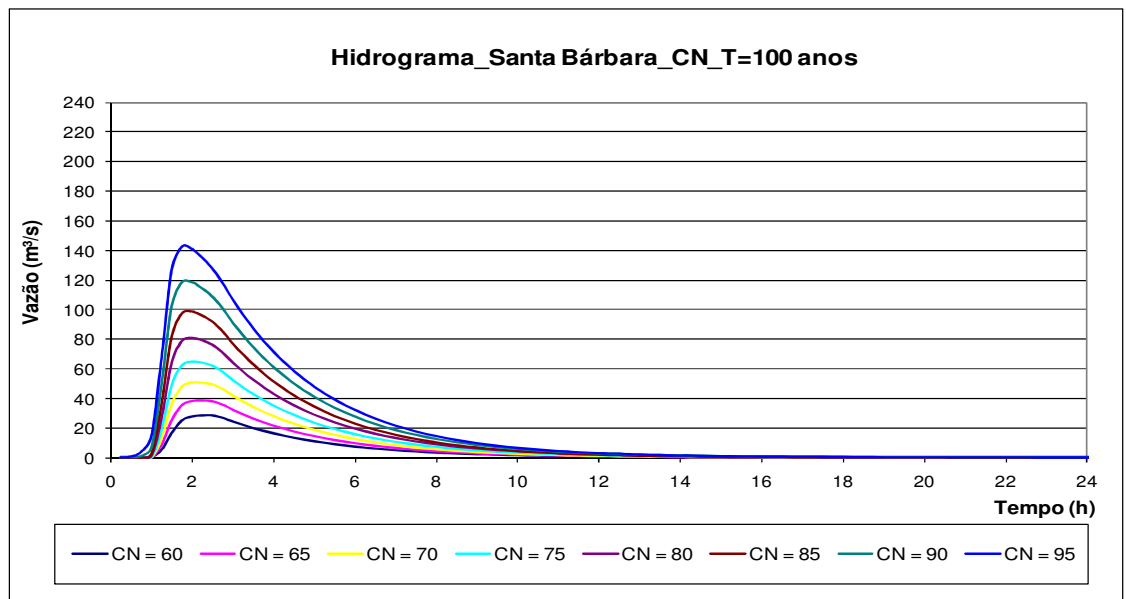

Figura 4.39 - Hidrograma de cheia para o método de Santa Bárbara, variação do $\mathrm{CN}$, período de retorno de 100 anos

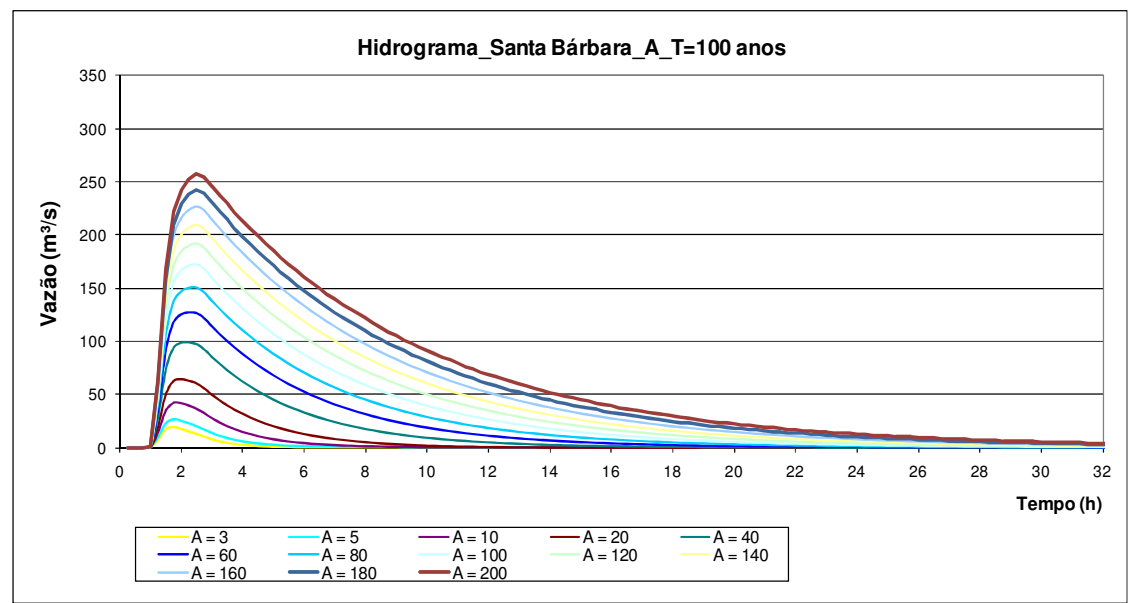

Figura 4.41 - Hidrograma de cheia para o método de Santa Bárbara, variação da área de drenagem, período de retorno de 100 anos 


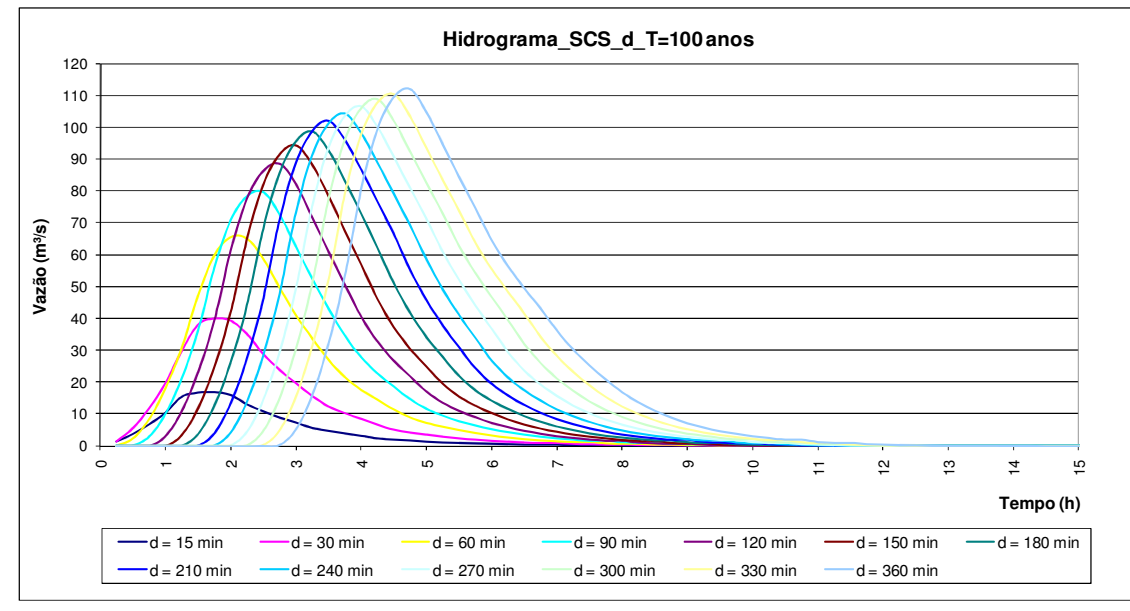

Figura 4.42 - Hidrograma de cheia para o método do SCS, variação da duração da chuva de projeto, período de retorno de 100 anos

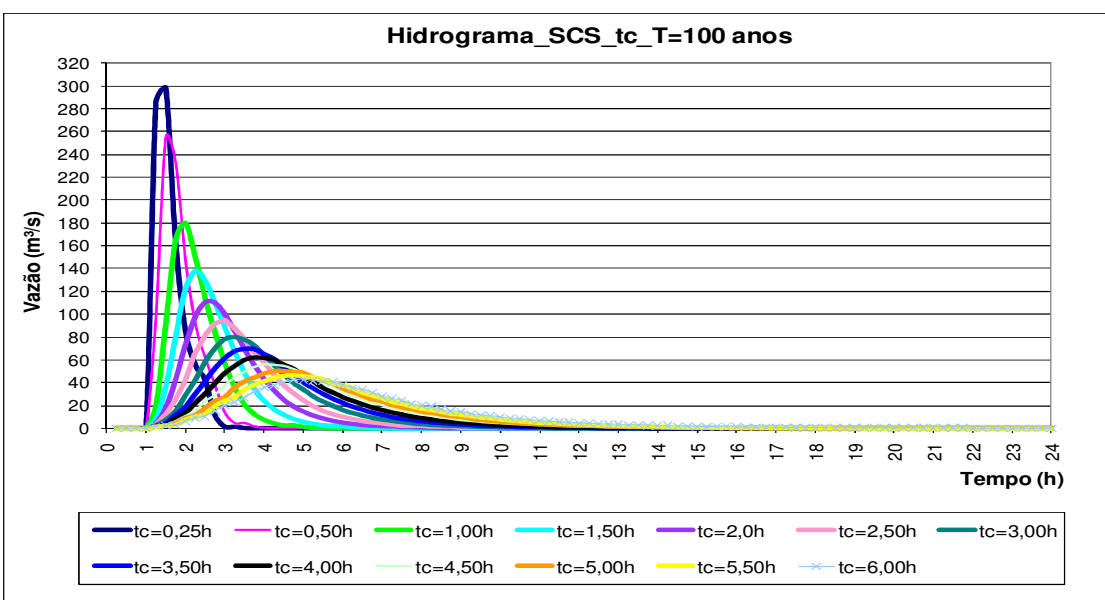

Figura 4.44 - Hidrograma de cheia para o método do SCS, variação do tempo de concentração, período de retorno de 100 anos

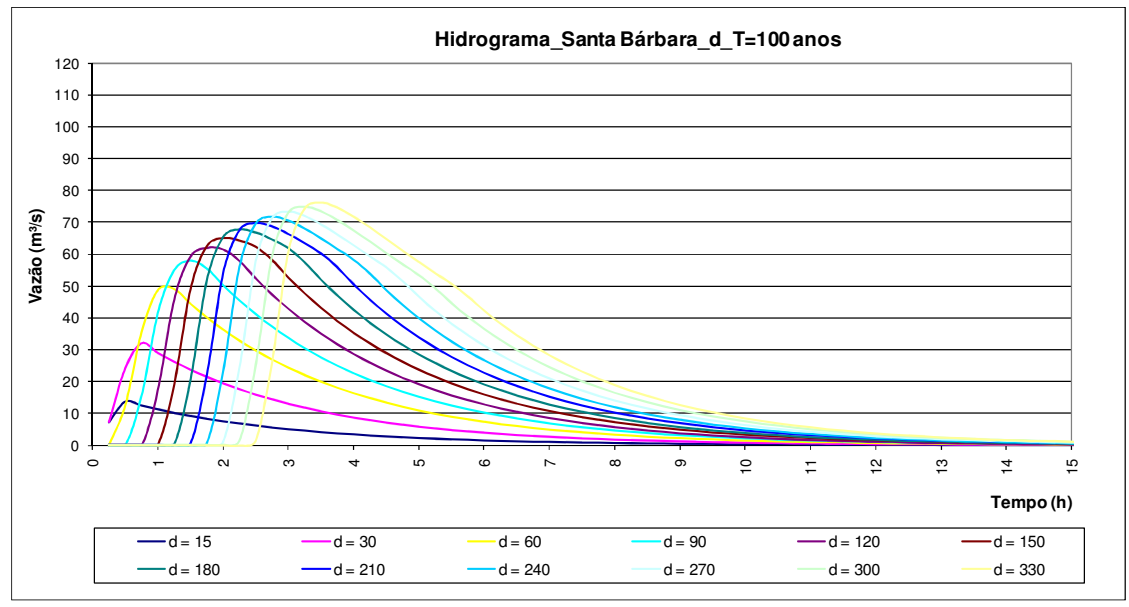

Figura 4.43 - Hidrograma de cheia para o método de Santa Bárbara, variação da duração da chuva de projeto, período de retorno de 100 anos

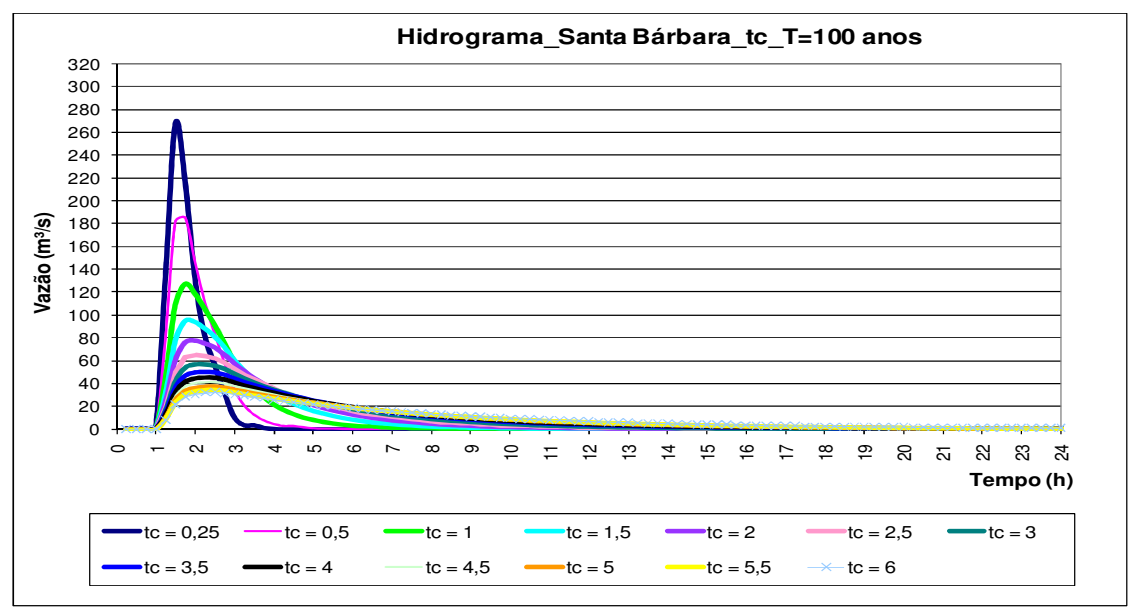

Figura 4.45 - Hidrograma de cheia para o método de Santa Bárbara, variação do tempo de concentração, período de retorno de 100 anos 
- Os volumes dos hidrogramas são iguais, uma vez que são determinados em função do método de cálculo de chuva excedente, mantido o mesmo nestas análises.

As tabelas 4.20 a 4.23 mostram a diferença percentual entre a vazão de pico para o método de SCS e para o método de Santa Bárbara, para as análises de sensibilidade quanto ao valor de $\mathrm{CN}$, área de drenagem, tempo de concentração e duração da chuva de projeto. A fórmula geral para a obtenção desta diferença é a seguinte:

$$
\left(Q_{S C S}-Q_{S B}\right) / Q_{S C S}
$$

Onde:

- $Q_{S c S}=$ vazão de pico referente à variável analisada, para o método do SCS;

- $\mathrm{Q}_{\mathrm{SB}}=$ vazão pico referente à variável analisada, para o método de Santa Bárbara.

Tabela 4.20 - Diferença percentual das vazões de pico entre os métodos de SCS e Santa Bárbara, variando o $\mathrm{CN}$

\begin{tabular}{|c|c|c|c|c|c|c|c|c|}
\hline \multirow{2}{*}{$\mathrm{CN}$} & \multicolumn{5}{|c|}{$\left(Q_{\mathrm{SCS}}-Q_{\mathrm{SB}}\right) / Q_{\mathrm{SCS}}$} & \multirow{2}{*}{ Média } & \multirow{2}{*}{ Máxima } & \multirow{2}{*}{ Mínima } \\
\hline & $\mathrm{T}=5$ anos & $\mathrm{T}=10$ anos & $\mathrm{T}=50$ anos & $\mathrm{T}=100$ anos & $\mathrm{T}=500$ anos & & & \\
\hline 60 & 0,29 & 0,29 & 0,30 & 0,31 & 0,31 & 0,30 & 0,31 & 0,29 \\
\hline 65 & 0,29 & 0,30 & 0,31 & 0,31 & 0,31 & 0,31 & 0,31 & 0,29 \\
\hline 70 & 0,31 & 0,31 & 0,31 & 0,31 & 0,31 & 0,31 & 0,31 & 0,31 \\
\hline 75 & 0,31 & 0,31 & 0,31 & 0,31 & 0,31 & 0,31 & 0,31 & 0,31 \\
\hline 80 & 0,31 & 0,31 & 0,31 & 0,31 & 0,30 & 0,31 & 0,31 & 0,30 \\
\hline 85 & 0,31 & 0,31 & 0,30 & 0,30 & 0,30 & 0,30 & 0,31 & 0,30 \\
\hline 90 & 0,30 & 0,30 & 0,30 & 0,30 & 0,30 & 0,30 & 0,30 & 0,30 \\
\hline 95 & 0,29 & 0,29 & 0,29 & 0,29 & 0,29 & 0,29 & 0,29 & 0,29 \\
\hline Média & 0,30 & 0,30 & 0,31 & 0,31 & 0,30 & - & - & - \\
\hline Máxima & 0,31 & 0,31 & 0,31 & 0,31 & 0,31 & - & - & - \\
\hline Minima & 0,29 & 0,29 & 0,29 & 0,29 & 0,29 & - & - & - \\
\hline & & & & & & & & $=0,30$ \\
\hline
\end{tabular}


Tabela 4.21 - Relação das vazões de pico entre os métodos de SCS e Santa Bárbara, variando a área de drenagem

\begin{tabular}{|c|c|c|c|c|c|c|c|c|}
\hline \multirow{2}{*}{$\begin{array}{c}\text { A } \\
\left(\mathrm{km}^{2}\right)\end{array}$} & \multicolumn{5}{|c|}{$\left(Q_{S C S}-Q_{S B}\right) / Q_{S C S}$} & \multirow{2}{*}{$\frac{\text { Média }}{\text { Média }}$} & \multirow{2}{*}{ Máxima } & \multirow{2}{*}{ Mínima } \\
\hline & $\mathrm{T}=5$ anos & $\mathrm{T}=10$ anos & $\mathrm{T}=50$ anos & $\mathrm{T}=100$ anos & $\mathrm{T}=500$ anos & & & \\
\hline 10 & 0,31 & 0,30 & 0,31 & 0,31 & 0,31 & 0,31 & 0,31 & 0,30 \\
\hline 20 & 0,31 & 0,31 & 0,31 & 0,31 & 0,31 & 0,31 & 0,31 & 0,31 \\
\hline 40 & 0,29 & 0,29 & 0,29 & 0,29 & 0,29 & 0,29 & 0,29 & 0,29 \\
\hline 60 & 0,27 & 0,27 & 0,28 & 0,28 & 0,27 & 0,27 & 0,28 & 0,27 \\
\hline 80 & 0,26 & 0,26 & 0,27 & 0,27 & 0,27 & 0,26 & 0,27 & 0,26 \\
\hline 100 & 0,25 & 0,25 & 0,25 & 0,25 & 0,26 & 0,25 & 0,26 & 0,25 \\
\hline 120 & 0,24 & 0,25 & 0,25 & 0,25 & 0,25 & 0,25 & 0,25 & 0,24 \\
\hline 140 & 0,24 & 0,24 & 0,24 & 0,24 & 0,24 & 0,24 & 0,24 & 0,24 \\
\hline 160 & 0,23 & 0,24 & 0,24 & 0,24 & 0,24 & 0,24 & 0,24 & 0,23 \\
\hline 180 & 0,23 & 0,23 & 0,23 & 0,23 & 0,23 & 0,23 & 0,23 & 0,23 \\
\hline 200 & 0,23 & 0,23 & 0,23 & 0,23 & 0,23 & 0,23 & 0,23 & 0,23 \\
\hline Média & 0,26 & 0,26 & 0,26 & 0,26 & 0,26 & - & - & - \\
\hline Máxima & 0,31 & 0,31 & 0,31 & 0,31 & 0,31 & - & - & - \\
\hline Minima & 0,23 & 0,23 & 0,23 & 0,23 & 0,23 & - & - & - \\
\hline & & & & & & & & $=0,26$ \\
\hline
\end{tabular}

Tabela 4.22 - Diferença percentual das vazões de pico entre os métodos de SCS e Santa Bárbara, variando o tempo de concentração

\begin{tabular}{|c|c|c|c|c|c|c|c|c|}
\hline \multirow{2}{*}{$\begin{array}{l}\text { tc } \\
\text { (h) }\end{array}$} & \multicolumn{5}{|c|}{$\left(Q_{S C S}-Q_{S B}\right) / Q_{S C S}$} & \multirow{2}{*}{ Média } & \multirow{2}{*}{ Máxima } & \multirow{2}{*}{ Mínima } \\
\hline & $\mathrm{T}=5$ anos & $\mathrm{T}=10$ anos & $\mathrm{T}=50$ anos & $\mathrm{T}=100$ anos & $\mathrm{T}=500$ anos & & & \\
\hline 0,5 & 0,23 & 0,22 & 0,26 & 0,27 & 0,29 & 0,25 & 0,29 & 0,22 \\
\hline 1 & 0,30 & 0,30 & 0,29 & 0,29 & 0,29 & 0,30 & 0,30 & 0,29 \\
\hline 1,5 & 0,30 & 0,31 & 0,31 & 0,31 & 0,31 & 0,31 & 0,31 & 0,30 \\
\hline 2 & 0,31 & 0,31 & 0,30 & 0,30 & 0,30 & 0,30 & 0,31 & 0,30 \\
\hline 2,5 & 0,31 & 0,31 & 0,31 & 0,31 & 0,31 & 0,31 & 0,31 & 0,31 \\
\hline 3 & 0,29 & 0,30 & 0,30 & 0,30 & 0,29 & 0,30 & 0,30 & 0,29 \\
\hline 3,5 & 0,28 & 0,28 & 0,28 & 0,28 & 0,28 & 0,28 & 0,28 & 0,28 \\
\hline 4 & 0,27 & 0,27 & 0,27 & 0,27 & 0,27 & 0,27 & 0,27 & 0,27 \\
\hline 4,5 & 0,26 & 0,26 & 0,27 & 0,27 & 0,27 & 0,26 & 0,27 & 0,26 \\
\hline 5 & 0,25 & 0,25 & 0,25 & 0,25 & 0,26 & 0,25 & 0,26 & 0,25 \\
\hline 5,5 & 0,24 & 0,25 & 0,25 & 0,25 & 0,25 & 0,25 & 0,25 & 0,24 \\
\hline 6 & 0,24 & 0,24 & 0,25 & 0,25 & 0,25 & 0,24 & 0,25 & 0,24 \\
\hline Média & 0,27 & 0,27 & 0,28 & 0,28 & 0,28 & - & - & - \\
\hline Máxima & 0,31 & 0,31 & 0,31 & 0,31 & 0,31 & - & - & - \\
\hline Minima & 0,23 & 0,22 & 0,25 & 0,25 & 0,25 & - & - & - \\
\hline
\end{tabular}

Média=0,28 
Tabela 4.23 - Diferença percentual das vazões de pico entre os métodos de SCS e Santa Bárbara, variando a duração da chuva

\begin{tabular}{|c|c|c|c|c|c|c|c|c|}
\hline \multirow{2}{*}{$\begin{array}{c}\mathrm{d} \\
(\min )\end{array}$} & \multicolumn{5}{|c|}{$\left(Q_{S C S}-Q_{S B}\right) / Q_{S C S}$} & \multirow{2}{*}{ Média } & \multirow{2}{*}{ Máxima } & \multirow{2}{*}{ Mínima } \\
\hline & $\mathrm{T}=5$ anos & $\mathrm{T}=10$ anos & $\mathrm{T}=50$ anos & $\mathrm{T}=100$ anos & $\mathrm{T}=500$ anos & & & \\
\hline 30 & 0,18 & 0,19 & 0,20 & 0,20 & 0,20 & 0,19 & 0,20 & 0,18 \\
\hline 60 & 0,24 & 0,24 & 0,25 & 0,25 & 0,26 & 0,25 & 0,26 & 0,24 \\
\hline 90 & 0,27 & 0,27 & 0,27 & 0,27 & 0,27 & 0,27 & 0,27 & 0,27 \\
\hline 120 & 0,29 & 0,30 & 0,30 & 0,30 & 0,30 & 0,30 & 0,30 & 0,29 \\
\hline 150 & 0,31 & 0,31 & 0,31 & 0,31 & 0,31 & 0,31 & 0,31 & 0,31 \\
\hline 180 & 0,32 & 0,32 & 0,32 & 0,31 & 0,31 & 0,32 & 0,32 & 0,31 \\
\hline 210 & 0,32 & 0,32 & 0,32 & 0,31 & 0,31 & 0,32 & 0,32 & 0,31 \\
\hline 240 & 0,32 & 0,32 & 0,32 & 0,31 & 0,31 & 0,32 & 0,32 & 0,31 \\
\hline 270 & 0,32 & 0,32 & 0,31 & 0,31 & 0,31 & 0,32 & 0,32 & 0,31 \\
\hline 300 & 0,32 & 0,32 & 0,31 & 0,31 & 0,31 & 0,32 & 0,32 & 0,31 \\
\hline 330 & 0,32 & 0,32 & 0,31 & 0,31 & 0,31 & 0,31 & 0,32 & 0,31 \\
\hline 360 & 0,32 & 0,32 & 0,31 & 0,31 & 0,31 & 0,31 & 0,32 & 0,31 \\
\hline Média & 0,30 & 0,30 & 0,29 & 0,29 & 0,29 & - & - & - \\
\hline Máxima & 0,32 & 0,32 & 0,32 & 0,31 & 0,31 & - & - & - \\
\hline Minima & 0,18 & 0,19 & 0,20 & 0,20 & 0,20 & - & - & - \\
\hline & & & & & & & & $=0,29$ \\
\hline
\end{tabular}

As figuras 4.46 a 4.49 mostram a relação entre os valores dos métodos de Santa Bárbara e do método do SCS, para o valor de CN, área de drenagem, tempo de concentração e duração da chuva de projeto.

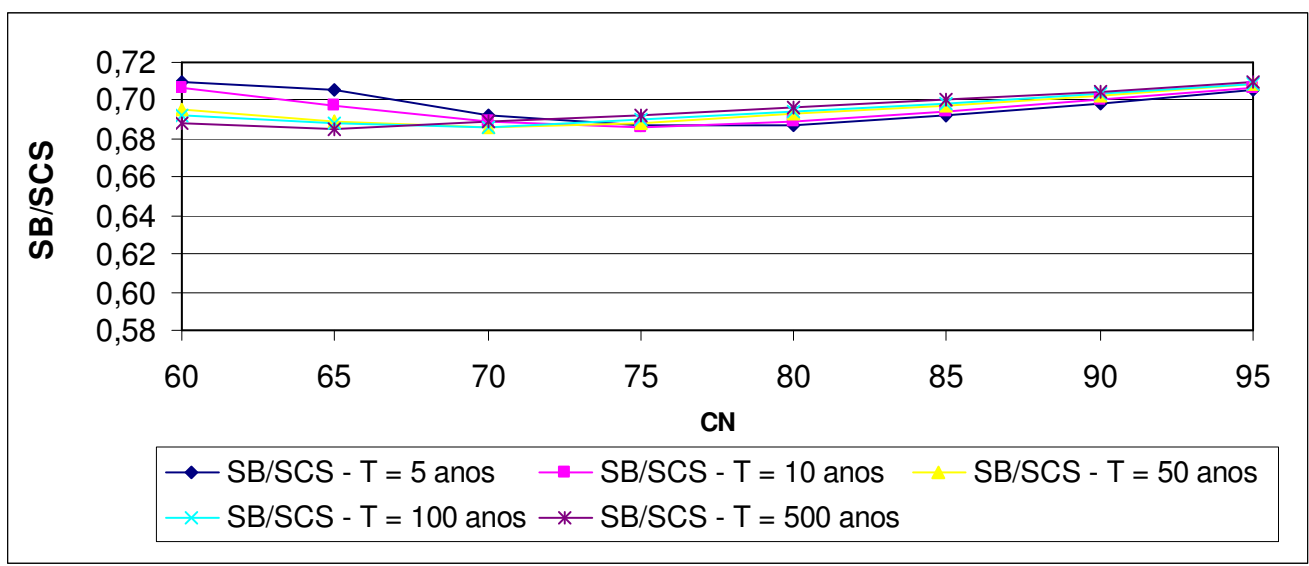

Figura 4.46 - Relação entre as vazões do método de Santa Bárbara e SCS, variando CN e período de retorno 


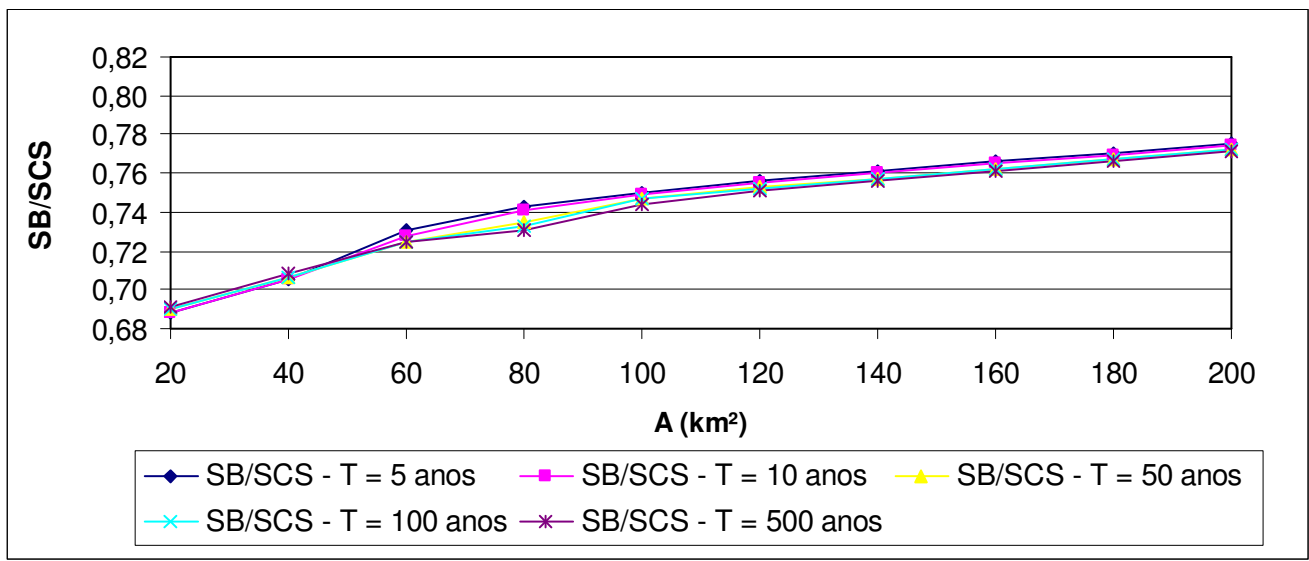

Figura 4.47 - Relação entre as vazões do método de Santa Bárbara e SCS, variando área de drenagem e período de retorno

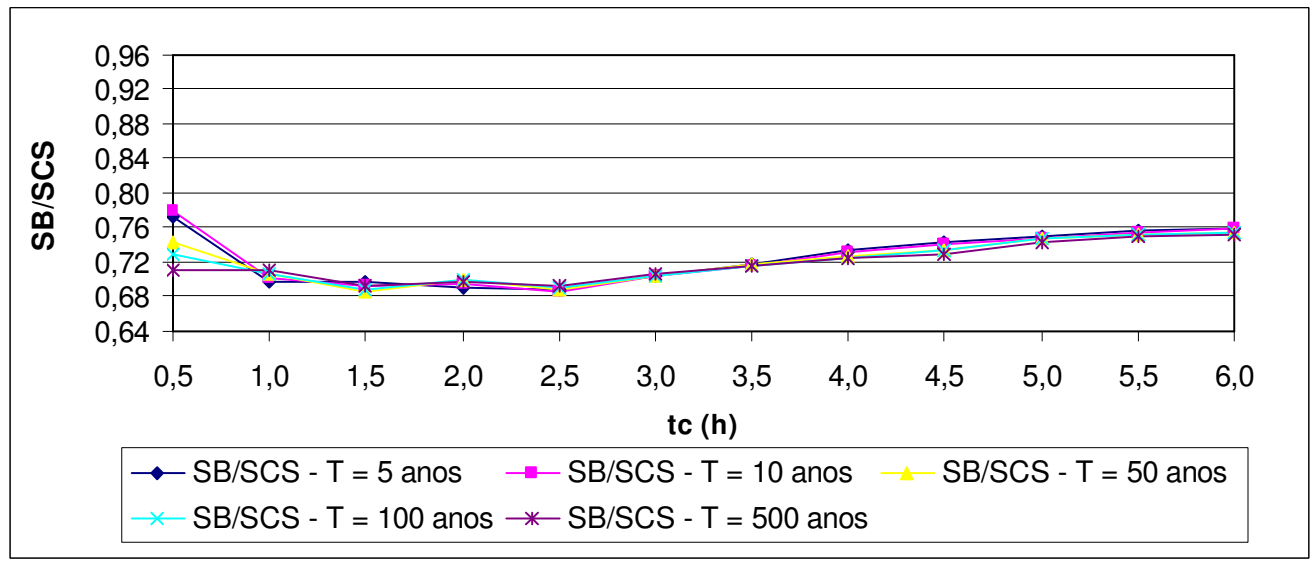

Figura 4.48 - Relação entre as vazões do método de Santa Bárbara e SCS, variando tempo de concentração e período de retorno

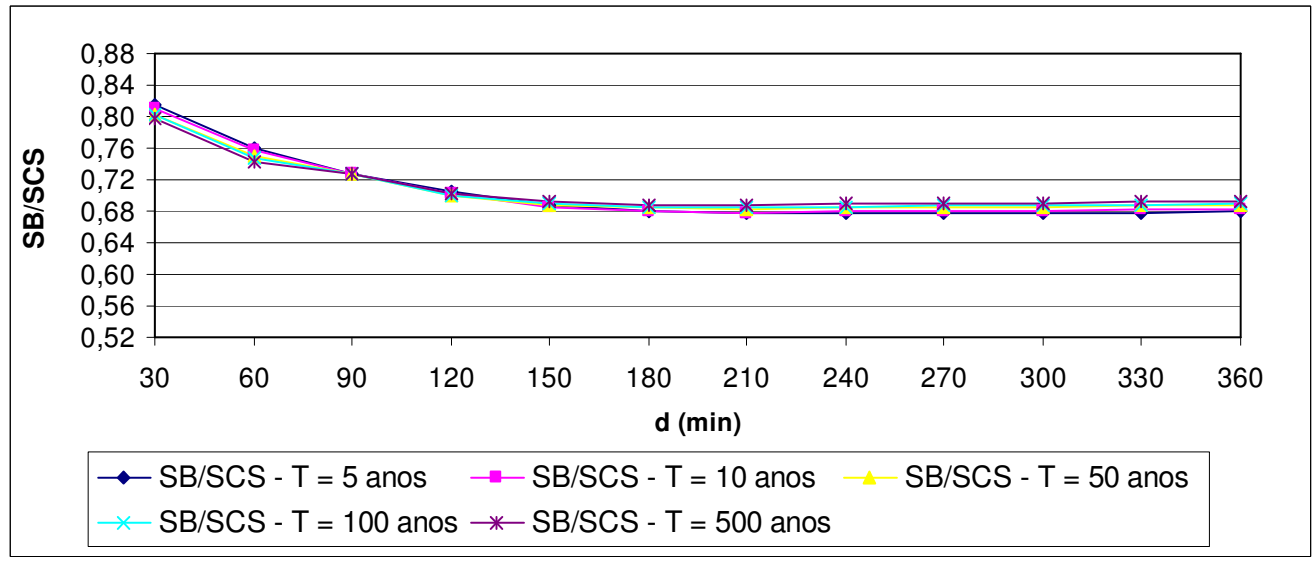

Figura 4.49 - Relação entre as vazões do método de Santa Bárbara e SCS, variando duração da chuva e período de retorno 
Das tabelas 4.20 a 4.23 e figuras 4.46 a 4.49 , nota-se que:

- Para a variável $\mathrm{CN}$, os valores das vazões de pico calculadas a partir do método de Santa Bárbara são em média 30\% menores que as calculadas a partir do método do SCS para os períodos de retorno avaliados;

- Os valores das vazões de pico variavam significativamente em função do valor da área de drenagem. Para a área de drenagem de 10 e $20 \mathrm{~km}^{2}$, as vazões de pico calculadas a partir do método de Santa Bárbara são aproximadamente $31 \%$ menores que as calculadas a partir do método do SCS. Para 40 km², 29\%; para 60 km², 27\%; para 80 km², 26\%; para 100 e 120 km², 25\%; para 140 e 160 km², 24\% e para 180 e 200 km², 23\%;

- Considerando as análises efetuadas para o tempo de concentração, a variação de vazão de pico é de $22 \%$ a $31 \%$. Em média, $28 \%$ menores que as vazões calculadas a partir do método do SCS;

- Para a duração da chuva de projeto, notam-se duas faixas de variação. Para duração da chuva de projeto de 30 a 90 minutos, a variação máxima é de 27\%, a mínima, $18 \%$ e a variação média de $24 \%$. Para a duração da chuva de projeto de 120 a 360 minutos, a variação máxima é de 32\%, a mínima, 29\% e a variação média de $31 \%$.

\subsubsection{Método do hidrograma unitário do SCS versus Clark}

Comparando-se o método do SCS e o método de Clark, a partir das análises de sensibilidade pode-se verificar que:

- Para a análise de sensibilidade quanto ao valor de $\mathrm{CN}$, a variação entre as vazões de pico são praticamente iguais. Já na análise de sensibilidade quanto à área de drenagem da bacia hidrográfica, as variações são praticamente iguais para todos os períodos de retorno avaliados, exceto para o intervalo de 20 a $40 \mathrm{~km}^{2}$. A diferença entre o método do SCS e Clark para este intervalo é de aproximadamente 7\%. Quando da análise de sensibilidade em relação ao 
tempo de concentração, as variações também são praticamente iguais, exceto para o intervalo de 0,5 a 1 hora, cuja diferença na variação das vazões de pico entre os métodos é de aproximadamente $10 \%$ para o período de retorno de 5 e 50 anos, 12\% para o período de retorno de 10 anos, 9\% para o período de retorno de 100 anos e 8\% para o período de retorno de 500 anos. Para as análises de sensibilidade quanto à duração da chuva de projeto, as variações na vazão de pico são praticamente as mesmas;

- Os tempos de ascensão e os tempos de base dos hidrogramas são diferentes entre os dois métodos e variam conforme mostram as tabelas 4.1, 4.3, $4.5 \mathrm{e}$ 4.9 (SCS) e 4.15, 4,16, 4.17 e 4.18 (Clark). Nota-se que os picos dos hidrogramas de cheia calculados pelo método de Clark ocorrem em um horário posterior aos obtidos pelo método do SCS. Esta análise também pode ser feita se observadas as figuras 4.50 a 4.57, que mostram o comportamento dos hidrogramas para o período de retorno de 100 anos para as análises de sensibilidade quanto ao valor de $\mathrm{CN}$, área de drenagem, duração da chuva de projeto e tempo de concentração;

- Os volumes dos hidrogramas são os mesmos, uma vez que são determinados em função do método de cálculo de chuva excedente que permaneceu o mesmo nestas análises.

As tabelas 4.24 a 4.27 mostram a diferença percentual entre a vazão de pico para o método de SCS e para o método de Clark, para as análises de sensibilidade quanto ao valor de $\mathrm{CN}$, área de drenagem, tempo de concentração e duração da chuva de projeto. A fórmula geral para a obtenção desta diferença é a seguinte:

$$
\left(Q_{\text {scs }}-Q_{\text {Clark }}\right) / Q_{\text {scs }}
$$

Onde:

- $\quad Q_{S C S}=$ vazão de pico referente à variável analisada, para o método do SCS;

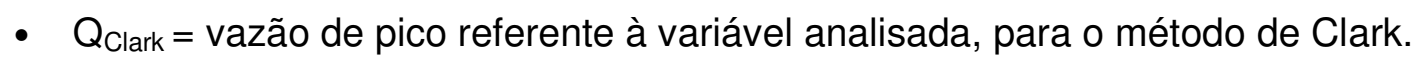




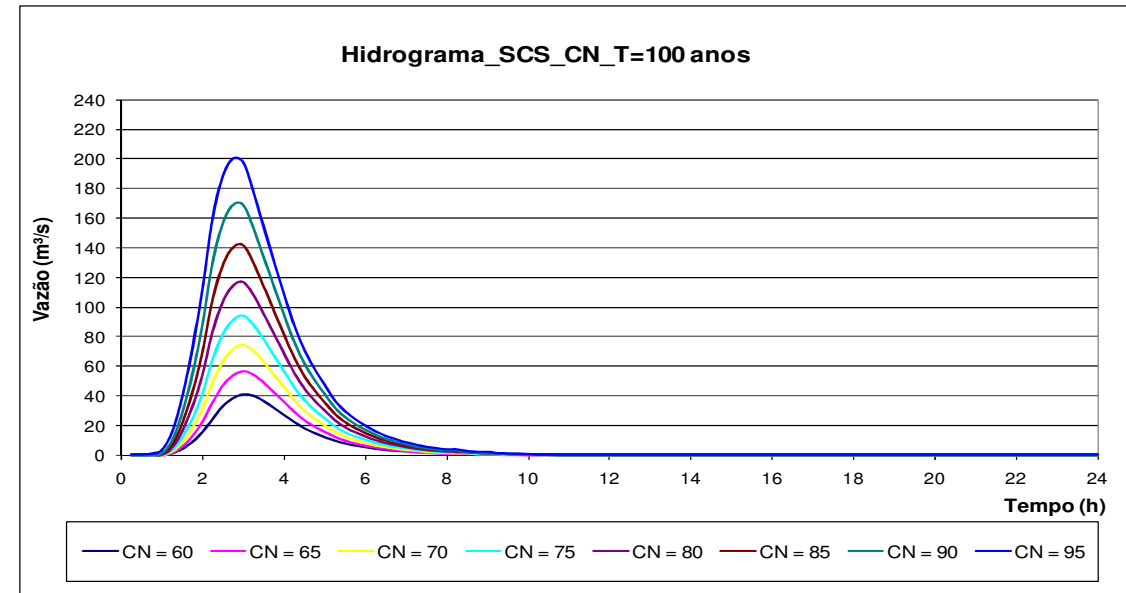

Figura 4.50 - Hidrograma de cheia para o método do SCS, variação do CN período de retorno de 100 anos

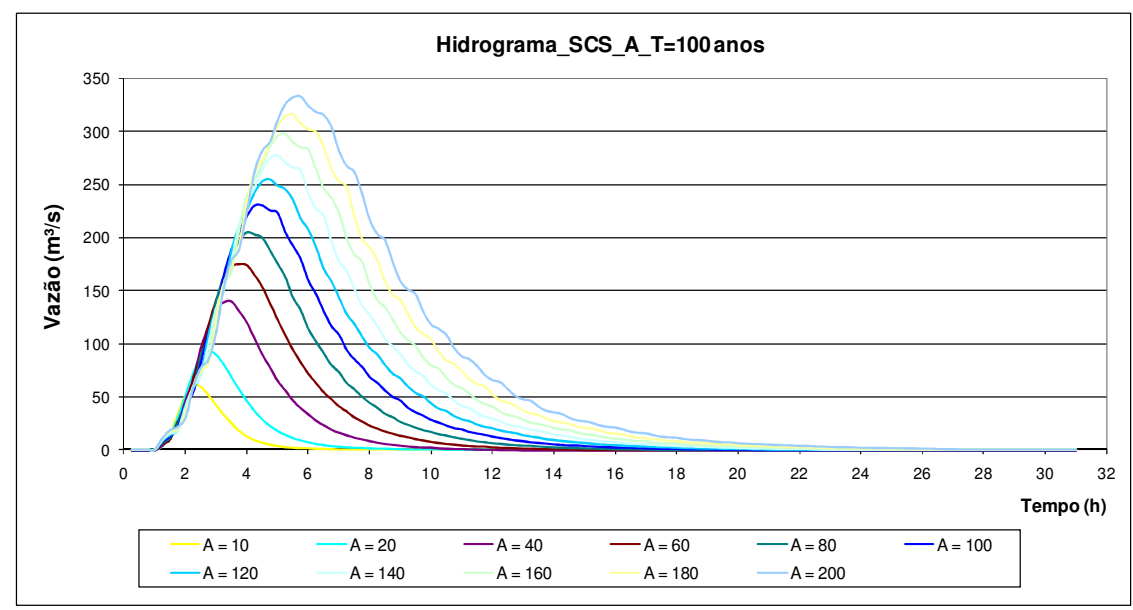

Figura 4.52 - Hidrograma de cheia para o método do SCS, variação da área de drenagem, período de retorno de 100 anos

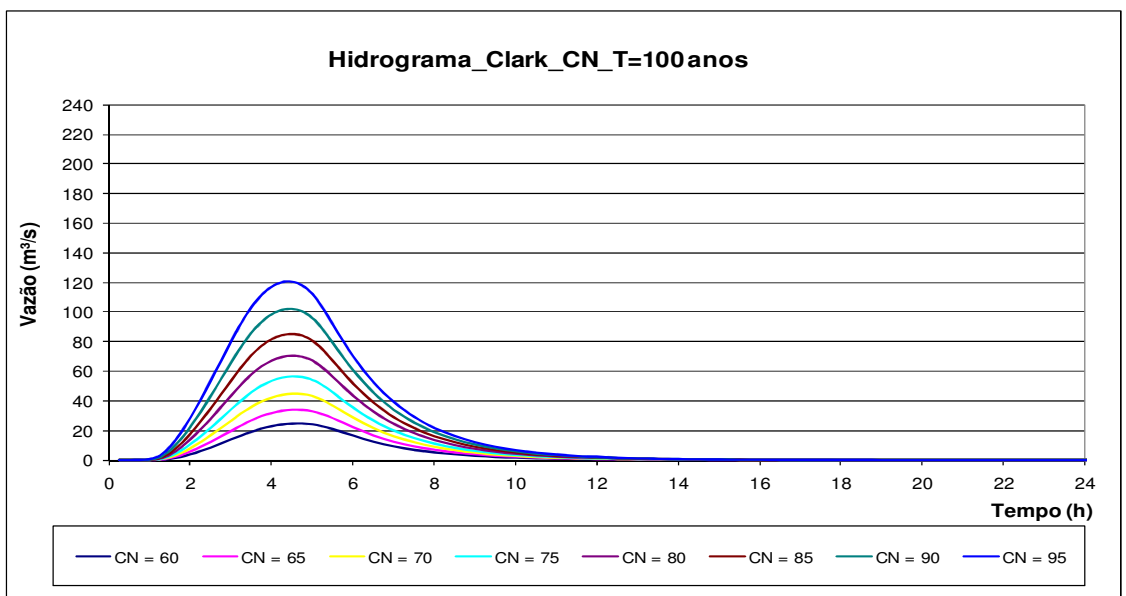

Figura 4.51 - Hidrograma de cheia para o método de Clark, variação do $\mathrm{CN}$, período de retorno de 100 anos

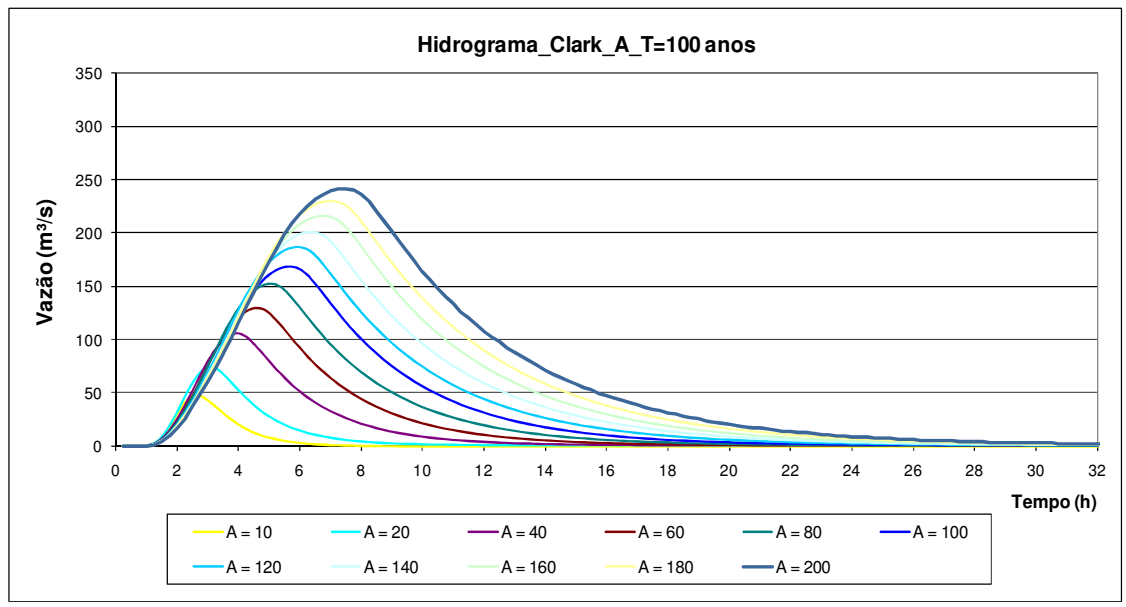

Figura 4.53 - Hidrograma de cheia para o método de Clark, variação da área de drenagem, período de retorno de 100 anos 


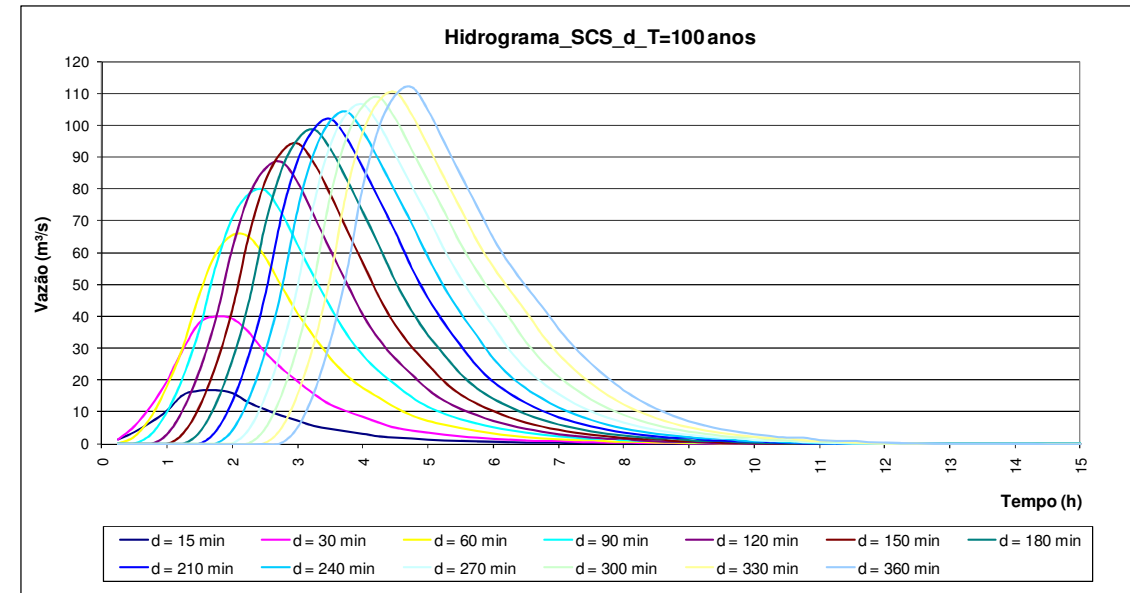

Figura 4.54 - Hidrograma de cheia para o método do SCS, variação da duração da chuva de projeto, período de retorno de 100 anos

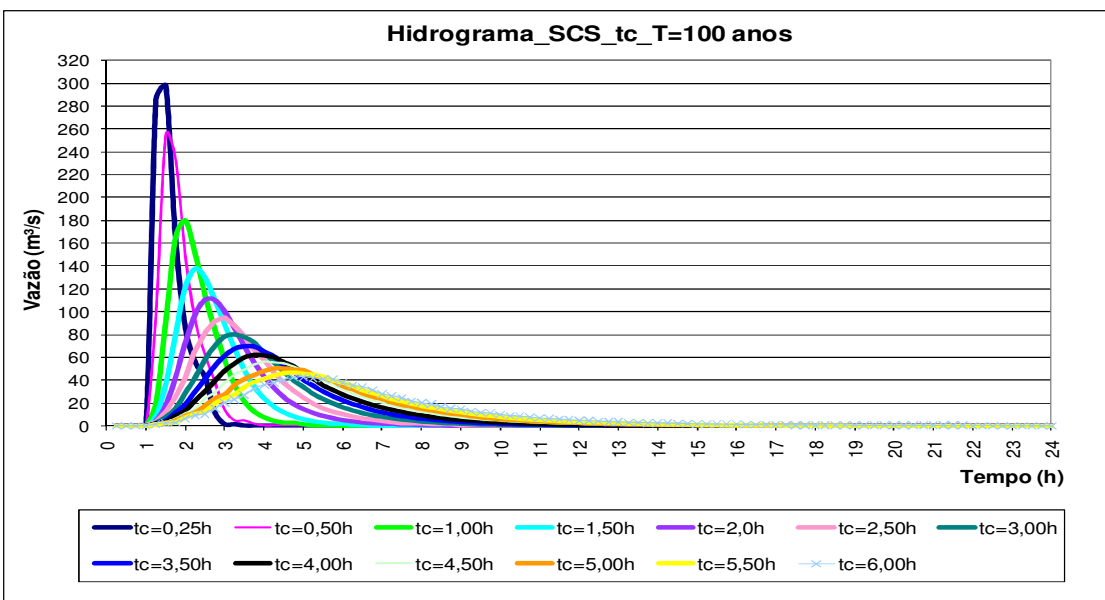

Figura 4.56 - Hidrograma de cheia para o método do SCS, variação do tempo de concentração, período de retorno de 100 anos

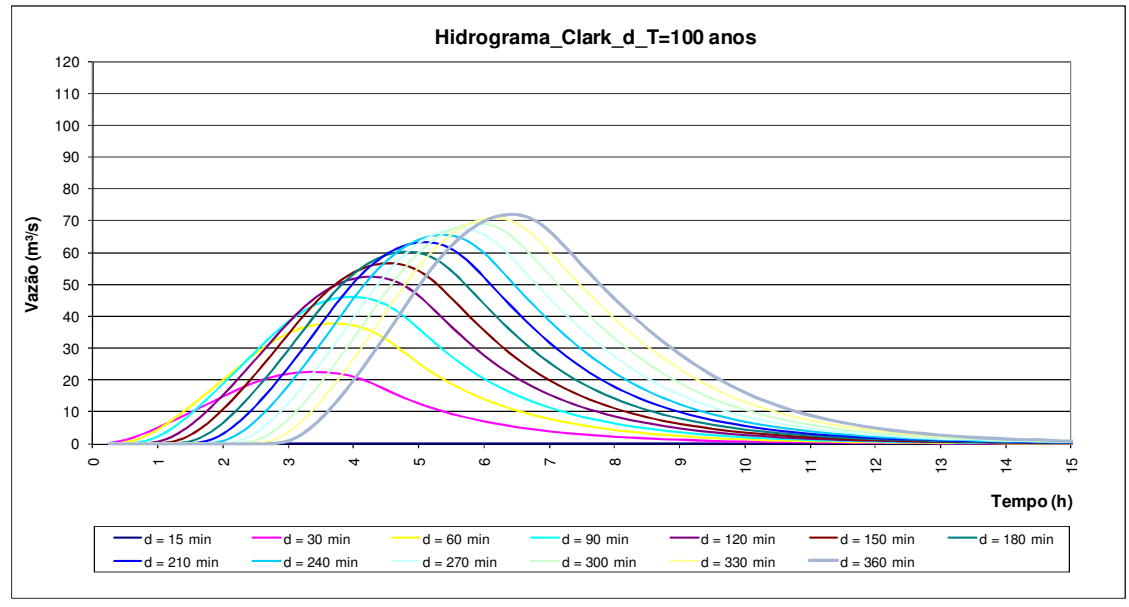

Figura 4.55 - Hidrograma de cheia para o método de Clark, variação da duração da chuva de projeto, período de retorno de 100 anos

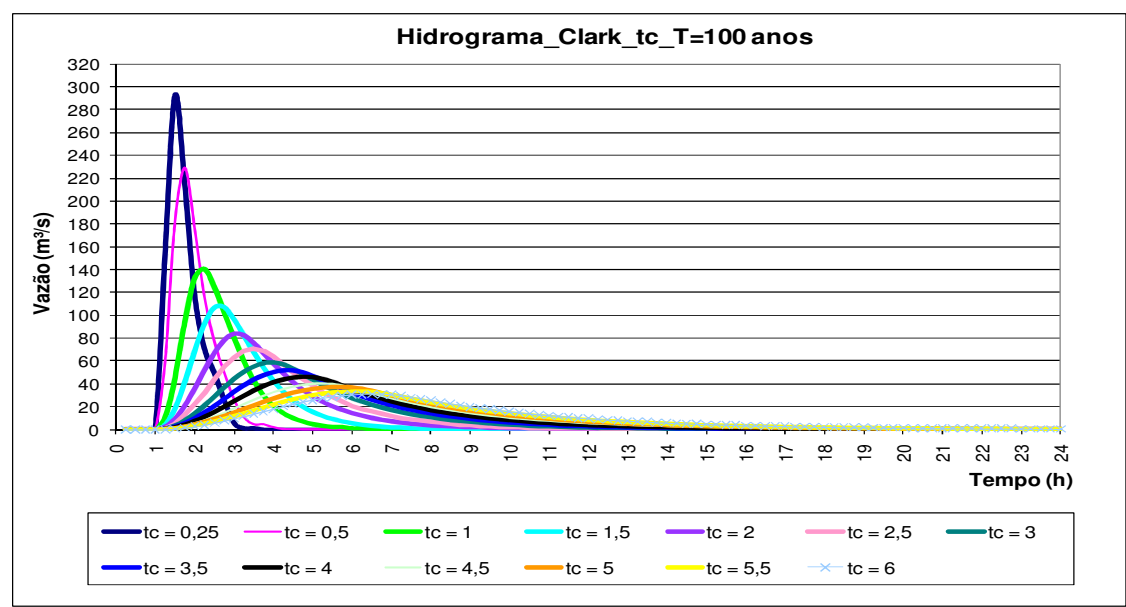

Figura 4.57 - Hidrograma de cheia para o método de Clark, variação do tempo de concentração, período de retorno de 100 anos 
Tabela 4.24 - Diferença percentual das vazões de pico entre os métodos de Clark e SCS, variando o CN

\begin{tabular}{|c|c|c|c|c|c|c|c|c|}
\hline \multirow{2}{*}{$\mathrm{CN}$} & \multicolumn{5}{|c|}{$\left(Q_{\text {SCS }}-Q_{\text {Clark }}\right) / Q_{\text {SCS }}$} & \multirow{2}{*}{ Média } & \multirow{2}{*}{ Máxima } & \multirow{2}{*}{ Mínima } \\
\hline & $\mathrm{T}=5$ anos & $\mathrm{T}=10$ anos & $\mathrm{T}=50$ anos & $\mathrm{T}=100$ anos & $\mathrm{T}=500$ anos & & & \\
\hline 60 & 0,40 & 0,39 & 0,39 & 0,39 & 0,40 & 0,39 & 0,40 & 0,39 \\
\hline 65 & 0,39 & 0,39 & 0,40 & 0,40 & 0,40 & 0,39 & 0,40 & 0,39 \\
\hline 70 & 0,39 & 0,40 & 0,40 & 0,40 & 0,40 & 0,40 & 0,40 & 0,39 \\
\hline 75 & 0,40 & 0,40 & 0,40 & 0,40 & 0,40 & 0,40 & 0,40 & 0,40 \\
\hline 80 & 0,40 & 0,40 & 0,40 & 0,40 & 0,40 & 0,40 & 0,40 & 0,40 \\
\hline 85 & 0,40 & 0,40 & 0,40 & 0,40 & 0,40 & 0,40 & 0,40 & 0,40 \\
\hline 90 & 0,40 & 0,40 & 0,40 & 0,39 & 0,40 & 0,40 & 0,40 & 0,39 \\
\hline 95 & 0,40 & 0,40 & 0,40 & 0,40 & 0,40 & 0,40 & 0,40 & 0,40 \\
\hline Média & 0,40 & 0,40 & 0,40 & 0,40 & 0,40 & - & - & - \\
\hline Máxima & 0,40 & 0,40 & 0,40 & 0,40 & 0,40 & - & - & - \\
\hline \multirow[t]{2}{*}{ Minima } & 0,39 & 0,39 & 0,39 & 0,39 & 0,40 & - & - & - \\
\hline & & & & & & & \multicolumn{2}{|c|}{ Média $=0,40$} \\
\hline
\end{tabular}

Tabela 4.25 - Diferença percentual das vazões de pico entre os métodos de Clark e SCS, variando a área de drenagem

\begin{tabular}{|c|c|c|c|c|c|c|c|c|}
\hline \multirow{2}{*}{$\begin{array}{c}\mathrm{A} \\
\left(\mathrm{km}^{2}\right)\end{array}$} & \multicolumn{5}{|c|}{$\left(Q_{S C S}-Q_{\text {Clark }}\right) / Q_{\text {SCS }}$} & \multirow{2}{*}{ Média } & \multirow{2}{*}{ Máxima } & \multirow{2}{*}{ Mínima } \\
\hline & $\mathrm{T}=5$ anos & $\mathrm{T}=10$ anos & $\mathrm{T}=50$ anos & $\mathrm{T}=100$ anos & $\mathrm{T}=500$ anos & & & \\
\hline 10 & 0,21 & 0,21 & 0,22 & 0,23 & 0,23 & 0,22 & 0,23 & 0,21 \\
\hline 20 & 0,21 & 0,21 & 0,21 & 0,21 & 0,21 & 0,21 & 0,21 & 0,21 \\
\hline 40 & 0,25 & 0,25 & 0,25 & 0,25 & 0,25 & 0,25 & 0,25 & 0,25 \\
\hline 60 & 0,26 & 0,26 & 0,26 & 0,26 & 0,26 & 0,26 & 0,26 & 0,26 \\
\hline 80 & 0,26 & 0,26 & 0,26 & 0,26 & 0,26 & 0,26 & 0,26 & 0,26 \\
\hline 100 & 0,27 & 0,27 & 0,27 & 0,27 & 0,27 & 0,27 & 0,27 & 0,27 \\
\hline 120 & 0,27 & 0,27 & 0,27 & 0,27 & 0,27 & 0,27 & 0,27 & 0,27 \\
\hline 140 & 0,27 & 0,27 & 0,27 & 0,27 & 0,27 & 0,27 & 0,27 & 0,27 \\
\hline 160 & 0,27 & 0,27 & 0,27 & 0,27 & 0,27 & 0,27 & 0,27 & 0,27 \\
\hline 180 & 0,27 & 0,27 & 0,27 & 0,27 & 0,27 & 0,27 & 0,27 & 0,27 \\
\hline 200 & 0,27 & 0,27 & 0,28 & 0,28 & 0,28 & 0,28 & 0,28 & 0,27 \\
\hline Média & 0,26 & 0,26 & 0,26 & 0,26 & 0,26 & - & - & - \\
\hline Máxima & 0,27 & 0,27 & 0,28 & 0,28 & 0,28 & - & - & - \\
\hline Minima & 0,21 & 0,21 & 0,21 & 0,21 & 0,21 & - & - & - \\
\hline
\end{tabular}

Média $=0,26$ 
Tabela 4.26 - Diferença percentual das vazões de pico entre os métodos de Clark e SCS, variando a duração do tempo de concentração

\begin{tabular}{|c|c|c|c|c|c|c|c|c|}
\hline \multirow{2}{*}{$\begin{array}{l}\text { tc } \\
\text { (h) }\end{array}$} & \multicolumn{5}{|c|}{$\left(Q_{s c s}-Q_{\text {Clark }}\right) / Q_{\text {scs }}$} & \multirow{2}{*}{ Média } & \multirow{2}{*}{ Máxima } & \multirow{2}{*}{ Mínima } \\
\hline & $\mathrm{T}=5$ anos & $\mathrm{T}=10$ anos & $\mathrm{T}=50$ anos & $\mathrm{T}=100$ anos & $\mathrm{T}=500$ anos & & & \\
\hline 0,5 & 0,08 & 0,06 & 0,09 & 0,10 & 0,12 & 0,09 & 0,12 & 0,06 \\
\hline 1 & 0,21 & 0,22 & 0,22 & 0,22 & 0,22 & 0,22 & 0,22 & 0,21 \\
\hline 1,5 & 0,20 & 0,21 & 0,22 & 0,22 & 0,23 & 0,22 & 0,23 & 0,20 \\
\hline 2 & 0,24 & 0,24 & 0,24 & 0,24 & 0,24 & 0,24 & 0,24 & 0,24 \\
\hline 2,5 & 0,25 & 0,25 & 0,25 & 0,25 & 0,25 & 0,25 & 0,25 & 0,25 \\
\hline 3 & 0,26 & 0,26 & 0,26 & 0,26 & 0,26 & 0,26 & 0,26 & 0,26 \\
\hline 3,5 & 0,26 & 0,26 & 0,26 & 0,26 & 0,26 & 0,26 & 0,26 & 0,26 \\
\hline 4 & 0,26 & 0,26 & 0,26 & 0,26 & 0,26 & 0,26 & 0,26 & 0,26 \\
\hline 4,5 & 0,27 & 0,27 & 0,27 & 0,27 & 0,27 & 0,27 & 0,27 & 0,27 \\
\hline 5 & 0,31 & 0,27 & 0,27 & 0,27 & 0,27 & 0,28 & 0,31 & 0,27 \\
\hline 5,5 & 0,28 & 0,28 & 0,28 & 0,28 & 0,28 & 0,28 & 0,28 & 0,28 \\
\hline 6 & 0,28 & 0,28 & 0,28 & 0,28 & 0,28 & 0,28 & 0,28 & 0,28 \\
\hline Média & 0,24 & 0,24 & 0,24 & 0,24 & 0,25 & - & - & - \\
\hline Máxima & 0,31 & 0,28 & 0,28 & 0,28 & 0,28 & - & - & - \\
\hline Minima & 0,08 & 0,06 & 0,09 & 0,10 & 0,12 & - & - & - \\
\hline & & & & & & & & $a=0,26$ \\
\hline
\end{tabular}

Tabela 4.27 - Diferença percentual das vazões de pico entre os métodos de Clark e SCS, variando a duração da chuva de projeto

\begin{tabular}{|c|c|c|c|c|c|c|c|c|}
\hline \multirow{2}{*}{$\begin{array}{c}\mathrm{d} \\
(\mathrm{min})\end{array}$} & \multicolumn{5}{|c|}{$\left(Q_{S C S}-Q_{\text {Clark }}\right) / Q_{S C S}$} & \multirow{2}{*}{ Média } & \multirow{2}{*}{ Máxima } & \multirow{2}{*}{ Mínima } \\
\hline & $\mathrm{T}=5$ anos & $\mathrm{T}=10$ anos & $\mathrm{T}=50$ anos & $\mathrm{T}=100$ anos & $\mathrm{T}=500$ anos & & & \\
\hline 30 & 0,43 & 0,43 & 0,43 & 0,43 & 0,43 & 0,43 & 0,43 & 0,43 \\
\hline 60 & 0,42 & 0,42 & 0,42 & 0,42 & 0,43 & 0,42 & 0,43 & 0,42 \\
\hline 90 & 0,42 & 0,42 & 0,42 & 0,42 & 0,42 & 0,42 & 0,42 & 0,42 \\
\hline 120 & 0,41 & 0,41 & 0,41 & 0,41 & 0,41 & 0,41 & 0,41 & 0,41 \\
\hline 150 & 0,40 & 0,40 & 0,40 & 0,40 & 0,40 & 0,40 & 0,40 & 0,40 \\
\hline 180 & 0,38 & 0,39 & 0,39 & 0,39 & 0,39 & 0,39 & 0,39 & 0,38 \\
\hline 210 & 0,37 & 0,38 & 0,38 & 0,38 & 0,38 & 0,38 & 0,38 & 0,37 \\
\hline 240 & 0,36 & 0,37 & 0,37 & 0,37 & 0,37 & 0,37 & 0,37 & 0,36 \\
\hline 270 & 0,35 & 0,36 & 0,37 & 0,37 & 0,37 & 0,36 & 0,37 & 0,35 \\
\hline 300 & 0,35 & 0,36 & 0,36 & 0,36 & 0,37 & 0,36 & 0,37 & 0,35 \\
\hline 330 & 0,35 & 0,35 & 0,36 & 0,36 & 0,36 & 0,36 & 0,36 & 0,35 \\
\hline 360 & 0,35 & 0,35 & 0,36 & 0,36 & 0,36 & 0,36 & 0,36 & 0,35 \\
\hline Média & 0,38 & 0,39 & 0,39 & 0,39 & 0,39 & - & - & - \\
\hline Máxima & 0,43 & 0,43 & 0,43 & 0,43 & 0,43 & - & - & - \\
\hline Minima & 0,35 & 0,35 & 0,36 & 0,36 & 0,36 & - & - & - \\
\hline
\end{tabular}


As figuras 4.58 a 4.61 mostram a relação entre os valores dos métodos de Clark e do método do SCS, para o valor de CN, área de drenagem, tempo de concentração e duração da chuva de projeto.

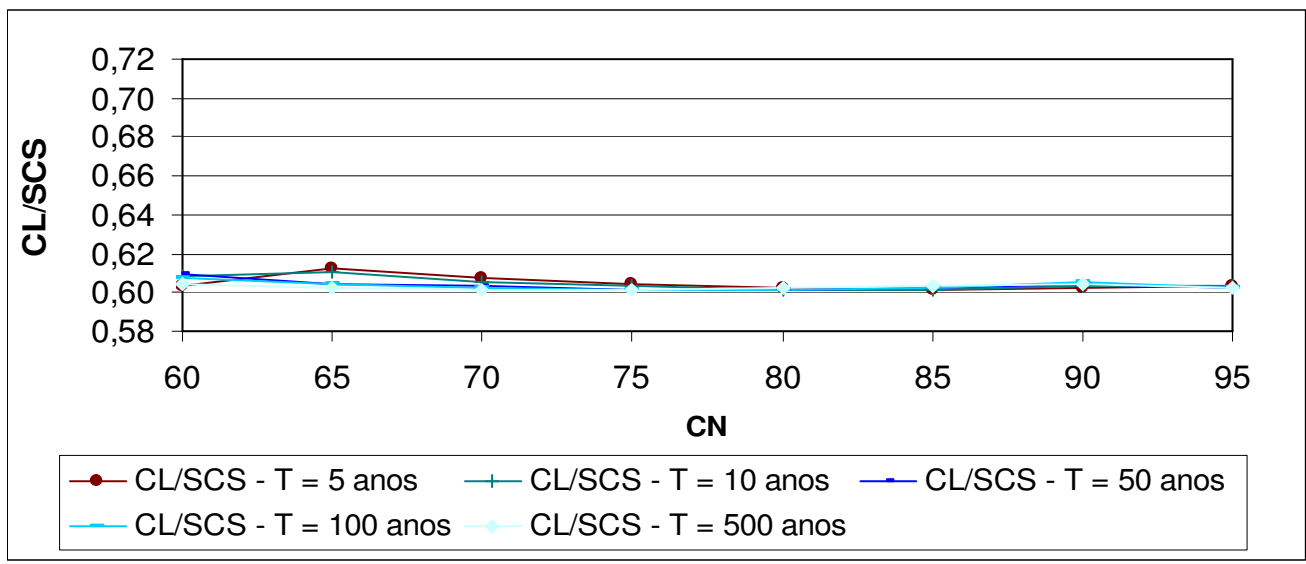

Figura 4.58 - Relação entre as vazões do método de Clark e SCS, variando CN e período de retorno

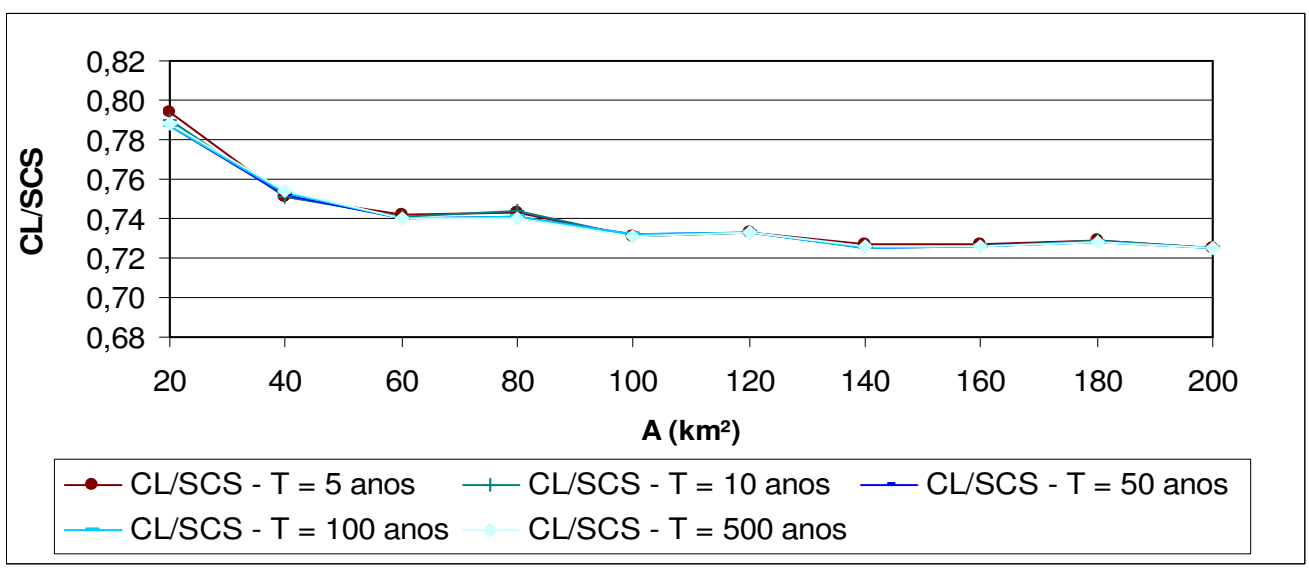

Figura 4.59 - Relação entre as vazões do método de Clark e SCS, variando área de drenagem e período de retorno

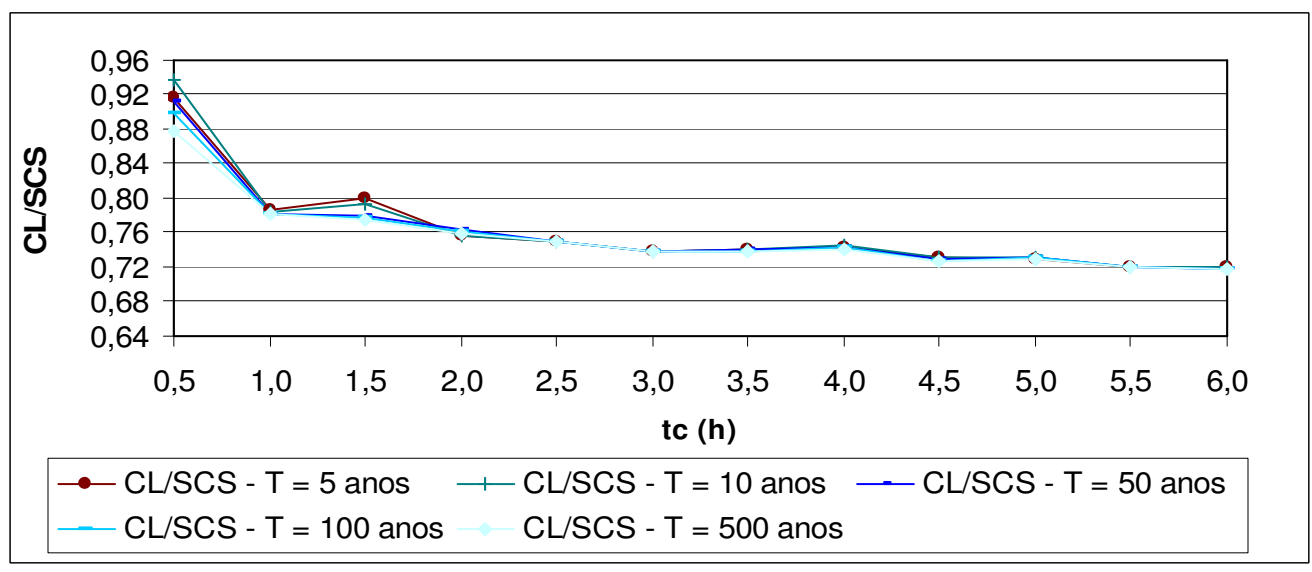

Figura 4.60 - Relação entre as vazões do método de Clark e SCS, variando tempo de concentração e período de retorno 


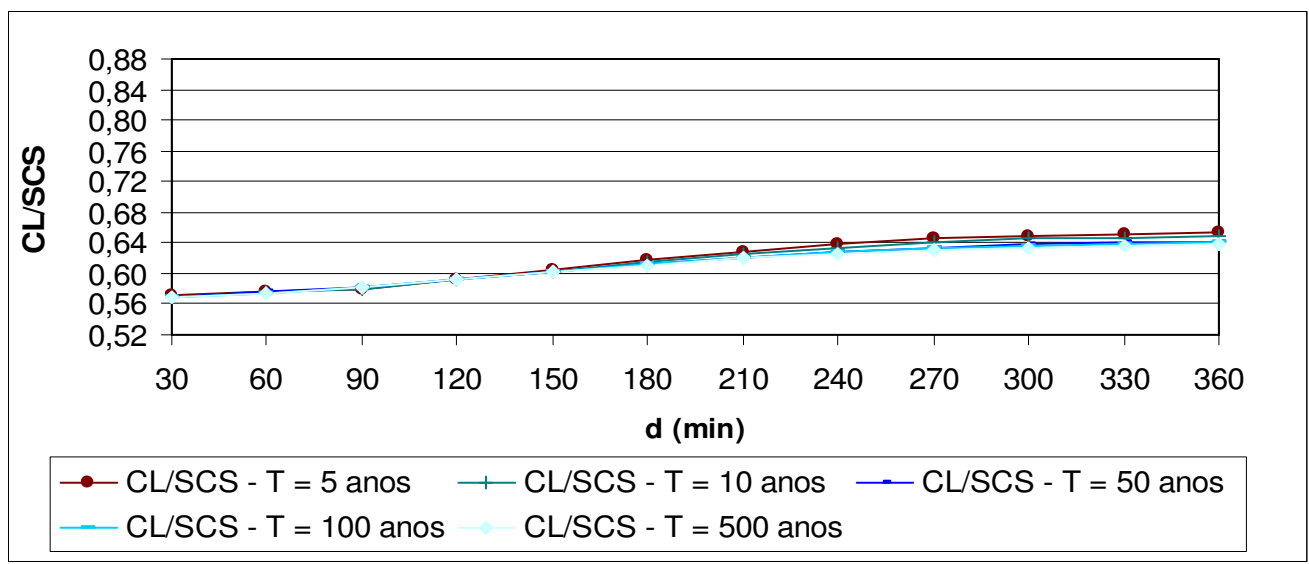

Figura 4.61 - Relação entre as vazões do método de Clark e SCS, variando tempo duração da chuva e período de retorno

Das tabelas 4.24 a 4.27 e figuras 4.58 a 4.61 , nota-se que:

- Para a variável $\mathrm{CN}$, os valores das vazões de pico calculadas a partir do método de Clark são, em média, 40\% menores que as calculadas a partir do método do SCS para os períodos de retorno avaliados;

- Os valores das vazões de pico variavam em função do valor da área de drenagem. Para a área de drenagem de $10 \mathrm{~km}^{2}$, a vazão de pico calculada a partir do método de Clark é aproximadamente $22 \%$ menor que as calculadas a partir do método do SCS. Para $20 \mathrm{~km}^{2}, 21 \%$, para $40 \mathrm{~km}^{2}, 25 \%$; para $60 \mathrm{e}$ $80 \mathrm{~km}^{2}, 26 \%$; de 100 a $180 \mathrm{~km}^{2}, 27 \%$ e para $200 \mathrm{~km}^{2}, 28 \%$;

- Para duração da chuva de projeto, a variação máxima é de $43 \%$, a mínima, $35 \%$ e a variação média de 39\%;

- Considerando as análises efetuadas para o tempo de concentração, a variação de vazão de pico para o tempo de concentração de 0,5 horas é, em média, para todos os períodos de retorno, 9\%. Para o intervalo de 1 a 6 horas, a variação de vazão de pico é de $20 \%$ a $31 \%$. - em média $28 \%$ menores que as vazões calculadas a partir do método do SCS. 
De maneira geral, em média, considerando-se os parâmetros avaliados, as vazões calculadas pelo método de Santa Bárbara são $28 \%$ menores que as calculadas pelo método do SCS. Em relação ao método de Clark, são, em média, 35\% menores que as calculadas pelo método do SCS. 


\section{ESTUDO DE APLICAÇÃO PRÁTICA}

Neste estudo de aplicação prática, foi desenvolvido o dimensionamento hidráulico de um canal e de um vertedor retangular de soleira livre.

O objetivo deste estudo de aplicação prática foi avaliar a influência no dimensionamento da altura do canal e na determinação da carga hidráulica sobre a soleira do vertedor, quando da alteração das variáveis que determinam o hidrograma de projeto, tais como: o valor do $\mathrm{CN}$, o tempo de concentração e a duração da chuva de projeto.

Nestas análises, não foram consideradas medidas de otimização de projeto, ou seja, as estruturas hidráulicas não foram dimensionadas, por exemplo, considerando-se sua máxima eficiência hidráulica ou a condição de mínimo custo. Com exceção da variação do nível d'água, todas as características do canal, do reservatório de controle de cheias e do vertedor foram mantidas.

Apesar desta pesquisa não se ater a avaliar questões de segurança e economia, tentou-se uma avaliação simbólica destes fatores quando se analisou o dimensionamento da altura do canal.

$\mathrm{Na}$ realização deste estudo, considerou-se um cenário de projeto representado por uma bacia hidrográfica, na qual as variáveis necessárias à determinação do hidrograma de projeto foram definidas como ideais. Imaginando-se que estas variáveis não foram coerentemente definidas, criaram-se os cenários alternativos.

As vazões e os hidrogramas de dimensionamento foram determinados utilizando-se como ferramenta de cálculo o SSD ABC 6.

As considerações teóricas para a determinação das características do canal, do reservatório de controle de cheias e do vertedor retangular de soleira livre são apresentadas sucintamente no início deste capítulo. As demais considerações teóricas utilizadas neste estudo de aplicação prática podem ser consultadas no Capítulo 2. 


\subsection{FUNDAMENTOS TEÓRICOS}

Canais e reservatórios de contenção de cheias são estruturas típicas de um sistema de drenagem urbana.

A drenagem urbana consiste em um conjunto de obras e medidas cujos principais objetivos são deter, reter ou afastar as águas excedentes de áreas críticas durante um intervalo de tempo, minimizando assim, os prejuízos causados pelas enchentes em ambientes urbanos.

Em resumo, um sistema de drenagem urbana é constituído pelo sistema de micro e macro drenagem. De maneira geral, as obras de microdrenagem são feitas em áreas onde os canais naturais não estão bem definidos. As obras típicas são sarjetas, bocas de lobo e bueiros. O objetivo de tais obras é o de evitar alagamentos localizados, problemas de trânsito e transtornos aos transeuntes. Hidrologicamente, estas obras são dimensionadas baseadas em vazões dadas pelo método racional, aplicável a bacias hidrográficas com área de drenagem inferiores a $5 \mathrm{~km}^{2}$. As obras de macrodrenagem são feitas em áreas onde os canais naturais são bem definidos e concentram as águas oriundas de parte da bacia hidrográfica. As obras típicas são canais artificiais e reservatórios de controle de cheias. O objetivo destas obras é o de evitar enchentes de maior porte que gerem problemas de saúde pública, danos de grande monta e desorganização da atividade urbana. As obras de macrodrenagem são dimensionadas em função de vazões calculadas pelos métodos sintéticos de obtenção de hidrogramas de projetos.

Canalizar significa modificar ou alterar a seção e/ou o traçado natural de um curso d'água. Existem dois tipos de canalização: as estruturas construídas a céu aberto, os canais, e as estruturas de contorno fechado, as galerias. As seções geométricas mais comuns para os canais são as seções: trapezoidal, retangular e circular. Os tipos de revestimentos mais comuns são: terra, enrocamento, pedra argamassada, concreto, gabião e terra armada. Ilustrativamente, a Figura 5.1 apresenta os tipos de revestimentos citados para os canais em formato trapezoidal e retangular. (DAEE, 2008). Os revestimentos estão ordenados sob o aspecto econômico. 
a1) terra

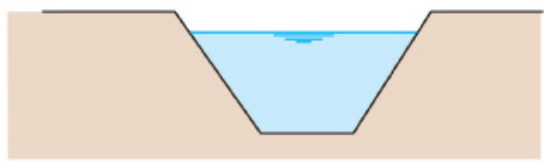

a3) gabião

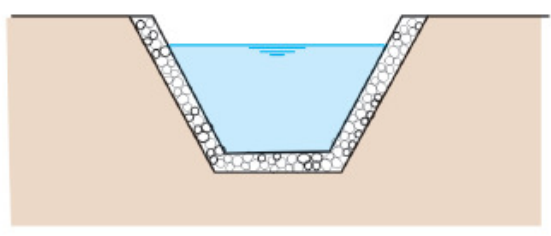

a5) concreto com fundo natural

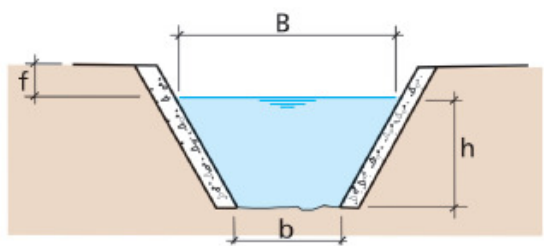

a2) enrocamento

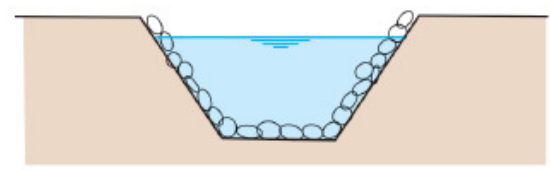

a4) pedra argamassada com fundo natural

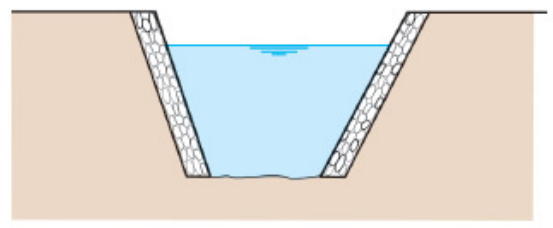

a6) concreto

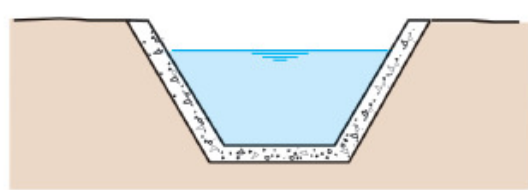

b1) gabião

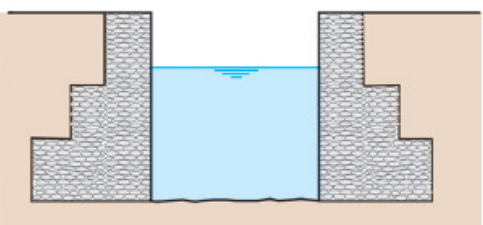

b3) concreto (terra armada)

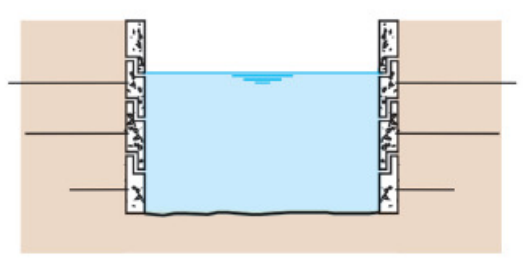

$\mathrm{b}=$ largura do canal

$\mathrm{h}=$ profundidade da lâmina d'água

$f=$ borda livre b2) pedra argamassada

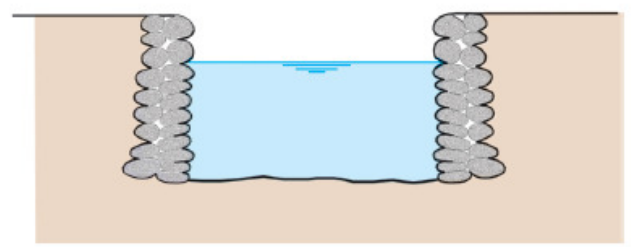

b4) concreto

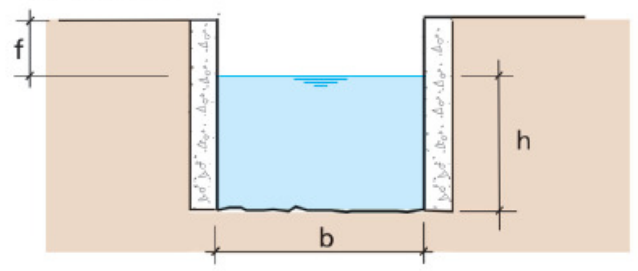

Figura 5.1 - Tipos de revestimentos para canais trapezoidais e retangulares Fonte: DAEE, 2008. p. 25.

Em geral, os canais são constituídos por trechos de diferentes tipos de revestimento, diversas seções transversais e declividade de fundo variável. Estas características conduzem a escoamentos gradual ou bruscamente variados para os quais é 
necessária a análise de curvas de remanso, no primeiro caso, ou, por exemplo, a análise de ressalto hidráulico, no segundo caso (CANHOLI, 2005).

Em casos mais complexos, é feita a utilização do regime não permanente na definição das características dos canais. Para casos mais simples, onde possa ser considerada a possibilidade de análise trecho a trecho do canal, para as quais as simplificações matemáticas são aceitáveis, a determinação das linhas d'água é feita a partir da teoria do regime permanente uniforme.

As grandezas fundamentais relativas à aplicação da teoria do regime permanente uniforme para o dimensionamento hidráulico de canais estão descritas a seguir e apresentadas esquematicamente na Figura 5.2.
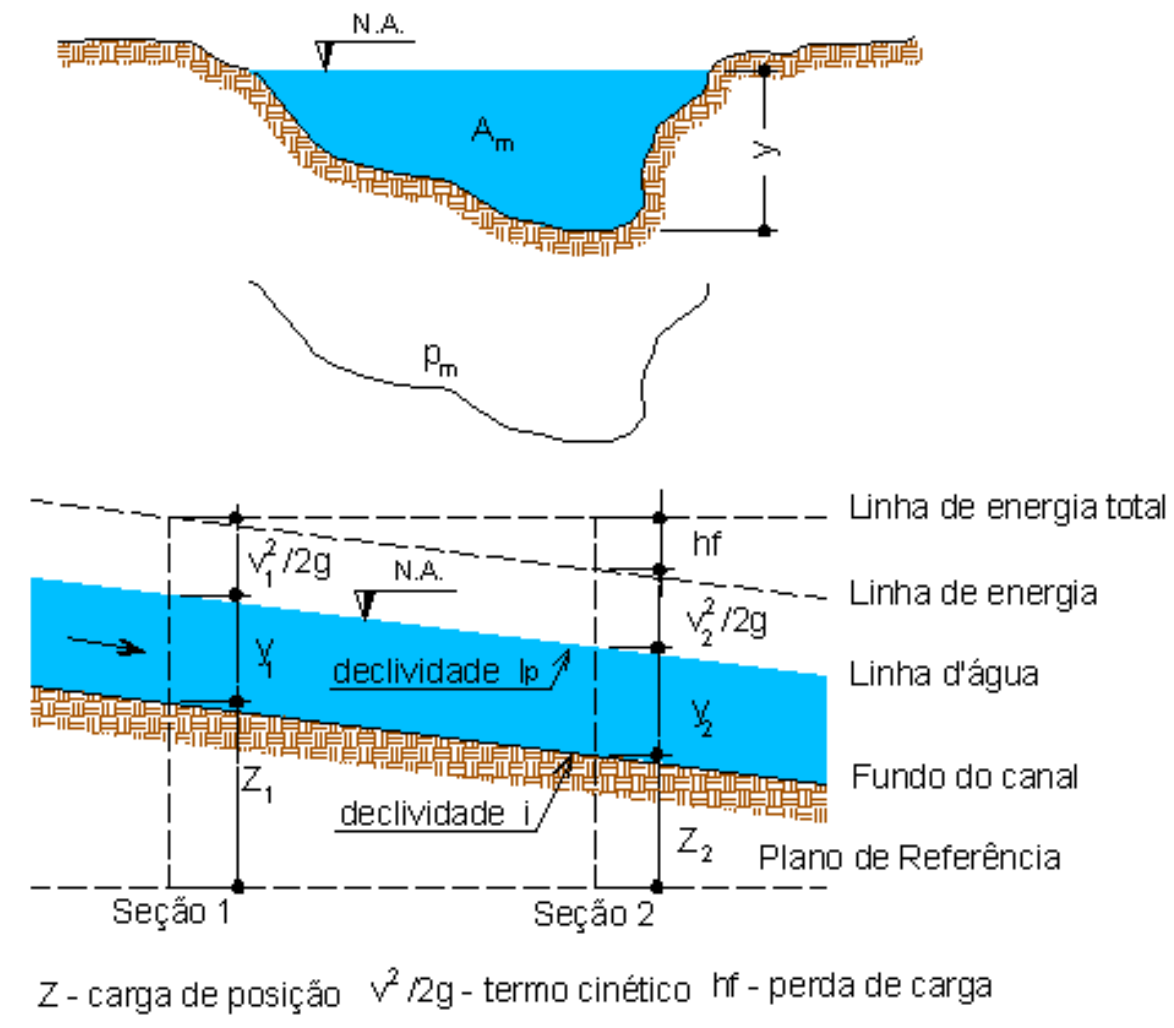

Figura 5.2 - Grandezas envolvidas no dimensionamento de canais

- Área Molhada $\left(A_{m}\right)$ : é a área da seção transversal do escoamento, normal à direção do fluxo; 
- Perímetro Molhado $\left(P_{m}\right)$ : é o comprimento da linha de contato do líquido com a fronteira sólida da seção do canal (fundo e paredes). A superfície livre, portanto, não faz parte do perímetro molhado;

- Raio Hidráulico $(R h)$ : é a relação entre a área molhada e o perímetro molhado;

- Diâmetro Hidráulico (Dh): corresponde a quatro vezes o raio hidráulico;

- Profundidade (y): é a distância vertical entre o ponto mais baixo da seção e a superfície livre;

- Declividade longitudinal do fundo do canal, representada por i;

- Declividade piezométrica ou da linha d'água, representada por Ip;

- Declividade da linha de energia, correspondente a variação da energia da corrente no sentido do escoamento, representada por $\mathrm{J}$;

O escoamento em regime uniforme ocorre quando em um canal com geometria e declividade constantes, a profundidade, a área molhada e a velocidade em todas as seções transversais são constantes e há o equilíbrio entre a energia disponível e a despendida pelo fluxo, de maneira a admitir-se que a linha de energia é paralela a linha d'água.

A eq.(5.1), denominada equação de Chézy, desenvolvida em 1769, representa o regime permanente uniforme.

$$
v=C \cdot \sqrt{R h . i}
$$

Onde:

- v: é a velocidade em $\mathrm{m} / \mathrm{s}$;

- C: é o coeficiente de Chézy;

- Rh: é o raio hidráulico, em m;

- i: é a declividade do fundo em $\mathrm{m} / \mathrm{m}$; 
Da equação da continuidade, $Q=v \cdot A_{m}$, pode-se reescrever a eq.(5.1), em termos da vazão, como mostra a eq. (5.2):

$$
Q=C \cdot A_{m} \cdot \sqrt{R h . i}
$$

Onde:

- Q: é a vazão em m³/s;

- C: é o coeficiente de Chézy;

- $A_{m}$ : é a área molhada em $\mathrm{m}^{2}$;

- Rh: é o raio hidráulico em $\mathrm{m}$;

- i: é a declividade do fundo $\mathrm{em} \mathrm{m} / \mathrm{m}$;

Nota-se que todos os elementos são geométricos, exceto a grandeza $C$, que é função da rugosidade, forma da seção e profundidade. Diversos autores propuseram fórmulas para a obtenção do valor de $\mathrm{C}$. Na prática $\mathrm{O}$ valor é obtido mediante experimentos de campo e de laboratório. A expressão mais conhecida para a determinação do coeficiente de Chézy é atribuída a Manning-Strickler (1889), apresentada a seguir:

$$
C=\frac{1}{n} R h^{\frac{1}{6}}
$$

Onde:

- C: é o coeficiente de Chézy;

- Rh: é o raio hidráulico, em m;

Associando a equação de Manning-Strickler à equação de Chézy, obtém-se a expressão de uso corrente e muito disseminada no meio técnico para o dimensionamento de canais.

$$
Q=\frac{1}{n} \cdot A_{m} \cdot R h^{2 / 3} \cdot i^{1 / 2}
$$


Onde:

- Q: é a vazão em m³/s;

- $A_{m}$ : é a área molhada em $\mathrm{m}^{2}$;

- Rh: é o raio hidráulico em m;

- i: é a declividade do fundo em $\mathrm{m} / \mathrm{m}$;

- $\mathrm{n}$ : é o coeficiente de Manning.

O valor de $\mathrm{n}$ de Manning depende de inúmeras variáveis, além da rugosidade da superfície do canal. O efeito da vegetação, as irregularidades nas paredes, as variações na seção hidráulica, as obstruções, o traçado do canal, a sedimentação e erosão, além das profundidades do canal, devem ser considerados nessa estimativa. (CANHOLI, 2005).

Chow (1973), baseado em trabalhos do U.S. Geological Survey, apresentou uma tabela expressiva de valores de $n$ para vários tipos e condições de canais. Por meio dessa referência e de outras, como a de Mays (2001), Canholi (2005) elaborou uma relação dos valores do coeficiente de Manning, voltado para os tipos de canais mais frequentes nas condições urbanas brasileiras.

O Departamento de Água e Energia do Estado de São Paulo sugere para projetos de canalização os valores dos coeficientes de Manning apresentados na Tabela 5.1.

\begin{tabular}{lc}
\multicolumn{1}{c}{ Tabela 5.1 - Valores de Manning sugeridos pelo DAEE } \\
\hline Terra & $\mathbf{n}$ \\
Rachão & 0,035 \\
Gabião & 0,035 \\
Pedra argamassada & 0,028 \\
Aço corrugado & 0,025 \\
Concreto & 0,024 \\
\hline
\end{tabular}

Fonte: DAEE, 2005. p. 28.

Os valores de velocidades máximas permissíveis relativas a alguns tipos de revestimentos, sugeridos pelo DAEE estão na Tabela 5.2. Os limites descritos nesta tabela são recomendados como valores de referência, com base em experiência de projetos. 
Tabela 5.2 - Limites superiores para velocidades em canais

\begin{tabular}{|c|c|}
\hline Revestimento & $\mathbf{v}_{\text {máx }}(\mathrm{m} / \mathrm{s})$ \\
\hline Terra & 1,5 \\
\hline Gabião & 2,5 \\
\hline Pedra argamassada & 3,0 \\
\hline Concreto & 4,0 \\
\hline
\end{tabular}

Fonte: DAEE, 2008. p. 29.

O DAEE sugere que deva ser mantida uma borda livre mínima que corresponda a $10 \%$ da lâmina d'água estimada para a cheia de projeto, mas não inferior a $0,4 \mathrm{~m}$ (b $\geq$ $0,1 y$, com a condição $b \geq 0,4 \mathrm{~m})$.

Os reservatórios de controle de cheias, também denominados "piscinões", são os mais difundidos na tentativa de mitigar os problemas de enchentes em áreas urbanas. Em São Paulo são 27 piscinões construídos. Estão em obras os piscinões RC-4a/Ford Fábrica, RC-5/Taboão e RPI-8/Olaria. A Tabela 5.3 apresenta a relação dos piscinões de São Paulo, por bacia, curso d’água, município e sua capacidade de armazenamento.

Tabela 5.3 - Relação dos piscinões do Estado de São Paulo

(continua)

\begin{tabular}{|c|c|c|c|c|}
\hline Bacia & Nome & Curso D’ Água & Município & Volume $\left(\mathrm{m}^{3}\right)$ \\
\hline \multirow{11}{*}{$\begin{array}{l}\text { Alto } \\
\text { Tamanduateí }\end{array}$} & RC-3 / Mercedes Bens & $\begin{array}{l}\text { Ribeirão dos } \\
\text { Couros }\end{array}$ & Diadema & 140.000 \\
\hline & $\begin{array}{l}\text { RC-2 / Piraporinha / Casa } \\
\text { grande }\end{array}$ & $\begin{array}{l}\text { Ribeirão dos } \\
\text { Couros }\end{array}$ & Diadema & 85.000 \\
\hline & RC-6 / Ecovias Imigrantes & Ribeirão Capela & Diadema & 120.000 \\
\hline & RT-1a / Paço Municipal & Córrego Taboão & Mauá & 136.000 \\
\hline & RT-3 / Petrobras & Rio Tamanduateí & Mauá & 800.000 \\
\hline & RT-3 a / Corumbé & Córrego Corumbé & Mauá & 105.000 \\
\hline & $\begin{array}{l}\text { RM-9 / Faculdade de } \\
\text { Medicina }\end{array}$ & $\begin{array}{l}\text { Ribeirão dos } \\
\text { Meninos }\end{array}$ & Santo André & 120.000 \\
\hline & RC-1 / Vila Rosa & $\begin{array}{l}\text { Ribeirão dos } \\
\text { Couros }\end{array}$ & SBC & 113.450 \\
\hline & $\begin{array}{l}\text { RM-2/RM-3 / Volks } \\
\text { Demarchi }\end{array}$ & $\begin{array}{l}\text { Ribeirão dos } \\
\text { Meninos }\end{array}$ & SBC & 170.000 \\
\hline & RM-4 / Chryler & Córrego Chrysler & SBC & 190.000 \\
\hline & RM-5 / Casa Grande & $\begin{array}{l}\text { Ribeirão dos } \\
\text { Meninos }\end{array}$ & SBC & 235.000 \\
\hline
\end{tabular}


Tabela 5.3 - Relação dos piscinões do Estado de São Paulo

(conclusão)

\begin{tabular}{|c|c|c|c|c|}
\hline Bacia & Nome & Curso D’ Água & Município & Volume $\left(\mathrm{m}^{3}\right)$ \\
\hline & $\begin{array}{l}\text { RM-6 / Praça dos } \\
\text { Bombeiros }\end{array}$ & Córrego Rotary & SBC & 34.000 \\
\hline & $\begin{array}{l}\text { RC-2a / Mercedes } \\
\text { Paulicéia }\end{array}$ & $\begin{array}{l}\text { Ribeirão dos } \\
\text { Couros }\end{array}$ & SBC & 380.000 \\
\hline & RM-7 / Canarinho & $\begin{array}{l}\text { Córrego } \\
\text { Saracantan }\end{array}$ & SBC & 95.000 \\
\hline & RC-9 / Ford - Av. Taboão & $\begin{array}{l}\text { Ribeirão dos } \\
\text { Couros }\end{array}$ & SBC & 340.000 \\
\hline & RC-4a / Ford Fábrica & Córrego Taboão & SBC & 82.000 \\
\hline & RC-5 / Taboão & Córrego Taboão & SBC & 180.000 \\
\hline & RM-11 / São Caetano & $\begin{array}{l}\text { Ribeirão dos } \\
\text { Meninos }\end{array}$ & $\begin{array}{l}\text { S. Caetano do } \\
\text { Sul }\end{array}$ & 235.000 \\
\hline & RO-1 / Jd. Sonia Maria & Córrego Oratório & São Paulo/Mauá & 120.000 \\
\hline & RO-4 / Oratório & Córrego Oratório & $\begin{array}{l}\text { São } \\
\text { Paulo/Santo } \\
\text { André }\end{array}$ & 320.000 \\
\hline \multirow{7}{*}{ Pirajuçara } & RPI-2 / Nova Republica & Córrego Pirajuçara & Embú das Artes & 110.000 \\
\hline & RPI-2a / CPTM & Córrego Pirajuçara & São Paulo & 120.000 \\
\hline & RPI-7 / Eliseu de Almeida & Córrego Pirajuçara & São Paulo & 113.000 \\
\hline & RPI-8 / Olaria & Córrego Olaria & São Paulo & 80.000 \\
\hline & RPI-6 / Sharp & Córrego Pirajuçara & $\begin{array}{l}\text { São } \\
\text { Paulo/Taboão } \\
\text { da Serra }\end{array}$ & 500.000 \\
\hline & RPI-4 / Parque Pinheiros & $\begin{array}{l}\text { Córrego Joaquim } \\
\text { Cachoeira }\end{array}$ & $\begin{array}{l}\text { Taboão da } \\
\text { Serra }\end{array}$ & 117.000 \\
\hline & RPO-2 / Portuguesinha & Córrego Poá & $\begin{array}{l}\text { Taboão da } \\
\text { Serra }\end{array}$ & 120.000 \\
\hline \multirow{3}{*}{$\begin{array}{l}\text { Ribeirão } \\
\text { Vermelho }\end{array}$} & RVBo-1 / Bonança & Córrrego Bonança & Osasco & 62.000 \\
\hline & RVBa-1 / Rochdale & $\begin{array}{l}\text { Córrrego } \\
\text { Baronesa }\end{array}$ & Osasco & 25.000 \\
\hline & RVVe-2 / Anhanguera & Ribeirão Vermelho & São Paulo & 105.000 \\
\hline
\end{tabular}

Fonte: DAEE, $2010{ }^{1}$

\footnotetext{
${ }^{12}$ Informação informal, obtida na Diretoria de Engenharia e Obras do DAEE.
} 
A Figura 5.3 mostra o piscinão RT-1a/Paço Municipal em Mauá.

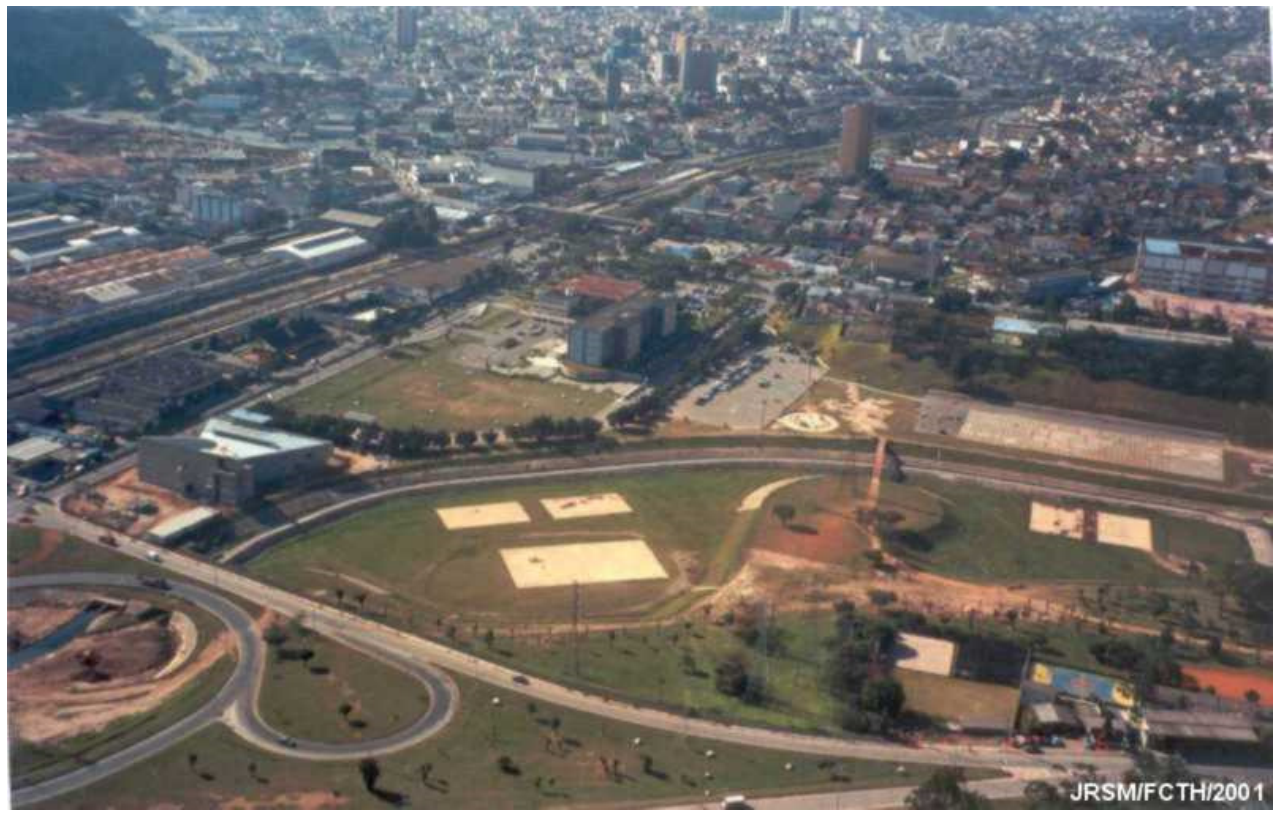

Figura 5.3 - Piscinão RT - 1a/Paço Municipal de Mauá Fonte: DAEE, 2010. ${ }^{13}$

O principal objetivo do reservatório de controle de cheia é o de armazenar temporariamente o volume do escoamento superficial direto excedente e restituí-lo no sistema de drenagem, de forma atenuada e controlada.

Os principais aspectos desfavoráveis na adoção dos piscinões como medida mitigadora das inundações urbanas são: a pouca disponibilidade de áreas para sua construção e os aspectos relacionados aos custos de manutenção, operação e a proliferação de vetores de doenças. Estudos recentes indicam que os piscinões são aceitos, mas não desejados pela população circunvizinha, em virtude destes pontos desfavoráveis (MARTINS, 2005).

Os reservatórios de controle de cheias são classificados em reservatórios de retenção e de detenção.

Os reservatórios de retenção são aqueles que dispõem de um espelho e volume de água permanente, e esta não é descarregada para um curso, mas armazenada por

13 Fotografia obtida no site do DAEE: <www.daee.sp.gov.br/acervoepesquisa/relatorios/fotos/ pasta16/pasta16.html>. Acesso em: 13 jan. 2010. 
um período de tempo, podendo ser consumida para diferentes fins, tais como: atividades de recreação, paisagística, abastecimento, recarga subterrânea, abastecimento humano e animal, irrigação, transposição de peixes e embarcações, entre outros. Desta forma, existirá uma diminuição do volume de água reservado independentemente da capacidade de descarga a jusante. Um exemplo de reservatório de retenção é o lago do Ibirapuera. A Figura 5.4 mostra uma vista do lago do Ibirapuera em São Paulo.

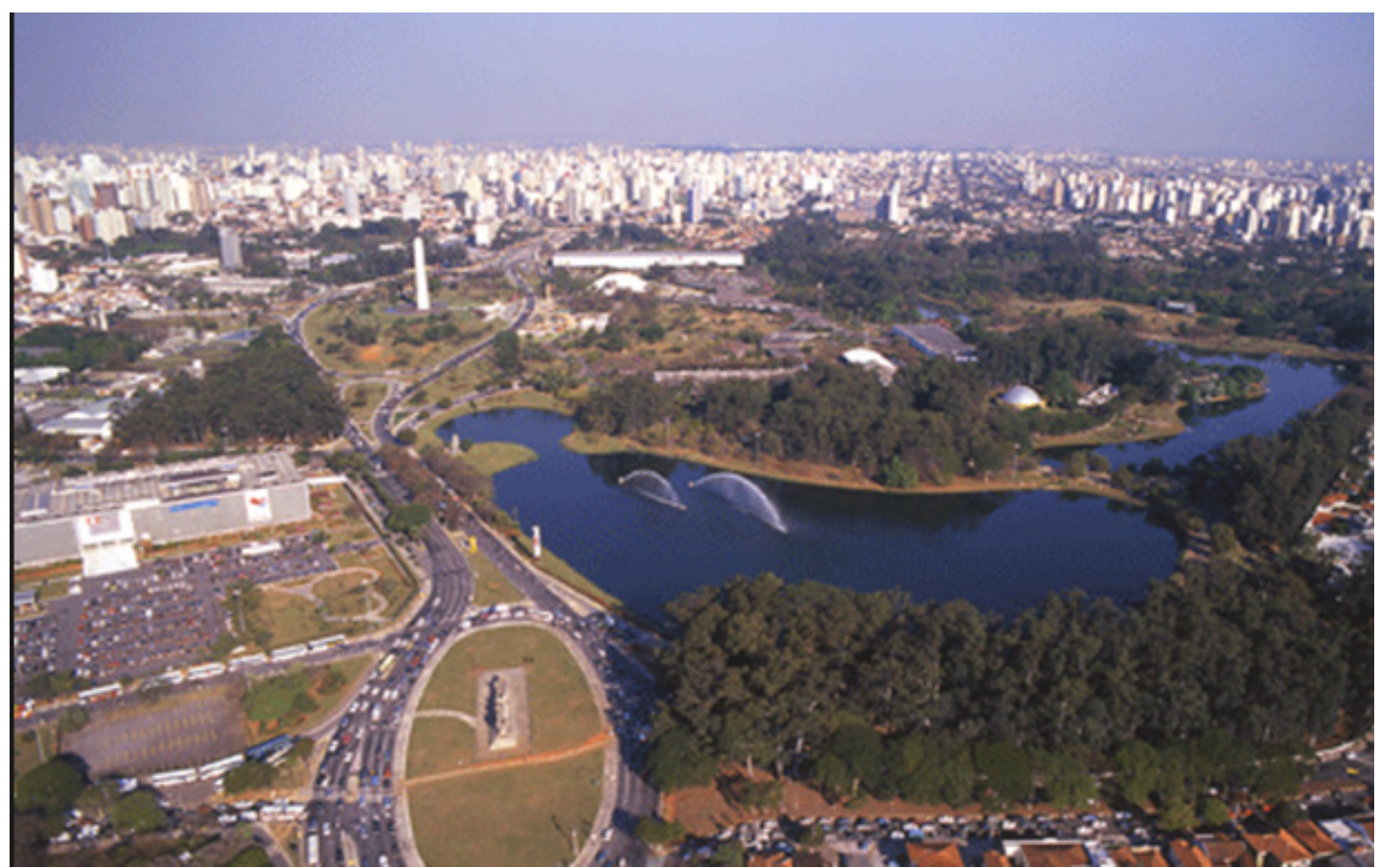

Figura 5.4 - Lago do parque do Ibirapuera

Fonte: Portal de São Paulo, 2010. ${ }^{14}$

Já os reservatórios de detenção são aqueles que não possuem espelho d'água e permanecem frequentemente secos. Durante um evento chuvoso, a água é armazenada e liberada de forma controlada. Estes não reduzem significativamente o volume de escoamento superficial, mas atuam sobre a vazão de pico, reduzindo e estendendo os períodos de recessão dos hidrogramas de cheia (CHOW; MAIDMENT; MAYS, 1988).

Quanto à localização no sistema de drenagem, os reservatórios de retenção e detenção podem ser em série e em paralelo:

\footnotetext{
${ }^{14}$ Extraída do site: <http://www.portaldesampa.kit.net/Postais/parquedoibirapuera.jpg> Acesso em: 12 fev. 2010.
} 
- Reservatórios em série: são aqueles que se localizam na linha principal do sistema de drenagem;

- Reservatórios em paralelo: não estão conectados na linha principal do sistema de drenagem, ou seja, o escoamento é desviado da linha principal para o armazenamento temporário.

Os reservatórios de detenção em série e em paralelo são apresentados nas figuras 5.5 e 5.6

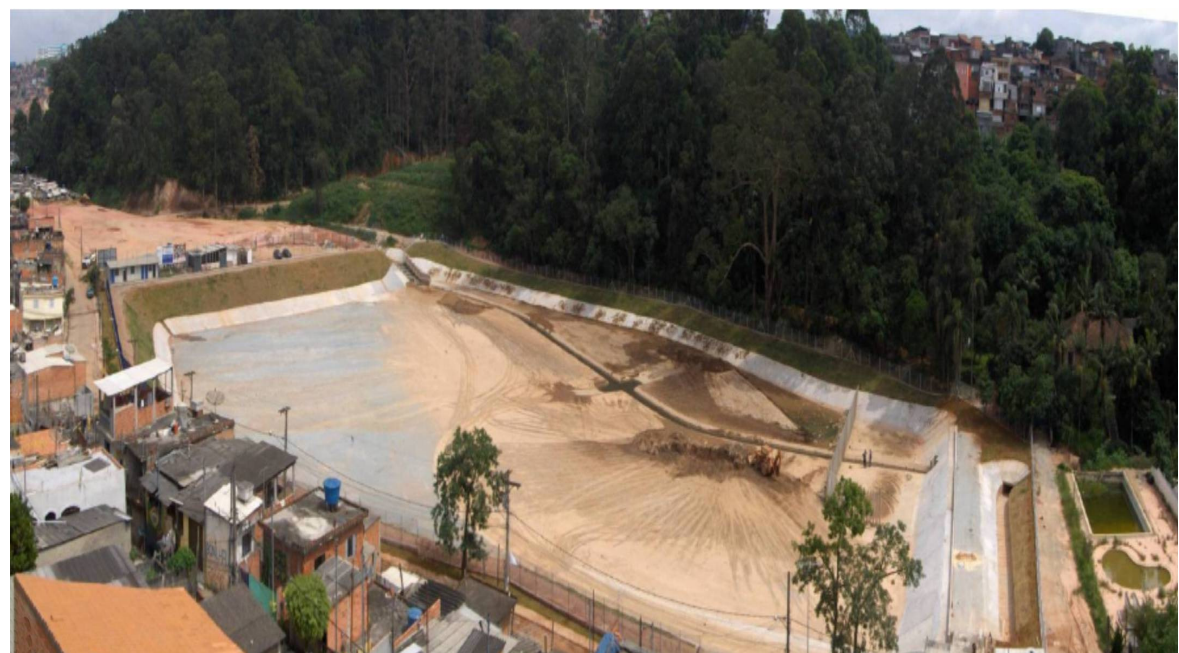

Figura 5.5 - Reservatório em série. Reservatório RVBo -1/Bonança Fonte: DAEE, 2010.

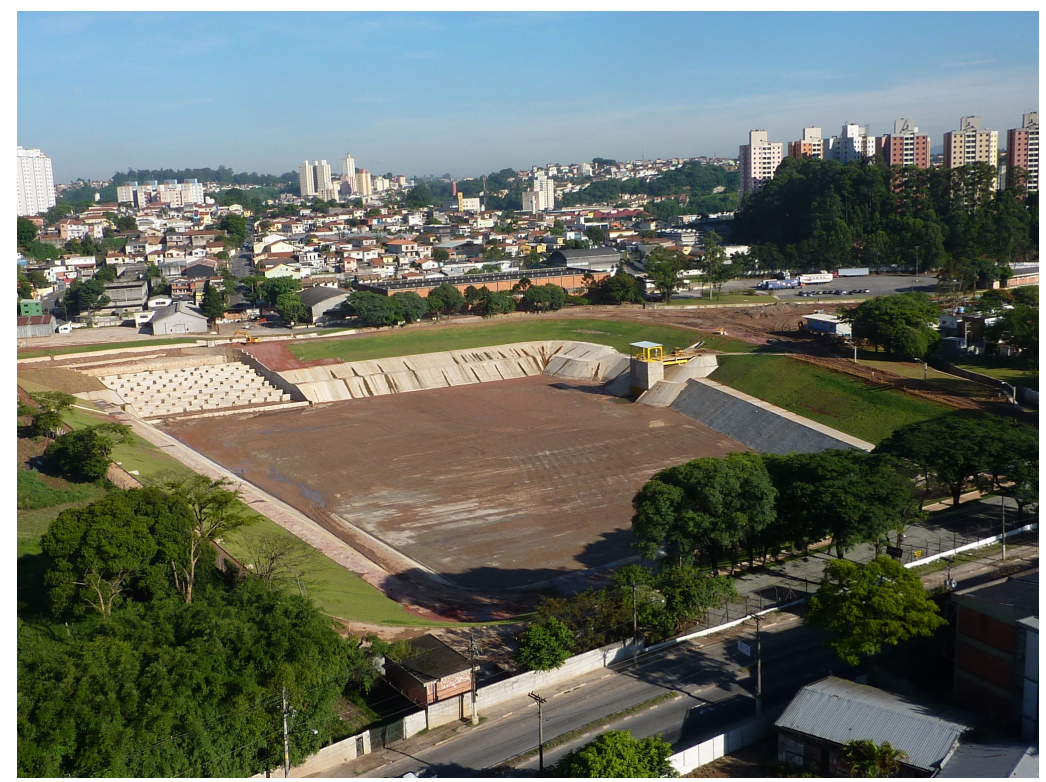

Figura 5.6 - Reservatório em paralelo. Reservatório RPI-6/Sharp Fonte: DAEE, 2010. 
Sinteticamente, os reservatórios de controle de cheias são constituídos pelas seguintes estruturas:

- Entrada;

- Dissipação de energia, e;

- Saída ou esvaziamento.

Um dos extravasores mais utilizados como estrutura de entrada é o do tipo vertedor lateral. A Figura 5.7 mostra um vertedor lateral.

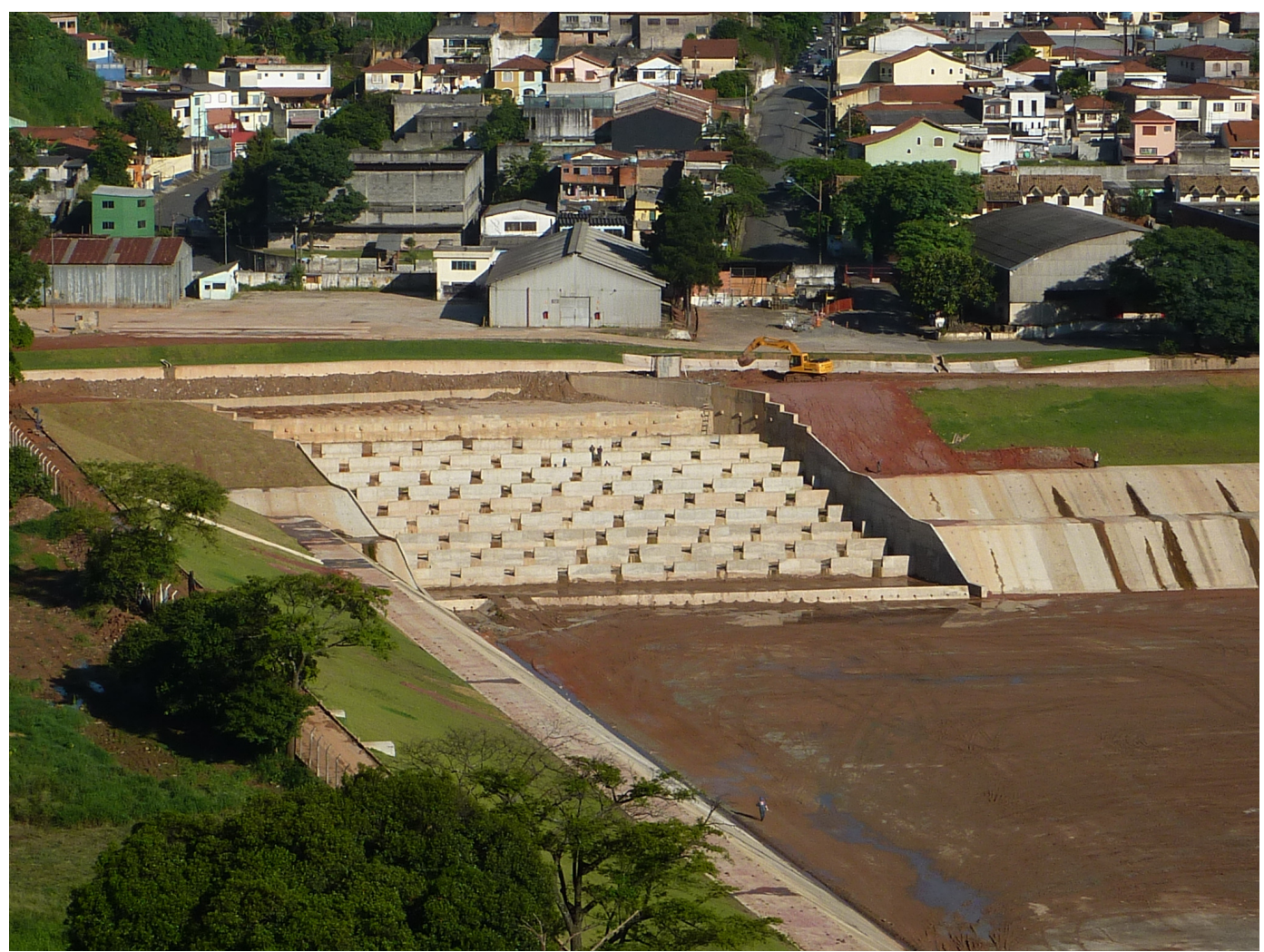

Figura 5.7 - Vertedor lateral do reservatório RPI-6/Sharp

Fonte: DAEE, 2010.

No caso de reservatórios em série, as estruturas de saída podem ser classificadas em três grupos principais:

- Orifícios;

- Soleiras vertentes;

- Tomadas perfuradas. 
Em reservatórios em paralelos, a vazão sai do reservatório de duas maneiras: por gravidade ou bombeamento.

É importante para a operação do reservatório, que além da estrutura de controle de saída normal exista um extravasor de emergência. Estes extravasores são compostos, preferencialmente, por vertedores de soleira livre.

Segundo Canholi (2005), ao se projetar um reservatório de controle de cheias, os dados de entrada são:

- O hidrograma de projeto;

- As características físicas do reservatório (curva cota-área-volume, níveis d’água máximo e mínimo admissíveis);

- A curva cota-vazão da estrutura de controle de saída.

Os resultados esperados são:

- O hidrograma das vazões efluentes;

- Os níveis d’água atingidos;

- O volume armazenado no reservatório.

Quanto à operação e manutenção dos reservatórios, é importante que sejam previstos acessos permanentes ao fundo dos destes, principalmente as estruturas de entrada e saída:

- Os reservatórios em série devem possui dispositivos de drenagem completa para a remoção de sedimentos;

- Os reservatórios com água permanente devem restringir lâminas d'água, de modo a prevenir a proliferação de plantas aquáticas;

- Os reservatórios subterrâneos devem prever acessos para limpeza mecanizada e sistemas de ventilação e iluminação.

A formulação matemática para o dimensionamento hidráulico das estruturas de 
entrada, dissipação de energia e estrutura de saída podem ser facilmente consultadas em manuais de hidráulica.

Especificamente para o vertedor retangular de soleira delgada o dimensionamento do vertedor é feito a partir da eq.(5.5):

$$
Q=\frac{2}{3} \cdot C d \cdot \sqrt{2 \cdot g} \cdot L_{v} \cdot H_{v}^{\frac{3}{2}}
$$

Onde:

- Q: é a vazão, em m³/s;

- Cd: é o coeficiente de vazão;

- $\mathrm{L}_{\mathrm{v}}$ : é o comprimento da crista da soleira, em m;

- $\mathrm{H}_{\mathrm{v}}$ : é a carga hidráulica acima da soleira, em $\mathrm{m}$.

O valor médio para o coeficiente de vazão é de 0,62 (AZEVEDO NETTO, 1998).

A Figura 5.8 ilustra o esquema representativo do escoamento sobre um vertedor de soleira delgada.

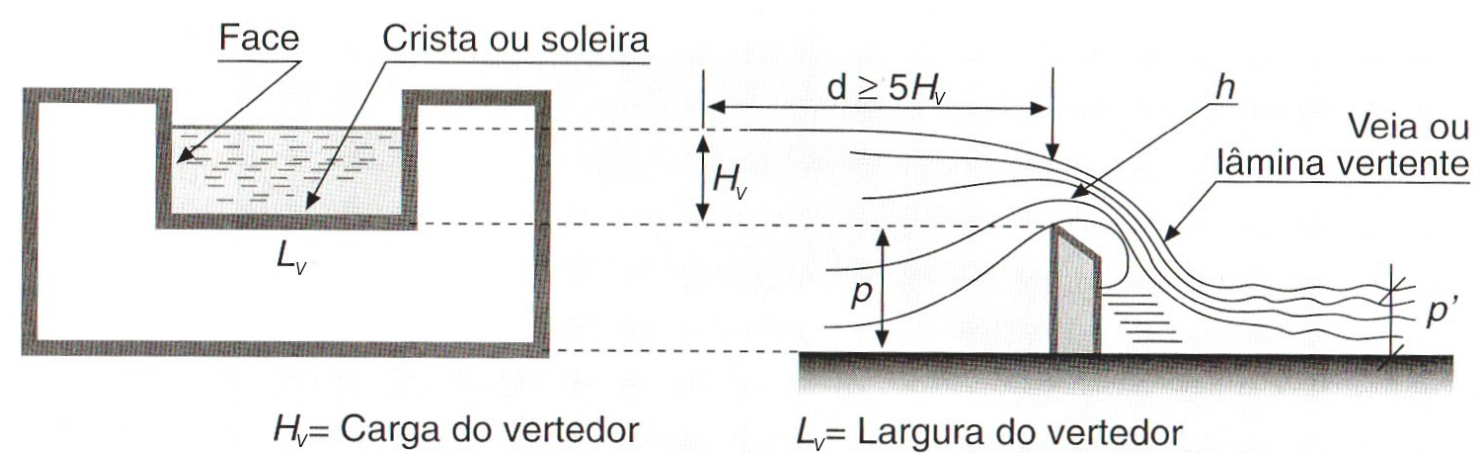

Figura 5.8 - Esquema representativo do escoamento sobre um vertedor de soleira delgada Fonte: Azevedo Netto, 1998. p. 88. 


\subsection{CENÁRIO DE PROJETO}

O cenário de projeto correspondeu à bacia hidrográfica, objeto dos estudos das análises de sensibilidade, apresentada no Capítulo 3.

A bacia hidrográfica possui as seguintes características:

- Área de drenagem, igual a $21,9 \mathrm{~km}^{2}$;

- Comprimento e declividade do talvegue, igual a $7.872 \mathrm{~m} \mathrm{e} 5,1 \mathrm{~m} / \mathrm{km}$, respectivamente;

- Tempo de concentração, igual a 2,5 h;

- O tipo de solo da bacia hidrográfica se aproxima da classificação do grupo hidrológico de solo do tipo $\mathrm{C}$ e da condição de umidade antecedente do tipo II do SCS;

- Considerou-se que a bacia hidrográfica sofreu alterações antrópicas e, portanto, o valor do CN igual a 75 passou para 80;

- A chuva de projeto foi obtida a partir da equação IDF de Magni e Mero (1986) para a cidade de Piracicaba, Estado de São Paulo. Adotou-se uma duração de 2,5 horas;

- O método de determinação da chuva excedente e obtenção do hidrograma sintético de projeto foi o proposto pelo SCS;

- Uma vez que tem sido aceito pelo meio técnico, adotou-se o período de retorno igual a 100 anos $^{15}$.

A Figura 5.9 mostra o hietograma e o hidrograma de projeto resultante para este cenário de projeto. 


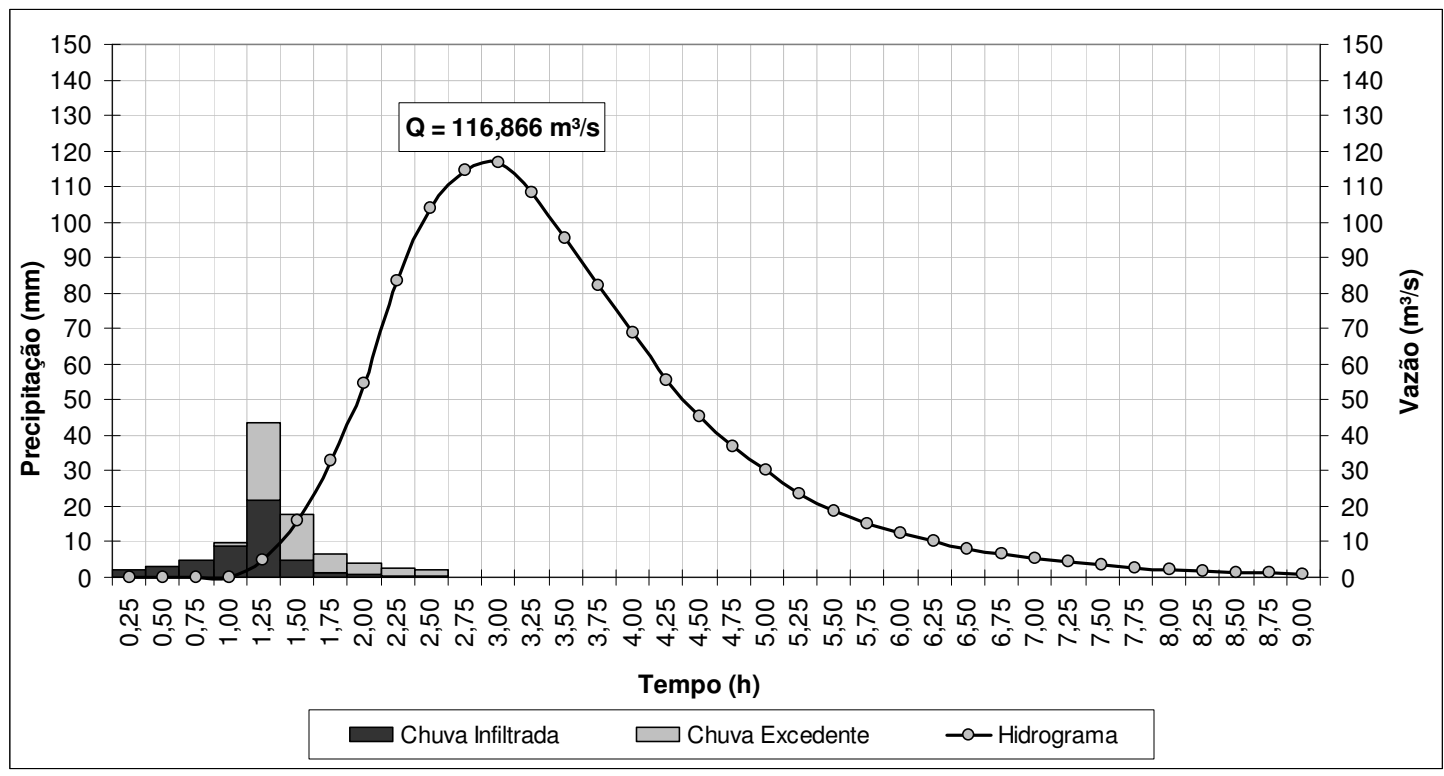

Figura 5.9 - Hietograma e hidrograma para o cenário de projeto

A Figura 5.9 mostra uma chuva de projeto igual a 96,29 mm. Da chuva de projeto, $48,79 \mathrm{~mm}$ infiltra-se no solo e $47,5 \mathrm{~mm}$ escoa superficialmente, transformando-se no hidrograma de cheia com uma vazão de pico, correspondente a 117 m³/s.

\subsubsection{Dimensionamento do canal para o cenário de projeto}

O canal foi dimensionado a partir da teoria do regime permanente, apresentada no item 5.1 .

Sabendo-se que:

- O revestimento do canal corresponde ao coeficiente de Manning, igual a 0,025;

- A inclinação de fundo é de $0,01 \mathrm{~m} / \mathrm{m}$, e;

- A largura é de 9,50m.

Determinou-se, a partir da equação de Manning-Strickler, associada à equação de Chézy, a lâmina d'água igual a 5,30 m. 
Da equação da continuidade, calculou-se a velocidade máxima do canal correspondente, a 2,30 m/s, permissível para o revestimento do canal, segundo critérios de dimensionamento do DAEE.

Adotou-se uma borda livre igual a $1 \mathrm{~m}$, maior que $10 \%$ da lâmina d'água estimada para a vazão de pico, segundo os mesmo critérios de dimensionamento do DAEE (2005).

As dimensões finais do canal correspondem a 9,50 m de largura e 6,30 m de altura. A Figura 5.10 mostra, esquematicamente, as dimensões do canal projetado para a vazão de pico de $117 \mathrm{~m}^{3} / \mathrm{s}$.

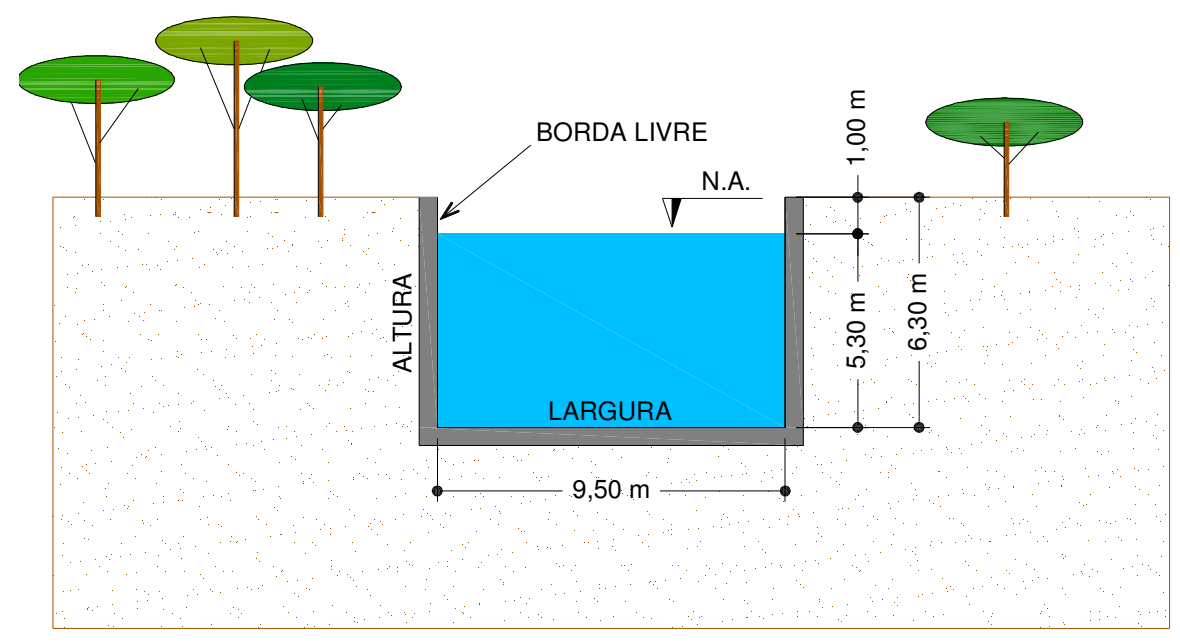

Figura 5.10 - Dimensões do canal para o cenário de projeto

\subsubsection{Dimensionamento do vertedor do reservatório de controle de cheias para o cenário de projeto, verificação da redução da vazão de pico e volume armazenado}

Para o dimensionamento da estrutura de saída ou esvaziamento do reservatório, foi considerado um vertedor retangular de soleira livre.

Considerou-se também um reservatório de retenção do em série, com formato retangular. O reservatório ocupa uma área igual a $72.000 \mathrm{~m}^{2}$. A relação que representa as características geométricas do reservatório é dada pela equação cota- 
volume expressa pela eq.(5.6). A Figura 5.11 mostra a curva cota-volume do reservatório.

$$
\mathrm{V}=72.000 \times \mathrm{El}
$$

Onde:

- V: é o volume, em $\mathrm{m}^{3}$;

- El: é a elevação do terreno, em $\mathrm{m}$.

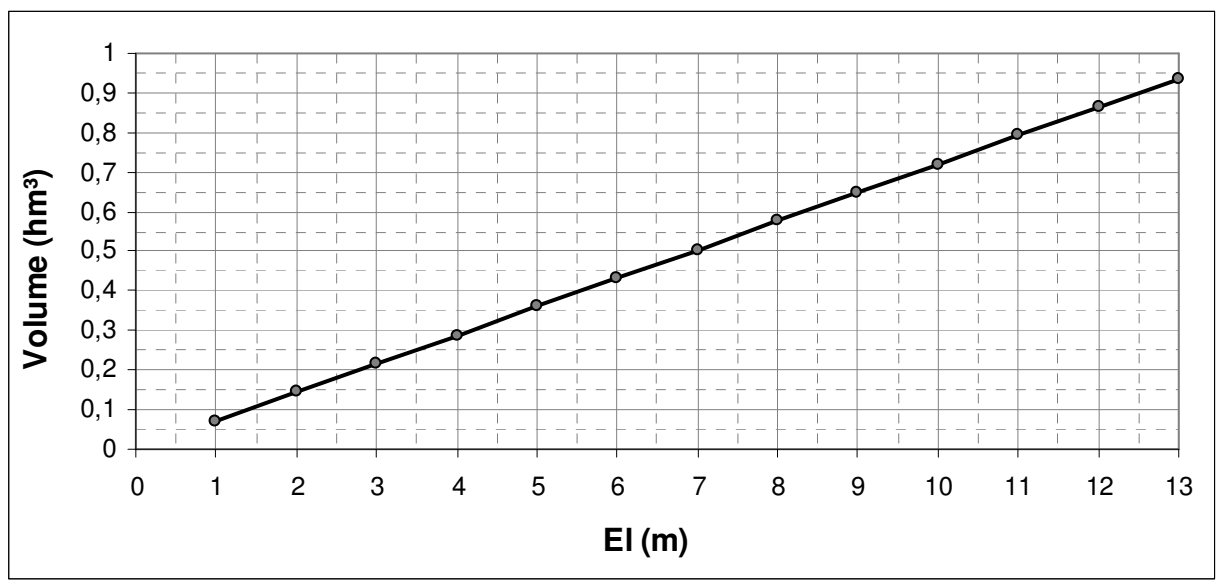

Figura 5.11 - Curva cota-volume

O hidrograma afluente corresponde ao obtido para o cenário de projeto e está apresentado na Figura 5.9.

A cota da crista do barramento está na elevação igual a 13,00 m. A cota de fundo do reservatório está na elevação igual a 00,00 m. Adotou-se uma borda livre para o barramento de $1,50 \mathrm{~m}$;

O vertedor foi dimensionado para uma carga hidráulica igual a 1,5 m. O vertedor está posicionado a $10,00 \mathrm{~m}$ da cota de fundo do reservatório. A equação de dimensionamento do vertedor retangular de soleira livre é dada por na eq.(5.5).

Foi considerado um coeficiente de descarga igual a 0,677. 
Diante destes dados, obtiveram-se, a partir das simulações no SSD ABC 6 , os seguintes resultados:

- Um vertedor com largura igual 9,60 m;

- O hidrograma efluente com uma vazão de pico de $35,371 \mathrm{~m} 3 / \mathrm{s}$;

- O volume armazenado de $0,828 \mathrm{hm}^{3}$.

A Figura 5.12 apresenta esquematicamente um corte transversal do reservatório de controle de cheias e a vista frontal do vertedor retangular de soleira livre.

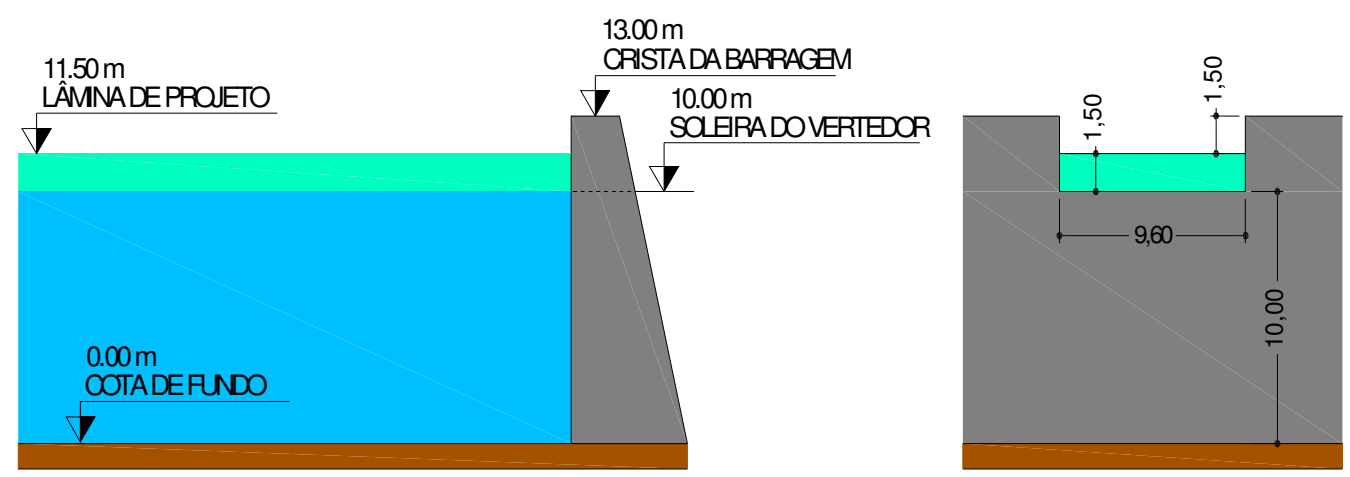

Figura 5.12 - Representação esquemática do perfil do reservatório e da seção onde está posicionado o vertedor de soleira livre

A Figura 5.13 apresenta os hidrogramas afluente e efluente, enquanto a Figura 5.14 demonstra o volume armazenado e a lâmina d'água em função do tempo. Neste caso, a lâmina d'água corresponde à distância do fundo do reservatório até a carga hidráulica sobre o vertedor.

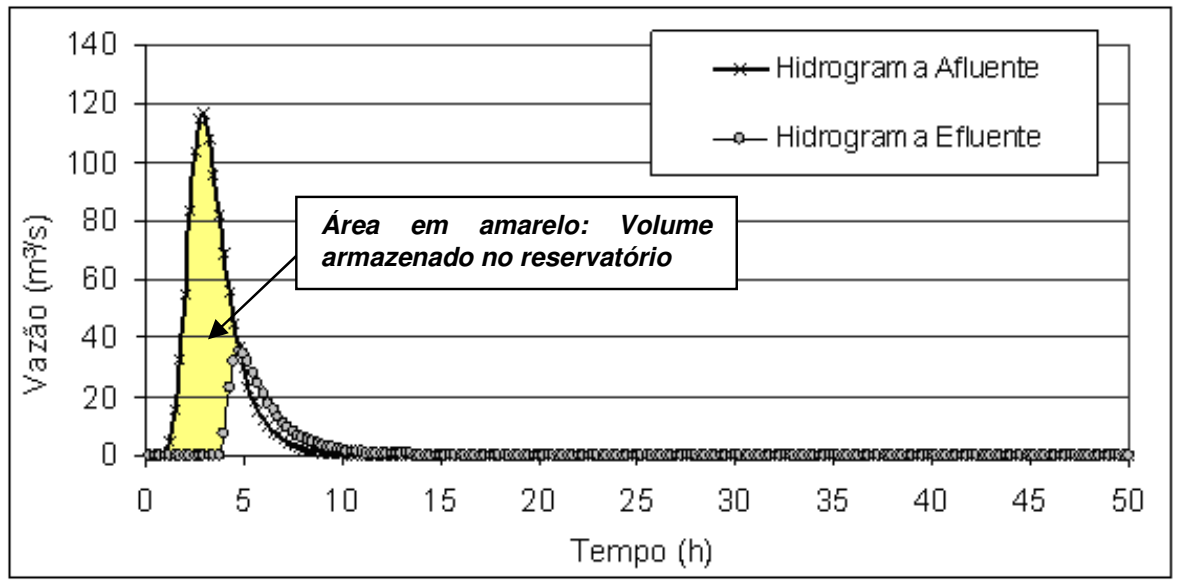

Figura 5.13 - Hidrogramas afluente e efluente ao reservatório de controle de cheias 


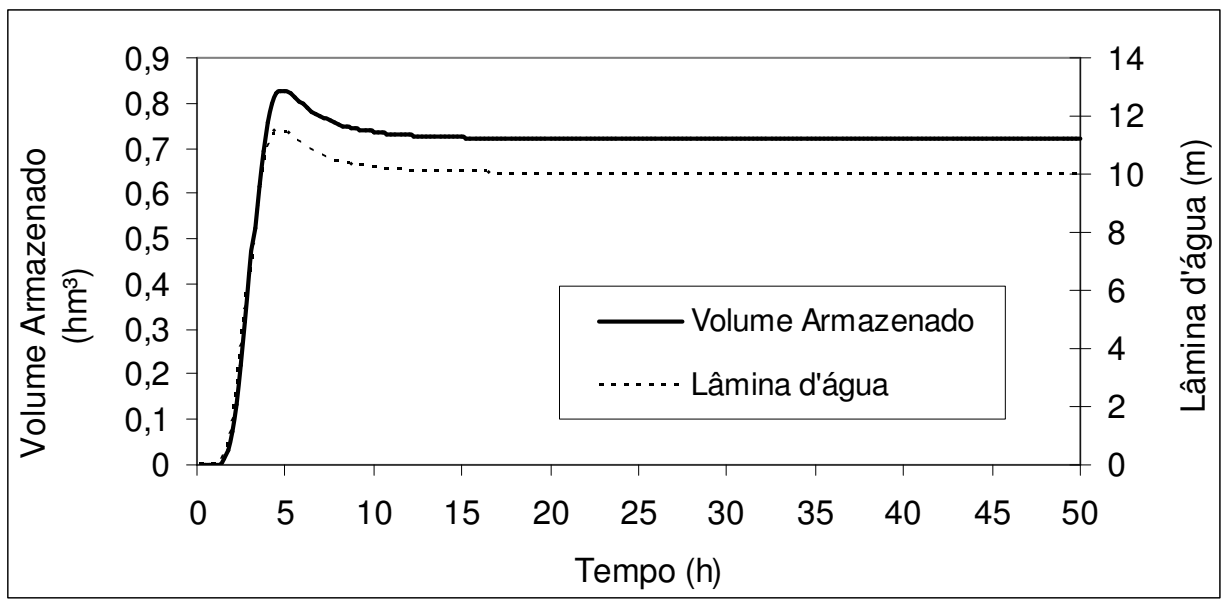

Figura 5.14 - Volume Armazenado e lâmina d'água em função do tempo

\subsection{CENÁRIOS DE PROJETO ALTERNATIVOS}

Para avaliar a influência no dimensionamento hidráulico das estruturas propostas a partir da alteração das variáveis estudadas na análise de sensibilidade foram criados cenários alternativos. A seguir, são mostradas as variáveis que foram alteradas para os cenários alternativos em relação ao cenário de projeto. As variáveis alteradas estão em negrito.

Tabela 5.4 - Variáveis do cenário de projeto e cenários alternativos

\begin{tabular}{crrrr}
\hline Cenário & CN & \multicolumn{1}{c}{$\begin{array}{c}\text { tc } \\
\text { (h) }\end{array}$} & $\begin{array}{c}\text { d } \\
\text { (min) }\end{array}$ & \multicolumn{1}{c}{ (anos) } \\
\hline Projeto & 80 & 2,5 & 150 & 100 \\
C - I & 75 & 2,5 & 150 & 100 \\
C - II & 85 & 2,5 & 150 & 100 \\
C - III & 80 & $\mathbf{1 , 5}$ & 150 & 100 \\
C - IV & 80 & $\mathbf{3 , 5}$ & 150 & 100 \\
C - V & 80 & 2,5 & 90 & 100 \\
C - VI & 80 & 2,5 & $\mathbf{2 1 0}$ & 100 \\
C - VII & 85 & $\mathbf{3 , 5}$ & $\mathbf{2 1 0}$ & 100 \\
C - VIII & 80 & 2,5 & 150 & $\mathbf{5 0}$ \\
\hline
\end{tabular}


Foram calculados, para os cenários alternativos, os respectivos hietogramas e hidrogramas de projeto, a carga hidráulica sob o vertedor de soleira livre, a variação da carga hidráulica para cada cenário alternativo em relação ao cenário de projeto e o volume armazenado no reservatório de controle de cheias. A Tabela 5.5 resume os resultados das simulações para o cenário de projeto e os cenários alternativos.

Tabela 5.5 - Resumo dos resultados das simulações

\begin{tabular}{|c|c|c|c|c|c|c|c|c|c|}
\hline \multirow{2}{*}{ Cenário } & \multicolumn{3}{|c|}{ Chuva (mm) } & \multicolumn{2}{|c|}{ Vazão (m³/s) } & \multirow{2}{*}{$\begin{array}{l}\text { Carga } \\
\text { Hidráulica } \\
\text { (m) }\end{array}$} & \multirow{2}{*}{$\begin{array}{l}\Delta \mathrm{H} \\
(\mathrm{m})\end{array}$} & \multirow{2}{*}{$\begin{array}{l}\Delta \mathrm{H} \\
(\%)\end{array}$} & \multirow{2}{*}{$\begin{array}{c}\text { Volume } \\
\text { Armazenado } \\
\left(\mathrm{hm}^{3}\right)\end{array}$} \\
\hline & Excedente & Infiltração & Total & & (m) & & & & \\
\hline Projeto & 47,50 & 48,79 & 96,29 & 116,866 & 35,371 & 1,50 & - & - & 0,828 \\
\hline I & 38,39 & 57,90 & 96,29 & 94,410 & 11,604 & 0,71 & $-0,79$ & $-53 \%$ & 0,771 \\
\hline II & 57,71 & 38,58 & 96,29 & 141,723 & 64,369 & 2,24 & 0,74 & $49 \%$ & 0,881 \\
\hline III & 47,50 & 48,79 & 96,29 & 172,315 & 47,472 & 1,83 & 0,33 & $22 \%$ & 0,852 \\
\hline IV & 47,50 & 48,79 & 96,29 & 86,600 & 28,338 & 1,30 & $-0,20$ & $-13 \%$ & 0,813 \\
\hline V & 39,10 & 46,68 & 85,78 & 100,468 & 13,383 & 0,79 & $-0,71$ & $-47 \%$ & 0,777 \\
\hline VI & 53,12 & 50,02 & 103,14 & 124,909 & 49,961 & 1,89 & 0,39 & $26 \%$ & 0,856 \\
\hline VII & 63,81 & 39,33 & 103,14 & 112,846 & 63,659 & 2,22 & 0,72 & $48 \%$ & 0,880 \\
\hline VIII & 41,02 & 47,19 & 88,21 & 100,915 & 18,108 & 0,96 & $-0,54$ & $-36 \%$ & 0,789 \\
\hline
\end{tabular}

As figuras 5.15 a 5.38 mostram os hietogramas e hidrogramas de projeto, os hidrogramas afluentes e efluentes, o volume armazenado e a lâmina d'água em função do tempo para os cenários alternativos. Neste caso, a lâmina d'água corresponde à distância do fundo do reservatório, somada à carga hidráulica sobre o vertedor. 


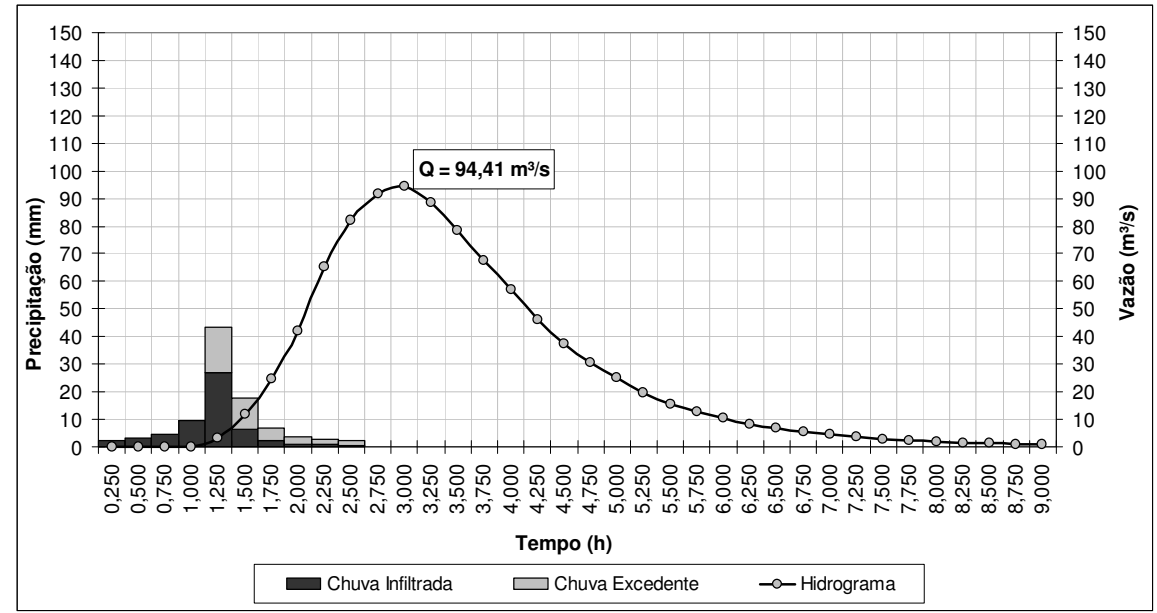

Figura 5.15 - Hietograma e hidrograma de projeto - C - I

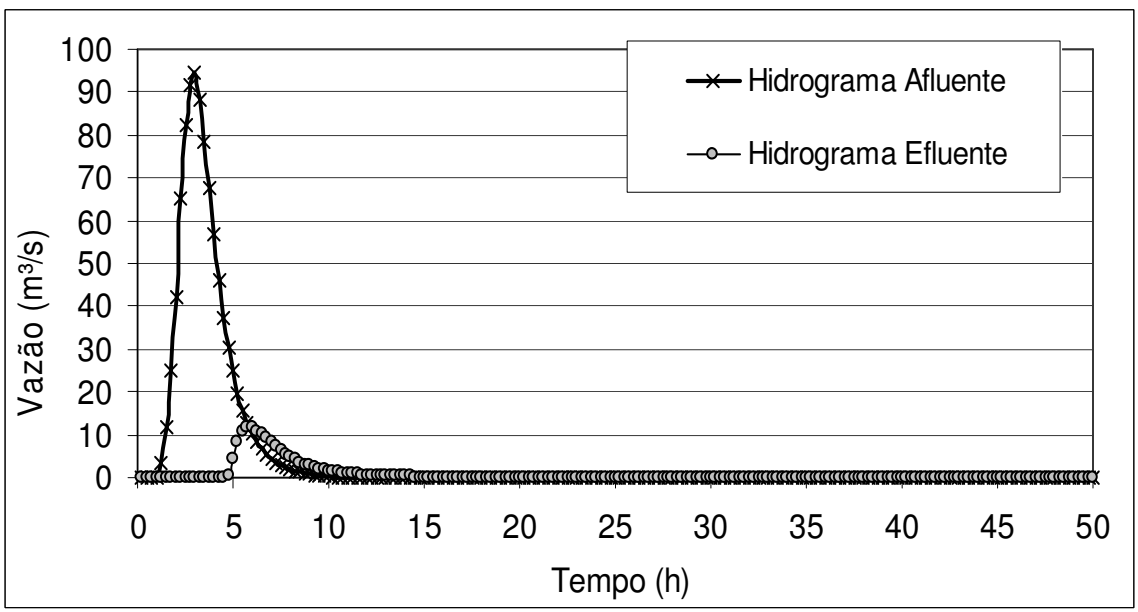

Figura 5.16 - Hidrograma afluente e efluente - C - I

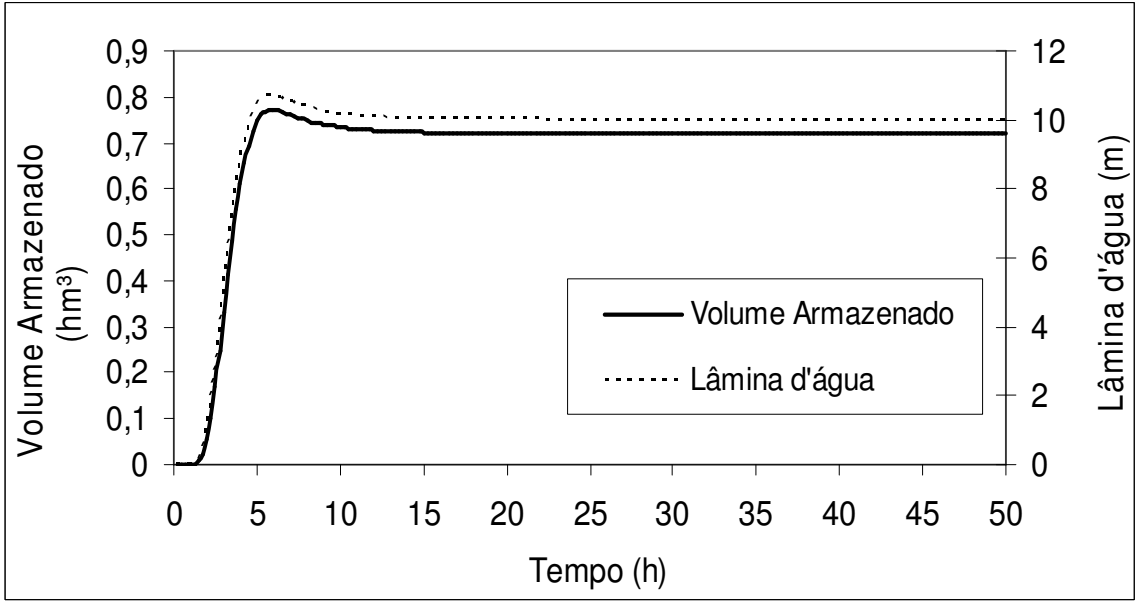

Figura 5.17 - Volume armazenado e lâmina d'água em função do tempo para o cenário $\mathrm{C}-\mathrm{I}$ 


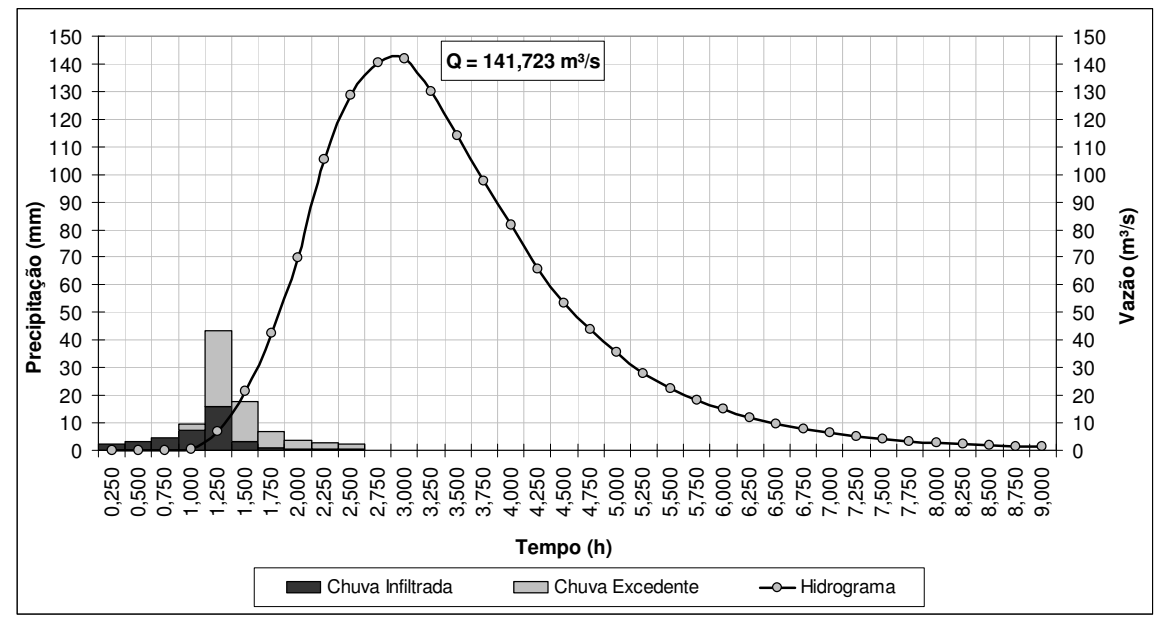

Figura 5.18 - Hietograma e hidrograma de projeto - C - II

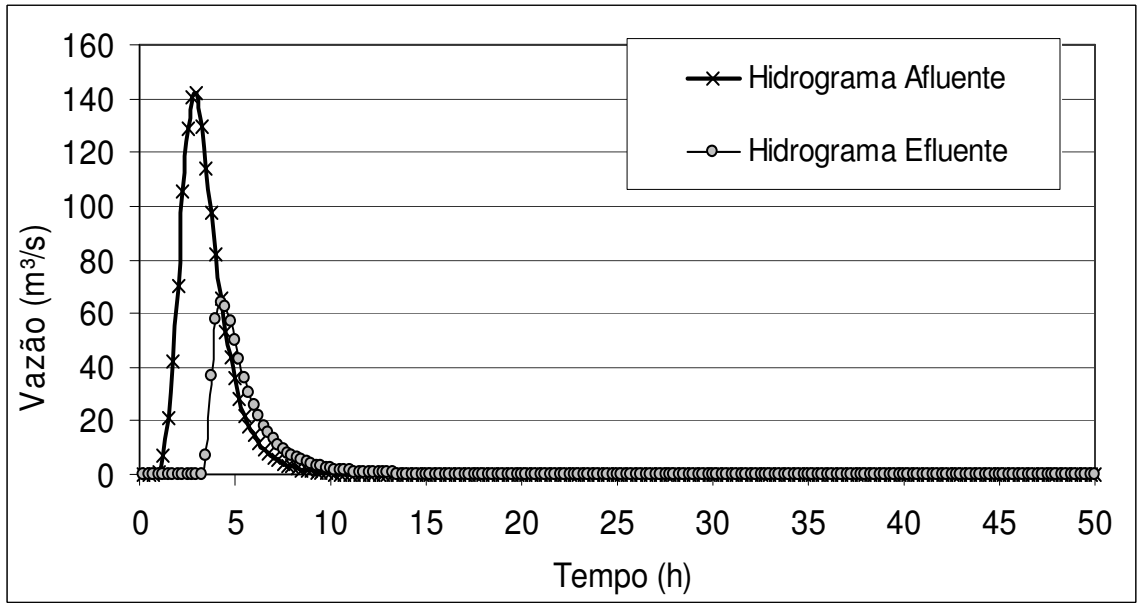

Figura 5.19 - Hidrograma afluente e efluente - C - II

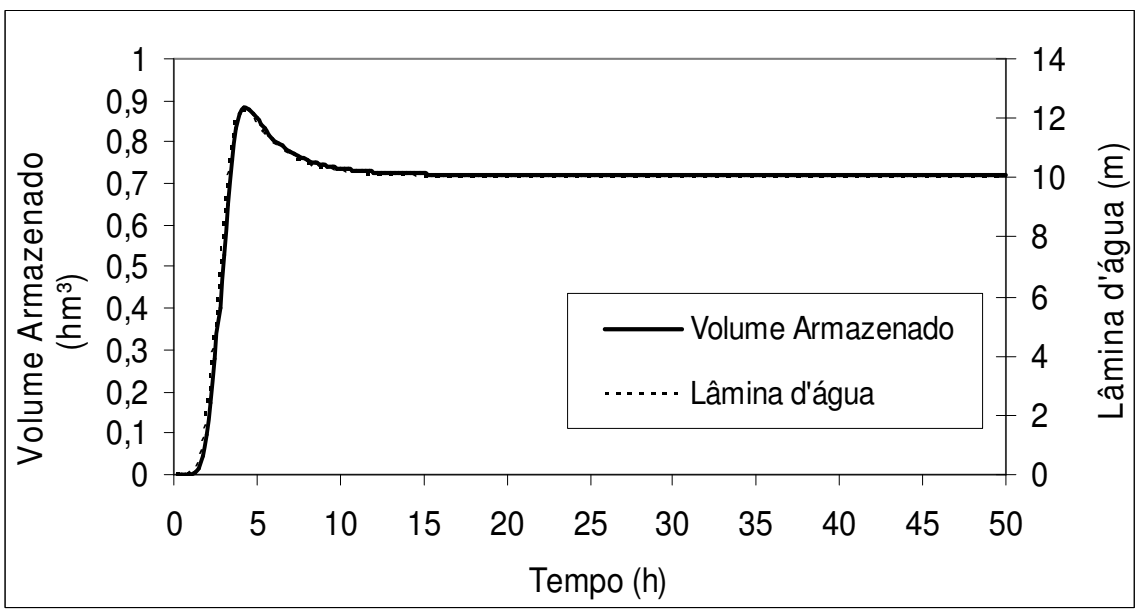

Figura 5.20 - Volume armazenado e lâmina d'água em função do tempo para o cenário $\mathrm{C}-\mathrm{II}$ 


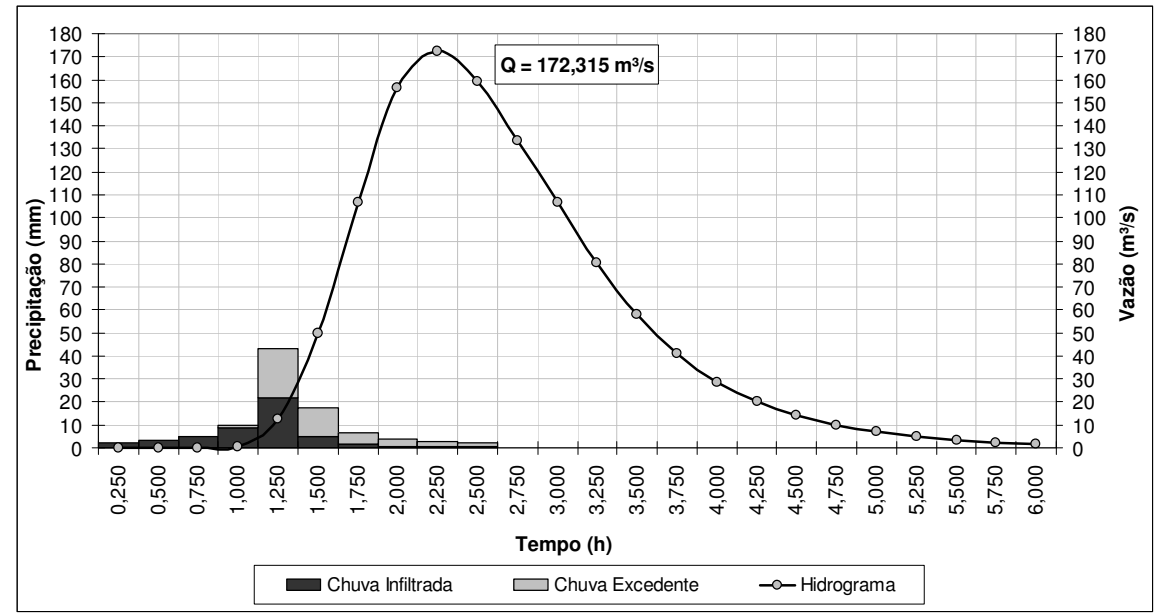

Figura 5.21 - Hietograma e hidrograma de projeto - C - III

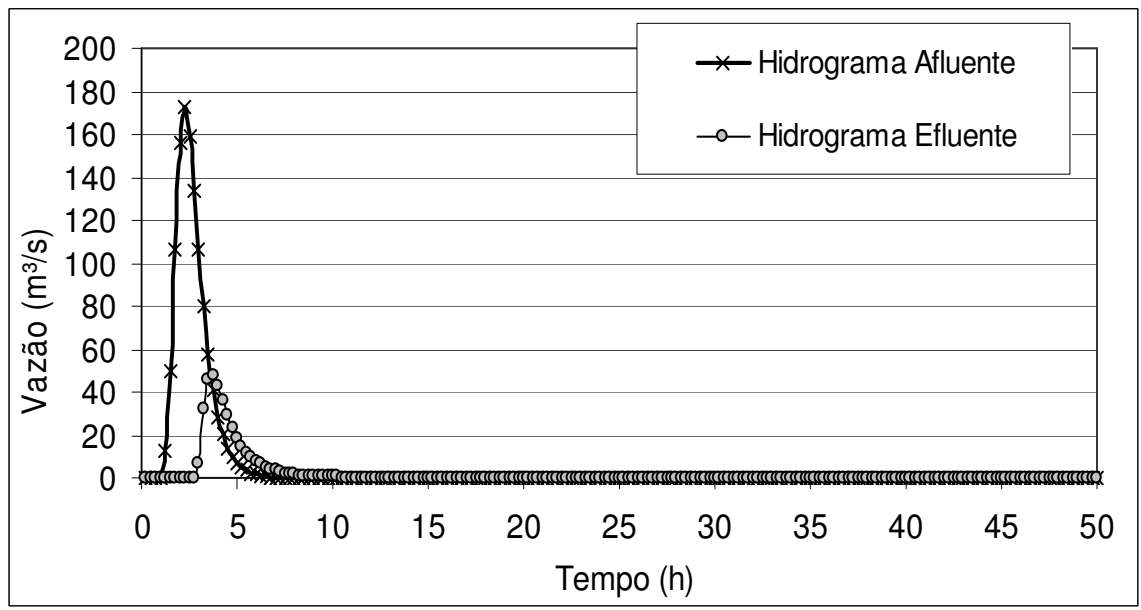

Figura 5.22 - Hidrograma afluente e efluente - C - III

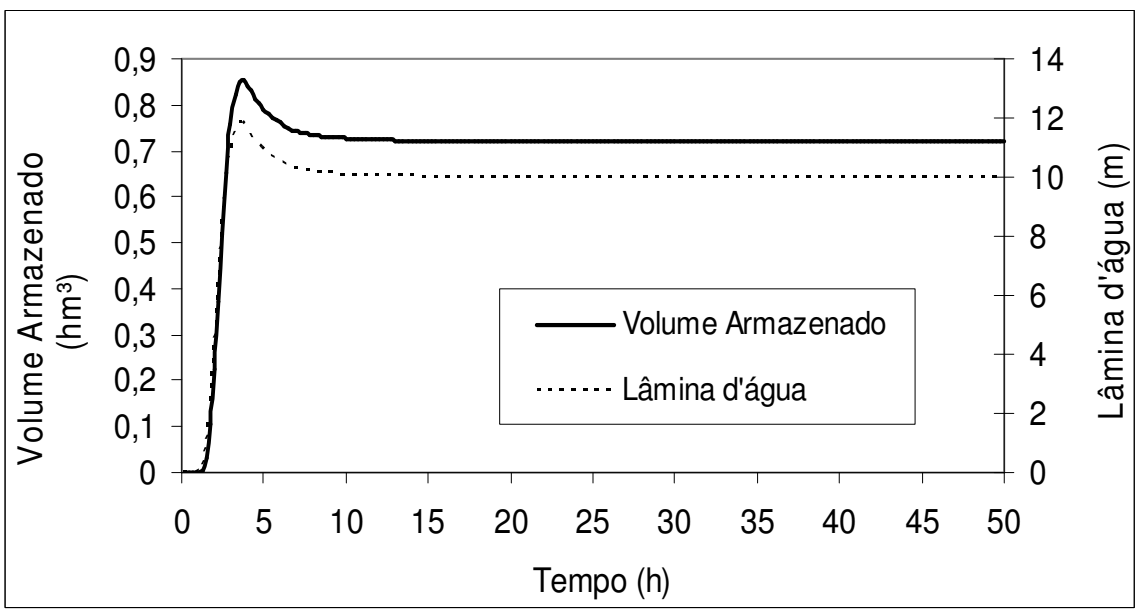

Figura 5.23 - Volume armazenado e lâmina d'água em função do tempo para o cenário C - III 


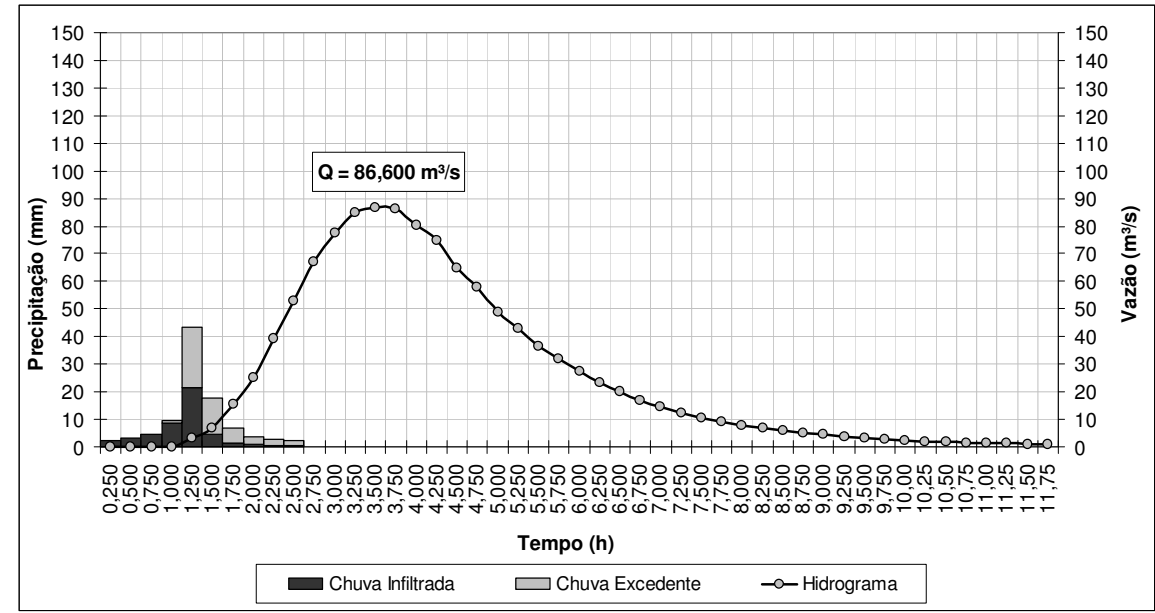

Figura 5.24 - Hietograma e hidrograma de projeto - C - IV

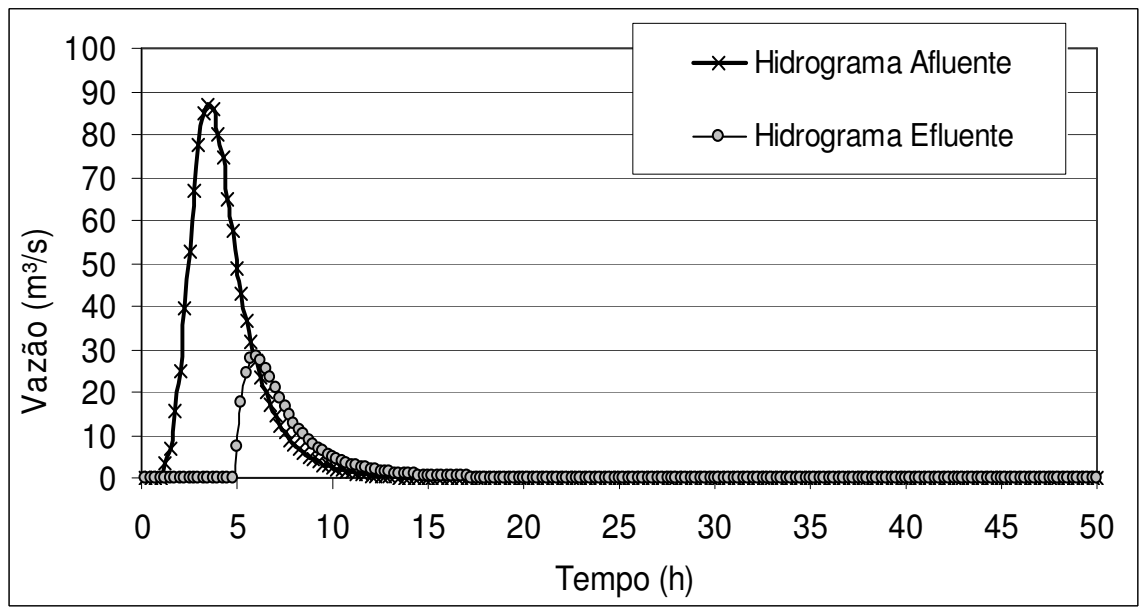

Figura 5.25 - Hidrograma afluente e efluente - C - IV

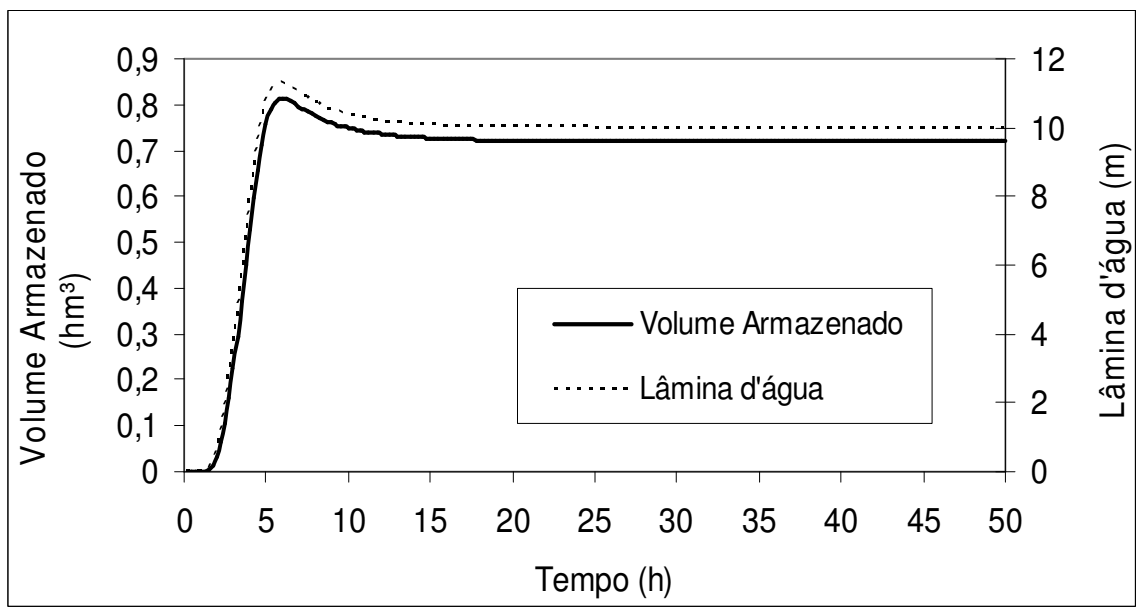

Figura 5.26 - Volume armazenado e lâmina d'água em função do tempo para o cenário C - IV 


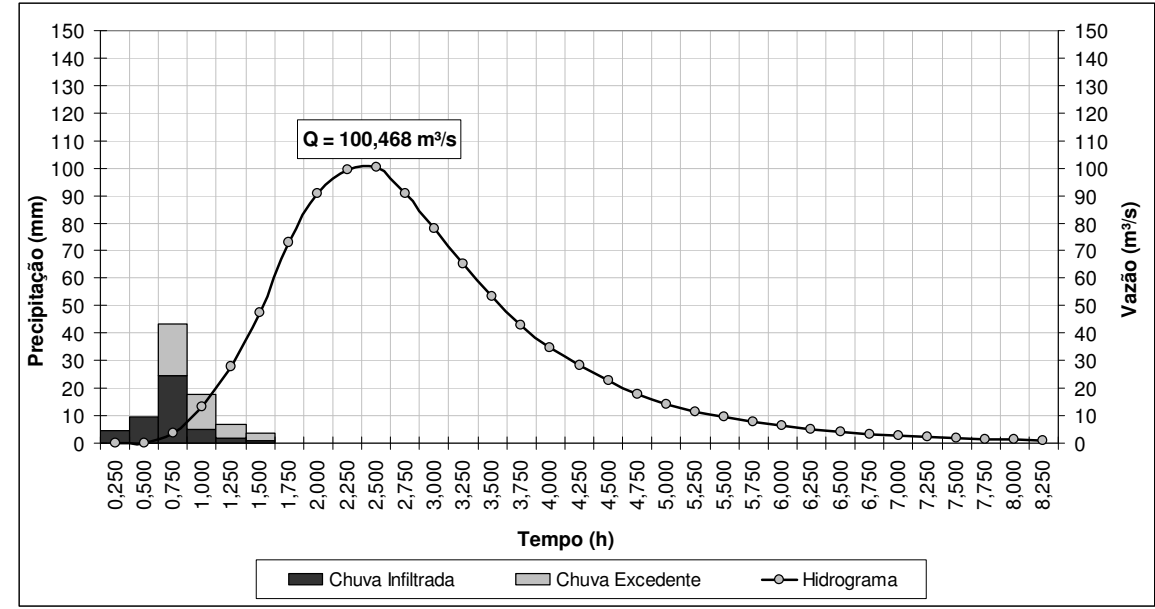

Figura 5.27 - Hietograma e hidrograma de projeto - C - V

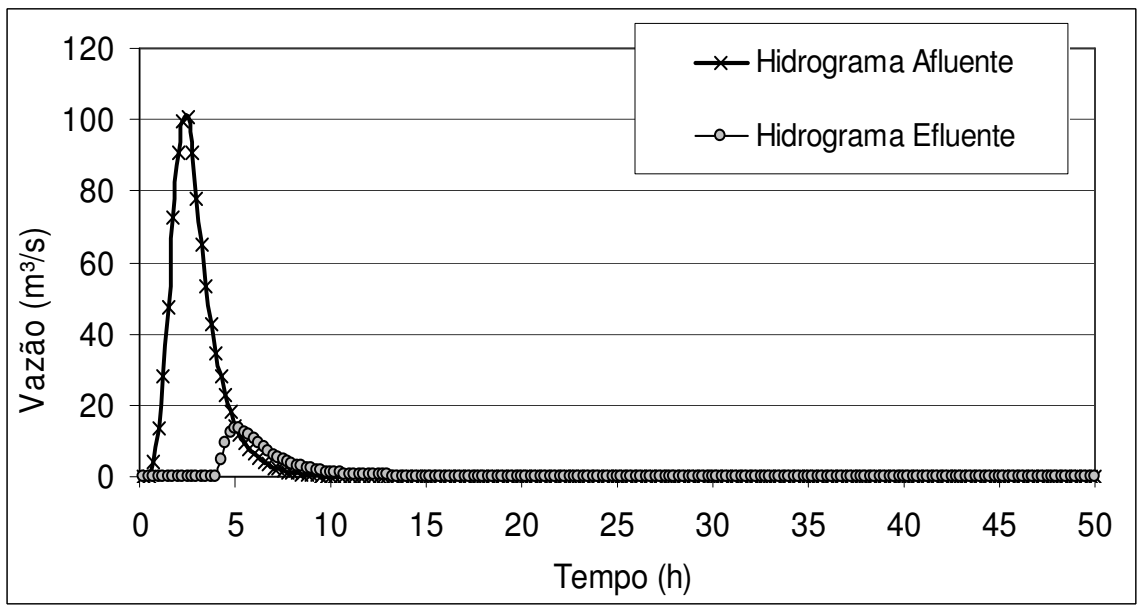

Figura 5.28 - Hidrograma afluente e efluente $-\mathrm{C}-\mathrm{V}$

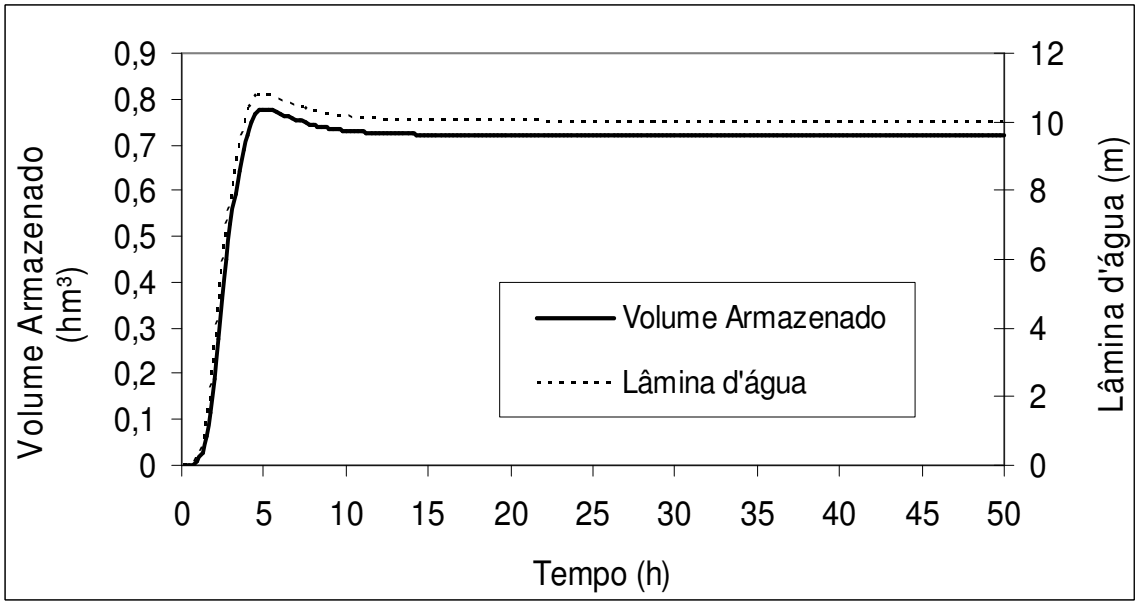

Figura 5.29 - Volume armazenado e lâmina d'água em função do tempo para o cenário $\mathrm{C}-\mathrm{V}$ 


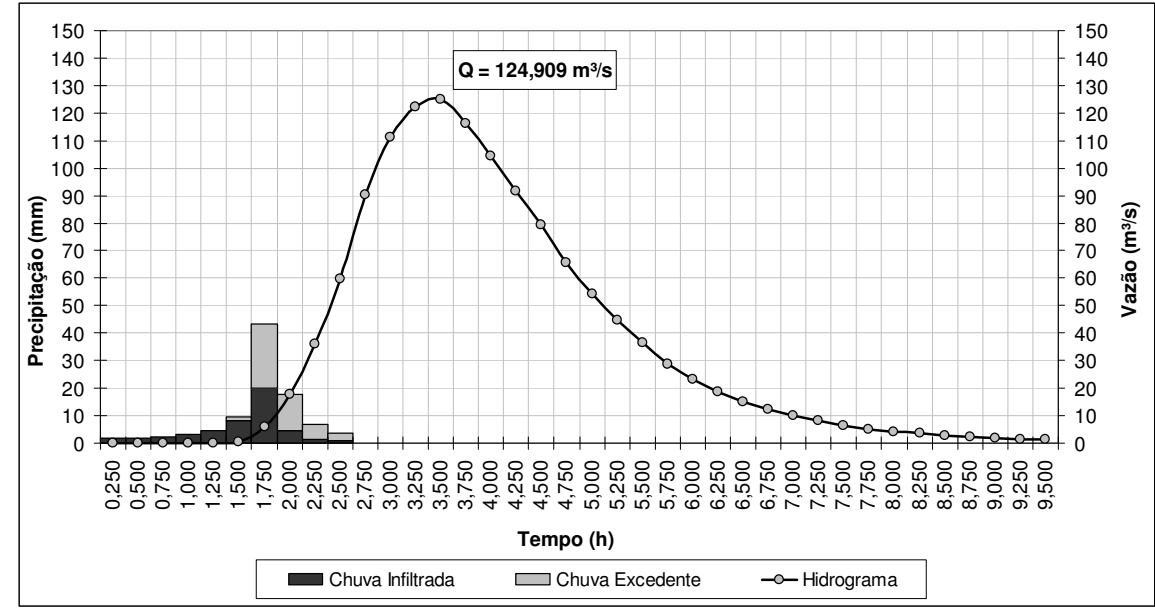

Figura 5.30 - Hietograma e hidrograma de projeto - C - VI

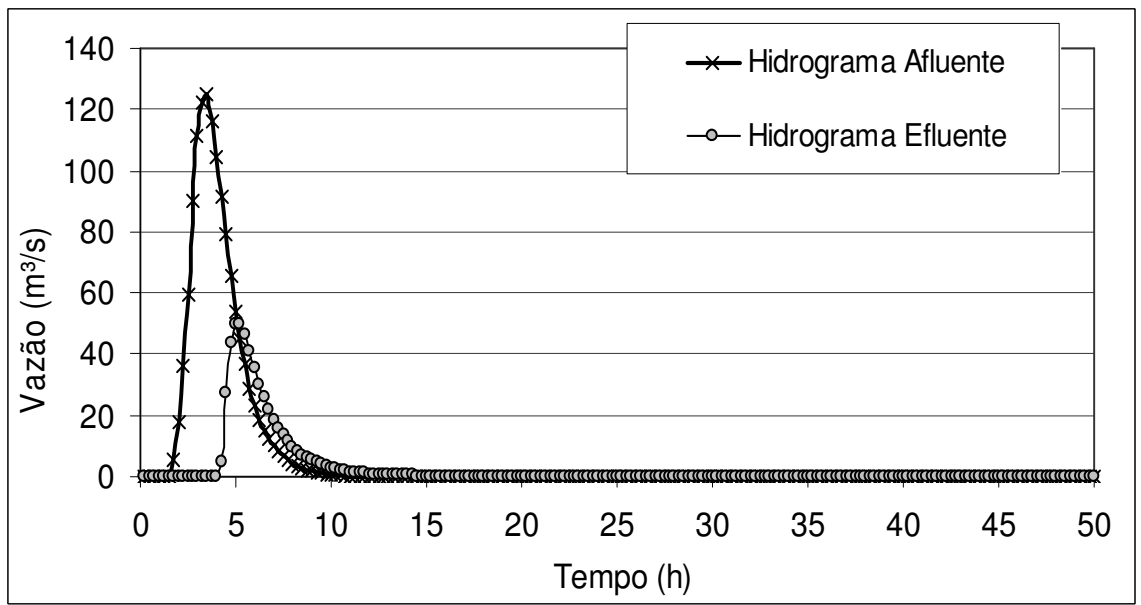

Figura 5.31 - Hidrograma afluente e efluente - C - VI

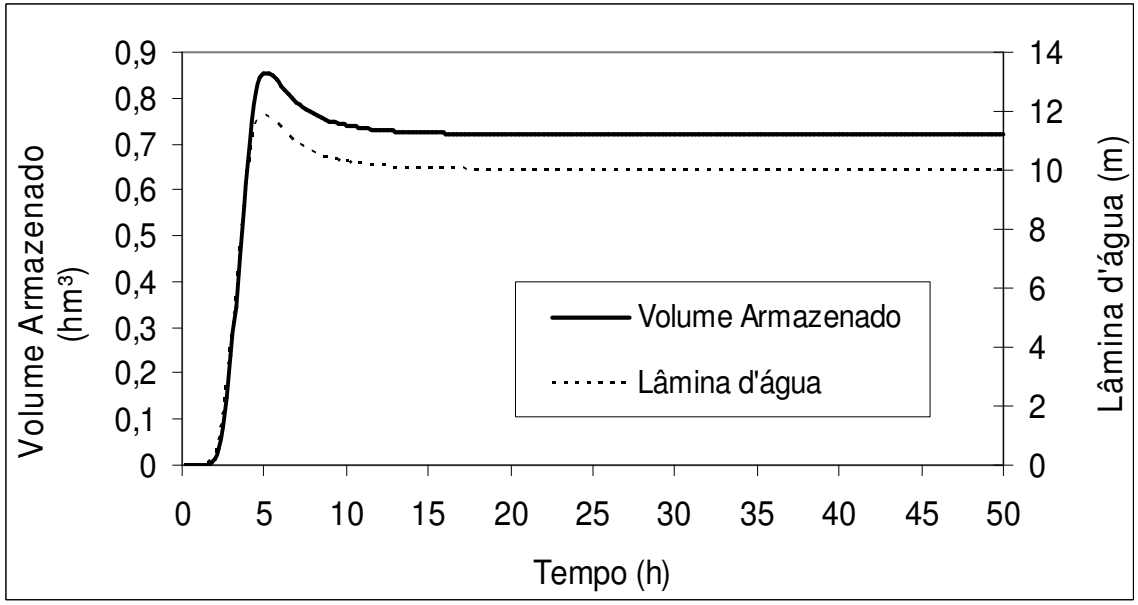

Figura 5.32 - Volume Armazenado e lâmina d'água em função do tempo para o cenário $\mathrm{C}-\mathrm{VI}$ 


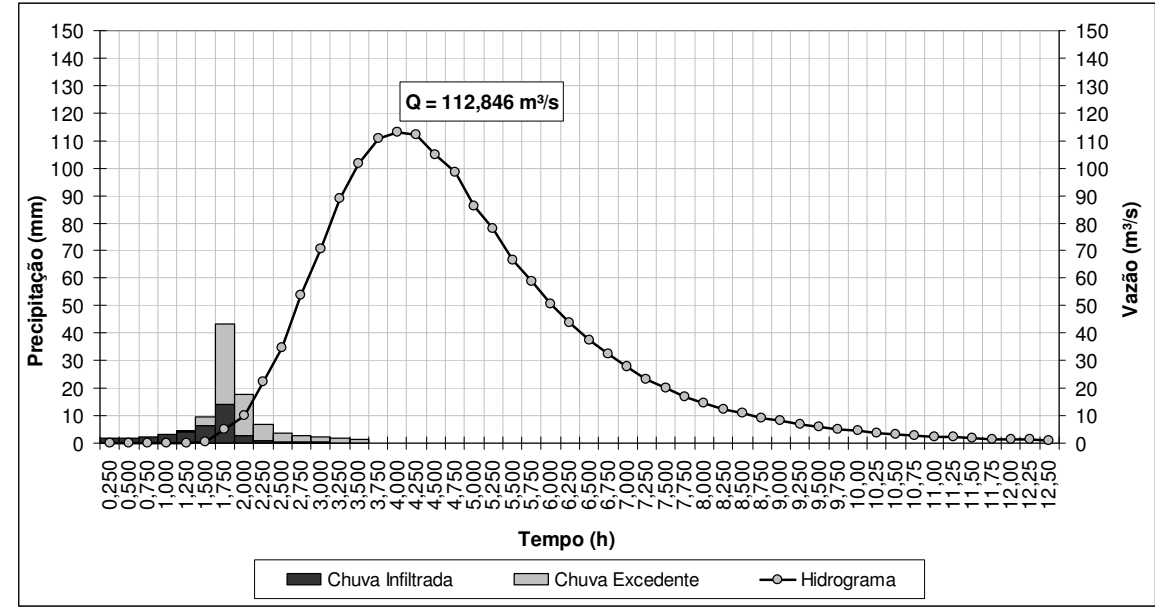

Figura 5.33 - Hietograma e hidrograma de projeto - C - VII

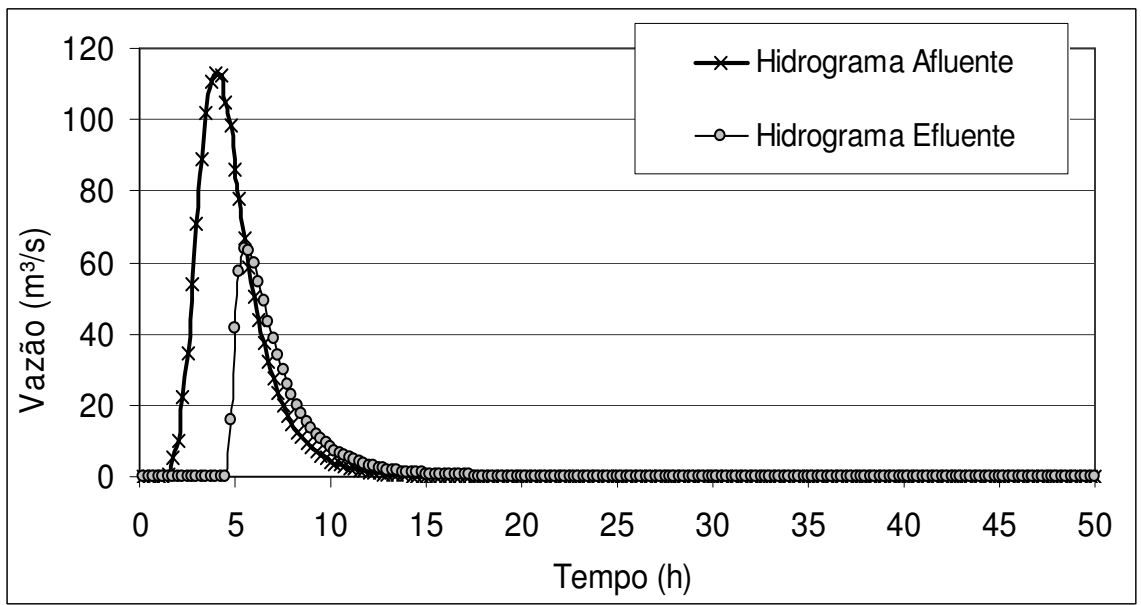

Figura 5.34 - Hidrograma afluente e efluente - C - VII

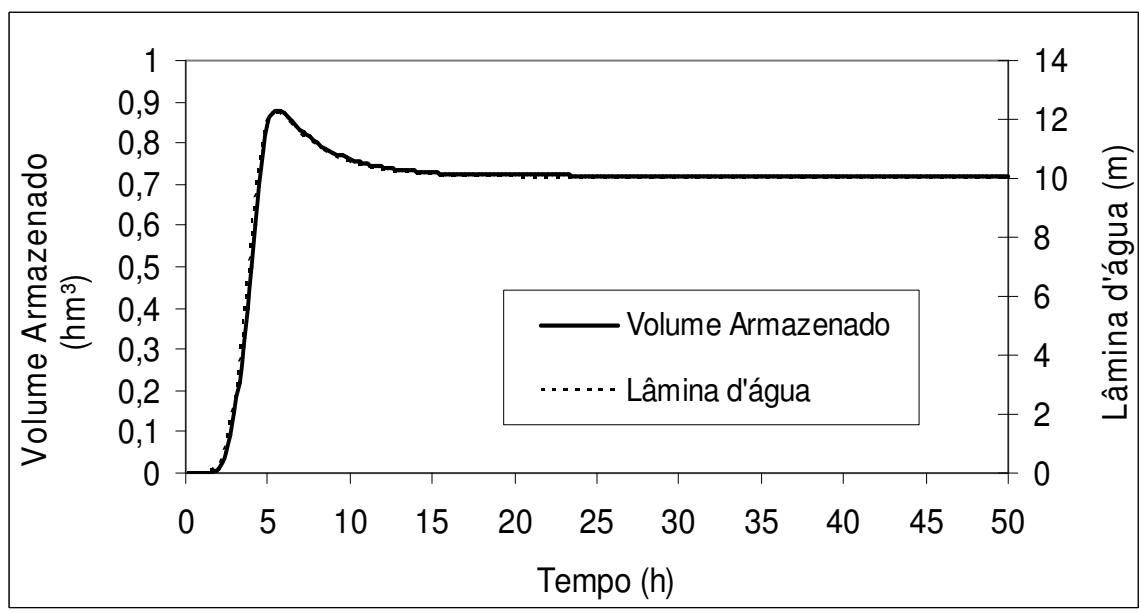

Figura 5.35 - Volume Armazenado e lâmina d'água em função do tempo para o cenário C - VII 


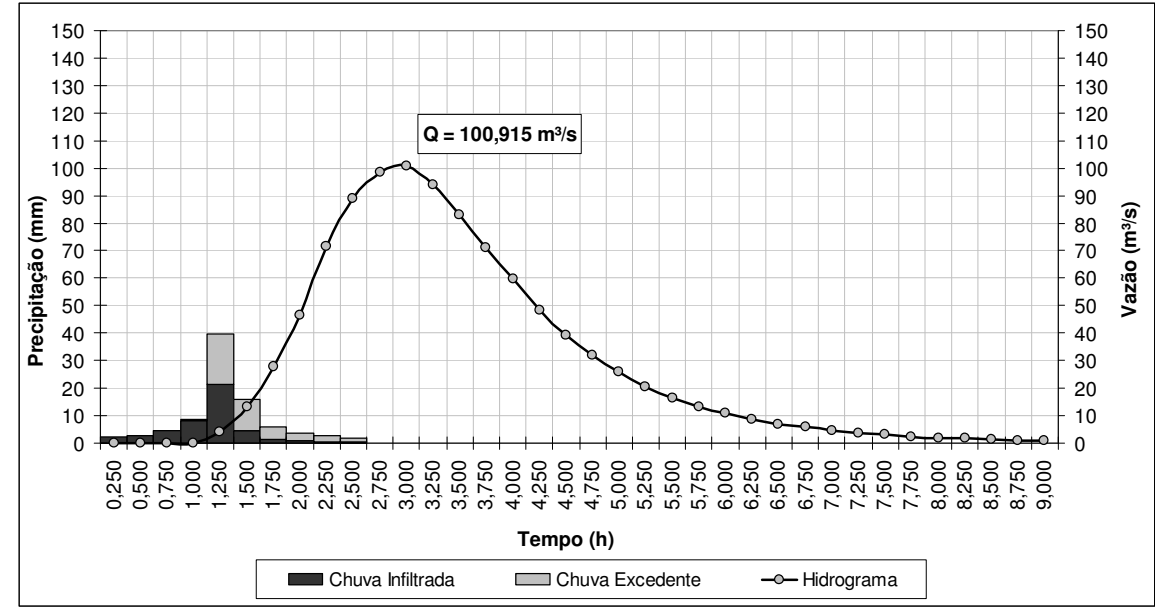

Figura 5.36 - Hietograma e hidrograma de projeto - C - VIII

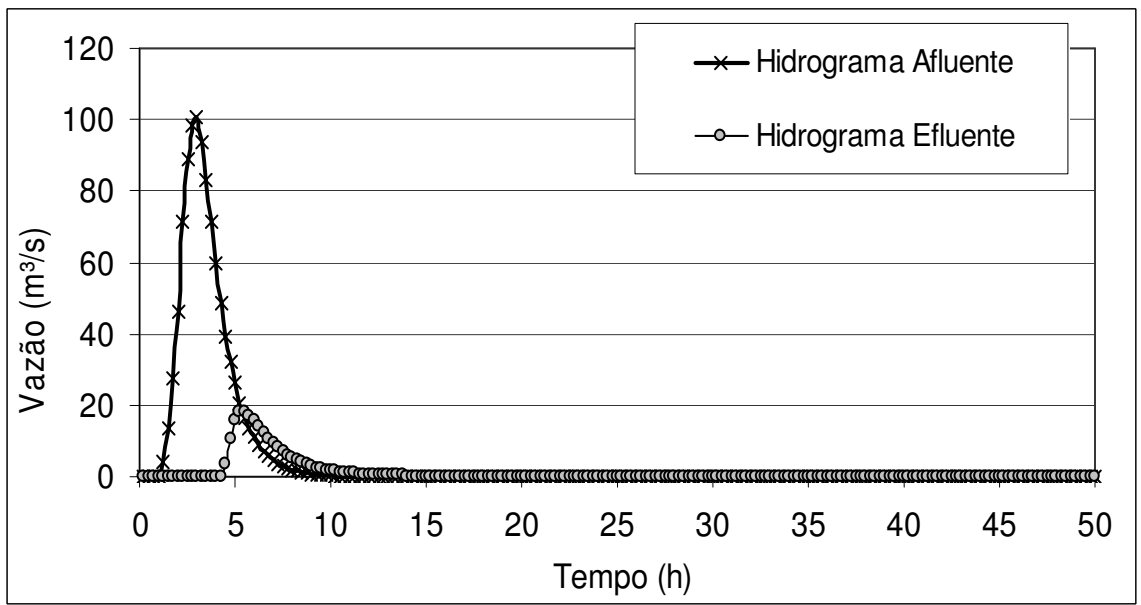

Figura 5.37 - Hidrograma afluente e efluente - C - VIII

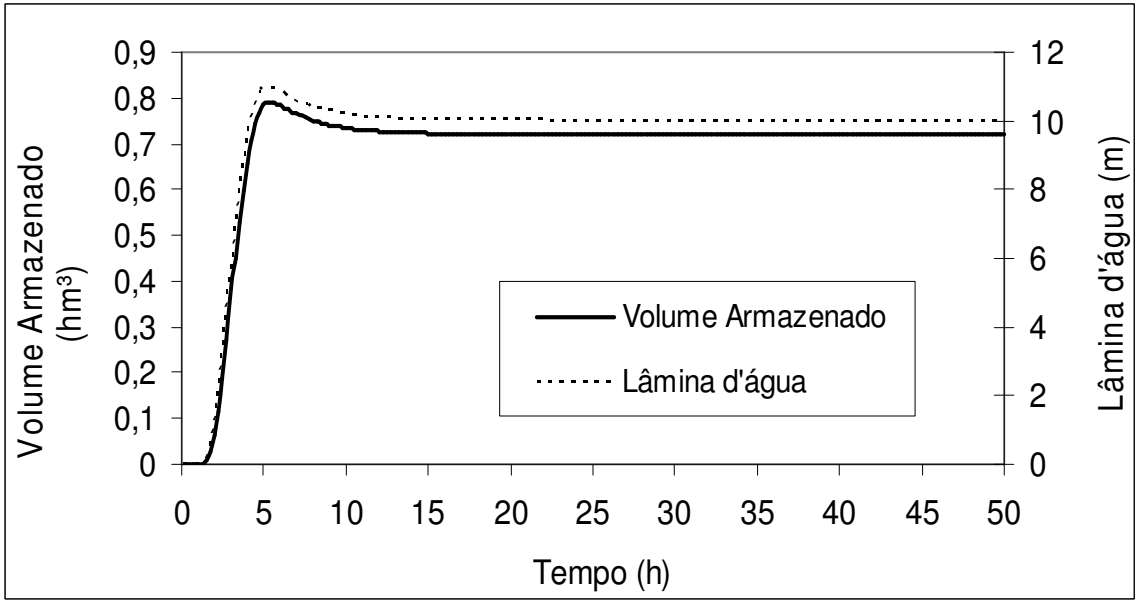

Figura 5.38 - Volume Armazenado e lâmina d'água em função do tempo para o cenário C - VIII 


\subsubsection{Verificação da lâmina d'água do canal para as vazões correspondentes aos cenários alternativos}

Mantendo-se as mesmas características do canal do cenário de projeto (revestimento, inclinação de fundo e largura) foi recalculada a partir da equação de Manning-Strickler, associada a equação de Chézy, a lâmina d'água para as vazões de pico correspondentes aos cenários alternativos, apresentada na Tabela 5.5.

Os resultados da lâmina d'água, velocidade máxima, altura do canal e as variações das vazões e lâmina d'água em relação ao cenário de projeto são apresentados na Tabela 5.6.

Tabela 5.6 - Lâmina d’água, velocidade máxima, altura do canal e variações das vazões e lâmina d'água

\begin{tabular}{|c|c|c|c|c|c|c|c|c|}
\hline \multirow[t]{2}{*}{ Cenário } & \multirow{2}{*}{$\begin{array}{l}\text { Vazão } \\
\text { de pico } \\
\left(\mathrm{m}^{3} / \mathrm{s}\right)\end{array}$} & \multirow{2}{*}{$\begin{array}{l}\text { Lâmina } \\
\text { d'água } \\
\text { (m) }\end{array}$} & \multirow{2}{*}{$\begin{array}{l}\text { Veloc. } \\
\text { máxima } \\
(\mathrm{m} / \mathrm{s})\end{array}$} & \multirow{2}{*}{$\begin{array}{l}\text { Altura do } \\
\text { canal } \\
(\mathrm{m})\end{array}$} & \multicolumn{2}{|c|}{$\begin{array}{l}\text { Variação da vazão } \\
\text { de pico }\end{array}$} & \multicolumn{2}{|c|}{$\begin{array}{c}\text { Variação da lâmina } \\
\text { d'água }\end{array}$} \\
\hline & & & & & $(\mathrm{m})$ & $(\%)$ & $(\mathrm{m})$ & $(\%)$ \\
\hline Projeto & 116,866 & 5,3 & 2,3 & 6,3 & & & & \\
\hline 1 & 94,410 & 4,5 & 2,2 & 5,5 & -23 & $-20 \%$ & $-0,8$ & $-15 \%$ \\
\hline II & 141,723 & 6,1 & 2,4 & 7,1 & 25 & $21 \%$ & 0,8 & $15 \%$ \\
\hline III & 172,315 & 7,1 & 2,5 & 8,1 & 55 & $47 \%$ & 1,8 & $34 \%$ \\
\hline IV & 86,600 & 4,2 & 2,2 & 5,2 & -30 & $-26 \%$ & $-1,1$ & $-21 \%$ \\
\hline V & 100,468 & 4,7 & 2,2 & 5,7 & -17 & $-15 \%$ & $-0,6$ & $-11 \%$ \\
\hline VI & 124,909 & 5,6 & 2,4 & 6,6 & 8 & $7 \%$ & 0,3 & $6 \%$ \\
\hline VII & 112,846 & 5,1 & 2,3 & 6,1 & -4 & $-3 \%$ & $-0,2$ & $-4 \%$ \\
\hline VIII & 100,915 & 4,7 & 2,2 & 5,7 & -16 & $-14 \%$ & $-0,6$ & $-11 \%$ \\
\hline
\end{tabular}

A Figura 5.39 mostra a variação da lâmina d'água para os cenários estudados. As setas amarelas indicam a redução e as verdes o aumento da lâmina d'água do cenário alternativo em relação ao cenário de projeto. 


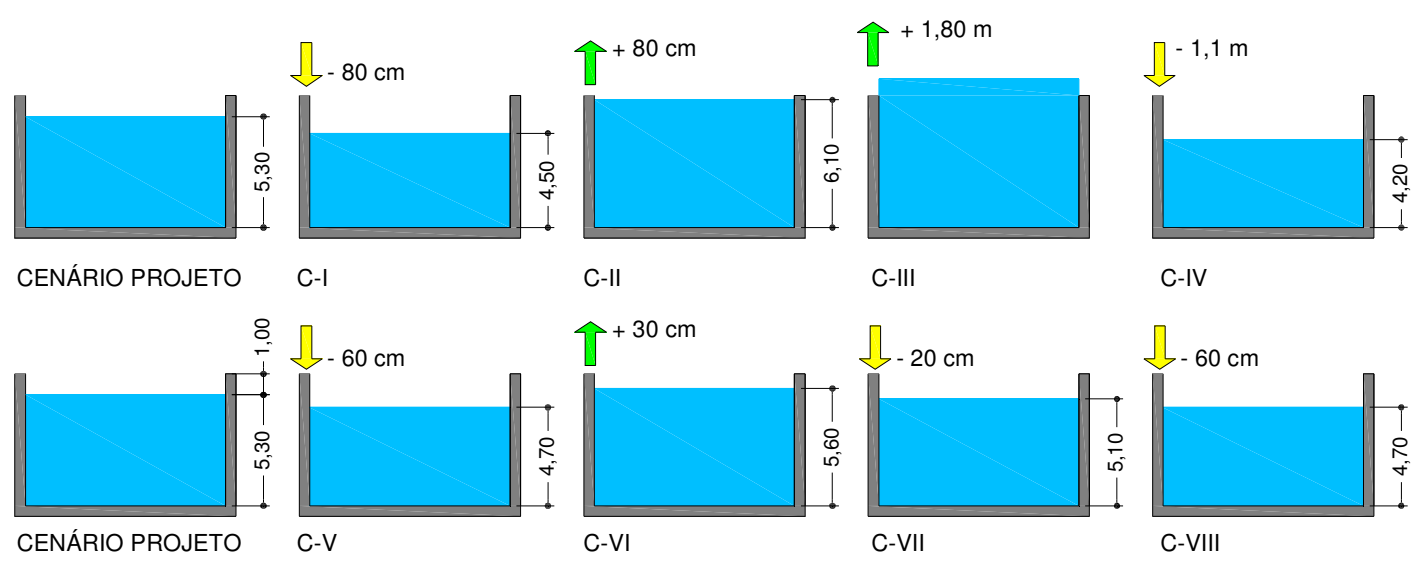

Figura 5.39 - Variação da lâmina d'água dos cenários alternativos em relação ao cenário de projeto

A Figura 5.40 mostra que a variação da vazão de pico não é diretamente proporcional a variação na lâmina d'água do canal.

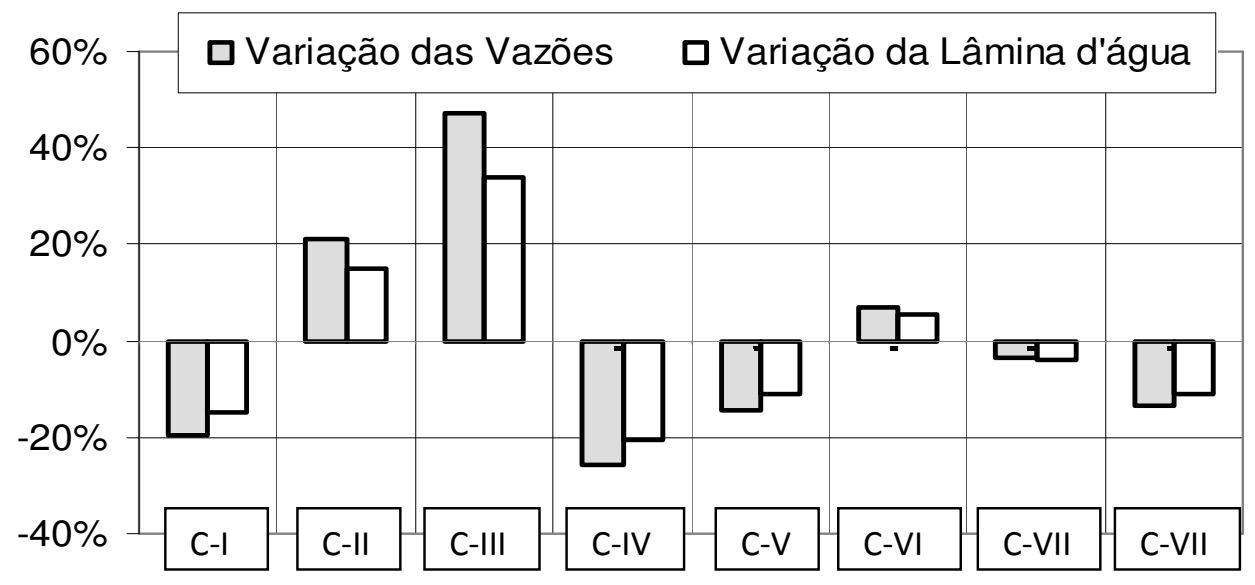

Figura 5.40 - Variações das vazões de pico e lâmina d'água no canal para os cenários alternativos

Para os cenários em que foram alteradas apenas uma das variáveis no cálculo do hidrograma de projeto, as maiores variações no cálculo da lâmina d'água ocorreram, em ordem decrescente, quando se alterou:

- O tempo de concentração (cenário C - III, aumento de 34\% e cenário C - IV, com redução de $21 \%$ na lâmina d'água em relação ao cenário de projeto). Nota-se que a variação é maior quando se reduz o tempo de concentração em relação ao adotado como ideal para a bacia hidrográfica; 
- O valor de $\mathrm{CN}$ (cenários C - I e C - II, com aumento e redução de $15 \%$ na lâmina d'água em relação ao cenário de projeto);

- A duração da chuva de projeto (cenário $\mathrm{C}-\mathrm{V}$, redução de $11 \%$ e cenário $\mathrm{C}$ VI, com aumento de $6 \%$ na lâmina d'água em relação ao cenário de projeto).

As alterações simultâneas das três variáveis, tempo de concentração, CN e duração da chuva de projeto, resultaram na diminuição de $4 \%$ da lâmina d'água em relação ao cenário de projeto.

Alterando-se o período de retorno de 100 anos para 50 anos, houve redução de $11 \%$. Neste caso, deve ser estudado se o aumento do risco da estrutura vir a falhar compensa os benefícios que esta criará.

Para os cenários em que houve redução na lâmina d'água, entende-se que não há comprometimento quanto à segurança da estrutura. Entretanto, como a estrutura está superdimensionada em relação ao período de retorno adotado, os recursos que serão gastos para sua construção serão maiores do que o necessário, o que faz com que a relação custo-benefício não seja a ótima.

Ao contrário, para os cenários C-II, C-III e C-VI, para os quais houve aumento da lâmina d'água, o risco da estrutura vir a falhar para o período de retorno proposto é maior do que o esperado em relação ao cenário de projeto. Nestes casos, seria necessária a readequação da obra para que fosse mantido o mesmo risco.

Para o cenário CIII, por exemplo, seria necessário escavar 1,80 $\mathrm{m}$ de terreno. Admitindo-se que o canal possua comprimento de $1 \mathrm{~km}$, o volume de terreno a escavar seria de $17.100 \mathrm{~m}^{3}$. De acordo com o TCPO (2008), o preço unitário da atividade "escavação", carga e transporte em solo de 1a categoria, utilizando trator sobre esteiras, para uma distância até $80 \mathrm{~m}$ é de $\mathrm{R} \$ 1,10 / \mathrm{m}^{3}$. A atividade de transporte e descarga de terra em caminhão basculante de $6 \mathrm{~m}^{3}$, para uma distância até $10 \mathrm{~km}$ é $\mathrm{R} \$ 17,11 / \mathrm{m}^{3}$. Seria, portanto, necessário o uso de aproximadamente 2.850 caminhões para transportar o volume escavado (sem considerar o empolamento do material). Em termos financeiros, apenas para estas duas atividades seria necessário um aditivo de aproximadamente $R \$ 312.000,00$. Deve se considerar ainda os custos adicionais como, por exemplo, de concreto, armação, 
revestimento e todas as outras atividades necessárias a construção do canal.

Esta mesma análise poderia ser feita aos demais cenários. Para os cenários onde houve redução na lâmina d'água, poderia se avaliar o percentual do valor economizado.

\subsubsection{Verificação da carga hidráulica sobre o vertedor do reservatório de controle de cheias e diferenças na redução da vazão de pico efluente e volume armazenado}

Para o reservatório de controle de cheias, foi verificada a variação na vazão de pico efluente, na carga hidráulica sobre o vertedor de soleira livre e no volume armazenado no reservatório para os cenários alternativos.

As características do reservatório de controle de cheias e do vertedor de soleira livre dimensionados para o cenário de projeto foram mantidas.

A Tabela 5.7 relaciona a vazão de pico efluente, a carga hidráulica sobre o vertedor de soleira livre, o volume armazenado no reservatório e suas respectivas variações em relação aos cenários alternativos.

Tabela 5.7 - Vazão de pico efluente, carga hidráulica sobre o vertedor, volume armazenado no reservatório e as respectivas variações

\begin{tabular}{|c|c|c|c|c|c|c|c|c|c|}
\hline \multirow[t]{2}{*}{ Cenário } & \multirow{2}{*}{$\begin{array}{c}Q_{\text {eflu }} \\
\left(\mathrm{m}^{3} / \mathrm{s}\right)\end{array}$} & \multicolumn{2}{|c|}{ Variação da $Q_{\text {eflu }}$} & \multirow{2}{*}{$\begin{array}{c}\text { Carga } \\
\text { (m) }\end{array}$} & \multicolumn{2}{|c|}{$\begin{array}{c}\text { Variação Carga } \\
\text { Hidráulica }\end{array}$} & \multirow{2}{*}{$\begin{array}{c}\text { Volume } \\
\text { Armazenado } \\
\left(\mathrm{hm}^{3}\right)\end{array}$} & \multicolumn{2}{|c|}{$\begin{array}{l}\text { Variação do } \\
\text { Volume }\end{array}$} \\
\hline & & $\left(\mathrm{m}^{3} / \mathrm{s}\right)$ & (\%) & & $(\mathrm{m})$ & $(\%)$ & & $\left(\mathrm{hm}^{3}\right)$ & $(\%)$ \\
\hline Projeto & 35,371 & - & - & 1,50 & - & - & 0,828 & - & - \\
\hline I & 11,604 & $-23,767$ & $-67 \%$ & 0,71 & $-0,79$ & $-53 \%$ & 0,771 & $-0,06$ & $-7 \%$ \\
\hline II & 64,369 & 28,998 & $82 \%$ & 2,24 & 0,74 & $49 \%$ & 0,881 & 0,05 & $6 \%$ \\
\hline III & 47,472 & 12,101 & $34 \%$ & 1,83 & 0,33 & $22 \%$ & 0,852 & 0,02 & $3 \%$ \\
\hline IV & 28,338 & $-7,033$ & $-20 \%$ & 1,30 & $-0,20$ & $-13 \%$ & 0,813 & $-0,02$ & $-2 \%$ \\
\hline V & 13,383 & $-21,988$ & $-62 \%$ & 0,79 & $-0,71$ & $-47 \%$ & 0,777 & $-0,05$ & $-6 \%$ \\
\hline VI & 49,961 & 14,59 & $41 \%$ & 1,89 & 0,39 & $26 \%$ & 0,856 & 0,03 & $3 \%$ \\
\hline VII & 63,659 & 28,288 & $80 \%$ & 2,22 & 0,72 & $48 \%$ & 0,880 & 0,05 & $6 \%$ \\
\hline VIII & 18,108 & $-17,263$ & $-49 \%$ & 0,96 & $-0,54$ & $-36 \%$ & 0,789 & $-0,04$ & $-5 \%$ \\
\hline
\end{tabular}


A Figura 5.41 mostra o esquema do reservatório na seção do vertedor onde é mostrada a posição da soleira livre e as diferentes cargas para o cenário de projeto e para os cenários alternativos.

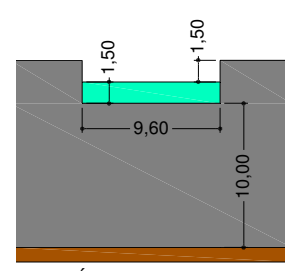

CENÁRIO PROJETO

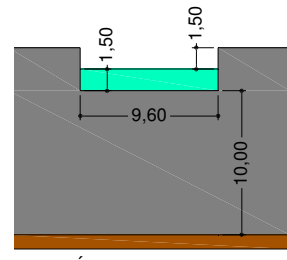

CENÁRIO PROJETO

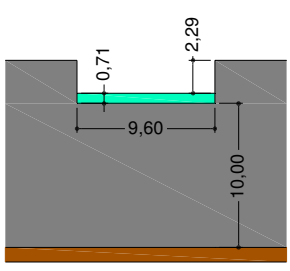

C-I

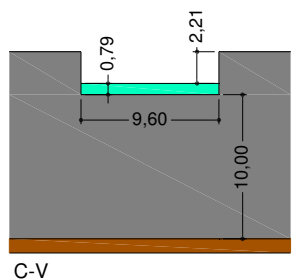

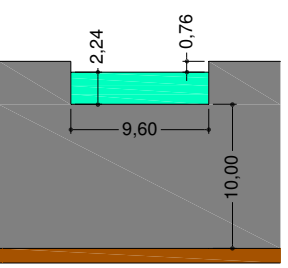

C-II

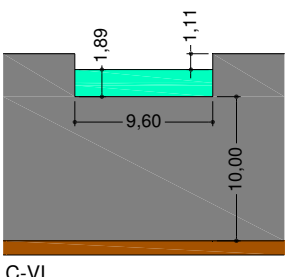

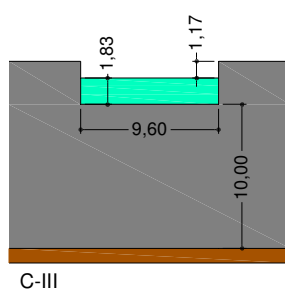

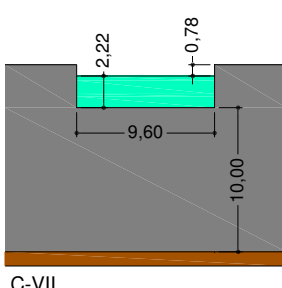

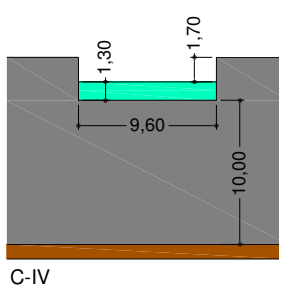

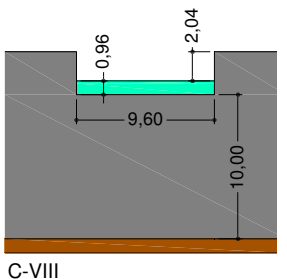

Figura 5.41 - Variação da carga hidráulica sobre o vertedor para os cenários alternativos em relação ao cenário de projeto.

A Figura 5.42 mostra que a variação da vazão efluente, da lâmina d'água e do volume armazenado. Nota-se que as variações entre a vazão de dimensionamento do e a carga hidráulica sobre o vertedor não são lineares.

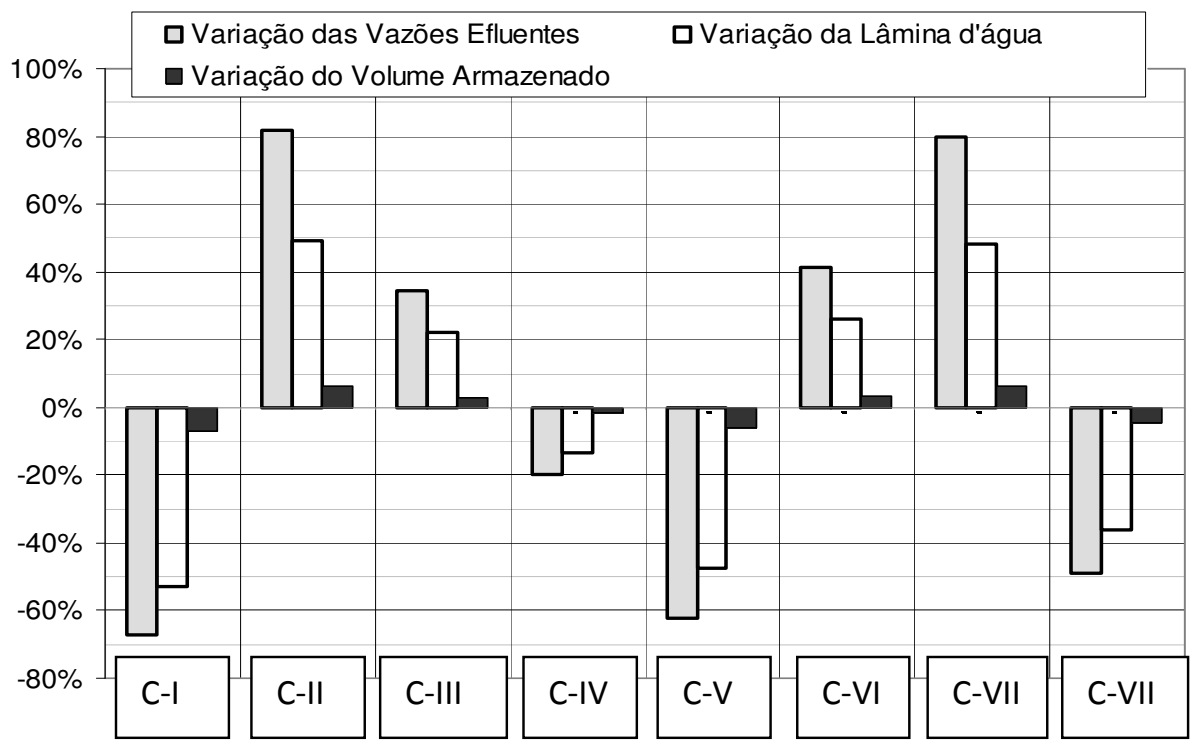

Figura 5.42 - Variação da vazão efluente, lâmina d'água e volume armazenado 
Dos resultados acima, nota-se que ao se alterar o valor da variável ( $\mathrm{CN}$, tempo de concentração e duração da chuva de projeto) na mesma proporção, para mais ou para menos, em relação ao valor adotado como ideal para a bacia hidrográfica, a variação na carga hidráulica sobre o vertedor não é a mesma. Por exemplo, ao se alterar o valor de CN de 80 para 75, a variação na carga hidráulica sobre o vertedor é de - $53 \%$, enquanto que ao se alterar o valor de CN de 80 para 85, a variação na carga hidráulica sobre o vertedor é de $+49 \%$.

Para as variáveis: $\mathrm{CN}$, tempo de concentração e duração da chuva de projeto, a variação mais crítica referente à carga hidráulica sobre o vertedor, ocorre quando os valores destas variáveis são reduzidos em relação aos considerados ideais para a bacia hidrográfica em análise.

As maiores variações na carga hidráulica sobre o vertedor ocorreram quando se alterou as variáveis $\mathrm{CN}$, duração da chuva de projeto e tempo de concentração. A maior variação ocorreu para o cenário C-I (alteração do valor de CN de 80 para 75) para qual a carga hidráulica sobre o vertedor foi 57 \% menor. A menor variação ocorreu para o cenário C-IV (alteração do valor da do tempo de concentração de 2,5 h para 3,5 h) para qual a carga hidráulica sobre o vertedor foi $13 \%$ menor.

Nota-se que, para todos os cenários alternativos as variações são elevadas e, portanto, a definição das variáveis na determinação dos hidrogramas deve ser cuidadosamente definida.

É importante salientar que as variações dependem das características das estruturas assim como da bacia hidrográfica em estudo. Nota-se, entretanto, que existe certo grau de importância em relação aos impactos que os hidrogramas de cheia geram nas obras de estruturas hidráulicas. Estes impactos podem ser de ordem econômica, financeira ou relativa à segurança estrutural das obras. 


\section{CONCLUSÕES}

As análises de sensibilidade mostraram que a vazão de pico do hidrograma de cheia é crescente com o valor do $\mathrm{CN}$, resultado já esperado, pois quanto maior o valor do $\mathrm{CN}$, maior é a impermeabilização da bacia hidrográfica e, portanto, menor a taxa de infiltração e maior o volume de escoamento superficial direto. Verificou-se que relação entre o valor do $\mathrm{CN}$ e da vazão de pico é fortemente não-linear, ou seja, para pequenas variações no valor de $\mathrm{CN}$, a variação da vazão de pico e do respectivo hidrograma são bastante acentuadas. As variações da vazão de pico diferem em função do período de retorno. Quanto menor o período de retorno, maior a variação na vazão.

A vazão de pico é crescente com a área de drenagem da bacia, pois quanto maior a área de drenagem, maior é o volume de escoamento superficial direto sobre a bacia. A relação entre a área de drenagem e o volume do hidrograma de cheia, nestas análises é linear, pois foi mantida a altura da chuva excedente. As análises de sensibilidade mostraram que para pequenas áreas de drenagem as variações nos valores da vazão de pico são significativas.

As análises de sensibilidade mostraram que a vazão de pico é decrescente com o tempo de concentração. A relação entre a vazão de pico e o tempo de concentração, também não é linear. $O$ tempo de concentração é um dos parâmetros que influencia significativamente a vazão de pico, portanto, sua escolha deve ser criteriosa. $O$ tempo de concentração não influencia o volume do hidrograma de cheia, mas altera a sua forma. Quanto maior o tempo de concentração, maior é o tempo de ascensão e mais achatado é o hidrograma.

$\mathrm{Na}$ análise de sensibilidade quanto à duração da chuva de projeto, nota-se, que a variação no valor da vazão de pico é maior em função do tempo de concentração do que em função da duração da chuva de projeto. As análises mostraram que as maiores variações nas vazões de pico dos hidrogramas ocorreram para chuvas com durações abaixo do tempo de concentração. Para durações acima, as variações foram reduzidas e os gradientes tendem a uma assíntota. A partir daí, as variações 
na vazão de pico tem a mesma ou menor precisão do que as medições de vazão. Confirma-se a teoria de que a duração da chuva de projeto a ser adotada deve ser igual ou superior ao tempo de concentração para pequenas bacias hidrográficas. A mesma análise é válida para as variações dos volumes dos hidrogramas.

As curvas de variação das análises de sensibilidade de todos os parâmetros avaliados mostram que as variações tendem a diminuir com o aumento do período de retorno.

Em relação aos métodos de obtenção dos hidrogramas de cheia, para a bacia hidrográfica estudada, as vazões de pico geradas pelo método de Santa Bárbara e Clark são menores do que as vazões de pico geradas pelo método do SCS. As vazões obtidas pelo método de Clark são maiores do que as obtidas pelo método de Santa Bárbara.

Excluindo a área de drenagem das análises, em virtude da baixa probabilidade de incertezas e erros em sua definição e, considerando que a duração da chuva de projeto seja sempre maior ou igual ao valor do tempo de concentração, pode-se concluir, para estes estudos, que o CN e o tempo de concentração são as variáveis que mais influenciam os valores das vazões de pico para a bacia hidrográfica considerada neste trabalho.

Quanto aos estudos de aplicação prática é importante salientar que as variações dependem das características das estruturas, assim como, da bacia hidrográfica em estudo. Nota-se, entretanto, que existe certo grau de importância em relação aos impactos que os hidrogramas de projeto geram nas obras de estruturas hidráulicas. Estes impactos podem ser de ordem econômica, financeira ou relativa à segurança estrutural das obras. 


\section{RECOMENDAÇÕES}

A escolha do valor do $\mathrm{CN}$ deve ser criteriosa. É necessário que toda a informação referente ao solo da bacia hidrográfica seja reunida e avaliada cuidadosamente.

Para bacias com pequenas áreas de drenagem, nos casos em que exista dúvida quanto à determinação desta área, recomenda-se a obtenção de imagens de satélite para minimizar a incerteza do valor a ser utilizado nos estudos. Atenção deve ser dada às bacias urbanas, que em geral, tem suas condições de drenagem alteradas devido às obras de intervenções, como obras de desvios e de transferência de águas. Nestes casos, além da obtenção da cartografia e imagens de satélites, faz-se necessária a consulta ao cadastro das intervenções feitas na região em estudo.

Quanto a determinação do tempo de concentração, deve-se estar atento ao tipo de bacia e o tipo de escoamento que as equações procuram representar, aplicando-as somente para bacias que se aproximem de tais casos.

Em pequenas bacias hidrográficas, a duração da chuva de projeto deve ser igual ou maior que o tempo de concentração. A escolha deve ser feita por tentativas, traçando-se o gráfico da vazão de pico e do volume do hidrograma de projeto em função da duração da chuva, de forma a se obter uma precisão aceitável.

A escolha do período de retorno deve atender aos critérios de projeto das entidades que atuam como gestor técnico das obras. Estudos econômicos, apesar de não levarem em conta certos aspectos que não são mensuráveis monetariamente, podem auxiliar na sua escolha do período de retorno.

Como recomendação geral, visto à facilidade no uso de ferramentas computacionais e sistemas de suporte à decisão, sugere-se que sempre seja realizada uma análise de sensibilidade nos estudos hidrológicos. A análise de sensibilidade irá permitir a avaliação dos erros que porventura possam ser cometidos quando da adoção de uma ou outra variável de entrada. 
Apesar deste trabalho ater-se ao estudo de métodos indiretos de determinação de hidrogramas de projeto, há de se destacar a importância do monitoramento hidrológico, cujo objetivo é o levantamento de dados fluviométricos, pluviométricos, evaporímetricos, sedimentómetricos e de qualidade de água, que possibilitam o conhecimento das características quali-quantitativas de nossos rios e dos índices pluviométicos, com suas distribuições no espaço e no tempo.

Neste sentido, vislumbra-se ainda, a implantação de bacias hidrográficas experimentais para aprimorar o entendimento e a representação da dinâmica dos processos hidrológicos. Dentre outros objetivos a implantação de bacias hidrográficas experimentais possibilita aprofundar os conhecimentos sobre métodos de previsão dos processos hidrológicos, a partir da análise crítica de modelos existentes, permitindo ainda uma reavaliação de trabalhos já desenvolvidos, como os de adequação do valor do CN para solos do estado de São Paulo e de calibragem das equações do tempo de concentração, especialmente, as de aplicação em bacias rurais. 


\section{REFERÊNCIAS BIBLIOGRÁFICAS}

ASCE. Design and Construction of Urban StormWater System. In: Manual of Practice no 77. New York: American Society of Civil Engineers, 1992.

AZEVEDO NETTO, J. M. Manual de hidráulica. 8. ed. São Paulo: Edgard Blucher, 1998. $669 \mathrm{p}$.

BERTHELOT, R. Curso de Hidrologia Sintética. Porto Alegre: Instituto de Pesquisas Hidráulicas, 1970.

BRASIL. Centrais Elétricas Brasileiras S.A - Eletrobrás. Diretrizes para estudos e projetos de pequenas centrais hidrelétricas. Brasília: 2007. $458 \mathrm{p}$.

CANHOLI, A. P. Drenagem urbana e controle de enchentes. São Paulo: Oficina de Textos, 2005. 302 p.

CHOW, V. T. Handbook of applied hydrology: a compendium of water-resources technology. New York: McGraw-Hill, 1964. 1 v.

. Open channel hydraulics. New York: McGraw Hill: 1973.

CHOW, V. T.; MAIDMENT, D. R. E.; MAYS, L. Applied Hydrology. New York: Mc Graw Hill, 1988. 572 p.

CLARK, C. O. Storage and the unit hydrograph. TRANS.ASCE, v.110, p.1414-1446, 1945.

DEPARTAMENTO DE ÁGUAS E ENERGIA ELÉTRICA. Guia prático para projeto de pequenas obras hidráulicas. 3. ed. rev. São Paulo: DAEE, 2008. 116 p.

. Acervo e pesquisa. Disponível em:

<http://www.daee.sp.gov.br/acervoepesquisa/relatorios/fotos/pasta16/F1.jpg $>$.

Acesso em: 06 fev. 2010.

SAISP - Sistema de alerta à inundações de São Paulo. Disponível em: < http://www.saisp.br/online >. Acesso em: 06 fev. 2010. 
DOOGE, J. C. I. Synthetic unit hydrographs based on triangular inflow. 1956.

Dissertação (Mestrado) - State University of lowa Library, lowa, 1956.

DOOGE, J. C. I. Linear theory of hydrologic Systems. Washington, D. C.: US Department of Agriculture, 1973.

EDIE - Enviromental Data Interactive Exchange. Data loggers for water level. Disponível em: < http://www.edie.net/products/view entry.asp?id=4001 $>$. Acesso em: 10 fev. 2010.

ESTADOS UNIDOS. NASA - National Aeronautics and Space Administration. Em: < http://trmm.gsfc.nasa.gov/>. Acesso em: 02 fev. 2010.

ESTADOS UNIDOS. USACE - US Army Corps of Engineers. Software. Em: < http://www.hec.usace.army.mil/software/>. Acesso em: 10 fev. 2010.

ESTADOS UNIDOS. USGS - United States Geological Survey. The water cycle. 2009. Disponível em: <http://ga.water.usgs.gov/edu/watercycle.html>. Acesso em 08 ago. 2009.

. SCS - Soil Conservation Service. National Engineering Handbook. Washington D.C: USDA, 1972.

. USDA-SCS. United States Department of Agriculture. Urban hydrology for small watersheds. Washington D.C.: USDA,1975.

. Urban hydrology for small watersheds. Washington D.C.: USDA,1986.

National engineering handbook. Washington, D.C: USDA, 1985. Sec. 4.

GARCEZ, L. N.; ALVAREZ, G. A. Hidrologia. 2. ed. São Paulo: Edgard Blucher, 1988. $291 \mathrm{p}$.

GENOVEZ, A. M. Avaliação dos métodos de estimação das vazões de enchente para pequenas bacias hidrográficas do Estado de São Paulo. 1991. 255 p. Tese (Livre Docência) - Faculdade de Engenharia Civil, Universidade Estadual de Campinas, Campinas, 1991. 
GUARISO, G. E.; WHERTNER, H. Enviromental Decision Support Systems. In: PORTO, R. L. L. (Org). Técnicas quantitativas para o gerenciamento de recursos hídricos. 2. ed. Porto Alegre: UFRGS; Porto Alegre: ABRH, 2002. 419 p.

HORTON, R. E. Analysis of runoff plat experiments with varying infiltration capacity. [S.I]: Trans. Am. Geopys. Union, 1939, p. 693-711.

KELTON, D. W.; SADOWSKI, R. P.; SADOWSKI, D. A. Simulation with Arena. New York: McGraw Hill, 2003. 631 p.

KIRPICH, Z. P. Time of concentration of small agricultural watersheds. In: CHOW, V. T.; MAIDMENT, D. R. E.; MAYS, L. Applied Hydrology. New York: Mc Graw Hill, 1988. $572 \mathrm{p}$.

KLEIN, M.; METHLIE, L. Expert systems: A Decision Support Approach. In: PORTO, R. L. L. (Org). Técnicas quantitativas para o gerenciamento de recursos hídricos. 2. ed. Porto Alegre: UFRGS; Porto Alegre: ABRH, 2002. 419 p.

Lee, Chahng-hah; Seung-mahn Ahn; Kyoo-seock Lee. Application of the GIS in the hydrologic effects caused by the second collective facility area development in MT. Kyeryong National Park. In: ESRI INTERNATIONAL USER CONFERENCE, 1. 1995, California. Proceedings. California: ESRI, 1995. Disponível em: < http://proceedings.esri.com/library/userconf/proc95/to250/p246.html> Acesso em: 02 fev. 2010.

LINSLEY, R.; FRANZINI, J. B. Engenharia de recursos hídricos. Tradução do Eng. Luiz Américo Pastorinho. São Paulo: McGraw-Hill; São Paulo: EDUSP, 1917. 798 p.

MARCELLINI, S. S. Análise de critérios para a determinação das tormentas de projeto e sua influência nos hidrogramas em pequenas bacias hidrográficas. 1994. 176 p. Dissertação (Mestrado) - Escola Politécnica da Universidade de São Paulo, São Paulo, 1994.

MARTINEZ JÚNIOR, F; MAGNI, N. L. G. Equações de chuvas intensas do Estado de São Paulo. São Paulo: DAEE; 1999. 125 p.

MAGNI, N. L. G.; F. MERO. Precipitações intensas no Estado de São Paulo. São Paulo: DAEE, 1982. $95 \mathrm{p}$. 
MARTINS, V. H. R. Por uma integração de uso e ocupação do solo e drenagem urbana - reservatórios de detenção na bacia do Córrego Pirajuçara. 2005. 107 p. Dissertação (Mestrado) - Escola Politécnica, Universidade de São Paulo, São Paulo, 2005.

MAYS, L. W. Stormwater drainage systems design handbook. [S.I]: 2001. 755 p.

McCUEN, R. A guide to hydrologic analysis using SCS methods. New Jersey, Prentice-Hall, 1982. 145 p.

McPHERSON, M. B. Discussion of synthetic storm pattern for drainage design. In: MARCELLINI, S. S. Análise de critérios para a determinação das tormentas de projeto e sua influência nos hidrogramas em pequenas bacias hidrográficas. 1994. 176p. Dissertação (Mestrado) - Escola Politécnica da Universidade de São Paulo, São Paulo, 1994.

MOREL-SEITOUX, H. J. Application of infiltration theory for the determination of excess rainfall hyetograph. In: MARCELLINI, S. S. Análise de critérios para a determinação das tormentas de projeto e sua influência nos hidrogramas em pequenas bacias hidrográficas. 1994. 176 p. Dissertação (Mestrado) - Escola Politécnica da Universidade de São Paulo, São Paulo, 1994.

PARKER, B. J.; AI-UTABI, G. A. Decision Support Systems: the reality that seems to be hard to accept? In: PORTO, R. L. L. (Org). Técnicas quantitativas para 0 gerenciamento de recursos hídricos. 2. ed. Porto Alegre: UFRGS; Porto Alegre: ABRH, 2002. 419 p.

PFAFSTETTER, O. Chuvas intensas no Brasil. Rio de Janeiro: Departamento Nacional de Obras de Saneamento, 1957. Não paginado.

PINTO, N. L. S. et al. Hidrologia básica. São Paulo: Edgard Blücher, 1976. 278 p.

PONCE, V. M.; HAWKINS, R. H. Runoff curve number: has it reached maturity? Journal of Hydrologic Engineering, v.1, n.1, p.11-19, 1996.

Portal de São Paulo. Parque do Ibirapuera. Em: <http://www.portaldesampa.kit.net/Postais/parquedoibirapuera.jpg>. Acesso em: 10 fev. 2010. 
PORTO, R. L. L. Escoamento superficial direto. In: TUCCI, C. E. M.; PORTO, R. L. L.; BARROS, M. T. (Org.). Drenagem urbana. Porto Alegre: ABRH; Porto Alegre: UFRGS, 1995. 428 p.

PORTO, R. L. L.; Azevedo, L. G. T. Sistemas de Suporte e Decisões Aplicados a Problemas de Recursos Hídricos. In: PORTO, R. L. L. (Org). Técnicas quantitativas para o gerenciamento de recursos hídricos. 2. ed. Porto Alegre: UFRGS; Porto Alegre: ABRH, 2002. $419 \mathrm{p}$.

PORTO, R. L. L. (Org). Técnicas quantitativas para o gerenciamento de recursos hídricos. Porto Alegre: Ed.Universitária/UFRGS/ABRH, 1997. 419 p. . 2. ed. Porto Alegre: UFRGS; Porto Alegre: ABRH, 2002. 419 p.

RENNÓ, C. D. Construção de um sistema de análise e simulação hidrológica: aplicação a bacias hidrográficas. 2004. 158 p. Tese (Doutorado) Instituto Nacional de Pesquisas Espaciais, São José dos Campos, 2003.

ROBERTO. A. N.; PORTO R. L. L.; ZAHED, K. F. Sistema de Suporte a Decisões para Análise de Cheias em Bacias Complexas. Anais do XII Simpósio Brasileiro de Recursos Hídricos. 1997. p.45.

SABOL, G. V. Clark unit hydrograph and R-parameter estimation. J. Hydraul. Eng., v.114, n. 1, p. 103-111, 1988.

SAGE, A. P. Decison Support Systems Engineering. In: PORTO, R. L. L. (Org). Técnicas quantitativas para o gerenciamento de recursos hídricos. 2. ed. Porto Alegre: UFRGS; Porto Alegre: ABRH, 2002. 419 p.

SCHOWENGERDT, R. A. Remote Sensing: models and methods for image processing. 2. ed. New York: Academic Press, 1997. 522 p.

SETZER, J.; PORTO, R. L. L. Tentativa de avaliação de escoamento superficial com o solo e o seu recobrimento vegetal nas condições do Estado de São Paulo.

Boletim técnico DAEE, São Paulo, v.2, n.2, p. 82-135, 1979.

SILVEIRA, A. L. L. Desempenho de formulas de tempo de concentração em bacias urbanas e rurais. Revista Brasileira de Recursos Hídricos: RBRH. v.10, p.5-23. 2005. 
SPRAGUE, R. H.; CARLSON, E. D. Building Effective Decision Support Systems. In: PORTO, R. L. L. (Org). Técnicas quantitativas para o gerenciamento de recursos hídricos. 2. ed. Porto Alegre: UFRGS; Porto Alegre: ABRH, 2002. 419 p.

SPRAGUE, R. H.; WATSON, H. J. The components of an architecture for DSS. In: PORTO, R. L. L. (Org). Técnicas quantitativas para o gerenciamento de recursos hídricos. 2. ed. Porto Alegre: UFRGS; Porto Alegre: ABRH, 2002. 419 p.

STRUBCHAER, J. M. The Santa Barbara urban hydrograph method. In: NATIONAL SYMPOSIUM ON URBAN HYDROLOGY AND SEDIMENT CONTROL, 1975, Kentucky. Proceedings... Kentucky: ASAE, 1975. 314p.

TAKAHASHI, Y.; RABINS, M. J.; AUSLANDER, D. M. Control and Dynamic Systems. In: TRIVELATO, G. C. Técnicas de modelagem e simulação de sistemas dinâmicos. São José dos Campos: INPE, 2003. 19 p.

TCPO - Tabela para composição de preços e orçamentos. 13. ed. [S.I]: Editora PINI, 2008. $630 \mathrm{p}$.

TUCCI, C. E. M. Hidrologia: Ciência e Aplicação. Porto Alegre: UFRGS; Porto Alegre: $A B R H ;$ 2004. 943 p.

$669 \mathrm{p}$.

. Modelos hidrológicos. Porto Alegre: UFRGS; Porto Alegre: ABRH, 1998.

Modelos hidrológicos. 2. ed. Porto Alegre: UFRGS, 2005. 678 p.

TUCCI, C. E. M.; PORTO, R. L. L.; BARROS, M. T. (Org.). Drenagem urbana. Porto Alegre: ABRH; Porto Alegre: UFRGS, 1995. 428 p.

TURBAN, E. Decision Support and Expert Systems. In: PORTO, R. L. L. (Org). Técnicas quantitativas para o gerenciamento de recursos hídricos. 2 . ed. Porto Alegre: UFRGS; Porto Alegre: ABRH, 2002. 419 p.

UEHARA, K. et al. Pequenas bacias hidrográficas do Estado de São Paulo Estudo de vazões médias e máximas. São Paulo: FDTE; EPUSP, 1980. 780 p. 
UNIVERSIDADE DE SÃO PAULO. Instituto Astronômico e Geofísico - IAG.

Observações de superfície efetuadas na estação meteorológica. São Paulo: 1997.

WANIELISTA, M. P.; KERSTEN, R.; EAGLIN, R. Hydrology and Water Quality Control. New York: J. Wiley and Sons, 1997. 567 p..

ZAHED FILHO, K.; MARCELLINI, S. S. Precipitações máximas. In: TUCCI, C. E. M.; PORTO, R. L. L.; BARROS, M. T. (Org.). Drenagem urbana. Porto Alegre: ABRH; Porto Alegre: UFRGS, 1995. 428 p. 


\section{BIBLIOGRAFIA CONSULTADA}

ABAS - Associação Brasileira de Águas Subterrâneas. Disponível em: $<$ http://www.abas.org/index.php $>$. Acesso em 15 jan. 2010.

ALAN A. SMITH INC. MIDUSS. Disponível em:

$<$ http://www.alanasmith.com/index.htm>.Acesso em: 20 jan. 2010.

ASCE - American Society of Civil Engineers. Disponível em: <http://www.asce.org >. Acesso em: 03 set. 2009.

BARROS, M. T. L.; PALOS, J. C. F. Análise de métodos hidrológicos empregados em projetos de drenagem urbana no Brasil. In: XII SIMPÓSIO BRASILEIRO DE RECURSOS HÍDRICOS/ABRH, 1997, Vitória. Anais... Vitória: ABRH, 1997. v. 3.

BARTH, F. T.; BARBOSA, W. E. S. Recursos hídricos. São Paulo: EPUSP, 1999.

BARTH, F. T. et al. Modelos para Gerenciamento de Recursos Hídricos. São Paulo: Nobel: ABRH (Coleção ABRH de Recursos Hídricos), 1987. v. 1.

BONI, R. C. Estudo comparativo da infiltração através da aplicação de modelo chuva-deflúvio a bacias do Estado de São Paulo. 1999. 142 p. Dissertação (Mestrado) - Faculdade de Engenharia Civil, Universidade de Campinas, Campinas, 1999.

BOTELHO, M. H. C. Águas de Chuva. São Paulo: Edgard Blücher, 1985. 236 p.

BRAZ, M. G.; UYEMURA, K. A Importância da implantação e operação de estações hidrológicas automáticas em bacias hidrográficas urbanas. In: XIII SIMPÓSIO BRASILEIRO DE RECURSOS HÍDRICOS, 1999, Belo Horizonte. Anais... Belo Horizonte: ABRH, 1999. CD-ROM.

CARVALHO, T. L. L. Análise regional de freqüências aplicada à precipitação pluvial. 2007. 96 p. Dissertação (Mestrado) - Instituto de Pesquisas Hidráulicas, Universidade Federal do Rio Grande do Sul, Porto Alegre, 2007.

COLORADO STATE UNIVERISTY. College of Engineering. Disponível em: $<$ http://www.engr.colostate.edu>. Acesso em: 05 dez 2009. 
CRUZ, M. A. S. et al. Aplicação do SIG na Obtenção do Hidrograma Unitário a partir do Histograma tempo-área. In: XII SIMPÓSIO BRASILEIRO DE RECURSOS HÍDRICOS/ABRH, 1997, Vitória. Anais... Vitória: ABRH, 1997. v. 1. p. 575.

DEPARTAMENTO DE ÁGUAS E ENERGIA ELÉTRICA/COMPANHIA DE TECNOLOGIA DE SANEAMENTO AMBIENTAL. Drenagem urbana: Manual de Projeto. São Paulo: DAEE, 1980. 468 p.

DINIS, H.; BRUNA, G. C. A Drenagem Urbana e o Uso e Ocupação do Solo. In: XVII SIMPÓSIO BRASILEIRO DE RECURSOS HÍDRICOS - 8 SIMPÓSIO DE HIDRÁULICA E RECURSOS HÍDRICOS DOS PAÍSES DE LÍNGUA OFICIAL PORTUGUESA, 2007, São Paulo. Anais... São Paulo: ABRH, 2007. CD-ROM.

DRUMOND, M. M.; NASCIMENTO, N. O.; BAPTISTA, M. B.; CABRAL, J. R. Determinação do tempo de concentração com a técnica de traçadores na bacia representativa de Juatuba - MG. In: XIII SIMPÓSIO BRASILEIRO DE RECURSOS HIDRICOS, 1999, Belo Horizonte. Anais... Belo Horizonte: ABRH, 1999. CD-ROM.

ESTEVES, R. L.; MENDIONDO, E. M. Análise comparativa entre equações e observações do tempo de concentração em uma bacia urbana de São Carlos, SP. In: XV SIMPÓSIO BRASILEIRO DE RECURSOS HÍDRICOS, 2003, Curitiba.

Desafios à gestão da água no limiar do Século XXI. Porto Alegre: $A B R H, 2003$. v.

FENDRICH, R. Importância das equações de chuvas intensas na drenagem urbana. In: XIII SIMPÓSIO BRASILEIRO DE RECURSOS HÍDRICOS, 1999, Belo Horizonte. Anais do XIII Simpósio Brasileiro de Recursos Hídricos, Belo Horizonte: ABRH, 1999. v. 1. p. 1-13.

GENOVEZ, A. M.; PIO, E. D. Avaliação da regionalização do hidrograma unitário e dos coeficientes de Snyder para bacias rurais. In: XIII SIMPÓSIO BRASILEIRO DE RECURSOS HÍDRICOS, 1999, Belo Horizonte. Anais.... Belo Horizonte: ABRH, 1999. CD-ROM.

GENOVEZ, A. M.; SARTORI, A.; LOMBARDI NETO, F. Métodos empíricos para a determinação do número da curva de escoamento superficial (CN) para solos com diferentes usos e manejos. In: XXI Congreso Latinoamericano de Hidráulica, 2004, São Pedro. Anais... Madri: IAHR - International Association of Hydraulic Research, 2004.

GRAY, D. M. Handbook on the Principles of Hydrology. Port Washington: National Research Council of Canada, 1975. 691 p. 
LENEASTRE, A.; FRANCO, F. M. Lições de Hidrologia. Lisboa: Universidade Nova de Lisboa, 1984. 451 p.

LINSLEY, R. K.; FRANZINI, J. B. Engenharia de Recursos Hídricos. 1 ed. São Paulo: McGraw-Hill; São Paulo: EDUSP, 1978. 798 p.

LINSLEY, R. K.; KOHLER, M. A.; PAULHUS, J. L. H. Hydrology for Engineers. New York: McGraw-Hill, 1982. 508 p.

MAIDMENT, D. R. (Ed.). Handbook of Hydrology. New York: McGraw-Hill, 1993. $1424 \mathrm{p}$.

MAGALHÃES, P. C. Hidrologia Superficial. In: Engenharia Hidrológica. Rio de Janeiro: ABRH; Rio de Janeiro: UFRJ, 1989. p. 201-289

NEMEC, J. Engineering Hydrology. New Delhi: McGraw-Hill, 1964. 316p.

PAIVA, J. B. D.; E.; PAIVA, M. C. D. (Org.). Hidrologia Aplicada à Gestão de Pequenas Bacias Hidrográficas. Porto Alegre: ABRH, 2003. 628 p.

PINTO, N. L. S.; HOLTZ, A. C. T.; MARTINS, J. A. Hidrologia de Superfície. São Paulo: Edgard Blücher, 1973. 179 p.

PONCE, V. M. Engineering Hydrology: Principles and Practices. New Jersey: Prentice Hall, 1989. 640 p.

PORTO, R. L. L. (Org). Hidrologia ambiental. São Paulo: EDUSP/Associação Brasileira de Recursos Hídricos, 1991. 414 p.

RAMOS, C. L.; BARROS, M. T. L.; PALOS, J. C. F. (Coord.). Diretrizes básicas para projetos de drenagem urbana no Município de São Paulo. [São Paulo]: Prefeitura do Município de São Paulo; [São Paulo]: Fundação Centro Tecnológico de Hidráulica - FCTH. 289 p. Disponível em < <http://www.fcth.br/public/cursos/canaismares/md.pdf > Acesso em: 08 ago. 2009.

RAMOS, F. et al. Engenharia hidrológica. Rio de Janeiro: UFRJ/ABRH, 1989. 404 p. 
RIGHETTO, A. M. Hidrologia e Recursos Hídricos. São Carlos: Escola de Engenharia de São Carlos - EESC; São Paulo: Universidade de São Paulo - USP, 1998. 819 p.

SANCHES, J. E. Fundamentos de Hidrologia. Porto Alegre: Instituto de Pesquisas Hidráulicas, UFRGS, 1987.

SANTOS, R. F. S. Hidrologia. Porto Alegre: Centro de Estudantes Universitários de Engenharia/UFRGS, 1975. 181 p.

SANTOS, R. F. S. Hidrologia. Porto Alegre: Centro de Estudantes Universitários de Engenharia/UFRGS, 1975. 158 p.

SARTORI, A.; GENOVEZ, A. M. Interpretação da Classificação Hidrológica do Solo proposta pelo Serviço de Conservação do Solo dos Estados Unidos. In: XXII Congresso Latinoamericano de Hidráulica - IAHR, 2006, Ciudad Guayana. XXII Congresso Latinoamericano de Hidráulica. Madrid: IAHR - International Association of Hydraulic Research.

SARTORI, A.; GENOVEZ, A. M.; LOMBARDI NETO, F. Tentative Hydrologic Soil Classification for Tropical Soils. In: 16th Congress of Asia and Pacific Division of International Association of Hydraulic Engineering and Research and 3rd IAHR International Symposium on Hydraulic Structures, 2008, Nanjing. 16th Congress of Asia and Pacific Division of International Association of Hydraulic Engineering and Research and 3rd IAHR International Symposium on Hydraulic Structures. Nanjing: IAHR, 2008.

Comparação de métodos para calibração do parâmetro CN. In: XVIII Simpósio Brasileiro de Recursos Hidrícos, 2009, Campo Grande. XVIII Simpósio Brasileiro de Recursos Hídricos. Campo Grande: ABRH, 2009.

SHAW, E. M. Hydrology in practice. Londres: Chapman and Hall, 1988. 540 p.

SILVA, K. A.; RIGHETTO, A. M. Análise de incertezas na determinação de hidrogramas de cheia em drenagem urbana. In: XII SIMPÓSIO BRASILEIRO DE RECURSOS HÍDRICOS, 1997, Vitória. Bases Técnicas para a Implementação dos Sistemas de Gestão de Recursos Hídricos. Vitória: ABRH, 1997. v. 2. p. 1522.

SILVA, R. A. P. Sistema de suporte à tomada de decisões em gerenciamento de cheias. 2006. 253 p. Dissertação (Mestrado) - Escola Politécnica, Universidade de São Paulo, São Paulo, 2006. 
SILVEIRA, A. L. L. Hidrologia urbana no Brasil. In: BRAGA, B.; TUCCI, C. E. M.; TOZZI, M.(Org.). Drenagem Urbana: Gerenciamento, Simulação, Controle. Porto Alegre: Editora da Universidade/UFRGS, 1998. 1 ed. p. 7-25.

SILVEIRA, G. L. Quantificação de vazão em pequenas bacias com carência de dados fluviométricos. 1997. 125 p. Tese (Doutorado) - Instituto de Pesquisas Hidráulicas, Universidade Federal do Rio Grande do Sul, Porto Alegre, 1997.

STEFFEN, J. L.; RONDON, M. A. C. Determinação da vazão de projeto em bacias urbanas. In: XXVIII Congresso Interamericano de Ingenieria Sanitaria y Ambiental, 2000, Porto Alegre. AIDIS 2000. Rio de Janeiro: ABES, 2000. p. 380-381.

STRAFACI, A. M. (Ed.). Essential hydraulics and hydrology. Waterbury: Haestad Press, 1998. $160 \mathrm{p}$.

TOMAZ, P. Cálculos Hidrológicos e Hidráulicos para Obras Municipais, Comercial. São Paulo: Hermano \& Bugelli, 2002. 475 p.

TUCCI, C. E. M. Coeficiente de escoamento e vazão máxima de bacias urbanas. Revista Brasileira de Recursos Hídricos: RBRH. v. 5. n. 1. p. 61-68. 2000.

Parâmetros dos Hidrogramas Unitário para bacias urbanas brasileiras.

Revista Brasileira de Recursos Hídricos, v. 8, n. 2, p. 195-199, 2003

2010.

. Blog do Tucci. Disponível em: <http://blog.rhama.net/>. Acesso em: 01 fev.

VILLELA, S. M.; MATTOS, A. Hidrologia aplicada. São Paulo: McGraw-Hill, 1975. $245 \mathrm{p}$.

WILKEN, P. S. Engenharia de drenagem superficial. São Paulo: CETESB, 1978. $477 \mathrm{p}$.

WISLER, C. O.; BRATTER, E. F. Hidrologia. Rio de Janeiro: Ao Livro Técnico, 1964. $484 \mathrm{p}$. 
ZAHED FILHO, K.; SÁ, D. S. S. Exploração do potencial de uma ferramenta de sistema de informações geográficas na obtenção de parâmetros para modelos de simulação hidrológica. In: XIII SIMPÓSIO BRASILEIRO DE RECURSOS HÍDRICOS, 1999, Belo Horizonte. Anais... Belo Horizonte: ABRH, 1999. CD-ROM. 


\section{APÊNDICE}

\section{RESUMO EXECUTIVO}

\section{I - OBJETIVO}

O objetivo do trabalho proposto é o de realizar a análise de sensibilidade de hidrogramas sintéticos, face a incertezas e erros na fixação das variáveis de entrada de seu cálculo.

\section{II - INTRODUÇÃO}

Para que as estruturas hidráulicas possam ser dimensionadas e construídas é necessário o conhecimento do hidrograma de projeto.

Em hidrologia, as vazões e os respectivos hidrogramas de projeto são determinados a partir da análise direta dos dados observados de vazões ou da análise indireta de determinadas características físicas da bacia hidrográfica e de dados observados de chuvas, que são menos escassos do que os dados de vazões e sofrem menor influência em decorrência de alterações antrópicas da bacia hidrográfica. Se, ainda os dados de chuva forem insuficientes, são usadas as equações intensidadeduração-frequência (IDF) da região mais próxima a do estudo.

Consta que a obtenção da vazão a partir de métodos indiretos, iniciou-se por volta do século XIX. O método Racional foi mencionado na literatura americana pela primeira vez, em 1889. Em 1932, Sherman propôs a teoria do hidrograma unitário (HU). Um dos primeiros hidrogramas sintéticos foi proposto por Snyder, em 1938 
(CHOW, 1964). No ano de 1945, consta uma publicação de Clark, que apresenta a teorização de um hidrograma sintético que considera os efeitos de translação e amortecimento do escoamento sobre a bacia (CLARK, 1945). Em 1972, foi introduzido pelo Departamento de Agricultura dos EUA, o método do hidrograma unitário sintético do SCS (SCS, 1972). O método de Santa Bárbara foi apresentado em 1975, por Stubchaer (STRUBCHAER, 1945).

Apesar de estes métodos serem embasados em teorias desenvolvidas há mais de 70 anos, são largamente utilizados em estudos para os quais o conhecimento do volume de escoamento superficial direto e a vazão de pico são fundamentais. Mesmo que sejam de aplicação consagrada, acredita-se que seja sempre importante que tais métodos sejam reavaliados e melhorados.

Não se deve esquecer que os métodos sintéticos são válidos desde que aplicados às condições que se aproximem daquelas para as quais foram desenvolvidos e que algumas vezes, são utilizados sem as devidas adaptações e análises mais criteriosas. Neste sentido, a técnica da análise de sensibilidade pode, em caráter preliminar, representar um instrumento útil, uma vez que permite a avaliação da importância dos parâmetros de entrada sobre o resultado final da vazão de pico e do respectivo hidrograma de projeto, importantes aos dimensionamentos de estruturas hidráulicas.

Estruturas mal dimensionadas comprometem, além da segurança, o bom uso dos recursos financeiros do Estado que, em geral, são escassos e devem ser usados em outras áreas, também importantes à população. A boa engenharia deve buscar a ótima relação entre estes dois aspectos, considerando, acima de tudo, o bem estar do ser humano e o uso sustentável dos recursos naturais.

Neste trabalho foi realizado uma análise de sensibilidade em relação aos parâmetros que definem os hidrogramas de cheias obtidos a partir do método do hidrograma unitário do SCS, do método de Santa Bárbara e do método de Clark.

Nas análises de sensibilidade foram avaliados número de curva $(\mathrm{CN})$, a área de drenagem (A), o tempo de concentração (tc) e a duração da chuva de projeto (d), em 
função do período de retorno, para os métodos que compõem o SSD ABC 6 . Também foi feita uma comparação entre estes métodos.

As análises foram feitas utilizando como ferramenta o Sistema de Suporte a Decisão ABC 6 (SSD ABC 6) desenvolvido no Laboratório de Sistemas de Suporte a Decisão (Labsid) do Departamento de Engenharia Hidráulica e Sanitária da Escola Politécnica da Universidade de São Paulo.

Além das análises de sensibilidade dos parâmetros, anteriormente descritos, foi elaborado um estudo de aplicação prática para analisar a influência das vazões no dimensionamento de estruturas hidráulicas, de maneira a evidenciar a importância na determinação dos hidrogramas de proejto.

\section{III - FUNDAMENTOS TEÓRICOS}

Porto (2002) considera que, qualquer coisa que ajude, ou mesmo apóie, uma tomada de decisão, pode ser considerada como um Sistema de Suporte a Decisões (SSD). Para a utilização correta dos SSD's e programas computacionais de simulação hidrológica, é necessário o conhecimento das bacias hidrográficas em análise, dos objetivos do estudo hidrológico, do julgamento da engenharia e de conhecimentos específicos de hidrologia e hidráulica.

Para o uso do SSD ABC6, é necessário que, além da operação do sistema, o usuário tenha o conhecimento sobre os seguintes assuntos:

- Intervalo de discretização dos dados e cálculos;

- Período de retorno;

- Características fisiográficas da bacia hidrográfica;

- Chuva (fenômeno, medição, disponibilidade, análise e extrapolação dos dados, equações IDF, distribuição espacial e temporal);

- Infiltração (fenômeno, métodos de determinação); 
- Hidrogramas (conhecimento das proposições do hidrograma unitário (HU) e os fundamentos teóricos dos hidrograma sintéticos do SCS, Clark e Santa Bárbara).

Nos modelos de simulação hidrológica, a escolha do intervalo de discretização é função da economia desejada e da precisão dos resultados que são conflitantes. À medida que o intervalo de discretização diminui, o custo para medir os dados da computação aumenta em favor da melhoria da precisão dos resultados (TUCCl, 2005).

O período de retorno é adotado em função da importância da obra e representa o risco da estrutura vir a falhar pelo menos uma vez, em sua vida útil (TUCCI, 2004). A ASCE (1992) recomenda que a escolha do período de retorno deva ser precedida de um estudo de risco associado aos danos provocados por um evento hidrológico superior ao de projeto durante a vida útil da estrutura hidráulica.

Há de se ressaltar que os sistemas de informações geográficas (SIG) ajudam a melhor definir as características fisiográficas das bacias, minimizando as incertezas na determinação destas características.

Uma das características fisiográficas mais importantes na determinação indireta da vazão é a área de drenagem, que representa a superfície total, a montante sobre um ponto do rio para onde o escoamento superficial direto converge (PINTO et al., 1976).

O tempo de concentração é o tempo necessário que a água precipitada no ponto mais distante na bacia leva para deslocar-se até a seção de saída. É importante que seja definido a partir de uma equação, cuja origem foi baseada em uma bacia semelhante àquela em estudo. Caso contrário, corre-se o risco de se representar um escoamento que não corresponde ao real (PORTO, 1995). Em relação ao tempo de concentração, restam as incertezas devidas à estimativa das velocidades do ESD sobre a superfície da bacia hidrográfica e dos canais. Sabendo-se da importância deste parâmetro em hidrologia urbana, sugere-se que em trabalhos futuros sejam pesquisadas equações aplicáveis a esta área de atuação. 
A chuva é a principal variável de entrada dos modelos chuva-vazão. Entende-se por chuva, as águas originadas do vapor de água atmosférico e que se precipitam sobre a superfície da terra (GARCEZ e ALVAREZ, 1988). Em geral, as medições são feitas com o uso de pluviômetros e pluviográfos. Mais recentemente, tem sido medidas através de radares e satélites meteorológicos (DAEE, 2008).

A infiltração pode ser determinada a partir dos métodos do SCS (USDA-SCS, 1985), Horton (CHOW; MAIDMENT; MAYS, 1988), Green-Ampt (CHOW; MAIDMENT; MAYS, 1988), e método do Índice Fi (LINSLEY; FRANZINI,1917).

É importante salientar que no SSD ABC 6 os parâmetros dos métodos de Horton, Índice Fi e Green-Ampt estão associados ao grupo hidrológico do solo proposto pelo SCS e ao valor de CN.

O valor de CN define o solo da bacia hidrográfica. Representa a capacidade de infiltração, dada em função do tipo, ocupação e umidade antecedente do solo. Nos estudos que envolvem a previsão de cenários futuros, existe grande dificuldade na estimativa deste parâmetro (PONCE e HAWKINS, 1986).

Genericamente, o hidrograma é a representação gráfica da variação da vazão em relação ao tempo numa determinada seção de controle do curso de água em estudo. A vazão nesta seção é a soma da precipitação recolhida diretamente pela superfície livre das águas, do escoamento superficial propriamente dito, do escoamento subsuperficial e da contribuição do lençol de água subterrâneo.

A forma do hidrograma é usualmente determinada em função de alguns parâmetros de tempo como os indicados na Figura I (TUCCl et al., 1995). 


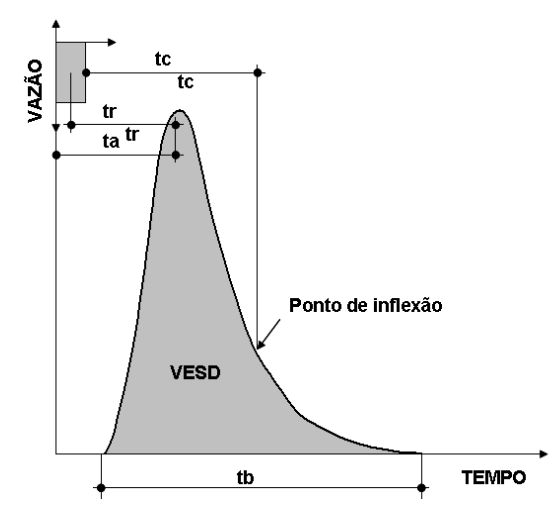

Figura I - Parâmetros do hidrograma

O tempo de concentração, $t_{c}$ é indicado na figura como o tempo decorrido desde o término da chuva até o ponto de inflexão situado no trecho descendente do hidrograma. Esta inflexão representa o instante em que a contribuição do ponto mais distante da bacia passa pela seção de controle. A partir deste ponto passará por esta seção somente a água que estava temporariamente armazenada em superfícies e canais da bacia. O tempo decorrido desde o início da chuva excedente até o pico do hidrograma é chamado "tempo de ascensão" ( $\left.\mathrm{t}_{\mathrm{a}}\right)$ e a duração total do escoamento superficial direto é chamada de tempo base ( $\left.t_{b}\right)$. O tempo de retardamento $\left(t_{r}\right)$ ou simplesmente retardamento é o tempo que vai do centro de massa do hietograma de chuva excedente até o pico do hidrograma (TUCCI et al., 1995).

O hidrograma unitário (HU) é o hidrograma resultante de um escoamento superficial de volume unitário. O volume unitário é decorrente da chuva unitária, que corresponde à altura pluviométrica e duração unitária. Conhecido o hidrograma unitário de uma bacia, pode-se calcular as ordenadas do escoamento superficial correspondentes a qualquer chuva, de intensidade uniforme e duração igual àquela que gerou o HU (CHOW; MAIDMENT; MAYS, 1988).

Os métodos sintéticos de obtenção dos hidrogramas cheia são de aplicação bastante simples. Principalmente em estudos ligados a drenagem urbana, são preferidos a métodos mais sofisticados, que exigem um número maior de variáveis para sua utilização. 
O método do hidrograma unitário do Soil Conservation Service (SCS) faz uma simplificação geométrica do processo físico, pois parte do princípio de que o volume precipitado é igual à área de um triângulo. Não considera os fenômenos de translação e amortecimento do escoamento superficial na bacia.

Os métodos de Santa Bárbara e Clark diferem na maneira como consideram o efeito de translação e amortecimento do escoamento superficial na bacia. O método de Santa Bárbara considera a bacia hidrográfica com apenas uma isócrona, cujo intervalo de tempo é igual ou menor ao tempo de concentração. No método de Clark, a bacia hidrográfica é dividida em mais de uma isócrona, possibilitando ao escoamento uma defasagem no tempo. No método de Santa Bárbara a constante linear que representa o amortecimento, varia em função do tempo de concentração. No método de Clark a constante linear é dada em relação ao comprimento do talvegue e área de drenagem da bacia hidrográfica.

\section{IV - DESENVOLVIMENTO}

Para o desenvolvimento das análises de sensibilidade foi considerada uma bacia hidrográfica hipotética com $A=21,9 \mathrm{~km}^{2}$; Comprimento e declividade do talvegue, igual a $7.872 \mathrm{~m}$ e $5,1 \mathrm{~m} / \mathrm{km}$, respectivamente; $\mathrm{tc}=2,5 \mathrm{~h}$ e $\mathrm{CN}=75$.

A chuva de projeto foi calculada a partir da equação IDF de Magni e Mero (1986) obtida para a cidade de Piracicaba (SP), considerando-se uma duração de 2,5 h.

Como ferramenta de cálculo para gerar os hidrogramas de projeto utilizou-se o SSD ABC6 desenvolvido no departamento de Engenharia Hidráulica e Sanitária da EPUSP.

As análises foram feitas para os períodos de retorno (T) de 5, 10, 50, 100 e 500 anos. Foram gerados hidrogramas para cada variável, período de retorno e método. 
A Tabela I mostra a faixa dos valores para cada um das variáveis analisadas para os métodos sintéticos de SCS, Santa Bárbara e Clark

\begin{tabular}{cccc}
\multicolumn{4}{c}{ Tabela I - Faixa de variação dos valores das variáveis analisadas } \\
\hline Variável & Faixa de Variação & Incremento & Unidade \\
\hline CN & 60 a 95 & 5 & - \\
A & 20 a 200 & 20 & $\mathrm{~km}^{2}$ \\
tc & 0,5 a 6 & 0,5 & $\mathrm{~h}$ \\
d & 30 a 360 & 30 & min \\
\hline
\end{tabular}

Para realização do estudo de aplicação prática foi dimensionado um canal e um vertedor retangular de soleira delgada. Para verificar a influência da vazão de cheia no dimensionamento hidráulico destas estruturas, verificou-se apenas a variação da lâmina d'água mantendo-se todas as suas demais características. Para representar a área em estudo, criou-se o cenário de projeto baseado na bacia hidrográfica hipotética. Nesta etapa, considerou-se que a bacia sofreu alterações antrópicas e o valor do $\mathrm{CN}=75$ passou para 80 . Para avaliar a variação da lâmina d'água das estruturas propostas em função da alteração dos parâmetros de entrada dos hidrogramas sintéticos, foram criados cenários alternativos, para os quais foi feita a alteração dos parâmetros como mostrado na Tabela II. Os parâmetros que foram alterados em relação ao cenário de projeto estão em negrito.

\begin{tabular}{ccccc}
\multicolumn{5}{c}{ Tabela II - Variáveis do cenário de projeto e cenários alternativos } \\
\hline Cenário & CN & $\begin{array}{c}\text { tc } \\
\text { (h) }\end{array}$ & $\begin{array}{c}\text { d } \\
\text { (min) }\end{array}$ & $\begin{array}{c}\text { T } \\
\text { (anos) }\end{array}$ \\
\hline Projeto & 80 & 2,5 & 150 & 100 \\
C - I & $\mathbf{7 5}$ & 2,5 & 150 & 100 \\
C - II & 85 & 2,5 & 150 & 100 \\
C - III & 80 & $\mathbf{1 , 5}$ & 150 & 100 \\
C - IV & 80 & $\mathbf{3 , 5}$ & 150 & 100 \\
C - V & 80 & 2,5 & $\mathbf{9 0}$ & 100 \\
C - VI & 80 & 2,5 & $\mathbf{2 1 0}$ & 100 \\
C - VII & 85 & $\mathbf{3 , 5}$ & $\mathbf{2 1 0}$ & 100 \\
C - VIII & 80 & 2,5 & 150 & $\mathbf{5 0}$ \\
\hline
\end{tabular}


O canal foi dimensionado com base na equação de Manning-Strickler associada à equação de Chézy (1). O vertedor retangular de soleira delgada foi dimensionado a partir da eq.(2).

$$
\begin{aligned}
& Q=\frac{1}{n} \cdot A_{m} \cdot R h^{2 / 3} \cdot i^{1 / 2} \\
& Q=\frac{2}{3} \cdot C_{d} \cdot \sqrt{2 \cdot g} \cdot L \cdot \cdot_{v} H_{v}^{\frac{3}{2}}
\end{aligned}
$$

Onde: $Q=$ vazão $\left(\mathrm{m}^{3} / \mathrm{s}\right) ; A_{m}=$ área molhada em $\left(\mathrm{m}^{2}\right)$; Rh=raio hidráulico $(\mathrm{m})$; $\mathrm{I}=$ declividade $(\mathrm{m} / \mathrm{m}) ; \mathrm{n}=$ coef. de Manning; $\mathrm{C}_{\mathrm{d}}=$ coef. de vazão ou de descarga; $g=$ aceleração da gravidade $\left(\mathrm{m} / \mathrm{s}^{2}\right) ; \mathrm{L}_{\mathrm{v}}=$ largura do vertedor $(\mathrm{m}) ; \mathrm{H}_{\mathrm{v}}=$ carga hidráulica(m)

\section{V - RESUltAdOS E DISCUSSÃO DAS ANÁLISES DE SENSIBILIDADE}

Os resultados das análises de sensibilidade estão apresentados nas Figuras II a IV.

(A)

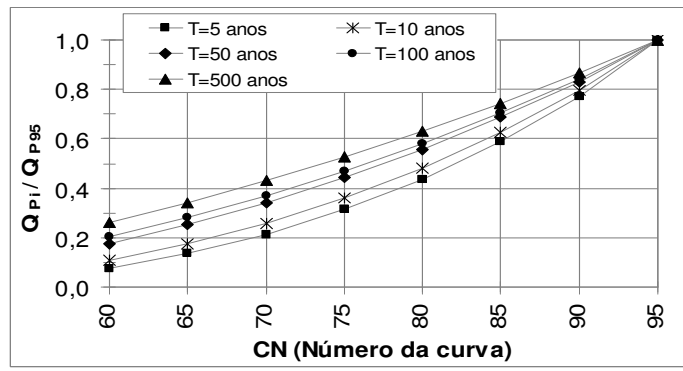

(C)

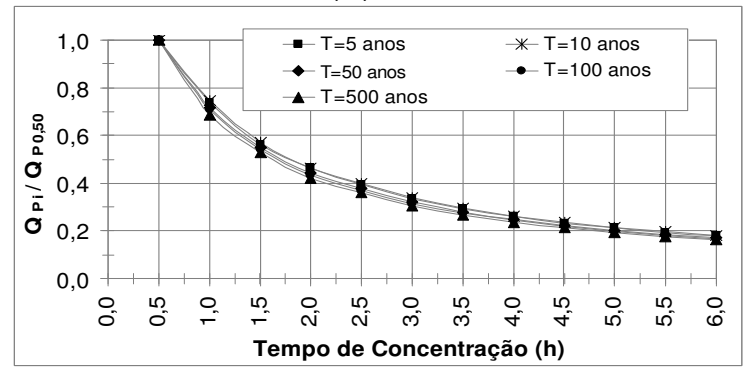

(B)

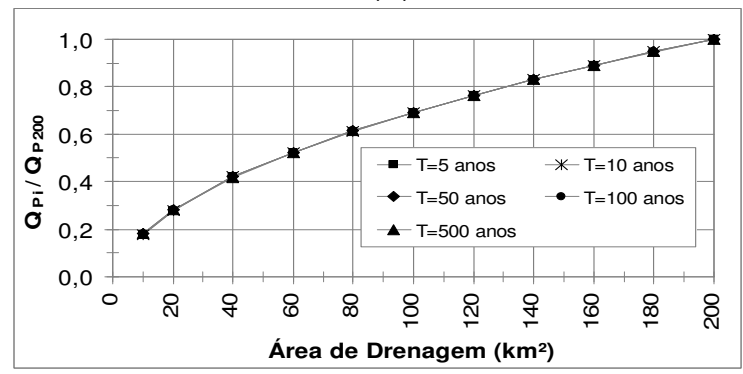

(D)

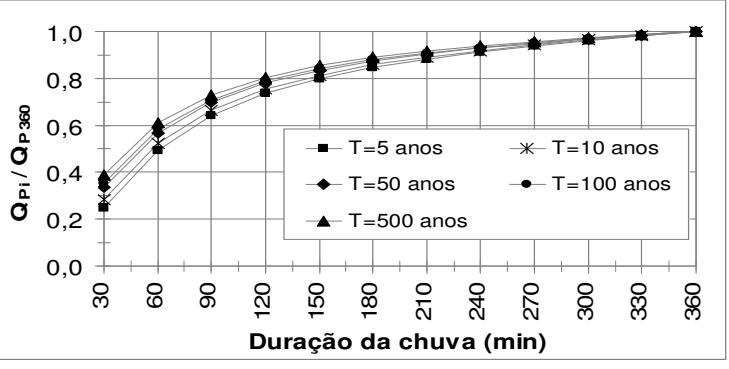

Figura II - Proporção da vazão de pico em relação ao valor da vazão de pico para (A) $C N=95$, (B) $A=$ $200 \mathrm{~km}^{2},(C)$ tc= 0,5h, (D) d= 360 min para o método do SCS. 
(A)

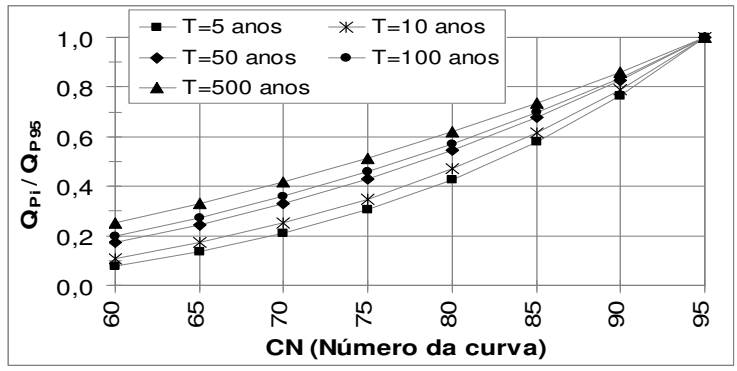

(C)

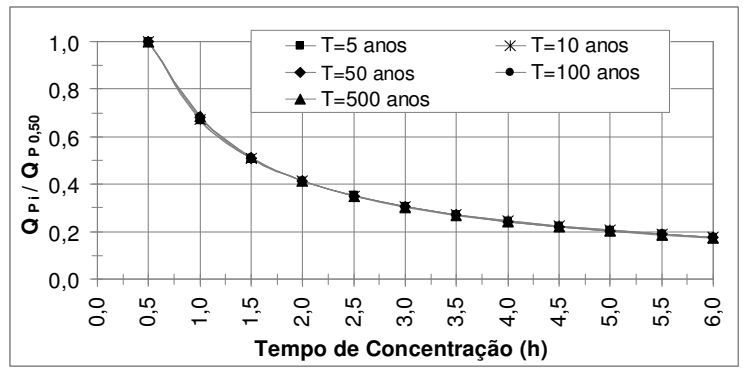

(B)

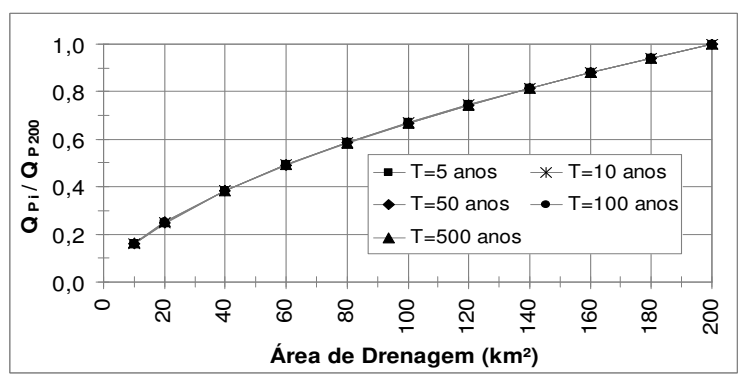

(D)

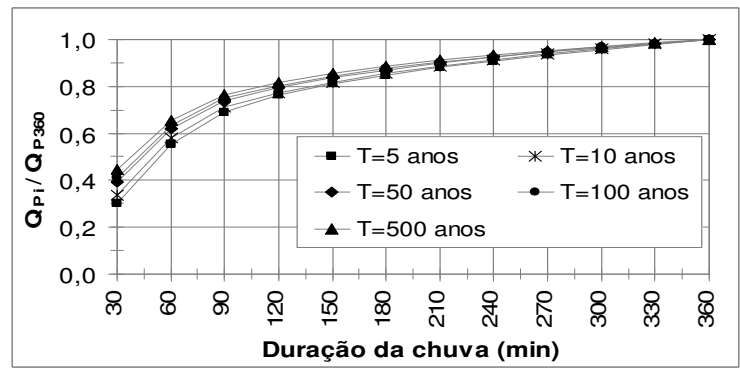

Figura III - Proporção da vazão de pico em relação ao valor da vazão de pico para (A) $C N=95$, (B) $A=$ $200 \mathrm{~km}^{2},(C)$ tc= 0,5h, (D) d= 360 min para o método de Santa Bárbara.

(A)

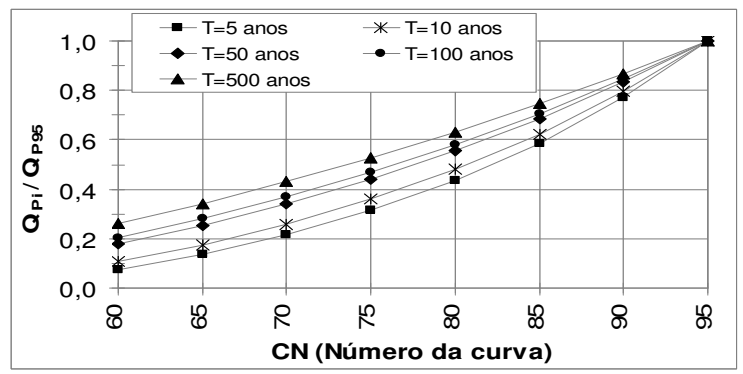

(C)

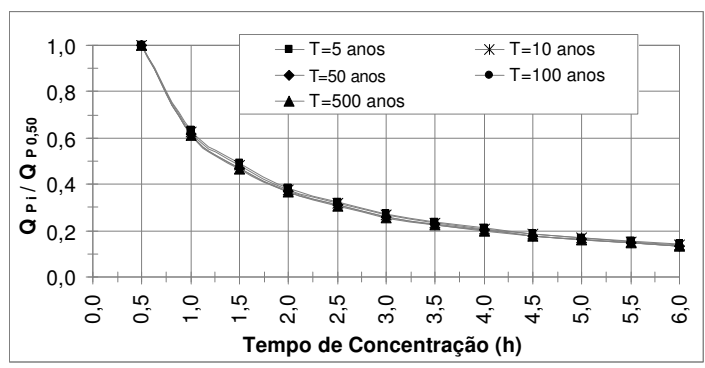

(B)

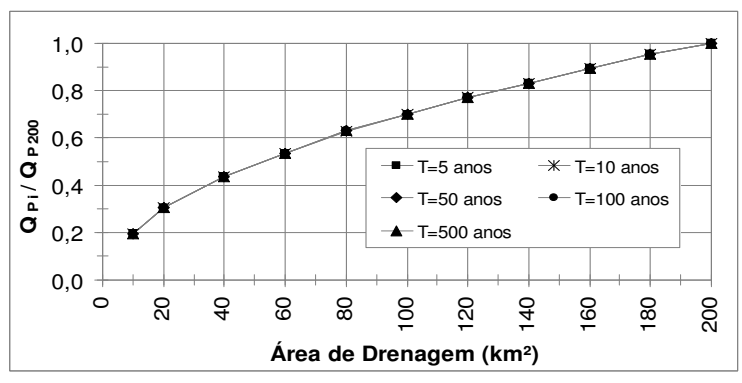

(D)

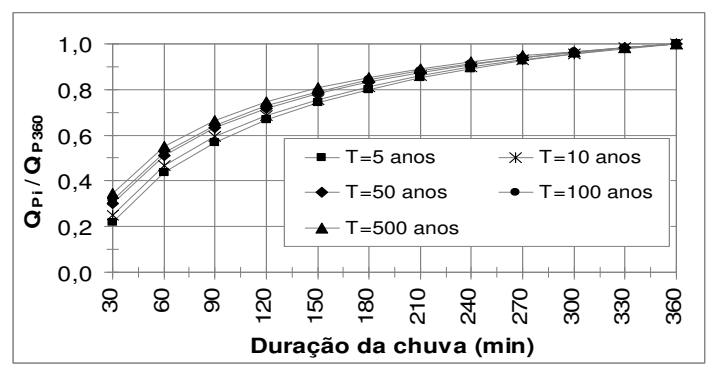

Figura IV - Proporção da vazão de pico em relação ao valor da vazão de pico para (A) $C N=95$, (B) $A=$ $200 \mathrm{~km}^{2},(C)$ tc=0,5h, (D) $d=360$ min para o método de Clark. 
A Tabela III mostra o valor das vazões de pico obtidas para o $\mathrm{CN}=95, A=200 \mathrm{~km}^{2}$, $\mathrm{tc}=0,5 \mathrm{~h}, \mathrm{~d}=360 \mathrm{~min}$, que resultaram na maior vazão de pico dentro da faixa de valores estudas e apresentada na Tabela I.

Tabela III - Vazões de pico para as variáveis estudadas em função do período de retorno e métodos de obtenção do hidrograma de cheia.

\begin{tabular}{|c|c|c|c|c|c|}
\hline \multicolumn{6}{|c|}{$\mathrm{CN}=95$ (Parâmetro variável:CN;Parâmetros Fixos: $A=21,9 \mathrm{~km}^{2}$, tc e d=2,5h) } \\
\hline \multirow{2}{*}{ Método } & \multicolumn{5}{|c|}{ Vazão de pico $\left(\mathrm{m}^{3} / \mathrm{s}\right)$} \\
\hline & $\mathrm{T}=5$ anos & $\mathrm{T}=10$ anos & $\mathrm{T}=50$ anos & $\mathrm{T}=100$ anos & $\mathrm{T}=500$ anos \\
\hline SCS & 115 & 135 & 181 & 200 & 245 \\
\hline SB & 81,0 & 95,6 & 128 & 142 & 174 \\
\hline \multirow[t]{2}{*}{$\mathrm{CL}$} & 69,3 & 81,6 & 109 & 121 & 148 \\
\hline & \multicolumn{5}{|c|}{$\mathrm{A}=200 \mathrm{~km}^{2}$ (Parâmetro variável: $\mathrm{A}$; Parâmetros Fixos: $\mathrm{CN}=75$, tc e $\mathrm{d}=2,5 \mathrm{~h}$} \\
\hline \multirow{2}{*}{ Método } & \multicolumn{5}{|c|}{ Vazão de pico (m³/s) } \\
\hline & $\mathrm{T}=5$ anos & $\mathrm{T}=10$ anos & $\mathrm{T}=50$ anos & $\mathrm{T}=100$ anos & $\mathrm{T}=500$ anos \\
\hline SCS & 128 & 172 & 283 & 333 & 457 \\
\hline SB & 99,1 & 133 & 219 & 257 & 352 \\
\hline \multirow[t]{2}{*}{$\mathrm{CL}$} & 92,7 & 125 & 205 & 242 & 331 \\
\hline & \multicolumn{5}{|c|}{ tc $=0,5 \mathrm{~h}$ (Parâmetro variável: tc; Parâmetros Fixos: $\mathrm{CN}=75, \mathrm{~A}=21,9 \mathrm{~km}^{2} \mathrm{~d}=2,5 \mathrm{~h}$ ) } \\
\hline \multirow{2}{*}{ Método } & \multicolumn{5}{|c|}{ Vazão de pico $\left(\mathrm{m}^{3} / \mathrm{s}\right)$} \\
\hline & $\mathrm{T}=5$ anos & $\mathrm{T}=10$ anos & $\mathrm{T}=50$ anos & $\mathrm{T}=100$ anos & $\mathrm{T}=500$ anos \\
\hline SCS & 91,2 & 122 & 212 & 255 & 360 \\
\hline SB & 70,4 & 95,3 & 157 & 185 & 256 \\
\hline $\mathrm{CL}$ & 83,6 & 115 & 193 & 229 & 317 \\
\hline \multicolumn{6}{|c|}{ d=360 min (Parâmetro variável: tc; Parâmetros Fixos: $C N=75, A=21,9 \mathrm{~km}^{2}$,tc=2,5h) } \\
\hline \multirow{2}{*}{ Método } & \multicolumn{5}{|c|}{ Vazão de pico $\left(\mathrm{m}^{3} / \mathrm{s}\right)$} \\
\hline & $\mathrm{T}=5$ anos & $\mathrm{T}=10$ anos & $\mathrm{T}=50$ anos & $\mathrm{T}=100$ anos & $\mathrm{T}=500$ anos \\
\hline SCS & 44,9 & 59,7 & 95,8 & 112 & 152 \\
\hline SB & 30,5 & 40,7 & 65,8 & 77,3 & 105 \\
\hline$C L$ & 29,4 & 38,7 & 61,5 & 71,8 & 96,6 \\
\hline
\end{tabular}

De maneira geral, os resultados mostram que a vazão de pico é crescente com o valor de $\mathrm{CN}, \mathrm{A}, \mathrm{d}$ e decrescente com o tc. 
A relação entre as vazões de pico e o valor de $\mathrm{CN}$ é fortemente não linear.

As variações das vazões de pico para as áreas de drenagem testadas são acentuadas para faixa de 20 a $80 \mathrm{~km}^{2}$ e diminuem para a faixa entre 100 a $200 \mathrm{~km}^{2}$. Para análise de sensibilidade em relação ao tempo de concentração, distinguiram-se aproximadamente três faixas de variação. A maior variação dos valores de vazão, para todos os períodos de retorno avaliados, ocorre no intervalo de 0,5 a 2 horas. $A$ segunda faixa compreende o intervalo de 2 a 4 horas. A menor variação ocorre no intervalo de 4 a 6 horas, mesmo neste intervalo a variação não é desprezível.

As maiores variações nas vazões de pico acontecem para as durações menores que o tempo de concentração da bacia $(2,5$ h), a partir daí, à medida que a duração da chuva aumenta, as variações nas vazões diminuem e tendem a uma assíntota.

As figuras IV a VII mostram a relação entre os valores do método de Santa Bárbara e o método do SCS e entre o método de Clark e SCS para o valor do CN, A, tc e d.

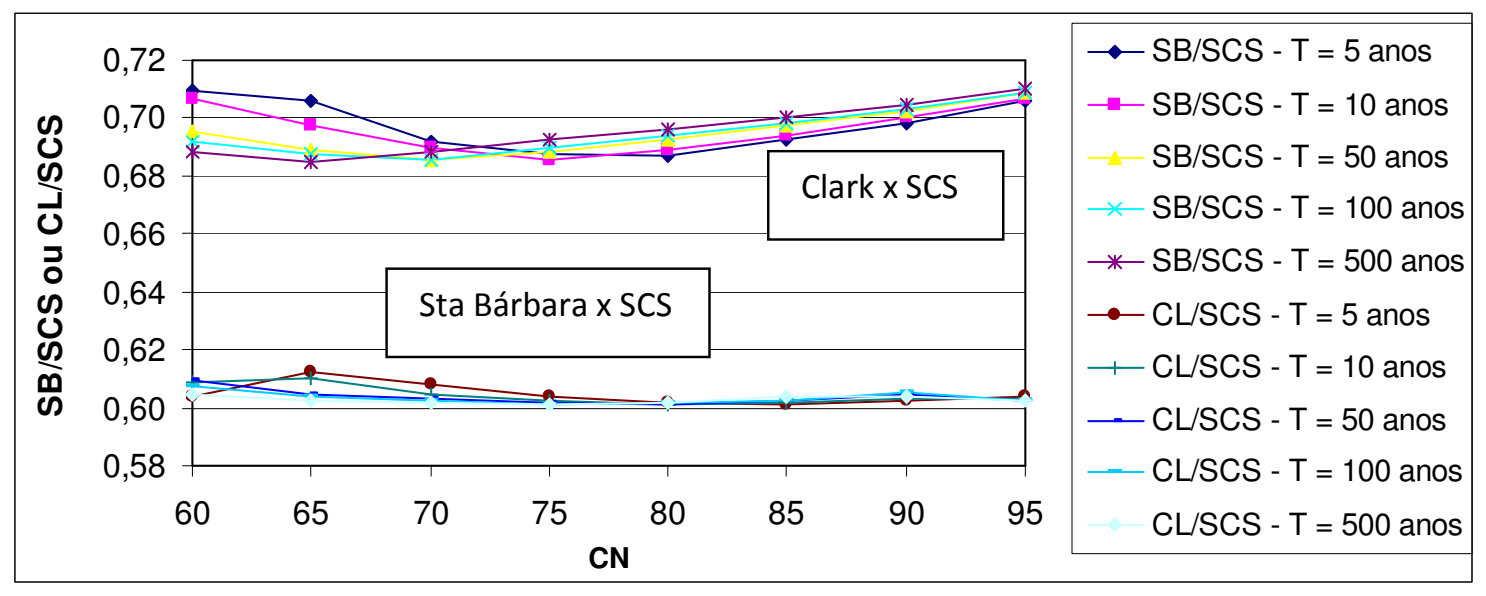

Figura V - Relação entre as vazões de pico entre os métodos de Santa Bárbara (ou Clark) e SCS para o valor de CN em função de $\mathrm{T}$.

Para o valor de $\mathrm{CN}$, os valores das vazões de pico calculadas pelo método de Santa Bárbara são, em média, 30\% menores que as calculadas a partir do método do SCS. Em relação ao método de Clark, são, aproximadamente, $40 \%$ menores que as calculadas pelo SCS. 


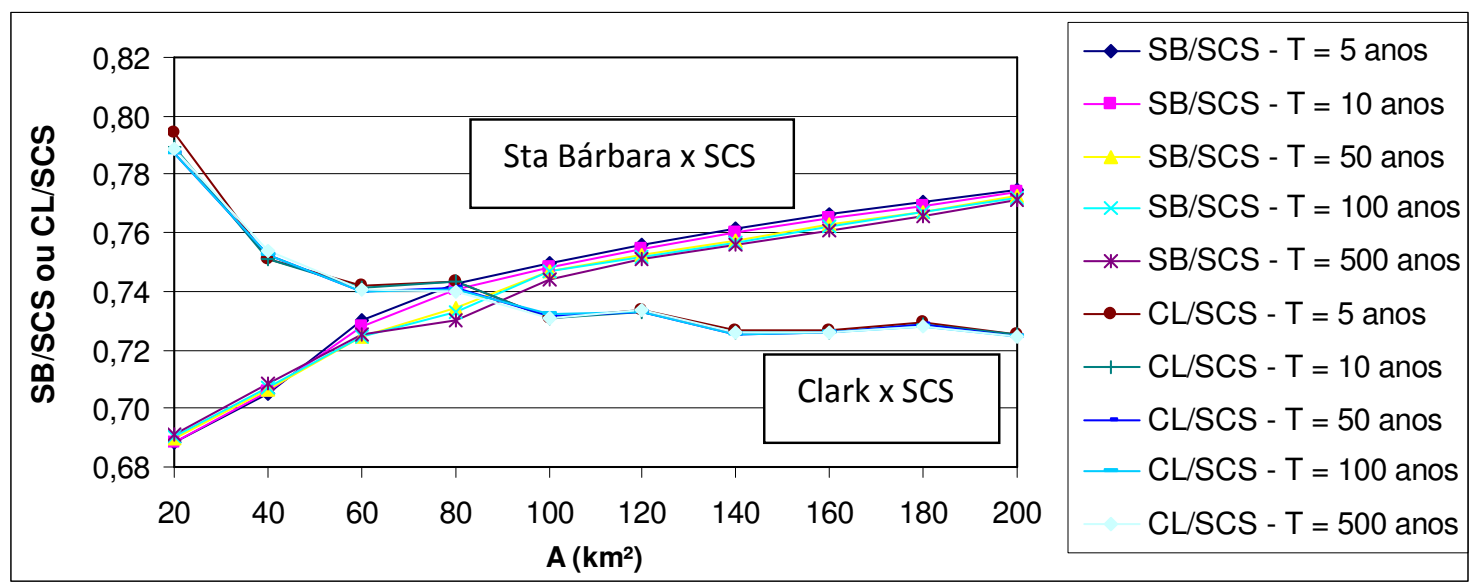

Figura VI - Relação entre as vazões de pico entre os métodos de Santa Bárbara (ou Clark) e SCS para a área de drenagem em função de $T$.

Para a área de drenagem de $20 \mathrm{~km}^{2}$, as vazões de pico calculadas a partir do método de Santa Bárbara são aproximadamente 31\% menores do que as calculadas pelo método do SCS. Para $40 \mathrm{~km}^{2}, 29 \%$; para $60 \mathrm{~km}^{2}, 27 \%$; para $80 \mathrm{~km}^{2}, 26 \%$; para 100 e $120 \mathrm{~km}^{2}, 25 \%$; para 140 e $160 \mathrm{~km}^{2}, 24 \%$ e para 180 e $200 \mathrm{~km}^{2}, 23 \%$;

Em relação ao método de Clark, para a área de drenagem de $20 \mathrm{~km}^{2}$, as vazões de pico são $21 \%$ menores que as obtidas pelo método do SCS. Para $40 \mathrm{~km}^{2}, 25 \%$; para 60 e $80 \mathrm{~km}^{2}, 26 \%$ e de 100 a $280 \mathrm{~km}^{2}$, aproximadamente, $28 \%$.

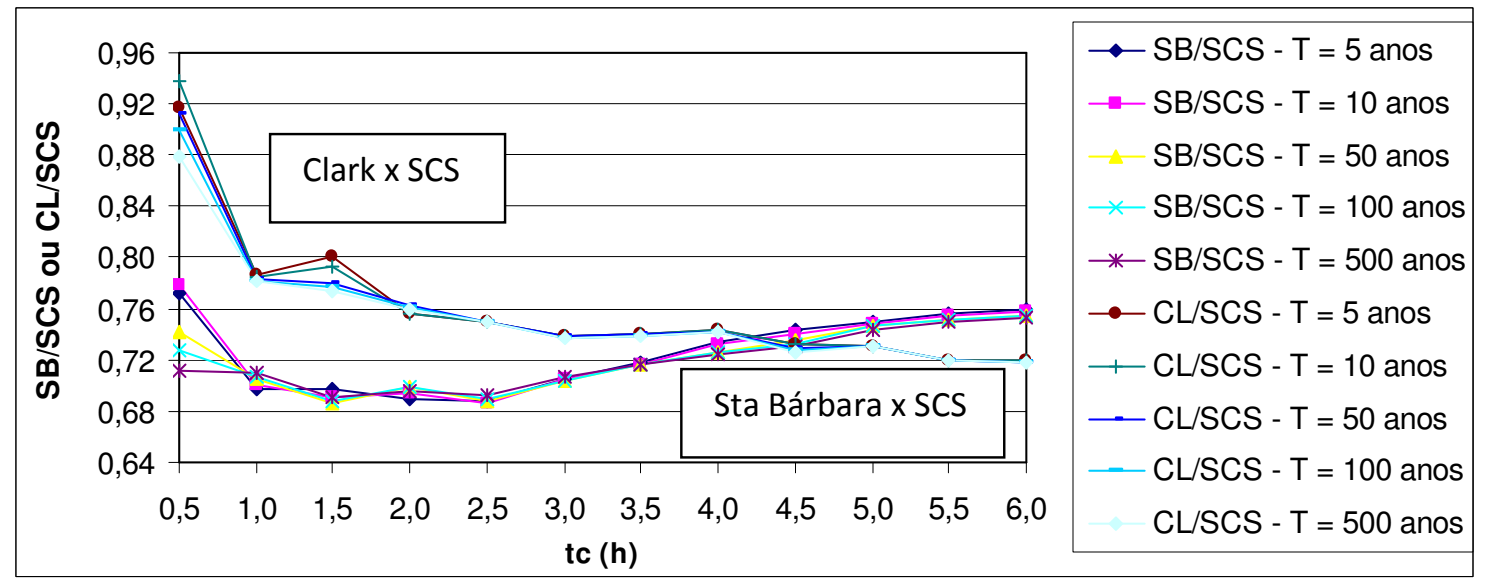

Figura VII- Relação entre as vazões de pico entre os métodos de Santa Bárbara (ou Clark) e SCS para o tempo de concentração em função de $T$. 
Para o tempo de concentração, a relação entre as vazões de pico para o método do SCS e Santa Bárbara, variam de $22 \%$ a 31\%. Em média, são 28\% menores que as vazões calculadas pelo método do SCS.

Para o método de Clark, a vazão de pico, para o tc=0,5 h, é aproximadamente, $9 \%$ menor do que a calculada pelo método do SCS. Para o intervalo de 1 a 6 horas, varia entre $20 \%$ a $31 \%$, em média, são $28 \%$ menores que as vazões calculadas pelo método do SCS.

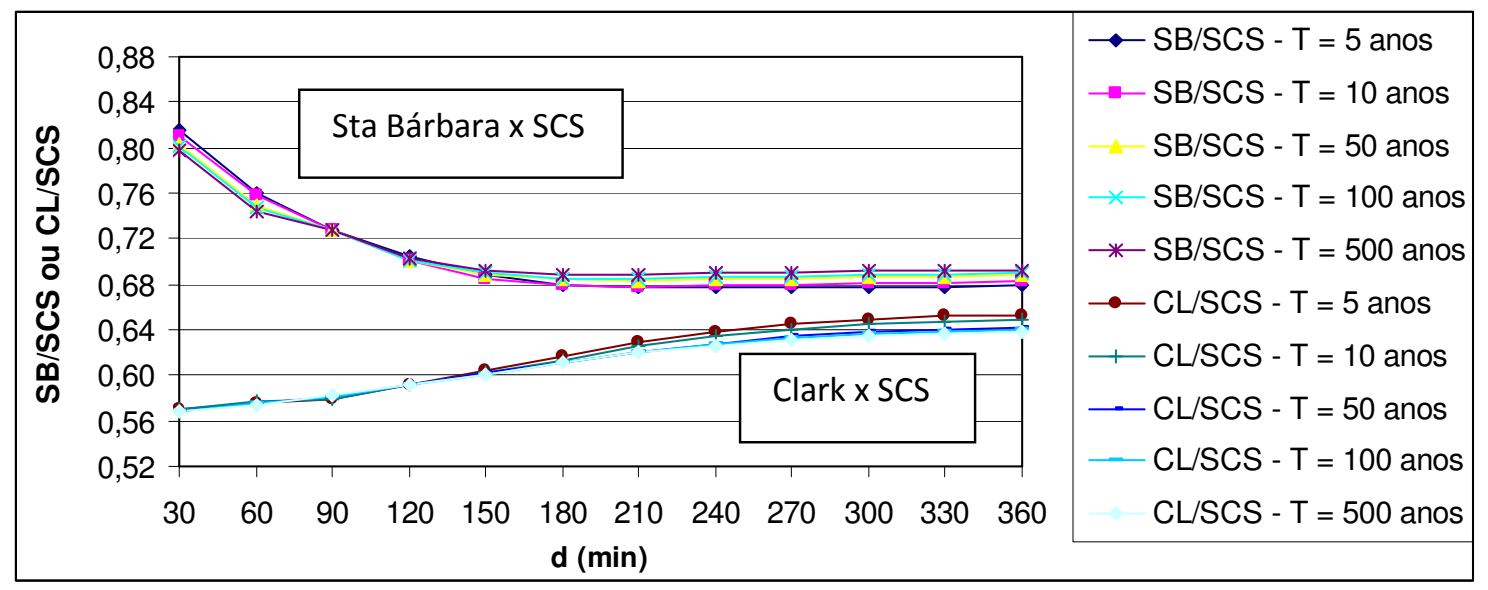

Figura VIII - Relação entre as vazões de pico entre os métodos de Santa Bárbara (ou Clark) e SCS para a duração da chuva de projeto em função de T.

Entre os métodos do SCS e Santa Bárbara, nota-se a variação máxima de $32 \%$ e mínima de 18\%. Em média, as vazões de pico são $30 \%$ menores do que as calculadas pelo método do SCS.

Em relação ao método de Clark, a variação máxima é de $43 \%$ e a mínima é de 35\%. Em média, são $39 \%$ menores que as determinadas pelo SCS.

\section{VI - ESTUDO DE APLICAÇÃO PRÁTICA}

A Tabela IV apresenta o resumo das simulações para o cenário de projeto e para os cenários alternativos. 
Tabela IV - Resumo dos resultados das simulações

\begin{tabular}{|c|c|c|c|c|c|c|c|c|c|}
\hline \multirow{2}{*}{ Cenário } & \multicolumn{3}{|c|}{ Chuva (mm) } & \multicolumn{2}{|c|}{ Vazão (m³/s) } & \multirow{2}{*}{$\begin{array}{c}\text { Carga } \\
\text { Hidráulica } \\
\text { (m) }\end{array}$} & \multirow{2}{*}{$\begin{array}{l}\Delta \mathrm{H} \\
(\mathrm{m})\end{array}$} & \multirow{2}{*}{$\begin{array}{l}\Delta \mathrm{H} \\
(\%)\end{array}$} & \multirow{2}{*}{$\begin{array}{c}\text { Volume } \\
\text { Armazenado } \\
\left(\mathrm{hm}^{3}\right)\end{array}$} \\
\hline & Excedente & Infiltração & Total & Alfuente & Efluente & & & & \\
\hline Projeto & 47,50 & 48,79 & 96,29 & 116,866 & 35,371 & 1,50 & - & - & 0,828 \\
\hline I & 38,39 & 57,90 & 96,29 & 94,410 & 11,604 & 0,71 & $-0,79$ & $-53 \%$ & 0,771 \\
\hline II & 57,71 & 38,58 & 96,29 & 141,723 & 64,369 & 2,24 & 0,74 & $49 \%$ & 0,881 \\
\hline III & 47,50 & 48,79 & 96,29 & 172,315 & 47,472 & 1,83 & 0,33 & $22 \%$ & 0,852 \\
\hline IV & 47,50 & 48,79 & 96,29 & 86,600 & 28,338 & 1,30 & $-0,20$ & $-13 \%$ & 0,813 \\
\hline V & 39,10 & 46,68 & 85,78 & 100,468 & 13,383 & 0,79 & $-0,71$ & $-47 \%$ & 0,777 \\
\hline VI & 53,12 & 50,02 & 103,14 & 124,909 & 49,961 & 1,89 & 0,39 & $26 \%$ & 0,856 \\
\hline VII & 63,81 & 39,33 & 103,14 & 112,846 & 63,659 & 2,22 & 0,72 & $48 \%$ & 0,880 \\
\hline VIII & 41,02 & 47,19 & 88,21 & 100,915 & 18,108 & 0,96 & $-0,54$ & $-36 \%$ & 0,789 \\
\hline
\end{tabular}

V. I - Dimensionamento do canal e do vertedor do reservatório de controle de cheias para o cenário de projeto

O canal retangular foi dimensionado de modo a escoar uma vazão de projeto de 117 $\mathrm{m}^{3} / \mathrm{s}$, correspondente à lâmina d'água de $5,30 \mathrm{~m}$. O revestimento do canal equivale ao coeficiente de Manning de 0,025. As características geométricas do canal são: $\mathrm{i}=$ $0,01 \mathrm{~m} / \mathrm{m} ; 9,50 \mathrm{~m}$ de largura e $6,30 \mathrm{~m}$ de altura.

Nas simulações para o dimensionamento do vertedor retangular de soleira livre foi considerado:

- Um reservatório de retenção em série, com formato retangular e área em planta de $72.000 \mathrm{~m}^{2}$.

- Cota da crista do barramento na elevação $13,00 \mathrm{~m}$.

- Cota de fundo do reservatório na elevação 00,00 m.

- Borda livre igual a 1,50 m; 
- O vertedor foi dimensionado para uma carga hidráulica igual a $1,5 \mathrm{~m} \mathrm{e}$ coeficiente de descarga igual 0,677. Está posicionado a 10,00 $\mathrm{m}$ da cota de fundo do reservatório.

Foram obtidos os seguintes resultados:

- Vertedor com largura igual 9,60 m;

- Hidrograma efluente com uma vazão de pico de $35 \mathrm{~m} 3 / \mathrm{s}$;

- Volume armazenado de 0,828 $\mathrm{hm}^{3}$.

A Figura IX apresenta, esquematicamente, as dimensões do canal.

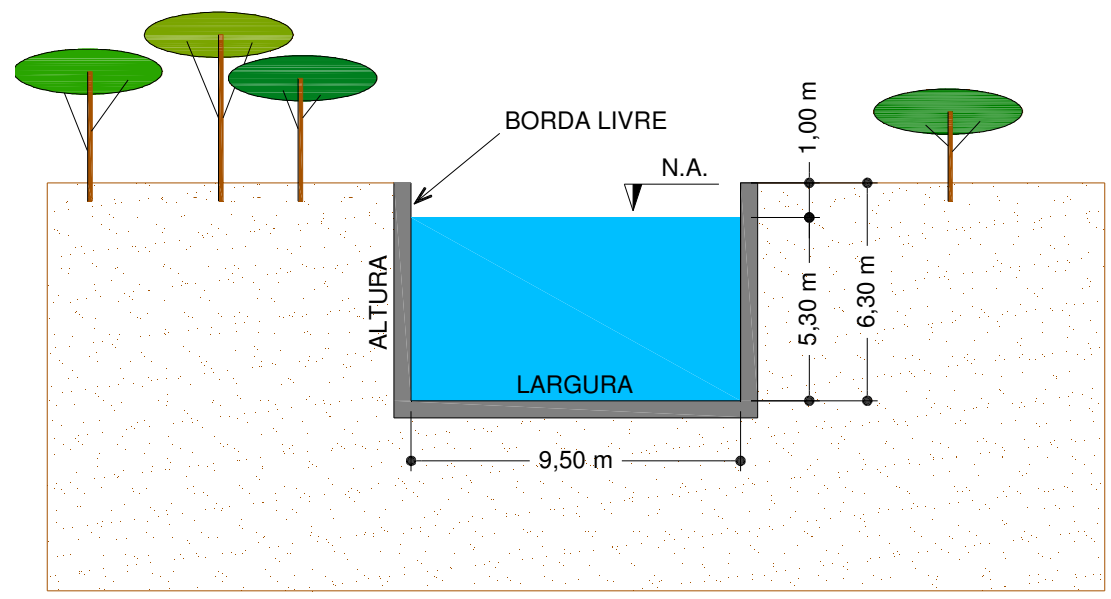

Figura IX - Dimensões do canal para o cenário de projeto

A Figura $X$ apresenta, esquematicamente, um corte transversal do reservatório de controle de cheias e a vista frontal do vertedor retangular de soleira livre.

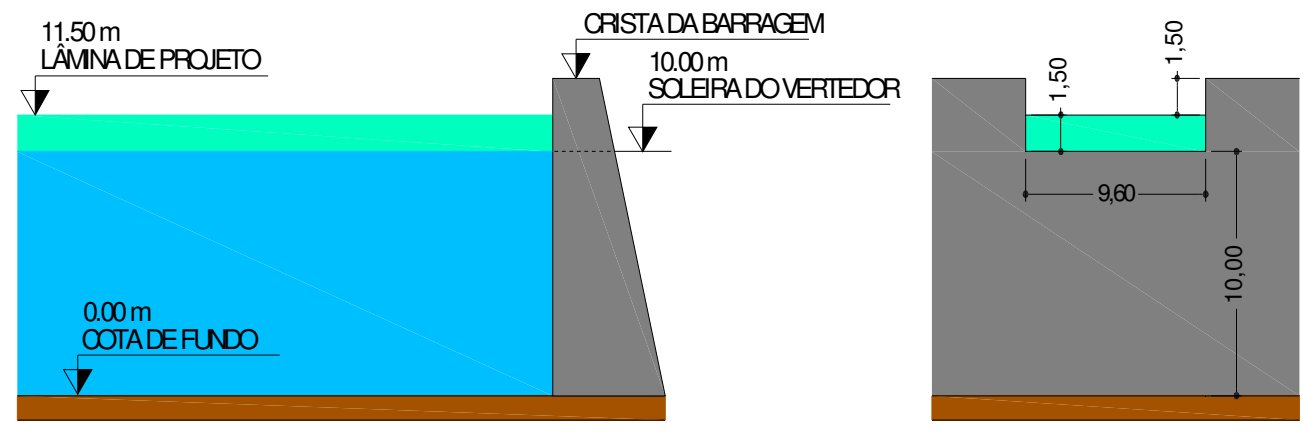

Figura X - Representação esquemática do perfil do reservatório e da seção onde está posicionado o vertedor de soleira livre 


\section{V.II - Verificação da lâmina d'água do canal}

Mantendo-se as mesmas características do canal do cenário de projeto foi recalculada a lâmina d'água para as vazões de pico correspondentes aos cenários alternativos, apresentada na Tabela IV. Os resultados da lâmina d'água, velocidade máxima, altura do canal e as variações das vazões e lâmina d'água em relação ao cenário de projeto são apresentados na Tabela $\mathrm{V}$.

Tabela V - Lâmina d'água, velocidade máxima, altura do canal e variações das vazões e lâmina d'água

\begin{tabular}{ccccccccc}
\hline Cenário & $\begin{array}{c}\text { Vazão } \\
\text { de pico }\end{array}$ & $\begin{array}{c}\text { Lâmina } \\
\text { d'água }\end{array}$ & $\begin{array}{c}\text { Veloc. } \\
\text { máxima }\end{array}$ & $\begin{array}{c}\text { Altura do } \\
\text { canal }\end{array}$ & \multicolumn{2}{c}{$\begin{array}{c}\text { Variação da vazão } \\
\text { de pico }\end{array}$} & \multicolumn{3}{c}{$\begin{array}{c}\text { Variação da lâmina } \\
\text { d'água }\end{array}$} \\
\hline Projeto & $\left.1 \mathrm{~m}^{3} / \mathrm{s}\right)$ & $(\mathrm{m})$ & $(\mathrm{m} / \mathrm{s})$ & $(\mathrm{m})$ & $(\mathrm{m})$ & $(\%)$ & $(\mathrm{m})$ & $(\%)$ \\
I I & 94,866 & 5,3 & 2,3 & 6,3 & & & & \\
II & 141,723 & 6,1 & 2,4 & 7,1 & 25 & $21 \%$ & 0,8 & $15 \%$ \\
III & 172,315 & 7,1 & 2,5 & 8,1 & 55 & $47 \%$ & 1,8 & $34 \%$ \\
IV & 86,600 & 4,2 & 2,2 & 5,2 & -30 & $-26 \%$ & $-1,1$ & $-21 \%$ \\
V & 100,468 & 4,7 & 2,2 & 5,7 & -17 & $-15 \%$ & $-0,6$ & $-11 \%$ \\
VI & 124,909 & 5,6 & 2,4 & 6,6 & 8 & $7 \%$ & 0,3 & $6 \%$ \\
VII & 112,846 & 5,1 & 2,3 & 6,1 & -4 & $-3 \%$ & $-0,2$ & $-4 \%$ \\
VIII & 100,915 & 4,7 & 2,2 & 5,7 & -16 & $-14 \%$ & $-0,6$ & $-11 \%$ \\
\hline
\end{tabular}

Para os cenários em que foram alteradas apenas uma das variáveis no cálculo do hidrograma de projeto, as maiores variações no cálculo da lâmina d'água ocorreram, em ordem decrescente, quando se alterou o tc, o valor de $\mathrm{CN}$ e a d.

As alterações simultâneas das três variáveis, tc, $\mathrm{CN}$ e d, resultaram na diminuição de $4 \%$ da lâmina d'água em relação ao cenário de projeto. Alterando-se o $T=100$ 
anos para $\mathrm{T}=50$ anos, houve redução de $11 \%$. Nota-se que a variação na vazão de pico não é proporcional a variação na lâmina d’água.

A Figura XI mostra que a variação da vazão de pico não e a variação na lâmina d'água do canal.

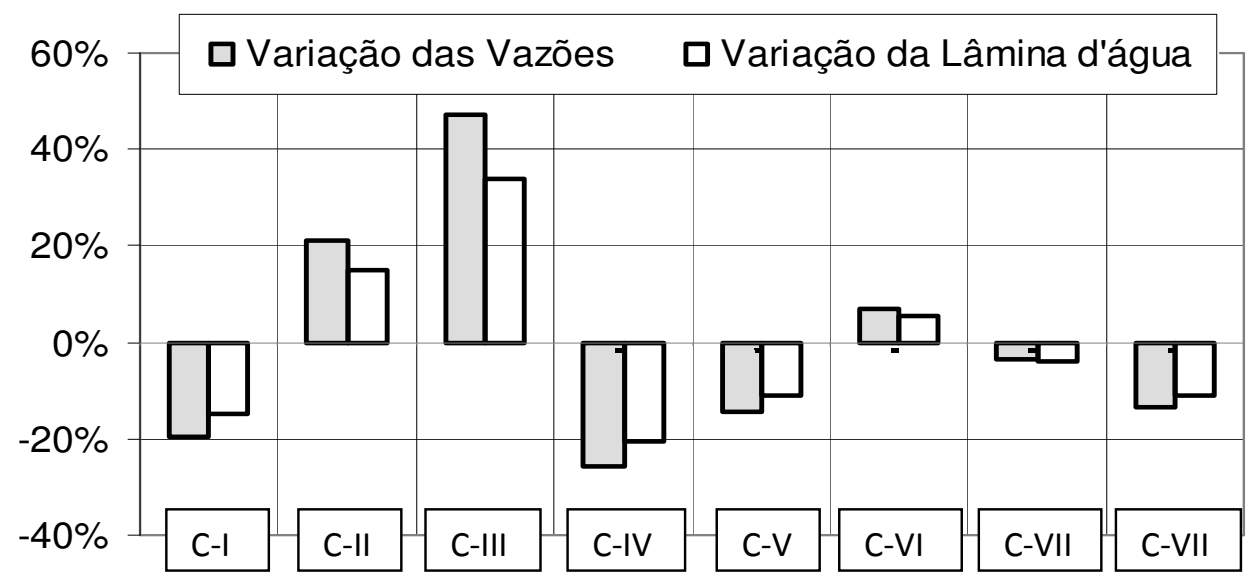

Figura XI - Variações das vazões de pico e lâmina d'água no canal para os cenários alternativos

V. III - Verificação da carga hidráulica sobre o vertedor do reservatório de controle de cheias

Para o reservatório de controle de cheias, foi verificada a variação na vazão de pico efluente, na carga hidráulica sobre o vertedor de soleira livre e no volume armazenado no reservatório para os cenários alternativos.

A Tabela VI relaciona a vazão de pico efluente, a carga hidráulica sobre o vertedor de soleira livre, o volume armazenado no reservatório e suas respectivas variações em relação aos cenários alternativos. 
Tabela VI - Vazão de pico efluente, carga hidráulica sobre o vertedor, volume armazenado no reservatório e as respectivas variações

\begin{tabular}{|c|c|c|c|c|c|c|c|c|c|}
\hline \multirow[t]{2}{*}{ Cenário } & \multirow{2}{*}{$\begin{array}{l}Q_{\text {eflu }} \\
\left(\mathrm{m}^{3} / \mathrm{s}\right) \\
\end{array}$} & \multicolumn{2}{|c|}{ Variação da $Q_{\text {eflu }}$} & \multirow{2}{*}{$\begin{array}{l}\text { Carga } \\
(\mathrm{m}) \\
\end{array}$} & \multicolumn{2}{|c|}{$\begin{array}{c}\text { Variação de Carga } \\
\text { Hidráulica }\end{array}$} & \multirow{2}{*}{$\begin{array}{c}\begin{array}{c}\text { Volume } \\
\text { Armazenado }\end{array} \\
\left(\mathrm{hm}^{3}\right) \\
\end{array}$} & \multicolumn{2}{|c|}{$\begin{array}{l}\text { Variação do } \\
\text { Volume }\end{array}$} \\
\hline & & $\left(\mathrm{m}^{3} / \mathrm{s}\right)$ & $(\%)$ & & $(\mathrm{m})$ & $(\%)$ & & $\left(\mathrm{hm}^{3}\right)$ & $(\%)$ \\
\hline Projeto & 35,371 & - & - & 1,50 & - & - & 0,828 & - & - \\
\hline 1 & 11,604 & $-23,767$ & $-67 \%$ & 0,71 & $-0,79$ & $-53 \%$ & 0,771 & $-0,06$ & $-7 \%$ \\
\hline II & 64,369 & 28,998 & $82 \%$ & 2,24 & 0,74 & $49 \%$ & 0,881 & 0,05 & $6 \%$ \\
\hline III & 47,472 & 12,101 & $34 \%$ & 1,83 & 0,33 & $22 \%$ & 0,852 & 0,02 & $3 \%$ \\
\hline IV & 28,338 & $-7,033$ & $-20 \%$ & 1,30 & $-0,20$ & $-13 \%$ & 0,813 & $-0,02$ & $-2 \%$ \\
\hline V & 13,383 & $-21,988$ & $-62 \%$ & 0,79 & $-0,71$ & $-47 \%$ & 0,777 & $-0,05$ & $-6 \%$ \\
\hline VI & 49,961 & 14,59 & $41 \%$ & 1,89 & 0,39 & $26 \%$ & 0,856 & 0,03 & $3 \%$ \\
\hline VII & 63,659 & 28,288 & $80 \%$ & 2,22 & 0,72 & $48 \%$ & 0,880 & 0,05 & $6 \%$ \\
\hline VIII & 18,108 & $-17,263$ & $-49 \%$ & 0,96 & $-0,54$ & $-36 \%$ & 0,789 & $-0,04$ & $-5 \%$ \\
\hline
\end{tabular}

A Figura XII mostra que a variação da vazão efluente, da carga hidráulica sobre o vertedor e do volume armazenado.

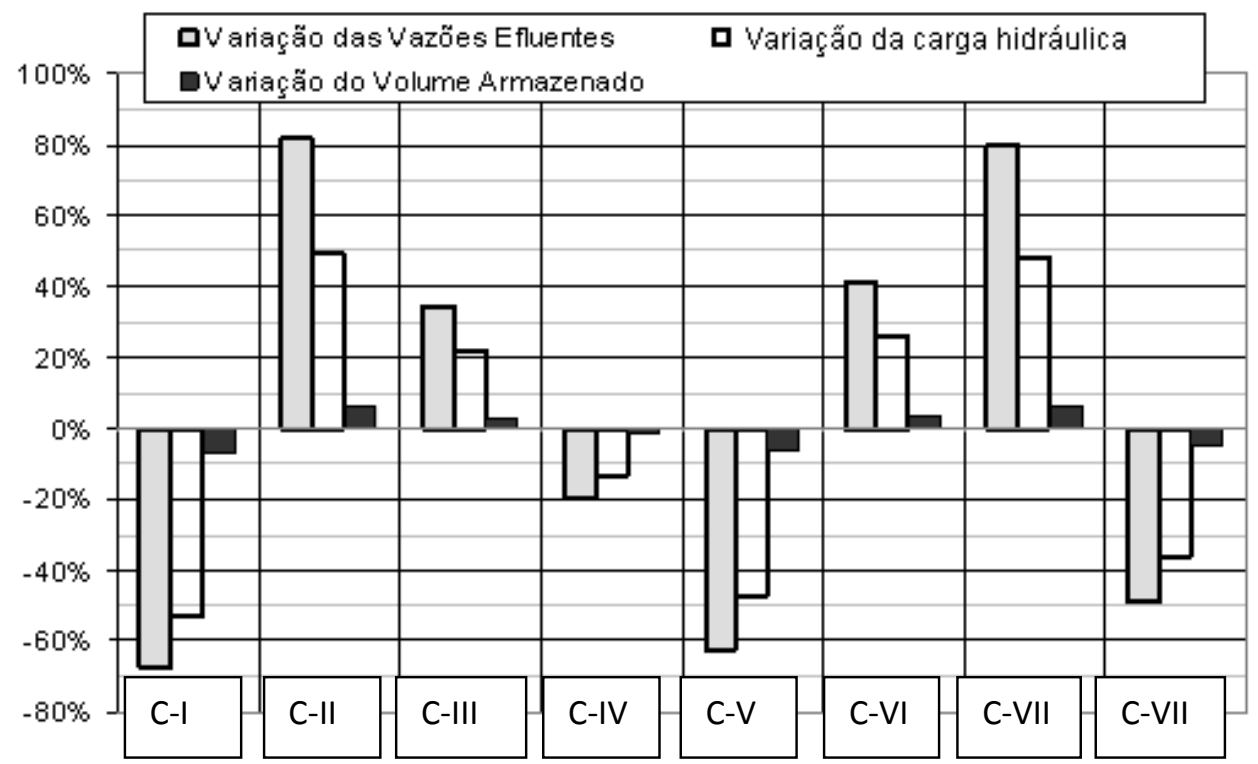

Figura XII - Variação da vazão efluente, carga hidráulica sobre o vertedor e volume armazenado 
Nota-se que as variações entre a vazão de dimensionamento e a carga hidráulica sobre o vertedor não são lineares. As maiores variações na carga hidráulica sobre o vertedor ocorreram quando se alterou as variáveis $\mathrm{CN}$, d e tc.

Nota-se que, para todos os cenários alternativos as variações são elevadas e, portanto, a definição das variáveis na determinação dos hidrogramas de projeto deve ser cuidadosamente definida.

\section{VII - CONCLUSÕES}

Dentre as variáveis estudadas, o valor de $\mathrm{CN}$ e o tc foram os parâmetros que se mostraram mais influentes na determinação da vazão de pico dos hidrogramas de projeto, e consequentemente, os que mais alteraram as características das estruturas hidráulicas avaliadas.

As análises de sensibilidade mostraram que a vazão de pico do hidrograma é crescente com o valor do $\mathrm{CN}$, área de drenagem e duração da chuva de projeto. A vazão de pico é decrescente com o tempo de concentração.

Para pequenas variações no valor de $\mathrm{CN}$, a variação da vazão de pico e do respectivo hidrograma são bastante acentuadas.

Para pequenas áreas de drenagem, as variações nos valores da vazão de pico são significantes.

Quanto a duração da chuva de projeto, observou-se que as maiores variações nas vazões de pico dos hidrogramas ocorrem para chuvas com durações abaixo do tempo de concentração. Para durações acima, as variações são reduzidas e os gradientes tendem a uma assíntota. 
Em comparação a análise de sensibilidade quanto à duração da chuva de projeto, nota-se, que a variação no valor da vazão de pico é maior em função do tempo de concentração do que em função da duração da chuva de projeto.

As curvas de variação das análises de sensibilidade, para todos os parâmetros avaliados, mostram que as variações tendem a diminuir com o aumento do período de retorno.

Em relação aos métodos de obtenção dos hidrogramas de cheia, para a bacia hidrográfica estudada, as vazões de pico geradas pelo método de Santa Bárbara e Clark são menores do que as vazões de pico geradas pelo método do SCS.

Quanto aos estudos de aplicação prática é importante salientar que as variações dependem das características das estruturas, assim como, da bacia hidrográfica em estudo. Nota-se, entretanto, que existe certo grau de importância em relação aos impactos que os hidrogramas de projeto geram nas obras de estruturas hidráulicas. Estes impactos podem ser de ordem econômica, financeira ou relativa à segurança estrutural das obras.

Em virtude da facilidade no uso de ferramentas computacionais, sistemas de suporte a decisão e modelos hidrológicos, como recomendação geral, sugere-se que sempre seja realizada uma análise de sensibilidade para a bacia hidrográfica em estudo, de maneira a avaliar os erros que possam ser cometidos quando da adoção de uma ou outra variável de entrada. 


\section{ARQUIVO DIGITAL}

Está afixado na contracapa deste trabalho um CD-ROM, onde estão salvos os arquivos com as saídas do SSD ABC 6 para as análises de sensibilidade e para o estudo de aplicação prática. Também está arquivada uma cópia da dissertação e do artigo a ser publicado no Boletim Técnico da EPUSP. Os arquivos estão organizados como mostra a Figura I.

\section{Apêndice \\ $\square$ Análises de Sensibilidade \\ Artigo \\ Dissertação \\ $\boxplus \square$ Estudo de Aplicação prática}

Figura I - Organização das pastas no CD-ROM

\section{I - Estrutura de arquivos das Análises de Sensibilidade}

Na pasta "Análises de Sensibilidade", os arquivos estão separados por método do traçado de hidrograma, como mostra a Figura II.

$\square$ Análises de Sensibilidade

$\oplus \square$ Clark

๑ Santa Bárbara

$\oplus \square \mathrm{SCS}$

Figura II - Organização da pasta Análises de Sensibilidade por métodos

Dentro de cada pasta, que organiza os arquivos para os métodos do SCS, Santa Bárbara e Clark, existe uma planilha resumo com os dados que permitiram o traçado das curvas das análises de sensibilidade para cada um dos parâmetros analisados. $O$ arquivo é nomeado como mostra a Figura III. Além do arquivo resumo, existem as pastas que ordenam os arquivos para cada parâmetro avaliado como mostra a Figura IV. A nomenclatura destas pastas segue o padrão mostrado na Figura V. 


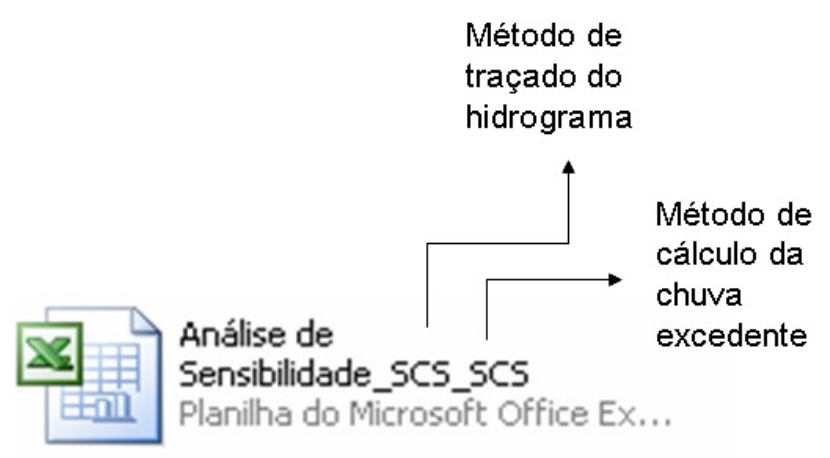

Figura III - Nomenclatura dos arquivos com os resumos de dados para traçado da curva de análise de sensibilidade

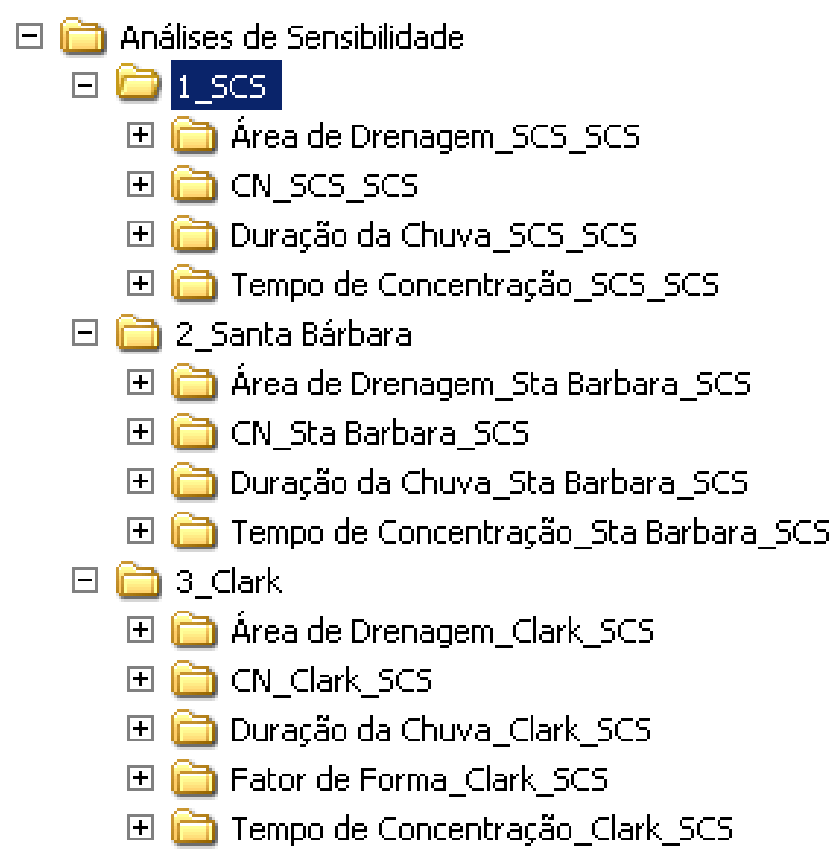

Figura IV - Estrutura de organização das pastas por método de traçado do hidrograma

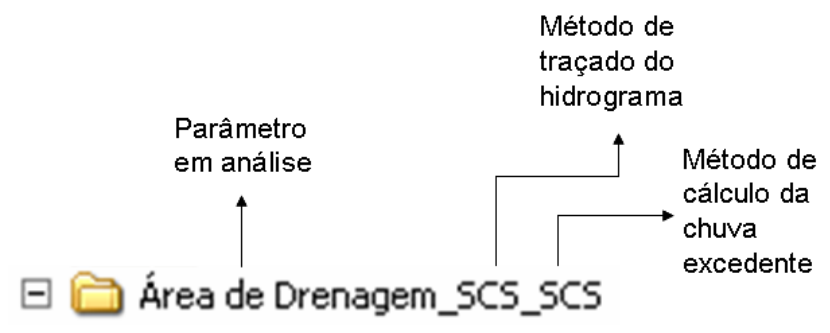

Figura $\mathrm{V}$ - Nomenclatura das pastas com os arquivos e saídas do SSD ABC 6 por parâmetro avaliado 
Dentro de cada pasta, que ordenam os parâmetros, existe uma pasta onde estão guardados os arquivos do SSD ABC 6, organizados por período de retorno, como mostra a Figura VI. A regra de nomeação destas pastas é mostrada na Figura VII. Além, destas pastas, existe um arquivo que armazena as saídas do programa. Foi a partir destes resultados que foram montadas as planilhas que possibilitaram 0 traçado das curvas de análises de sensibilidade. O arquivo é nomeado como mostra a Figura VIII.

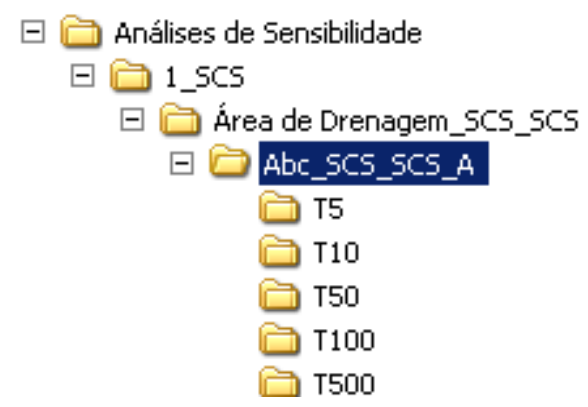

Figura VI - Organização das saídas do SSD ABC 6 por parâmetro avaliado

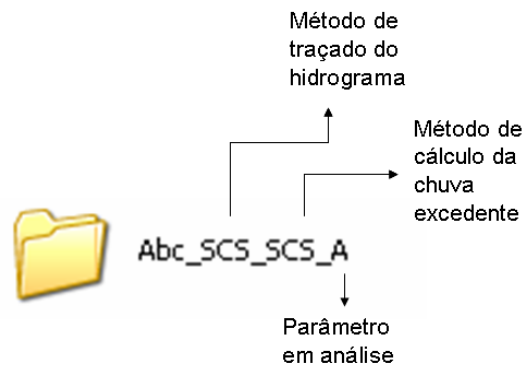

Figura VII - Nomenclatura das pastas com os arquivos do SSD ABC 6

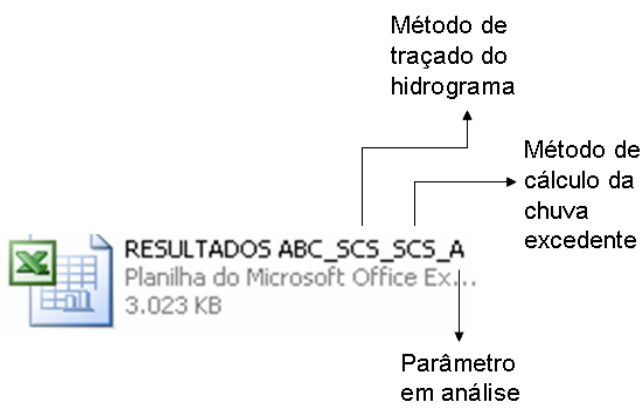

Figura VIII - Nomenclatura dos arquivos com as saídad do SSD ABC 6 
A Figura IX mostra a estrutura de organização para o método do SCS. As pastas para os demais métodos estão organizadas da mesma maneira, seguindo as regras de nomeação já descritas.

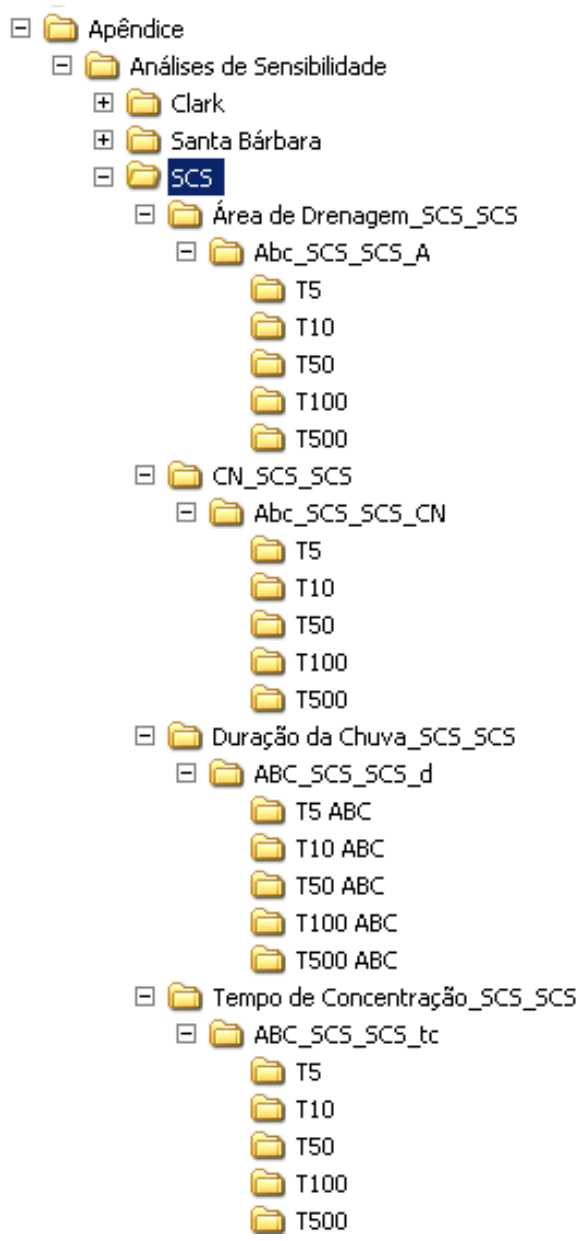

Figura IX - Estrutura de organização da pasta SCS

\section{II - Estrutura de arquivos do Estudo de aplicação prática}

Na pasta "Estudo de Aplicação Prática", estão armazenados os arquivos do SSD $\mathrm{ABC}, 6$ para o cenário de projeto e cenários alternativos, assim como, um arquivo no formato .xls com as saídas para os cenários mencionados. 